UNIVERSIDAD NACIONAL DE LA PLATA

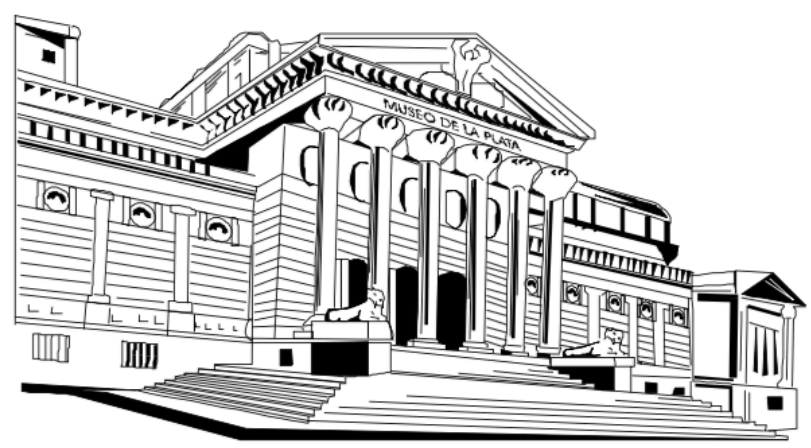

FACULTAD DE CIENCIAS NATURALES

Y MUSEO DE LA PLATA

DEPARTAMENTO CIENTIFICO

PALEONTOLOGIA DE VERTEBRADOS

PASEO DEL BOSQUE, 1900 LA PLATA, ARGENTINA

\title{
Estudios taxonómicos y paleobiológicos sobre los Metatheria (Mammalia) del Mioceno medio de La Venta, Colombia
}

Trabajo de Tesis para optar por el título de Doctor en Ciencias Naturales

\section{TOMO 1}

Tesista: Sandra Catalina Suárez Gómez

Director: Dr. Francisco Javier Goin 

A la República Argentina, por abrirme las puertas,

convertirse en mi hogar y brindarme grandes oportunidades.

A su educación pública y gratuita. 


\section{AGRADECIMIENTOS}

Al Consejo Nacional de Investigaciones Científicas y Técnicas - CONICET, por haber financiado mis estudios de doctorado. Al Instituto Smithsonian de Investigaciones Tropicales, el Vertebrate Paleontology Endowment Fund (Museo de Historia Natural de la Universidad de Florida), el Doris O. and Samuel P. Welles Research Fund (Museo de Paleontología de la Universidad de California, Berkeley), K. Campbell (Museo de Historia Natural del Condado de Los Ángeles) y A. Stenger, por financiación adicional. A Stella Alvarez (Museo Argentino de Ciencias Naturales Bernardino Rivadavia), Patricia Holroyd (Museo de Paleontología de la Universidad de California, Berkeley), Richard Hulbert (Museo de Historia Natural de Florida), Marcelo Reguero (Museo de La Plata), Rodrigo L. Tomassini (INGEOSUR-CONICET), Richard Kay (Universidad de Duke) y Masanaru Takai (Universidad de Kioto), por permitirme el acceso a materiales y colecciones a su cargo. Al Museo de La Plata, por haber sido mi segundo hogar durante más de cinco años.

Al Francisco J. Goin, por los grandes conocimientos que me aportó y la formación que recibí de su parte durante estos años. Al equipo de docentes y ayudantes de las cátedras de Anatomía Comparada, Paleontología de Vertebrados, Introducción a la Taxonomía y Mastozoología (Facultad de Ciencias Naturales y Museo, Universidad Nacional de La Plata). A Analía Forasiepi, Martin de Los Reyes y Carolina Vieytes por su colaboración, discusiones, aporte de conocimientos y guía durante este doctorado. A Natalia Zimicz, Troy Myers, Alfredo Carlini, Leopoldo Soibelzon, Soledad Gouiric-Cavalli, Malena Lorente, Marcela Tomeo, Bruno Pianzolla, Marcelo Bourguet, Juan José Moly, Leonel Acosta, Santiago Reuil, Felipe Vasconcellos, Juan Merlano y Jorge Moreno, por su ayuda en diferentes asuntos concernientes al desarrollo de esta tesis. A Gabriel M. Martin, Analia M. Forasiepi y Adriana M. Candela, por sus sugerencias e importantes contribuciones a este documento durante su arbitraje.

A Carlos Jaramillo, por su apoyo incondicional y guía durante tantos años. A Carlos Castillo y demás habitantes de Villavieja por su colaboración en mis actividades de campo en el Desierto de La Tatacoa. A Anyelo Vanegas, Eugenia Arnaudo y Silvia Martínez, por su compañía durante todas las etapas de este doctorado, especialmente en los momentos más difíciles. A Erica Nadal (QEPD), por cambiar mi perspectiva. Al Complejo Deportivo Poseidón y a Christian Cordón por cuidar mi salud fisica y mental. A mi mamá y mi hermana Sofía, por acompañarme en todos los caminos de mi vida, por apoyarme siempre en todos mis proyectos y ayudarme a cumplir mis sueños. 


\section{ÍNDICE}

\section{TOMO 1}

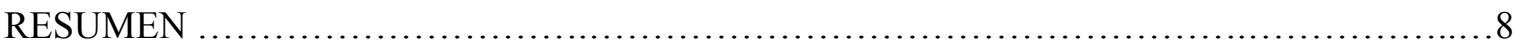

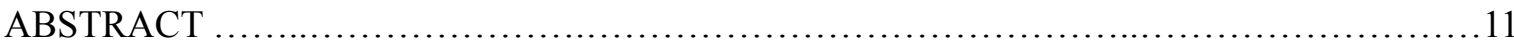

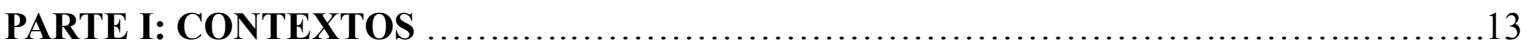

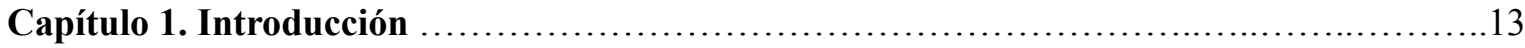

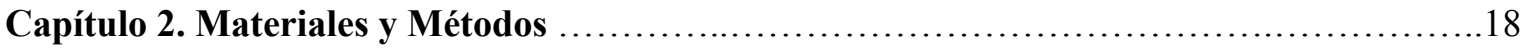

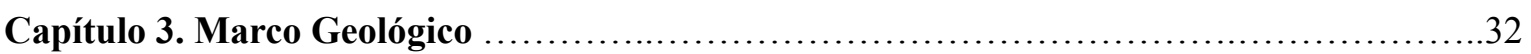

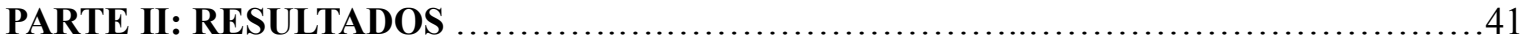

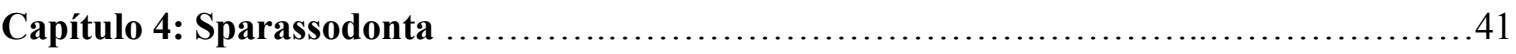

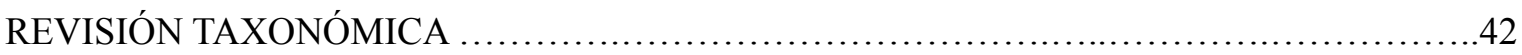

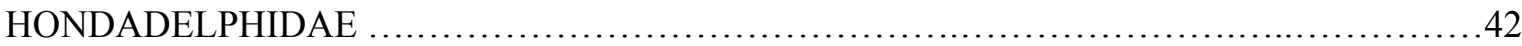

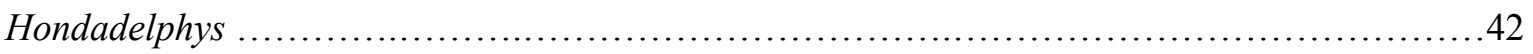

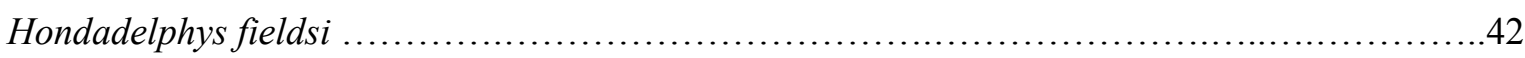

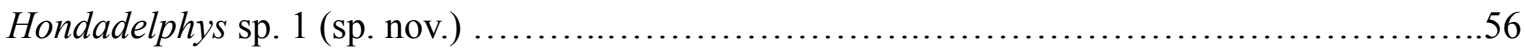

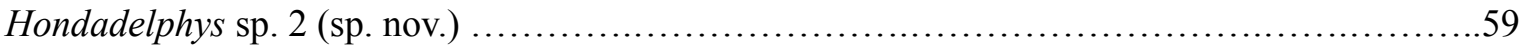

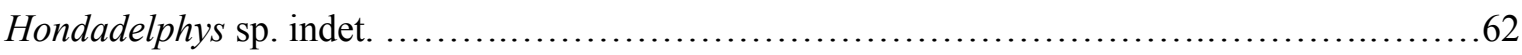

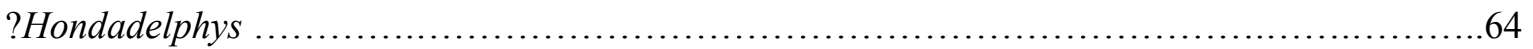

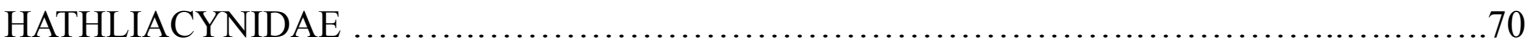

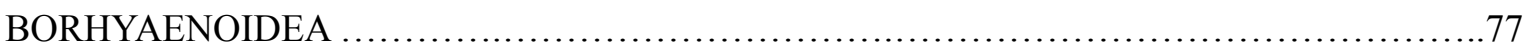

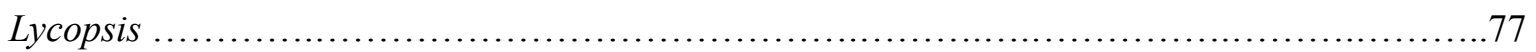

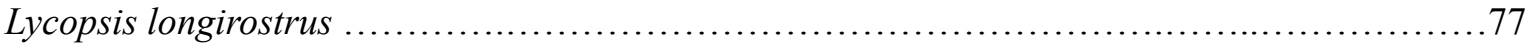

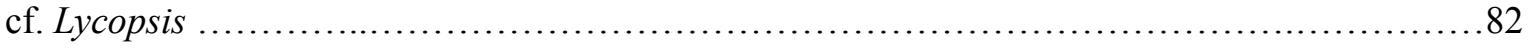

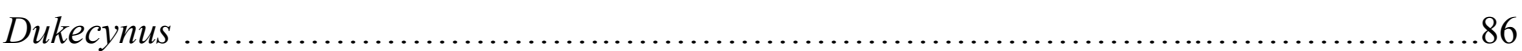

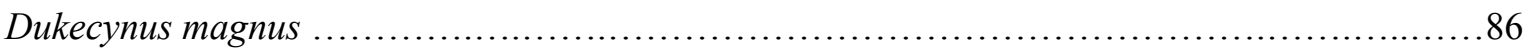

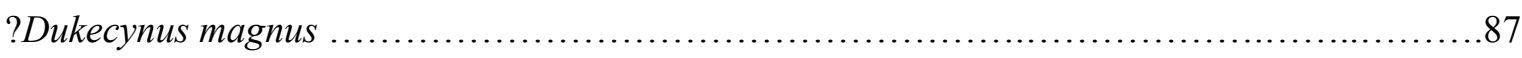

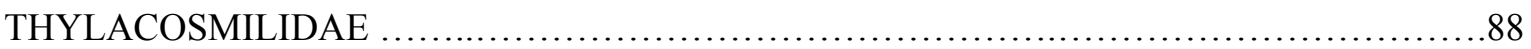

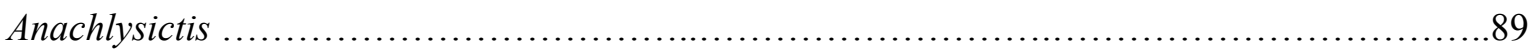

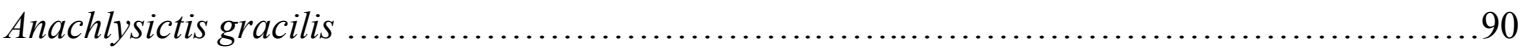

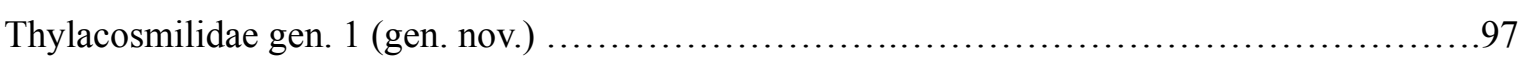

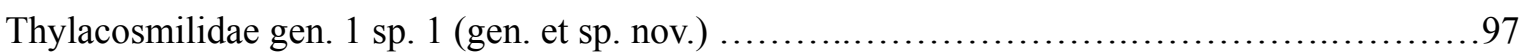

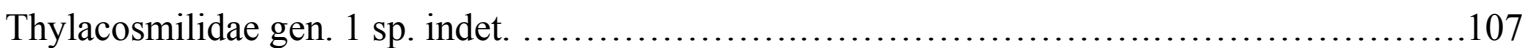

BORHYAENOIDEA, fam. et gen. icertae sedis ......................................... 113

Tomo 1 


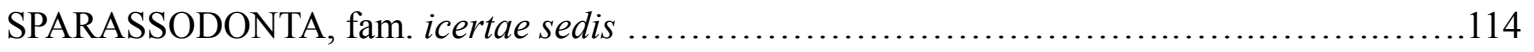

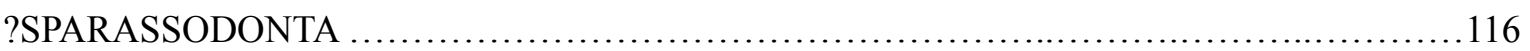

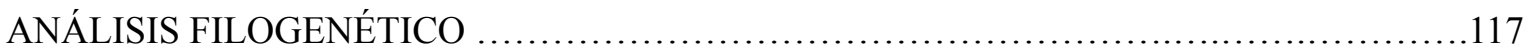

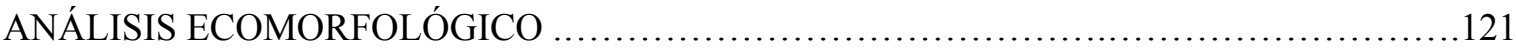

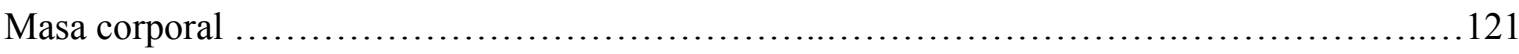

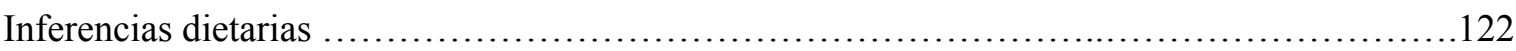

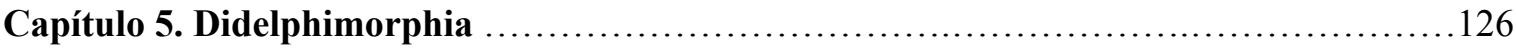

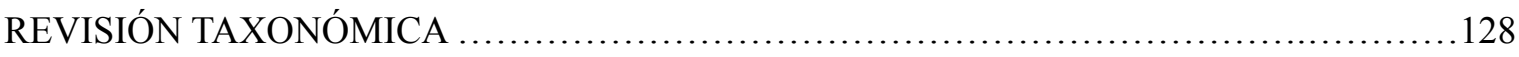

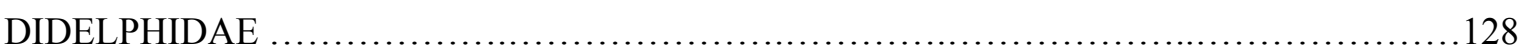

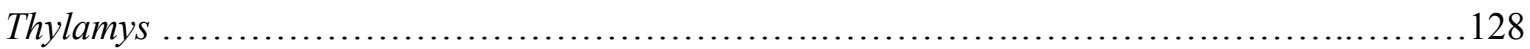

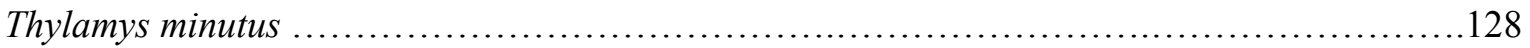

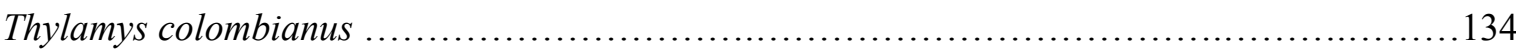

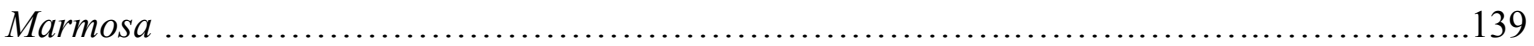

Marmosa (Micoureous) laventica ....................................................... 140

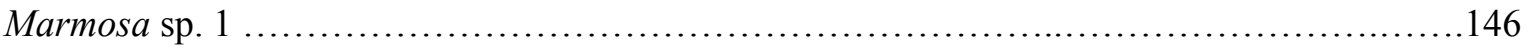

Marmosini cf. Tlacuatzin ................................................................. 150

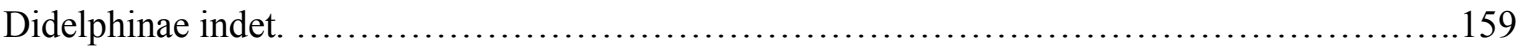

DIDELPHIMORPHIA fam. incertae sedis ............................................. 165

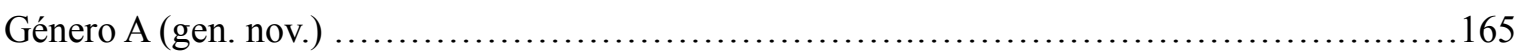

Género A sp. 1 (gen. et sp. nov.) ....................................................... 165

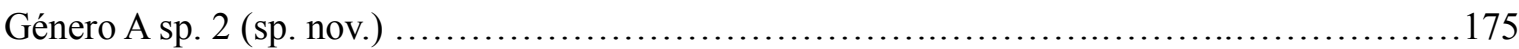

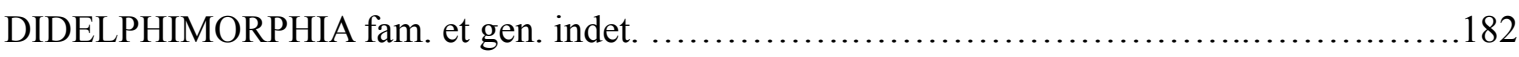

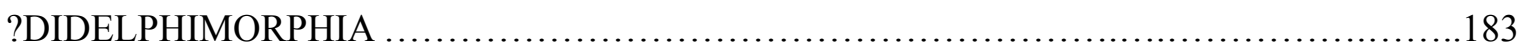

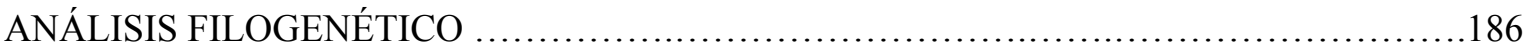

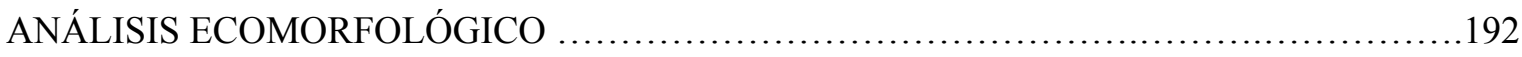

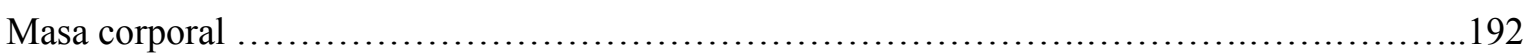

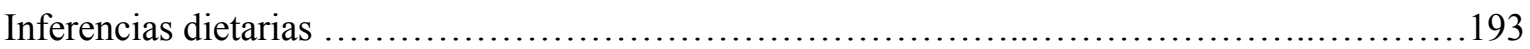

Capítulo 6. Otros taxones "ameridelfios": ?Sternbergiidae .................................. 196

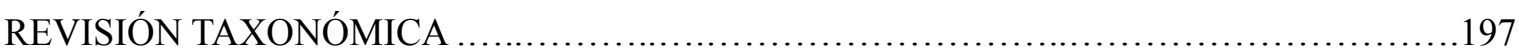

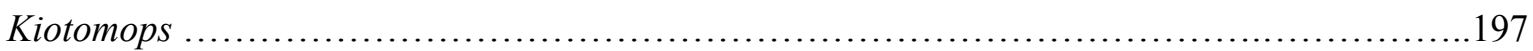

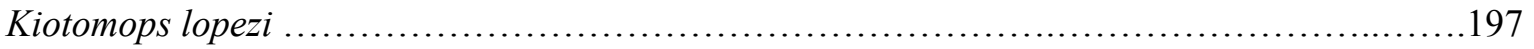

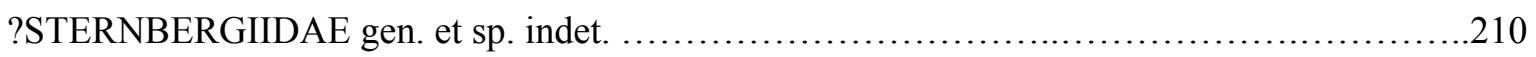

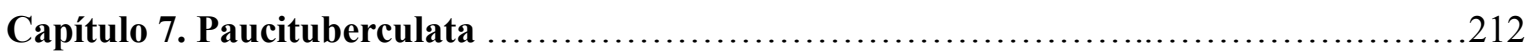

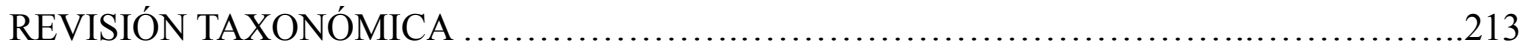

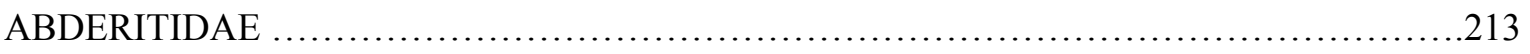

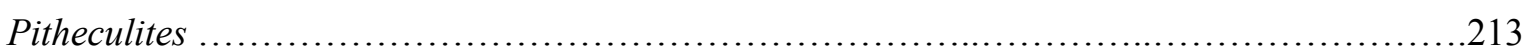

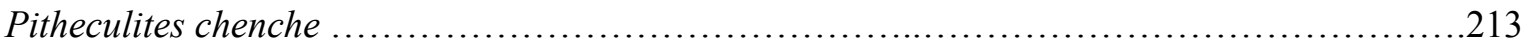

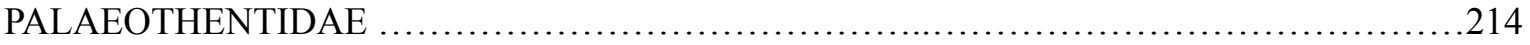




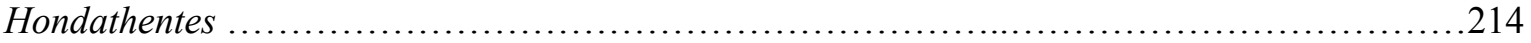

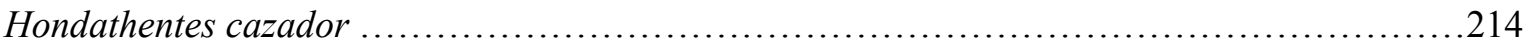

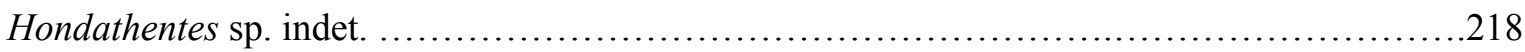

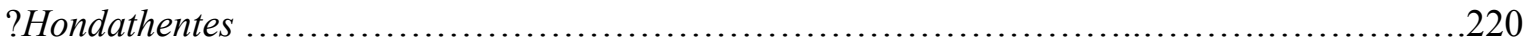

PALAEOTHENTOIDEA fam., gen. et sp. indet. ...................................... 222

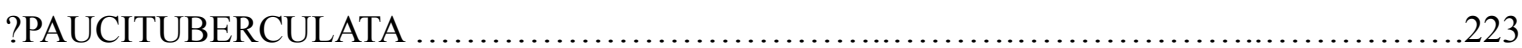

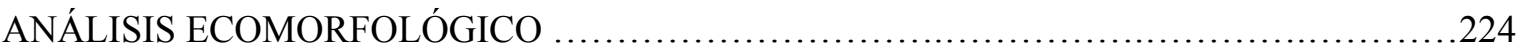

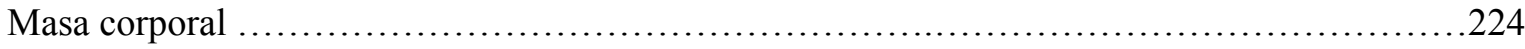

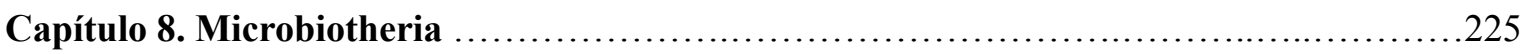

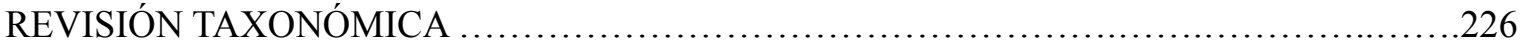

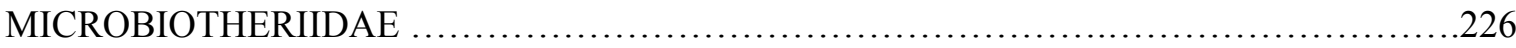

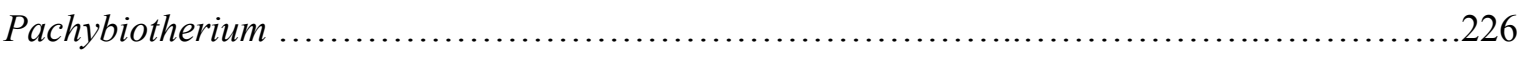

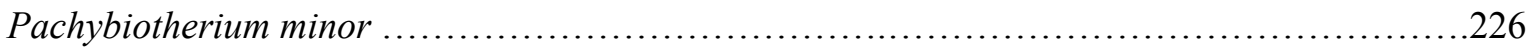

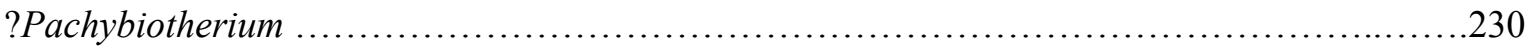

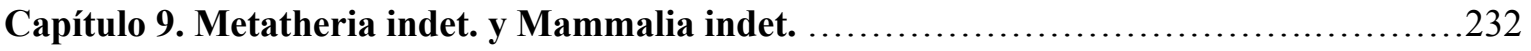

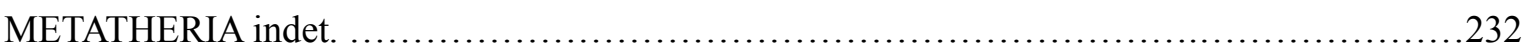

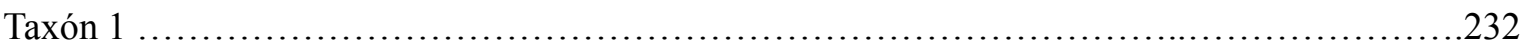

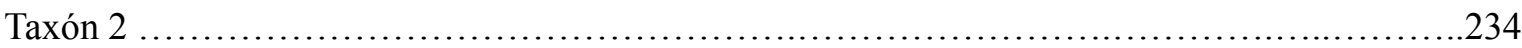

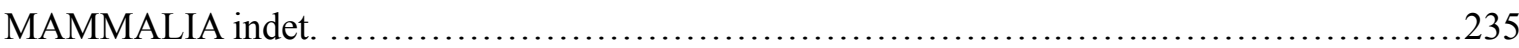

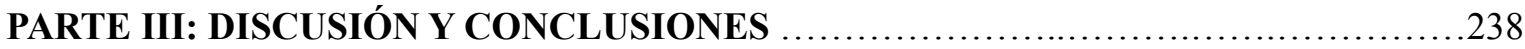

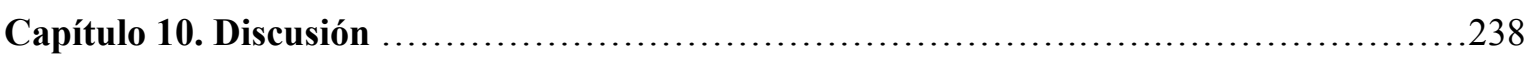

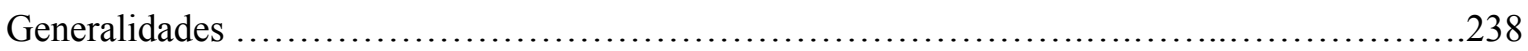

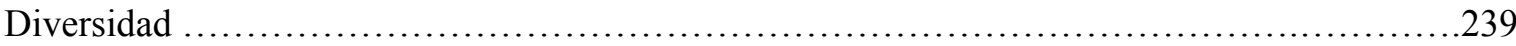

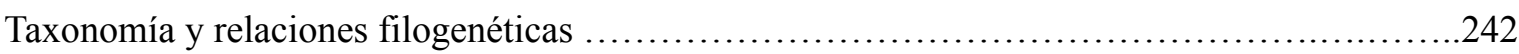

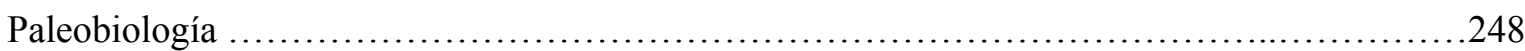

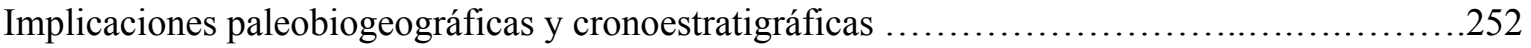

Comentarios sobre algunas homologías en los molares de los didélfidos ......................260

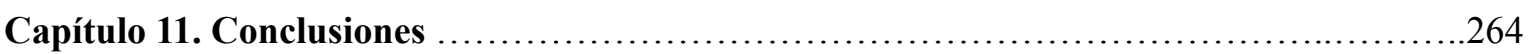

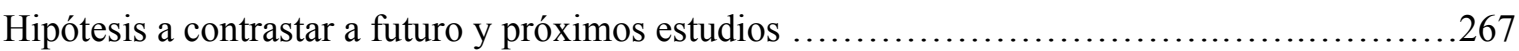

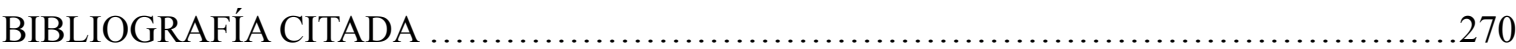

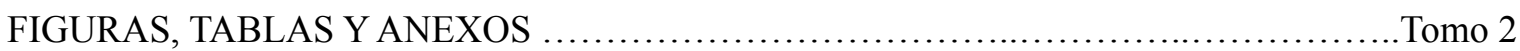




\section{RESUMEN}

En el presente trabajo se realizó la revisión taxonómica de los Metatheria fósiles pertenecientes la asociación de vertebrados de La Venta, Colombia, así como también el análisis de su filogenia y paleobiología. Se revisó casi la totalidad de especímenes que componen esta asociación de metaterios. Estos materiales actualmente forman parte de colecciones en Estados Unidos (Museo de Paleontología de la Universidad de California, Berkeley), Japón (Primate Research Institute de la Universidad de Kioto) y Colombia (Servicio Geológico Colombiano y Museo de Villavieja, Departamento del Huila). Muchos de estos se encuentran temporalmente alojados (en préstamo) en la Universidad de Duke (Estados Unidos) y algunos en el Museo de La Plata. Adicionalmente, nuevos ejemplares fueron colectados en campo como parte de las actividades relacionadas con la presente tesis doctoral, los cuales formarán parte de la colección del Museo Geológico Nacional 'José Royo y Gómez', del Servicio Geológico Colombiano (Bogotá, Colombia).

Este estudio permitió ampliar significativamente el espectro de taxones conocidos para esta asociación, el conocimiento previo sobre su anatomía, adaptaciones y relaciones filogenéticas, así como agregar nuevos datos sobre la paleobiología de estos. Se estudiaron 130 ejemplares representativos de al menos 22 especies, 17 géneros, siete familias y cuatro órdenes. Adicionalmente, se incluyen algunos géneros que no están clasificados dentro de familias definidas (e.g., Lycopsis, que se clasifica como un borienoideo basal) y taxones "ameridelfios" incertae sedis.

Los nuevos taxones reconocidos permitieron ampliar la proporción de metaterios en la asociación de mamíferos de La Venta, siendo mayor que otras faunas importantes del Neógeno de América del Sur, como las de Quebrada Honda (Mioceno medio, Bolivia) y Arroyo Chasicó (Mioceno tardío, Argentina), e incluso ligeramente mayor que la de Santa Cruz (Mioceno temprano, Argentina). Por lo tanto, la asociación de metaterios de La Venta sería la más diversa para el Neógeno sudamericano.

En la revisión taxonómica se encontraron representantes de la mayoría de los principales órdenes metaterios: Sparassodonta, Didelphimorphia, Paucituberculata y Microbiotheria. Para cada uno de estos se realizó la descripción de los ejemplares disponibles, comparaciones, clasificación y la identificación de nuevos taxones. Estos últimos serán publicados en artículos que se encuentran siendo elaborados actualmente. Se realizaron análisis filogenéticos para los grupos mejor representados (por materiales más completos; i.e., Sparassodonta y Didelphimorphia) y análisis ecomorfológicos (i.e., estimación de masa corporal e inferencias dietarias) para aquellos con materiales disponibles que lo permitieran (i.e., Sparassodonta, Didelphimorphia y Paucituberculata; y estimaciones de masa corporal para algunos ejemplares referidos a "Ameridelphia" incertae sedis y Microbiotheria).

Para la revisión taxonómica y el análisis filogenético se realizaron comparaciones tanto con ejemplares fósiles de otras asociaciones, como con ejemplares actuales. El análisis filogenético se 
llevó a cabo por medio de búsquedas heurísticas realizadas usando el programa TNT 1.1. En todos los casos, los árboles de consenso calculados fueron de consenso estricto. Las estimaciones de masa corporal se realizaron con base en variables independientes correspondientes a medidas tomadas en la dentición y las inferencias dietarias se realizaron por medio de análisis cualitativos (morfología comparativa) y cuantitativos (índices morfométricos).

Entre los resultados que se destacan en la presente revisión se encuentra la reclasificación del género Kiotomops, el cual había sido inicialmente descripto como un quiróptero y que en el presente trabajo es identificado como un metaterio ("Ameridelphia incertae sedis). Esta clasificación había sido sugerida previamente, pero no se había realizado un estudio detallado para corroborar dicha hipótesis. Además de sumar un nuevo taxón metaterio para La Venta, la revisión de Kiotomops permitió reportar en bajas latitudes (La Venta) y durante el Mioceno medio, la presencia de taxones estrechamente relacionados con formas paleógenas de latitudes mayores (i.e., Itaboraiense, Brasil), ya que aparentemente se trataría de un sternbérgido o eventualmente podría pertenecer a una nueva familia filogenéticamente cercana a estos. Por otro lado, se destaca el primer registro de hatliacínidos para La Venta, grupo que está mucho más ampliamente representado en otras faunas neógenas del continente; la excepcionalidad de la presencia de Pachybiotherium, un microbiotérido, en el neotrópico; la diversidad de tilacosmílidos, incluyendo una de las especies más basales de esta familia; la presencia de un didelfimorfio basal, posiblemente taxón hermano de los didelfoideos, y a la vez, la presencia de didélfidos pertenecientes a géneros con representación actual.

Muchos de estos hallazgos, además, permitieron identificar a La Venta como un ejemplo tanto del modelo "cradle" (área de altas tasas de diversificación) como del modelo "museum" (área de bajas tasas de extinción), ya que aparentemente allí se estarían presentando ambos fenómenos, aunque aparentemente existirían más ejemplos de este último.

En cuanto a inferencias paleobiológicas se encontró que el nicho carnívoro es el mejor representado entre los taxones de La Venta. Sin embargo, aparentemente no incluye grandes quiebrahuesos y los pequeños carnívoros (e.g., hatliacínidos) están pobremente representados. Resulta inquietante por ejemplo la ausencia de grandes didelfinos. Sin embargo, esto puede deberse a que su nicho ecológico es ocupado por otros taxones de morfología y hábitos similares (e.g., Hondadelphys, Thylacosmilidae gen.1, o incluso hatliacínidos). Por otro lado, el nicho menor representado por el momento es el de los arborícolas frugívoros (e.g., no se presentan calurómidos ni cenoléstidos, aunque se presentan unos pocos paleoténtidos y abderítidos, además de Pachybiotherium), pero podría estar siendo compartido con algunos taxones euterios (e.g., primates).

Entre las inferencias paleobiogeográficas, se destaca el hecho de que la comparación entre la fauna de La Venta y otras faunas neógenas sudamericanas está mostrando en general una tendencia al provincialismo controlado por la latitud. Por ejemplo, no existen especies compartidas entre La Venta y la fauna contemporánea de Quebrada Honda. Únicamente existen taxones compartidos a 
nivel de género (i.e., Miocochilius y Acarechimys). Sin embargo, esto no aplica para los grandes carnívoros, los esparasodontes, que a nivel genérico muestran varios ejemplos de amplia dispersión a lo largo del continente (en el caso de La Venta, Lycopsis), tal como ocurre entre los grandes carnívoros euterios.

Los resultados y conclusiones obtenidos en el presente estudio permiten afianzar la asociación de metaterios de La Venta como una referencia obligada en el estudio de las asociaciones neógenas de la América tropical y del Hemisferio Sur, siendo un elemento de gran importancia en el conocimiento de las radiaciones neógenas de los metaterios de América del Sur. 


\section{ABSTRACT}

A taxonomic revision, together with phylogenetic and paleobiological analyses, was performed for the metatherian association from La Venta, Colombia. Almost the totality of the materials available for this association were studied. These specimens belong to collections from the United States (University of California Museum of Paleontology, Berkeley), Japan (Primate Research Institute of the Kyoto University) and Colombia (Colombian Geological Survey and Museum of Villavieja, Huila). Many of these materials are temporarily allocated (on loan) in the Duke University (USA), and a some others in La Plata Museum. Additional materials were collected in the field as part of the activities related to this doctoral thesis and will be allocated in the National Geological Museum ‘José Royo y Gómez’, from the Colombian Geological Survey (Bogotá, Colombia).

This study contributed to increase of the number of taxa recognized for this association, as well as the knowledge about their anatomy, adaptations and phylogenetic relationships, and also added new data about their paleobiology. About 130 specimens were studied, representing at least 22 species, 17 genera, seven families and four orders. Additionally, some genera not classified within the known families (e.g., Lycopsis, which is classified as a basal borienoid), taxa classified as "Ameridelphia" incertae sedis, and some indeterminate specimens were included.

The new taxa added in this work are increasing the proportion of metatherians vs. eutherians for the La Venta association, being higher than in other important Neogene South American faunas, such as Quebrada Honda (middle Miocene, Bolivia) and Arroyo Chasicó (late Miocene, Argentina), and even slightly higher than in Santa Cruz (early Miocene, Argentina). This proportion suggests that La Venta would be the most diverse metatherian association for the Neogene of South America.

The taxonomic revision allowed the recognition of taxa from most of the metatherian orders: Sparassodonta, Didelphimorphia, Paucituberculata, and Microbiotheria. Descriptions of the referable material, comparisons, classification, and the identification of new taxa, were made for each of these groups. These new taxa are currently included in manuscripts in process. Additionally, phylogenetic analyses were carried out for the best represented groups (those with the most complete materials; i.e., Sparassodonta and Didelphimorphia), and ecomorphological analyses (including body mass estimations and dietary inferences) were made when possible (i.e., for Sparassodonta, Didelphimorphia and Paucituberculata). However, a few body mass estimations were made for other groups (i.e., "Ameridelphia" incertae sedis and Microbiotheria) although an ecomorphological analysis per se was not developed (because of the scarce information).

Comparisons made for the taxonomic revision and the phylogenetic analysis included both fossil and extant specimens. The phylogenetic relationships were tested through a parsimony analyses conducted in the program TNT 1.1. In all cases, the consensus trees were calculated through strict consensus. The body mass estimations were calculated using independent variables from dental measurements, and the dietary inferences were made through qualitative (comparative 
morphology) and quantitative (morphometric indexes) analyses.

Some results standing out from this study include the reclassification of the genus Kiotomops, which was originally described as a Chiroptera and in this work is identified as a metatherian ("Ameridelphia" incertae sedis). This classification has been previously suggested, but none detailed study was performed in order to evaluate this hypothesis. Kiotomops is not only adding a new metatherian taxon to La Venta, but it also represents the first record of a taxon closely related to the sternbergids in low latitudes during the middle Miocene. This family is only reported for the Paleogene of higher latitudes (i.e., Itaboraian from Brazil). On the other hand, other relevant results from this study include the first record of hathliacinids for La Venta, a group more highly represented in other South American Neogene faunas; the exceptional presence of Pachybiotherium in the neotropics; the thylacosmilid diversity in La Venta, which includes one of the most basal species of this family; and the presence of a basal didelphimorph, probably the sister taxon to didelphoids, together with the presence of didelphids belonging to extant genera.

These findings allow to identify La Venta as an example of both "cradle" (area with high rates of diversification) and "museum" (area with low rates of extinction) models, simultaneously. However, although both models are occurring in this area, there are apparently more examples representing the last one ("museum").

The paleobiological analyses suggest that the carnivore niche is the best represented among La Venta metatherians. However, it apparently does not include "bone breakers", and small carnivores (e.g., hathliacinids) are underrepresented. The absence of large didelphines is also remarkable; however, it could be the case that their ecological role was performed by other taxa, similar in habits and morphology (e.g., Hondadelphys, Thylacosmilidae gen. 1 sp. 1, or even hathliacinids). On the other hand, the less represented niche in La Venta is that of the small arboreal frugivores (e.g., there are not records of caluromyids or caenolestids, but there are some palaeothentids and abderitids, and also Pachybiotherium could be included); however, it could be shared with some eutherian taxa, such as primates.

The study of La Venta metatherian association also allowed the analysis of some paleobiogeographical issues. Provincialism in South America is reflected in the La Venta association, compared with other Neogene South American faunas. For instance, there are no common species between Quebrada Honda, a middle latitude association from the same age (Laventan), and there are only genera in common (i.e., Miocochilius and Acarechimys). However, this is apparently not reflected in the large carnivores, the sparasodonts, which show several examples at generic level with a wide distribution over the continent (in the case of La Venta, Lycopsis), as it occurs in large eutherian carnivores.

The results and conclusions obtained in the present study allowed to strengthen our knowledge of the metatherian association of La Venta as an obligatory reference for the study of the Neogene associations of tropical America, and the Southern Hemisphere, being an important element in the knowledge of the Neogene radiations for the metatherians in South America. 


\section{PARTE I: CONTEXTOS}

\section{CAPÍTULO 1. INTRODUCCIÓN}

La asociación de mamíferos exhumada en niveles del Mioceno medio de La Venta, en Colombia, constituye una de las más diversas hasta ahora conocidas para el Neógeno de la parte intertropical de América del Sur. Constituye, además, una referencia obligada para el estudio de varios linajes de mamíferos vivientes (e.g., Didelphidae; véase más abajo). Los restos en los que se basa esta asociación, recolectados en numerosas localidades y niveles fosilíferos referibles al Grupo Honda, permitieron a Madden et al. (1997) proponer una (para entonces) nueva unidad cronoestratigráfica, el Piso Laventense, datado entre 13,5 y 11,8 Ma. La Edad-mamífero Laventense, basada en dicho piso, no encuentra correlato temporal equivalente en las secuencias del Cono Sur sudamericano.

Los metaterios (marsupiales y grupos afines) del Mioceno medio de La Venta constituyen una de las asociaciones más extraordinarias de mamíferos sudamericanos neógenos. En el presente trabajo de tesis se reconocen al menos 22 especies referibles a 17 géneros, siete familias y cuatro órdenes. Si, adicionalmente, se consideran los taxones dudosos o no considerados en esta revisión (por estar basados en materiales muy incompletos), la nómina de especies sería de alrededor de 30, un número jamás alcanzado por ninguna asociación local viviente de marsupiales sudamericanos. La proporción de metaterios para la asociación de mamíferos de La Venta (mayor al 25\%) indica una cifra desconocida para las asociaciones de mamíferos sudamericanos vivientes (cercana al 10\%; Goin et al. 2016). El estudio de los metaterios de La Venta constituye, en suma, una referencia obligada en el análisis de las radiaciones neógenas, en particular de las regiones intertropicales de América.

Los primeros metaterios del Mioceno medio de La Venta fueron originalmente descriptos por Marshall (1976a, 1977a). Posteriormente, Dumont y Bown (1997) y Goin (1997) dieron a conocer nuevos materiales y taxones, al tiempo que este último revisó parte de la taxonomía previamente reconocida por Marshall. Los taxones reconocidos por Dumont y Bown (1997) y Goin (1997) son los siguientes: Hondadelphidae (Sparassodonta): Hondadelphys fieldsi Marshall 1976; Borhyaenoidea (Sparassodonta): Lycopsis longirostrus Marshall 1977, Dukecynus magnus Goin 1997; Thylacosmilidae (Sparassodonta): Anachlysictis gracilis Goin 1997; Didelphidae (Didelphimorphia): Thylamys minutus Goin 1997, T. colombianus Goin 1997, Marmosa (Micoureus) laventicus Marshall 1976; Palaeothentidae (Paucituberculata): Hondathentes cazador Dumont y Bown 1997; Abderitidae (Paucituberculata): Pitheculites chenche Dumont y Bown 1997; y Microbiotheriidae (Microbiotheria): Pachybiotherium minor Goin 1997. Entre los 
didélfidos de La Venta, tanto Thylamys como Micoureus incluyen especies vivientes de amplia distribución en América Central y del Sur.

Las especies nominadas en estas revisiones no agotan la totalidad de taxones de Metatheria susceptibles de ser reconocidos para La Venta. Además de una serie de materiales no referidos aún a taxones específicos, aunque mencionados en las revisiones previas, en la actualidad se cuenta con varios restos adicionales en diversas colecciones (Universidad de Duke y Museo de Paleontología de la Universidad de California, Berkeley, en EE. UU; Primate Research Institute de la Universidad de Kioto, en Japón; y Museo de Villavieja, Huila, en Colombia), los cuales no han sido aún estudiados o no pudieron ser referidos a ningún taxón en particular en las revisiones previamente realizadas. Varios de los especímenes ya mencionados en la literatura habían sido referidos previamente por Goin (1997) como (1) "Marmosini, gen. et sp. indet" (p. 194), (2) "Didelphinae, gen et sp. indet." (p. 194); (3) "Hondadelphidae, gen. et sp. indet." (p. 197); (4) "Borhyaenoidea, fam. et gen. incertae sedis (?Thylacosmilidae)" (p. 203); (5) "Sparassodonta, fam. et gen. indet." (p. 204). A estos materiales debe agregarse (6) Kiotomops lopezi Takai et al. 1991, originalmente referido a un quiróptero Molossidae, si bien posteriormente F. Goin (en Czaplewski et al. 2003, p. 265) sugirió que se trataba de un marsupial.

Algunos de los taxones reconocidos han sido objeto de análisis filogenéticos por parte de varios autores. Por ejemplo, Forasiepi (2009) incluyó a Hondadelphys y a Lycopsis en su análisis filogenético de Sparassodonta; Bown y Fleagel (1993) incluyeron a Hondathentes en sus análisis de los Palaeothentidae, mientras Abello $(2007,2013)$ y Engelman et al. (2017) revisaron las afinidades de Pitheculites; Goin y Abello (2013) incluyeron a Pachybiotherium en su análisis de los Microbiotheriidae; y varios autores (e.g., Voss y Jansa, 2003, 2009, 2014; Teta et al. 2009; Giarla et al. 2010; entre otros) han incluido en sus análisis a Thylamys o Marmosa (incluyendo el subgénero Micoureus), aunque aún no han sido evaluadas las afinidades de las especies fósiles presentes en La Venta. Otros taxones, por el contrario, no han sido aún objeto de descripciones pormenorizadas, reconocimiento taxonómico o análisis filogenéticos. Se destacan, en particular: (1) la situación de Kiotomops, cuya morfología molar resulta sumamente llamativa en el contexto de los metaterios neógenos, (2) los materiales referidos a "Didelphinae, gen. et sp. indet." por Goin (1997: p. 194), posiblemente representativos de un nuevo (y basal) taxón de Sparassocynidae (Goin, datos no publicados) y (3) el enigmático "Borhyaenoidea, fam. et gen. incertae sedis (? Thylacosmilidae)" ya referido por Goin (1997: p. 203).

Desde el punto de vista paleobiológico se han mencionado en forma sólo somera los eventuales roles ecológicos de los metaterios de La Venta (e.g., Goin 1997), mientras los estudios que han especificado valores estimativos de la masa corporal sólo involucran unas pocas especies de esta asociación (algunas son estimaciones indirectas, realizadas a partir de especies de "tamaño" cercano). En la presente revisión se buscó contrastar, por ejemplo, algunas hipótesis en cuanto a hábitos alimenticios (ver más abajo) y tomar las estimaciones de masa corporal realizadas a la fecha (e.g., Prevosti et al., 2013; Ercoli et al., 2014; Suarez et al., 2016; Abello et al., 2018) como 
hipótesis a contrastar en un análisis paleobiológico más comprehensivo.

Otro aspecto a considerar es el biogeográfico, ya que son numerosas las referencias en la última década al carácter dual de la biogeografía sudamericana: por un lado, la Región Neotropical (Reino Holotropical), ocupando la mayor parte del continente hasta aproximadamente los $40^{\circ}$ de latitud sur y una estrecha faja cordillerana que llega hasta los Andes centrales; por el otro, la Región Andina (Reino Austral), incluyendo dicha faja cordillerana más el territorio patagónico (véase Goin et al. 2012 y bibliografía citada). Una hipótesis a contrastar sugiere que las radiaciones neógenas en cada una de estas regiones debieron haber sido diferenciadas, tanto en su composición taxonómica como trófica.

El desarrollo de la presente tesis doctoral ha permitido, por un lado, estudiar tanto los especímenes ya conocidos como los nuevos materiales disponibles de metaterios de La Venta, así como también revisar las relaciones filogenéticas de varias de las especies de esta asociación. En segundo lugar, evaluar parámetros ecomorfológicos de los metaterios de La Venta a los efectos de contrastar diversas hipótesis sobre la paleobiología de los distintos grupos de edad Laventense. Por último, formular hipótesis sobre la radiación miocénica de los metaterios intertropicales de América del Sur en comparación con aquellos de latitudes más altas en este continente (fundamentalmente, Patagonia).

El principal objetivo de este trabajo fue ampliar y actualizar el conocimiento sobre la evolución y paleobiología de la asociación de metaterios del Mioceno medio de Colombia, y compararlo con aquel derivado del registro miocénico de las latitudes australes de América del Sur, fundamentalmente de la Patagonia. Específicamente, se buscó revisar la taxonomía de los metaterios del Mioceno medio de La Venta (Colombia) y evaluar afinidades filogenéticas de grupos seleccionados (i.e., Didelphimorphia y Sparassodonta); analizar parámetros paleobiológicos y ecomorfológicos de los metaterios de esta asociación (i.e., inferencias dietarias y estimaciones de masa corporal); comparar las radiaciones miocénicas de los metaterios sudamericanos intertropicales con aquéllos de altas latitudes; y contextualizar la evolución neógena de los metaterios sudamericanos intertropicales en un marco biogeográfico.

Con el estudio de los metaterios del Mioceno medio de La Venta (Colombia) se buscó contrastar algunas hipótesis que habían sido planteadas previamente por algunos autores, además de nuevas hipótesis surgidas a partir de revisión bibliográfica y observación de algunos materiales. Las hipótesis que se esperaba contrastar (algunas ya mencionadas arriba), comprendieron aspectos de diversidad, taxonomía, filogenia, paleobiología y paleobiogeografía de esta asociación, como se menciona a continuación:

Diversidad:

- La asociación de metaterios exhumada en niveles del Mioceno medio de La Venta (Colombia) constituye una de las más diversas hasta ahora conocidas para el Neógeno de la parte intertropical de América del Sur. Sin embargo, aparentemente, es menos diversa que algunas asociaciones de latitudes altas en este continente (e.g., la del 
Mioceno temprano de Santa Cruz, Argentina).

- Las especies de metaterios reconocidas hasta el momento no agotan la totalidad de taxones metaterios para esta asociación.

Taxonomía y filogenia:

- El género Hondadelphys se encuentra relacionado filogenéticamente con los esparasodontes (Forasiepi, 2009; Engelman y Croft, 2014; Forasiepi et al., 2015; Suarez et al., 2016).

- Las especies de Lycopsis conforman un grupo monofilético (Suarez et al., 2016).

- Dukecynus se encuentra más estrechamente relacionado con los "protilacínidos" que con los boriénidos (Goin, 1997).

- El enigmático ejemplar identificado por Goin (1997: p. 203) como "Borhyaenoidea, fam. et gen. incertae sedis (?Thylacosmilidae)" representa un nuevo taxón para la asociación de metaterios de La Venta, el cual encuentra estrechamente relacionado a los tilacosmílidos (Goin, 1997).

- Hipótesis alternativa: este taxón podría representar un linaje distinto de borienoideos que, paralelamente a los tilacosmílidos, desarrollaron adaptaciones similares, como ocurre en muchos taxones de dientes de sable euterios (Goin, 1997).

- Los materiales referidos a "Didelphinae, gen. et sp. indet." por Goin (1997: p. 194) y materiales no publicados asociados, posiblemente representan un nuevo (y basal) taxón de Sparassocynidae.

- Los didélfidos de La Venta representan el registro más antiguo de algunos géneros vivientes de amplia distribución en América Central y del Sur (e.g., Thylamys y Marmosa; Goin, 1997).

- Kiotomops lopezi (Takai et al. 1991), originalmente referido a un quiróptero Molossidae, es en realidad un metaterio (Czaplewski et al. 2003)

Paleobiología:

- En cuanto a la masa corporal, se toman las estimaciones realizadas a la fecha para algunas especies de metaterios de La Venta (e.g., Prevosti et al., 2013; Ercoli et al., 2014; Suarez et al., 2016; Abello et al., 2018) como hipótesis a contrastar en un análisis paleobiológico más comprehensivo.

- Se hipotetizan hábitos insectívoros para los Didelphidae de pequeño tamaño, insectívoro-frugívoros para los Paucituberculata y Microbiotheria, omnívorocarnívoros para los "Didelphinae indet." (Didelphimorphia) mencionados por Goin (1997) y predominantemente carnívoros para los esparasodontes.

- En la asociación de vertebrados de La Venta (Colombia), el rol ecológico de los depredadores sería ocupado por los esparasodontes y algunos reptiles (i.e., crocodilomorfos). 


\section{Paleobiogeografía:}

- El carácter dual de la biogeografía sudamericana (Goin et al. 2012 y bibliografía allí citada) se vería reflejado en la asociación de metaterios de La Venta (Colombia). Por lo tanto, sería esperable que esta asociación de metaterios no comparta taxones (o comparta muy pocos) con otras asociaciones sudamericanas contemporáneas (e.g., Quebrada Honda, Bolivia). 


\title{
CAPÍtulO 2. MATERIALES Y MÉTODOS
}

\section{GENERALIDADES}

\section{Abreviaturas}

Las siguientes son las abreviaturas utilizadas a lo largo del texto principal de esta tesis (i.e., TOMO 1). Las abreviaturas de las tablas, figuras y anexos, se indican en cada una de esas secciones (TOMO 2) para facilitar la lectura:

\begin{abstract}
Abreviaturas institucionales: IGM, Ingeominas (actual Servicio Geológico Colombiano), Bogotá, Colombia; IGM\#, número de campo IGM (los ejemplares así identificados no tienen número de colección asignado); KU, Primate Research Institute, Universidad de Kioto, Inuyama, Japón; MACN, Museo Argentino de Ciencias Naturales "Bernardino Rivadavia", Buenos Aires, Argentina; MLP, Museo de La Plata, La Plata, Argentina; MMP, Museo Municipal de Ciencias Naturales de Mar del Plata, Mar del Plata, Argentina; MNHN-Bol, Museo Nacional de Historia Natural, La Paz, Bolivia; UCMP, University of California Museum of Paleontology, Berkeley, EE.UU.; UF, Florida Museum of Natural History, Gainesville, EE.UU.
\end{abstract}

\footnotetext{
Abreviaturas de la dentición: I1-5/i2-5, incisivos superiores/inferiores; C/c, caninos superiores/ inferiores; P/p1-3, premolares superiores/inferiores; M/m1-4, molares superiores/inferiores; StA$\mathbf{E}$, cúspides estilares.
}

Otras abreviaturas: CS, número de campo de Catalina Suarez (repositorio: Servicio Geológico Colombiano, sin número de colección asignado; materiales colectados en una campaña realizada como parte de las actividades de la presente tesis doctoral); Log, logaritmo común (en base 10); In, logaritmo natural (en base e); Ma., Megannum (un millón de años en la escala radioisotópica de tiempo); \%PE, porcentaje de error de predicción; $\mathbf{R}^{2}$, coeficiente de determinación; SALMA, South American Land Mammal Age (i.e., Edad Mamífero de América del Sur); SE, factor de corrección ("smearing estimate"); $\mathbf{S N}$, sin número.

\section{Medidas}

La mayoría de las medidas evaluadas en los ejemplares revisados fueron tomadas sobre el material 
en físico, por medio de un calibre digital. En aquellos casos en los que la medida era difícil de tomar físicamente (e.g., medidas en la cuenca del talónido, longitudes de las crestas, etc.; también cuando el material era demasiado chico, o porque era muy delicado y podría ser dañado), estas se tomaron sobre fotografías digitales usando el Software 'Image J', un programa para el procesamiento de imágenes basado en Java, el cual es de dominio público y se encuentra disponible online (Schneider et al., 2012). Este software también fue usado para medir ángulos.

\section{Nomenclatura}

A continuación, se detalla la nomenclatura utilizada a lo largo de esta tesis y se realizan aclaraciones acerca de algunos términos. Esta nomenclatura fue utilizada tanto en la revisión taxonómica como en los análisis filogenéticos y ecomorfológicos.

Términos posicionales: postcráneo: anterior, posterior, lateral, medial, proximal y distal. Cráneo: anterior, posterior, lateral, medial, dorsal y ventral. Dentario: anterior, posterior, lateral, medial, oclusal y ventral. Dentición: del C/c al M/m4, se usaron los términos anterior, posterior, labial, lingual y oclusal; para los incisivos se emplearon los términos "mesial" y "distal" en lugar de anterior y posterior, para evitar confusiones, ya que la hilera incisiva se va curvando anteriormente, por lo que el término "anterior" podría ser confundido con "labial" y "posterior" con "lingual".

Nota aclaratoria — en la descripción de los molares se utilizó también el término "mesial" para describir la posición relativa del paracónido en algunos molares inferiores (normalmente el $\mathrm{m} 1$ ), ya que en este caso el término es más adecuado que "anterior", para indicar que la estructura se ubica en una posición adelantada y hacia un punto medio entre el protocónido y el metacónido.

Nomenclatura de las descripciones: Cráneo-la nomenclatura craneana, en lo posible, sigue a Wible (2003). Adicionalmente, la Nomina Anatomica Veterinaria (e.g., Schaller, 2007) y otras publicaciones (e.g., Muizon, 1998; Forasiepi, 2009) también fueron tomadas como referencia para detalles y discusiones. A continuación, se realizan algunos comentarios sobre la nomenclatura de los forámenes palatales. En un estado ontogenético inicial, el paladar de los metaterios no está fenestrado. En la mayor parte de los didelfimorfios vivientes, como así también de los dasiúridos, el hueso se reabsorbe durante la ontogenia, formándose así vacuidades palatales (Forasiepi, 2009, car. 22; e.g., Parker, 1886; Clark y Smith, 1993; Abdala et al., 2001). Esta característica es muy variable en marsupiales vivientes (véase Martin, 2005, 2009, 2013) y también aparece en algunos metaterios extintos (e.g., Pediomys, Alphadon, Asiatherium, Andinodelphys y los estagodóntidos). La nomenclatura de las vacuidades palatales en los metaterios varía entre diferentes autores (e.g., Voss y Jansa, 2009, Tabla 6).

En los mamíferos en los que está presente el foramen palatino mayor (foramen palatinum majus), la arteria y nervio palatino mayor (ramas de la arteria y nervio maxilar) llegan al paladar a 
través de este (Forasiepi, 2009; e.g., Sisson, 1965; Evans, 1993; Hiatt y Gartner, 2001; Schaller, 2007). En las especies de metaterios donde no se forman vacuidades (e.g., Sparassocynus, Thylateridium y Caluromys), se observa claramente un foramen palatino mayor (en algunos muy pequeño), el cual se ubica sobre o cerca de la sutura maxilopalatina (pers. obs.). En aquellas especies con vacuidades palatales bien desarrolladas, la arteria y nervio palatino mayor pasarían a través de la vacuidad maxilopalatina (sensu Archer, 1976a), vacuidad maxilopalatina (sensu Hershkovitz, 1992, 1997), vacuidad palatina posterior (sensu Osgood, 1921) o fenestra maxilopalatina (sensu Voss y Jansa, 2003, 2009; Voss et al., 2004). Por esta razón, algunos autores (e.g., Wible, 2003; Forasiepi, 2009, car. 23; Engelman y Croft, 2014; Suarez et al., 2016) utilizan el término "foramen palatino mayor", dado que serían estructuras homólogas. En el presente trabajo se decidió usar también el término "foramen palatino mayor", ya que se está siguiendo la nomenclatura de Wible (2003) y teniendo en cuenta que por esta abertura pasaría un nervio y una arteria: en general, se considera como fenestra a una simple abertura, zona sin hueso (donde este pudo ser reabsorbido) o perforación; mientras que un foramen es una abertura por donde pasa un nervio, una vena o una arteria (Martin, pers. comm.). Cabe aclarar que, a pesar de que, entre los metaterios analizados, esta estructura suele abrir al nivel de la sutura entre el palatino y el maxilar, no ocurre así en todos los casos (e.g., Deltatheridium y Caluromys, en los que se ubica en el palatino).

En los esparasodontes, esta estructura suele estar ausente, pero suelen presentarse (además de forámenes nutricios) pequeños forámenes circulares (simétricos) sobre la superficie palatal del maxilar, algunos de ellos alineados cerca de los dientes, los que probablemente transmitirían la misma irrigación del foramen palatino mayor (Forasiepi, 2009), como ocurre en algunos euterios (e.g., Wible y Gaudin, 2004).

Dentición - la nomenclatura molar (Fig. 2.1) sigue a Goin et al. (2016, Fig. 1.2). A esta nomenclatura se le hicieron dos modificaciones: (1) el uso del término "cingúlido anterior" en lugar de "cíngulo anterior" para los molares inferiores; y (2) para la ubicación del cíngulo posterior de los molares inferiores se siguió a Luo et al. (2003) y Cifelli (1993), como se explica a continuación (Fig. 2.2): el postcingúlido (o cíngulo posterior) corresponde a un cíngulo transversal ubicado en la pared posterior del talónido, por encima del nivel de la encía en los molares inferiores (Luo et al, 2003: car. 67). Este rasgo es evaluado en el carácter 82 de la matriz de Didelphimorphia en la presente tesis doctoral (capítulo 5). El cíngulo que aparece dibujado en la pared posterior de los molares inferiores de la fig. 1.2 de Goin et al. (2016), corresponde al postcingúlido labial (o postcingúlido labial del hipoconúlido) que se evalúa en el carácter 187 de la matriz de Sparassodonta en la presente tesis doctoral (capítulo 4) y en los caracteres 81 de Luo et al. (2003) y 187 de Forasiepi (2009). Dicho cíngulo, el postcingúlido labial, se origina en el ápice del hipoconúlido y desciende sobre la pared posterior del talónido en dirección a la base del hipocónido, extendiéndose hasta su cara labial cuando está bien desarrollado; por lo tanto, no es homólogo al cíngulo posterior, ya que claramente presenta una relación diferente con las cúspides 
del talónido (Fig. 2.2).

Postcráneo-descripciones de postcráneo realizadas en esta tesis se encuentran dentro del capítulo de Sparassodonta (capítulo 4). Por lo tanto, se optó por seguir la nomenclatura usada por Forasiepi (2009), quien realizó una muy completa y detallada descripción de una especie de este grupo (i.e., Arctodictis sinclairi). Adicionalmente, la Nomina Anatomica Veterinaria (e.g., Schaller, 2007) y otras publicaciones (e.g., Flores, 2009; Flores y Díaz, 2009; Szalay, 2006) también fueron tomadas como referencia para detalles, información complementaria y discusiones.

\section{Fórmula dentaria}

A lo largo del presente documento se tendrá en cuenta la siguiente fórmula dentaria:

$$
I \frac{1,2,3,4,5}{2,3,4,5}, C \frac{1}{1}, P \frac{1,2,3}{1,2,3}, M \frac{1,2,3,4}{1,2,3,4}
$$

\section{Estratigrafía y localidades fosilíferas}

La estratigrafía utilizada en el presente trabajo sigue a Guerrero (1997) y Anderson et al. (2016) (véase más adelante: Marco Geológico). La ubicación estratigráfica de las localidades de metaterios de La Venta se presenta en la Tabla 3.1. La información estratigráfica para cada uno de los ejemplares estudiados se muestra en las Tablas 4.1, 5.1, 6.1, 7.1, 8.1 y 9.1. En la figura 3.1 se muestra la ubicación geográfica de la gran mayoría de las localidades fosilíferas de metaterios en el área de La Venta. Este mapa está basado en Guerrero (1997, Fig. 2.9). Adicionalmente, la información de las localidades de la Universidad de Kioto fue tomada de Takai et al. (1992). No se obtuvieron datos precisos para las localidades del UCMP (cuya nomenclatura comienza con una letra V), las localidades de screenwashing de la Universidad de Duke (con nomenclatura "CVP") y algunas de la Universidad de Kioto, por lo cual no aparecen en el mapa. Del mismo modo, las localidades que no aparecen en la Tabla 3.1, son aquellas de las cuales se desconoce la ubicación estratigráfica precisa.

\section{REVISION TAXONOMICA}

Para la realización de la presente tesis doctoral se revisó integralmente la taxonomía de todos los Metatheria descriptos hasta ahora para la asociación fosilífera de La Venta. Esta revisión se llevó a cabo a partir de la observación de materiales que forman parte de las colecciones del Museo de Paleontología de la Universidad de California (Berkeley, EE.UU.), el Primate Research Institute de la Universidad de Kioto (Inuyama, Japón), el Museo de Villavieja (Departamento del Huila, Colombia) y el Servicio Geológico Colombiano (antiguo Ingeominas; Bogotá, Colombia). Los 
materiales pertenecientes a esta última colección fueron colectados en una campaña conjunta entre el Ingeominas y la Universidad de Duke (Durham, Estados Unidos); la mayoría de ellos se encuentran temporalmente alojados (en préstamo) en dicha universidad y algunos pocos en el Museo de La Plata (La Plata, Argentina). Adicionalmente, como parte de las actividades de este doctorado, se colectaron nuevos materiales en campo, cuyo repositorio será el Museo Geológico Nacional 'José Royo y Gómez', del Servicio Geológico Colombiano (Bogotá, Colombia), pero como aún no se les ha asignado un número de colección, en la presente tesis se utiliza la abreviatura "CS" (numeración de campo de Catalina Suárez) para identificarlos.

Para las comparaciones y los diferentes análisis se utilizaron materiales disponibles en colecciones argentinas, incluyendo la del Museo de La Plata y la del Museo Argentino de Ciencias Naturales - Bernardino Rivadavia (en Buenos Aires). Otros ejemplares fueron estudiados a partir de calcos, fotografías y material bibliográfico.

Nota: se están preparando tres publicaciones en las que serán nombradas formalmente las especies que en esta tesis son mencionadas como Thylacosmilidae gen. $1 \mathrm{sp} .1$, Thylacosmilidae gen. 2 sp. 1 y Didelphimorphia Género A (spp. 1 y 2).

\section{Sistemática}

Sparassodonta: La clasificación usada para Sparassodonta a lo largo de la presente tesis doctoral, siguió el arreglo obtenido en el árbol de consenso resultante en el análisis filogenético (capítulo 4).

Didelphimorphia: En el presente trabajo se siguió a Goin et al. (2016) para la clasificación general de los Didelphimorhia, en la cual este orden incluye las superfamilias Peradectoidea (i.e., Peradectidae + Caroloameghiniidae) y Didelphoidea (i. e., Didelphidae + Sparassocynidae).

Para la clasificación general de los Didelphidae se siguió a Voss y Jansa (2009), en lugar de los agrupamientos obtenidos en la presente tesis doctoral (ver Análisis Filogenético, en el capítulo 5), teniendo en cuenta que la revisión de Voss y Jansa (2009) es la más completa realizada hasta el momento para los didélfidos actuales; adicionalmente, la presente revisión no pretende reevaluar la filogenia de los Didelphidae, sino determinar la relación de los taxones de La Venta con los demás miembros de la familia. Este grupo se encuentra representado mayormente por especies vivientes y, para realizar una reevaluación de su filogenia, sería necesario un estudio mucho más detallado, que incluya tanto caracteres morfológicos como moleculares, así como una muestra mucho más grande de material codificable. La clasificación que Voss y Jansa (2009) proponen para los didélfidos actuales, se basa mayormente en los resultados obtenidos con base en los análisis del set de datos combinados (caracteres no moleculares + moleculares) que excluye a Chacodelphys, particularmente en el árbol de consenso de mayoría - 50\% (Voss y Jansa, 2009: Fig. 35). En esta clasificación, la familia está conformada por cuatro subfamilias: Glironiinae (Voss y Jansa, 2009), que incluye únicamente a Glironia; Caluromyinae (Kirsch, 1977), que incluye a Caluromys y 
Caluromysiops; Hyladelphinae (Voss y Jansa, 2009), que incluye únicamente a Hyladelphys; y Didelphinae (Gray, 1821), que se subdivide en cuatro tribus: Marmosini (i.e., Marmosa, Monodelphis y Tlacuatzin), Metachirini (que incluye únicamente a Metachirus), Didelphini (i.e., Chironectes, Didelphis, Lutreolina y Philander) y Thylamyini (i.e., Chacodelphys, Cryptonanus, Gracilinanus, Lestodelphys, Marmosops y Thylamys).

"Ameridelphia" incertae sedis (?Sternbergiidae): Para la clasificación de los taxones "ameridelfios" referidos con dudas a la familia Sternbergiidae (capítulo 6), se siguió a Goin et al. (2016), quien clasifica a esta familia como "Ameridelphia" incertae sedis, junto con otras ocho (i.e., Pediomyidae, Pucadelphyidae, Pucadelphyidae, Jaskhadelphyidae, Mayulestidae, Protodidelphidaey y Derorhynchidae) y algunos taxones de familia indeterminada.

Paucituberculata: Para la clasificación general de los Paucituberculata se siguió a Abello et al. (2018), quienes realizan una muy completa revisión de este orden, clasificándolo en dos superfamilias: Caenolestoidea, que incluye a Caenolestidae, y Palaeothentoidea, que incluye a Palaeothentiidae (i.e., Palaeothentinae y Acdestinae), Abderitidae y Pichipilidae. Dentro del análisis filogenético de Abello et al. (2018) se incluye a Pitheculites chenche, una de las dos especies de paucituberculados descriptas para La Venta (Colombia), clasificándose dentro de los Abderitidae. Adicionalmente, para clasificar a Hondathentes, se siguió a Abello (2013), quien lo había referido a los Palaeothentinae.

\section{Conteo de taxones}

Para las discusiones acerca de la diversidad de los metaterios de La Venta (capítulo 10, tomo 1 y 2), se llevó a cabo un análisis comparativo, teniendo en cuenta la riqueza de metaterios y mamíferos en general, en La Venta y otras faunas cenozoicas sudamericanas: el número de especies de metaterios por familia (o superfamilia, para taxones que no entran dentro de las familias definidas; e.g., Lycopsis y Dukecynus, que son clasificados dentro de Borhyaenoidea, pero no son referibles a ninguna de las familias definidas dentro de esta superfamilia), el número de géneros y especies de metaterios por orden y el número total de especies de mamíferos. A partir de esos datos, de calculó el porcentaje de metaterios respecto al total de especies de mamíferos en cada fauna.

Para el conteo de los taxones se tuvieron en cuenta las especies claramente identificadas previamente, incluso si no han sido nombradas pero que sin duda son referibles a una nueva especie para esa fauna. Sólo se tuvieron en cuenta aquellas identificadas como "sp." (e.g., Cimolestes sp., para Tiupampa) cuando eran la única representante de ese género para determinada fauna, o si se diferencian claramente cuando son varias (e.g., sp. 1, sp. 2); y las especies indeterminadas, únicamente cuando sean claramente identificadas como nueva especie para esta 
fauna o sean el único representante de un clado de rango superior. En el caso de la asociación de metaterios de La Venta, se tuvo en cuenta tanto los taxones previamente reconocidos, como aquellas entidades que en la presente tesis fueron claramente identificadas como nuevos taxones, independientemente de que se les haya asignado o no una diagnosis, o haya sido usada nomenclatura abierta. Estos fueron identificados como indeterminados, pero sin duda no son referibles a ninguno de los taxones hasta ahora reconocidos para esta asociación, por lo que fueron tenidos en cuenta en el conteo. Aquellos taxones de los que sí se tenía dudas, porque podrían eventualmente representar un taxón ya descripto, no fueron tenidos en cuenta en el conteo. Por ejemplo, a pesar de que, eventualmente, se registrarían dos géneros de hatliacínidos para La Venta (según los resultados de esta tesis), existen algunas dudas sobre una asignación taxonómica más precisa (debido a la preservación), por lo que se consideró que lo más prudente era contabilizar uno solo, ya que al menos se presenta un género y una especie.

\section{ANÁLISIS FILOGENÉTICOS}

En la presente tesis doctoral sólo se realizaron análisis filogenéticos para los clados Sparassodonta y Didelphimorphia, ya que, a pesar de que esta incluye el estudio de otros grupos (e.g., Paucituberculata, Microbiotheria y otros metaterios), estos están representados por material muy escaso, principalmente dientes aislados.

La matriz utilizada para el análisis de Sparassodonta se basó en aquella confeccionada por Forasiepi (2009), modificada posteriormente en otros estudios (i.e., Engelman y Croft, 2014; Forasiepi et al., 2015; Suarez et al., 2016) y en el presente análisis. En esta versión de la matriz se realizaron modificaciones y correcciones en la descripción de los caracteres o sus estados, modificaciones en la codificación, y se agregaron algunos caracteres y taxones (ver Anexo 1.2).

La matriz elaborada para el análisis de Didelphimorphia se basó, mayormente, en la matriz de Voss y Jansa (2009), pero también incluye caracteres de otros autores, así como nuevos caracteres propuestos en el presente trabajo (ver Anexo 2.2). Algunos de los caracteres de Voss y Jansa (2009) fueron modificados (ver comentarios en la lista de caracteres: Anexo 2.2) y otros no fueron tenidos en cuenta porque no aplicaban para el presente análisis (e.g., aquellos que permitían diferenciar a los didélfidos de los australidelfios y paucituberculados). En algunos casos se cambió la nomenclatura usada, para mantener una consistencia a lo largo de toda la tesis. Se decidió conservar los caracteres cariotípicos y de morfología externa (ambos quedando sin codificar en los taxones fósiles), ya que muchas de las relaciones entre los didélfidos actuales están soportadas por dichos caracteres. La matriz de Voss y Jansa (2009) incluía muchas más especies de didélfidos actuales de las que se utilizaron en el presente estudio.

Debido a que se agregaron nuevos caracteres y se modificaron o eliminaron algunos de los que tenía dicha matriz, fue necesario revisar nuevamente materiales de todas las especies evaluadas 
por dichos autores. Dado que no se tenía materiales disponibles de todas ellas, muchos de estos caracteres quedaron sin codificar. En los primeros ensayos, al correr la matriz, muchas de las relaciones quedaban sin resolver (muchas politomías); si bien se ha visto que las entradas faltantes no necesariamente producen un efecto negativo en la resolución de los árboles, sino que es dependiente de la información que contiene la matriz (ver Nixon y Davis, 1991; Platnick et al., 1991; Maddison, 1993; Prevosti y Chemisquy 2010 y literatura allí citada), se decidió ensayar eligiendo algunos representantes de cada género de los cuales se tuviera material disponible para revisar, para que pudieran ser completamente o casi completamente codificados. Esto resultó en una mejor resolución, por lo que se optó por realizar una filogenia más sencilla, incluyendo estos taxones seleccionados. Además de estos didélfidos actuales, la matriz del presente trabajo incluyó didélfidos extintos y otros didelfimorfios fósiles, entre los que se encuentran algunos de los taxones de La Venta.

La codificación de los nuevos caracteres, nuevos taxones y los cambios en la codificación respecto a previas versiones de las matrices usadas, fueron hechos a partir de la observación de materiales originales, calcos o fotografías, además de información adicional tomada de la literatura. En algunas ocasiones se utilizaron únicamente recursos bibliográficos, cuando ningún otro recurso estaba disponible. Las listas completas de los taxones y materiales revisados para estos análisis se presentan en los Anexos 1.1 (Sparassodonta) y 2.1 (Didelphimorphia). Las matrices utilizadas en los diferentes análisis filogenéticos fueron editadas en el programa Mesquite versión 3.3 (Maddison y Maddison, 2017). El análisis se llevó a cabo por medio de búsquedas heurísticas realizadas usando el programa TNT 1.1 (Goloboff et al., 2008). Los árboles iniciales fueron obtenidos a partir de 1000 réplicas aleatorias. Los árboles de Wagner resultantes fueron tratados como dicotómicos y se les aplicó el método de intercambio de ramas (ing. "branchswaping") con bisección del árbol y reconexión (TBR). En todos los casos, los árboles de consenso calculados fueron de consenso estricto.

\section{ANÁLISIS ECOMORFOLÓGICO}

\section{Masa corporal}

Las estimaciones de masa corporal de los metaterios de La Venta se realizaron con base en variables independientes correspondientes a medidas tomadas en la dentición, las cuales corresponden al largo o al área de diferentes molares. En el caso del ancho, se tomó el ancho máximo del molar, bien sea el del talónido o el del trigónido, dependiendo de cada caso particular. Al momento de elegir la variable más adecuada para la estimación de masa corporal se deben tener en cuenta los parámetros utilizados para medir la bondad del ajuste de cada ecuación (i.e., error de predicción porcentual: \%PE; y error estándar porcentual de la estimación: \%SEE), que se utilizan para determinar cuál es la mejor predicción: a menor valor de estos parámetros, mejor será el 
potencial predictivo de la ecuación. También se debe tener en cuenta el Coeficiente de Determinación $\left(\mathrm{R}^{2}\right)$, que toma valores de 0 a 1: cuanto más cercano a 1 ese valor mejor es el ajuste del modelo (Sokal y Rohlf, 1995). Las mejores variables predictivas varían entre los diferentes autores. Los valores más bajos de \% $\mathrm{PE}$ (secundariamente, el $\% \mathrm{SEE}$ ) junto con un valor de $\mathrm{R}^{2}$ cercano a 1, indicarán la mejor opción en cada caso.

Para el análisis de los esparasodontes se realizaron estimaciones basadas principalmente en dos grupos de ecuaciones. El primero corresponde a las ecuaciones elaboradas por Zimicz (2012), las que son una adaptación de aquellas de Gordon (2003), construidas sobre la misma base de datos que incluye marsupiales generalizados de las familias Didelphidae y Dasyuridae. El segundo grupo de ecuaciones corresponde a aquellas provenientes de la base de datos de dasiuromorfos de Myers (2001). Este último fue elegido debido a que mostraba los valores más bajos de \%PE respecto a los demás set de ecuaciones presentados por dicho autor.

Las mejores variables predictivas contempladas en el análisis de Sparassodonta se encuentran dentro del grupo de ecuaciones de Zimicz (2012), y corresponden al largo del segundo molar para la dentición superior, y el largo del tercer molar para la dentición inferior. Sin embargo, estos molares no se preservan en todos los ejemplares estudiados en la presente revisión, por lo cual para cada caso se utilizó la mejor variable disponible según la preservación del material, que no siempre corresponde a aquella con mejores indicadores de bondad del ajuste.

Las ecuaciones de Zimicz (2012) están expresadas como logaritmo natural (logaritmo en base $e=\ln$ ), mientras que Myers (2001) utiliza logaritmo decimal (logaritmo en base $10=\log$ ). Cada variable independiente fue incluida en la ecuación correspondiente y el valor logarítmico resultante fue detransformado (i.e., detransformación logarítmica: usando $e^{\mathrm{y}}$ y $10^{\mathrm{y}}$ para $\ln$ y $\log$, respectivamente). Este valor detransformado fue posteriormente multiplicado por su correspondiente factor de corrección. Ambos autores utilizan el factor de corrección conocido como "smearing estimate" (SE), que es utilizado para minimizar las desviaciones en las estimaciones causadas por la transformación y detransformación de los datos. Este factor es un término no paramétrico que, en ocasiones, puede aparecer expresado como porcentaje, como es el caso de las ecuaciones de Myers (2001). Como lo indica Smith (1993: p. 32), "un típico valor para un factor de corrección, por ejemplo 1,085, indicaría que la estimación de masa corporal derivada de la ecuación está subestimando en un 8,5\% la masa media aritmética para cada valor de la variable independiente" (inglés en el original). Esto se debe tener en cuenta al momento de aplicar el factor de corrección cuando este se encuentre expresado como porcentaje, ya que, si se multiplica directamente por tal valor, la estimación estaría sobreestimada. Por lo tanto, un valor de $\%$ SE de 3,5 (i.e., 3,5\%), correspondería a un valor de SE de 1,035 y este último valor será el que deba ser multiplicado por el valor detransformado resultante de la ecuación.

La clasificación de tamaños usada para los esparasodontes sigue las categorías de tamaño para mamíferos carnívoros de Prevosti et al. (2013): tamaño pequeño, por debajo de $7 \mathrm{~kg}$; tamaño mediano, entre 7 y $15 \mathrm{~kg}$; y tamaño grande, por encima de $15 \mathrm{~kg}$. 
Las estimaciones realizadas para los didelfimorfios de La Venta siguieron la misma metodología que se usó para los esparasodontes, pero en este caso sólo se usaron las ecuaciones de Zimicz (2012). Al igual que en los esparasodontes de La Venta, no siempre se preservan los molares que representan las mejores variables predictivas, por lo cual, para cada caso se utilizó la mejor variable disponible según la preservación del material, que no siempre corresponde a aquella con mejores indicadores de bondad del ajuste.

La masa corporal de los "ameridelfios" incertae sedis (Tablas 6.3-6.4) y los microbioterios (Tabla 8.3) fue estimada usando la misma metodología del análisis realizado para los didelfimorfios. Los taxones con dientes plagiaulacoideos (los Paucituberculata) fueron analizados con la ecuación de Zimicz (2004), siguiendo el mismo procedimiento anteriormente mencionado.

\section{Inferencias dietarias}

Se realizaron análisis cualitativos y cuantitativos para estimar los hábitos alimentarios de las diferentes especies de La Venta. En el análisis cualitativo se observó la morfología del talónido y se tuvo en cuenta la presencia de adaptaciones para la carnivoría, siguiendo los parámetros sugeridos por Zimicz (2012), quien plantea que en los hipercarnívoros, los talónidos se caracterizan por presentar una sola cúspide central y sectorial (Van Valkenburgh, 1991); por otro lado, las especies más omnívoras presentan talónidos acuencados con dos cúspides simétricas y similares en tamaño; mientras aquellos casos intermedios en los que el talónido no está totalmente transformado en cuenca y en los que hay dos cúspides principales, pero el hipocónido es bucal y mayor al entocónido, son considerados propios de las especies mesocarnívoras (Zimicz, 2012).

Para el análisis cuantitativo se evaluaron algunos parámetros morfométricos en los diferentes grupos estudiados, con el fin de medir el grado relativo de carnivoría de sus molares. Estos se llevaron a cabo calculando índices a partir de medidas tomadas en la dentición superior o inferior. A continuación, se explicarán cada uno de estos índices:

Área relativa de molienda (RGA): este parámetro se evaluó siguiendo a Prevosti et al. (2013) y se utilizó en el análisis ecomorfológico de los esparasodontes. El factor RGA es un índice de carnivoría basado en el área relativa de molienda del $\mathrm{m} 4$. Este molar presenta los rasgos carnívoros más pronunciados en los esparasodontes, siendo análogo al m1 de los Carnivora (Werdelin, 1987; Prevosti et al., 2013).

$$
R G A=\frac{A T M}{L T r i}
$$

Este índice fue calculado siguiendo a Prevosti et al. (2013; modificado de Van Valkenburgh, 1991), a partir de la relación entre el área total de molienda (ATM), que corresponde al área de la 
cuenca del talónido (largo x ancho), y el largo del trigónido (LTri). A partir del resultado obtenido se pueden clasificar los taxones en diferentes categorías (según Prevosti et al., 2013):

- Hipercarnívoro, cuando el RGA está entre 0-0,48.

- Mesocarnívoro, con un RGA entre 0,48-0,54.

- Omnívoro, con RGA mayor a 0,54.

Este parámetro no se usó en el análisis ecomorfológico de los didelfimorfios de La Venta, ya que todos ellos presentan talónidos con cuencas relativamente bien desarrolladas, por lo que entrarían dentro de la categoría de omnívoros.

Longitud relativa del trigónido del molar carnicero: este parámetro se evaluó siguiendo a Zimicz (2012) y se utilizó en el análisis ecomorfológico de los esparasodontes.

Como ya se explicó en el parámetro anterior, el m4 es considerado el molar carnicero en los metaterios. Este índice relaciona el largo del trigónido de dicho molar (LTriMC) respecto a su largo total (LMC), siguiendo la siguiente fórmula:

$$
L R T M C=\frac{L T \operatorname{tri} M C}{L M C}
$$

Este índice permite clasificar las diferentes especies dentro de las siguientes categorías:

- LRTMC> 0,9: hipercarnívoros comedores de carne.

- LRTMC entre 0,8 y 0,9: hipercarnívoros quebrantahuesos.

- LRTMC entre 0,7 y 0,8: mesocarnívoros.

- $\quad$ LRTMC $<0,7$ : omnívoros

Longitud relativa de la postmetacrista vs. la postprotocrista: este parámetro se evaluó siguiendo a Voss y Jansa (2003 y 2009) y se utilizó en el análisis ecomorfológico de los taxones didelfimorfios. "Entre las muchas estructuras afectadas por la carnivoría, la postmetacrista ("metacrista" en Voss y Jansa, 2003) es la más fácil de medir y su hipertrofia respecto a la postprotocrista se relaciona convenientemente por medio de un indice, la razón entre sus longitudes.." (Voss y Jansa, 2003, pág. 37, pie de página 10). A mayor diferencia entre las longitudes de estas dos estructuras (i.e., una postmetacrista más larga respecto a la postprotocrista), mayor será el grado de carnivoría del molar. Estas longitudes deben ser medidas en el M3 (Voss y Jansa, 2003).

En el presente documento se menciona este índice relativo de carnivoría como "longitud relativa de la postmetacrista" (LRPM) y se calcula a partir de la razón entre la longitud de la postmetacrista (LPM; MCL en Voss y Jansa, 2003) y la longitud de la postprotocrista (LPPr; PCL en Voss y Jansa, 2003), como se expresa a continuación (siguiendo a Voss y Jansa, 2003, pág. 37, pie de página 10$)$ : 


$$
L R P M=\frac{L P M}{L P P r}
$$

La lontitud de la postmetacrista (LPM) se mide desde el ápice del metacono hasta la posición de la StE, mientras la longitud de la postprotocrista (LPPr) se mide desde el ápice del protocono hasta la base del metacono (Voss y Jansa, 2003, pág. 37, pie de página 10).

Para tomar las medidas de la postprotocrista se tuvo en cuenta que Voss y Jansa $(2003,2009)$ habían asumido que el metacónulo estaba ausente en todos los didélfidos; por lo tanto, estaría ausente la cresta postmetaconular (véase más arriba, "Comentarios acerca de algunas homologías"). Esto significa que, en aquellos didélfidos vivientes en los que en la presente revisión se identificó un metacónulo vestigial (carácter 112 en la matriz de Didelphimorphia) y por consiguiente se presenta una cresta postmetaconular, la longitud tomada por estos autores correspondería a la postprotocrista + la cresta postmetaconular (hasta la base del metacono). Debido a que en el presente análisis se comparan con otros taxones siguiendo a Voss y Jansa (2003 y 2009), se tomaron los mismos parámetros de medición para mantener una consistencia en los datos. Sin embargo, sería importante que en el futuro se pudieran realizar nuevamente estos cálculos en todas las especies teniendo en cuenta las longitudes reales de la postprotocrista, o intentar analizar si estas dos crestas se comportan en conjunto como una sola estructura, al menos hasta llegar a la base del metacono.

Los resultados de los índices calculados para los metaterios de La Venta se ubicaron en la gráfica de Voss y Jansa (2003, Fig. 12), para revisar con cuáles taxones coincidían y así poder agruparlos dentro de una de las categorías usadas por Voss y Jansa (2009; dentro de la descripción de cada taxón mencionan la categoría que le corresponde). Cabe resaltar que estas categorías no son propuestas en este trabajo, sino que son tomadas de Voss y Jansa (2009), quienes las utilizaron para describir la morfología molar de diferentes taxones siguiendo los agrupamientos obtenidos en la Fig. 12 de Voss y Jansa (2003). En esta categorización se utilizará el término "carnasialización" ("carnasializado"), que en el presente trabajo fue adaptado del inglés "carnassialization", el cual ha sido usado previamente por varios autores (Reig y Simpson, 1972; Voss y Jansa 2003, 2009).

A continuación, se listan las diferentes categorías usadas por Voss y Jansa (2009) y cada uno de los taxones que dichos autores incluyen dentro de ellas:

- No carnasializado: la postmetacrista es subigual a la postprotocrista (e.g., Caluromysiops y el subgénero de Caluromys (Mallodelphys).

- Ligeramente carnasializado: la postmetacrista es ligeramente más larga que la postprotocrista (e.g., Glironia, Hyladelphys y el subgénero Caluromys Caluromys).

- Moderadamente carnasializado: la postmetacrista es visiblemente más larga que la postprotocrista (e.g., Marmosa y Tlacuatzin).

- Fuertemente carnasializado: la postmetacrista es marcadamente más larga que la 
postprotocrista (e.g., Monodelphis, Metachirus, Chironectes, Didelphis, Lutreolina, Philander, Chacodelphys, Cryptonanus, Lestodelphys, Marmosops y Thylamys).

En aquellos taxones de La Venta en los que estas longitudes no pudieron ser medidas por no preservar el M3, se realizó una comparación cualitativa a partir de los índices ya medidos por Voss y Jansa (2003), comparando las longitudes relativas de estas crestas en los molares superiores preservados, con aquellas de los loci correspondientes en las especies a las que estos autores ya habían estudiado, y de esta forma se les asignó una de las categorías.

Compresión areal del talónido (área relativa del talónido): este parámetro se evaluó siguiendo a Zimicz (2012) y se utilizó en el análisis ecomorfológico de los didelfimorfios. Evalúa la compresión del área del talónido respecto a la del trigónido. Se calcula por medio de un índice de compresión areal (CA), que relaciona el área de las superficies oclusales del talónido (ATal; i.e., largo x ancho) y el trigónido (ATri; i.e., largo x ancho). Cada área se obtiene multiplicando el largo por el ancho de cada estructura. Este índice se calcula preferiblemente en el m2 (Zimicz, 2012), por medio de la siguiente fórmula:

$$
C A=\frac{A T a l}{A T r i}
$$

El valor 1 indica que ambas superficies presentan áreas similares, mientras que los valores superiores indican una expansión del talónido respecto al trigónido, y los inferiores, una compresión. Estos resultados pueden clasificarse dentro de las siguientes categorías (Zimicz, 2012):

- CA > 1: hábitos granívoros o frugívoros; caracterizados por presentar talónidos más amplios que los trigónidos.

- $\mathrm{CA}=1$ : hábitos folívoros o insectívoro/frugívoros; caracterizados por presentar talónidos tan amplios como los trigónidos.

- CA < 1: hábitos insectívoros estrictos o faunívoros; caracterizados por presentar talónidos de área reducida respecto a la de los trigónidos.

Compresión longitudinal del talónido (longitud relativa del talónido): este parámetro se evaluó siguiendo a Zimicz (2012) y se utilizó en el análisis ecomorfológico de los didelfimorfios. Evalúa la compresión anteroposterior del talónido respecto a la longitud anteroposterior del trigónido. Se evalúa por medio de un índice de compresión longitudinal (CL), que relaciona la longitud anteroposterior del talónido (LTal) y la longitud anteroposterior del trigónido (LTri). Se calcula preferiblemente en los m2 (Zimicz, 2012), por medio de la siguiente fórmula:

$$
C L=\frac{L T a l}{L T r i}
$$


El valor 1 indica que las longitudes de ambas estructuras son similares en longitud; el valor superior a 1 indica que el talónido es más largo que el trigónido, mientras el valor inferior indica que el talónido está comprimido en sentido anteroposterior respecto a la longitud anteroposterior del trigónido. Estos resultados pueden clasificarse dentro de las siguientes categorías (Zimicz, 2012):

- CL > 1: hábitos granívoros o frugívoros; caracterizados por presentar talónidos expandidos anteroposteriormente respecto al trigónido.

- $\mathrm{CL}=1$ : hábitos folívoros o insectívoro/frugívoros; caracterizados por presentar talónidos y trigónidos con la misma longitud anteroposterior.

- $\mathrm{CL}<1$ : hábitos insectívoros estrictos o faunívoros; caracterizados por presentar talónidos anteroposteriormente comprimidos respecto a los trigónidos. 


\section{CAPÍtulO 3. MARCO GEOLÓGICO}

\section{GRUPO HONDA}

\section{Definición y Antecedentes}

El Grupo Honda es una unidad sedimentaria continental que aflora en varias localidades a lo largo del Valle Superior y Medio del Río Magdalena, el cual se ubica entre las cordilleras Central y Oriental de Los Andes colombianos (Guerrero, 1997: Fig. 2.1). La localidad tipo del Grupo Honda se ubica en cercanías de los municipios de Honda (Departamento del Tolima) y La Dorada (Departamento de Caldas), en el Valle Medio del Río Magdalena. Otras localidades donde aflora el Grupo Honda son: Puerto Salgar y Cambao en el Departamento de Cundinamarca; Perico (en Honda), Girardot, Carmen de Apicalá, Coyaima, Chaparral y Natagaima en el Departamento del Tolima; y La Victoria, Villavieja, Aipe, Baraya, Campoalegre y Gigante en el Departamento del Huila.

Los mejores afloramientos y las secciones fosilíferas más productivas del Grupo Honda se encuentran en la zona conocida como "área de La Venta" (Fig. 3.1), ubicada en el Desierto de La Tatacoa, en el Valle Superior del Río Magdalena. A esta zona se le denominó "área de La Venta" por el área a lo largo de la quebrada que lleva ese mismo nombre, donde se hallan los niveles fosilíferos de mayor abundancia. La asociación fosilífera de La Venta incluye plantas (maderas), algunos invertebrados (crustáceos) y vertebrados: peces, reptiles, aves y mamíferos.

A grandes rasgos, el Grupo Honda es una secuencia de litoarenitas volcánicas color gris claro (conocidas como "sal y pimienta"), lodolita café rojizo, lodolita gris verdosa, y en menor proporción, conglomerados (Guerrero, 1997). En el área de La Venta los depósitos son en general lodolitas y areniscas, poco consolidadas que se erodan fácilmente, produciéndose de este modo un paisaje semidesértico (Guerrero, 1997).

El Grupo Honda fue definido originalmente por Hettner (1892) con el nombre de Honda Sandstein, en cercanías a la población de Honda (Departamento del Tolima), sobre el río Magdalena (Valle Medio del Magdalena). En el Valle Superior del Magdalena el nombre de Series de Honda fue introducido por Stille $(1907,1938)$ en el área entre Coyaima y Natagaima. Es Royo y Gómez (1942) quien propone el nombre de Formación Honda para la secuencia aflorante al norte de Villavieja (Huila), y divide la Formación en Honda superior, caracterizada por guijos de roca volcánica en los conglomerados, y Honda inferior, carente de material volcánico, más arcillosa y 
de colores abigarrados.

Stirton (1953) eleva la unidad a la categoría de Grupo y, como Fields (1959), insiste en que las divisiones establecidas corresponden a unidades informales. Stirton presentó una lista de fauna, encontrada en capas con numerosos cantos de cuarzo, rocas volcánicas, arena con hornblenda y minerales opacos. Fields (1959) presenta una descripción detallada del Grupo Honda en la región de Villavieja, y localiza y describe la fauna nombrada por Stirton (1953). Asimismo, propone que la sedimentación del Grupo Honda no comenzó al mismo tiempo en todo el valle del Magdalena.

En 1970, Wellman divide los sedimentos del Grupo Honda en dos formaciones; la Formación La Dorada, con los miembros Puerto Salgar y Pericos; y la suprayacente Formación Villavieja, con los miembros Baraya y Cerro Colorado. De Porta (1974) discute el sentido del término Grupo Honda usado en el extremo sur del Valle Medio y en el Valle Superior del Magdalena, e indica que se trata de dos unidades que se han utilizado con el mismo nombre, pero que tienen sentido diferente. Según él, la redefinición de Wellman (1970) es inadecuada, ya que utiliza nomenclatura y subdivisiones que son comunes en el Valle Medio y Superior del Magdalena, y desconoce los planteamientos de Fields (1959) y De Porta (1966) relacionados con la presencia de dos cuencas separadas durante la sedimentación del Grupo Honda. Por otra parte, la asimilación de las unidades en cada cuenca no es muy precisa si se tiene en cuenta que en el Valle Superior es difícil reconocer la Formación La Dorada y en el Valle Medio se dificulta la identificación de la Formación Villavieja.

En la estratigrafía propuesta por Takai (1992), el Grupo Honda en el área de La Venta comprende tres unidades: la Formación Cerbatana (escrito en dicha publicación como "Cervetana Formation”), la Formación Villavieja y la Formación Las Mesitas. Como se puede apreciar en la Tabla 3.2, esta sección no incluiría lo que actualmente se conoce como Formación La Victoria.

Guerrero (1990) propone una nueva variante, que es parcialmente complementada en su tesis doctoral (Guerrero, 1993). El autor propone introducir el nombre Formación La Victoria para referirse al conjunto sedimentario que yace en inconformidad sobre las vulcanitas del Miembro Prado de la Formación Saldaña, en el Cerro Chacarón, y cuya parte superior la conforman las Capas del Conglomerado de Cerbatana (Guerrero, 1990). La Formación La Victoria es equivalente a las unidades El Líbano y Cerbatana (excluidas las Arcillas de San Nicolás) de Fields (1959) o también lo que Wellman (1970) llama el Miembro Perico de la Formación La Dorada.

Posteriormente, Guerrero (1997) publicó la revisión estratigráfica más completa que se ha hecho hasta ahora en el área de La Venta, basado en sus trabajos anteriores y nuevos estudios estratigráficos y geocronológicos. La correlación entre las unidades propuestas por Guerrero (1997) y algunos de los trabajos estratigráficos previos de otros autores se muestran en la Tabla 3.2. Después de muchas divisiones y nombres propuestos por diferentes autores para la unidad, finalmente se ha aceptado la división presentada por Guerrero (1997), en la que se propone llamar la unidad Grupo Honda, y dividirla en las formaciones La Victoria y Villavieja.

Cabe destacar que Parra (2015) y Parra-Sánchez y Restrepo-Moreno (2015) han propuesto 
una nueva unidad denominada 'Grupo La Venta', que incluiría a los niveles que afloran en el desierto de La Tatacoa. Sin embargo, la estratigrafía de dicha unidad no ha sido publicada formalmente y por el momento sólo está disponible en resúmenes de congresos. Sin embargo, recientemente Anderson et al. (2016) realizaron una revisión detallada de la estratigrafía del área de La Venta, que incluye análisis paleogeográficos (Fig. 3.2) y cálculos de precipitaciones (Fig. 3.3), y continúan utilizando las unidades y nomenclatura propuestas por Guerrero (1997). Por consiguiente, la estratigrafía utilizada en el presente trabajo sigue a Guerrero (1997) y Anderson et al. (2016).

\section{Geología Estructural}

El Valle Superior del Magdalena se encuentra limitado al oeste por el sistema de fallas de Chusma, un sistema de cabalgamiento Eoceno-Oligoceno que define el frente oriental de la Cordillera Central (Butler y Schamel, 1988; Mojica y Franco, 1990; van der Wiel y van den Bergh, 1992; Sarmiento and Rangel, 2004). El límite oriental del Valle Superior del Magdalena está definido por el sistema de fallas de Algeciras (convergencia oeste a noroeste), una serie compleja de fallas de cabalgamiento, transpresionales y de rumbo dextral (Anderson et al., 2016). Este complejo sistema de fallas separa rocas graníticas jurásicas (monzogranito de Algeciras) de rocas metamórficas de alto grado (gneis, esquistos y migmatitas) del Mesoproterozoico-Neoproterozoico temprano, marca la expresión sur de mayor transpresión activa en Colombia y ha sido dominada por tectónica transcurrente a lo largo del Cuaternario (Chorowicz et al., 1996; Velandia et al., 2005; Bustamante et al., 2010). Sin embargo, el hecho de que se presente un pronunciado relieve estructural a lo largo de los más de $15 \mathrm{~km}$ de extensión de la zona de falla de Algeciras a pesar del bajo ángulo de buzamiento $\left(\sim 15^{\circ} \mathrm{SE}\right)$, requiere que haya existido un desplazamiento inverso durante una gran parte de su historia (Anderson et al., 2016; Bakioglu, 2014). Se considera que una transición temporal entre compresión y deformación de rumbo habría ocurrido entre el Mioceno más tardío y el Plioceno, pero aún no es clara una datación más precisa (Velandia et al., 2005; Egbue y Kellogg, 2010; Egbue et al., 2014).

\section{Estratigrafía}

El Grupo Honda en el Valle del Magdalena Medio es una unidad bien diferenciada, limitada en su tope y base por inconformidades (Fig. 3.3; Guerrero, 1997: Fig. 2.8). Se ubica en inconformidad angular sobre las andesitas de la Formación Saldaña (Triásico-Jurásico) y depósitos del Cretácico a Oligoceno (Guerrero, 1997). La sucesión descansa sobre una discordancia erosiva conocida como el Hiato oceánico del Neógeno (NH3) (Guerrero 1997), de edad Mioceno medio, debajo de las rocas de las formaciones Neiva y Gigante (Guerrero 1997), incluidas por Guerrero (1993) en el Grupo Huila. Estratigráficamente se encuentra ubicada entre dos superficies discordantes que 
reflejan importantes episodios de vulcanismo y levantamiento de los Andes colombianos (Guerrero et al, 1997).

En la localidad de La Venta, el Grupo Honda está dividido en las formaciones La Victoria y Villavieja (Fig. 3.3; Guerrero, 1997: Fig. 2.8). Estas unidades están separadas por un nivel conglomerático de guijos clastosoportados, que presenta un espesor de 5 a $10 \mathrm{~m}$. Este nivel corresponde al Conglomerado de Cerbatana, el cual aflora al norte de la Cuenca de Neiva (Guerrero, 1997).

De estas dos unidades, la más antigua es la Formación La Victoria. Esta se encuentra compuesta principalmente por lodolitas bioturbadas, con bandas color gris, violeta y verde. Muchos intervalos contienen nódulos de carbonato, con rizolitos bien desarrollados cerca del tope de la sección (Guerrero, 1997). Estas arcillolitas y limolitas son interrumpidas periódicamente por capas métricas de arenisca con estratificación cruzada y bases erosivas. Aunque la mayoría se acuña lateralmente alrededor de $\operatorname{los} 20-30 \mathrm{~m}$, varios intervalos de arenisca más gruesos son continuos a lo largo de los $2-4 \mathrm{~km}$ de ancho de la cuenca y forman importantes capas guía (Guerrero, 1997). La Formación La Victoria se depositó bajo una tasa de subsidencia de $950 \mathrm{~mm} /$ 1000 años (Guerrero 1997). Tiene un espesor de aproximadamente $500 \mathrm{~m}$ en la sección tipo, aumentando de espesor hacia el sur hasta alcanzar los $1000 \mathrm{~m}$ cerca de Gigante. Ha sido interpretada como un sistema de río meandriforme con un desarrollo significativo de suelos en depósitos finos de llanuras aluviales (Wellman, 1970; Guerrero, 1997).

La Formación Villavieja tiene un espesor de $580 \mathrm{~m}$ en la sección tipo y suprayace de manera concordante al Conglomerado de Cerbatana (Fig. 3.3). Mientras la base contiene lodolitas fosilíferas color verde a gris y paleosuelos similares a los de la Formación La Victoria, los $350 \mathrm{~m}$ superiores se caracterizan por presentar paleosuelos y lodolitas rojos brillantes, referidos a las Capas Rojas de Polonia. Los nódulos de carbonato son menos comunes y no tan bien desarrollados como en las capas rojas, pero aún así ocurren en horizontes discretos (Anderson et al., 2016). Las areniscas con estratificación cruzada en artesa son comunes en esta formación, mostrando hacia el tope un incremento relativo con respecto a los depósitos de llanura aluvial (Anderson et al., 2016). La tasa de subsidencia durante la depositación de la Formación Villavieja fue de 413 mm/1000 años (Guerrero 1997).

Contrario a lo que ocurre con los grandes canales de la Formación La Victoria, las areniscas de la Formación Villavieja están restringidas a niveles canalizados de $1-5 \mathrm{~m}$ de espesor que no se extienden más allá de 10-20 m a lo largo del rumbo (Anderson et al., 2016). En La Venta, el contacto entre la Formación Villavieja y la suprayaciente Formación Gigante (Grupo Huila sensu Guerrero, 1997) está marcado por una inconformidad angular de bajo grado; mientras hacia el sur, cerca de Gigante, este contacto es una conformidad (van der Wiel et al., 1992; Guerrero, 1997). Allí la Formación Villavieja presenta un menor espesor $(\sim 250 \mathrm{~m})$ y una mayor proporción de facies de canal a llanura aluvial que en la localidad de La Venta (van der Wiel y van den Bergh, 1992).

En general, la unidad más fosilífera del Grupo Honda corresponde a la Formación Villavieja 
(Guerrero, 1997; Kay y Madden, 1997; pers. obs.). Esto probablemente se deba simplemente a un sesgo preservacional, debido a que las condiciones de depositación de la Formación La Victoria eran menos aptas para la preservación de restos fósiles, al haber ocurrido bajo un sistema de mayor energía que aquel bajo el que se depositaron los sedimentos de formación suprayacente (pers. obs.). Dentro de la Formación Villavieja, los niveles más fosilíferos son las denominadas "Capa de Peces" y la "Capa del Mono". Aunque los fósiles que han sido colectados en el área de La Venta han sido hallados en niveles a lo largo de toda la secuencia del Grupo Honda, de los dos niveles anteriormente mencionados se ha extraído la mayor cantidad de material (Guerrero, 1997).

La unidad Capa del Mono fue propuesto formalmente por Guerrero (1997) para designar un paquete de 14,8 $\mathrm{m}$ de areniscas y lodolitas grises verdosas extremadamente fosilíferas, ubicado hacia la base del Miembro Baraya de la Formación Villavieja (sensu Guerrero, 1997). A la base de esta unidad se presenta un contacto concordante bien marcado entre las formaciones Villavieja y La Victoria. A pesar de que la Capa del Mono está compuesta predominantemente por lodolitas, las intercalaciones de areniscas son ligeramente más espesas que las que se presentan en unidades más superiores del Miembro Baraya. Una típica secuencia granodecreciente de la Capa del Mono consiste en: un nivel de arenisca de grano medio de $1 \mathrm{~m}$ de espesor seguida por 4,5 $\mathrm{m}$ de lodolita arenosa color marrón rojizo, 1,2 m de lodolita color verde pálido, y hacia el tope, 0,8 $\mathrm{m}$ de lodolita color marrón rojiza (Guerrero, 1997). Esta capa contiene mayormente restos de mamíferos, incluyendo metaterios, roedores y una gran cantidad de primates (entre otros). Las dataciones por trazas de fisión recalculadas por Guerrero (1990) muestran una edad de 13,00 $\pm 0,88$ Ma. para esta unidad.

La unidad Capa de Peces está compuesta por arcillolita y lodolita verdes con un enorme contenido de restos de peces desarticulados (especialmente espinas, vértebras y dientes). La unidad presenta un espesor que varía entre 1,2 m y 6 m (Guerrero, 1997; Fields, 1959). Los mejores afloramientos están expuestos al norte de la Quebrada La Venta. Aparentemente se depositó en un ambiente de lago o pantano. La naturaleza fragmentaria de los fósiles y la abundancia de coprolitos sugieren que muchos de estos fragmentos son en realidad residuos de depredadores. Además de los restos de peces, también son abundantes los dientes aislados de mamíferos y vértebras de serpiente. La continuidad lateral de la capa (al menos en dirección este-oeste) también es un indicador de ambientes deposicionales lacustres o pantanosos, en un área de al menos $10 \mathrm{~km}$ de diámetro.

Además de estas dos unidades, los materiales estudiados en el presente trabajo fueron colectados en la unidad entre las Capas de Arenisca del Chunchullo y de Tatacoa, otros niveles no identificados de la Formación La Victoria; y de la Formación Villavieja, la unidad entre las Capas Rojas de La Venta y de El Cardón, las Capas Rojas de El Cardón y las Capas Rojas de Polonia (véase Tablas 3.1, 4.1, 5.1, 6.1, 7.1, 8.1 y 9.1). 


\section{Geocronología}

Se han realizado varias dataciones para esta unidad, basadas en análisis radiométricos y estudios magnetoestratigráficos, como los realizados por Guerrero (1993) y Flynn et al. (1997). Estos métodos incluyen dataciones con 40Ar/39Ar y correlaciones paleomagnéticas en diferentes unidades del Grupo Honda. Se ha establecido una edad de 13,5 Ma. hacia la base de la Formación La Victoria (unidad inferior) y de 10,1 Ma. en la base del Grupo Huila (Guerrero, 1997).

El Grupo Honda comprende el intervalo entre 13,8 y 11,6 Mi (Guerrero, 1997). El contacto entre la Formación La Victoria y la Formación Villavieja fue estimado en 12,5 Mi (Guerrero, 1993; Flynn et al., 1997). Según estas dataciones y el espesor de las unidades, aparentemente estaría ocurriendo un incremento en las tasas de acumulación de sedimento desde la depositación de la Formación La Victoria ( $\sim 400 \mathrm{~m} / \mathrm{m}$.a.) a la de la Formación Villavieja ( $\sim 500 \mathrm{~m} / \mathrm{m}$.a.) (Anderson et al., 2016). Esto es consistente con un cambio pronunciado en la arquitectura sedimentaria, al pasar de cinturones de canal espesos y amalgamados en la Formación La Victoria, a pequeños cuerpos de canal aislados en la Formación Villavieja (Leeder, 1977; Mackey y Bridge, 1995; Heller y Paola, 1996; Anderson et al., 2016).

\section{Piso y Edad Laventense}

Las faunas sudamericanas del Mioceno medio han sido agrupadas tradicionalmente dentro de una única unidad biocronológica informal, la Edad Mamífero Sudamericana (SALMA) "Friasense", usada por primera vez por Ameghino (1906) en referencia a una fauna descubierta en la cabecera del Río Frías, en el sur de Chile. Kraglievich (1993) reformuló esta unidad, incluyendo el Friasense (sensu stricto), el Colloncurense y el Mayoense. A partir de la publicación de Patterson y Pascual (1968), se incluían dentro del "Friasense" todas las faunas que fueran más jóvenes que el Santacrucense y más antiguas que el Chasiquense. Estudios posteriores que intentaron clarificar la cronología de las Edades Mamífero del Mioceno (Flynn y Swisher, 1995; Madden et al., 1997) reconocieron nuevamente la diferenciación de Kraglievich (1930), sugiriendo que el "Friasense" sensu lato esté subdividido en unidades más restringidas, incluyendo el Friasense sensu stricto (i.e., el periodo representado en la localidad tipo en Chile) y otras unidades basadas en faunas del Mioceno medio (Croft, 2007).

La fauna de La Venta fue originalmente referida a la Edad Mamífero "Friasense" (Stirton, 1953). Sin embargo, Madden et al. (1997) reconocen que esta asociación muestra bajos niveles de semejanza, tanto con las faunas del Friasense y el Colloncurense, como con las del Colhuehuapense y Santacrucense y que tales niveles de similitud no permiten una correlación precisa. Así mismo, algunos taxones conducían a correlaciones ambiguas, ya que en La Venta estaban presentes fósiles guía tanto del Santacrucense como del "Friasense". Aún así, las comparaciones con taxones del Mioceno de la Argentina indican ubicación entre las faunas del Colloncurense y Mayoense, es decir, dentro de la Edad Mamífero "Friasense", como lo había 
sugerido Stirton (1953). Sin embargo, durante el Mioceno medio de Argentina se presenta una marcada discontinuidad o cambio abrupto en el registro fósil, entre el Colloncurense y el Chasiquense; en la Patagonia, este cambio ocurre durante el "Friasense", entre el Colloncurense y el Mayoense, donde se reporta un hiato cronológico entre 15.7 y $11.8 \mathrm{Ma}$, que no está representado por rocas portadoras de mamíferos fósiles (Madden et al., 1997).

Los estudios sobre la asociación de mamíferos de La Venta permiten a Madden et al. (1997) proponer una nueva unidad cronoestratigráfica, el Piso Laventense, caracterizado por la Zona de Asociación Miocochilius, correspondiente a la parte fosilífera del Grupo Honda, portador de la fauna de La Venta. El Piso Laventense se extiende desde 11.8 hasta 13.5 Ma, según dataciones de ${ }^{40} \mathrm{Ar} /{ }^{39} \mathrm{Ar}$ y correlaciones magnetoestratigráficas. También proponen una nueva geocronológica, la Edad Laventense, equivalente y basada en el Piso Laventense, que se encontraría dentro del hiato temporal reconocido en la secuencia de mamíferos en Patagonia (Madden et al.,1997). Por lo tanto, en la secuencia de Edades Mamífero Sudamericanas, se ubicaría entre el Colloncurense y el Mayoense.

Además de La Venta, una asociación fosilífera sudamericana claramente referible a la Edad Laventense, es la fauna de Quebrada Honda, del Departamento de Tarija, Bolivia. Sin embargo, su asignación al Piso Laventense aún no es clara, ya que son sólo dos los taxones compartidos entre esta y la asociación de La Venta (i.e., Miocochilius y Acarechimys), únicamente a nivel de género; y de los taxones fósiles que definen la Zona de Asociación Miocochlilius (al menos 14 especies de diferentes linajes de mamíferos; Madden et al., 1997), el único compartido es el género Miocochilius, aunque la especie de Quebrada Honda (i.e., M. federicoi) no corresponde a ninguna de las especies de Miocochilius que definen esa unidad bioestratigráfica, ni ha sido reportada hasta el momento en La Venta. Hasta el momento, no ha sido encontrado en Sudamérica registro alguno que tenga correlato con el Piso Laventense.

\section{Paleotopografía, paleocorrientes y ambientes de depositación}

La depositación de la Formación La Victoria (entre 13,5 y 12,9 Ma) se inició durante un periodo de levantamiento y vulcanismo activos de la Cordillera Central, la cual fue el área fuente al oeste de la cuenca (Guerrero, 1997). Las direcciones de paleocorrientes de esta unidad, en sentido este y sudeste, indican que la Cordillera Oriental no existía en ese momento. Los ríos que depositaron los sedimentos de la la Formación La Victoria eran aparentemente continuos hacia el este con los depósitos costeros de la Formación Pebas, en el Amazonas (Guerrero, 1997).

Al iniciarse la depositación de la Formación Villavieja (entre 12,9 y 11,5 Ma), no sólo ocurrieron eventos de vulcanismo y levantamiento activos de la Cordillera Central sino que además se desarrolla el levantamiento de una nueva cadena montañosa: la Cordillera Oriental. Estudios petrográficos recientes (Anderson et al., 2016) identificaron tres etapas para el levantamiento del Macizo de Garzón en la parte sur de la Cordillera Oriental colombiana. La Formación Villavieja se 
habría depositado durante la primera etapa, que abarca un rango temporal entre ca. 12,5 y 6,4 Ma. Durante esta primera etapa la cordillera no representaba una barrera topográfica muy significativa.

En general, las paleocorrientes registradas en el Grupo Honda describen el proceso de levantamiento de esta nueva barrera topográfica. En la parte inferior del Grupo Honda, correspondiente la Formación La Victoria, se registra una dispersión de sedimento en sentido predominantemente este. En la sección intermedia, incluyendo al Conglomerado de Cerbatana, aparentemente ocurre una alternancia entre paleoflujos que corren en sentido este y oeste. Estos depósitos son suprayacidos por un intervalo que presenta paleoflujos que se dirigen hacia el norte, registrados en la parte superior de la Formación Villavieja (Anderson et al., 2016). Los cambios en las paleocorrientes, junto con los cambios que ocurren simultáneamente en las tasas de sedimentación y arquitectura de los canales, se consideran indicadores de la transición entre un sistema fluvial meandriforme no confinado que se dirige en sentido este, y un sistema fluvial anastomosado axial confinado por el desarrollo de topografía en el Macizo de Garzón y una más amplia Cordillera Oriental, los cuales se ubican al este del área de La Venta (Fig. 3.2; Anderson et al., 2016; Guerrero, 1997).

Algunos estudios que relacionan las paleocorrientes, las asociaciones palinológicas y los mamíferos fósiles sugieren que el proceso en que el antiguo sistema de drenaje del sur del Orinoco es capturado por el Río Amazonas y aislado del sistema de drenaje interandino del Magdalena, fue impulsado principalmente por el levantamiento Neógeno de la Cordillera Oriental y los Andes de Mérida (Hoorn, 1994; Hoorn et al., 1995; Díaz de Gamero, 1996). Otros análisis más recientes, reconocen la influencia fundamental de los arcos de basamento del antepaís, los sistemas decompresivos y la acumulación de sedimentos en la evolución del drenaje (Mora et al., 2010; Roddaz et al., 2010; Silva et al., 2013; Caballero et al., 2013; Horton et al., 2015).

\section{Paleoclima}

Se ha estimado que, durante el Mioceno medio, la temperatura en el área de La Venta era similar a la actual. Sin embargo, en aquella época la precipitación anual era mayor (entre 1100 y $1400 \mathrm{~mm}$ anuales, sensu Anderson et al., 2016). Adicionalmente, los fósiles de plantas y animales indican que los periodos de sequía probablemente eran más cortos y menos marcados que en la actualidad. En el área de La Venta se ha hallado madera fósil de especies como Goupioxylon stutzeri, que pertenecen a la familia de las Goupiaceas (Pons, 1969; Kay y Madden, 1997). Las Goupiaceas actuales (género Goupia) viven a menos de 1000 metros sobre el nivel del mar (lo que es concordante con la topografía baja anteriormente mencionada), en hábitats donde las lluvias superan los $2000 \mathrm{~mm}$ anuales y la temperatura varía entre $23^{\circ}$ y $30^{\circ} \mathrm{C}$ (Kay y Madden, 1997). Otra especie encontrada es Terminalioxylon portae (Mirioni, 1965; Pons 1983), perteneciente a la familia Combretaceae, que está relacionada con las actuales Terminaliinae (e.g., Terminalia catappa). La presencia de esta especie indica la ausencia de largos períodos de sequía durante el 
año, muy diferente a las condiciones del actual Desierto de La Tatacoa. El pez pulmonado Lepidosiren puede sobrevivir dentro y fuera del agua. Su presencia en el área de La Venta indica que alternaban períodos de sequía con períodos de inundaciones, ya que esta especie podría habitar cuerpos de aguas temporales (Kay y Madden, 1997).

Son mínimos los cambios paleoclimatológicos atribuidos al levantamiento topográfico detectados durante el período de depositación del Grupo Honda (13,8-11,6 Ma.). Se presentan pocos cambios en las composiciones isotópicas de oxígeno de los carbonatos de suelos en la cuenca Neiva, y las estimaciones basadas en el índice de meteorización de la precipitación media anual (Fig. 3.3) sugieren que la cuenca se hizo más húmeda, en lugar de más seca, como cabría esperar con el desarrollo de sombra de lluvia orográfica ("efecto sombra") producida por un levantamiento al este (Anderson et al., 2016). Estas condiciones, sumadas a los cambios que ocurren en las fuentes de aporte de sedimentos inferidas a partir de análisis de procedencia, sugieren que el macizo de Garzón no formó una barrera topográfica elevada sustancial durante las primeras etapas del levantamiento del basamento. Estos hallazgos son congruentes con los datos biológicos, que sugieren que la flora y fauna en el Valle del Magdalena comenzaron a diferenciarse de la Cuenca del Amazonas recién hacia los ca. 10 Ma (Hoorn et al., 2010; Ochoa et al., 2012; Aguilera et al., 2013). 


\section{PARTE II: RESULTADOS}

\section{CAPÍTULO 4. PARASSODONTA}

Durante gran parte del Cenozoico, los Sparassodonta (Mammalia, Metatheria) fueron los mamíferos depredadores dominantes en América del Sur. A diferencia de otras regiones, en los ecosistemas terrestres de este continente el nicho carnívoro fue compartido por mamíferos, aves (Phorusrhacoidea), grandes cocodrilos (e.g., Sebecidae, Purussaurus), grandes serpientes (Madsoiidae y Boidae), y ocasionalmente anfibios (Marshall, 1977a; Marshall y Cifelli, 1990; Head, et al. 2009; Degrange, 2012; Degrange et al., 2012; Fernicola and Albino, 2012; Scheyer et al., 2013; Prevosti y Forasiepi, 2018). El registro de los esparasodontes es exclusivamente sudamericano y se extiende por aproximadamente 60 millones de años, desde el Paleoceno temprano al Plioceno tardío. Los representantes de este grupo de metaterios incluyen diversas morfologías, incluyendo la de los Hathliacynidae, cuya apariencia ha sido comparada con la de los felinos (Marshall, 1979), los Borhyaenidae, más parecidos a cánidos (Marshall, 1978a), los "quiebrahuesos" Proborhyeaenidae y los "tigres dientes de sable" Thylacosmilidae (Riggs, 1933).

Teniendo en cuenta el número de ejemplares preservados, los esparasodontes representan la mayor parte de los metaterios de La Venta. Algunos de estos ejemplares están representados por materiales muy completos, preservándose elementos tanto craneanos como postcraneanos; los otros grupos de metaterios están representados mayormente por piezas dentarias.

Previamente a la presente revisión, habían sido descriptas y nombradas para La Venta cuatro especies de esparasodontes: Hondadelphys fieldsi (Marshall, 1976a), Lycopsis longirostrus (Marshall, 1977a), Anachlysictis gracilis (Goin, 1997) y Duckecynus magnus (Goin, 1997). En el presente documento se realiza una actualización de estas descripciones, incluyendo una descripción pormenorizada de Anachlysictis gracilis, y se describe una nueva especie de esparasodonte tilacosmílido que Goin (1997: pág. 203) había referido de modo preliminar a "Borhyaenoidea, fam. et gen. incertae sedis (Thylacosmilidae?)". Adicionalmente, se describen al menos otras tres especies de Sparassodonta, incluyendo el primer registro de Hathliacynidae para Colombia y dos nuevas especies de Hondadelphys, y se describen algunos materiales indeterminados que podrían o no estar representando a alguna de estas especies. Esta información permitió realizar una revisión de la taxonomía, filogenia y paleobiología de los esparasodontes de La Venta. 


\title{
REVISIÓN TAXONÓMICA
}

\author{
MAMMALIA Linnaeus, 1758 \\ METATHERIA Huxley, 1880 \\ SPARASSODONTA Ameghino, 1894 \\ HONDADELPHIDAE Marshall, Case and Woodburne, 1990
}

Hondadelphys Marshall, 1976a

Especie Tipo-Hondadelphys fieldsi Marshall, 1976a

Especies Referidas_La especie tipo, Hondadelphys sp. 1 y Hondadelphys sp. 2.

Distribución-Área de La Venta (Desierto de La Tatacoa, Valle Superior del Magdalena, Departamento del Huila, Colombia); Laventense, Mioceno medio.

Diagnosis Enmendada-Esparasodonte de pequeño tamaño con protoconos bien desarrollados, moderadamente expandidos anteroposteriormente y con cuenca amplia; bases del paracono y metacono en contacto pero no fusionadas; centrocrista recta; metacono en el M4 presente aunque fuertemente reducido; metacónido distinguible al menos en los m2-4, aunque marcadamente reducido; y talónidos bien desarrollados, con la cuenca amplia y relativamente profunda (modificada de Marshall, 1976a).

Comentarios-Hondadelphys sp. 1 y Hondadelphys. sp. 2 (ver más abajo) son dos especies que se proponen en el presente trabajo, con base en ejemplares que fueron mencionados por primera vez en la revisión de Goin (1997).

\section{Hondadelphys fieldsi Marshall, 1976a}

(Figs. 4.1-4.5)

Holotipo-UCMP 37960 (Figs. 4.1-4.3), cráneo incompleto que preserva los siguientes elementos: porción basicraneal; fragmento de techo craneano (a la altura del proceso postorbital); fragmento de maxilar derecho unido al lacrimal casi completo y un fragmento del yugal, con el alvéolo del canino, las raíces del P1, el P2 completo, el P3 roto en la punta de la cúspide principal, el M1 completo, el M2 roto (sólo se preserva el protocono) y los M3-4 completos; fragmento de maxilar izquierdo unido a un fragmento de premaxilar (pequeño) y de yugal, con el alvéolo del canino, las raíces de los $\mathrm{P} 1-2$, los $\mathrm{P} 3-\mathrm{M} 1$ completos, fragmento anterior del M2 (incluyendo paracono, protocono y parte anterior de la base del metacono), el M3 casi completo (roto en la esquina anterolabial) y el M4 sin plataforma estilar; mandíbula derecha con alvéolos de los i2-4, los c-p2, alvéolos de los p3-m2, el $\mathrm{m} 3$ roto y el $\mathrm{m} 4$ completo; gran parte del fémur izquierdo, porción proximal del radio izquierdo, porción glenoidea de la escápula izquierda, gran parte del 
atlas, una vértebra; fragmentos óseos no identificados.

Paratipo-UCMP 39251, rama mandibular derecha incompleta con la base del c, los p1-3 completos, base del $\mathrm{m} 1$, el $\mathrm{m} 2$ incompleto y raíz anterior del $\mathrm{m} 3$; fragmento de rama mandibular izquierda con el p3 y talónido del $\mathrm{m} 1$, el $\mathrm{m} 2$ completo; fragmento de maxilar izquierdo con la base del C; fragmento de maxilar derecho con porción posterior del P3 y el M1 completo. Los P3/p3 en proceso de erupción.

Ejemplares Referidos-KU LV-2-A, IGM 250833, IGM 250961, IGM 253049, IGM 253050, IGM 253078, IGM 253079, UCMP 38855, IGM \# 92-04. Figs. 4.4-4.5.

Distribución Geográfica y Estratigráfica-Área de La Venta (Desierto de La Tatacoa, Valle Superior del Magdalena, Departamento del Huila, Colombia); Grupo Honda, Laventense, Mioceno medio (Tablas 3.1 y 4.1; Fig. 3.1).

Diagnosis Enmendada-Molares superiores con una fuerte reducción de las cúspides estilares y la StC comprimida lateralmente y alargada posteriormente, más desarrollada hacia el M1. Se diferencia de las demás especies de Hondadelphys (véase más abajo) en la expansión de las mejillas del maxilar menos desarrollada; el menor número de diastemas; el protocono ligeramente menos expandido anteroposterormente y ligeramente más angosto; y la mayor reducción de la plataforma estilar al nivel labial al paracono. Se diferencia de $H$. sp.1 en el menor tamaño; el diastema entre los P1-2 más corto; el largo relativo de los molares, incrementando del M1 al M3; el M4 más ancho que el M3; el tamaño relativo del metacono respecto al paracono, aumentando del M1 al M3; la fuerte reducción de las cúspides estilares; y los premolares inferiores menos globosos. Se diferencia de $H$. sp. 2 en el mayor tamaño; la sutura nasolacrimal más corta; la posición más posterior del foramen infraorbitario; la diferencia de tamaño entre el P2 y el P3 más marcada; los procesos postorbitales más desarrollados; el fémur menos grácil, con el trocánter menor menos desarrollado y la tróclea más simétrica, con un cóndilo medial relativamente menos desarrollado respecto al lateral y un epicóndilo lateral menos saliente (modificada de Marshall, 1976a).

Medidas-Tablas 4.2-4.5.

Comentarios-Parte de la descripción original de Hondadelphys fieldsi realizada por Marshall (1976a) se basa en el paratipo de esta especie. La ilustración que aparece en la publicación original (Marshall, 1976a) es una reconstrucción hecha con base en el holotipo y el paratipo. Durante la revisión de la colección de la Universidad de Berkeley, el paratipo no fue encontrado y hasta el momento se encuentra perdido. Por esta razón, no pudo ser estudiado en la presente revisión.

\section{UCMP 37960 (Holotipo)}

Localidad y Estratigrafía-localidad V4521 (UCMP), área de La Venta (Desierto de La Tatacoa, Valle Superior del Magdalena, Departamento del Huila, Colombia); Capas del Mono, Miembro Baraya, Formación Villavieja, Grupo Honda. 
Comentarios-La descripción que se presena a continuación se realizó con el fin de revisar los rasgos previamente reconocidos y señalar rasgos morfológicos no reportados previamente, o que vale la pena resaltar por ser de interés taxonómico. Por ejemplo, Marshall (1976a) es muy sintético en la descripción del basicráneo de Hondadelphys fieldsi y utiliza términos que no tienen un correlato con la estructura que debió haber contenido en vida (e.g., foramen lacerum medium, foramen lacerum posterius, foramen carotideo posterior). En la presente revisión se siguió Wible (2003) para ajustar la nomenclatura del basicráneo de Hondadelphys fieldsi y se detalló más su descripción.

Descripción-En el cráneo, la sutura entre el maxilar y el premaxilar es regular y recta. El proceso facial del maxilar está incompleto, pero en vista ventral se puede observar que la porción preservada presenta una expansión lateral por detrás del foramen infraorbitario, el cual abre al nivel del M1. Esta expansión de las "mejillas" del maxilar está presente en muchos esparasodontes (e.g., Cladosictis patagónica, Sipalocyon spp., Australohyaena antiqua, Lycopsis torresi, Prothylacynus patagonicus, Arctodictis, Thylacosmilus, entre otros). Sobre la superficie facial del maxilar derecho, en vista lateral, se preserva aproximadamente el $70 \%$ del foramen infraorbitario, el cual abre al nivel de la raíz posterior del P3 / raíz anterior del M1. Se preserva gran parte del lacrimal derecho, en el cual se observa un foramen lacrimal que abre adentro de la órbita. El punto de contacto entre el yugal, lacrimal y maxilar se ubica al nivel de la raíz posterior del M1 y se unen por medio de suturas irregulares. La sutura maxiloyugal es oblicua, con una inclinación de aproximadamente $130^{\circ}$.

En vista dorsal, la sutura nasofrontal presenta forma de "W" abierta. Esta condición está presente en general en los esparasodontes (al menos en todos los taxones revisados en este análisis, excepto Callistoe vincei; carácter 14), más abierta en algunos taxones, siendo casi una línea posteriormente convexa; pero se presenta en pocos metaterios no esparasodontes (e.g., Deltatheridium pretrituberculare, Herpetotherium fugax, Dasyurus). Esta condición es diferente a la que se presenta en los demás metaterios, incluyendo los didelfimorfios, donde esta sutura presenta una forma de "V" o de "W" muy cerrada. Estos rasgos difieren de las observaciones realizadas por Marshall (1976a). Los procesos postorbitales se encuentran relativamente bien desarrollados, al menos comparados con los de otros esparasodontes (excepto Thylacosmilus que presenta una barra postorbital). Se preserva una porción anterior y el extremo posterior de la cresta sagital, la cual está bien desarrollada. No se observa claramente si se extiende o no anteriormente hasta los frontales, ya que la sutura frontoparietal no es clara por el estado de preservación. A pesar de que la zona posterior del cráneo se encuentra muy fracturada, es posible observar que el interparietal se encuentra presente, ya que se preservan algunas porciones de la sutura entre este y los parietales. En vista posterior, no se identifica el interparietal en el escudo occipital; aparentemente llega hasta la cresta nucal.

En la porción de basicráneo preservada (Fig. 4.1), en vista ventral, no se observa el límite entre el preesfenoides y el basiesfenoides: no es claro si el preesfenoides no alcanza a preservarse 
en esta porción o si en realidad se encuentran fusionados. El basiesfenoides (o basiesfenoides más preesfenoides) presenta una morfología triangular y su superficie ventral es bastante homogénea, sin crestas ni tubérculos. Al menos en la porción preservada, los pterigoides no entran en contacto cubriendo ventralmente al basiesfenoides. Se presenta una fractura justo en la zona donde debería ubicarse la sutura entre el basiesfenoides y el pasioccipital. La estructura que Marshall (1976a) identifica como foramen lacerum medium o "foramen entocarotídeo", por su ubicación, es interpretada en la presente revisión como el foramen carotideo de Wible (2003). Este abre en una posición anterior a la sutura entre el basiesfenoides y el basioccipital.

El aliesfenoides está parcialmente preservado. El proceso timpánico del aliesfenoides está presente. El foramen oval está completamente rodeado por el aliesfenoides y se presenta un foramen oval secundario. El seno hipotimpánico está formado por el escamoso, petroso y el aliesfenoides. Se presenta un proceso cóncavo del aliesfenoides que contribuye a la porción anterodorsal de este seno. Adicionalmente, se presentan senos extra posteriores al seno hipotimpánico. En el margen posteromedial del aliesfenoides, en vista ventral, cerca del límite con el basiesfenoides, se presentan unos surcos largos y angostos, que marcan el pasaje del tubo de Eustaquio. Aparentemente, el foramen transverso está ausente. El aliesfenoides no contribuye a la cavidad glenoidea, ya que el proceso glenoideo del aliesfenoides está ausente.

La cavidad glenoidea está compuesta por el escamoso. Es relativamente angosta, siendo su ancho menor a dos veces la longitud anteroposterior. El proceso postglenoideo es ancho y bajo. El foramen postglenoideo se ubica en posición medial al proceso postglenoideo. El meato acústico externo es más largo que ancho. El proceso postimpánico del escamoso está poco desarrollado y se encuentra proyectado anteroventralmente. Algunos trabajos (e.g., Muizon, 1994, 1998, 1999; Muizon et al., 1997) hablan de un proceso medial del escamoso proyectado hacia el foramen oval como rasgo característico Sparassodonta. Debido al estado de preservación del holotipo, no pudo ser evaluada la presencia de este rasgo. Sin embargo, se pudo observar que este no es un rasgo que aparezca en todos los esparasodontes (e.g., Arctodictis sinclairi; véase Forasiepi, 2009). En vista lateral, en el escamoso se observa que el foramen suprameático se ubica por encima de la cresta suprameática. Este foramen es relativamente grande y presenta una forma ovalada, con el eje axial mayor orientado en dirección posterodorsal-anteroventral. El escamoso forma parte del escudo occipital: en vista posterior, se observa una porción de hueso que corresponde a un proceso del escamoso, ubicado sobre la porción lateroventral de la cresta nucal. Se observa una clara sutura entre este proceso y el exoccipital. En este proceso del escamoso, en vista posterior, se observa la presencia de un foramen, posiblemente correspondiente al foramen postemporal.

El petroso está incompleto, pero se pueden identificar algunos rasgos. Se ubica al nivel del margen ventral de la caja craneana y no se encuentra fusionado al escamoso. La porción mastoidea del petroso, aparentemente, no forma parte del escudo occipital. El meato acústico interno es somero y presenta una comisura prefacial delgada. La fosa subarcuata es profunda. La fosa estapedial es pequeña y poco profunda. No se presentan forámenes para las ramas temporales ni un 
canal o muesca postemporal.

El supraoccipital es visible en vista posterior y lateral. Contribuye a la porción dorsal del escudo occipital. En vista posterior, el supraoccipital contacta dorsalmente con el interparietal, al nivel de la cresta nucal, aparentemente por medio de una sutura que se ubica a lo largo de esta cresta. La cresta nucal se encuentra bien desarrollada; se ubica en una posición posterior al nivel de los cóndilos, proyectándose posterodorsalmente y posterolateralmente. Presenta una textura rugosa en su superficie posterior.

Adicionalmente, el supraoccipital contacta lateralmente con el escamoso y ventralmente con los exoccipitales. Sin embargo, como se explica a continuación, no es clara la ubicación de esta última sutura. Se presentan dos fracturas a cada lado del escudo occipital, dorsomediales a las facetas articulares condilares. Las suturas con los exoccipitales podrían estar coincidiendo con estas fracturas. Sin embargo, esto no es del todo claro, ya que, en un punto más dorsal, pareciera presentarse una sutura muy débil, la cual es menos evidente hacia el eje medial, que también podría corresponder a la sutura entre el supraoccipital y los exoccipitales. De ser este último el caso, se encontrarían casi fusionados y aparentemente el supraoccipital no contribuiría al margen dorsal del foramen magnum (estaría compuesto únicamente por los exoccipitales). Por otro lado, si estas suturas se ubicaran en el punto donde se encuentran las fracturas mencionadas, el supraoccipital sí estaría formando parte del margen dorsal del foramen magum. Por lo tanto, la contribución de este hueso al margen dorsal de este foramen es dudosa.

La superficie posterior del supraoccipital es ligeramente cóncava. Sobre toda la superficie se presentan minúsculos forámenes, pero cerca de la cresta nucal, hacia la porción más medial, se presentan algunos un poco más grandes y profundos, con una morfología alargada dorsoventralmente.

El exoccipital se presenta como un hueso par que bordea el foramen magnum y conforma al menos la mayor parte del cóndilo occipital. Es visible en vista ventral, posterior y lateral. En vista ventral, contacta medialmente con el basioccipital y lateralmente con el escamoso. Esta última sutura es mucho más clara que la primera, la cual no está tan bien definida. En vista posterior, contacta con el escamoso dorsolateralmente y el supraoccipital dorsalmente. Como se dijo anteriormente, debido a que no es clara la sutura con el supraoccipital, tampoco es claro si el margen dorsal del foramen magnum se encuentra compuesto únicamente por los exoccipitales o si también contribuye el supraoccipital.

El cóndilo occipital es ovalado, protruyente posteriormente y se orienta posteroventralmente. Debido a que las facetas articulares condilares están incompletas, no es claro si existe una conexión ventral entre estas o si están interrumpidas. En vista ventral, anteriormente a los cóndilos, se presenta una depresión, la fosa condiloidea, sobre la cual abre aparentemente un único foramen hipogloso.

El proceso paracondilar del exoccipital está poco desarrollado, siendo similar en tamaño al proceso postimpánico del escamoso $\mathrm{y}$, al igual que este, se encuentra proyectado 
anteroventralmente. Anterolateralmente a los procesos paracondilares, sobre los márgenes laterales de los exoccipitales (entre el exoccipital y el petroso), se presentan dos forámenes. En ambos casos, los exoccipitales están contribuyendo a su borde posteromedial. Uno de ellos es el foramen yugular (correspondiente al foramen lacerum posterius de Marshall, 1976a), el cual está incompleto, pero se puede observar que es más grande que la fenestra vestibular. Anteromedialmente a este foramen, se presenta otro que sí está completo y es aparentemente más pequeño, el cual es identificado por Marshall (1976a) como foramen carotídeo posterior. Siguiendo la nomenclatura de Wible (2003), por su ubicación, correspondería al foramen para el seno petroso inferior ("foramen for the inferior petrosal sinus"). Sin embargo, es notable que este foramen se encuentra bastante separado del foramen yugular. Adicionalmente, se observa un surco poco profundo entre el foramen para el seno del petroso inferior y el foramen hipogloso.

El basioccipital es visible en vista ventral. Contacta con el basiesfenoides anteriormente, con los exoccipitales posterolateralmente y con el petroso lateralmente. Aparentemente, también contacta con el aliesfenoides anterolateralmente (está incompleto). La superficie ventral del basioccipital es en general homogénea, aunque se presenta una quilla medial muy poco desarrollada (no está bien definida). Los márgenes laterales son homogéneos, no presentan crestas ni tubérculos. El basioccipital está incompleto en su extremo posterior, pero aparentemente contribuye a la porción más medial (en vista ventral) de los cóndilos occipitales.

En la mandíbula, la rama horizontal es relativamente baja, aguzándose anteriormente e incrementando su altura posteriormente. El margen ventral del dentario es curvo en toda su extensión. Existen al menos dos forámenes mentonianos: el de mayor tamaño por debajo de la raíz anterior del p2 y otro por debajo de la raíz anterior del p3. Por debajo del $\mathrm{m} 2$ se observa lo que parece ser un foramen mentoniano, en una posición más ventral; el mismo se encuentra justo sobre una fractura, por lo que es difícil determinar si realmente se trata de un foramen. Otros ejemplares que en la presente revisión fueron asignados a Hondadelphys fieldsi muestran un foramen mentoniano en esta ubicación (e.g., IGM \# 92-04, IGM 253079) o incluso posterior a esta (e.g., IGM 253050). En la parte posterior de la rama horizontal existe un espacio retromolar, rasgo generalizado en metaterios, con algunas excepciones (e.g., Deltatheroides, Deltatheridium y Glasbius; véase Rougier et al., 1998, car. 63; Rougier et al., 2004, car. 63; Forasiepi, 2009, car. 101; y carácter 101 en el análisis filogenético del presente capítulo [Anexos 1.3 y 1.4]). La rama horizontal está incompleta, pero se puede observar que la fosa masetérica es amplia y la cresta coronoidea está aparentemente poco verticalizada (es imposible medir un ángulo porque sólo se preserva la base).

En la dentición superior no se preservan los caninos, pero a juzgar por la forma del alvéolo del canino superior, se trataba de un canino relativamente grande, con un largo cercano (ligeramente menor) al del M3 (ver Tablas 4.2-4.3), y de sección ovalada, poco comprimida lateralmente. La especie presenta tres premolares superiores, todos paralelos a la hilera dentaria. Las raíces de los premolares son tan anchas como la corona (no bulbosas). A simple vista podría 
parecer que el P1 es más largo que el P2, pero en realidad esto es un efecto de perspectiva, ya que las raíces del P1 se encuentran más inclinadas un solo: el P1 es de menor tamaño que el P2. El P2 es bien comprimido labiolingualmente, mientras que el P3 es relativamente más globoso y de mayor tamaño. En los P2-3 se aprecia una cúspide muy reducida en el talón posterior, proporcionalmente más desarrollada en el P3. Existe un diastema entre los P1 y P2, que del lado derecho mide $3 \mathrm{~mm}$ y del izquierdo $3,45 \mathrm{~mm}$.

Los molares presentan un incremento moderado de tamaño del M1 al M3, aumentando en largo del M1 al M3 y en ancho del M1 al M4. Todos los molares presentan tres raíces.

El metacono se ubica en una posición lingual al paracono en los M1-4 y es de mayor tamaño en el M1 ( $\sim 30 \%$ más alto) y el M3 ( $\sim 80 \%$ más alto); en el M2 (izquierdo) está incompleto. En el M4, el metacono está bien diferenciado pero muy reducido, teniendo una altura inferior al $50 \%$ de la altura del paracono, y ubicado en una posición relativamente más lingual que en los otros molares. El paracono es de sección circular en los M1-2 y subtriangular en los M3-4. El metacono es de sección circular en el M1 (en el M2 no se preserva), más comprimido labiolingualmente en el M3 (ligeramente triangular) y comprimido anteroposteriormente en el M4. Las bases del paracono y metacono están en contacto pero no fusionadas (Fig. 4.3A-C). El protocono está bien desarrollado, moderadamente expandido anteroposteriormente, con una cuenca amplia y la pre- $\mathrm{y}$ postprotocrista bien definidas. La cuenca del protocono (trígono) es amplia, más que la de cualquier otro esparasodonte, y va aumentando ligeramente en profundidad hacia el M4. El paracónulo y el metacónulo están presentes en los M1-3, y sólo el paracónulo está presente en el M4. En todos los molares el paracónulo y el metacónulo presentan crestas en forma de "ala" (la condición "winged" de la terminología anglosajona) y están ubicados hacia la base del para- y metacono (más cerca de estos que del protocono). Adicionalmente, estos cónulos presentan unas pequeñas crestas verticales sobre su cara lingual, que se dirigen hacia el protocono y son paralelas a crestas similares que se presentan en la cara lingual del paracono y el metacono.

La centrocrista es recta. La preparacrista está presente en todos los molares, conectando el paracono con la StA (Marshall, 1976a señala que está presente en los M2-4 y que conecta con la StB). Su longitud aumenta del M1 al M4. Es ligeramente oblicua en el M1, orientada anterolabialmente con un ángulo de aproximadamente $20^{\circ}$ respecto al eje longitudinal del diente. Posteriormente, este ángulo va aumentando, haciéndose casi perpendicular al eje en el M4. El cíngulo anterior está bien desarrollado y conecta la StA con la cresta preparaconular. La postmetacrista está bien desarrollada en los M1-3, es más larga que la preparacrista, y tiene una orientación posterolabial. En el M4, la postmetacrista está muy reducida y se dirige en sentido anterolabial hasta conectarse con un ectocíngulo; este último corre a lo largo del borde posterolabial de la plataforma estilar, y labialmente conecta con una cresta vertical que recorre la cara lingual del metacono hasta el extremo posterior de la postprotocrista, formando en conjunto (postmetacrista + ectocíngulo + cresta vertical) un reborde que rodea al diente labial y posterioremente. Los rasgos de la plataforma estilar del M4 pueden verse claramente observando 
en conjunto el molar derecho e izquierdo, ya que la porción no preservada en uno sí se preserva en el otro.

La plataforma estilar se hace más ancha del M1 al M3, pero su ancho no es uniforme sino que muestra una reducción en la porción labial al paracono, que se hace más marcada del M3 al M1, estando prácticamente ausente en este último. Por lo contrario, en el M4 la plataforma estilar se reduce marcadamente en su porción posterior, a partir del nivel del metacono, y su porción labial al paracono es más ancha que la del M3. La StA, muy reducida, está presente en los M1-3, aumentando en tamaño hacia el M3. Está claramente diferenciada en los M1-2, pero en el M3 forma parte de un cíngulo o reborde que rodea al paracono anterolabialmente (conformado por la unión entre el cíngulo anterior y un ectocíngulo labial al paracono, los que confluyen al nivel de la StA). Sin embargo, a pesar de formar parte de este reborde, en el M3 izquierdo (menos desgastado) se observa claramente el ápice de esta cúspide. La StB está ausente en el M1 y presente en el M2 aunque incompleta (la porción labial del diente está rota a partir de ese punto). En el M3, la StB también forma parte del ectocíngulo labial al paracono (carácter 154, estado 1). Esto se puede concluir debido a que su ápice, aunque casi vestigial, está claramente diferenciado. Esta observación contradice aquella hecha por Goin (1997), quien afirma que H. fieldsi no presenta una StB. El cíngulo o reborde anterolabial que rodea al paracono sólo se presenta en el M3 y su extremo posterior conecta con una $\mathrm{StC}$ muy reducida y también confluyente con este cíngulo, pero claramente diferenciada, sobre todo en su mitad posterior, donde ya no está el ectocíngulo y por lo tanto presenta una morfología de cúspide mucho más clara. Las tres cúspides estilares son marcadamente reducidas, pero la $\mathrm{StC}$ es la más pequeña, siendo casi vestigial.

El M1 tiene un ectocíngulo posterior que se origina en un punto intermedio entre la posición correspondiente a la StB (ausente en este molar) y la StC. Sin embargo, en este caso no se logra identificar la presencia de ninguna cúspide estilar, por lo cual no se puede establecer ninguna homología. Del M2 sólo se preserva una pequeña porción anterior de la plataforma estilar (en el M2 izquierdo) hasta el nivel de la StB, por lo cual se desconoce la presencia de un ectocíngulo posterior. En el M3 se presenta un ectocíngulo posterior vestigial cerca de la esquina metastilar. En el cíngulo que rodea posterior y labialmente al M4 no se diferencia ninguna cúspide estilar.

En la dentición inferior no se aprecian diastemas, aunque existe un pequeño espacio entre los p1 y p2, ligeramente más corto que las raíces de estos premolares. El holotipo preserva tres alvéolos de incisivos inferiores. El segundo de ellos se ubica lingual a los demás, indicando que se trata de un i3, lo cual nos permite inferir que los alvéolos presentes corresponden a los i2-4. Esto concuerda con las observaciones realizadas por Goin (1997) al respecto y difiere de las realizadas por Marshall (1976a) en la descripción original del ejemplar. El canino inferior es de tamaño moderado, de sección ligeramente ovalada y procumbente. Los premolares no son globosos y el ancho de las raíces no supera el de la corona. El tamaño del p1 es notoriamente menor que el del $\mathrm{p} 2$, y este último es ligeramente más pequeño que el p3 (Tabla 4.4). Al menos en el p1 y el p2 aparece una cúspide posterior (posterobasal) reducida, ligeramente más desarrollada en el p2. 
Al menos en el m3, el lóbulo posterior de la corona se ubica a un nivel más bajo que el anterior (los m1-2 no se preservan y el rasgo no está presente en el m4). La configuración del trigónido es abierta, con el paracónido anterolingual. El metacónido está presente al menos en los m3-4, bien diferenciado, pero extremadamente reducido, incluso más que en los borhiénidos. El protocónido y paracónido son subtriangulares en sección transversal. La cresta vertical anterolingual del paracónido forma una quilla. El cingúlido anterior está reducido, restringido a la base del paracónido, aunque más desarrollado en el m4.

El talónido está bien desarrollado y su cuenca es amplia y profunda, más en el m3 que en el $\mathrm{m} 4$. El entocónido es comprimido labiolingualmente y es la cúspide más alta del talónido en el m3, ligeramente más bajo que el hipoconúlido en el $\mathrm{m} 4$. El hipoconúlido está bien desarrollado, es alto y se ubica apareado al entocónido en la esquina posterolingual del talónido; es saliente posteriormente y presenta forma triangular en vista oclusal, siendo más notorio en el m4. Hacia la base de estas dos cúspides del talónido, ambas están fusionadas formando un solo bloque. Este bloque se ubica en la esquina posterolingual del talónido, posterior al nivel del hipocónido (más marcado en el $\mathrm{m} 4$ que en $\mathrm{m} 3$, donde es ligeramente posterior). Es comprimido lateralmente y esta porción de la corona se encuentra a un nivel más elevado respecto al hipocónido, formado así en su cara labial una pared bastante verticalizada. Esta pared genera en la superficie de la cuenca del talónido una morfología muy particular, presentando una porción lingual muy verticalizada y plana, y una porción labial subhorizontal y cóncava. La preentocrístida se encuentra bien desarrollada y sale del entocónido en sentido labial al trigónido. El hipocónido es la cúspide más baja del talónido; se ubica en una posición entre la mitad del borde labial del talónido y el extremo posterior del diente, mostrando en vista oclusal un ángulo claramente definido (no es curvo) formado entre el borde labial y el posterior del talónido, siendo este último oblicuo al eje principal del diente. Adicionalmente, la crístida oblicua se dirige hacia el protocónido, con una orientación casi paralela al eje anteroposterior del diente en el m3, mientras que en el m4 tiene una orientación ligeramente más medial.

Nota aclaratoria: los alveolos de los p3-m2 en el holotipo están presentes, pero en la porción correspondiente al $\mathrm{m} 2$ el hueso fue restaurado con yeso, por lo cual pudieron ser alteradas sus dimensiones. Por lo tanto, en la presente revisión se tomaron medidas de estos alveolos exceptuando el del $\mathrm{m} 2$ (Tablas 4.4 y 4.5 ).

\section{Ejemplares referidos}

\section{IGM 250833}

Material—Fragmentos de mandíbula y dientes aislados rotos (m2-4?).

Localidad y Estratigrafía-Localidad 22 (Universidad de Duke), San Nicolás, área de La Venta; Capas del Mono, Miembro Baraya, Formación Villavieja, Grupo Honda.

Comentarios-Ejemplar referido a H. fieldsi por Goin (1997). La morfología de los molares 
se asemeja a la del ejemplar IGM 253049 (ver más abajo).

\section{IGM 250961}

Material-Porción anterior de la rama horizontal izquierda con los alvéolos de los i2-4, porción intraalveolar del canino, el p1 completo y el p2 roto.

Localidad y Estratigrafía-Localidad 113 (Universidad de Duke), área de La Venta; unidad entre las Capas de Arenisca de Chunchullo y las Capas de Arenisca de Tatacoa, Formación La Victoria, Grupo Honda.

Comentarios-Ejemplar referido a H. fieldsi por Goin (1997). Se preserva la región anterior del dentario, donde claramente se observan los alvéolos de tres incisivos, al igual que en el holotipo de $\mathrm{H}$. fieldsi, lo cual concuerda con observaciones previas. Este ejemplar es ligeramente más pequeño que el holotipo (Tabla 4.4). Tanto el foramen mentoniano más anterior como la cúspide posterior del p2 son similares a los observados en el ejemplar IGM 253049 (ver más abajo).

\section{IGM 253049}

Material - Rama horizontal de mandíbula izquierda con los alvéolos (incompletos) del c-p1, los p2-3 completos, el alvéolo del m1, y los m2-4 completos (Fig. 4.4A).

Localidad y Estratigrafía — Localidad desconocida (Universidad de Kioto), área de La Venta; Grupo Honda.

Comentarios-Ejemplar referido a H. fieldsi por Goin (1997). Esta clasificación es ratificada en la presente revisión, ya que el ejemplar sólo muestra diferencias sutiles con el holotipo, mientras que presenta bastantes similitudes, muchas de ellas representando rasgos muy particulares de $H$. fieldsi.

La rama horizontal es similar en morfología al holotipo, con un margen ventral curvo, fusiforme en la región anterior y aparentemente aumentando en altura posteriormente (no se preserva la porción posteroventral). El foramen mentoniano más anterior se ubica por debajo de la raíz anterior del p2, al igual que en el holotipo, pero en una posición más ventral (más cerca del margen ventral del dentario) y su morfología es más elongada (más alargado y comprimido dorsoventralmente). El segundo foramen, más pequeño, se ubica por debajo de la raíz posterior del p2, posterodorsal al primero y muy cercano a este, lo cual varía respecto al holotipo, donde se ubica en una posición más posterior y más separada del primer foramen. El tercer foramen se ubica más dorsal respecto a los dos primeros, a una altura intermedia del dentario, por debajo del $\mathrm{m} 1$.

Los premolares presentan una pequeña cúspide posterior, más desarrollada en el p3 que en el p2 y aparentemente más desarrollada que en el holotipo de H. fieldsi. Se presenta un pequeño espacio entre los p2-3 de 0,65 mm. Al menos en los m2-3 (no se preserva el $\mathrm{m} 1$ y no ocurre en el m4) el lóbulo posterior de la corona se encuentra a un nivel más bajo que el anterior, ligeramente más bajo en el $\mathrm{m} 2$ que en el $\mathrm{m} 3$. El trigónido de los m2-4 presenta una configuración abierta, con 
el paracónido anterolingual. Los molares tienen rasgos particulares de H. fieldsi, como el talónido bien desarrollado, presentando el mismo desnivel con un bloque labial elevado respecto al resto del talónido; una cuenca del talónido profunda, con una porción lingual aplanada y verticalizada y una labial más horizontal y cóncava; finalmente, el metacónido es extremadamente reducido, pero bien diferenciable al menos en los m2-4 (el m1 no se preservó en este ejemplar).

\section{IGM 253050}

Material-Fragmento de rama mandibular derecha con un fragmento del talónido del m1, el $\mathrm{m} 2$ completo y los $\mathrm{m} 3-4$ incompletos (Fig. $4.5 \mathrm{~A}-\mathrm{C}$ ).

Localidad y Estratigrafía_Localidad desconocida (Universidad de Kioto), área de La Venta; Grupo Honda.

Comentarios-Ejemplar referido a H. fieldsi por Goin (1997). El ángulo entre el borde alveolar y el borde anterior del proceso coronoides es de $c a$. $118^{\circ}$. En la porción preservada del dentario se observan dos forámenes mentonianos, uno por debajo de la raíz posterior del $\mathrm{m} 1$ y otro por debajo de la raíz anterior del $\mathrm{m} 3$. El holotipo presenta otra fractura en la posición de este último foramen y está restaurado con resina, por lo que se desconoce si el holotipo presentaba este foramen tan posterior.

El lóbulo posterior de la corona de los molares se encuentra a un nivel más bajo que el lóbulo anterior, al menos en los $\mathrm{m} 2-3$ (no observable en el $\mathrm{m} 1$ y ausente en el $\mathrm{m} 4$ ). Este rasgo es más marcado en el m3, diferente de IGM 253049 (el holotipo no es comparable ya que no preserva el $\mathrm{m} 2)$.

El metacónido es extremadamente reducido, con un desarrollo aparentemente similar al del holotipo de H. fieldsi; está presente al menos en los m2-4. El talónido está bien desarrollado, más desarrollado en el $\mathrm{m} 2$ que en el $\mathrm{m} 1$, y se reduce en tamaño del $\mathrm{m} 2$ al $\mathrm{m} 4$. La cueca del talónido se hace más profunda del $\mathrm{m} 1 \mathrm{al} \mathrm{m} 3$, y en el $\mathrm{m} 4$, es menos profunda que en el $\mathrm{m} 3$ (como en el holotipo). La morfología de las cúspides y la cuenca del talónido son similares a las del holotipo, pero en este caso se preservan los cuatro talónidos y es posible apreciar cómo el ángulo formado

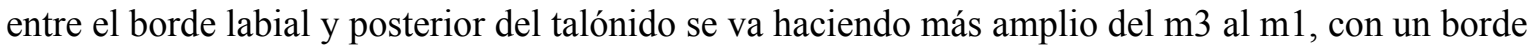
posterior más oblicuo y curvo en vista oclusal. Adicionalmente, en el m1 el entocónido se ubica en una posición más anterior (más cercana a la mitad del borde labial del talónido) y, aparentemente, está más diferenciado, aunque no es clara la presencia de un hipoconúlido debido al desgaste. De la misma manera, se observa que ese abrupto desnivel entre la porción labial y lingual del talónido se presenta principalmente en los $\mathrm{m} 2-4$, ya que en el talónido del $\mathrm{m} 1$ el entocónido presenta una altura subigual a la del hipocónido.

\section{IGM 253078}

Material-Fragmento de rama mandibular derecha con los $\mathrm{m} 2-4$ y otro fragmento con el p2 y las raíces del p1. 
Localidad y Estratigrafía—Localidad desconocida (Universidad de Kioto), área de La Venta; Grupo Honda.

Comentarios-Ejemplar referido a H. fieldsi por Goin (1997). La morfología del dentario muy similar a la de IGM 253050 e IGM 253079. Los molares están pobremente preservados. E1 p2 presenta una morfología similar al de $H$. fieldsi.

\section{IGM 253079}

Material-Fragmento de rama mandibular izquierda con la raíz posterior del p3, raíces y fragmento posterior de la corona (borde posterior del talónido) del m1, el trigónido del m1 aislado, el $\mathrm{m} 2$ completo y los m3-4 incompletos (Fig. 4.5D-G).

Localidad y Estratigrafía_-Localidad desconocida (Universidad de Kioto), área de La Venta; Grupo Honda.

Comentarios-Ejemplar referido a H. fieldsi por Goin (1997). La morfología del dentario y de la dentición en general, así como el grado de desgaste, son muy similares a los del ejemplar IGM 253050. Sin embargo, este último se encuentra mucho mejor preservado (más completo).

$\mathrm{El}$ ángulo entre el borde alveolar y el borde anterior del proceso coronoides es de $c a .120^{\circ}$. En la porción preservada del dentario se observan dos forámenes mentonianos, uno por debajo de la raíz anterior del $\mathrm{m} 1$ y otro ligeramente más ventral por debajo del $\mathrm{m} 2$, la misma posición del foramen dudoso que se presenta en el holotipo.

Los dientes están rotos y muy desgastados. A pesar de que la cara labial de la corona está rota, se puede apreciar que, al menos en los $\mathrm{m} 2-3$, el lóbulo posterior de la corona se encuentra a un nivel más bajo que el lóbulo anterior (rasgo ausente en el m4), más bajo en el m3 que en el m2, a diferencia del ejemplar IGM 253049 y similar al ejemplar IGM 253050. El tamaño del trigónido aumenta del $\mathrm{m} 1$ al $\mathrm{m} 4$. El trigónido del $\mathrm{m} 1$ presenta una típica morfología esparasodonte, con las cúspides principales alineadas en una hilera longitudinal (no conforman un triángulo reverso como en los didélfidos). En los demás molares el trigónido es de configuración abierta, con el paracónido anterolingual. El paracónido del $\mathrm{m} 1$ es bajo y confluente con el cingúlido anterior. El metacónido está extremadamente reducido, de un modo similar al del holotipo de H. fieldsi; está presente al menos en los m2-3 (los $\mathrm{m} 1$ y $\mathrm{m} 4$ no preservan esta porción). El talónido está bien desarrollado y su cuenca es profunda, reduciendo su tamaño al menos del $\mathrm{m} 2$ al m4. Las cúspides del talónido se encuentran muy desgastadas (al igual que las del trigónido), pero claramente puede observarse el bloque lingual más elevado que el hipocónido y la morfología de la cuenca del talónido es característica de $H$. fieldsi.

Todos los rasgos anteriormente mencionados están presentes en $H$. fieldsi y no se encontró ninguna diferencia evidente respecto esta especie.

\section{UCMP 38855}

Material-Esqueleto incompleto. 
Localidad y Estratigrafía—Localidad V4528 (UCMP); Capas Rojas de El Cardón, Miembro Cerro Colorado, Formación Villavieja, Grupo Honda.

Comentarios-Ejemplar referido a H. fieldsi por Marshall (1976a). Este autor menciona que el material consta de un esqueleto muy pobremente preservado con la dentición inferior asociada. Sin embargo, cuando visité la colección del UCMP en Berkeley, encontré que este ejemplar (catalogado en la colección como "esqueleto incompleto") estaba conformado por material postcraneano pobremente preservado y sin preparar, y no encontré evidencia de elementos craneales ni dentarios (posiblemente se hayan perdido?). Por estas razones, el ejemplar no pudo ser estudiado, pero se deja consignado en este trabajo con fines informativos y no se le hace ninguna modificación a su clasificación, ya que no se dispone de argumentos para hacerlo.

\section{Nuevos ejemplares referidos}

A continuación se presentan los ejemplares referibles a $H$. fieldsi que no han sido descriptos en trabajos previos.

\section{IGM \# 92-04}

Material-Rama mandibular izquierda incompleta, con los c-p2, los m2-4 y los alvéolos de los p3-m1 (Fig. 4.7C).

Localidad y Estratigrafía_Localidad desconocida (Universidad de Duke), área de La Venta; Grupo Honda.

Comentarios-El ejemplar fue colectado durante la expedición paleontológica IngeominasUniversidad de Duke del año 1992. El número corresponde al número de campo, ya que no tiene número de colección asignado. Excepto por algunas diferencias menores (i.e., largo del m3 vs. m4, ubicación de forámenes mentonianos y presencia de corto diastema anterior a p1), que podrían entrar dentro del rango de variabilidad intraespecífica, el ejemplar es casi idéntico al holotipo de $H$. fieldsi. Por esta razón, es referido sin dudas a esta especie.

Descripción-Se preserva la rama horizontal y una porción anterior de la base de la rama horizontal del dentario, donde se observa una pequeña porción de la fosa masetérica y la base de la cresta coronoidea. A partir del pequeño fragmento de la cresta coronoidea se midió un ángulo de aproximadamente $120^{\circ}$ entre el borde anterior del proceso coronoides y la línea alveolar. Este ejemplar es consistente en morfología y tamaño con $H$. fieldsi, siendo ligeramente más chico que el holotipo (ver Tablas 4.4 y 4.5). El dentario presenta una morfología cercana a la del holotipo de $H$. fieldsi, con una altura similar, que se incrementa posteriormente y disminuye anteriormente (fusiforme en la porción anterior), y un margen ventral curvo en toda su extensión. Al igual que en el holotipo, se observan tres forámenes mentonianos, pero en posiciones ligeramente distintas. El foramen de mayor tamaño es el más anterior y se ubica por debajo del espacio entre el p1 y el p2; los otros dos forámenes son subiguales en tamaño, apareciendo uno por debajo de la unión entre el 
p3 y el m1, y el otro por debajo de la unión entre el m1 y el m2. Los tres forámenes se ubican cerca del borde ventral del dentario.

En la dentición inferior se observa un corto diastema entre el canino y el p1 ( $2 \mathrm{~mm})$, el cual no existe en el holotipo. Al igual que en el holotipo de H. fieldsi, se aprecia un corto espacio entre el p1 y el p2 (1,53 mm, más corto que cualquiera de las raíces adyacentes) y el espacio retromolar está presente. El canino es de tamaño moderado, cónico y procumbente, como en el holotipo de $H$. fieldsi. Los premolares muestran una morfología similar a la del holotipo de $\mathrm{H}$. fieldsi, no son globosos y el ancho de las raíces no supera el de la corona. El tamaño del p1 es marcadamente menor que el del p2, y este último es ligeramente más pequeño que el p3 (Tabla 4.4). Al menos en el p1 y el p2 aparece una cúspide posterior muy reducida, casi vestigial en el p1, más reducida que en el holotipo, y el talón del p2 está ligeramente más desarrollado que el del holotipo. Sin embargo, estas diferencias son muy sutiles ya que las estructuras en ambos ejemplares están bastante reducidas.

Los molares también presentan una morfología muy similar a la del holotipo de $H$. fieldsi. Al menos en los m2-3, el lóbulo posterior de la corona se ubica a un nivel más bajo que el anterior. Este rasgo es más marcado en el $\mathrm{m} 3$ que en el $\mathrm{m} 2$ (el $\mathrm{m} 1$ no se preserva y el rasgo está ausente en el m4), de modo similar a lo que ocurre en los ejemplares IGM 253050 e IGM 253079. El m3 es subigual al m4 en su longitud anteroposterior, siendo ligeramente más largo, a diferencia del holotipo, donde el $\mathrm{m} 4$ es ligeramente más largo que el $\mathrm{m} 3$. Esto es debido a que el talónido del $\mathrm{m} 4$ en el ejemplar IGM \# 92-04 está ligeramente más reducido. Sin embargo, esta sutil diferencia no es muy relevante, ya que en los metaterios la morfología de los $\mathrm{M} / \mathrm{m} 4$ suele ser variable entre ejemplares de una misma especie (e.g., Martin, 2005), como ocurre en el último molar de otros mamíferos (e.g., carnívoros). El trigónido es más largo que el talónido al menos en los m2-4, y es más ancho que el talónido en los m3-4 y subigual en el m2. La configuración del trigónido es abierta, con el paracónido en posición anterolingual. El paracónido y protocónido están bien desarrollados (siendo este último la cúspide principal) y son subtriangulares en sección transversal; el metacónido está presente al menos en los $\mathrm{m} 2-4$; es extremadamente reducido pero bien diferenciado. La cresta vertical anterolingual del paracónido forma una quilla. El cingúlido anterior está reducido, restringido a la base del paracónido, aunque más desarrollado en el m4.

El talónido está más reducido en el $\mathrm{m} 2$ que en el m3, siendo el del m4 el más reducido. Las cúspides del talónido presentan la misma configuración que el holotipo y todos los demás ejemplares arriba descriptos, al igual que la morfología de su cuenca. En este ejemplar, al igual que en el IGM 253050 puede verse cómo el ángulo dibujado en entre el borde labial y posterior del talónido en vista oclusal se hace más abierto y curvo en el $\mathrm{m} 2$ que en el m3. Adicionalmente, el nuevo ejemplar referido presenta un menor grado de desgaste; esto permite diferenciar claramente las cúspides, las cuales presentan la misma posición y desarrollo que en el holotipo. El hipoconúlido es saliente y de morfología triangular en vista oclusal, al igual que en el holotipo. La entocrístida está bien definida y se dirige en sentido labial al trigónido. 


\section{KU 2000-2}

Material-Trigónido de un m4 izquierdo (Fig. 4.4C).

Localidad y Estratigrafía-Localidad El Cuzco (Universidad de Kioto), área de La Venta; unidad Capas Rojas de La Venta, Formación Villavieja, Grupo Honda.

Comentarios-Este trigónido presenta un desarrollo similar al del m4 del holotipo de $H$. fieldsi, siendo tan ancho como este último pero ligeramente más corto $(0,07 \mathrm{~mm}$ de diferencia). Comparado con el m3 del holotipo, es más grande en cualquiera de sus dimensiones. Por esta razón, probablemente se trate de un $\mathrm{m} 4$. La configuración del trigónido es abierta, con el paracónido en posición anterolingual. Al igual que en el holotipo de $H$. fieldsi, el metacónido está presente y presenta el mismo grado de desarrollo; se observa una cresta vertical sobre la cara anterior del paracónido, formando una quilla; el cingúlido anterior es reducido, restringido sólo a la base del paracónido.

Sólo se diferencia del holotipo de $H$. fieldsi en la ligera diferencia de tamaño anteriormente mencionada. Morfológicamente, es idéntico al trigónido del $\mathrm{m} 4$ del holotipo de $H$. fieldsi.

\section{KU LV-2-A}

Material—Un m3 izquierdo sin las raíces (Fig. 4.5H).

Localidad y Estratigrafía - Localidad El Cuzco - Tasajera (Universidad de Kioto), área de La Venta; Formación Villavieja, Grupo Honda.

Comentarios-No se observan diferencias entre este molar y el $\mathrm{m} 3$ de otros especímenes de H. fieldsi. La corona está bastante completa y su grado de desgaste es muy bajo, por lo que puede ser usado como material de referencia en próximos estudios, ya que en el holotipo el paracónido y protocónido están incompletos.

\section{Hondadelphys sp. 1}

sp. nov.

(Figs. 4.6-4.7A)

Holotipo-IGM 184041, cráneo incompleto con la dentición yugal pobremente preservada, la rama mandibular izquierda con la raíz del c, los p1-2 completos, alvéolos de los p2-m4, y un fragmento de la rama horizontal derecha con parte del canino y los p1-2 completos.

Localidad y Estratigrafía-Localidad 49 (Universidad de Duke), área de La Venta; niveles fosilíferos por debajo de las Capas de Arenisca de Cerro Gordo, Formación La Victoria, Grupo Honda (Tablas 3.1 y 4.1; Fig. 3.1).

Diagnosis-Se diferencia de la especie tipo en el menor tamaño; la expansión de las mejillas del maxilar mucho más marcada; el diastema entre los P1-2 más largo y la presencia de un diastema entre los P2-3 (ausente en $\mathrm{H}$. fieldsi); el largo relativo de los molares, siendo 
$\mathrm{M} 1<\mathrm{M} 2>\mathrm{M} 3>\mathrm{M} 4$ y $\mathrm{M} 1 \approx \mathrm{M} 3$ (incrementando del M1 al M3 en H. fieldsi); el ancho del M4, menor respecto al del M3; el tamaño relativo del metacono respecto al paracono, que disminuye del M2 al M4; la plataforma estilar más amplia, con la reducción de la porción labial al paracono menos marcada; la StC muy desarrollada; los premolares inferiores más globosos; y la presencia de un diastema entre el p1 y el p2. Se diferencia de $H$. sp. 2 en el mayor tamaño; la sutura nasolacrimal más corta; la ubicación más posterior del foramen infraorbitario; la mayor diferencia de tamaño entre el P2 y el P3 (P3 notoriamente más grande); la presencia de un diastema claramente definido entre los P2-3; y la mayor longitud de los diastemas entre los P1-2 y p1-2.

Medidas-Tablas 4.2-4.4.

Comentarios-El ejemplar IGM 184041 había sido identificado por Goin (1997: pág. 197) como "Hondadelphidae, gen. et sp. indet (Hondadelphys?)". Sin embargo, en la presente revisión se pudo determinar que es referible a Hondadelphys y sus diferencias con $H$. fieldsi permiten establecer que se trata de una especie diferente.

Descripción-El ejemplar IGM 184041 es aproximadamente un 10\% menor en tamaño que el holotipo de H. fieldsi (ver Tablas 4.2-4.4 y 4.7); las medidas de la dentición son en su mayoría aproximadas, ya que esta se encuentra mal preservada y sin preparar. El cráneo está muy fracturado y deformado. Es difícil observar algunas de las suturas, pero se observan claramente la sutura nasofrontal, que presenta una forma de "W" abierta, y la sutura nasolacrimal, diagnóstica de los esparasodontes. Posterior a la sutura nasofrontal, se preservan algunos fragmentos de la base de la cresta sagital. El margen orbitario del lacrimal aparentemente presenta una pequeña cresta. En vista lateral, el foramen infraorbitario se ubica en la misma posición que en el holotipo de $H$. fieldsi, en un punto por encima del P3. Otro rasgo identificable, presente en Sparassodonta, es el paladar óseo no fenestrado. Adicionalmente se observa la expansión de las mejillas del maxilar presente en la mayoría de los esparasodontes, aunque en este caso se ve mucho más marcada que en el holotipo de $H$. fieldsi.

Del dentario se preserva la rama horizontal izquierda casi completa, con ausencia de algunos fragmentos del margen alveolar, y la porción anteroventral de la rama vertical. Presenta una altura intermedia (altura por debajo de los m3-4 / largo total = entre 0,15 y 0,2 ), aparentemente mayor que el holotipo de H. fieldsi. La altura del dentario aumenta en sentido posterior y su borde ventral es curvo en toda su extensión, como en $H$. fieldsi. Sin embargo, por delante del p2, el dentario se dobla dorsalmente, generando una curvatura poco usual en la porción anterior. Aún teniendo en cuenta que un fragmento del borde alveolar posterior al p2 está ausente (está roto y por este motivo la curvatura parece más pronunciada), esta curvatura es bastante marcada, más que en el holotipo de $H$. fieldsi o cualquier otro de los ejemplares referidos a esta especie (Fig. 4.7). Esta curvatura es bastante particular y no se descarta que se deba a una patología, aunque no se observa evidencia que permita sustentar esta hipótesis, más allá de ser una morfología que no ha sido observada en ningún otro metaterio. Por consiguiente, en la presente revisión no se toma como rasgo diagnóstico de esta especie. 
Se aprecian al menos tres forámenes mentonianos, todos ellos ubicados aproximadamente a la misma altura. El foramen mentoniano más anterior es muy alargado, ligeramente más que en el ejemplar IGM 253049 (referido a H. fieldsi). Se extiende desde el nivel del contacto entre el p1 y el p2 hasta el nivel de la raíz anterior del p2 (en el holotipo de $H$. fieldsi se ubica por debajo de la raíz anterior del p2). El segundo y tercer forámenes son mucho más pequeños que el primero, circulares. Su ubicación exacta es difícil de determinar (ya que no son claros los alvéolos de los dientes), pero aproximadamente se ubicarían por debajo del p3 y el m2, respectivamente.

La dentición superior se encuentra pobremente preservada y sin preparar, pero se preservan más elementos que en la inferior y es posible observar algunos rasgos diagnósticos de Hondadelphys: los protoconos están bien desarrollados, con una amplia cuenca, aparentemente más desarrollados que los de $\mathrm{H}$. fieldsi; las bases del metacono y el paracono son independientes (no fusionadas); y en el M3 derecho se observa claramente una centrocrista recta.

Se observa un diastema de aproximadamente 4,1 mm entre los P1-2, siendo más largo que el del holotipo de $H$. fieldsi, y otro mucho más corto, de aproximadamente 2,1 mm entre los P2-3. En el holotipo de $H$. fieldsi aparece un pequeño espacio entre los P2-3, el cual es más corto que la longitud de cualquiera de las raíces adyacentes, por lo cual no fue considerado como un diastema (definido como un espacio de longitud igual o al menos la mitad de la longitud de un diente adyacente: Zan et al., 2006).

Los molares superiores se hacen más anchos del M1 al M3, siendo el M4 ligeramente más angosto que el M3. El largo de los molares disminuye del M2 al M4, mientras que el M1 es más corto que el M2 y subigual (ligeramente más corto) que el M3 (ver Tabla 4.3). Esta relación de longitudes es diferente a la de $H$. fieldsi, donde el ancho de los molares superiores aumenta del M1 al M4, mientras el largo aumenta del M1 al M3. El M4 es relativa y absolutamente más corto, más angosto y más comprimido anteroposteriormente que el del holotipo de $H$. fieldsi.

Las cúspides principales sólo se pueden observar en los M2-4 y se encuentran fuertemente desgastadas. A juzgar por la morfología de las bases preservadas del paracono y el metacono, y el incremento posterior en la longitud de la preparacrista y disminución de la postmetacrista, el tamaño del metacono disminuye respecto al paracono del M2 al M4. Esto es diferente a lo que ocurre en $\mathrm{H}$. fieldsi, donde el metacono aumenta en tamaño relativo del M1 al M3. En ambos ejemplares, el metacono está muy reducido en el M4 (ligeramente más reducido en el presente ejemplar); este es un rasgo muy generalizado en los esparasodontes (en algunos incluso es vestigial o ausente). En el M4, la postmetacrista está extremadamente reducida y se dirige en sentido anterolabial hasta conectarse con un ectocíngulo que corre a lo largo del borde posterolabial de la plataforma estilar, al igual que en $\mathrm{H}$. fieldsi. No se observa claramente la porción correspondiente a la cresta vertical que sale del metacono. Al menos en el M3, aparentemente están presentes el paracónulo y el metacónulo (no es posible ver otras cúspulas debido al desgaste).

La plataforma estilar del ejemplar IGM 184041 es diferente a la de H. fieldsi. Está menos reducida, con una reducción menos marcada en la porción labial al paracono. Al menos en el M3 se 
observa una estructura alargada en la posición de la StB, que bien podría tratarse un ectocíngulo anterior que posteriormente no llega al nivel de la $\mathrm{StC}$, siendo más corto que en $\mathrm{H}$. fieldsi; o una StB alargada y muy comprimida labiolingualmente. No es claro cuál de estas dos condiciones es la que se presenta, debido a que la plataforma estilar está rota en su extremo anterior, por lo que no es posible saber si la estructura mencionada se extiende anteriormente hasta la posición de la StA, formando un cíngulo, como ocurre en la especie tipo. Al menos en los M2-3 la StC es de gran tamaño, mucho más desarrollada que en $\mathrm{H}$. fieldsi, mostrando en el M2 una ligera elongación posterior. La preservación del ejemplar no permite evaluar la presencia de otras cúspides estilares. Adicionalmente, en los M1-3 se observa un remanente de un cíngulo anterior cuya extensión en sentido lingual no es clara debido al desgaste.

Este conjunto de rasgos de la plataforma estilar podría estar indicando una morfología más plesiomórfica que en $H$. fieldsi, mostrando un proceso en el cual la plataforma estilar se reduce, los ectocíngulos se hacen más desarrollados y las cúspides estilares menos diferenciables. El ectocíngulo anterior se originaría a partir de un cíngulo que se ubica en la posición de la StB, que en $H$. fieldsi se une a la $\mathrm{StC}$, la cual se reduce relativamente y se fusiona a este formando un cíngulo más largo (en este caso también incluye la StA, no preservada en el ejemplar IGM 184041); mientras el ectocíngulo posterior se origina a partir de un alargamiento posterior de la StC.

En la dentición inferior no se preserva ningún elemento de la serie molar y el borde alveolar del dentario está muy pobremente preservado por detrás del p2, por lo cual no es posible tomar medidas de los alvéolos. El canino inferior muestra una morfología similar a la del holotipo de $H$. fieldsi. Los premolares inferiores están muy desgastados; aparentemente son más globosos que los del holotipo de $H$. fieldsi pero presentan una relación de tamaño muy similar. Se presenta al menos un diastema, entre el p1 y el p2, que mide $2,6 \mathrm{~mm}$; en el holotipo de $H$. fieldsi hay un pequeño espacio en esta posición, más corto que cualquiera de las raíces adyacentes, por lo que no es considerado como un diastema.

El ejemplar IGM 184041 muestra varios rasgos diagnósticos de Hondadelphys, por lo que puede ser claramente referible a este género. Por otro lado, presenta notorias diferencias respecto a H. fieldsi, sugieriendo que se trata de una especie diferente.

\section{Hondadelphys sp. 2}

sp. nov.

(Figs. 4.8-4.9)

Holotipo-IGM 250364, porción anterior del cráneo con la dentición superior pobremente preservada (todos los elementos incompletos), incluyendo $\mathrm{C}-\mathrm{P} 3$ izquierdos, $\mathrm{C}-\mathrm{M} 1$ derechos y porción anterior del M2 derecho; fragmento de mandíbula izquierda con el p1, raíces del p2, y los 
p3-m1; cintura pélvica incompleta (ilion e isquion derecho e izquierdo); fémur derecho.

Localidad y Estratigrafía - Localidad 11-B (Universidad de Duke), área de La Venta; Capas de Arenisca de Tatacoa, Formación La Victoria, Grupo Honda (Tablas 3.1 y 4.1; Fig. 3.1).

Diagnosis-Se diferencia de las demás especies de Hondadelphys en el menor tamaño; la sutura nasolacrimal más larga; la ubicación del foramen infraorbitario, en una posición más anterior; y la menor diferencia de tamaño entre el P2 y el P3 (P2<P3, pero casi subiguales). Se diferencia de $H$. fieldsi en los procesos postorbitales menos desarrollados; la presencia de un diastema entre el $\mathrm{C}$ y el $\mathrm{P} 1$; el fémur más grácil, con el trocánter menor más desarrollado y la tróclea más asimétrica, con un cóndilo medial relativamente más desarrollado respecto al lateral y un epicóndilo lateral más saliente. Se diferencia de $H$. sp. 1 en la menor longitud de los diastemas entre los P1-2 y p1-2.

Medidas-Tablas 4.4-4.5.

Comentarios-El ejemplar IGM 250364 fue identificado por Goin (1997: pág. 203) como "Hondadelphidae, gen. et sp. indet (Hondadelphys?)". Sin embargo, en la presente revisión se determinó que es referible a Hondadelphys y muy probablemente representa otra especie diferente de $H$. fieldsi y de $H$. sp. 1.

Descripción-Esta especie es más pequeña que $H$. fieldsi y que $H$. sp. 1. En vista dorsal del cráneo se observa el contacto yugal-lacrimal, a la altura del contacto M1-2. Es visible el contacto nasolacrimal, el cual presenta una sutura muy extensa $(8,35 \mathrm{~mm})$. El margen orbitario del lacrimal presenta una pequeña cresta, bien definida. Esta aparentemente estaría presente también en el ejemplar IGM 184041 ( $H$. sp. 1) y se desconoce su presencia en $H$. fieldsi. Los procesos postorbitales están menos desarrollados que en $H$. fieldsi. La sutura nasofrontal es similar a $H$. fieldsi, en forma de "W" abierta. En vista lateral, el foramen infraorbitario se ubica a nivel del contacto P2-3, con su borde posterior a nivel de la raíz anterior del P3, estando en una ubicación más anterior que en el IGM 184041 y el holotipo de $H$. fieldsi.

En vista ventral presenta un paladar no fenestrado y con pequeños forámenes circulares alineados cerca de la hilera dentaria, al igual que en el IGM 184041 (los forámenes del IGM 184041 son menos evidentes por la pobre preservación), tal como los que aparecen comúnmente en otros esparasodontes. En los representantes de este orden suele estar ausente el foramen palatino mayor, pero suelen presentarse (además de forámenes nutricios) pequeños forámenes circulares, simétricos y alineados sobre la superficie palatal del maxilar. Según Forasiepi (2009), como el foramen palatino mayor está ausente, es probable que, como ocurre en algunos euterios (e.g., Wible y Gaudin, 2004), los pequeños forámenes en el paladar transmitieran el nervio y vasos que en otros mamíferos pasan a través del foramen palatino mayor (ver Materiales y Métodos: Nomenclatura de las descripciones - cráneo). Otro rasgo observable en vista ventral es la expansión de las "mejillas" del maxilar, presente en la mayoría de esparasodontes.

La rama horizontal del dentario es, aparentemente, más similar a la de $H$. fieldsi que a la de IGM 184041, o al menos no es curva en la porción anterior. Se observa un foramen mentoniano 
por debajo de la raíz anterior del p2, siendo su morfología similar a la del holotipo de $H$. fieldsi.

La dentición superior está pobremente preservada. El canino superior tiene un desarrollo similar a $H$. fieldsi pero es más comprimido lateralmente (i.e., es más ovalado). Como lo menciona Goin (1997), la diferencia de tamaño entre el P2 y el P3 (P2<P3) es menor que en $H$. fieldsi y $H$. sp. 1, siendo casi subiguales (diferencia de $0,18 \mathrm{~mm}$; véase tabla 4.2). Se presenta un diastema bastante corto entre el C y el P1 ( 1,43 mm), otro más largo entre el P1 y el P2 (2,25 mm) y un pequeño espacio entre el P2 y el P3, pero al ser más corto que cualquiera de las raíces adyacentes (i.e., 1,12 mm) no fue considerado como un diastema. Al menos en el M2 derecho se pueden apreciar algunos rasgos diagnósticos de Hondadelphys, como el protocono bien desarrollado (aunque aparentemente es más ancho y está más extendido anteroposteriormente que en $\mathrm{H}$. fieldsi, similar a IGM 184041); las bases del metacono y el paracono en contacto, pero no fusionadas; y la centrocrista recta. Aparentemente, la plataforma estilar se encuentra menos reducida a nivel del paracono que en $H$. fieldsi (similar al IGM 184041).

En la dentición inferior, se presenta un corto diastema entre el p1 y el p2 (1,69 mm), más siendo más corto que el de $H$. sp. 1 . Entre el p2 y el p3 se presenta un pequeño espacio (i.e., 1,20 $\mathrm{mm}$ ), siendo más corto que cualquiera de las raíces adyacentes, por lo que no fue considerado como un diastema. En los molares inferiores, el lóbulo posterior de la corona del $\mathrm{m} 1$ se encuentra a un nivel más bajo que el lóbulo anterior. Este rasgo no ha podido ser evaluado claramente hasta ahora en $H$. fieldsi, ya que no se presenta un $\mathrm{m} 1$ completo, sólo trigónidos o talónidos por separado. Comparándolo con ejemplares referidos a H. fieldsi, este desnivel está ligeramente menos marcado que en el m2. La cúspide principal del trigónido es el protocónido. El paracónido es pequeño y presenta un metacónido vestigial. Goin (1997: pág. 198) afirma que este último es un rasgo diagnóstico de Hondadelphys. Sin embargo, se desconoce la presencia del metacónido en el m1, ya que esta porción del primer molar no se encuentra preservada en el holotipo ni en ningún ejemplar referido: no se preserva ningún $\mathrm{m} 1$ completo referible a esa especie y el único trigónido preservado está incompleto en esa porción. La presencia de un metacónido en el m1 no se puede inferir a partir de su presencia en los demás molares, ya que podría ser el caso que esté presente en los m2-4 y ausente en el $\mathrm{m} 1$, condición presente en muchos esparasodontes con metacónido fuertemente reducido en los m2-4 (e.g., Lycopsis longirostrus, Borhyaena tuberata, Arctodictis munizi, Arctodictis sinclairi, Australohyaena antiqua). Esto no implica que en $H$. fieldsi ocurra lo mismo que en estos taxones (podría ocurrir que esté presente en todos los molares, tal como ocurre en Stylocynus paranensis), pero claramente ninguna de las dos condiciones se puede inferir a partir de la condición en los m2-4. Este rasgo sólo será aclarado cuando se encuentre un ejemplar claramente referible a $H$. fieldsi que preserve esta porción del trigónido en el m1. El tamaño de este molar también podría ser consistente con Thylacosmilidae gen. 1 sp. 1 (gen. et sp. nov.; ver más adelante), pero se descarta que se trate de este taxón, ya que en este último se presenta una gran diferencia de tamaño entre los p1-2 y el p3, y amplios diastemas entre ellos. Esto no ocurre en el caso de IGM 250364; adicionalmente el trigónido de Thylacosmilidae gen. 1 sp. 1 es más largo 
respecto al talónido que en el ejemplar IGM 250364.

El fémur del ejemplar IGM 250364 es más grácil que el del holotipo de H. fieldsi, y su trocánter menor es más desarrollado. La tróclea es más asimétrica, con un cóndilo medial relativamente más desarrollado respecto al lateral y un epicóndilo lateral más saliente.

El ejemplar IGM 250364 presenta varios caracteres diagnósticos de Hondadelphys, que hacen indudable su asignación a este género. Sin embargo, muestra algunas diferencias notorias respecto a $H$. fieldsi, varias de ellas compartidas con el ejemplar IGM 184041; también presenta algunas diferencias con este último, por lo que muy probablemente se trata de una especie diferente de $H$. fieldsi y de $H$. sp. 1 .

\section{Hondadelphys sp. indet.}

(Fig. 4.10A-C)

\section{KU 1995-4}

Material-Fragmento de maxilar derecho con el M3 incompleto y el M4; fragmento de mandíbula derecha con alvéolos de los p1-2, el p3 y los m3-4; fragmento de mandíbula izquierda con un protocónido y otro fragmento no determinado; fragmento de mandíbula izquierda con un trigónido roto y un talónido parcialmente preservado de otro molar; un incisivo aislado; fragmentos de hueso en matriz sin preparar (Fig. 4.10A-C).

Localidad y Estratigrafía - Localidad Los Mesones (Universidad de Kioto), área de La Venta; nivel estratigráfico desconocido del Grupo Honda (Tabla 4.1).

Medidas-Tablas 4.3-4.5.

Comentarios-El ejemplar está alojado en la colección del Primate Research Institute de la Universidad de Kioto, Japón, y no ha sido descripto previamente. El material se encuentra pobremente preservado, muy frágil (cubierto por una capa de pegamento o consolidante) y le falta preparación. Los dientes perdieron parte del esmalte, posiblemente por meteorización o al momento de ser colectado. No se identifican los alvéolos de los m1-2, pudiéndose apreciar sólo unos fragmentos muy pequeños de diente, sin que quede claro a qué molar corresponden. La superficie labial del dentario está muy fracturada y cubierta por sedimento muy cementado. Se identifica al menos un foramen mentoniano aparentemente por debajo del $\mathrm{m} 2$ o la raíz posterior del m1 (el foramen es claro, mas no la ubicación de los molares).

Se presenta una fosa palatal (carácter 21) entre el M3 y el M4 (también presente en el holotipo de $\mathrm{H}$. fieldsi). Los M3-4 están parcialmente cubiertos de sedimento y con los protoconos rotos (sólo se preserva la base). El M3 es más ancho que el M4, como ocurre en Hondadelphys sp. 1. El metacono está roto, pero aparentemente es más grande que el paracono y se encuentra ubicado en una posición más lingual. Las bases del metacono y paracono están en contacto pero no fusionadas y la centrocrista es recta, como ocurre en las especies de Hondadelphys. A pesar de que 
las cúspides del M4 están parcialmente cubiertas, es evidente la presencia de un metacono, aparentemente más desarrollado que en $\mathrm{H}$. fieldsi, siendo este molar relativamente más largo que en $H$. fieldsi (menos comprimido anteroposteriormente). El protocono está moderadamente expandido anteroposteriormente y aparentemente presenta un desarrollo similar al de $\mathrm{H}$. fieldsi, aunque está incompleto en su porción lingual. El paracónulo y metacónulo están presentes al menos en el M3 (cubiertos en el M4), ubicándose hacia la base del para- y metacono y presentando crestas aladas. La preparacrista en el M3 está orientada anterolabialmente al eje de la hilera dentaria, mientras la postmetacrista está bien desarrollada, siendo más larga que la preparacrista. El cíngulo anterior está bien desarrollado, expandido hasta conectar con la cresta preparaconular. En la plataforma estilar no son visibles las cúspides estilares (por la preservación), pero sí se observa que se encuentra reducida labialmente al paracono y presenta un ectoflexo profundo, al menos en el M3.

En la dentición inferior, el p1 es aparentemente paralelo al eje de la hilera dentaria (menos de 19: carácter 119). El p1 es claramente más pequeño que el p2 y aparentemente el p2 es ligeramente más pequeño que el p3. Existe un pequeño espacio entre el p1 y el p2, menor a la longitud de una raíz, por lo que no fue considerado como un diastema (definido como un espacio de longitud igual o al menos la mitad de la longitud de un diente adyacente: Zan et al., 2006). El p3 no es globoso, diferente de $H$. fieldsi (i.e., ligeramente globoso), sus raíces no sobrepasan el ancho de la corona y su cúspide principal tiene el borde anterior más convexo que el posterior. Tanto el p3 como el m4 están completamente erupcionados. El m4 es más largo que el m3, con el trigónido más largo que el talónido en ambos molares. El ancho del trigónido del $\mathrm{m} 3$ es subigual al del talónido, mientras que en el $\mathrm{m} 4$ el talónido está más reducido respecto a su trigonido y respecto al talónido del m3. El talónido se encuentra aparentemente más reducido que en $H$. fieldsi. El trigónido de ambos molares es abierto, con el paracónido anterolingual. Los paracónidos están pobremente preservados. El metacónido está extremadamente reducido en el m3 y es vestigial en el m4. El protocónido está notablemente gastado, probablemente erodado; aparentemente era un 25$35 \%$ más alto que el hipocónido.

La cuenca del talónido es aparentemente menos profunda que en H. fieldsi. El hipocónido está localizado ligeramente más posterior a la mitad del margen labial del talónido. El entocónido presenta un alto grado de desgaste en el $\mathrm{m} 3$ y el hipocónido está roto en el $\mathrm{m} 4$, por lo cual no es posible saber cuál de las dos cúspides es más alta en ninguno de los dos molares, aunque en el m3 aparentemente es el hipocónido. Esta última cúspide se ubica hacia la mitad del borde labial del talónido. El entocónido está ubicado entre el metacónido y el margen posterior del diente, ligeramente más cerca del borde posterior y más posterior en el m4. No se logró identificar la entocrístida. El hipoconúlido tiene una ubicación posterolingual y se encuentra apareado al entocónido. En el m4 el hipoconúlido es alto, más alto que el entocónido, lo que puede verse mejor en vista lingual. Adicionalmente, en esta misma vista se observa que las bases de estas dos cúspides forman un bloque, y que la pared lingual de la cuenca del talónido es muy vertical y 
plana. Este rasgo no se puede ver en el $\mathrm{m} 3$ debido al desgaste, pero se aprecia la estrecha cercanía entre estas cúspides bien diferenciadas.

El conjunto de rasgos observados en este ejemplar refleja una morfología relacionada con las especies de Hondadelphys, presentando varios rasgos diagnósticos de este género (i.e., tamaño pequeño; protoconos bien desarrollados, moderadamente expandidos anteroposteriormente; las bases del paracono y metacono en contacto pero no fusionadas, la centrocrista recta; el metacónido distinguible en los molares preservados, aunque marcadamente reducido; y talónidos relativamente bien desarrollados). Como se puede ver en la descripción, este ejemplar presenta algunas diferencias puntuales respecto a $H$. fieldsi y algunos rasgos comunes. Aparentemente, es más cercano en tamaño a $H$. fieldsi pero, a pesar de su similitud, no es posible observar con claridad los rasgos diagnósticos de esta especie y varios de los otros rasgos compartidos no son evaluables por el momento en las otras dos especies, ya que no se preservaron. Por tales motivos, el ejemplar es referido por el momento a Hondadelphys sp. indet.

\section{?Hondadelphys}

(Fig. 4.10D-E)

A continuación, se describen ejemplares cuyo carácter fragmentario o mala preservación impiden referirlos claramente al género Hondadelphys. Algunos de estos ejemplares (IGM 250578, IGM 250471, IGM 250962, IGM 251215) habían sido identificados por Goin (1997) como "Hondadelphidae, gen. et sp. indet (Hondadelphys?)". El ejemplar KU LV-1 es un material inédito.

\section{UCMP 37885}

Material-Fragmento de mandibula derecha con un fragmento anterior de un p?3?, alvéolos del p?2? y parte posterior del alvéolo de otro diente anterior a este (p?1? o C?) (Fig. 4.10D).

Localidad y Estratigrafía-Localidad "El Mono", V4517 (UCMP); Capas del Mono, Miembro Baraya, Formación Villavieja, Grupo Honda (Tablas 3.1 y 4.1).

Comentarios-Este ejemplar fue referido a Hondadelphys fieldsi por Marshall (1976a). En esta porción de dentario, el único rasgo notorio es la presencia de un foramen mentoniano de gran tamaño, ubicado a nivel de la raíz posterior del p?2?. La preservación de la dentición es muy pobre, dificultándose incluso la identificación del locus correspondiente para los alvéolos presentes. Si los alvéolos preservados correspondieran a molares, se descartaría que se tratara de Hondadelphys, ya que en este ejemplar los talónidos estarían mucho más reducidos. Sin embargo, estos alvéolos encajan más con una morfología de premolares (al menos los de los dos dientes más posteriores).

No se presentan diastemas entre los tres dientes. El p?1? está ligeramente orientado en un ángulo diferente a los otros dos premolares, aunque este ángulo es inferior a $19^{\circ}$. Aparentemente el tamaño de los premolares se incrementa gradualmente del p?1? al p?3? 
La mala preservación de la dentición impide apreciar algún rasgo diagnóstico. A juzgar por el tamaño en general, se descarta que se trate de algún Metaterio no esparasodonte ya descripto para La Venta. Comparado con los esparasodontes de esta asociación, es mucho más pequeño que Lycopsis, Anachlysictis y Dukecynus. La morfología de los alvéolos no corresponde a la de Thylacosmilidae gen. 1 (gen. nov.; ver más adelante), ya que en este último se presenta una gran diferencia de tamaño entre los p1-2 y el p3, y amplios diastemas entre ellos, cosa que no ocurre en el caso de UCMP 37885. Por esta razón, se refiere el ejemplar a ?Hondadelphys (con dudas), ya que debido a la mala preservación del material, no es posible realizar una identificación más precisa.

\section{IGM 250471}

Material—Un canino inferior? aislado.

Localidad y Estratigrafía-Localidad 106 (Universidad de Duke), área de La Venta; unidad entre las Capas de Arenisca de Tatacoa y Conglomerado de Cerbatana, Formación La Victoria, Grupo Honda (Tablas 3.1 y 4.1; Fig. 3.1).

Comentarios-La morfología de los caninos de los metaterios de La Venta no es muy variable y las diferencias que se observan son, en general, en cuanto a tamaño. El único grupo que podría presentar alguna particularidad en la morfología del canino son los tilacosmílidos, en los cuales son lateralmente comprimidos, siendo el superior notoriamente agrandado (en el caso de los más basales) o hiperdesarrollado (en el caso de los más derivados). No es el caso de este canino, de aspecto mucho más generalizado. Por su tamaño podría ser referible a Hondadelphys.

\section{IGM 250578}

Material—Fragmento de corona y raíz posterior del p3.

Localidad y Estratigrafía-Localidad CVP-14 (Universidad de Duke), área de La Venta; unidad Capas de Peces, Miembro Baraya, Formación Villavieja, Grupo Honda (Tablas 3.1 y 4.1; Fig. 3.1).

Comentarios-Es similar en morfología y tamaño al ejemplar IGM 253049. Entre todos los Metaterios de La Venta, el que más se asemeja en forma y tamaño es Hondadelphys.

\section{IGM 250962}

Material—Fragmento de mandibular con raíces de los m3-4.

Localidad y Estratigrafía_Localidad 113 (Universidad de Duke), área de La Venta. Nivel entre las Capas de Arenisca de Chunchullo y las Capas de Arenisca de Tatacoa, Formación La Victoria, Grupo Honda (Tablas 3.1 y 4.1; Fig. 3.1).

Comentarios-La morfología del dentario no se asemeja a la del holotipo de $H$. fieldsi, aunque sí en tamaño. Al no preservarse ninguna corona, es muy difícil su asignación efectiva. 


\section{IGM 251215}

Material-Fragmento de mandibular derecha con las raíces y un fragmento de corona del $\mathrm{m} 4$.

Localidad y Estratigrafía_Localidad 132 (Universidad de Duke), área de La Venta; unidad entre las Capas de Arenisca de Chunchullo y las Capas de Arenisca de Tatacoa, Formación La Victoria, Grupo Honda (Tablas 3.1 y 4.1; Fig. 3.1).

Comentarios-El tamaño del dentario es similar al de H. fieldsi pero su preservación es muy pobre.

KU LV-1 (Fig. 410E)

Material-Molar inferior izquierdo (m3? o 4?) incompleto.

Localidad y Estratigrafía - Localidad desconocida (Universidad de Kioto), área de La Venta; Grupo Honda.

Comentarios - La corona del talónido está incompleta (no preserva parte de su porción posterior y posterolingual), pero siguiendo la morfología de su base se aprecia que sus dimensiones respecto al trigónido son similares a las del holotipo de $H$. fieldsi. Aparentemente, el ángulo entre el borde labial y posterior del talónido es ligeramente más abierto y el trigónido es ligeramente más cerrado que el $\mathrm{m} 4$, más parecido al del $\mathrm{m} 3$. A pesar de que no se preserva la punta del protocónido, se puede apreciar que el hipocónido es muy bajo respecto a este. Presenta un metacónido vestigial.

\section{Comentarios generales sobre Hondadelphys}

La posición sistemática de Hondadelphys ha sido tema de debate entre diferentes autores. Inicialmente, Hondadelphys fue clasificado como Didelphimorphia (e.g., Marshall, 1976a; Reig et al., 1987). Dicha hipótesis fue posteriormente puesta en duda debido a la presencia de algunos caracteres inusuales entre los representantes de este orden (e.g., centrocrista recta en los molares superiores, reducción en la porción anterior de la plataforma estilar en el M2; Crochet, 1980). Otros autores propusieron incluir a Hondadelphys dentro de Sparassodonta (e.g., Aplin y Archer, 1987; Marshall et al., 1990; Goin, 1997), e incluso consideraron a Hondadelphys como el único género conocido de una nueva familia, Hondadelphidae, Superfamilia Borhyaenoidea (Marshall et al., 1990).

En resumen, los rasgos destacados por dichos autores para excluir a Hondadelphys de Didelphimorphia fueron los siguientes: (1) la centrocrista recta (Aplin y Archer, 1987) en todos los molares superiores (Goin, 1997; en los didelfimorfios puede presentarse en algunos, no en todos a la vez); (2) el proceso timpánico del aliesfenoides poco desarrollado (Aplin y Archer, 1987); (3) la ausencia de contribución del mastoides en la superficie posterior del cráneo (Aplin y Archer, 1987); (4) la reducción en el número de incisivos (Marshall et al., 1990; Goin, 1997); (5) los paray metacónulo más desarrollados que en los didelfoideos (Goin, 1997); (6) la preparacrista 
conectando con la StA (al menos en los M1-2), no con la StB, como ocurre en la mayoría de los didelfimorfios (Goin, 1997; contra Marshall, 1976a); (7) plataforma estilar reducida y sin StB (Goin, 1997; aunque en la presente revisión sí se identifica una StB); (8) la extrema reducción del metacónido (Goin, 1997); y (9) la gran reducción del cingúlido anterior (Goin, 1997). Adicionalmente, Marshall (1976a) ya había mencionado algunos rasgos del basicráneo presentes en Hondadelphys, que están ausentes en los didelfimorfios: (10) pérdida del pars mastoidea y proceso timpánico del petroso; (11) la ausencia de un canal transverso; y (12) el agrandamiento del foramen carotídeo (i.e., foramen lacerum medium sensu Marshall, 1976a) y el foramen para el seno petroso inferior (i.e., foramen carotídeo posterior sensu Marshall, 1976a).

Hasta la revisión de Goin (1997) quedaba claro que Hondadelphys debía ser excluido de Didelphimorphia, siendo incluido dentro de Sparassodonta. Sin embargo, no eran claras las afinidades con los demás miembros de este grupo, aunque Goin (1997) destaca algunos rasgos presentes en Hondadelphys que no se presentan en Borhyaenoidea (e.g., gran desarrollo del talónido y profundidad de su cuenca; ausencia de imbricación molar en la serie yugal). Posteriormente, algunos análisis filogenéticos que incluyeron a Hondadelphys dentro de los taxones estudiados (e.g., Forasiepi, 2009; Engelman y Croft, 2014; Forasiepi et al., 2015; Suarez et al., 2016) mostraron su posición basal dentro del clado Sparassodonta y por fuera de la Superfamilia Borhyaenoidea. Durante la presente revisión se analizó la totalidad de ejemplares colectados asociados a Hondadelphys, algunos ya publicados y otros inéditos, con el objetivo de contrastar estas hipótesis. Estas observaciones fueron incluidas dentro del análisis filogenético que se muestra más adelante en este capítulo.

Aplin y Archer (1987) señalaron que no es posible observar el contacto nasolacrimal en el holotipo de H. fieldsi. Sin embargo, en dos de los ejemplares que en la presente revisión fueron asignados al género Hondadelphys (IGM 184041 e IGM 250364), es posible observar una clara sutura (de gran longitud) marcando el contacto nasolacrimal, rasgo que ya había notado Goin (1997) en estos ejemplares. Con la identificación de este material como Hondadelphys se suma un argumento de peso para ratificar la clasificación de este taxón dentro de Sparassodonta, ya que dicho contacto es un rasgo diagnóstico del grupo. Adicionalmente, estos ejemplares presentan otro rasgo típico de Sparassodonta, que es la ausencia de fenestración en el paladar. Tanto en el holotipo de H. fieldsi como en los ejemplares referidos a Hondadelphys, la sutura nasofrontal presenta una morfología en forma de "W" abierta, condición está presente en general en los esparasodontes (al menos en todos los taxones revisados en este análisis, excepto Callistoe vincei; carácter 14)

El proceso facial del maxilar está incompleto en el holotipo de $H$. fieldsi, pero en vista ventral se puede observar que la porción preservada presenta una expansión lateral por detrás del foramen infraorbitario. Esta expansión de las "mejillas" del maxilar está presente en muchos esparasodontes (e.g., Cladosictis patagonica, Sipalocyon, Australohyaena antiqua, Lycopsis torresi, Prothylacynus patagonicus, Arctodictis, Thylacosmilus). Este carácter había sido codificado en análisis filogenéticos previos (e.g., Forasiepi, 2009) como ausente, pero en esta 
revisión se observa claramente una expansión, incluso cuando la mejilla se encuentra incompleta. Este rasgo puede ser confuso cuando no se tiene un cráneo completo, ya que puede ser malinterpretado dependiendo del ángulo de observación si se tiene un fragmento aislado de maxilar. En los esparasodontes que presentan esta condición la serie molar se encuentra ligeramente inclinada medialmente, por lo cual la vista oclusal de estos no coincide exactamente con el plano horizontal. Al tener un fragmento suelto, se tiende a orientarlo ubicando la superficie oclusal de los molares coincidiendo con el plano horizontal, pero esta no sería su posición natural en el cráneo (ver ejemplo en el Anexo 1.8, Fig. A1.2). Esto puede conducir a soslayar este rasgo. En este caso, se tuvo como referencia los demás dientes y la porción más anterior del maxilar para la correcta orientación del material. Por otro lado, este rasgo sí se observa fácilmente en los ejemplares IGM 184041 (Hondadelphys sp. 1) e IGM 250364 (Hondadelphys sp. 2), ya que esta porción del cráneo se encuentra completa.

En su descripción original, Marshall (1976a) menciona que el holotipo de H. fieldsi presenta cuatro incisivos inferiores. Sin embargo, en revisiones posteriores (e.g., Marshall et al., 1990, Goin, 1997) y en la presente revisión, se observan claramente tres alvéolos de incisivos, tanto en el holotipo como en el ejemplar IGM 250961 (referido a H. fieldsi), poniendo en duda la presencia de un cuarto incisivo, del cual no se tiene clara evidencia. Goin (1997) ya había notado que el segundo incisivo de la secuencia preservada se encuentra en una posición escalonada (la condición "staggered" de la terminología anglosajona; véase Hershkovitz, 1982); esto es, desplazado lingualmente respecto a los demás. Esto indica que se trata del i3, conocido como el "incisivo sobremontado" (staggered), característico de la mayoría de los metaterios (excepto Dromiciops). Por lo tanto, los incisivos presentes en el holotipo corresponderían a i2, i3 e i4. La reducción en el número de incisivos inferiores (sólo se observan tres) permite diferenciar a Hondadelphys de los didelfimorfios, los cuales no presentan reducción en el número de incisivos (tienen invariablemente cuatro), cosa que sí ocurre en otros grupos de Metaterios (Goin, 1997).

Al menos en los m2-3 de H. fieldsi, el lóbulo posterior de la corona se ubica a un nivel más bajo que el anterior. Entre los metaterios observados en esta revisión, este rasgo sólo se presenta en borienoideos (con algunas excepciones) y en Sminthopsis crassicaudata. En dichos taxones, esta condición se expresa en los m1-2 y ligeramente desarrollada, o en los m1-3 y fuertemente desarrollada. En Hondadelphys, aparentemente, esta condición se expresa en los m1-3 (aparece en el m1 del ejemplar IGM 250364) pero está fuertemente desarrollada sólo en los m2-3, y en general es más marcada en el $\mathrm{m} 3$ que en el $\mathrm{m} 2$. Algo similar ocurre en algunos tilacosmílidos como Anachlysictis gracilis y Thylacosmilidae gen. 1 sp. 1 (gen y sp. nov; ver más adelante), aunque en estos se encuentra ligeramente más marcado en el $\mathrm{m} 2$ que en el $\mathrm{m} 3$.

En el holotipo de H. fieldsi el m1 está ausente y el paratipo que Marshall (1976a) propone en la descripción original de la especie (actualmente perdido) preservaba el $\mathrm{m} 1$ incompleto. En la presente revisión se encontraron varios ejemplares que preservan el $\mathrm{m} 1$ parcialmente, y gracias a que las porciones que no se preservan en unos sí se preservan en otros, se puede tener una clara 
idea de cómo era el $\mathrm{m} 1$ completo, excepto por la porción correspondiente a la posición del metacónido. En el $\mathrm{m} 1$ de $H$. fieldsi las cúspides principales están alineadas en una hilera longitudinal, como se observa en el $\mathrm{m} 1$ de los esparasodontes, no conforman un triángulo reverso como en los didelfimorfios (ver carácter 161 del análisis filogenético: Anexo 1.3). En los demás molares inferiores la configuración del trigónido es abierta, con el paracónido anterolingual, como ocurre en los esparasodontes y diferente de los didelfoideos, cuya configuración es aguda, con el paracónido en una ubicación más posterior (carácter 162, Anexo 1.3).

En H. fieldsi el metacónido es extremadamente reducido y está presente al menos en los m24, pero no se ha encontrado un ejemplar claramente referible a esta especie que preserve la porción de la corona correspondiente al metacónido en el m1. Sin embargo, en el ejemplar IGM 253064 , identificado como una especie diferente de Hondadelphys (i.e., H. sp. 2), el $\mathrm{m} 1$ presenta un metacónido vestigial. Independientemente del grado de desarrollo del metacónido, en el conjunto de esparasodontes revisados en el presente estudio (Anexo 1.1) se encontraron en general dos condiciones respecto a la presencia o ausencia del metacónido: presente en todos los m1-4 o presente en los $\mathrm{m} 2-4$; y en ningún caso se observó que el metacónido estuviera presente únicamente en el m1, por lo que es muy probable que en el ejemplar IGM 253064 el metacónido esté presente en los m1-4. Sin embargo, por la misma razón, en el caso de H. fieldsi no es posible deducir la presencia del metacónido en el $\mathrm{m} 1$ a partir de su presencia en los $\mathrm{m} 2-4$. Esto sugiere que: (1) al menos en una especie de Hondadelphys, diferente a H. fieldsi, el metacónido está presente en los m1-4, mientras que (2) en H. fieldsi el metacónido está presente al menos en los $\mathrm{m} 2-4$.

El hipocónido de $H$. fieldsi se ubica en una posición entre la mitad del borde labial del talónido y el extremo posterior del diente, mostrando en vista oclusal un ángulo claramente definido (no es curvo) formado entre el borde labial y el posterior del talónido, siendo este último oblicuo al eje principal del diente. Esta condición es similar pero no igual a la de los didelfimorfios: en estos el hipocónido se ubica en la esquina posterolingual del talónido (más posterior que en Hondadelphys) y forma también un ángulo bien definido entre el borde labial y posterior del talónido, pero este último no es oblicuo sino paralelo al eje del diente. En los esparasodontes, en general, el hipocónido suele estar ubicado hacia la mitad del borde labial del talónido, y el borde posterior suele ser ligeramente más oblicuo. Sin embargo, al presentarse un ángulo más abierto y el hipocónido más reducido, en vista oclusal no se aprecia un ángulo bien definido sino más bien una curva. En $H$. fieldsi el ángulo es más cerrado y mejor definido en los $\mathrm{m} 3-4$, haciéndose más amplio del $\mathrm{m} 3$ al $\mathrm{m} 1$, con un borde posterior más oblicuo y un perfil más curvo en vista oclusal.

Otro rasgo particular presente en el talónido de H. fieldsi (se desconoce en las otras especies), es la morfología del bloque formado por el hipoconúlido y el entocónido en los m2-4 (ver descripción del holotipo de Hondadelphys fieldsi). Entre todos los metaterios revisados en este análisis, este rasgo sólo es compartido con los tilacosmílidos (excepto Thylacosmilus). 
Como pudo observarse en la presente revisión, Hondadelphys muestra una variedad de rasgos craneanos y dentarios que sustentan su posición dentro de Sparassodonta. Esta hipótesis es apoyada por los resultados del análisis filogenético presentado en este trabajo, en los que Hondadelphys aparece como uno de los taxones basales dentro de este clado (Fig. 4.29). En esta revisión se pudo observar que los rasgos compartidos con los didelfimorfios son fundamentalmente dentarios (e.g., el desarrollo del protocono y el talónido) y que más que indicar alguna relación con este clado lo que sugieren es el desarrollo de una morfología más compatible con hábitos omnívoros que la de esparasodontes más especializados. Hondadelphys desarrolla rasgos claramente orientados a la carnivoría (e.g., la extrema reducción del metacónido, protocónido bien desarrollado, crestas del trigónido bien desarrolladas y cortantes), pero también muestra otros relacionados a la omnivoría (e.g., protocono y talónido bien desarrollados, de cuenca una amplia y profunda), reflejando una amplitud en el uso de los dientes.

Además de los rasgos anteriormente discutidos, que relacionan a Hondadelphys con los esparasodontes, en el análisis filogenético se identificaron los siguientes rasgos presentes en Hondadelphys que fueron recuperados como sinapomorfias para Sparassodonta: la altura del protocono, entre $60 \%$ y $80 \%$ la altura de los para/metacono; la orientación de la postprotocrístida/ metacrístida, paralela u oblicua al eje anteroposterior; el metacono más grande que el paracono; y la orientación de la preparacrista, anterolabial al eje anteroposterior.

En la presente revisión se encontró que H. fieldsi no es la única especie de Hondadelphys presente en La Venta, sino que existen dos especies más, las cuales comparten rasgos en común con $H$. fieldsi, pero, a su vez, presentan diferencias notorias que permiten diferenciarlos como especies independientes.

HATHLIACYNIDAE Ameghino, 1894

gen. et sp. indet.

(Fig. 4.11A-E)

\section{KU 1995-5}

Material-Fragmento craneal que incluye parte del maxilar derecho con los M1-4 altamente desgastados y fragmentos del frontal, parte de la plataforma orbital y un fragmento del yugal; fragmento anterior del maxilar derecho con el C, el P1 y la raíz anterior del P2, y parte del nasal?; fragmento de maxilar izquierdo con el P2 incompleto; tres premolares aislados (P1 izquierdo y los P3) y un fragmento de incisivo (Fig. 4.11A-E).

Localidad y Estratigrafía_Localidad San Alfonso (Universidad de Kioto), límite noreste del área de La Venta; Formación La Victoria?, Grupo Honda (Tabla 4.1).

Medidas-Tablas 4.2-4.3.

Comentarios-Se trata de un ejemplar inédito, alojado en las colecciones del Primate 
Research Institute de la Universidad de Kioto (Japón). El material no está del todo preparado ya que algunas partes están cubiertas por sedimento.

Descripción -En la porción preservada del cráneo se observan algunos rasgos destacables. En la plataforma orbital se preservan marcas del canal infraorbitario. A pesar de que no se preserva su abertura, por su recorrido se puede apreciar que abre en algún punto anterior al nivel del M1. En vista lateral, en la parte anterior del maxilar se presenta una yuga alveolaria marcada (i.e., protuberancia presente en el borde anterior del maxilar, definida por la raíz del canino, la cual se proyecta dorsalmente siguiendo la sutura con el nasal: Forasiepi y Carlini, 2010), aunque no tan desarrollada como en Thylacosmilidae gen. 1 sp. 1, descripto más abajo. En la porción posterior, por encima de los M3-4, se preserva un pequeño fragmento del yugal, con una sutura maxiloyugal irregular. La corta porción de sutura preservada tiene una orientación oblicua, entre 95 y 140 grados (carácter 17), pero esto no implica que toda la sutura tenga esta inclinación (e.g., Lycopsis padillai: Suarez et al., 2016).

Se observa una expansión de las mejillas del maxilar, posterior al nivel del foramen infraorbitario, la cual es más claramente visible en vista palatal. Esta expansión ocurre en muchos esparasodontes (e.g., Cladosictis patagonica, Sipalocyon spp., Australohyaena antiqua, Lycopsis torresi, Prothylacynus patagonicus, Arctodictis, Thylacosmilus). Al menos dos fosas palatales están presentes, el más profundo entre el M3 y el M4, y otro entre el M2 y el M3. Adicionalmente, se observa una depresión mucho más superficial entre el M1 y el M2, que podría ser una fosa poco profunda. Este rasgo también es observado en algunos metaterios basales (i.e., Deltatheroides y Deltatheridium), australidelfios y peradéctidos (Mimoperadectes presenta uno), pero no se presenta en los didélfidos.

Debido a que el material no se encuentra completamente preparado, la porción de paladar preservada está parcialmente cubierta por sedimento. Por esta razón, no es posible observar si está fenestrado, aunque sí se observa un gran número de pequeños forámenes nutricios cerca de los molares y, adicionalmente, se presentan unos forámenes de mayor tamaño que los nutricios (pero siendo aún pequeños), circulares (simétricos) y alineados, en las porciones de maxilar preservadas de ambos lados, al nivel del P2. Estos forámenes son similares a aquellos presentes sobre la superficie palatal del maxilar de los esparasodontes (véase Materiales y Métodos: Nomenclatura de las descripciones - cráneo). En el paladar también se preserva un fragmento del proceso palatino medial.

En la dentición, el canino superior es relativamente agrandado (no tan desarrollado como en otros esparasodontes pero sí más grande que en otros taxones), grácil, ligeramente comprimido labiolingualmente y su implantación es vertical. El ejemplar tenía tres premolares, los cuales aumentan en tamaño gradualmente del P1 al P3. El P1 se encuentra implantado en línea con la hilera dentaria (no oblicuo) y sus raíces son ligeramente bulbosas. La corona del P2 está incompleta. La corona del P3 es menos comprimida lateralmente (la diferencia entre largo y ancho es menor) que la del P1 y presenta un notorio desgaste apical, pero el ancho de sus raíces no 
sobrepasa el de la corona. Se presenta un diastema muy pequeño entre el C y el P1, subigual al largo de la raíz anterior del P1, y otro mucho más largo entre el P1 y el P2.

Los molares se encuentran muy desgastados, si bien es posible apreciar algunos rasgos destacables. El ancho de los molares aumenta del M1 al M3, siendo el M3 subigual al M4 (ligeramente más ancho; Tabla 4.3). El largo aumenta del M1 al M3. A partir de la morfología de la base del protocono, se aprecia que este se va elongando lingualmente del M1 al M3 (haciéndose más comprimido anteroposteriormente y más saliente lingualmente) y está más reducido en el M4 que en el M3. El M4 presenta tres raíces y un ligero ensanchamiento posterior en la corona, pero al estar tan gastado, no es posible determinar si existía o no un metacono. La plataforma estilar está aparentemente reducida y en el M1 aparentemente se presenta una fuerte reducción labial al paracono. La esquina parastilar del M1 es saliente anteriormente (como en Hondadelphys, Lycopsis, Sipalocyon, Cladosictis, Australohyaena, y muchos otros esparasodontes) y la esquina metastilar es alargada (como en los esparasodontes), por lo que el molar es elongado anteroposteriormente. En el M1 aparentemente se presenta un reborde o ectocíngulo posterior, que se extiende aproximadamente desde la posición correspondiente a la StC (aunque no se observa una $\mathrm{StC}$ ). Se aprecia un ectoflexo relativamente profundo sólo en el M3.

Comentarios-Debido a la morfología de los molares (particularmente los M2-4), inicialmente se estudió la posibilidad de que se tratara de un didelfimorfio, de mayor tamaño que los que ya están descriptos para esta asociación. La morfología general de los molares no se aleja demasiado de taxones como Hiperdidelphys o Thylophorops. El tamaño se ajusta al de Thylophorops chapalmalensis y es ligeramente más grande que Hyperdidelphys dimartinoi. También es similar la morfología de la base del protocono, pero este no es un criterio confiable, ya que por el alto grado de desgaste no es posible saber si tenía un protocono con una cuenca bien desarrollada, como la de un didelfimorfio, o poco desarrollada (o vestigial), como en los hatliacínidos (en algunos hatliacínidos, como Sipalocyon, la base tiene un desarrollo cercano, pero la cuenca está muy reducida). $H$. dimartinoi presenta un rostro relativamente más corto y no presenta una yuga alveolaria ni la expansión de las mejillas en el maxilar; el P3 es más cónico (menos comprimido labiolingualmente); la plataforma estilar de los molares está menos reducida; la esquina parastilar del M1 es notoriamente menos saliente anteriormente y la esquina metastilar es más corta (y por lo tanto lo sería su metacrista, la cual no se observa en el ejemplar KU 1995-5 debido al desgaste); el M1 muestra un perfil oclusal más cuadrangular (la proporción largo vs ancho es menor), no tan alargada como en el ejemplar KU 1995-5; finalmente, el M3 es notoriamente más ancho que el M4. Si bien T. chapalmalensis muestra varias similitudes con este ejemplar, las diferencias son considerables: el canino es similar en tamaño pero en el KU 1995-5 está más verticalizado; en T. chapalmalensis no se presenta el desarrollo de la yuga alveolaria; el P1 es similar en tamaño pero en KU 1995-5 está en línea con la hilera dentaria, mientras que en $T$. chapalmalensis es más oblicuo; en los molares de T. chapalmalensis se presentan las mismas diferencias que en los de H. dimartinoi. 
Algunos caracteres que presenta KU 1995-5 lo hacen más cercano a los esparasodontes que a los didelfimorfios: las raíces del P1 globosas; el tamaño de los premolares, que aumenta gradualmente del P1 al P3 (en los didelfimorfios se presenta un cambio abrupto de tamaño, generalmente entre los $\mathrm{P} / \mathrm{p} 1$ y $\mathrm{P} / \mathrm{p} 2-3$ ); la morfología general del M1 es más cercana a los esparasodontes, siendo alargado anteroposteriormente (en los didelfimorfios la apariencia del M1 es más 'cuadrada') y con la plataforma estilar muy reducida labial al paracono; la presencia de fosas palatales y de pequeños forámenes simétricos y alineados en la porción palatal del maxilar; y la expansión de las "mejillas" (flaring of maxillary "cheecks"), que se presenta en muchos esparasodontes.

El ejemplar es ligeramente más pequeño que Hondadelphys fieldsi (ver Tablas 4.2, 4.3 y 4.7), el esparasodonte más pequeño hasta ahora descripto para a asociación de La Venta. Se diferencia de este en algunos rasgos como la morfología de los premolares, menos comprimidos lateralmente en KU 1995-5; la esquina metastilar de los molares es más alargada posteriormente que en $H$. fieldsi, el protocono más comprimido anteroposteriormente y más saliente lingualmente. Adicionalmente, en $H$. fieldsi sólo se presenta una fosa palatal y no se presenta una yuga alveolaria.

Este ejemplar presenta algunos rasgos comunes con los tilacosmílidos, aunque mucho menos desarrollados (e.g., el desarrollo de la yuga alveolaria en el proceso facial del maxilar y la morfología del canino, que presentan un aspecto similar, aunque menos marcado, que en Thylacosmilidae gen. 1 sp. 1). El tilacosmílido más cercano en tamaño es Thylacosmilidae gen. 1 sp. 1 (ver más adelante), siendo ligeramente más pequeño que el ejemplar IGM 251108 y subigual en tamaño al ejemplar KU 2000-4-A. La yuga alveolaria está menos desarrollada que en Thylacosmilidae gen. 1 sp. 1, y el canino es más pequeño y menos comprimido labiolingualmente, aunque presenta una implantación vertical similar. Thylacosmilidae gen. 1 sp. 1 sólo preserva un premolar superior ( $\mathrm{P} 1$ derecho) y está extremadamente reducido (al igual que el p1), siendo mucho más pequeño que el del ejemplar KU 1995-5. A partir de los premolares inferiores de Thylacosmilidae gen. 1 sp. 1 se puede inferir que los P2-3 eran mucho más desarrollados que el P1, mientras que en el ejemplar KU 1995-5 todos los premolares están bien desarrollados y aumentan de tamaño gradualmente del P1 al P3. Adicionalmente, en el ejemplar KU 1995-5 no se presentan los amplios diastemas que se presentan entre los premolares de Thylacosmilidae gen. 1 sp. 1. No se preserva ningún molar superior de Thylacosmilidae gen. 1 sp. 1. Sin embargo, a partir de la morfología de los talónidos se puede inferir que los protoconos tenían un desarrollo similar a los del ejemplar KU 1995-5, aunque aparentemente no eran tan elongados lingualmente.

El ejemplar se encuadra en el rango de tamaño de los hatliacínidos y adicionalmente comparte algunos rasgos presentes en este grupo, a saber: el gradual incremento en el tamaño de los premolares, la implantación del P1 paralela a la hilera dentaria, el desarrollo similar del protocono, la presencia de un ectoflexo en el M3 y la reducción de la plataforma estilar. Sin embargo, en general, presenta algunas diferencias sutiles, como lo son las raíces ligeramente 
bulbosas en el P1 y el ancho del M3 subigual al del M4 (aunque ligeramente más ancho el M3). Entre la variedad de morfologías de los hatliacínidos, las más cercanas al ejemplar KU 1995-5 son la de Sipalocyon y Cladosictis. Sin embargo, presenta algunas diferencias con cada uno de estos. Comparado con Sipalocyon externa, el ejemplar KU 1995-5 es más grande, su protocono es más desarrollado y expandido lingualmente, la esquina parastilar está más desarrollada mientras que la esquina metastilar está menos alargada (indicando una postmetacrista más corta), y el ectoflexo es similar en profundidad. Si bien su tamaño es cercano al de Sipalocyon gracilis, en esta última especie el protocono es más comprimido anteroposteriormente que en KU 1995-5, el metacono es menos desarrollado, la plataforma estilar es más reducida labial al paracono en los M1-3 y menos reducida en el M4, y la esquina parastilar es más reducida. Comparado con Cladosictis, los protoconos de KU 1995-5 son notoriamente más desarrollados, la esquina metastilar es menos desarrollada y el ectoflexo más profundo.

En general, la morfología y tamaño de este ejemplar se ajustan más a los de Sipalocyon que a los de Cladosictis o cualquier otro hatliacínido o esparasodonte conocido. Sin embargo, su pobre estado de preservación, el alto grado de desgaste y las diferencias mencionadas, no permiten distinguir los rasgos diagnósticos de este taxón. Esto quedó evidenciado en una prueba que se realizó para evaluar la posición filogenética de este taxón, la cual no fue concluyente (véase Anexo 1.6): en el árbol de consenso, este taxón se encontraba conformando una politomía con los hatliacínidos y los borienoideos, ya que, en algunos de los árboles más parsimoniosos, conformaba un grupo monofilético con los hatliacínidos, mientras en otros se encontraba a la base de los borienoideos. Lo único que pudo ser corroborado fue su posición dentro de Sparassodonta. No obstante, el análisis morfológico sugiere que, entre los esparasodontes, la morfología de los hatliacínidos es la más cercana a la de este taxón, aunque por el momento es difícil establecer una clasificación más detallada (i.e., a nivel de género y especie).

\section{KU 1995-2}

Material-Fragmento de dentario con el $\mathrm{m} 4$ ? derecho incompleto, preservando el talónido y la raíz anterior (Fig. 4.11F).

Localidad y Estratigrafía-Cerro Gordo (Universidad de Kioto), área de La Venta; Formación La Victoria, Grupo Honda (Tabla 4.1).

Comentarios-El talónido es relativamente reducido, siendo más angosto y mucho más corto que el trigónido. El desgaste no permite apreciar claramente la diferencia de altura entre el entocónido y el hipocónido, pero aparentemente son subiguales o incluso el entocónido pareciera ser ligeramente más alto. El hipocónido está localizado cerca de la mitad del borde labial del talónido. El borde posterior del talónido es oblicuo al eje principal del diente. La preentocrístida se dirige, aparentemente, en sentido anterolabial hacia el trigónido. El hipoconúlido está bien definido, es saliente posteriormente, y se ubica en una posición cercana a la mitad del borde posterior del talónido, aunque ligeramente lingual, más cerca del entocónido que del hipocónido. 
El hipoconúlido es aparentemente más alto que el entocónido, como suele ocurrir en los m4 de los metaterios con un hipoconúlido distinguible en este molar. En vista labial, la corona preserva la porción posterior de un postcingúlido, ubicado hacia la porción más anterior del talónido.

Se descarta que se trate de un didelfimorfio debido a la reducción del talónido y el gran tamaño relativo del trigónido. Adicionalmente, la morfología del hipocónido es diferente: en los didelfimorfios, se ubica en la esquina posterolabial del diente, mostrando en vista oclusal un ángulo formado entre el borde labial y el posterior del talónido, siendo este último perpendicular al eje principal del diente; mientras que en el ejemplar KU 1995-2 el hipocónido se ubica hacia la mitad del borde labial del talónido y su borde posterior es oblicuo al eje principal del diente, dando una apariencia más curva (no un ángulo) en vista oclusal.

Entre los esparasodontes de La Venta, el taxón más cercano en tamaño es Hondadelphys, si bien el talónido del ejemplar KU 1995-2 es mucho más reducido (comparado con cualquier locus). También se diferencian en la forma y ubicación del hipocónido, ya que en Hondadelphys la morfología es más cercana aquella de los didelfimorfios (i.e., formando un ángulo, aunque con el borde posterior más oblicuo que en los didelfimorfios); en la orientación de la entocrístida, que en Hondadelphys se dirige en sentido lingual al trigónido (en el ejemplar KU 1995-2 es más anterolabial, hacia la base del trigónido); y en la ubicación del hipoconúlido, que en Hondadelphys es más lingual, apareado con el entocónido.

Otro taxón de La Venta con un tamaño cercano es Thylacosmilidae gen. 1 (véase más abajo: Thylacosmilidae), pero este es ligeramente más grande que KU 1995-2. Adicionalmente, Thylacosmilidae gen. 1 presenta un "desnivel” o "escalón” en el talónido, ausente en KU 1995-2: la mitad labial del talónido está a un nivel más bajo que la mitad lingual, con la mitad lingual de la superficie de la cuenca formando una pared aplanada y casi vertical, y la labial más cóncava y presentando una orientación subhorizontal. Esta morfología en el talónido de Thylacosmilidae gen. 1 se presenta en los molares posteriores al $\mathrm{m} 1$. Sin embargo, se descarta que el ejemplar KU 1995-2 sea un $\mathrm{m} 1$ de Thylacosmilidae gen. 1 debido a la morfología del hipoconúlido, que en el ejemplar KU 1995-2 es mucho más saliente, alto, mejor definido, y se ubica en una posición menos lingual; la altura del hipocónido respecto al entocónido (el hipocónido es más alto que el entocónido en el $\mathrm{m} 1$ de Thylacosmilidae gen. 1); la orientación de la entocrístida, que en Thylacosmilidae gen. 1, se dirige en sentido lingual al trigónido (en KU 1995-2 es más anterolabial, hacia la base del trigónido); y el ancho del trigónido respecto al talónido (menor en Thylacosmilidae gen. 1).

Descartando a Hondadelphys y Thylacosmilidae gen. 1, el único grupo de esparasodontes que se mantiene en este rango de tamaño es la familia Hathliacynidae. Este grupo se encuentra ampliamente distribuido en América del Sur, desde la Patagonia (Villarroel y Marshall, 1982; Marshall, 1981) hasta latitudes más bajas, como en Perú (Antoine et al., 2013) y Bolivia (Patterson y Marshall, 1978; Villarroel y Marshall, 1982; Forasiepi et al., 2006), pero hasta el momento no ha sido reportado ningún representante en La Venta ni ninguna otra localidad de Colombia. Uno de los 
hatliacínidos que presenta tamaño similar (aunque ligeramente menor) al ejemplar de La Venta es Sipalocyon gracilis, y adicionalmente las proporciones del talónido vs. trigónido son similares. Sin embargo, existen algunas diferencias en la morfología del talónido: en S. gracilis, el hipocónido presenta una morfología en vista oclusal más similar a la ya mencionada para $\mathrm{H}$. fieldsi; el hipoconúlido está menos diferenciado (no se diferencia claramente del entocónido); y no se presenta un postcingúlido labial. La entocrístida de Sipalocyon, al igual que en el KU 1995-2, se dirige hacia la base del trigónido.

Entre los demás hatliacínidos, la morfología del talónido más cercana es la de Cladosictis. El ejemplar KU 1995-2 es mucho más pequeño que C. patagónica y la especie más cercana en tamaño (aunque ligeramente más grande), es C. tricuspidata. El ejemplar de La Venta presenta proporciones del trigónido vs. talónido similares al $\mathrm{m} 3$ de C. tricuspidata, ya que el talónido del m4 es aparentemente más reducido (al menos en el ejemplar estudiado: ver Anexo 1.1). La dentición del ejemplar de C. tricuspidata comparado (MLP 11-64) presenta un alto grado de desgaste y no se pueden ver claramente las cúspides del talónido del m3. Sin embargo, en el m2 se puede apreciar en vista oclusal que el hipoconúlido presenta una morfología y ubicación similar a la del ejemplar de La Venta: saliente posteriormente, ubicado casi en posición ligeramente posterolingual, casi posteromedial pero más cerca del entocónido. La ubicación y morfología del hipocónido también es similar a la del ejemplar de La Venta: ubicado cerca de la mitad del borde labial del talónido (con el borde posterior oblicuo) y con una apariencia curva en vista oclusal. La preentocrístida de Cladosictis, al igual que en el KU 1995-2 y Sipalocyon, se dirige en sentido anterolabial hacia la base del trigónido. Adicionalmente, en Cladosictis puede estar presente el postcingúlido labial (e.g., en C. patagonica este carácter es polimórfico: puede estar presente o ausente).

La morfología y tamaño de este ejemplar se ajustan bastante a los de Cladosictis, aunque también existen algunas similitudes con Sipalocyon. Es importante tener en cuenta el hecho de que, muy probablemente, se trata de un $\mathrm{m} 4$, ya que en los esparasodontes la morfología de este molar es muy variable (sobre todo en el talónido), observándose diferencias claras incluso entre ejemplares de la misma especie. Sin embargo, el hecho de que exista otro ejemplar hatliacínido mucho más completo (KU 1995-5), más probablemente referible Sipalocyon que a Cladosictis, no necesariamente hace menos probable que se trate de dos géneros diferentes. Como se observa en las comunidades actuales, es más probable que trate de diferentes géneros y no del mismo, viviendo en un mismo lugar y tiempo (Martin pers. comm.). Sin embargo, dada la mala preservación y escasez del material, no es prudente clasificarlo dentro de cualquiera de los dos géneros. Sea cual fuere el caso, se puede concluir que en La Venta se presenta al menos una especie de hatliacínido, que se trataría del primer reporte de esta familia para Colombia y el registro más septentrional para América del Sur. 
BORHYAENOIDEA Simpson, 1930

Lycopsis Cabrera, 1927

Especie Tipo-Lycopsis torresi Cabrera, 1927 (Provincia de Santa Cruz, Argentina; Formación Santa Cruz, Santacrucense, Mioceno temprano)

Especies Referidas-La especie tipo, Lycopsis longirostrus Marshall, 1977a (La Venta, Colombia; Mioceno medio), Lycopsis viverensis Forasiepi et al., 2003 (Provincia de Buenos Aires, Argentina; Formación Arroyo Chasicó, Chasiquense, Mioceno tardío), y Lycopsis padillai Suarez et al., 2016 (La Guajira, Colombia; Formación Castilletes, Mioceno medio, Langhiense).

Distribución-América del Sur. Santacrucense (Mioceno temprano) a Chasiquense (Mioceno tardío).

Diagnosis-Esparasodonte de tamaño mediano a grande; orientación del P1/p1 paralela a la hilera dentaria; molares superiores con protocono grande y con cuenca, ligeramente más pequeño en el M4; plataforma estilar muy reducida; ectocíngulo presente, labial al paracono; ectoflexo poco profundo en el M3, labial al metacono; sínfisis mandibular no fusionada en adultos; molares inferiores con el protocónido cortante que dobla en altura al paracónido; talónido bien desarrollado y con cuenca en los m1-3 (Suarez et al., 2016; modificada de Marshall, 1977).

\section{Lycopsis longirostrus Marshall, 1977a}

(Figs. 4.12-4.14)

Holotipo-UCMP 38061 (Figs. 4.12-4.13), esqueleto casi completo, incluyendo la porción derecha del cráneo y la rama mandibular derecha.

Ejemplares referidos-IGM 250974, KU 1997-1-A, KU 1997-1-B, CS-048.

Distribución Geográfica y Estratigráfica-Área de La Venta (Desierto de La Tatacoa, Valle Superior del Magdalena, Departamento del Huila, Colombia); Grupo Honda, Laventense, Mioceno medio (Tablas 3.1 y 4.1 ; Fig. 3.1).

Diagnosis—véase Marshall (1977a).

Medidas-Tablas 4.2-4.5.

\section{UCMP 38061 (Holotipo)}

Localidad y Estratigrafía-localidad V4527 (UCMP), área de La Venta (Desierto de La Tatacoa, Valle Superior del Magdalena, Departamento del Huila, Colombia); unidad entre las Capas Rojas de La Venta y Capas Rojas de El Cardón, Formación Villavieja, Grupo Honda.

Comentarios-A continuación, se mencionan algunos rasgos que no han sido mencionados en publicaciones previas o que vale la pena resaltar o detallar debido a su importancia anatómica. 
El postcráneo del holotipo de L. longirostrus ya ha sido detalladamente estudiado (e.g., Argot, 2004a y b), por lo cual no fue tratado en la presente revisión. El cráneo de holotipo se encuentra altamente fracturado y algunas de las suturas son difíciles de identificar, por lo cual sólo es posible observar rasgos generales ya mencionados por Marshall (1977a). Sin embargo, en la presente revisión se observaron algunas discrepancias respecto a la descripción del cráneo que presenta Marshall (1977a). Por ejemplo, se observó que los procesos postorbitales están bien desarrollados (contra Marshall, 1977a); y se está en desacuerdo con la interpretación de este autor sobre algunos forámenes del cráneo. Forasiepi (2006) hace una reinterpretación de estos forámenes con base en comparaciones con didélfidos y siguiendo a Wible (2003). En la presente tesis se sigue esta reinterpretación, la cual se resume a continuación.

La estructura que Marshall (1977a) identifica como foramen transverso y que se ubica en una posición anteromedial al foramen oval, correspondería al foramen carotídeo (sensu Wible, 2003). Esta abertura es relativamente grande, siendo tan solo ligeramente más pequeña que el foramen oval (Forasiepi, 2006; contra Marshall, 1977a) y se ubica sobre el margen lateral del basiesfenoides, anterior a la sutura con el basioccipital. Más anteriormente, se presenta otro foramen identificado por Marshall (1977a) como foramen lacerum médium y que, por su ubicación, correspondería al foramen transverso (sensu Wible, 2003; diferente a la interpretación que se dio en el caso de Hondadelphys fieldsi, donde correspondería al foramen carotídeo). Adicionalmente, Marshall (1977a) menciona un foramen lacerum posterium, que describe como grande y bilobado. Siguiendo a Wible (2003), el lóbulo posterior de esta abertura correspondería al foramen yugular, mientras el anterior, correspondería al foramen para el seno petroso inferior (Forasiepi, 2006). Finalmente, Marshall (1977a) menciona un foramen diminuto que abre en el extremo más anterior del foramen oval, el cual identifica como un remanente del foramen carotídeo. Sin embargo, Forasiepi (2006) interpreta este pequeño foramen como un foramen vascular, del cual se desconoce su ocupante, similar al que se presenta en Arctodictis (Forasiepi, 2006; 2009)

Respecto al dentario, se observó que, efectivamente, su borde ventral es recto, como lo indica Marshall, 1977a. Sin embargo, cabe resaltar que esto no ocurre en toda su extensión, únicamente por debajo de los p3-m4, siendo curvo por detrás del nivel del m4 (carácter 98) y por delante del p3.

El paracono y metacono son bastante cónicos (sección transversal circular) en el M1 y van adquiriendo una morfología más triangular en sección hacia el M4. La preparacrista se hace más desarrollada del M1 al M4, siendo más corta que la postmetacrista en los M1-3 y más larga en el M4. Va cambiando su orientación, siendo tan sólo ligeramente oblicua (casi paralela al eje dentario) en el M1, haciéndose más oblicua hacia el M3, y siendo casi perpendicular al eje dentario en el M4. La postmetacrista se desarrolla más del M1 al M3. El paracónulo está presente al menos en los M2-4 (el M1 presenta una ruptura en ese punto) y el metacónulo está presente en los M1-4. Esto difiere parcialmente de la descripción original (Marshall, 1977a), donde se expresa que estas 
cúspulas están presentes en los M1-3. Ambas cúspulas presentan crestas anteriores y posteriores (pre- y postparaconular / pre- y postmetaconular), las cuales divergen desde la cúspide oblicuamente, generando una morfología de ala (crestas aladas).

El cíngulo anterior está incompleto en el M1. En el M2, se extiende lingualmente hasta conectar con la cresta preparaconular (¿o preprotocrista?), mientras que en el M3 es corto, sin llegar a conectarse con esta cresta. En el M1 se observa cómo conecta con una StA bien desarrollada. Este primer molar no presenta StB. En los M2-3 se presenta un cíngulo en la esquina anterolabial (parastilar), formado por la unión entre el cíngulo anterior y un ectocíngulo al nivel del paracono, el cual rodea labial y anteriormente al paracono a manera de un "bolsillo" (como lo llama Marshall, 1977a). En estos molares, en la esquina donde el cíngulo anterior y ectocíngulo se unen, se observa una minúscula cúspula, que probablemente sea una StA vestigial.

Uno de los rasgos diagnósticos de L. longirostrus descriptos por Marshall (1977) es que el p2 supera en tamaño al p3. Sin embargo, es necesario tener en cuenta que el p3 del holotipo no se encuentra completamente erupcionado; adicionalmente, la porción posterior de la corona del p2 está a un nivel bastante más bajo que la anterior, generando una longitud aparente mayor que la del largo real, la cual debe ser tomada perpendicular al plano oclusal. De hecho, si se toma la medida de ese largo aparente, el resultado es una cifra similar a la dada por Marshall (1977). En realidad, ambos premolares son subiguales en tamaño. Esto fue corroborado al medir el largo real, tanto con un calibre como por medio de fotografías digitales en vista oclusal, dando como resultado que el p2 es ligeramente más corto el p3 (Tabla 4.4), aunque más ancho.

El paracónido del $\mathrm{m} 1$ es bajo pero bien diferenciado, no confluyente con el cingúlido anterior como ocurre en la mayoría de los esparasodontes. Este cíngulo, bien definido en todos los molares, es corto, estando restringido a la base del paracónido. En la descripción original de L. longirostrus, Marshall (1977) señala que el metacónido está ausente. Sin embargo, en esta revisión se encontró que el metacónido está presente al menos en los m2-4 y, aunque es vestigial, es claramente diferenciable (un poco más reducido que el de Hondadelphys y mucho más reducido que en taxones como Arctodictis, Pharsophorus, Borhyaena, entre otros; en la matriz [carácter 169] fue codificado como vestigial). En el $\mathrm{m} 1$, la corona presenta una ruptura en esta zona, por lo que es difícil determinar si está presente el metacónido, pero aparentemente no lo está.

\section{Ejemplares referidos}

\section{IGM 250974}

Material-Rama mandibular derecha con el p2 completo, el m4 incompleto y fragmentos de raíces del $\mathrm{m} 2$; un incisivo y el p1 (¿izquierdo?) aislados; fragmento de cintura pélvica; otros fragmentos postcraneales (Fig. 4.14A-E).

Localidad y Estratigrafía-Localidad 113 (Universidad de Duke), área de La Venta; unidad entre las Capas de Arenisca de Chunchullo y las Capas de Arenisca de Tatacoa, Formación La 
Victoria, Grupo Honda.

Comentarios-El ejemplar fue referido a Lycopsis longirostrus por Goin (1997). Es consistente en tamaño y morfología general con el holotipo de L. longirostrus. El borde ventral del dentario presenta la misma morfología que el holotipo de L. longirostrus, siendo recto al nivel de los molares y curvo por detrás del $\mathrm{m} 4$. La altura del dentario al nivel del p2 es aparentemente mayor que en el holotipo. Presenta cinco forámenes mentonianos, uno menos que en el holotipo. Los dientes preservados son ligeramente más largos que en el holotipo (Tablas 4.2 y 4.3).

Las diferencias que presenta respecto al holotipo son menores y podrían hallarse dentro del rango de variabilidad de la especie, o como sugiere Goin (1997), podrían deberse a cambios relacionados con la edad, ya que este individuo es claramente un adulto, mientras que el holotipo es un subadulto con el p3 y el m4 sin haber erupcionado completamente.

El p2 está bien preservado y su morfología es prácticamente idéntica a la del holotipo. El m4 está incompleto y no se preserva ningún otro elemento. Por eso no es posible observar rasgos adicionales a los ya mencionados, y por lo tanto se mantiene la clasificación asignada por Goin (1997).

\section{Nuevos ejemplares referidos}

\section{KU 1997-1-A}

Material-Fragmento labial de un M2 izquierdo (Fig. 4.14J).

Localidad y Estratigrafía - Localidad El Líbano (Universidad de Kioto), área de La Venta; Formación La Victoria, Grupo Honda.

Comentarios-El molar preserva la plataforma estilar, el paracono, metacono, paracónulo completo y porción labial del metacónulo (se alcanzan a preservar sus crestas). La morfología es bastante similar a la del M2 del holotipo. Los para- y metacónulo son pequeños pero bien diferenciables y ambos presentan crestas conulares formando un ala. El cíngulo anterior se extiende hasta conectar con la cresta preparaconular, como ocurre en el M2 del holotipo. Se presenta el mismo cíngulo en la esquina anterolabial rodeando al paracono a manera de un "bolsillo", el cual presenta un desarrollo similar al del M2 del holotipo. Sin embargo, en el punto que corresponde a la ubicación de la $\mathrm{StB}$ es evidente el ápice de una cúspide, lateralmente comprimida, de la cual salen unas crestas anterior y posterior, formando ese ectocíngulo labial al paracono. Por lo tanto, es posible homologar este ectocíngulo a la StB. La cresta anterior que sale de la StB (formando el ectocíngulo) se dirige anteriormente hacia la esquina antrolabial del diente, hasta la posición de la StA, donde es posible ver una minúscula protuberancia (más clara en vista labial); la misma podría tratarse del ápice de la StA vestigial, fusionada al ectocíngulo.

La plataforma estilar presenta reducción en la porción labial al paracono y está fuertemente reducida (casi ausente) en un punto labial al metacono, pero es relativamente amplia en la porción posterior a esta última cúspide. En la porción posterior del borde estilar es posible ver una pequeña 
cúspula en ubicada en un punto entre la posición correspondiente a la StD y la esquina metastilar. Ocupa una posición muy posterior respecto de la StD, por lo que podría tratarse de una StE vestigial. Esta cúspula también aparece en el holotipo.

\section{CS-048}

Material—M1 derecho, M2 izquierdo; trigónido del m1 derecho, el m1 y el m4 izquierdos, el m3? derecho; dos caninos (uno incompleto), un premolar; y fragmentos de hueso asociados (Fig. 4.14F-I).

Localidad y Estratigrafía-Localidad 22 (Universidad de Duke), al oeste de la carretera frente a la casa de Carlos Pascuas, San Nicolás, área de La Venta; Capas del Mono, Miembro Baraya, Formación Villavieja, Grupo Honda.

Comentarios-Este ejemplar fue colectado durante una campaña en el área de La Venta, realizada como parte de este estudio, en el año 2016. El número mostrado corresponde al número de campo. El ejemplar actualmente tiene como repositorio el Servicio Geológico Colombiano (SGC) pero aún no se le ha asignado un número de colección.

La morfología de la dentición en general es casi idéntica a la del holotipo. En el M2, el ectocíngulo al nivel del paracono es ligeramente más corto y menos comprimido lateralmente que en el holotipo y el ejemplar KU 1997-1-A, por lo cual, en su extremo posterior, tiene aspecto de cúspide; al igual que en los demás ejemplares, se aprecia que forma parte del ectocíngulo. En el M1 esta cúspide es mucho más clara y está conectada con el cíngulo anterior, al igual que en el holotipo. La preparacrista en el M1 está más marcada que en el holotipo. Tanto el paracónulo como el metacónulo están presentes en los molares preservados (M1 y M3); son pequeños pero distinguibles y presentan crestas en forma de ala.

Las proporciones entre el trigónido y el talónido, así como morfología del talónido y su cuenca, son consistentes con las de Lycopsis longirostrus, aunque el talónido del m4, que ya está extremadamente reducido en el holotipo, está ligeramente más reducido en este nuevo ejemplar. Las cúspides del trigónido muestran la misma disposición que en el holotipo, estando alineadas en el m1 y con el paracónido en una posición más anterolingual en los demás molares. Las cúspides presentan la misma morfología de sección subtriangular. Sin embargo, en el $\mathrm{ml}$ se observa que el protocónido tiene una morfología cónica, de sección más circular. Es difícil saber si esto ocurre también en el holotipo, ya que la cúspide está incompleta.

El paracónido del $\mathrm{m} 1$ es bajo, pero bien diferenciado, no confluye con el cingúlido anterior, una condición similar a la del holotipo; en este ejemplar el cíngulo es más corto que en el holotipo. El metacónido está ausente en el $\mathrm{m} 1$, mientras que en el $\mathrm{m} 3$ ? y el $\mathrm{m} 4$ se presenta un pequeño cíngulo en esta posición, que podría tratarse de un metacónido vestigial. Este rasgo está mostrando que en L. longirostrus esta cúspide puede estar extremadamente reducida o vestigial en los m2-4 y ausente en el $\mathrm{m} 1$. La ausencia del metacónido en el $\mathrm{m} 1$ de este ejemplar soporta la hipótesis (difícil de comprobar por una ruptura de la corona) de que en el holotipo esta cúspide no se presenta en el 
primer molar.

\section{Borhyaenoidea, cf. Lycopsis}

(Fig. 4.15)

\section{IGM 182937}

Material—p3? derecho (Fig. 4.15A).

Localidad y Estratigrafia-Villavieja. Formación Villavieja, Grupo Honda.

Comentarios-Es consistente en tamaño con L. longirostrus. La simetría de la cúspide principal y del talón, así como la concavidad y longitud de la cresta posterior, son similares a las del p3 del holotipo de dicha especie. No se observan diferencias respecto a L. longirostrus y no presenta una apariencia similar a la de ningún otro esparasodonte reportado en La Venta; sin embargo, dado que los premolares no suelen presentar rasgos diagnósticos que permitan clasificar con certeza un ejemplar a nivel de especie, se realiza su clasificación como cf. Lycopsis.

\section{KU 1997-1-B}

Material-Premolar

Localidad y Estratigrafía - Localidad El Líbano (Universidad de Kioto), área de La Venta; Formación La Victoria, Grupo Honda.

Comentarios-El material está muy meteorizado y perdió casi todo su esmalte. Sin embargo, por proporciones y tamaño, concuerda más con los premolares de Lycopsis longirostrus que con cualquier otra especie reportada en La Venta.

\section{Ejemplar sin numeración (Museo de Villavieja)}

Material-Fragmentos de una rama horizontal derecha, incluyendo la base de la rama horizontal, con la raíz posterior del $\mathrm{m} 1$, raíz anterior y talónido incompleto del $\mathrm{m} 2$, y los m3-4 casi completos; porción sinfisaria de la mandíbula articulada, con las raíces de los i2-4, parte de los alvéolos de los i3-4 izquierdos con fragmentos de raíz, el canino derecho completo, los p1-2 izquierdos y el alvéolo de la raíz anterior del p3 izquierdo.

Localidad y Estratigrafía—Localidad desconocida del área de La Venta; Grupo Honda.

Comentarios-Este material se encuentra alojado en el Museo Paleontológico de la Población de Villavieja (Departamento del Huila, Colombia), ubicada en el área de La Venta. Fue colectado en el área de La Venta por pobladores de la región y donado al museo, sin información geográfica detallada ni estratigráfica. El ejemplar se encuentra sin preparar y hasta el momento no se le ha asignado un número de colección, ya que este pequeño museo no posee un sistema de numeración en la actualidad. Está muy pobremente preservado, con la superficie del hueso altamente fracturada y el esmalte de los dientes bastante gastado. 
El material es consistente en tamaño y morfología dentaria con aquellos referibles a Lycopsis longirostrus. La rama horizontal de la mandíbula es aparentemente alta, pero debido a que el cuerpo mandibular está incompleto no es posible precisar más. Sin embargo, se tomó un índice correspondiente a la altura al nivel de la unión entre el $\mathrm{m} 3$ y el $\mathrm{m} 4$ vs el largo de la serie m2-4, y el resultado fue 0,94 , siendo mucho más alta (al menos en esta porción) que en Lycopsis longirrostrus, donde el índice calculado (sobre el holotipo) fue 0,61. El borde ventral del dentario es aparentemente horizontal por delante del $\mathrm{m} 4$, y se curva posteriormente a este nivel, pero aparentemente se verticaliza menos que en el holotipo de Lycopsis longirrostrus, siendo más parecido al del ejemplar IGM 250974. La cresta coronoide está orientada a $114^{\circ}$ respecto a la hilera dentaria, ligeramente menos inclinada que en el holotipo de L. longirostrus (109 ${ }^{\circ}$; no obstante, ambos presentan una inclinación intermedia (carácter 104, estado 1) y, de hecho, esto podría ocurrir debido a una diferencia en edad de los ejemplares. La fosa masetérica está bien desarrollada. Al menos un foramen mentoniano está presente, por debajo del nivel de la raíz posterior del m1 (no se puede ver más por la mala preservación). La sínfisis mandibular no está fusionada (habría sido ligamentosa) y se extiende al menos hasta el nivel del p2.

Se observan los alvéolos con raíces de al menos tres incisivos inferiores. El incisivo del medio se ubica en una posición lingual respecto a los otros dos, por lo cual se identificó como el i3, el incisivo sobremontado de los metaterios. Por lo tanto, los incisivos presentes corresponderían a los i2-4. Aparentemente sólo se presentan estos tres incisivos, ya que no se observa espacio suficiente en el dentario para uno adicional. Los alvéolos de los incisivos son pequeños y comprimidos lateralmente (ovalados en sección transversal). El canino es de tamaño moderado y grácil, ligeramente comprimido lateralmente y de implantación oblicua, curvándose hacia arriba.

Los p1-3 izquierdos están pobremente preservados y parcialmente cubiertos por sedimento, que cubre incluso la zona entre el canino y el primer premolar visible. Están fuertemente desgastados, pero presentan una morfolgía similar a la de los premolares de L. longirostrus en vista labial. El p1 es más pequeño que el p2. Este último está peor preservado, ya que se perdió la porción de la corona correspondiente al talón.

Los molares preservados presentan proporciones y morfología general similares a los de $L$. longirostrus. No se observa el talónido del $\mathrm{m} 4$ pero la corona está rota en su extremo posterior, por lo cual no es claro si está ausente o si se perdió. De haber estado presente, debería haber sido extremadamente reducido, ya que la raíz posterior no se extiende mucho más allá de la porción preservada de corona.

La morfología dentaria en general es consistente con la de L. longirostrus. Sin embargo, la rama mandibular es mucho más alta y la preservación no permite ver rasgos más detallados, como otros forámenes mentonianos (si los hubiere). Por estas razones, se refiere el material a cf. Lycopsis. 


\section{Comentarios generales sobre Lycopsis}

Para la elaboración de esta tesis se revisaron la totalidad de las especies de Lycopsis, a los efectos de hacer comparaciones y testear las relaciones filogenéticas de este grupo (ver Análisis Filogenético). La diagnosis enmendada surge a partir de dicha revisión y fue propuesta recientemente en Suarez et al. (2016), donde se describe una nueva especie de Lycopsis ( $L$. padillai), proveniente de La Alta Guajira, Colombia, y colectada en niveles de la Formación Castilletes (Mioceno medio).

En las especies de Lycopsis donde se preserva el P1 o p1 (todas excepto L. padillai), se observa que estos dientes se implantan de modo ligeramente oblicuo a la hilera dentaria (Marshall, 1977a). Sin embargo, este ángulo fue medido y resultó ser inferior a $19^{\circ}$ en todas las especies, por lo cual es tomado como "paralelo" a la hilera dentaria (véase el carácter 119).

En la diagnosis enmendada que surgió a partir de la presente revisión (Suarez et al., 2016) se menciona que Lycopsis tiene el ectoflexo poco profundo en el M3. En todas las especies de Lycopsis este ectoflexo aparece al menos en el M3. Sólo en Lycopsis longirostrus aparece adicionalmente otro ectoflexo (menos profundo) en el M2. Con respecto a la profundidad del ectoflexo, aunque aparentemente podría describirse como profundo, este es poco profundo comparado con otros taxones con un ectoflexo mucho más marcado (e.g., Dasyurus, Deltatheridium). En análisis filogenéticos previos a esta revisión (e.g., Rougier et al., 1998; Forasiepi, 2009; Engelman and Croft, 2014; Forasiepi et al., 2015; Suarez et al., 2016) este carácter ha sido tratado como "ectoflexo profundo" (presente en los M2-3, presente sólo en el M3, fuertemente reducido o ausente). A pesar de que el ectoflexo en Lycopsis es poco profundo, en este caso fue codificado como presente (en los M2-3 para L. longirostrus y el M3 para las demás especies) con base en comparaciones con los demás esparasodontes ya codificados en dichos análisis, y debido a que claramente no está fuertemente reducido ni ausente (ver carácter 152).

En la diagnosis enmendada que Marshall (1977a) propone para Lycopsis, menciona que los molares superiores carecen de plataforma estilar. Sin embargo, en esta revisión se observó que sí presenta una plataforma estilar, aunque fuertemente reducida, con la reducción más marcada en la porción labial al paracono. Esta misma condición aparece en todas las especies de Lycopsis, al igual que en otros esparasodontes (e.g., los taxones utilizados en el análisis filogenético de este trabajo excepto los Borhyaenidae, Thylacosmilus, Callistoe y Patene; ver carácter 151). Por el contrario, la plataforma estilar es vestigial o ausente en la mayoría de los Borhyaenidae, en Thylacosmilus y en Callistoe. Los ejemplares estudiados permitieron establecer las homologías de la estructura anterolabial al paracono en forma de "bolsillo", que como ya lo había dicho Marshall (1977a), está formada por la unión entre un ectocíngulo labial al paracono y el cíngulo anterior. Con la observación de los ejemplares revisados se pudo concluir que este ectocíngulo incluye a la $\mathrm{StB}$ y se extiende hasta fusionarse a la StA, que aún preserva vestigios de su ápice. En consecuencia, la StA se ubicaría en la unión de estos dos cíngulos. 
En la descripción original, Marshall (1977a: pág. 636) menciona que "el paracónulo está ausente en el M1; los para- y metacónulos son pequeños pero bien distinguibles en los M1-3". Allí se aprecia una contradicción, ya que primero se dice que el paracónulo está ausente en el M1 y después que está presente (probablemente se trató de un error de escritura). Al revisar el holotipo, se observó que presenta una fractura en la zona donde se ubicaría el paracónido del M1 (es posible que se haya roto posterior a la descripción original), por lo cual, de estar presente, no se preservaría y por lo tanto no sería posible hacer ninguna afirmación al respecto. Sin embargo, en el ejemplar CS-048 se preserva esta porción, donde se aprecia un paracónulo pequeño pero bien diferenciado. Adicionalmente, en el holotipo se observa que el M4 presenta para- y metacónulo, con el metacónulo ligeramente reducido, y ambos presentan una reducción en el desarrollo de sus crestas. Gracias a estas observaciones podemos afirmar que los para- y metacónulo están presentes en toda la serie molar superior, son pequeños pero distinguibles y presentan crestas en forma de ala.

En el holotipo de L. longirostrus se observa la presencia de un metacónido extremadamente reducido en los $\mathrm{m} 2-4$, pero no se preserva esta porción de la corona en el $\mathrm{m} 1$. Sin embargo, en el m1 del ejemplar CS-48 se preserva esta porción, donde no se observa ninguna evidencia de la presencia de un metacónido. Por lo tanto, se podría concluir que el metacónido está presente únicamente en los m2-4, como ocurre en los demás Borhyaenoidea. Lycopsis longirostrus sería hasta el momento la única especie del género que preserva el metacónido, aunque este es vestigial. Esta variación dentro de un mismo género no sería extraña si se tiene en cuenta que, por ejemplo en algunos carnívoros euterios con una fuerte reducción del metacónido (e.g., cánidos), la presencia o ausencia de este puede variar incluso entre ejemplares de una misma una misma especie.

En la diagnosis de Suarez et al. (2016) se menciona el talónido bien desarrollado y con cuenca en los m1-3. Cabe resaltar que en el $\mathrm{m} 4$ el talónido está presente, aunque bastante reducido y su cuenca es pequeña y poco profunda.

La monofilia de Lycopsis ha sido previamente cuestionada debido a que los rasgos usados para caracerizar este taxón eran considerados plesiomorfías (e.g., Forasiepi, 2009). Las diferencias más significativas que se observaron durante el presente estudio (habiendo revisado todas las especies del género), tienen que ver con la gran diferencia en tamaño entre sus especies, siendo Lycopsis longirostrus la más grande de ellas. Adicionalmente, en la presente revisión se resalta la presencia de un metacónido extremadamente reducido en L. longirostrus, ausente en las otras especies. Sin embargo, la morfología general de la dentición es muy similar entre las especies de Lycopsis, con algunas variantes propias de cada especie. Las mismas, sin embargo, no justifican la asignación de alguna de estas especies en otro taxón. Los resultados del análisis filogenético (véase también Suarez et al., 2016) soportan la monofilia del género. 
Dukecynus Goin, 1997

Especie Tipo-Dukecynus magnus Goin, 1997

Especies Referidas-Sólo la especie tipo.

Distribución-Área de La Venta (Desierto de La Tatacoa, Valle Superior del Magdalena, Departamento del Huila, Colombia); Laventense, Mioceno medio.

\section{Dukecynus magnus Goin, 1997}

Holotipo-IGM 251149, cráneo incompleto; rama mandibular derecha casi completa con la dentición incompleta y pobremente preservada; fragmento de rama mandibular izquierda, los $\mathrm{m} 2$, m4 y M?3 aislados; fragmentos craneanos y elementos postcraneanos-asociados, pobremente preservados (véase Goin, 1997, Figs. 11.1H-I y 11.5).

Distribución Geográfica y Estratigráfica-Área de La Venta (Desierto de La Tatacoa, Valle Superior del Magdalena, Departamento del Huila, Colombia); Grupo Honda, Laventense, Mioceno medio (Tablas 3.1 y 4.1; Fig. 3.1).

Diagnosis—Véase Goin (1997: pág. 199).

Medidas-Tablas 4.3 y 4.5 .

\section{IGM 251149 (Holotipo)}

Localidad y Estratigrafí_-Localidad 140 (Universidad de Duke), área de La Venta (Desierto de La Tatacoa, Valle Superior del Magdalena, Departamento del Huila, Colombia); Capas Rojas de Polonia, Formación Villavieja, Grupo Honda.

Comentarios-El material se encuentra muy pobremente preservado y deformado. Cuando fue descripto por Goin (1997), la familia Borhyaenidae estaba subdividida en "Borhyaeninae" y "Prothylacyninae". Esta última subfamilia ya no es válida, ya que no constituye un grupo monofilético, mientras que la subfamilia Borhyaeninae pasó a tener rango de familia (i.e., Borhyaenidae). Goin (1997) clasificó a Dukecynus como "protilacinino" debido a que presentaba algunos rasgos diagnósticos de ese grupo (sensu Marshall, 1979) y a las importantes diferencias con los borieninos. Aquí se considera a Dukecynus dentro del clado Borhyaenoidea, como los demás taxones "protilacininos". Sin embargo, como lo afirma Goin (1997), es difícil encontrar afinidades claras con dichos taxones. Debido al mal estado de preservación del material disponible no fue posible codificar gran parte de los caracteres, pero los que se incluyeron fueron suficientes para establecer sus posibles afinidades (véase más abajo).

El talónido de D. magnus es reducido (aparentemente vestigial en el $\mathrm{m} 4$ ), carece de entocónido (rasgo diagnóstico de la especie) y presenta una única cúspide bien desarrollada en una posición posterior. Según Goin (1997), esta cúspide corresponde al hipoconúlido. Esta homología 
puede ser sustentada a partir de la presencia de una crístida oblicua que no se conecta con esta cúspide. Cuando en un taxón se presenta la "pérdida" (por reducción) de alguna de sus cúspides, en ocasiones se preservan las crestas asociadas a dicha cúspide. En los metaterios, la crístida oblicua se origina en el hipocónido y se dirige hacia la base del trigónido, con un ángulo que varía entre los diferentes grupos. El hecho de que en D. magnus esta cresta no se conecte con la única cúspide del talónido, sugiere que dicha cúspide no corresponde al hipocónido y por lo tanto correspondería al hipoconúlido. En el extremo posterior de la crístida oblicua no se identifica claramente una cúspide, por lo que el hipocónido es vestigial o ausente.

\section{?Dukecynus magnus}

\section{UCMP 39250}

Material - Cráneo fragmentario con la base del canino y de los dos primeros molares, un molar inferior anterior ( $\mathrm{m} 1 \mathrm{o} \mathrm{m} 2$ izquierdo) y postcráneo asociado.

Localidad y Estratigrafía-Localidad V4521 (UCMP), área de La Venta; Capas del Mono, Miembro Baraya, Formación Villavieja, Grupo Honda (Tablas 3.1 y 4.1).

Comentarios-Este ejemplar fue mencionado por Stirton (1953) y Marshall (1976a, 1977a, 1978a) y referido por este último a cf. Arctodictis. Marshall (1978a: p. 58) realiza esta asignación argumentando que se trata de un individuo de gran tamaño, con caninos de estructura masiva (cuyas raíces muestran surcos longitudinales) y premolares imbricados, de implantación oblicua en el p1 y en menor grado en el p2 (el p1 esta implantado con cierto ángulo respecto al eje anteroposterior del dentario y el p2 imbrica a este diente). Goin (1997), quien no tuvo acceso a este material, sugiere revisarlo para descartar que se trate de Dukecynus magnus.

Posteriormente, Forasiepi et al. (2004) afirman que no existen rasgos, más allá de su gran tamaño, que permitan asignarlo al género Arctodictis o a algún otro boriénido conocido; y que ninguno de los rasgos mencionados por Marshall (1978a) es exclusivo de Arctodictis, sino que aparecen con frecuencia en otros Borhyaenidae. Forasiepi et al. (2004) aclaran que el carácter oblicuo del p1 en el ejemplar UCMP 39250 es apenas moderado, mientras que el p2 está implantado casi paralelo al eje dentario (diferente de la condición observable en Arctodictis y más cercana a la de Dukecynus); y que la sínfisis mandibular no fusionada, interpretada por Marshall (1978a) como consecuencia del carácter juvenil del ejemplar, está presente en otros esparasodontes, independientemente de su edad.

Sobre este último rasgo es necesario agregar que Forasiepi (2004: p. 20) mencionan una serie de argumentos que permiten descartar que el ejemplar corresponda a un juvenil, por lo que la presencia de una sínfisis no fusionada en un individuo adulto se suma a la lista de caracteres que diferencian al ejemplar UCMP 39250 de Arctodictis (el cual presenta una sínfisis fuertemente anquilosada). Forasiepi et al. (2004) agregan que la gracilidad de la rama mandibular, la 
morfología de la cavidad glenoidea, el fuerte desarrollo del talónido ("en lugar de una cúspula posterior") y la ausencia de un lóbulo basal descendente sobre la raíz posterior de los molares, permiten descartar la pertenencia de este ejemplar al género Arctodictis y a los "Borhyaeninae" en general. Finalmente, mencionan algunos rasgos compartidos entre el ejemplar UCMP 39250 y la especie tipo de Dukecynus, que sugerirían una mayor afinidad con este género que con otro borienoideo hasta ahora conocido: las raíces de los dientes poco globosas, la implantación oblicua poco marcada del p1 y los talónidos bien desarrollados. Con base en estos argumentos, clasifican a este ejemplar como cf. Dukecynus magnus.

A pesar de no haber podido acceder a los materiales referidos y sobre la base de las observaciones de Marshall (1976a, 1977a, 1987a), Forasiepi et al. (2004) y la descripción que Goin (1997) hace de Dukecynus magnus, se encontró una inconsistencia acerca de uno de los rasgos mencionados por Forasiepi et al. (2004), correspondiente al desarrollo de los talónidos: en Dukecynus magnus, los talónidos se encuentran moderadamente reducidos en los m1-3 y presentan una única cúspide bien desarrollada en una posición posterior (i.e., hipoconúlido), mientras que el talónido del m4 es vestigial (Goin, 1997; pers. obs.), contrario a la observación de Forasiepi et al. (2004). Si el ejemplar UCMP 39250 presenta talónidos fuertemente desarrollados en lugar de una cúspula posterior, como indica Forasiepi (2004), esta sería una notable diferencia con Dukecynus (al menos con D. magnus), quizás la más relevante.

Se consideró que las observaciones aquí discutidas no son suficientes para aceptar o rechazar la asignación del ejemplar UCMP 39250 a Dukecynus magnus (sugerida por Goin, 1997 y Forasiepi et al., 2004) y tampoco lo son para referirlo a otro taxón. Adicionalmente, al no tener acceso al material original, no se pudo corroborar o refutar las observaciones de los autores aquí mencionados. Por estas razones y dado que, entre la variedad de morfologías de los esparasodontes de La Venta, la de Dukecynus magnus aparentemente sería la más cercana, se decidió clasificarlo por el momento como ?Dukecynus magnus.

THYLACOSMILIDAE (Riggs, 1993) Marshall, 1976b

Especies Referidas-Thylacosmilus atrox Riggs, 1933, Patagosmilus goini Forasiepi y Carlini, 2010 y Anachlysictis gracilis Goin, 1997. Nuevas especies pendientes de publicación: Thylacosmilidae gen. 1 sp. 1 (ver más abajo) y Thylacosmilidae gen. 2 sp. 1 (Suarez et al., in prep.).

Distribución-América del Sur. Colhuehuapiense (Mioceno temprano) a ChapadmalalenseMarplatense (Plioceno tardío).

Diagnosis Emendada-Metaterios esparasodontes con fórmula incisiva reducida (dos o menos incisivos inferiores); canino inferior lateralmente comprimido y de implantación subvertical a vertical y oblicua a la hilera dentaria, con un surco lingual bien desarrollado; $p 1$ extremadamente 
reducido o ausente; dentario de morfología sigmoide en vista oclusal: lateralmente cóncavo al nivel de la serie canino-premolar, y lateralmente convexo al nivel de la serie molar; región sinfisaria expandida (no fusiforme) en vista lateral, que en las formas más derivadas desarrolla un proceso sinfisario bien desarrollado; margen anterior de la rama horizontal aplanado, formando una cresta lateral; y foramen mentoniano más anterior ubicado a un nivel marcadamente más ventral respecto a los demás forámenes (Modificada de Riggs, 1934).

Comentarios-De los rasgos mencionados en la diagnosis enmendada para Thylacosmilidae, seis fueron recuperados como sinapomorfías en el análisis filogenético (véase Nodo 84 y lista de sinapomorfías en el Anexo 1.5; para la definición de los caracteres, ver Anexo 1.3): (1) presencia de dos o menos incisivos inferiores (carácter 113); (2) presencia de un gran surco principal sobre la superficie lingual en el canino inferior (carácter 117); (3) la altura de la porción anterior del dentario incrementándose anteriormente, con el margen ventral doblándose hacia arriba en un ángulo $\geq 40^{\circ}$ y formando una cresta anterolabial (carácter 311); (4) el forámen mentoniano más anterior ubicado a un nivel claramente más ventral respecto a los demás forámenes (carácter 313); (5) el canino inferior muy comprimido (i.e., largo/ancho $\geq 1,60$; carácter 314); y (6) la implantación subvertical de los caninos inferiores (inclinación de la raíz $>60^{\circ}$ respecto al plano horizontal; carácter 316). Cabe aclarar que este último rasgo se obtiene como sinapomorfía, ya que esta es la condición en los taxones más basales del grupo (i.e., Thylacosmilidae gen. 1 sp. 1 y Thylacosmilidae gen. 2 sp. 1); sin embargo, otras especies presentan una condición más derivada de este carácter (implantación vertical, estado 2; i.e., Thylacosmilus atrox y Anachlysictis gracilis), por lo tanto fue descripto en la diagnosis como "de implantación subvertical a vertical".

La especie aquí mencionada como Thylacosmilidae gen. 2 sp. 1, corresponde a una especie inédita, que está siendo descripta (Suarez et al., in prep.) a partir de un ejemplar proveniente de la Formación Arroyo Chasicó, Argentina (véase Anexo 1.1: Thylacosmilidae).

\section{Anachlysictis Goin, 1997}

Especie Tipo-Anachlysictis gracilis Goin, 1997

Especies Referidas-Sólo la especie tipo.

Distribución-Área de La Venta (Desierto de La Tatacoa, Valle Superior del Magdalena, Departamento del Huila, Colombia); Laventense, Mioceno medio.

Diagnosis-La misma de la especie tipo (Goin, 1997: p. 202). 
Anachlysictis gracilis Goin, 1997

(Figs. 4.16-4.17)

Holotipo-IGM 184247, fragmento del techo craneano (porción postorbital), rama mandibular derecha casi completa con $\operatorname{los} \mathrm{m} 2-4$ y las raíces de los $\mathrm{p} 2-\mathrm{m} 1$, fragmento rama mandibular izquierda con los $\mathrm{m} 2-3$ y fragmento de proceso sinfisario izquierdo; atlas casi completo, fragmento de la primera vértebra sacra, fragmentos de arco neural, pre y postzigapófisis, fragmentos de costillas; porción proximal de escápula derecha, magnum derecho, piramidal?, dos fragmentos distales de metapodios, falange proximal; fragmentos postcraneanos ineterminados.

Ejemplar Referido-UCMP 39705, fragmento posterior de rama mandibular derecha, incluyendo el cóndilo y el proceso angular.

Distribución Geográfica y Estratigráfica-Área de La Venta (Desierto de La Tatacoa, Valle Superior del Magdalena, Departamento del Huila, Colombia); Grupo Honda, Laventense, Mioceno medio (Tablas 3.1 y 4.1; Fig. 3.1).

Diagnosis-Difiere de Thylacosmilus atrox en el menor tamaño, mandíbula más grácil y con el proceso sinfisario mucho menos desarrollado; premolares inferiores con dos raíces y aparentemente no cónicos; talónidos pequeños pero distinguibles en los m1-3; distancia desde el m4 al cóndilo mandibular comparativamente mucho mayor; fosa masetérica mucho más desarrollada; porción craneana aparentemente aplanada, con el proceso ascendente del maxilar muy reducido o ausente; barra postorbital ausente (Goin, 1997: pág. 202).

Medidas-Tablas 4.4-4.5.

Comentarios-El género y especie Anachlysictis gracilis fueron descriptos por Goin (1997) sobre la base del fragmento craneano y la mandíbula del holotipo, mencionando sólo de manera general los demás restos. En la presente revisión se realiza la descripción de la totalidad del material preservado de ese ejemplar y se reporta un nuevo ejemplar referible a la misma especie.

Algunas de las comparaciones que se realizan entre Anachlysictis y Patagosmilus (e.g., rasgos en el dentario y la dentición inferior) se basaron en las observaciones hechas sobre un ejemplar identificado como B:p2-154 (MNHN-Bol), proveniente de Río Rosario, una localidad cercana a Quebrada Honda (Departamento de Tarija, Bolivia), el cual es claramente referible a $P$. goini (véase más adelante Comentarios generales sobre Thylacosmilidae y Anexo 1.1, Patagosmilus goini) y fue mencionado pero no descripto por Goin y Carlini (1993), comparándolo con los holotipos de A. gracilis y $P$. goini (que para ese momento no habían sido descriptos ni nombrados).

\section{IGM 184247 (Holotipo)}

Localidad y Estratigrafía-Localidad 75 (Universidad de Duke), área de La Venta; unidad entre las Capas de Arenisca del Chunchullo y Capas de Arenisca de Tatacoa, Formación La Victoria, Grupo Honda, Laventense. 
Descripción-El fragmento craneano preservado corresponde a una porción a la altura del proceso postorbital, en el que se observa el contacto entre los huesos frontal, lacrimal y nasal. Presenta un proceso postorbital bien desarrollado al igual que en Patagosmilus, en lugar de una barra postorbital como en Tylacosmilus. La sutura entre el nasal y el lacrimal es casi recta, y la sutura entre estos dos huesos y el frontal es irregular. El punto de contacto entre los tres huesos ocurre aproximadamente sobre el proceso postorbital al igual que en Patagosmilus (la apariencia de esta porción craneal es prácticamente idéntica), ubicándose mucho más posterior que en los demás esparasodontes que presentan proceso postorbital (e.g., Hondadelphys, Sallacyon, Acyon, Cladosictis, Prothylacynus, Arctodictis, Pharsophorus, Callistoe). En Thylacosmilus, la relación entre estos tres huesos es diferente, ya que el maxilar se extiende posteriormente sobre la superficie dorsal del cráneo, formando un proceso ascendente del maxilar que interrumpe el contacto entre el nasal y el lacrimal al menos en esta superficie. Sin embargo, se observa que el extremo posterior de la sutura entre el lacrimal y el frontal sobrepasa el nivel de la barra postorbital, siendo incluso más posterior que en Anachlysictis y Patagosmilus. Además de estos tres taxones tilacosmílidos, en ningún otro de los metaterios revisados en el presente estudio (ni en los de La Venta ni en el resto de los taxones estudiados en el análisis filogenético) se observa que el lacrimal alcance el nivel del proceso postorbital (barra postorbital en el caso de Thylacosmilus). Sin embargo, por el momento no es posible determinar si esta es una sinapomorfía de Thylacosmilidae, ya que las demás especies del grupo no preservan esta porción del cráneo.

El dentario es de altura intermedia (i.e., altura al nivel del contacto $\mathrm{m} 3-\mathrm{m} 4 /$ largo total $=$ 0,17 [carácter 97]) y la rama horizontal representa aproximadamente el $60 \%$ de la longitud total. El borde ventral del dentario es casi horizontal por detrás del nivel del p2. Por delante del p2, la altura del dentario aumenta y su borde ventral se expande ventralmente, formando un proceso sinfisario característico de las formas derivadas de Thylacosmilidae. A pesar de que el proceso sinfisario de la rama mandibular derecha está incompleto, el fragmento de proceso sinfisario izquierdo aislado incluye la porción anteroventral que no se preserva en el derecho. Esto permite observar claramente la morfología y tamaño del proceso completo (Fig. 4.16), mostrando que se encuentra menos desarrollado que en Thylacosmilus. El dentario es lateralmente cóncavo al nivel de la serie canino-premolar y lateralmente convexo al nivel de la serie molar, resultando una morfología sigmoide similar a la de Thylacosmilus, pero mucho menos pronunciada.

Existen tres forámenes mentonianos: uno en la porción ventral del proceso sinfisario, otro por debajo de la unión entre el p2 y el p3 y otro por debajo de la raíz anterior del m1. La altura del proceso coronoides es al menos el doble de la de la rama horizontal, estando mucho más desarrollado que en Thylacosmilus, donde se encuentra fuertemente reducido. El ángulo entre el borde anterior del proceso coronoides y el borde alveolar es aproximadamente $116^{\circ}$, siendo más amplio que en Thylacosmilus (de unos $90^{\circ}$ ). El borde ventral del dentario es casi recto en toda su extensión posterior al p2 y la cresta coronoidea inferior es horizontal por delante del proceso condilar, estando alineada con el borde ventral. La fosa masetérica es amplia, no muestra la fuerte 
reducción que existe en Thylacosmilus y presenta un minúsculo foramen, posiblemente nutricio. El foramen mandibular es grande y se ubica a la altura de la línea media del proceso coronoides. El cóndilo es cilíndrico, con una morfología de "gota" en vista posterior y con un cuello bien definido. El proceso angular está incompleto, pero aparentemente es angosto, no muy expandido medialmente.

El dentario derecho muestra una ruptura en su extremo anterodorsal, que abarca la zona donde se ubicarían el canino y los incisivos. A pesar de esto, tanto en el dentario derecho como en el fragmento sinfisario izquierdo se puede apreciar parte del alveolo del canino. Sin embargo, no se observa ninguna evidencia de los incisivos, y el espacio donde podrían estar alojados es muy restringido. Es imposible discernir si están ausentes o si una reducción importante en su número y tamaño. Existen sólo dos premolares, como en Thylacosmilus, los que corresponderían a los p2-3 (véase más abajo: Comentarios generales sobre Thylacosmilidae). A pesar de que sólo se preservan sus raíces, se puede apreciar que los premolares están orientados en forma paralela al eje del dentario y que el p2 es aproximadamente un 30\% más pequeño que el p3.

Los molares aumentan marcadamente de tamaño del $\mathrm{m} 1 \mathrm{al} \mathrm{m} 4$. Los m2-3 izquierdos están mejor preservados que los del lado derecho, ya que estos últimos presentan varias rupturas en la corona. En vista labial se observa que el lóbulo posterior de la corona es más bajo que el anterior, al menos en los m2-3, siendo este rasgo más marcado en el $\mathrm{m} 2$. Este desnivel es similar al observado en el ejemplar B:p2-154 (referible a Patagosmilus goini; véase Anexo 1.1), está más marcado que en Thylacosmilidae gen. 1 sp. 1 (véase más adelante) y mucho más que en Hondadelphys fieldsi. La configuración del trigónido es abierta en los molares preservados, con el paracónido en posición anterolingual. El protocónido es la cúspide principal del trigónido en todos los molares preservados. Tanto el paracónido como el protocónido aumentan significativamente de tamaño posteriormente. E1 metacónido está ausente, al menos en los m2-4. La cresta vertical anterolingual del paracónido forma una quilla. El precingúlido está reducido, extendiéndose sólo sobre la base del paracónido. Entre estas dos estructuras se forma claramente una muesca para la articulación con el molar precedente. La postparacrístida y preprotocrístida están bien desarrolladas en los m2-4, formándose entre ellas una muesca carnasial. La postprotocrístida es larga, bien definida y se dirige hacia la esquina anterolingual del talónido.

El talónido muestra una reducción de tamaño del $\mathrm{m} 2$ al $\mathrm{m} 4$; en el $\mathrm{m} 4$ es casi vestigial y soporta una cúspide minúscula. El trigónido es más largo que el talónido en los m2-4 (en el m2 el trigónido tiene un tamaño mayor a tres veces el del talónido). El ancho del talónido es subigual al del trigónido en el m2 y ligeramente menor en el m3. La cuenca del talónido del m2 es ligeramente más ancha que larga y mucho más ancha que larga en el m3. Esta cuenca se encuentra dividida en dos porciones: una labial cuya superficie es cóncava y subhorizontal, y una lingual mucho más aplanada y verticalizada. En los m2-3, el hipocónido es reducido y se ubica hacia la mitad del borde labial del talónido. El entocónido está ubicado en una posición posterolingual y, aparentemente, un hipoconúlido vestigial apareado a este, en una posición ligeramente posterior. 
Se observa que las bases de estas dos cúspides se encuentran fusionadas, formando un sólo bloque, si bien todavía se aprecia el ápice de ambas. Este bloque lingual del talónido es comprimido lateralmente y está más elevado respecto al hipocónido (puede apreciarse claramente el desnivel de la corona en vista posterior), formando así en su cara labial una pared bastante verticalizada, que correspondería a la porción lingual verticalizada de la cuenca del talónido. La preentocrístida está bien desarrollada y sale del entocónido en sentido labial al trigónido. En vista lateral, en la cara labial del talónido se observa un postcingúlido, presente al menos en los m2-3 (probablemente también estaba en el ml, si bien este diente no se preservado) y posiblemente ausente en el m4 (la corona está rota en este punto); el postcingúlido es más marcado en el m2. Esta morfología del talónido (tanto la morfología general como la de la cuenca y la distribución y morfología de las cúspides) es similar a la observada en el ejemplar B:p2-154 (referible a Patagosmilus goini (véase Anexo 1.1).

Del postcráneo, el atlas preserva gran parte del arco neural, con su porción dorsal completa, las fóveas articulares craneales (la derecha más completa), la fóvea articular posterior izquierda, una porción proximal del proceso transverso izquierdo, y el intercentro desarticulado. La porción dorsal del arco neural es menos robusta que en Thylacosmilus. El tubérculo dorsal se ubica en el medio del borde anterior y es notoriamente ancho. Las fóveas articulares craneales son muy cerradas, más que las de Thylacosmilus, con su margen dorsal (interno) más cóncavo que el resto de la faceta. A diferencia de Thylacosmilus, en el cual estas fóveas no se diferencian del arco dorsal y forman un borde anterior continuo con este, en Anachlysictis son salientes anteriormente, similares a las de Prothylacynus y Lycopsis longirostrus, aunque no están bien separadas del arco como en Arctodictis y Borhyaena. Esto probablemente indique unos cóndilos occipitales menos salientes y menos desarrollados que los de Thylacosmilus, probablemente similares a los de Patagosmilus (preservados en el ejemplar B:p2-154; véase Anexo 1.1, Patagosmilus goini).

Contrariamente a lo que ocurre en Arctodictis y Borhyaena, en Anachlysictis el surco anterior está cerrado formando un foramen atlantal, como ocurre en L. longirostrus, Prothylacynus y Thylacosmilus. Los forámenes atlantales (intervertebrales) de Anachlysictis son más grandes que los de L. longirostrus y Prothylacynus, y proporcionalmente similares en tamaño a los de Thylacosmilus. Se ubican sobre la superficie dorsal de los arcos neurales, por detrás de las fóveas articulares craneales. Abren en sentido posterolateral, diferente de Thylacosmilus, en el cual abren más lateralmente. Estos forámenes representan la abertura de un canal que corre anteromedialmente hacia la superficie interna del arco, donde a su vez cada uno de ellos abre a través de un pequeño foramen cerca al borde anterior del arco, medial a las fóveas articulares craneales. Además del foramen atlantal (y su abertura interna), se presentan otros tres forámenes. El más grande de ellos se ubica en vista dorsal, entre el proceso transverso y el arco neural, por delante de la fóvea articular posterior, y abre en sentido posterolateral. El segundo foramen se ubica en vista ventral entre el proceso transverso y el arco, y abre en sentido posterolateral. E1 foramen más pequeño se ubica sobre la superficie interna del arco neural, casi en el borde 
posterior, anteromedial a la fóvea articular posterior, y abre en sentido posteromedial. No se observa un foramen transverso.

Entre la porción dorsal del arco neural y el proceso transverso se forman dos muescas: una anterior y una posterior. La anterior (muesca atlantal), que en este caso y en el de Thylacosmilus está marcando el margen dorsal del foramen atlantal, es profunda, más cerrada que en Arctodicis y Prothylacynus, y ligeramente más abierta que en Thylacosmilus. La muesca posterior es más abierta y pequeña que la anterior y se ubica en el borde posterior del atlas. El proceso transverso (izquierdo) está incompleto, pero se observa que anteriormente se extiende al menos hasta el nivel del foramen atlantal y, posteriormente, más allá de las fóveas articulares posteriores. Las fóveas articulares posteriores son ligeramente ovaladas (casi circulares) y su superficie articular es plana.

El intercentro tiene forma trapezoidal. La superficie ventral es plana, con un pequeño tubérculo ventral en el medio de su borde posterior. La superficie dorsal (interna) está dividida en dos planos: uno horizontal y otro orientado anterodorsalmente. Este último se continúa con las superficies ventrales de las fóveas articulares craneales, que se unen en la línea media a través de este plano.

Del sacro se preserva el primer elemento (S1) incompleto, menos de la mitad ventral derecha del cuerpo vertebral y un fragmento de proceso transverso ("ala" del sacro) derecho con parte de la superficie articular (para la articulación con el ilium). El cuerpo vertebral es ancho, anteroposteriormente cóncavo y presenta una cresta ventral más desarrollada anteriormente. La superficie articular anterior del cuerpo es plana y oblicua, orientada anteroventralmente. El proceso transverso es lateralmente angosto, pero se desconoce su extensión anteroposterior. Entre el proceso transverso y la parte posterior del cuerpo se observa parte del foramen sacral ("dorsal" en vista dorsal y "ventral" en vista ventral), que es, aparentemente, de gran tamaño o al menos es amplio anteroposteriormente, ya que su margen medial ocupa casi un cuarto de la extensión lateral del cuerpo vertebral. Se aprecia, además, un amplio surco que corre anteroposteriormente entre el proceso transverso y el cuerpo vertebral.

Además de estos dos elementos axiales descriptos, se preservan algunos fragmentos muy incompletos, que incluyen pre- y postzigapófisis de vértebras cervicales, torácicas y lumbares; un fragmento proximal de espina neural de vértebra dorsal con postzigapófisis, y un fragmento de espina neural de una vértebra dorsal con la postzigapófisis izquierda. Debido a que el material es tan fragmentario, no fue posible determinar una posición más precisa en la columna vertebral.

En el esqueleto apendicular, de la cintura escapular sólo se preserva la porción proximal de la escápula derecha. La cavidad glenoidea es alargada, elipsoidal y anteriormente estrecha. El tubérculo supraglenoideo está bien definido, es redondeado y se proyecta anteromedialmente. El proceso coracoides está poco desarrollado, medialmente no sobrepasa la altura del borde medial de la cavidad glenoidea y anteriormente no sobrepasa el tubérculo supraglenoideo. Un surco amplio y profundo separa el proceso coracoides del borde medial de la cavidad glenoidea. En vista posterior, sobre el cuello de la escápula se preserva, parcialmente, una superficie cóncava rugosa, la cual 
corresponde al área de origen del músculo triceps brachii caput longus (Osgood, 1921).

El magnum derecho se preserva completo. Este hueso carpal presenta cuatro caras principales, conformando una estructura piramidal irregular. La porción proximal del magnum es subesférica y tiene dos facetas, una para el semilunar y otra para el escafoides. La faceta articular para el semilunar se extiende sobre la porción proximal de la cara palmar. La faceta articular para el escafoides se extiende desde la porción proximal de la cara medial hasta la mitad proximal de la superficie dorsal. La faceta articular para el unciforme se ubica sobre la porción dorsal de la cara lateral del magnum. Presenta una forma bilobulada, con la superficie proximal cóncava y la distal plana. La faceta articular para el trapezoide se ubica en la porción distal de la cara medial del magnum, es de forma trapezoidal, con el borde distal cóncavo. En la superficie distal del magnum se encuentra una amplia faceta articular para la articulación con el metacarpal III. Esta superficie presenta una forma similar a un trapecio rectángulo (i.e., dos ángulos rectos adyacentes, dos bases paralelas, un lado perpendicular a las bases y el otro oblicuo), con el borde lateral más corto que el medial y un borde lateropalmar más o menos curvo, el cual termina en un tubérculo palmar bien desarrollado.

Entre los esparasodontes, la morfología que más se asemeja al magnum bajo estudio es la de Patagosmilus goini. En general, sólo se diferencia en que Anachlysictis gracilis presenta un tubérculo palmar mejor definido y la porción proximal más esférica y relativamente más pequeña respecto a la porción distal. Tanto Patagosmilus goini como Anachlysictis gracilis se diferencian de Thylacosmilus, Arctodictis y Borhyaena, en que estos últimos presentan una morfología del magnum más piramidal, mientras que en Anachlysictis gracilis y en Patagosmilus goini es mucho más prismática, con sus caras más verticalizadas.

Se preserva un hueso que claramente corresponde a un elemento del autopodio (Fig. 4.17C) y fue tentativamente identificado como un piramidal (también llamado ulnar o cuneiforme). Fue comparado con el material de carpales y tarsales disponible (i.e., didélfidos actuales; el ejemplar MLP 85-VII-3-1, esqueleto de Arctodictis sinclairi descripto por Forasiepi, 2009; y el ejemplar FMNH P14531, holotipo de Thylacosmilus atrox). Entre el material revisado, se encontró que la morfología más cercana a este hueso corresponde a la de un piramidal. También pudo observarse que el piramidal presenta una notable variación morfológica entre diferentes especies, por lo cual no se pudo identificar claramente si se trata de este elemento. Sin embargo, el hueso al que más se asemeja corresponde al piramidal de T. atrox. Asumiendo que efectivamente se trata de este elemento, se presentan claras diferencias respecto a este mismo en $T$. atrox: además de que la morfología general es diferente, siendo el de A. gracilis más triangular y el de T. atrox más circular (en vista proximal y distal), presenta una notable diferencia, que es la morfología de la faceta articular para la ulna, la cual en T. atrox es relativamente circular y cóncava, bastante profunda, mientras en $A$. gracilis es ligeramente más ovalada y poco profunda; la faceta articular para el semilunar es relativamente más pequeña (respecto faceta para la ulna); adicionalmente, la morfología de la faceta articular para el unciforme presenta una silueta más irregular, es más 
extensa y ligeramente convexa, mientras en $T$. atrox es más circular y ligeramente cóncava.

De los metapodios se preserva una porción distal de un elemento y una epífisis distal de otro. En el elemento más completo se observa que la diáfisis es ovalada en sección transversal. La tróclea es asimétrica, con uno de los cóndilos más desarrollado que el otro, separados por una cresta media bien marcada. La cabeza es ligeramente elipsoidal. Proximal a la cabeza, en vista dorsal, existe una cavidad triangular, poco profunda y amplia, cuyo borde distal es tan ancho como la epífisis. Existe otra depresión lateroproximal a esta cavidad, aún más amplia y profunda. Esta cavidad extra probablemente daba lugar a la inserción de un ligamento y no se observa en ninguno de los metapodios de Thylacosmilus. Sobre cada lado de la epífisis distal existe una pequeña concavidad circular, donde se insertaba el ligamento colateral, similar a otros esparasodontes (véase Forasiepi, 2009). La epífisis distal del otro elemento es robusta. Por su morfología podría tratarse, aparentemente, del metacarpal del dedo I derecho; no tiene una cabeza bien definida, la tróclea es asimétrica (más que la del otro elemento), con uno de los cóndilos mucho más grande (que sería el cóndilo medial), sobrepasando el borde distal del otro cóndilo (cóndilo lateral). Este último está bordeado por una cresta lateral muy marcada. En vista dorsal, proximal a la epífisis, existe una concavidad ovalada y bastante profunda.

La falange proximal preservada está completa y su largo duplica el ancho de la epífisis proximal, la cual es más ancha que la distal. La faceta articular proximal es cóncava y en su borde ventral (palmar o plantar) presenta dos grandes tubérculos para la inserción del tendón de la musculatura flexora (Evans y de Lahunta, 1972), que son subiguales en tamaño y se encuentran separados por una muesca profunda. La diáfisis es de sección ovalada; en vista palmar (¿plantar?), sobre los bordes medial y lateral, presenta dos pequeños tubérculos proximales a la epífisis distal. La epífisis distal está conformada por una tróclea simétrica.

\section{Nuevo ejemplar referido}

\section{UCMP 39705}

Material-fragmento posterior de una rama mandibular derecha, incluyendo el cóndilo y el proceso angular.

Localidad y Estratigrafía -V4531 - "Cerro Gordo 2" (Universidad de Berkeley), área de La Venta; unidad entre las Capas de Arenisca de Chunchullo y Capas de Arenisca de Tatacoa, Formación La Victoria, Grupo Honda.

Comentarios-Este material es referido a A. gracilis debido a que su morfología y tamaño concuerdan bastante con el holotipo. Además, el cóndilo es cilíndrico, con una morfología de "gota" en vista posterior y con un cuello bien definido, como en A. gracilis. El proceso angular presenta un desarrollo y morfología similares al holotipo de esa especie. 


\section{Thylacosmilidae gen. 1}

gen. nov.

Especie Tipo-Thylacosmilidae gen. 1 sp. 1.

Especies Referidas-Únicamente la especie tipo.

Distribución-Área de La Venta (Desierto de La Tatacoa, Valle Superior del Magdalena, Departamento del Huila, Colombia); Laventense, Mioceno medio.

Diagnosis - La misma que la especie tipo.

\section{Thylacosmilidae gen. 1 sp. 1}

gen. et sp. nov.

(Figs. 4.18-4.22)

Holotipo-IGM 251108 (Figs. 4.18-4.21), porción posterior del cráneo; fragmento de maxilar derecho con el $\mathrm{C}$ incompleto y las raíces del $\mathrm{P} 1$; rama mandibular derecha incompleta (rama horizontal y la base de la rama vertical) con los $\mathrm{c}-\mathrm{p} 3$ incompletos, el $\mathrm{m} 1$, el $\mathrm{m} 2$ con el protocónido incompleto y el $\mathrm{m} 4$ incompleto; fragmento de rama mandibular izquierda con raíces de los c-p2 y alvéolos de los p3-m2 con la raíz anterior del p3 y la posterior del m1; axis, dos vértebras cervicales, dos vértebras torácicas, cinco vértebras lumbares, sacro, tres vértebras caudales anteriores, vértebra caudal posterior aislada, y otros fragmentos vertebrales indeterminados; porción proximal de ambos húmeros, porción proximal de la ulna y el radio izquierdo articulados; fragmento de isquión derecho, porción acetabular izquierda de la cintura pélvica articulada a un fragmento proximal de fémur izquierdo, ala ilíaca derecha; fragmento de epífisis distal de fémur izquierdo articulado con la porción proximal de la tibia, un fragmento de fíbula, la patella y la parafíbula; porción proximal y un fragmento del cóndilo lateral del fémur derecho; autopodio posterior derecho incompleto, con un pequeño fragmento de epífisis distal de la tibia derecha articulado al astrágalo y falanges aisladas.

Ejemplar Referido-KU 1995-1-A, m3 derecho.

Distribución Geográfica y Estratigráfica-Área de La Venta (Desierto de La Tatacoa, Valle Superior del Magdalena, Departamento del Huila, Colombia); Grupo Honda, Laventense, Mioceno medio (Tablas 3.1 y 4.1 ; Fig. 3.1).

Diagnosis-Tilacosmílido de pequeño tamaño con el canino superior de sección ovalada y muy verticalizado; el p1 presente y extremadamente reducido respecto a los p2-3; paracónido del m1 bajo, pero bien diferenciado, no confluyente con el cingúlido anterior. Difiere de otros tilacosmílidos en la presencia de un proceso sinfisario pobremente desarrollado, canino superior más desarrollado que el inferior pero sin doblarlo en tamaño, canino inferior menos comprimido, molares inferiores con los talónidos bien desarrollados y con cuenca más profunda. 
Medidas-Tablas 4.2-4.5.

Comentarios - La diagnosis enmendada se propuso sobre la base del análisis morfológico. Ninguno de estos rasgos fue recuperado como sinapomorfía en el análisis filogenético. Las sinapomorfías recuperadas se indican en el Anexo 1.5 (Fig. A1.1 y lista de sinapomorfías).

El holotipo de esta especie fue clasificado por Goin (1997) como "Borhyaenoidea, fam. et gen. incertae sedis (Thylacosmilidae?)" y descripto sobre la base de la mandíbula y el fragmento de maxilar. Sin embargo, ninguno de los otros restos de este ejemplar fue descripto debido a que en aquel momento estaban sin preparar. La preparación la completó Santiago Reuil entre el 2010 y el 2012. El material se encuentra en malas condiciones de preservación (la superficie del hueso está altamente fracturada), lo cual dificultó su preparación, que sólo se pudo realizar parcialmente (e.g., las piezas articuladas no fueron separadas), para evitar cualquier daño irreparable al material. En la presente revisión se realiza la descripción de la totalidad del material, se formula una diagnosis y se propone un nuevo género y especie. Adicionalmente, se reporta otro ejemplar referible a esta especie, que no había sido publicado previamente.

\section{IGM 251108 (Holotipo)}

Localidad y Estratigrafía-Localidad 132 (Universidad de Duke), área de La Venta; unidad entre las Capas de Arenisca de Chunchullo y Capas de Arenisca de Tatacoa, Formación La Victoria, Grupo Honda.

Comentarios-En muchas de las comparaciones, se utilizó la especie Arctodictis sinclairi como referencia para facilitar la visualización de tamaños, ángulos, algunos rasgos anatómicos de los esparasodontes, etc., ya que es uno de los esparasodontes del que se tiene disponible material más completo.

Descripción—Del cráneo se preserva una porción izquierda, posterior a la constricción postorbital. Está muy pobremente preservado, por lo cual no fue posible realizar una descripción detallada. Las escasas estructuras identificables se indican en la Fig. 4.18.

Del maxilar se preserva un fragmento de la porción facial anterior al foramen infraorbitario y un pequeño fragmento de la porción palatal, que se extiende desde el borde anterior del canino hasta el nivel de un diastema posterior al P1. En vista lateral, la yuga alveolar (protuberancia definida en la porción facial del maxilar debido a la implantación del canino) está muy marcada, mucho menos que en Patagosmilus pero mucho más que en cualquier esparasodonte no tilacosmílido.

El dentario es de altura moderada (i.e., altura a nivel de los $\mathrm{m} 3-\mathrm{m} 4 /$ largo total del dentario $=$ entre 0,15 y 0,2 [carácter 97]) y constante a lo largo de casi toda su extensión; por delante del p2, la altura aumenta y el margen ventral del hueso se expande ligeramente, pero no lo suficiente como para formar un proceso sinfisario tan desarrollado como en Anachlysictis y Thylacosmilus, sino uno pobremente desarrollado. El dentario es ligeramente cóncavo lateralmente a nivel de la serie canino-premolar y ligeramente convexo lateralmente a nivel de la serie molar, generando la 
morfología sigmoide característica del dentario de los tilacosmílidos, pero mucho menos marcada que en los demás taxones de este grupo. En vista anterior se observa un foramen por debajo del canino. Se identifican al menos tres forámenes mentonianos: uno por debajo del p1, muy cerca del borde ventral del dentario, otro por debajo del diastema entre el p1 y el p2, y otro por debajo del p3. De la rama vertical se preserva una pequeña porción anterior al foramen mandibular (este no alcanza a preservarse), incluyendo la base de la fosa masetérica, parte anterior de la cresta coronoidea inferior (= cresta masetérica) y la base de la cresta coronoidea anterior. El ángulo entre la línea alveolar y el borde anterior del proceso coronoides, medido a partir de la porción de cresta coronoidea anterior preservada, mide entre $95^{\circ}$ y $105^{\circ}$.

En la dentición superior el canino es de implantación vertical y de sección ovalada, a diferencia de Thylacosmilus y Patagosmilus, en los que el canino superior está mucho más comprimido lateralmente y es de sección aproximadamente triangular (con la cara labial dividida en dos facetas planas; carácter 315). La porción extraalveolar es aparentemente lisa (presenta varias fracturas), sin surcos ni crestas. Existe un diastema muy pequeño entre el $\mathrm{C}$ y el P1, aproximadamente de la longitud de la raíz anterior del P1, y otro posterior al P1 de longitud desconocida (ahí termina el fragmento preservado). A juzgar por las raíces preservadas, el P1 era muy pequeño, proporcional al tamaño del p1.

En la dentición inferior se preserva, aparentemente, al menos el alvéolo de un incisivo, posiblemente dos (esto no es claro debido a la mala preservación). El canino es de implantación oblicua respecto a la hilera dentaria (como en Thylacosmilus) y subvertical, (más verticalizado que en Thylacosmilidae gen. 2 sp. 1) más verticalizado que en esparasodontes como Arctodictis, Australohyaena y Callistoe, que presentan también una implantación subvertical, pero menos que en Thylacosmilus, en cuya implantación es claramente vertical. Es muy comprimido lateralmente como en Thylacosmilus, mucho más que en cualquier esparasodonte no tilacosmílido. La porción extraalveolar del canino presenta un surco principal amplio y poco profundo en su cara lingual, menos profundo que el de Thylacosmilus, y pequeñas estrías lineales paralelas al surco. Los premolares y molares están orientados siguiendo la curvatura del dentario. Hay tres premolares presentes, los cuales son pequeños y gráciles, con un cambio abrupto de tamaño entre el p1 y los p2-3, siendo el p1 extremadamente reducido respecto a los otros dos premolares, y el p2 más pequeño que el p3. Se presentan tres diastemas: el más largo entre el c y el p1, el siguiente (ligeramente más pequeño) entre el p1 y el p2, y el más corto entre el p3 y el m1. Las raíces de los premolares son tan anchas como la corona.

Debido a que el holotipo no preserva el m3, para la descripción de algunos rasgos se tuvo en cuenta el ejemplar KU 1995-1-A (véase más abajo), un m3 derecho referible a esta especie. Todo lo que en la presente descripción haga referencia al m3 (a menos que se exprese lo contrario) fue observado en dicho ejemplar. Los molares inferiores presentan un marcado aumento de tamaño del $\mathrm{m} 1$ al m4 (teniendo en cuenta la longitud del alveolo del $\mathrm{m} 3$ del holotipo). El trigónido es más largo que el talónido en todos los molares (sólo ligeramente más largo en el m2), mientras el ancho 
del talónido es mayor al del trigónido en el $\mathrm{m} 1$, subigual en el $\mathrm{m} 2$ y menor en los m3-4. En vista labial, el lóbulo posterior de la corona es más bajo que el anterior en los m1-3, siendo este desnivel más marcado en el $\mathrm{m} 2$ y mucho menos en el $\mathrm{m} 1$. Este rasgo es menos marcado que en Anachlysictis gracilis pero más marcado que en Hondadelphys fieldsi.

Las cúspides del trigónido en el m1 están alineadas en dirección anteroposterior. En los m2-4 la configuración del trigónido es abierta, con el paracónido en posición anterolingual. El protocónido es la cúspide principal del trigónido en todos los molares. El paracónido y el protocónido aumentan de tamaño posteriormente. En el $\mathrm{m} 1$, el paracónido es bajo pero bien diferenciado, no confluye con el cingúlido anterior, de modo similar a lo que se observa en Lycopsis longirostrus. El metacónido está ausente al menos en los $\mathrm{m} 2-4$; la corona del $\mathrm{m} 1$ presenta una ruptura en esta área, siendo imposible determinar su presencia. Sin embargo, entre los esparasodontes revisados (Anexo 1.1), no se observa ninguno donde el metacónido se presente únicamente en el $\mathrm{m} 1$. La cresta vertical anterolingual del paracónido forma una quilla. El precingúlido está bien desarrollado, extendiéndose desde la base del paracónido hasta la base del protocónido. La postparacrístida es vestigial en el m1, corta en el m2, un poco más larga en el m3 y no se preserva en el $\mathrm{m} 4$ (debido a la ruptura de la corona); teniendo en cuenta las dimensiones del paracónido, era probablemente más larga que la del m3. La preprotocrístida está bien desarrollada en el $\mathrm{m} 1$, siendo más larga que en el $\mathrm{m} 3$, y no se preserva en el $\mathrm{m} 2$ y ni en el $\mathrm{m} 4$. La postprotocrístida está bien desarrollada, alargándose del $\mathrm{m} 1 \mathrm{al} \mathrm{m} 4$ (el protocónido está incompleto en el $\mathrm{m} 2$ y el $\mathrm{m} 4$, pero se infiere a partir de sus dimensiones), y se extiende hasta la esquina anterolingual del talónido.

El talónido está bien desarrollado en los m1-4, más desarrollado que en Anachlysictis. El talónido del $\mathrm{m} 1$ es menos desarrollado que el del $\mathrm{m} 2$ y se reduce en tamaño del $\mathrm{m} 2 \mathrm{al} \mathrm{m} 4$ (teniendo en cuenta el ejemplar KU 1995-1-A, ver más abajo). La cuenca del talónido es ligeramente más larga que ancha en el m1, mientras que en los m2-4 estas dos dimensiones son subiguales, y es más profunda que en Anachlysictis. Adicionalmente, en los m2-4 la cuenca presenta un desnivel, con su porción lingual muy verticalizada y aplanada, y una labial mucho más horizontal y cóncava, como ocurre en Anachlysictis. El hipocónido está ubicado casi en la esquina posterolabial del talónido en el m1, y se va haciendo ligeramente más anterior hacia el m4, en el cual se ubica, aproximadamente, hacia la mitad del borde labial del talónido. Es más alto que el entocónido en el m1 y más bajo en los m2-4, y está más desarrollado que en Anachlysictis. El entocónido e hipoconúlido se encuentran formando un sólo "bloque" (sus bases están fusionadas) como ocurre en Anachlysictis, pero sus ápices están diferenciados y se observa que el del hipoconúlido se ubica en una posición más posterior que en Anachlysictis. Este bloque lingual está bien comprimido lateralmente y su pared labial (correspondiente a la porción lingual de la cuenca del talónido) se encuentra más verticalizada que en Anachlysictis, por lo que está más elevado respecto al hipocónido que en Anachlysictis. Este rasgo también puede observarse en Hondadelphys fieldsi (junto con la particular división en la cuenca), aunque menos marcado: los ápices del entocónido e 
hipoconúlido son claramente diferenciables (mucho más que en Thylacosmilidae gen. 1), el bloque lingual se encuentra poco elevado respecto al hipocónido, y este último se encuentra más desarrollado. En vista lateral, en la cara labial del talónido se observa un postcingúlido, presente en los m1-3 y aparentemente ausente en el m4 (la corona está rota). El postcingúlido es más desarrollado en el $\mathrm{m} 1$, reduciéndose hacia el $\mathrm{m} 3$.

En el esqueleto axial, las principales regiones de la columna vertebral están representadas, aunque por unas pocas vértebras incompletas. Algunos de estos elementos están articulados, pero debido a su pobre estado de preservación no fue posible determinar su ubicación precisa dentro de cada una de las regiones. Por esta razón, cuando en la descripción se hace referencia a la 'primera vértebra', 'segunda vértebra', etc., no implica necesariamente su ubicación real en la secuencia, sino a una posición relativa dentro de la porción preservada. Adicionalmente, debido a que no fue posible desarticular estos elementos, no pudieron ser observados (y, por lo tanto, descriptos) algunos de los rasgos vertebrales.

El axis está casi completo y sus elementos están fusionados. La porción anterior del cuerpo del axis está comprimida dorsoventralmente y ensanchada sobrepasando lateralmente el nivel del arco neural. Las superficies articulares anteriores son ovaladas, convexas, y están orientadas anterolateralmente. La cara posterior del cuerpo del axis es plana, ovalada, y está orientada posterodorsalmente. El proceso odontoides está bien desarrollado y presenta forma de barra. Está orientado anterodorsalmente y claramente diferenciado de las superficies articulares anteriores. La cresta ventral (cresta sagital) está incompleta; aparentemente estaba menos desarrollada que en Thylacosmilus. Se extiende desde la base del proceso odontoides hasta el extremo posterior de la vértebra, hacia donde incrementa su altura. La espina neural preserva la porción ventral, por lo cual no es posible determinar su altura. Aunque no se preserva su extremo, posterior se observa que se extiende al menos a lo largo de toda la extensión del cuerpo vertebral, llegando anteriormente al nivel del extremo anterior del proceso odontoides. El proceso transverso es ligeramente más ancho que en Thylacosmilus y, aunque no preserva su porción distal, aparentemente está orientado posterolateralmente, más posteriormente que en Thylacosmilus. El foramen transverso está completamente cerrado. Las postzigapófisis son protruyentes, más salientes que las de Thylacosmilus, y su faceta articular está orientada lateroventralmente.

Se preservan dos vértebras cervicales incompletas y articuladas. Fueron identificadas tentativamente como la cuarta y quinta vértebra cervical (C4? y C5?) debido a los siguientes rasgos: el primer cuerpo vertebral es notoriamente más pequeño que en el axis, sugiriendo que había al menos una vértebra entre ellos; la presencia de una cresta ventral (hipoapófisis) marcada, bien definida en la primera vértebra de la secuencia, y de una lámina inferior bien desarrollada e inclinada lateroventralmente, hacen menos probable que se traten de las últimas dos vértebras cervicales. Los cuerpos vertebrales son ligeramente más largos que anchos, con sus caras articulares ovaladas y oblicuas. La cara articular anterior de C4? está incompleta pero es evidente que está orientada anterodorsalmente, mientras que la superficie articular posterior de C5?, más 
comprimida dorsomedialmente, está orientada posterodorsalmente.

En vista ventral, la cresta ventral de C4? está bien definida y es más alta posteriormente; la de C5? está presente pero incompleta. En general, en los esparasodontes (e.g., Arctodictis) esta cresta se va reduciendo hacia los elementos posteriores, siendo casi vestigial en C6 y C7. Esta cresta separa dos concavidades profundas, limitadas lateralmente por la lámina inferior. Los arcos neurales de ambas vértebras están incompletos y deformados. Los procesos transversos protruyen posteriormente y encierran un foramen transverso de gran tamaño.

La lámina inferior es oblicua, inclinándose lateroventralmente respecto a la superficie ventral del cuerpo vertebral. En C4? está orientada lateroposteriormente respecto al eje anteroposterior del cuerpo vertebral. Los pedicelos están deformados pero aparentemente son verticales y su superficie lateral es cóncava. Las láminas del arco vertebral están orientadas laterodorsalmente. En esparasodontes como Arctodictis, las láminas de las vértebras cervicales más anteriores definen entre sí un ángulo obtuso, mientras las posteriores son casi horizontales. Las pre- y postzigapófisis son protruyentes, con las facetas articulares orientadas dorsomedialmente en las prezigapófisis y lateroventralmente en las postzigapófisis. El canal neural es notoriamente más amplio que la cara anterior del cuerpo vertebral.

De la región torácica se preserva un segmento articulado que incluye dos vértebras, un fragmento del disco óseo anterior de la siguiente y un fragmento de tuberculum de una costilla izquierda. Estas vértebras tienen diapófisis y parapófisis bien definidas, indicando su ubicación en la porción más anterior de la región torácica. Sólo en la segunda vértebra se preserva el cuerpo vertebral completo, que es robusto, cilíndrico y más pequeño en la primera vértebra. El arco neural de la segunda vértebra está mejor preservado que el de la primera, de la cual sólo se preservan algunos fragmentos. Los procesos transversos protruyen casi lateralmente. Las diapófisis están incompletas. El canal neural es de sección circular y su diámetro es menor que el del cuerpo vertebral.

De la región lumbar se preserva una porción articulada, compuesta por cuatro vértebras casi completas y un fragmento anterior de la siguiente. Por el estado de preservación del material, no fue posible determinar con precisión a qué vértebras de la zona lumbar corresponden, pero debido a que por lo general los marsupiales (Flower, 1885) y los esparasodontes (Sinclair, 1906; Babot, 2005; Forasiepi, 2009) presentan seis vértebras lumbares, podrían tratarse de L1-5 o L2-6.

El cuerpo vertebral es robusto, ligeramente más ancho que largo en la primera vértebra de la secuencia y se hace más largo posteriormente, siendo más largo que ancho en la cuarta vértebra. Existen dos depresiones amplias y poco profundas que se extienden sobre la superficie ventral a cada lado del cuerpo. Aunque incompletos, los procesos transversos se preservan en la segunda, tercera y cuarta vértebra de la secuencia. Estos protruyen anterolateralmente y son aparentemente pequeños, pero debido a la mala preservación del material es difícil determinar claramente su extensión. Su tamaño va aumentando posteriormente, siendo tan solo una pequeña protuberancia en la segunda vértebra y un proceso bien definido en la cuarta. La lámina del arco vertebral es 
extensa anteroposteriormente. Las espinas neurales están inclinadas hacia adelante y su extremo dorsal es achatado. Las prezigapófisis protruyen en sentido anterolateral, con la faceta articular dorsomedial. Sobre el extremo anterior de las prezigapófisis se preservan unas metapófisis bien desarrolladas. Las postzigapófisis protruyen posterolateralmente y su faceta articular se orienta ventrolateralmente. Las anapófisis protruyen en sentido posterolateral, superando la extensión posterior de las postzigapófisis.

El sacro está articulado al ala ilíaca derecha y sobre su lado izquierdo se preserva un fragmento de ilion. El sacro está conformado por dos vértebras, que incluyen más de la mitad posterior de la primera vértebra sacra (S1) y la porción anterior de la segunda (S2). Los cuerpos vertebrales están fusionados, apreciándose una línea de sutura muy sutil entre ellos. La vértebra S1 es considerablemente más grande que la S2. A pesar de que los procesos transversos están incompletos, es evidente que aquel de la $\mathrm{S} 1$ se proyecta lateralmente, mientras que el de la S2 lo hace anterolateralmente, definiendo entre ambos los forámenes sacrales dorsal y ventral. Siguiendo la morfología de las porciones preservadas, aparentemente estos forámenes eran ovalados y subiguales en tamaño. Sobre la lámina de la vértebra $\mathrm{S} 1$ hay un pequeño foramen a cada lado de la espina neural, de la cual se preserva sólo la base. Existe una pequeña cresta medial que se origina en el extremo posterior del arco neural de la S1 y continúa posteriormente hasta contactar la espina neural de la S2.

Las tres primeras vértebras caudales anteriores (sensu Lessertisseur y Saban, 1967) se preservan asociadas a un fragmento de isquion. De la vértebra Cd1 se preserva el cuerpo vertebral incompleto y parte del proceso transverso derecho; de la $\mathrm{Cd} 2$, el cuerpo vertebral, los procesos transversos incompletos y la parte posterior del arco neural; de la $\mathrm{Cd} 3$, el cuerpo y la parte anterior del arco neural con la base de los procesos transversos. El cuerpo vertebral es más largo que ancho, con las caras articulares ovaladas. El extremo anterior y posterior es más ancho que la parte media del cuerpo. Existen dos crestas ventrales paralelas en cada cuerpo vertebral. Los procesos transversos se originan sobre el cuerpo vertebral y la longitud anteroposterior de su base no supera la del cuerpo. Las pre- y postzigapófisis son funcionales (se articulan entre vértebras adyacentes). Las prezigapófisis protruyen en sentido anterolateral, con las facetas orientadas dorsomedialmente. Las postzigapófisis protruyen posterolateralmente, con facetas articulares orientadas ventrolateralmente. El canal neural es pequeño respecto al cuerpo vertebral.

Las vértebras caudales posteriores son aquellas en las que las pre- y postzigapófisis carecen de superficies articulares funcionales (Lessertisseur y Saban, 1967). De esta sección caudal posterior se preserva un elemento con el cuerpo vertebral completo, el proceso transverso derecho, la porción posterior del izquierdo y las pre- y postzigapófisis incompletas. El cuerpo es mucho más alargado que en las vértebras caudales anteriores y presenta caras articulares circulares, la anterior más grande que la posterior. El extremo anterior y posterior es más ancho que la parte media del cuerpo. Los procesos hemales anteriores y posteriores están bien definidos. Los procesos transversos se extienden de manera continua a lo largo de todo el cuerpo vertebral formando 
lateralmente una lámina de borde convexo (no están divididos). Existe una pequeña muesca anterior entre el proceso transverso y el cuerpo vertebral. Las pre- y postzigapófisis están muy reducidas respecto a aquellas de las vértebras caudales anteriores y carecen de carillas articulares, sugiriendo que no podrían articular con aquellas de las vértebras adyacentes. Las prezigapófisis se orientan anterolateralmente. Las postzigapófisis, más reducidas, están orientadas dorsalmente y están casi fusionadas entre sí. No existe canal neural. La presencia de un sólo proceso transverso extenso y continuo a cada lado del cuerpo vertebral, sumado a que las zigapófisis aún están claramente definidas (en especial las anteriores), sugiere que este elemento se ubicaba en la porción anterior del segmento posterior de la región caudal.

En el esqueleto apendicular, el húmero se encuentra ligeramente deformado. Es de apariencia grácil, con una epífisis proximal poco robusta respecto al diámetro de la diáfisis. La cabeza humeral es redondeada, circular en vista proximal y ligeramente alargada ventralmente en vista posterior. El tubérculo mayor está bien diferenciado aunque no alcanza la altura de la cabeza humeral; es aplanado lateralmente, formando un reborde dorsal curvo que se conecta con la cresta deltoidea. El tubérculo menor se diferencia claramente de la cabeza humeral y se ubica a un nivel ligeramente más bajo que el tubérculo mayor. En vista anterior, el surco bicipital es más amplio y profundo proximalmente. La cresta deltoidea es baja y redondeada; se origina en el tubérculo mayor y desciende sobre la superficie anterior de la diáfisis. En vista lateral se aprecia una superficie ovalada bien definida y rugosa, donde se habría insertado el músculo infraspinatus (Osgood, 1921; Forasiepi, 2009, Fig. 32). La línea tricipital se origina en el borde posterior de la faceta de inserción del músculo infraspinatus como una cresta muy tenue y oblicua, que se extiende al menos a lo largo de toda la porción de la diáfisis preservada. En vista posterior se aprecia una cresta alta, bien definida y protruyente posteriormente, la que se origina por debajo de la cabeza humeral y se extiende distalmente sobre la diáfisis. Esta cresta divide la superficie posterior de la diáfisis en dos fosas. La fosa más lateral está restringida a la porción más proximal de esta superficie. La fosa medial es más profunda y extensa distalmente, y está limitada medialmente por una cresta que se origina por debajo del tubérculo menor. Esta cresta es corta pero bien definida, haciéndose más amplia distalmente hasta desaparecer.

La ulna se encuentra ligeramente deformada y en muy mal estado de preservación, y adicionalmente se encuentra articulada al radio, por lo cual muy pocos rasgos son observables. Aparentemente, es lateralmente comprimida (aunque esto podría deberse a la deformación) y su borde posterior se curva anteriormente. El olécrano está, aparentemente, bien desarrollado.

Del radio sólo se puede observar que es de apariencia grácil y su faceta articular proximal (fovea capitis radii) es ligeramente ovalada.

De la cintura pélvica se preserva la porción acetabular izquierda, incluyendo fragmentos de ilion, isquion y pubis, con un fragmento de epífisis proximal de fémur articulado, un fragmento de isquion derecho asociado a las vértebras caudales proximales, un fragmento de ilion izquierdo y el ala ilíaca del derecho (con el borde anterior roto) articulados con el sacro. El fragmento de isquion 
derecho comprende una porción entre el borde posterodorsal del foramen obturador y el tubérculo isquial. El ala ilíaca es aparentemente convexa en vista medial (aunque se encuentra muy deformada) y en vista lateral presenta una fosa glútea ovalada y cóncava, aparentemente muy profunda. La cresta acetabular (que separa la fosa glútea de la fosa iliaca, desde el tubérculo para el rectus femoris y termina en la eminencia iliaca anteroventral) está bien definida y corre desde el extremo anteroventral del ala ilíaca hasta el tubérculo para el recti femoris (ubicado en el extremo posteroventral del ala ilíaca). Este tubérculo es elipsoidal, muy elongado anteroposteriormente, grande (el diámetro mayor es mayor al diámetro de la cabeza femoral) y protruye lateralmente. La fosa ilíaca es muy angosta, aunque se amplía a medida que se acerca al tubérculo del recti femoris. La cresta púbica, que separa la fosa ilíaca de la cara medial del ilion, está poco definida. El tubérculo isquial es plano en su borde posterodorsal.

El fémur se encuentra muy fracturado y aparentemente deformado, la cabeza femoral está bien diferenciada, con un cuello bien marcado y protruye anteromedialmente. El trocánter mayor es más bajo que la cabeza femoral. El trocánter menor está orientado posteromedialmente y no sobrepasa la mitad de la extensión medial de la cabeza femoral. La fosa trocantérica es profunda. El cóndilo lateral está comprimido anteroposteriormente. El cóndilo medial está ligeramente más extendido que el cóndilo lateral. La fosa intercondilar de la tróclea femoral es amplia y profunda. La patella izquierda está presente y permanece articulada al fémur.

La tibia (Fig. 4.21C) presenta una epífisis proximal poco robusta, de forma triangular en vista proximal. El cóndilo medial es más protruyente que el lateral, lateralmente aplanado y con su extremo posterior circular en vista medial. En vista posterior, por debajo del cóndilo lateral (cubierto por el fragmento de fíbula) existe una profunda concavidad, alargada distalmente y más profunda proximalmente, probablemente para la inserción del músculo peroneus tibialis (Jouffroy et al., 1971). En vista anterior, la tuberosidad tibial está bien definida, es triangular y aplanada. Su borde distomedial está conectado con una cresta más baja que delimita el cóndilo medial distalmente. Una pequeña tuberosidad adicional, de forma circular irregular, se localiza entre la tuberosidad tibial (en su esquina lateroproximal) y el cóndilo lateral. Por debajo de la tuberosidad tibial, la cresta tibial (= cresta cnemial) está bien definida y desciende sobre la superficie anterior de la diáfisis dividiéndola en dos superficies cóncavas poco profundas, siendo la medial más amplia que la lateral.

Parte del autopodio posterior derecho se preserva articulado y en muy mal estado de preservación, asociado a un fragmento de epífisis distal de tibia. Están presentes el astrágalo, calcáneo, navicular?, mesocuneiforme?, cuboides, porción proximal de los metatarsales II, III, IV y $\mathrm{V}$, y algunos fragmentos óseos indeterminados sobre los demás elementos en vista plantar. Adicionalmente, se preservan tres falanges aisladas.

El astrágalo está muy pobremente preservado. Se distingue la cabeza astragalar y parte de la superficie articular proximal, la cual pareciera ser plana (i.e., la faceta articular tibial no forma una tróclea). 
El calcáneo está constituido por un tubérculo posterior y un cuerpo anterior. El tubérculo del calcáneo es largo, grácil, circular en sección transversal y ligeramente curvado medialmente. Su longitud representa, aproximadamente, el $40 \%$ de la longitud total del calcáneo. Presenta una tuberosidad en su extremo posterior con estrías en su superficie para la inserción el músculo gastrocnemius (Sisson, 1965; Jouffroy et al., 1971). En vista posterior, sobre el tubérculo, se observa un surco poco profundo, orientado lateromedialmente. Sobre la superficie laterodorsal del tubérculo existe una concavidad alargada y profunda, posterior al proceso proximal del calcáneo. No es clara la homología de esta concavidad, pero podría tratarse de la depresión para la inserción del ligamento caláneo-fibular. El cuerpo anterior es alargado anteroposteriormente y presenta tres procesos principales: el proceso proximal, el sustentaculum tali y el proceso peroneal. Sobre el proceso proximal, en vista dorsal, la faceta calcáneo-fibular es fuertemente convexa. El proceso peroneal es alargado anteroposteriormente y poco protruyente. El surco para la inserción del tendón del peroneus longus, ubicado sobre el proceso peroneal, es poco profundo. En vista plantar, el sustentaculum tali pareciera extenderse distalmente hasta la faceta calcáneo-cuboidal.

El cuboides se ubica distal al calcáneo. Presenta una forma más o menos cúbica. La faceta calcáneo-cuboidal es convexa, oblicua, orientada lateroproximalmente y extendida sobre más de la mitad de la superficie lateral del cuboides. A partir de este punto, la superficie lateral se orienta casi paralela a la superficie medial, la cual es ligeramente convexa. El tubérculo plantar está bien desarrollado. La faceta distal está articulada a los metatarsales IV y V.

Dos huesos tarsales se preservan en posición proximal a los metatarsales II y III (Fig. 4.21). Por su ubicación podrían tratarse del ectocuneiforme y el mesocuneiforme, pero no es posible determinarlo debido a su estado de preservación. No se descarta que se trate de otros elementos, desplazados postmortem a esta posición.

De los huesos metatarsales se preserva la porción proximal de los elementos II, III, IV y un pequeño fragmento del V. La epífisis proximal de los metatarsales (al menos II y III) es asimétrica, con un proceso dirigido lateralmente. El metatarsal II imbrica al metatarsal III.

Además del autopodio articulado, se preserva una falange proximal completa aislada y dos fragmentos de otras falanges. En la falange proximal, la epífisis proximal es más ancha que la distal. La epífisis distal presenta una tróclea bien definida.

\section{Nuevo ejemplar referido}

\section{KU 1995-1-A}

Material—m3 derecho.

Localidad y Estratigrafía - La Venta (Universidad de Kioto), área de La Venta; Grupo Honda.

Comentarios-Este molar es consistente en morfología con un posible m3 derecho de Thylacosmilidae gen. 1 sp. 1, aunque el individuo es ligeramente más pequeño. La configuración del trigónido es abierta, con el paracónido en posición anterolingual. El protocónido es la cúspide 
principal del trigónido. El paracónido está bien desarrollado y el metacónido está ausente. La cresta vertical anterolingual del paracónido forma una quilla. El precingúlido está bien desarrollado, extendiéndose desde la base del paracónido hasta la base del protocónido. La postparacrístida está bien desarrollada, más larga que en el $\mathrm{m} 2$ del holotipo de Thylacosmilidae gen. 1 sp. 1. La postprotocrístida está bien desarrollada y se extiende hasta la esquina anterolingual del talónido.

El talónido está bien desarrollado, pero más reducido respecto al del m2, y más desarrollado que el del m4. La cuenca del talónido presenta el mismo desnivel que en el holotipo, pero es más desarrollado que en el $\mathrm{m} 2$ y menos que en el $\mathrm{m} 4$. El lóbulo posterior del diente es más bajo respecto al anterior, y este rasgo es menos marcado que en el $\mathrm{m} 2$ del holotipo. El postcingúlido está presente.

\section{Thylacosmilidae gen. 1 sp. indet.}

(Fig. 4.22B)

\section{KU LV-4}

Material-Fragmento de mandíbula derecha con los m3-4 incompletos y las raíces del m2.

Localidad y Estratigrafía - Localidad dudosa del área de La Venta (la única información en el rótulo era “Kioto Site?"); nivel estratigráfico desconocido del Grupo Honda (Tabla 4.1; Fig. 3.1).

Medidas-Tabla 4.5.

Comentarios-Los molares presentan un aumento posterior de tamaño marcado y son consistentes tamaño con Thylacosmilidae gen. $1 \mathrm{sp} .1$ y cercanos a los de Hondadelphys fieldsi. Sin embargo, los talónidos se encuentran mucho más reducidos que en este último. El trigónido es más largo y ancho que el talónido en los molares preservados, y el talónido es más reducido en el m4 que en el m3, similar a las proporciones entre el ejemplar KU 1995-1-A y el holotipo de Thylacosmilidae gen. 1 sp. 1. En vista labial, el lóbulo posterior de la corona es más bajo que el anterior en el $\mathrm{m} 3$ y este rasgo no se presenta en el m4. En la cara labial del talónido del $\mathrm{m} 3$ se presenta un cíngulo posterior bien desarrollado, como en Thylacosmilidae gen. $1 \mathrm{sp}$. 1. Se presenta un foramen mentoniano al nivel del $\mathrm{m} 2$, del cual se desconoce su presencia en Thylacosmilidae gen. $1 \mathrm{sp} .1$, ya que la superficie lateral de la mandíbula del holotipo está altamente fracturada.

De todos los esparasodontes de La Venta, la morfología de Thylacosmilidae gen. $1 \mathrm{sp} .1$ es la que más se acerca a la de este ejemplar. Las cúspides están pobremente preservadas, por lo que no es posible observar detalles particulares. Sin embargo, sí se observan detalles generales que, claramente, están presentes en dicha especie. Por esta razón, se refiere el ejemplar a Thylacosmilidae gen. 1 sp. indet., no descartando la posibilidad de que se trate de la misma especie. 


\section{Comentarios generales sobre Thylacosmilidae}

Goin (1997) señaló que, a juzgar por la porción craneana preservada en Anachlysictis gracilis (al nivel del postorbital), se puede inferir que su techo craneano sería más aplanado que en Thylacosmilus, que no se presenta una barra postorbital (ya que existe un proceso postorbital) y que no hay evidencia de un proceso ascendente del maxilar. En esta revisión se concluye que este último está claramente ausente, ya que el lacrimal, nasal y frontal están en contacto a la altura del proceso postorbital. Goin (1997) advirtió que estos rasgos estarían indicando que la porción intraalveolar del canino superior estaba mucho menos desarrollada que en Thylacosmilus, y reflejando una morfología facial diferente, menos especializada. Esta hipótesis queda reafirmada al observar a Patagosmilus (descripto años después), cuya porción craneana es casi idéntica a la de Anachlysictis, y donde claramente el techo craneano es mucho más plano que en Thylacosmilus, no se presenta el proceso ascendente del maxilar, el canino superior es menos desarrollado y no existe barra postorbital sino un proceso postorbital como en Anachlysictis. Esto indica que tanto Anachlysictis como Patagosmilus son menos especializados que Thylacosmilus, si bien su morfología básica está enmarcada en la tendencia evolutiva general de los Thylacosmilidae, donde se observa una profunda modificación de la región rostral, tanto en el cráneo como en la mandíbula. Además, es muy probable que el cráneo de Anachlysictis sea muy similar al de Patagosmilus.

En Thylacosmilus, la presencia de una barra postorbital, la particular morfología facial y del techo craneano (debido a la presencia de los procesos ascendentes del maxilar), la gran extensión intraalveolar de los caninos superiores y además la morfología de los cóndilos occipitales (altos y salientes) constituyen un conjunto de caracteres que han sido relacionados con una particular postura de cráneo, reflejada también en la especializada morfología del atlas, y una estrategia predatoria específica (véase Goin y Pascual 1987). En el ejemplar B:p2-154, proveniente de Río Rosario, una localidad cercana a Quebrada Honda y referible a Patagosmilus goini (véase Anexo 1.1, Patagosmilus goini), se preservan los cóndilos occipitales y se observa que son tan sólo ligeramente salientes, mucho menos que en Thylacosmilus. Adicionalmente, la morfología del atlas de Anachlysictis es mucho más plesiomórfica que en Thylacosmilus, presentando varias similitudes con aquella observada en los Borhyaenidae (véase Argot, 2004). Estos rasgos se suman a las características craneales arriba mencionadas, como indicadores de un proceso evolutivo que culmina en la altamente especializada morfología de Thylacosmilus.

Thylacosmilidae gen. 1 sp. 1 presenta rasgos aún más plesiomórficos que Anachlysictis y Patagosmilus. A pesar de que no se ha preservado la porción anterior del techo craneano (se desconoce el área del proceso postorbial), sí se conserva una porción que permite confirmar las inferencias anteriormente mencionadas: una yuga alveolar bien desarrollada y un canino superior de implantación verticalizada, desproporcionadamente más grande que el inferior (longitud anteroposterior ca. 50\% mayor), aunque mucho más pequeño que el de Patagosmilus y 
Thylacosmilus y sin esa morfología de sable. La yuga alveolaria está mucho más desarrollada que en los esparasodontes no tilacosmílidos, pero menos desarrollada que en Patagosmilus. Esta yuga alveolaria es una protuberancia en la porción facial del maxilar, al nivel del canino superior, cuyo desarrollo está relacionado con el de la porción intraalveolar del canino: a mayor desarrollo de la porción intraalveolar del canino, mayor será el tamaño de la yuga alveolaria. En Patagosmilus no hay proceso ascendente del maxilar pero se presenta una yuga alveolaria extremadamente desarrollada, mucho más que en Thylacosmilidae gen. 1, y un canino mucho más desarrollado (pero menos que en Thylacosmilus) con una robusta porción intraalveolar, la cual asciende ligeramente dentro del cráneo. Esta porción craneana está mostrando un proceso evolutivo en el cual, a medida que la porción intraalveolar del canino crece, empieza a ascender dentro del cráneo, y simultáneamente ocurre lo mismo con la porción del maxilar donde se encuentra implantado, la cual aumenta de tamaño y empieza a ascender sobre el techo craneano hasta formar un proceso ascendente del maxilar como el de Thylacosmilus.

El proceso evolutivo de los tilacosmílidos también es evidente en la mandíbula y en la dentición inferior. Se observa que, en todos los taxones, la altura de la rama horizontal mandibular permanece constante a lo largo de casi toda su extensión, excepto en la porción anterior, donde su altura se incrementa formando un proceso sinfisario ausente en Thylacosmilidae gen. 2 sp. 1 (Suarez et al., in prep.: proveniente de la Formación Arroyo Chasicó, Argentina; véase Anexo 1.1, 1.3 y 1.4), pobremente desarrollado en Thylacosmilidae gen. 1, bien desarrollado en Anachlysisctis y mucho más desarrollado en Thylacosmilus (no se preserva en Patagosmilus). Se observa cómo a medida que este proceso sinfisario es más desarrollado, se reduce el número de incisivos, el canino inferior se vuelve más vertical y más comprimido lateralmente, y los premolares se reducen en tamaño, siendo esta reducción extremadamente marcada en el p1, el cual desaparece en las formas más especializadas (e.g., Anachlysictis, Patagosmilus y Thylacosmilus).

En la dentición inferior se observa que tanto Anachlysictis como Thylacosmilus presentan una reducción en el número de premolares, teniendo sólo dos. Por otro lado, Thylacosmilidae gen. 1 conserva los tres premolares, pero el p1 se encuentra extremadamente reducido respecto a los otros dos premolares y se presentan amplios diastemas anterior y posteriormente a este diente. Gracias a este rasgo de Thylacosmilidae gen. 1 se puede apreciar, claramente, que el premolar que se reduce, hasta desaparecer en las formas más especializadas, es el p1 (similar discusión e interpretación en Forasiepi 2006; 2009, carácter 118). Adicionalmente, los p2-3 son relativamente chicos en los tres taxones, siendo el p2 menor en tamaño que el p3, y en Thylacosmilus presentan una morfología bastante cónica y con una sola raíz, mientras que en los demás tilacosmílidos son biradiculados y más comprimidos lateralmente.

En los molares inferiores se observa cómo el talónido de los m1-3 se va reduciendo en tamaño, estando bien desarrollado y con una cuenca relativamente profunda en Thylacosmilidae gen. 1 (similar a Hondadelphys), algo reducido en Anachlysictis y Patagosmilus (observaciones en el ejemplar B:p2-154; véase Anexo 1.1, Patagosmilus goini), y fuertemente reducido en 
Thylacosmilus. El talónido del m4 también se va reduciendo en tamaño, estando aún bien definido y con cuenca en Thylacosmilidae gen. 1, extremadamente reducido y sin cuenca (es prácticamente una cúspide) en Anachlysictis y Patagosmilus, y vestigial en Thylacosmilus. También se observa cómo las cúspides del talónido se van fusionando mientras otras se reducen, pero en este caso no se observa un proceso "lineal" de Thylacosmilidae gen. 1 a Thylacosmilus, sino que ocurren dos tipos de cambio. En Thylacosmilidae gen. 1, se observan las tres cúspides bien desarrolladas. Sin embargo, el hipoconúlido no sólo está apareado con el entocónido, sino que sus bases están fusionadas formando un sólo bloque en conjunto, aunque todavía se logra diferenciar claramente el ápice de ambas cúspides, estando el del hipoconúlido ligeramente posterior al del entocónido. Este bloque lingual del talónido es comprimido lateralmente, se encuentra mucho más elevado respecto al hipocónido y presenta una pared labial vertical, por lo cual la cuenca del hipocónido presenta esa particular morfología, con su porción lingual mucho más alta y vertical que su porción labial. Esta condición es similar a la que se ve en Hondadelphys fieldsi, aunque en dicho taxón el hipoconúlido está más diferenciado (se ve más desarrollado y menos fusionado al entocónido), si bien se aprecia un bloque elevado y una pared verticalizada en la cuenca del talónido. En el caso de Anachlysictis y Patagosmilus, se ve cómo esta fusión aumenta, formando prácticamente una sola cúspide (aunque todavía se alcanza a diferenciar ligeramente el hipoconúlido) que se ubica en una posición más posterolingual (se desplaza más posteriormente respecto a Thylacosmilidae gen. 1), y también está elevada respecto al hipocónido, el cual se reduce fuertemente, estando extremadamente reducido en el $\mathrm{m} 3$. Por esta razón, es muy probable que la cúspide que se ve en el m4 sea homologable al entocónido + hipoconúlido fusionados.

Por otro lado, se observa que el talónido de Thylacosmilus está compuesto básicamente por una cúspide principal, como lo afirman Goin y Pascual (1987). Esta cúspide es bien diferenciable en los m1-3 y vestigial en el m4, aunque Goin y Pascual (1987) identifican esta cúspide vestigial del $\mathrm{m} 4$ como un talónido extremadamente reducido que, aparentemente, no presenta cúspide alguna, lo cual sería una interpretación que no se descarta dada la dificultad para establecer homologías en una estructura tan reducida. Estos autores no mencionan a qué cúspide podría ser homologable aquella presente en los m1-3. Posteriormente, Forasiepi (2009) codifica en su matriz la ausencia del hipocónido, la presencia del hipoconúlido y de un entocónido vestigial. A partir de esta codificación se entiende que se está asumiendo una homología en la cual el hipoconúlido sería esta cúspide principal del talónido. En la presente revisión se observó que se presenta una cúspide principal en una posición posterior, pero además se presenta una cúspide extremadamente reducida, casi vestigial, en posición lingual, que dada su ubicación podría ser homologable a un entocónido, tal como lo codificó Forasiepi (2009). Puede observarse que, en esta especie, está ocurriendo un proceso opuesto al que ocurre en Anachlysictis y Patagosmilus, ya que el entocónido no es la cúspide dominante, sino que se reduce fuertemente hasta casi desaparecer. Adicionalmente, se presenta una cresta que se dirige desde la cúspide principal del talónido hacia la base del trigónido, cuya asignación corresponda, más probablemente, la crístida oblicua. 
Sin embargo, es necesario aclarar la homología de la cúspide principal en Thylacosmilus, ya que podría tratarse de un hipoconúlido (tal como fuera codificado por Forasiepi, 2009) o de un hipocónido que se desplazó a una posición más posterior. Para intentar establecer esta homología se tuvo en cuenta el planteamiento que realizan Goin et al. (2007a) sobre las homologías del talónido en algunos borienoideos (que en ese momento se agrupaban en "Borhyaeninae" y "Prothylacyninae", dentro de la familia Borhyaenidae; téngase en cuenta que esta clasificación ya no es válida). Estos esparasodontes también presentan una gran reducción en el talónido (rasgo relacionado con la carnivoría), que en formas más especializadas preserva, básicamente, una cúspide principal posterior. Después de realizar un análisis observando formas plesiomórficas y derivadas, Goin et al. (2007a) llegaron a la conclusión de que en los "protilacininos" la cúspide principal del talónido era homologable al hipocónido, mientras en los "borieninos" sería el entocónido (o entocónido + metacónido). Con esto no se pretende establecer una relación entre los tilacosmílidos y alguno de estos grupos, sino simplemente entender el espectro de variación de estas estructuras en otros esparasodontes con especializaciones orientadas a la carnivoría. Asumiendo que la cúspide extremadamente reducida en el margen lingual del talónido de Thylacosmilus corresponde al entocónido y teniendo en cuenta que la crístida oblicua conecta con la cúspide principal del talónido (contrario a lo que ocurre por ejemplo en Dukecynus magnus), la hipótesis más probable es que la cúspide principal corresponda en realidad al hipocónido, que se desplazó a una posición posterior, y que el hipoconúlido desapareció o incluso se fusionó con alguna de las otras dos cúspides. De hecho, podría ser que una fusión entre hipoconúlido e hipocónido explicara esta posición tan posterior del hipocónido, como ocurre con el bloque entocónido + hipoconúlido de los otros tilacosmílidos, que se desplaza hacia una posición más posterior (posterolingual) en las formas más especializadas.

Es evidente que Thylacosmilidae gen. 1 y Anachlysictis son piezas claves para entender el proceso de los cambios anatómicos que conllevaron a desarrollar esa morfología tan especializada de Thylacosmilus. Por mucho tiempo fue dudosa la clasificación de Thylacosmilidae gen. 1 (ejemplar IGM 251108) dentro de los Thylacosmilidae, pero en la presente revisión se realizó una minuciosa descripción que permitió reafirmar esta hipótesis, que fue sustentada además en el análisis filogenético.

Asimismo, la redescripción del holotipo de Anachlysictis gracilis también permitió realizar comparaciones con Patagosmilus goini (que no había sido descripto cuando Anachlysictis fue publicado). En la presente revisión se pudieron observar algunos rasgos comunes entre los holotipos de estas dos especies, como lo son: el tamaño cercano; la morfología de la porción craneana donde se ubica el proceso postorbital y el punto de contacto entre los huesos frontal, lacrimal y nasal, ubicado casi sobre este proceso; la morfología del protocono de P. goini, consistente con la del talónido de A. gracilis; y la morfología casi idéntica del magnum. Desafortunadamente, entre estos dos ejemplares no se presentan elementos homólogos más allá del fragmento craneano y el magnum (e.g., no se preserva dentición superior en A. gracilis ni inferior 
en $P$. goini). Forasiepi y Carlini (2010) habían advertido la similitud entre estas dos especies, pero aún así, deciden proponer un nuevo taxón con base en algunas diferencias, mayormente basadas en rasgos inferidos para estructuras no preservadas en $A$. gracilis. (i.e., la pronunciada curvatura en forma sigmoide de la hilera dentaria superior en $P$. goini, menos marcada en la hilera inferior de $A$. gracilis; la distancia entre la cavidad glenoidea y el final de la postmetacrista en el M3, más corta en $P$. goini y $T$. atrox que en otros esparasodontes, mientras que en $A$. gracilis esta distancia sería mayor que en estos tilacosmílidos y similar a la de los demás esparasodontes, infiriéndose a partir de la distancia entre el cóndilo del dentario y la preprotocrístida del m4; y el canino superior de A. gracilis sería más pequeño que el de $P$. goini, inferido a partir del desarrollo del proceso sinfisario de la mandíbula), afirmando que la morfología de $P$. goini sería más derivada y más cercana a la de Thylacosmilus que a la de Anachlysictis.

Uno de los rasgos que destacan estos autores y que sí es observable directamente, es la marcada morfología sigmoide de la hilera dentaria superior de Patagosmilus, más marcada que aquella observada en la hilera inferior de Anachlysictis, aunque en la presente revisión se pudo observar que es menos marcada que en Thylacosmilus. Esta morfología sigmoide tan marcada puede observarse tanto en la hilera dentaria superior como en la inferior y el dentario del ejemplar B:p2-154 (véase Anexo 1.1, Patagosmilus goini), donde está claramente más marcada que en Anachlysictis. Este material fue mencionado pero no descripto por Goin y Carlini (1993), comparándolo con el ejemplar que unos años después sería designado como el holotipo de Anachlysictis gracilis (Goin, 1997) y el que sería posteriormente el holotipo de P. goini (Forasiepi and Carlini, 2010), y sugiriendo que los tres ejemplares pertenecerían a una misma especie o al menos a especies estrechamente relacionadas. En la presente revisión se logró determinar que este material es referible a $P$. goini, con base en la morfología de la dentición superior y la marcada morfología sigmoide de la hilera dentaria (tanto superior como inferior). De no ser porque se encontraba preservada la dentición superior y por la marcada morfología sigmoide de la inferior (y el dentario), este ejemplar hubiera sido referido a $A$. gracilis, ya que la morfología de los molares inferiores es casi idéntica a la de esta especie, siendo esto es aún más evidente en el talónido (discutido más arriba).

Las similitudes en los rasgos craneanos y dentarios observados entre estos dos taxones, sumados a su cercanía en tamaño (véase Análisis Ecomorfológico) y a la morfología casi idéntica del magnum, sugieren que estos estarían estrechamente relacionados. Esta cercanía es reflejada en los resultados del análisis filogenético, que muestran a estas especies como taxones hermanos. Las pocas diferencias entre estos taxones quizá sean suficientes para clasificarlos como dos especies diferentes. Sin embargo, observando el gran número de similitudes, no se descarta que en realidad estos dos taxones puedan clasificarse al menos dentro del mismo género. 
BORHYAENOIDEA, fam. et gen. incertae sedis

(?Borhyaenidae; Fig. 4.23)

Los ejemplares descriptos a continuación presentan una morfología que no es consistente con la de ningún borienoideo registrado para La Venta y aparentemente tampoco con la de ningún otro borienoideo no boriénido entre los revisados en este estudio. Adicionalmente, la morfología globosa y robusta de ambos ejemplares es más consistente con la de los boriénidos. Sin embargo, dado que la evidencia es tan escasa para poder realizar una asignación taxonómica más precisa, estos ejemplares se clasificaron como Borhyaenoidea fam. et gen. incertae sedis (?Borhiaenidae). Debido a esta dudosa asignación, no fueron tenidos en cuenta en los conteos de especies discutidos en el capítulo 10.

\section{IGM 250475}

Material—Fragmento de maxilar con el P1 derecho (Fig. 4.23A).

Localidad y Estratigrafía_-Localidad 106 (Universidad de Duke), área de La Venta; unidad entre las Capas de Arenisca de Tatacoa y Capas de Conglomerado de Cerbatana, Formación La Victoria, Grupo Honda (Tablas 3.1 y 4.1; Fig. 3.1).

Medidas-Tabla 4.2.

Comentarios-Goin (1997) clasifica este ejemplar como "Sparassodonta, fam. et gen. indet.". Por la orientación de las raíces, muy inclinadas anteriormente, se puede deducir que el premolar preservado se trata de un P1. Es de gran tamaño y presenta unas raíces muy globosas, dándole una apariencia bastante robusta. Goin (1997) comenta que el gran tamaño del espécimen y el robusto y globoso P1 sugieren que tal vez se trate de un boriénido de gran tamaño. Sin embargo, agrega que este diente se encuentra implantado en línea con la hilera dentaria (no oblicuo) y que esta no es la condición que comúnmente se presenta en este grupo. En la clasificación propuesta en este trabajo se incluye a este ejemplar dentro de los Borhyaenoidea para diferenciarlos de los hatliacínidos y esparasodontes basales, ya que claramente no entra dentro del rango de dimensiones de los premolares de esos taxones, los cuales son más pequeños y gráciles. Entre los borienoideos existen varios taxones que presentan una implantación similar (e.g., Lycopsis y los thylacinidos), paralela o casi paralela a la hilera dentaria (i.e., en ángulo menor a 19: carácter 119 en el análisis filogenético). Sin embargo, ninguno de estos presenta esas raíces tan globosas y robustas.

\section{KU 2000-1}

Material—Canino inferior (Fig. 4.23B).

Localidad y Estratigrafía-Localidad Ventana (Universidad de Kioto), área de La Venta; nivel desconocido del Grupo Honda.

Medidas-Tabla 4.4.

Comentarios-Se trata de un canino inferior de un borienoideo de gran tamaño, bastante 
robusto y con la raíz globosa. La porción extraalveolar cubierta por esmalte es ancha y corta (no alargada como en Lycopsis). Presenta una morfología más cercana a la de los boriénidos que a la de los borienoideos presentes en La Venta, ya que es mucho más robusto.

\section{Sparassodonta, fam. incertae sedis}

(Fig. 4.24A-B)

\section{IGM 184041-B}

Material-Elementos apendiculares (huesos largos).

Localidad y Estratigrafía-Localidad 49 (Universidad de Duke), área de La Venta; niveles fosilíferos por debajo de las Capas de Arenisca de Cerro Gordo, Formación La Victoria, Grupo Honda (Tablas 3.1 y 4.1; Fig. 3.1).

Comentarios-Goin (1997: pág. 198) señaló que estos restos se encontraban asociados al ejemplar IGM 184041, pero aparentemente pertenecían a un taxón diferente, correspondiente a un esparasodonte de gran tamaño. Debido a que no se tuvo acceso a dicho material, se lista en esta sección, ya que por el momento no se tiene certeza acerca de su clasificación, pero se consideró necesario reportarlo.

\section{KU 1995-1-B}

Material-Fragmento labial M2? derecho (Fig. 4.24A).

Localidad y Estratigrafia_-Localidad desconocida en el área de La Venta; Grupo Honda.

Comentarios - El fragmento preserva toda la plataforma estilar, el metacono y paracono. El metacono es subigual (ligeramente más grande) al paracono. Tiene una ubicación ligeramente lingual al paracono (como en Cladosictis). El paracono y metacono son cónicos y sus bases están unidas. La postmetacrista está bien desarrollada. El cíngulo anterior es vestigial. La plataforma estilar es vestigial en su porción labial al paracono y está fuertemente reducida posterior a este.

La StA está presente y bien diferenciada; la StC está reducida y se conecta con un pequeño ectocíngulo que se extiende posteriormente hasta la posición que correspondería a la StD, pero esta cúspide no está diferenciada, contrario a lo que ocurre con la $\mathrm{C}$, que sí está claramente definida.

El tamaño es cercano al de Hondadelphys fieldsi. Sin embargo, difiere de este en que la plataforma estilar está más reducida, las bases del para- y metacono están apareadas, el paracono es más grande, el ectocíngulo posterior más reducido, metacono ubicado más labialmente (aunque sigue siendo ligeramente lingual al paracono).

Comparado con Cladosictis, el para- y el metacono están ligeramente más separados, la postmetacrista está menos desarrollada, la plataforma estilar más reducida, al igual que la StA. El ectocíngulo posterior es similar al de Cladosictis lustrata pero en el ejemplar KU 1995-1-B está ligeramente más extendido posteriormente. 
No se conocen molares superiores de Thylacosmilidae gen. 1, pero es consistente en tamaño con este, por lo que no se descarta que se trate de un molar superior de esta especie.

\section{KU 2000-4-A}

Material—m1 derecho (Fig. 4.24B).

Localidad y Estratigrafía-Localidad El Cuzco (Universidad de Kioto), área de La Venta; unidad Capas Rojas de La Venta, Formación Villavieja, Grupo Honda (Tablas 3.1 y 4.1; Fig. 3.1).

Medidas-Tabla 4.5.

Comentarios-Se trata de un molar de un esparasodonte pequeño, de tamaño similar al de Hondadelphys fieldsi. Sin embargo, su morfología es ligeramente diferente a la del trigónido del m1 de IGM 253079 (el único ejemplar asignado sin dudas a Hondadelphys fieldsi que preserva el trigónido), ya que en el ejemplar KU 2000-4-A el paracónido está mucho más reducido respecto al protocónido, y se diferencia de IGM 253050 (único ejemplar de Hondadelphys fieldsi disponible en esta revisión que preserva el talónido — y la raíz anterior - del m1) en que en el ejemplar KU 2000-4-A el talónido está más reducido y el trigónido es más largo respecto al talónido.

También es comparable en tamaño y morfología con el ejemplar IGM 250364 (Hondadelphys sp. 2), destacando que ambos presentan un metacónido vestigial en el m1, pero en este último el talónido está aparentemente más desarrollado (más ancho y largo), siendo el trigónido más corto que en el ejemplar KU 2000-4-A respecto al talónido. Ya se descartó que el ejemplar IGM 250364 se trate de Thylacosmilidae gen. 1 (ver comentarios arriba: Hondadelphys sp. 2). No son muchos más los rasgos comparables con dicho ejemplar debido al mal estado de preservación que presenta.

Por otro lado, el ejemplar KU 2000-4-A es, en general, similar en morfología a Thylacosmilidae gen. $1 \mathrm{sp}$. 1. Sin embargo, se diferencian en que este último es ligeramente más grande y presenta un precingúlido y un postcingúlido labial bien desarrollados, mientras que en el ejemplar KU 2000-4-A el precingúlido está extremadamente reducido y no se presenta el postcingúlido labial. Un rasgo para destacar es que el ejemplar KU 2000-4-A tiene un metacónido vestigial. La presencia o ausencia de esta cúspide no es observable en el holotipo de Thylacosmilidae gen. 1 sp. 1 debido a la preservación del material. Entre los esparasodontes revisados en este estudio (Anexo 1.1) no se encontró ningún caso en el que el metacónido estuviera presente sólo en el m1. Sin embargo, sí se observó que la presencia o ausencia de metacónido puede variar entre especies de un mismo género (e.g., Lycopsis longirostrus que presenta metacónido al menos en los m2-4, mientras que está ausente en las demás especies que preservan dentición inferior). Podría darse el caso que se trate de otra especie de Thylacosmilidae gen. 1, que presenta un metacónido vestigial. El talónido del Thylacosmilidae gen. $1 \mathrm{sp} .1$ es absoluta y relativamente (respecto al trigónido) más reducido, y el trigónido es absoluta y relativamente más largo. La cuenca del talónido es más amplia y profunda en el ejemplar KU 2000-4-A, el hipocónido es más alto, y el hipoconúlido está más desarrollado y más diferenciado del entocónido 
(en Thylacosmilidae gen. 1 sp. 1 es casi indiferenciable).

A que a pesar de que el ejemplar KU 2000-4-A tiene muchas similitudes con Thylacosmilidae gen. 1, no existen materiales suficientes para determinar si las diferencias entran dentro del rango de variabilidad de este taxón. Adicionalmente, la similitud con el ejemplar IGM 250364 (Hondadelphys) hace dudar la clasificación de KU 2000-4-A como Thylacosmilidae.

\section{METATHERIA indet.}

(?Sparassodonta; Fig. 4.24C)

\section{KU LV-2-C}

Material—Fragmento anterior de un trigónido.

Localidad y Estratigrafía-El Cuzco - Tasajera (Universidad de Kioto), área de La Venta; Formación Villavieja, Grupo Honda.

Comentarios-Es un fragmento de trigónido que preserva el paracono y la mitad anterior de la base del protocono. Por el tamaño (largo: 5,6 mm; ancho: 4,35 mm) podría tratarse de un esparasodonte pequeño o un Didelphimorphia de gran tamaño. Entre los esparasodontes hasta ahora descriptos para La Venta es comparable en tamaño con Hondadelphys o Thylacosmilidae gen. 1. Sin embargo, no se puede hacer una aproximación taxonómica a partir de una porción tan fragmentaria. 


\section{ANÁLISIS FILOGENÉTICO}

Para el análisis filogenético de los esparasodontes de La Venta se tuvieron en cuenta no sólo los holotipos sino también algunos materiales referidos, lo que permitió realizar una codificación más completa de los taxones (ver Anexo 1.1). Este análisis incluye la mayoría de los taxones de La Venta, excepto aquellos cuyo material es muy escaso o se encuentra muy pobremente preservado (e.g., un posible hatliacínido y un posible boriénido), siendo así el análisis más inclusivo y completo que se ha hecho hasta el momento para los esparasodontes de esta asociación.

El análisis incluye un total de 47 taxones de metaterios, entre los cuales 27 son esparasodontes. El taxón outgroup seleccionado fue Deltatheridium pretrituberculare, ya que la codificación en la matriz estaba mucho más completa que la de Deltatheroides cretacicus. También se incluyeron algunos metaterios basales, algunos representantes del grupo corona Marsupialia y otros metaterios no esparasodontes (Anexo 1.1). Entre los esparasodontes de La Venta, se incluyó a Hondadelphys fieldsi, Lycopsis logirostrus, Dukecynus magnus, Thylacosmilidae gen. 1 sp. 1 (gen. et sp. nov.) y Anachlysictis gracilis. Adicionalmente, se incluyó a Thylacosmilidae gen. 2 sp. 1, que corresponde un nuevo género y especie de tilacosmílido que actualmente está siendo descripto sobre la base de un ejemplar colectado en la Formación Arroyo Chasicó, Argentina (Anexo 1.1, Thylacosmilidae; Suarez et al., in prep.). La lista completa de los taxones incluidos y materiales revisados se presenta en el Anexo 1.1.

La matriz utilizada para este análisis corresponde a aquella confeccionada por Forasiepi (2009), modificada posteriormente en otros estudios (i.e., Engelman y Croft, 2014; Forasiepi et al., 2015; Suarez et al., 2016) y en el presente análisis. En esta versión de la matriz se realizaron modificaciones en la codificación y se agregaron o modificaron algunos taxones (Anexo 1.2), a saber: se cambió Hondadelphys fieldsi por Hondadelphys spp., ya que en la codificación también se tuvieron en cuenta aquellos ejemplares de Hondadelphys que, claramente, pertenecen a otra especie diferente de $H$. fieldsi (i.e., ejemplares IGM 250364 e IGM 184041); se agregaron tres taxones de tilacosmílidos (i.e., Anachlysictis gracilis, Thylacosmilidae gen. 1 sp. 1 y Thylacosmilidae gen. 2 sp. 1); y se agregó a Dukecynus magnus, que no había sido utilizado en ningún análisis previo. Se dejaron todas las especies de Lycopsis, que habían sido agregadas para la publicación de Suarez et al. (2016), debido a la presencia de este género en La Venta y porque se realizaron algunos cambios en la codificación posteriores a dicha publicación, por lo cuál se consideró importante evaluar si dichos cambios alteraban de alguna forma la monofilia del grupo. Tal como ocurrió en análisis previos, se excluyó a Thylacinus cynocephalus del análisis, debido a la gran cantidad de convergencias que presenta con los esparasodontes. En el Anexo 1.1 se presenta una lista de los taxones y el material correspondiente revisado para el presente análisis.

La matriz está compuesta de 317 caracteres, incluyendo 113 caracteres craneanos (1-107 y 308-313), 84 dentarios (108-187 y 314-317) y 120 postcraneanos (188-307). A los nuevos caracteres presentados en el trabajo de Suarez et al. (in prep.: i.e., caracteres 308-316) se agregó 
uno más (el carácter 317). 52 de los caracteres se tomaron como ordenados: a los 49 de la versión más reciente de la matriz se sumaron 3 (i.e., 312, 316 y 317), que corresponden a caracteres basados en rasgos de los tilacosmílidos. A todos los caracteres se les dio el mismo peso. Los cambios realizados en la matriz, incluyendo modificaciones en la descripción de los caracteres o sus estados, nuevos estados y cambios en la codificación, se muestran en el Anexo 1.2. La lista completa de caracteres se presenta en el Anexo 1.3.

La matriz fue editada en el programa Mesquite versión 3.3 (Maddison y Maddison, 2017). El análisis se llevó a cabo por medio de búsquedas eurísticas realizadas usando el programa TNT 1.1 (Goloboff et al., 2008). Los árboles iniciales fueron obtenidos a partir de 1000 replicas aleatorias. Los árboles de Wagner resultantes fueron tratados como dicotómicos y se les aplicó el método de intercambio de ramas (branch swaping) con bisección del árbol y reconexión (TBR).

\section{Resultados del análisis}

Se hallaron cuatro árboles más parsimoniosos (Figs. 4.25-4.28), todos ellos con una longitud de 1075 pasos, un índice de consistencia (CI) de 0,370 y un índice de retención (RI) de 0,683. A partir de estos se obtuvo un árbol de consenso estricto (Fig. 4.29) con una longitud de 1109 pasos, $\mathrm{CI}=$ 0,359 y $\mathrm{RI}=0,667$. Las sinapomorfías para cada uno de los nodos del árbol de consenso se muestran en el Anexo 1.5 (Fig. A1.1 y Lista de sinapomorfías).

Se calcularon los soportes de Bremer para los diferentes grupos obtenidos en el árbol de consenso (Fig. 4.30). El tipo de soporte elegido fue el absoluto y colapsaron aquellos nodos con soporte 0 . Como resultado se obtuvo que 8 de los grupos presentan soporte de 5 o más, 10 grupos con soporte 3 y 20 grupos con valores inferiores a 3, incluyendo un grupo con soporte 0 , por lo cual el nodo colapsó (nodo 51).

En general, los agrupamientos se mantienen entre los diferentes árboles más parsimoniosos y las únicas variaciones entre ellos son la ubicación de Alphadon, y la relación entre Paraborhyaena boliviana y Callistoe vincei (véase más abajo). En el presente análisis, los estagodóntidos (i.e., Didelphodon y Eodelphis) aparecen en todos los árboles como el grupo hermano de Sparassodonta. Sin embargo, este grupo (Stagodontidae + Sparassodonta) es justamente el nodo que colapsó en la búsqueda de los Soportes de Bremer (i.e., tenía sporte 0), indicando que que esta relación no tiene soporte alguno en este análisis. Los estagodóntidos ya habían sido considerados como un grupo estrechamente relacionado con los esparasodontes (e.g., Marshall et al., 1990), pero esta idea ha sido fuertemente debatida ya que dicha relación se basa en caracteres homoplásicos asociados a la carnivoría (Fox y Naylor, 1995; Rougier et al., 1998; Forasiepi, 2006, 2009). Recientemente Wilson et al. (2016) publicaron la revisión de un material craneano bastante completo de Didelphodon, lo que permitió reconocer rasgos hasta ese momento desconocidos. Tanto la descripción como la codificación de caracteres realizados por Wilson et al (2016), fueron tenidos en cuenta para codificar muchos caracteres faltantes en la matriz del presente análisis filogenético 
(Anexo 1.2).

El agrupamiento general dentro de Sparassodonta se mantiene en todos los árboles, mostrando, además de los esparasodontes más basales (i.e., Patene, Hondadelphys y Stylocynus), dos clados principales: Hathliacynidae y Borhyaenoidea. El clado Hathliacynidae aparece completamente resuelto y la relación entre sus taxones difiere de otros análisis previos en los que se usó esta misma matriz (i.e., Forasiepi, 2009; Engelman y Croft, 2014; Forasiepi et al., 2015; Suarez et al., 2016). En esta distribución aparece Cladosictos + Acyon como grupo hermano de Sipalocyon + Notogale, y Sallacyon como taxón basal del grupo.

Dentro de clado Borhyaenoidea, el género Lycopsis aparece en una posición basal, lo cual es consistente con los análisis previos mencionados, mientras que los Borhyaenidae son el grupo más derivado. La relación de Callistoe vincei y Paraborhyaena boliviana varía entre los diferentes árboles más parsimoniosos: en dos de ellos (árboles 2 y 3: Figs. 4.26 y 4.27), Callistoe vincei y Paraborhyaena boliviana conforman un grupo monofilético, grupo hermano de Borhyaenidae; en los otros dos árboles (1 y 4: Figs. 4.25 y 4.28), conforman un grupo parafilético basal a Borhyaenidae. En este análisis no se recupera a Thylacosmilidae como grupo hermano directo de Callistoe y Paraborhyaena (contra Babot et al., 2002; Forasiepi, 2009; Engelman y Croft, 2014; Forasiepi et al., 2015; y Suarez et al., 2016), sino que se ubica en una posición más basal.

Al igual que en el análisis de Suarez et al. (2016), en este análisis se usaron todas las especies de Lycopsis y el resultado mostró igualmente un grupo monofilético, a pesar de algunos cambios que se realizaron en la codificación, posteriores a dicha publicación (Anexo 1.2, Cambios en la codificación). En todos los árboles obtenidos Lycopsis padillai es el taxón hermano de L. torresi, el taxón hermano de $L$. padillai $+L$. torresi es $L$. viverensis, y L. longirostrus es el taxón hermano de todos ellos, siendo la especie más basal del grupo a pesar de no ser la más antigua (ver Discusión: Implicaciones paleobiogeográficas y cronoestratigráficas).

En La Venta se registran dos géneros de tilacosmílidos, ambos monoespecíficos: Anachlysictis (Goin, 1997) y Thylacosmilidae gen. 1 (este trabajo). En el presente análisis se buscaba testear la relación que existe entre las dos especies de tilacosmílidos de La Venta (i.e., $A$. gracilis y Thylacosmilidae gen. 1 sp. 1) y los demás tilacosmílidos, y adicionalmente, corroborar que Thylacosmilidae gen. 1 sp. 1 en efecto pertenece a dicha familia, hipótesis que surgió a partir del análisis morfológico y que ya había sido planteada por Goin (1997). Es por esto que, además de dichas especies, en el análisis se incluyeron las demás especies de tilacosmílidos reconocidas hasta el momento (i.e., Thylacosmilus atrox y Patagosmilus goini) y una nueva especie cuya publicación se encuentra en preparación (i.e., Thylacosmilidae gen. 2 sp. 1; Anexo 1.1).

Los resultados del presente análisis filogenético soportan la monofilia de Thylacosmilidae, así como la inclusión de Thylacosmilidae gen. 1 sp. 1 dentro de esta familia. El taxón más basal del grupo es Thylacosmilidae gen. 2 sp. 1 (proveniente de la Formación Arroyo Chasicó, Argentina; Anexo 1.1), seguido de Thylacosmilidae gen. 1 sp. 1, mientras T. atrox se ubica como taxón hermano de $P$. goini y A. gracilis. Sin embargo, la morfología Thylacosmilidae gen. 2 sp. 1 no es 
del todo plesiomórfica, sino que presenta una combinación de rasgos muy particular, con algunos caracteres plesiomórficos en la porción anterior de la mandíbula (i.e., en el dentario y dentición anterior a los molares) y una morfología bastante derivada en los molares, incluso más derivada que en $P$. goini y $A$. gracilis (e.g., paracónido bajo y confluente con el cungúlido anterior; la cuenca del talónido más reducida; el entoconido e hipoconulido completamente fusionados). Esto sugiere que se diferenció tempranamente del grupo y retuvo algunos rasgos plesiomórficos en el dentario (ver Discusión: Implicaciones paleobiogeográficas y cronoestratigráficas). Por otro lado, en los demás tilacosmílidos se observa un claro proceso evolutivo en la morfología del dentario y la dentición general, en los cuales T. atrox presenta los rasgos más derivados del grupo, aunque también presenta algunas diferencias particulares en la dentición (e.g., homologías de las cúspides del talónido; ver Comentarios generales sobre Thylacosmilidae en la Revisión Taxonómica). El presente análisis también soporta la estrecha relación entre $P$. goini y A. gracilis, ya que se recuperan como taxones hermanos, siendo esto congruente con las similitudes encontradas entre estos taxones en el análisis morfológico (véase Comentarios generales sobre Thylacosmilidae). Muchas de estas similitudes se observaron en comparaciones con el ejemplar identificado como B:p2-154, proveniente de Río Rosario, una localidad cercana a Quebrada Honda (véase Anexo 1.1, Patagosmilus goini), que es claramente referible a $P$. goini y por lo tanto fue utilizado para completar parte de la codificación de esta especie en la matriz del presente análisis.

El esparasodonte más grande de La Venta, Dukecynus magnus, fue incluido por primera vez en un análisis filogenético. Debido a la pobre preservación del holotipo y único ejemplar disponible de esta especie, fueron pocos los caracteres que pudieron ser codificados dentro de la matriz. Sin embargo, fueron suficientes para obtener una posición filogenética clara, constante en todos los árboles obtenidos. D. magnus se encuentra estrechamente relacionado (como taxón hermano) a un grupo monofilético conformado por Callistoe vincei, Paraborhyaena boliviana y Borhyaenidae. Goin (1997) había sugerido la relación de D. magnus con los "protilacininos", habiéndolo clasificado dentro de esa subfamilia (para ese entonces válida). Los taxones estudiados en el presente análisis y que en ese entonces eran incluidos en dicho grupo (i.e., Lycopsis, Prothylacynus patagonicus, Pharsophorus lacerans y Dukecynus magnus ), aquí se encuentran conformando un grupo polifilético. 


\section{ANÁLISIS ECOMORFOLÓGICO}

\section{Masa corporal}

Las estimaciones de masa corporal de los esparasodontes de La Venta se realizaron con base en variables independientes, correspondientes a medidas tomadas en la dentición (Tabla 4.6). Al momento de elegir la variable más adecuada para la estimación de la masa corporal se tuvieron en cuenta los parámetros utilizados para medir la bondad del ajuste de cada ecuación (i.e., \%PE, error de predicción porcentual; \%SEE, error estándar porcentual de la estimación; y $\mathrm{R}^{2}$, Coeficiente de Determinación; ver Materiales y Métodos).

Se realizaron estimaciones basadas principalmente en dos grupos de ecuaciones. El primero de ellos corresponde a las ecuaciones construidas por Zimicz (2012), que son una adaptación de aquellas de Gordon (2003), construidas sobre la misma base de datos que incluye marsupiales generalizados de las familias Didelphidae y Dasyuridae. El segundo grupo de ecuaciones corresponde a aquellas provenientes de la base de datos de dasyuromorfos de Myers (2001). El procedimiento que se llevó a cabo para realizar las estimaciones de masa corporal es detallado en la sección de Materiales y Métodos (Parte I).

Las mejores variables predictivas contempladas en el presente análisis se encuentran dentro del set de ecuaciones de Zimicz (2012) y corresponden al largo del M2, para la dentición superior, y el largo del m3, para la dentición inferior. Sin embargo, estos molares no se preservan en todos los ejemplares estudiados en la presente revisión, por lo cual para cada caso se utilizó la mejor variable disponible según la preservación del material, que no siempre corresponde a aquella con mejores indicadores de bondad del ajuste. Las estimaciones seleccionadas se presentan en la Tabla 4.7 (ver otras estimaciones en la Tabla 4.8).

En el presente análisis se siguieron las categorías de masa corporal para mamíferos carnívoros propuestas por Prevosti et al. (2013): tamaño pequeño para masa corporal por debajo de $7 \mathrm{~kg}$; mediano, entre 7 y $15 \mathrm{~kg}$; y grande, por encima de $15 \mathrm{~kg}$. Según los resultados obtenidos en la estimación de masa corporal (Tabla 4.7), 5 especies de esparasodontes de La Venta se encuentran dentro de la categoría de tamaño corporal pequeño: Hondadelphys fieldsi, las dos posibles nuevas especies de Hondadelphys, Thylacosmilidae gen. 1 sp. 1 y el hatliacínido. Este último, con una estimación de 3,16 kg, es el esparasodonte más pequeño de La Venta. Las demás especies se encuentran dentro de la categoría de tamaño corporal grande, estando algunos incluso por encima de los $40 \mathrm{~kg}$ (como L. longirostrus y D. magnus). La especie más grande hasta ahora reportada en La Venta es D. magnus, cuya masa corporal estimada es de aproximadamente $50 \mathrm{~kg}$. En este análisis se constató el amplio rango de tamaño corporal que presenta el género Lycopsis, encontrándose entre los 18 y los $40 \mathrm{~kg}$ aproximadamente.

Entre las especies de Hondadelphys los resultados muestran que H. fieldsi presenta mayor masa corporal que Hondadelphys sp. 1, lo cual concuerda con las proporciones observadas a 
simple vista en el análisis morfológico. Por otro lado, la masa corporal estimada para Hondadelphys sp. 2 es mayor que la estimada para las otras dos especies. Sin embargo, este resultado no refleja las proporciones observadas en el material estudiado, ya que esta nueva especie aparentemente es al menos más chica que H. fieldsi. Para la estimación de masa corporal de Hondadelphys sp. 2 se utilizó el largo del m1 como variable independiente. Dicha estimación presenta un valor de $\% \mathrm{PE}$ bastante alto (i.e., 27,00) respecto a las dos estimaciones realizadas para H. fieldsi $(\% \mathrm{PE}=7,03$ y 12,82$)$ y aquella realizada para Hondadelphys sp. $1(\% \mathrm{PE}=7,03)$, lo cual podría explicar esta incongruencia en los datos obtenidos. Aún así, no fue posible realizar otra estimación usando una mejor variable debido al pobre estado de preservación del material.

Los tilacosmílidos de La Venta se encuentran dentro de un rango de tamaño intermedio respecto a los demás tilacosmílidos, ya que Thylacosmilidae gen. $1 \mathrm{sp} .1$ es de mayor tamaño que Thylacosmilidae gen. 2 sp. 1, el tilacosmílido más pequeño reportado hasta el momento, y Anachlysisctis gracilis es más chico que Thylacosmilus atrox, el tilacosmílido más grande. Además de las estimaciones realizadas utilizando la mejor variable predictora disponible para cada caso (Tabla 4.7), se realizaron estimaciones adicionales para todas las especies conocidas de tilacosmílidos (Tabla 4.8). En todas las estimaciones (Tablas 4.7 y 4.8 ) se muestra que $A$. gracilis es notoriamente más grande que Thylacosmilidae gen. $1 \mathrm{sp}$. 1, ubicándose en la categoría de tamaño corporal grande. Esta especie es ligeramente más grande que $P$. goini, si bien la diferencia de tamaño es considerablemente baja; teniendo en cuenta el amplio rango de tamaño observable en un mismo género de Sparassodonta (e.g., Lycopsis), esta diferencia no constituye un criterio confiable para diferenciar ambos taxones como géneros diferentes.

Estos datos estarían mostrando un fenómeno notable entre los esparasodontes de La Venta y es que no habría especies de tamaño intermedio (según las categorías de Prevosti et al. 2013; ver Materiales y Métodos). Esto resulta llamativo porque pareciera que existe un hiato importante en el rango de masa corporal de los metaterios de esta asociación, ya que tampoco habría especies entre los otros grupos que pudieran ocupar este "vacío" (son más pequeños). Dentro de este rango de masa corporal se ubican algunos euterios (e.g., algunos primates como Stirtonia victoriae y $S$. tatacoensis, notoungulados como Miocochilius anomopodus o incluso algunos litopternos pequeños, como Megadolodus); sin embargo, ninguno de ellos refleja en su morfología hábitos alimenticios similares a los de los esparasodontes, ya que no se reporta ningún euterio carnívoro o mesocarnívoro (ver más adelante en 'Dieta'), por lo que no estarían ocupando el mismo nicho ecológico de este grupo.

\section{Inferencias dietarias}

Se realizaron algunas inferencias dietarias para los esparasodontes de La Venta, mostrando que estarían abarcando un amplio espectro de hábitos alimenticios, desde dietas hipercarnívoras hasta dietas con tendencia a la omnivoría. Uno de los parámetros cualitativos que se usó para estimar 
estos hábitos es la forma del talónido, en la que se evalúa la presencia de adaptaciones para la carnivoría. Por ejemplo, los talónidos que presentan una sola cúspide central y sectorial son característicos de las especies hipercarnívoras (Van Valkenburgh, 1991). Por el contrario, aquellos que presentan talónidos acuencados con dos cúspides simétricas y cercanas en tamaño, son característicos de las especies más omnívoras. Aquellos casos intermedios en los que el talónido no está totalmente transformado en cuenca y en los que hay dos cúspides pero el hipocónido se encuentra en una posición labial y es mayor al entocónido, son considerados propios de las especies mesocarnívoras (Zimicz, 2012).

Si se tiene en cuenta este criterio cualitativo, la especie con la morfología más cercana a la hipercarnivoría entre los taxones de La Venta sería la de Dukecynus magnus, ya que su talónido en los m1-3, a pesar de estar menos reducido que en los boriénidos o en Thylacosmilus, no es acuencado y presenta una sola cúspide central (el hipoconúlido bien desarrollado) al menos en el $\mathrm{m} 2$ (no se preservan bien los $\mathrm{m} 1$ y $\mathrm{m} 3$ ), mientras el talónido es vestigial en el m4. Adicionalmente, el trigónido también muestra una morfología que se relaciona con la carnivoría, con el metacónido ausente y crestas bien desarrolladas y cortantes, con la paracrístida formando en vista labial y lingual un ángulo bastante abierto (entre la postparacrístida y la preprotocrístida), mucho más que en Anachlysictis, Lycopsis o cualquier otro taxón de La Venta, mostrando una tendencia a alinearse formado una cuchilla, como aquella presente en el molar carnasial de los Carnivora.

La morfología de Hondadelphys fieldsi sería claramente omnívora, con talónidos bien desarrollados y acuencados y sus cúspides bien desarrolladas, similar a la morfología de algunos didélfidos. Por otro lado, Lycopsis longirostrus presenta una morfología intermedia que podría indicar aparentemente una dieta de tipo mesocarnívora, presentando un talónido bastante reducido pero acuencado, con el hipocónido en una posición labial (en un punto medio del borde labial del talónido) y mayor al entocónido. Entre los tilacosmílidos de La Venta, Anachlysictis presenta un talónido mucho más reducido que en $L$. longirostrus en los $\mathrm{m} 1-3$, presentando una cuenca más pequeña y las cúspides bastante más reducidas, mientras que es vestigial en el $\mathrm{m} 4$, como en $D$. magnus; esto indicaría unos hábitos claramente hipercarnívoros, pero menos que en D. magnus. Por otro lado, Thylacosmilidae gen. 1 sp. 1 tendría hábitos más mesocarnívoros, presentando un talónido con desarrollo similar al de L. longirrostrus, aunque ligeramente más desarrollado respecto al trigónido.

En el presente análisis ecomorfológico se realizó el cálculo de un índice de carnivoría basado en el área relativa de molienda del m4 (RGA: ing., Relative Grinding Area; Prevosti et al., 2013, modificado de Van Valkenburgh, 1991). En los esparasodontes, el cálculo de este índice se realiza en base al último molar ya que este presenta los rasgos carnívoros más pronunciados, siendo homólogo al m1 de los euterios Carnivora (Werdelin, 1987; Prevosti et al., 2013). El índice se calcula como la raíz cuadrada de la relación entre el área de molienda (cuenca del talónido) y el largo del trigónido (véase: Materiales y Métodos). Cuando este índice se encuentra entre 0 y 0,48, el taxón es considerado hipercarnívoro; cuando se encuentra entre 0,48 y 0,54 , es considerado 
mesocarnívoro; y cuando es mayor a 0,54, es considerado omnívoro (Prevosti et al., 2013).

El cálculo de este índice se realizó para aquellas especies de La Venta que preservaban el m4 completo y que presentan un talónido con cuenca en dicho molar (i.e., Hondadelphys fieldsi, Lycopsis longirostrus y Thylacosmilidae gen. $1 \mathrm{sp} .1$ ). Aquellos taxones que no presentan cuenca en el talónido (i.e., Anachlysictis gracilis y Dukecynus magnus) fueron considerados en el presente análisis como hipercarnívoros, ya que el área de molienda sería equivalente a cero. Los resultados de los índices calculados se muestran en la Tabla 4.9.

Tanto H. fieldsi como Thylacosmilidae gen. $1 \mathrm{sp} .1$ se encontrarían dentro de la categoría de los omnívoros. Sin embargo, este último se ubica muy cerca del límite de la categoría de los mesocarnívoros. Según las observaciones realizadas en la revisión taxonómica, ambos taxones muestran rasgos derivados asociados a la carnivoría bastante desarrollados, como lo son la reducción del metacónido (ausente en Thylacosmilidae gen. 1 sp.1), un protocónido bien desarrollado y crestas del trigónido bien desarrolladas y cortantes. Sin embargo, el índice RGA calculado indica una dieta omnívora, ya que la cuenca del talónido aún se encuentra bien desarrollada (mucho más en $\mathrm{H}$. fieldsi). En el presente estudio se interpretó que este conjunto de rasgos podría estar indicando una dieta oportunista, en la que existiría una tendencia a la carnivoría, pero en caso de escasez de presas podrían consumir otro tipo de alimento, ya que su dentición presenta las características adecuadas para una dieta omnívora o no exclusivamente carnívora.

En el caso de L. longirostrus, estudios anteriores (e.g., Prevosti et al., 2013) lo han puesto dentro de la categoría de hipercarnívoro con base en el cálculo realizado sobre la dentición de $L$. torresi. Si se tomara en cuenta esa clasificación, ya que a simple vista el talónido de $L$. longirostrus presenta un desarrollo similar al de la especie tipo, sería lógico pensar que el RGA fuera similar. Sin embargo, el talónido del holotipo de $L$. torresi se encuentra fuertemente desgastado y no se observa claramente su cuenca, por lo que la medida del área de esta es muy tentativa. Caso contrario ocurre en el holotipo de L. longirostrus, en el que el talónido presenta poco o nada de desgaste. Las medidas que se tomaron en el $\mathrm{m} 4$ son aproximadas debido a que el molar no está completamente erupcionado. La medida que más error presenta es el largo del trigónido, ya que no se llega a observar el margen anterior del diente. Con estas medidas aproximadas, el índice calculado ubica a L. longirostrus dentro de la categoría de los mesocarnívoros, aunque se encontraría dentro de los valores más inferiores de este rango, acercándose a la hipercarnivoría. Esto podría interpretarse como una condición de mesocarnívoro pero con una mayor tendencia a la carnivoría.

Además del índice RGA, las observaciones en el análisis morfológico muestran que, en general, los taxones de La Venta presentan una tendencia a consumir mayormente tejidos blandos, ya que ningún taxón muestra morfologías "quiebrahuesos"; por el contrario, todos presentan mandíbulas relativamente gráciles (incluso el más grande, D. magnus), con dentarios bajos a intermedios y denticiones gráciles y cortantes, diferentes de la dentición robusta y fuertes 
mandíbulas características de los boriénidos.

Para analizar esto cuantitativamente se calculó un índice que evalúa la longitud relativa del trigónido del molar carnicero (LRTMC). Este parámetro relaciona el largo del trigónido con el largo total del molar (véase: Materiales y Métodos). Los resultados arrojados en este análisis (Tabla 4.10) muestran que Hondadelphys entraría dentro de la categoría de omnívoro, Thylacosmilidae gen. 1 sp. 1 sería mesocarnívoro, mientras que Lycopsis entraría dentro de la categoría de hipercarnívoro quiebrahuesos. Este resultado para Lycopsis (calculado con base en L. longirostrus) es algo inesperado, ya que la morfología de sus molares y mandíbula es bastante grácil, no presenta una morfología tan robusta como los típicos rompehuesos (e.g., los boriénidos). La morfología de los molares de L. longirostrus sugieren más una dieta mesocarnívora con tendencia a la hipercarnivoría, pero más de tipo comedor de carne que quiebrahuesos. He aquí la importancia de realizar análisis cualitativos, ya que muchas veces sólo los índices podrían estar mostrando información parcializada o simplemente equivocada, debido a que no se tiene en cuenta la estructura de las cúspides de cada molar y solo se basa en las dimensiones generales del este o su relación con la serie molar. Por otro lado, tanto Dukecynus como Anachlysictis presentan un talónido vestigial en el $\mathrm{m} 4$, siendo el largo del trigónido equivalente a prácticamente a la totalidad de la longitud del molar; por lo tanto, el valor del índice LRMC es casi 1, indicando que eran hipercarnívoros comedores de carne.

Todos estos resultados indican que los esparasodontes de La Venta eran más probablemente depredadores que carroñeros. Aun así, teniendo en cuenta las estimaciones de masa corporal obtenidas en esta tesis y los datos de masa corporal para otros mamíferos de La Venta publicados previamente (e.g., Kay y Madden, 1997), aparentemente no llegarían a abarcar todo el rango de presas disponible en La Venta (siguiendo a Ercoli et al., 2014; ver Materiales y Métodos), ya que no sólo existirían "vacíos" dentro del espectro de masa corporal de los esparasodontes, los mamíferos predadores de esta asociación (i.e., no se reportan especies de tamaño intermedio, sensu Prevosti et al., 2013), sino que tampoco se reportan especies de más de $50 \mathrm{~kg}$ que pudieran abarcar los tamaños de presa mayores. Aunque esto último es esperable (e.g., ocurre actualmente con los elefantes adultos, que se encuentran por fuera del rango de predación de los grandes depredadores que cohabitan con ellos), eventualmente podrían entrar dentro de este rango especies aún no reportadas. Sin embargo, es importante tener en cuenta que algunas especies de gran tamaño o con fuertes corazas (gliptodontes) o caparazones (tortugas), probablemente serían presa fácil para grandes reptiles con enormes y robustos dientes, como Purussaurus neivensis, presente en esta asociación de vertebrados. No obstante, quedaría aún sin ocupar el rango de tamaño intermedio de los predadores (sensu Prevosti et al., 2013), ya que para esta asociación no se reportan hasta ahora mamíferos carnívoros o mesocarnívoros, bien sean metaterios o euterios, que se encuentren dentro de este rango de masa corporal. 


\section{CAPÍtULO 5. DIDELPHIMORPHIA}

Los didelfimorfios representan, después de los esparasodontes, el segundo mayor grupo de metaterios para la asociación de La Venta, tanto por la cantidad de taxones como de ejemplares preservados. Sin embargo, la mayoría de las especies de este grupo están representadas por elementos dentarios aislados y algunos fragmentos mandibulares que preservan parte de la dentición. En la presente revisión se reportan nuevos materiales, incluyendo un nuevo taxón representado por un cráneo parcial, fragmentos mandibulares y dentición; además, se realiza la revisión de aquellos materiales ya publicados.

Previamente a la presente revisión habían sido reportados para esta asociación únicamente didelfimorfios que fueron referidos a la familia Didelphidae (específicamente a la subfamilia Didelphinae). En estos estudios (i.e., Goin, 1997; Marshall, 1976), fueron reconocidas para La Venta tres especies de didélfidos: Marmosa laventica (Marshall, 1976), Thylamys colombianus (Goin, 1997) y Thylamys minutus (Goin, 1997). Durante la presente tesis se realizó una revisión detallada de cada uno de los ejemplares referidos a estas especies y se encontró que algunos de estos eran referibles a taxones diferentes de los previamente asignados. Entre estos, se encontraron varios ejemplares que pertenecen a una misma especie y que son confrontables al género Tlacuatzin; otros materiales fueron identificados como pertenecientes al género Marmosa, pero claramente no son referibles a $M$. laventica y probablemente representen una nueva especie de este género.

Se estudiaron materiales inéditos alojados actualmente en las colecciones de la Universidad de Duke (su repositorio oficial es el Servicio Geológico Colombiano pero se encuentran en préstamo en la Universidad de Duke) y de la Universidad de Kioto. Entre estos, se encontraron ejemplares que pudieron ser referibles a las especies de didélfidos arriba mencionadas y otros materiales más fragmentarios que no pudieron ser claramente referidos a una especie particular (i.e., ejemplares identificados como Didelphinae indet., Didelphimorphia indet. y ? Didelphimorphia). Adicionalmente, se reporta un nuevo género para La Venta (aquel representado por elementos craneanos, mandibulares y dentición) con dos especies claramente diferenciables, el cual sería un didelfimorfio basal estrechamente relacionado con los Didelphoidea (Didelphidae + Sparassocynidae).

Se realizó un análisis filogenético con el fin de establecer las relaciones de algunos taxones de La Venta con los demás didelfimorfios. Este análisis no sólo permitió identificar a un didelfimorfio basal en La Venta, sino también confirmar las afinidades de las especies de esta asociación con los géneros referidos en la revisión taxonómica. A pesar de que en este análisis no 
se recuperaron algunos de los agrupamientos mostrados por Voss y Jansa (2009; e.g., Didelphinae, Thylamyini y Marmosini), se decidió seguir usando dicha clasificación a lo largo de esta tesis, teniendo en cuenta que es la revisión más completa realizada hasta el momento para los didélfidos actuales y que en ningún momento el presente análisis pretende reevaluar la filogenia de ese grupo, ya que para esto sería necesario un estudio mucho más detallado (que incluya caracteres morfológicos y moleculares), así como una muestra mucho más grande de material codificable.

Además del análisis filogenético se realizó un análisis ecomorfológico que permitió establecer rangos de masa corporal y categorías dietarias para los taxones de La Venta, encontrando dos rangos marcados de tamaños y hábitos alimenticios relativamente similares entre las diferentes especies, mayormente omnívoros, pero con algunas variaciones en el grado de carnivoría.

Los resultados de la presente revisión permitieron reafirmar la condición de la asociación de didelfimorfios de La Venta como un importante referente para el estudio de linajes actuales, pudiendo ser interpretada como el origen de una radiación neógena, tal como había sido prevamente sugerido por Goin (1997), ya que todas las especies de didélfidos de La Venta pertenecen a géneros con representantes vivientes y representan el registro más antiguo de estos. Por otro lado, al identificarse también un didelfimorfio basal en esta asociación, se presenta un escenario en el que La Venta representa a la vez un ejemplo tanto de "cradle" ("cuna": área de alta tasa de diversificación) como de "museum" ("museo": área de baja tasa de extinción; véase Stenseth, 1984; MacFadden, 2006; Mannion et al., 2014). Este fenómeno será tratado más adelante en la Discusión de esta tesis (Implicaciones paleobiogeográficas y cronoestratigráficas: La Venta como ejemplo de "cradle" o "museum"). 


\title{
REVISIÓN TAXONÓMICA
}

\author{
MAMMALIA Linnaeus, 1758 \\ METATHERIA Huxley, 1880 \\ DIDELPHIMORPHIA (Gill, 1872) Marshall, Case y Woodburne, 1990 \\ DIDELPHOIDEA Gray, 1821 \\ DIDELPHIDAE Gray, 1821 \\ DIDELPHINAE Gray 1827 \\ THYLAMYINI Hershkovitz, 1992
}

\section{Thylamys Gray 1843}

Especie Tipo-T. elegans Waterhouse, 1839

Especies Referidas-T. bruchi Thomas, 1921; T. citellus Thomas, 1912; T. karimii Petter, 1968; T. fenestrae Marelli, 1932; T. macrurus Olfers, 1818; T. pallidior Thomas, 1902; T. pulchellus Cabrera, 1934; T. sponsorius Thomas, 1921; T. sponsorius Thomas, 1921; T. tatei Handley, 1957; T. velutinus Wagner, 1842; T. venustus Thomas,1902 (incluyendo T. cinderella Thomas, 1902. Más información en Martin (2008, 2009), Giarla et al. (2010) y Teta et al. (2018).

Especies fósiles-T. minutus Goin, 1997 y T. colombianus Goin, 1997.

Comentarios-Para la revisión de los ejemplares de La Venta referibles Thylamys no se siguió una diagnosis en particular, ya que no se encontró una que se enfoque en caracteres dentarios (que son los preservados en estos materiales), ya que, al ser un género representado por especies actuales, la morfología externa suele ser elemento fundamental en la diagnosis, no profundizando en la morfología dentaria. Es por esto que la presente revisión se basó en descripciones de recientes revisiones de Thylamys y sus diferentes especies (e.g., Solari, 2003; Martin, 2009, 2009; Giarla et al., 2010; Voss y Jansa, 2010) y en comparaciones con materiales disponibles. En la presente tesis no se propone una diagnosis enmendada para el género a partir del análisis filogenético, ya que en este sólo se incluyeron dos especies vivientes y dos fósiles, por lo cual no es posible proponer una diagnosis para todo el género a partir de sinapomorfías recuperadas para cuatro especies.

Thylamys minutus Goin, 1997

(Fig. 5.1)

Holotipo-IGM 253042, fragmento de dentario derecho con m3-4 completos y alveolos del $\mathrm{m} 2$ con fragmentos de las raíces (Fig. 5.1A).

Ejemplares Referidos-IGM 253032, IGM 253043, IGM 253045 e IGM 253052. 
Ejemplar Tentativamente Referido-IGM 251013.

Distribución Geográfica y Estratigráfica-Área de La Venta (Desierto de La Tatacoa, Valle Superior del Magdalena, Departamento del Huila, Colombia); Grupo Honda, Laventense, Mioceno medio (Tablas 3.1 y 5.1; Fig 3.1).

Diagnosis Emendada-Una de las especies más pequeñas conocidas de Thylamys; difiere de otras especies del género en que el metacónido del m4 es reducido respecto a los m1-3, la crístida oblicua termina anteriormente debajo de la muesca carnasial de la metacrístida y el cingúlido anterior está poco desarrollado (modificada de Goin, 1997).

Medidas-Tablas 5.2-5.3.

Comentarios-Para información sobre los ejemplares IGM 251013, IGM 251232 y UCMP 108563, clasificados por Goin, 1997 como T. minutus, ver más adelante (Didelphinae indet. y Marmosini cf. Tlacuatzin).

\section{IGM 253042 (Holotipo)}

Localidad y Estratigrafía - Localidad 22 (Universidad de Duke), San Nicolás, área de La Venta (Desierto de La Tatacoa, Valle Superior del Magdalena, Departamento del Huila, Colombia); Capas del Mono, Miembro Baraya, Formación Villavieja, Grupo Honda.

Comentarios-Este ejemplar fue designado como el holotipo de T. minutus por Goin (1997). El fragmento de dentario corresponde a una porción posterior de la rama horizontal; está bastante roto y no muestra rasgos informativos. Los dos molares presentes se encuentran bien preservados. En ambos molares preservados el lóbulo posterior de la corona se ubica a un nivel más bajo que el anterior, siendo este rasgo mucho más marcado en el $\mathrm{m} 3$ y muy sutil en el $\mathrm{m} 4$. El trigónido del $\mathrm{m} 4$ es más grande que el del m3 y el talónido es más reducido. En el m3, el talónido es más ancho y ligeramente más corto que el trigónido, mientras que en el m4 es mucho más angosto que el trigónido y relativamente más corto respecto al del m3. El protocónido es la cúspide principal del trigónido, seguido en tamaño por el metacónido y el paracónido, aunque el paracónido está bien desarrollado y claramente diferenciado. Tanto el paraconido como el protoconido son triangulares en sección transversal, mientras que el metacónido es algo más circular (excepto por su cara posterior aplanada). En ambos molares preservados el metacónido se encuentra casi alineado al protocónido posteriormente, aunque con un muy ligero desplazamiento en sentido posterior (más marcado en $\mathrm{m} 4$ que en $\mathrm{m} 3$ ), haciendo que la metacristida sea ligeramente oblicua respecto al eje longitudinal del molar. El cingúlido anterior está poco desarrollado, extendiéndose sólo sobre la base del paracónido.

El talónido del m3 es casi tan largo como ancho, mientras que en el m4, el talónido es bastante más largo que ancho. El hipocónido es la cúspide principal del talónido. Es ligeramente saliente labialmente respecto al protocónido, como ocurre en la mayoría de didélfidos (excepto Chacodelphys, Lestodelphys, Lutreolina, Monodelphis, Hyperdidelphys y Thylatheridium) y se ubica en el extremo posterolabial del talónido, generando que la posthipocrístida sea perpendicular 
al eje longitudinal del diente; en vista oclusal, la posthipocrístida forma junto con la crístida oblicua un ángulo claramente definido, menor a $90^{\circ}$. El entocónido es más alto que el hipoconúlido pero más bajo que el hipocónido, y ligeramente comprimido labiolingualmente. El hipoconúlido se ubica junto al entocónido y presenta una morfología circular en vista oclusal. La crístida oblicua contacta el trigónido por debajo de la muesca carnasial en los molares preservados. La preentocrístida se orienta en sentido paralelo al eje longitudinal del diente. Se presenta un pequeño cíngulo labial al ectofléxido, que se forma donde la crístida oblicua se desvía hacia la base del trigónido.

\section{Ejemplares referidos}

\section{IGM 253032}

Material—m3 derecho (Fig. 5.1C).

Localidad y Estratigrafía-Localidad 22 (Universidad de Duke), San Nicolás, área de La Venta; Capas del Mono, Miembro Baraya, Formación Villavieja, Grupo Honda.

Comentarios-Este ejemplar fue referido a T. minutus por Goin (1997). El material está erosionado, sobre todo en el trigónido, donde se aprecia una gran ruptura al nivel del protocónido y metacónido; en consecuencia, no es posible observar algunos detalles, si bien son deducibles la morfología general y la relación entre las diferentes estructuras. El lóbulo posterior de la corona se ubica en un nivel más bajo que el anterior. El trigónido es ligeramente más largo que el talónido; el talónido es más ancho que el trigónido. El protocónido es la cúspide principal del trigónido y el metacónido es aparentemente ligeramente más grande que el paracónido, el cual está bien diferenciado y desarrollado. El metacónido presenta un muy sutil desplazamiento posterior respecto del protocónido, si bien están casi alineados posteriormente. El cingúlido anterior no se preserva completamente; aparentemente estaba poco desarrollado, extendiéndose sólo por la base del paracónido.

El talónido es casi tan largo como ancho. El entocónido está poco comprimido labiolingualmente, aparentemente es subigual o ligeramente más alto que el hipocono, aunque esta condición no es clara ya que el hipocónido está fuertemente desgastado, mucho más que el entocónido; por otra parte, el entocónido es marcadamente más alto que el hipoconúlido. El hipocónido es saliente labialmente con respecto al protocónido y se ubica en el extremo posterolabial del talónido, por lo que la posthipocrístida aparece como perpendicular al eje longitudinal del diente, como ocurre en el holotipo de T. minutus; en vista oclusal, la posthipocrístida forma junto con la crístida oblicua un ángulo menor a $90^{\circ}$. El hipoconúlido se ubica junto al entocónido y presenta una morfología circular en vista oclusal. La parte anterior de la crístida oblicua no está bien preservada, pero siguiendo la orientación de la porción posterior, aparentemente se dirige hacia la muesca carnasial de la metacrístida. La preentocrístida se orienta en sentido paralelo al eje longitudinal del diente. Se aprecia un pequeño cíngulo labial al 
ectofléxido.

Los rasgos más sobresalientes de este ejemplar son congruentes con una morfología típica de las especies de Thylamys. Sin embargo, el entocónido parece ser más alto que el del holotipo de esa especie, siendo aparentemente subigual o ligeramente más alto que el hipocónido (en el holotipo es más bajo que esa cúspide); sin embargo, el hipocónido se encuentra mucho más desgastado que el entocónido, por lo que cabe la posibilidad de que esta no sea la condición original. Cabe resaltar que, a excepción de este rasgo en duda, todos los demás rasgos son similares a los de T. minutus (e.g., orientación de la crístida oblicua, orientación de la posthipocrístida y ubicación del hipocónido, ubicación del metacónido respecto al protocónido, desarrollo del cingúlido anterior) y por esto se decidió que, momentáneamente, el ejemplar IGM 253032 se mantiene como referido a la misma especie que el ejemplar IGM 253042, ya que es la morfología que más se aproxima entre la diversidad de formas presentes en La Venta.

\section{IGM 253043}

Material-Fragmento de mandíbula derecha con raíces de p2, p3 completo y $\mathrm{m} 1$ casi completo.

Localidad y Estratigrafía-Localidad 22 (Universidad de Duke), San Nicolás, área de La Venta; Capas del Mono, Miembro Baraya, Formación Villavieja, Grupo Honda.

Comentarios-Este ejemplar fue encontrado entre el material que actualmente se encuentra en la Universidad de Duke. No hay ninguna referencia sobre este material en la revisión de Goin (1997). En dicha publicación aparece mencionado un ejemplar con un número similar (IGM 253045), colectado en la misma localidad y clasificado por el autor como T. minutus; dicho ejemplar no fue encontrado en ninguna de las colecciones visitadas para la realización de esta tesis. Al momento de realizar esta revisión se pensó que podría tratarse del mismo ejemplar y que hubiese un error de tipificación en la numeración. Sin embargo, dicho material es descripto por Goin (1997) como un "fragmento de mandíbula derecha con raíces de p2 y m1, y el p3 roto", lo cual no coincide exactamente con lo preservado en el ejemplar IGM 253043. Una alternativa es que se trata del mismo ejemplar y que con posterioridad a la revisión de Goin (1997) se le hayan adosado el p3 y el fragmento faltante del $\mathrm{m} 1$, ausentes hasta dicha revisión. En ausencia de información más concluyente, en este trabajo se considera que se trata de dos ejemplares independientes. La preservación del material es pobre y los dientes presentes no corresponden a ningún locus observable en el holotipo de T. minutus, por lo que no es posible realizar una comparación morfológica detallada. Sin embargo, la especie a la que más se ajusta teniendo en cuenta la morfología en su aspecto general y especialmente por su tamaño, es asociada a $T$. minutus. La morfología general y el tamaño son muy similares a los del ejemplar IGM 253052.

\section{IGM 253045}

Material—Fragmento de mandíbula derecha con raíces de p2 y m1, y el p3 roto. 
Localidad y Estratigrafía-Localidad 22 (Universidad de Duke), San Nicolás, área de La Venta; Capas del Mono, Miembro Baraya, Formación Villavieja, Grupo Honda.

Comentarios-El ejemplar IGM 253045 es mencionado por Goin (1997). Entre las colecciones revisadas no se encontró ningún ejemplar con esta numeración (ver Nota en comentarios del ejemplar IGM 253043). Sin embargo, se menciona aquí ya que, al no haber podido estudiarlo ni confirmar su existencia, no se realizaron cambios respecto a su clasificación.

\section{IGM 253052}

Material-Fragmento de mandíbula izquierda con los alvéolos del p2 preservando fragmentos de las raíces, y los p3-m1 completos (Fig. 5.1B).

Localidad y Estratigrafía_Localidad desconocida (Universidad de Duke), área de La Venta; Grupo Honda.

Comentarios-Este ejemplar fue referido a T. minutus por Goin (1997). El p2 es aparentemente más grande que el p3; no se preserva la corona del p2 pero se aprecia que es más largo que el p3. El p3 es grácil, comprimido labiolingualmente, con crestas cortantes anterior y posterior bien desarrolladas y un cíngulo posterior. La cúspide principal es asimétrica, siendo más larga posteriormente y con su borde posterior algo convexo. El p3 es similar en morfología y tamaño al del ejemplar IGM 253043.

En el $\mathrm{m} 1$ el lóbulo posterior de la corona se ubica a un nivel ligeramente más bajo que el anterior. Entre los ejemplares referibles a T. minutus estudiados en la presente revisión, ninguno preserva el m2, pero sí los m3-4, los cuales también muestran el lóbulo posterior más bajo. Por esta razón es posible deducir que el $\mathrm{m} 2$ también lo tenía.

El trigónido es subigual en largo al talónido y más angosto. El protocónido es la cúspide principal del trigónido. El paracónido es la cúspide más pequeña del trigónido, si bien está bien diferenciado. El metacónido se encuentra ligeramente desplazado posteriormente con respecto al protocónido (el rasgo, en este locus, es un poco más notorio que en los m3-4); por este motivo la metacrístida es ligeramente oblicua con respecto al eje longitudinal del molar. El cingúlido anterior está poco desarrollado, extendiéndose sólo por la base del paracónido.

El talónido es casi tan largo como ancho. El hipocónido es saliente labialmente respecto del protocónido y se ubica en el extremo posterolabial del talónido, por lo que la posthipocrístida es perpendicular al eje longitudinal del diente, tal como ocurre en el holotipo de T. minutus; también presenta la misma morfología en ángulo agudo. El entocónido y el hipoconúlido se encuentran algo desgastados aunque en morfología y tamaño son similares a los del holotipo de T. minutus. La crístida oblicua tiene un fuerte desgaste si bien se aprecia que, anteriormente, termina al nivel de la muesca carnasial de la metacrístida.

El tamaño y los rasgos observables en este ejemplar son consistentes con T. minutus.

Nota-En la tabla 11.1 de Goin (1997), este ejemplar aparece como IGM 253051. Sin embargo, en el texto aparece como IGM 25305 y es así como está marcado el material. 


\section{Ejemplar tentativamente referido}

\section{IGM 251013}

Material-M2 derecho aislado (Fig. 5.1D).

Localidad y Estratigrafía-CVP-8 (localidad de screenwashing, Universidad de Duke); Capa de Peces, Miembro Baraya, Formación Villavieja, Grupo Honda.

Comentarios-El paracono es más chico que el metacono. El protocono está bien desarrollado y está algo expandido anteroposteriormente. Aparentemente existe un metacónulo vestigial, no pudiéndose identificar un paracónulo. La plataforma estilar está algo reducida, más marcadamente al nivel del paracono. El ectoflexo es poco profundo pero claramente distinguible. El esmalte de la corona está desgastado (aparentemente erodado) en su porción labial, por lo cual no es posible identificar las cúspides estilares. El cíngulo anterior está aparentemente poco desarrollado, llegando apenas a contactar sutilmente la preprotocrista; no se aprecia un cíngulo continuo amplio, sino que se reduce fuertemente en la zona de contacto entre estas dos estructuras. La preparacrista se encuentra orientada casi perpendicular al eje longitudinal del molar; no se alcanza a apreciar su relación con las cúspides estilares debido al desgaste del borde labial, pero aparentemente termina en la StB o en un punto cercano a esta (entre las StA y StB). La centrocrista presenta morfología en "V". La postmetacrista está bien desarrollada, siendo marcadamente más larga que la preparacrista; adicionalmente, es visiblemente más larga que la postprotocrista, presentando una carnasialización moderada (véase Materiales y Métodos: Longitud relativa de la postmetacrista vs. la postprotocrista). La cresta postmetaconular se extiende posterolabialmente, alrededor de buena parte de la base del metacono (abarcando casi completamente su cara posterior), formando así un surco en la cara posterior del trígono (ver Discusión: Comentarios sobre algunas homologías en los molares de los didélfidos).

Este ejemplar fue referido a T. minutus por Goin (1997). Su tamaño es consistente con el de esta especie y, en general, su morfología es cercana a la de Thylamys. Sin embargo, presenta algunos rasgos que difieren ligeramente de los de este género. La centrocrista presenta una clara forma de V pero la inflexión es ligeramente menor que en los M2 de Thylamys, siendo más similar a la de Marmosa o Tlacuatzin; la postmetacrista es un poco más corta aunque visiblemente más larga que la postprotocrista, presentando una carnasialización similar a la de Marmosa y Tlacuatzin, mientras que en Thylamys es relativamente más larga, estando fuertemente carnasializada (ver Materiales y Métodos: Longitud relativa de la postmetacrista vs. la postprotocrista). Los molares de Thylamys son más estilizados, más comprimidos anteroposteriormente y elongados labiolingualmente, y la esquina metastilar es un poco más amplia. Uno de los rasgos que permiten diferenciar a Thylamys de los marmosinos (i.e., Marmosa, Tlacuatzin y Monodelphys) es que el cíngulo anterior está interrumpido y no contacta la preprotocrista formando un cíngulo anterior completo (sensu Archer, 1976b: pág. 3). Sin embargo, esta condición a veces puede variar a lo largo de la hilera dentaria, por lo que es recomendable 
evaluarlo siempre en el M3 (Voss y Jansa, 2003: carácter 60). En el presente ejemplar estas estructuras alcanzan a estar en contacto, pero el material corresponde a un M2. Sin embargo, este contacto es aparentemente muy sutil, por lo que no se descarta que en un M3 se encuentre interrumpido. En síntesis, entre la variedad morfológica de didélfidos de La Venta, el ejemplar IGM 251013 es más referible a T. minutus que a cualquier otro taxón; sin embargo, se mantiene como tentativamente referido debido a las diferencias y dudas anteriormente mencionadas.

\section{Comentarios generales sobre Thylamys minutus}

Se realizó una modificación en la diagnosis debido a que los molares superiores referidos previamente a esta especie fueron asignados a otro taxón en la presente revisión (i.e., Marmosini cf. Tlacuatzin) y únicamente se dejó un molar superior como tentativamente referido (IGM 251013). Por esta razón, la diagnosis está ahora basada únicamente en caracteres de la denticion inferior. Además de los rasgos diagnósticos que la diferencian de otras especies de Thylamys, en general, la morfología de T. minutus incluye los siguientes rasgos: el lóbulo posterior de la corona ubicado a un nivel más bajo que el anterior en todos los molares; el metacónido ligeramente desplazado posteriormente, siendo este rasgo más marcado en el $\mathrm{m} 1$ y m4, y muy sutil en el m3; el cingúlido anterior poco desarrollado, extendiéndose sólo sobre la base del paracónido y bastante angosto; la metacrístida ligeramente oblicua respecto al eje longitudinal del diente y la posthipocrístida perpendicular; el talónido casi tan largo como ancho en al menos el m1 y el m3, probablemente en el $\mathrm{m} 2$ (no se preserva el $\mathrm{m} 2$ pero es probable que sea así, ya que es así tanto en el m1 como en el m3), y más largo que ancho en el m4; el hipocónido ubicado en el extremo posterolabial del diente y presentando una forma de ángulo agudo en vista oclusal; el entocónido poco o nada comprimido labiolingualmente; y el hipoconúlido poco desarrollado, poco saliente y de sección circular.

\section{Thylamys colombianus Goin, 1997}

(Fig. 5.2)

Holotipo-IGM 251010, m2? derecho aislado (Fig. 5.2A).

Ejemplares Referidos-IGM 253031, IGM 253033 e IGM 253034.

Ejemplares Tentativamente Referidos-IGM 251009 e IGM\# 93-142.

Distribución Geográfica y Estratigráfica-Área de La Venta (Desierto de La Tatacoa, Valle Superior del Magdalena, Departamento del Huila, Colombia); Grupo Honda, Laventense, Mioceno medio (Tablas 3.1 y 5.1; Fig 3.1).

Diagnosis Enmendada—Similar en tamaño a la especie Thylamys elegans; difiere de otras 
especies del género en sus talónidos comparativamente más grandes y ligeramente más alargados, entocónidos lateralmente más comprimidos y cingúlido anterior menos desarrollado, aunque más desarrollado que en T. minutus (modificada de Goin, 1997)

Medidas-Tablas 5.2-5.3.

Comentarios-Esta especie presenta un tamaño mayor al de T. minutus.

\section{IGM 251010 (Holotipo)}

Localidad y Estratigrafía-Localidad CVP-9, (localidad de screenwashing, Universidad de Duke), área de La Venta (Desierto de La Tatacoa, Valle Superior del Magdalena, Departamento del Huila, Colombia); Capa de Peces, Miembro Baraya, Formación Villavieja, Grupo Honda.

Comentarios-Este ejemplar fue designado como el holotipo de T. colombianus por Goin (1997). Se trata de un molar inferior derecho, aparentemente el m2. En este molar el trigónido es más largo que el talónido y el talónido es ligeramente más ancho que el trigónido. El protocónido es la cúspide principal del trigónido, seguido del metacónido y el paracónido. El paracónido está bien diferenciado y presenta un muy sutil desplazamiento (casi imperceptible) en sentido labial (no está claramente alineado lingualmente con el metacónido). El metacónido se encuentra ligeramente desplazado posteriormente respecto al protocónido, si bien este desplazamiento es, también, bastante sutil. El cingúlido anterior, a pesar de no ser fuertemente desarrollado, se encuentra más desarrollado que en T. minutus, extendiéndose desde la base del paracónido hasta la porción anterior de la base del protocónido. La preprotocrístida es bastante abierta y no está alineada con la postparacrístida, formando con esta un ángulo obtuso bastante abierto; su orientación es más cercana a la del eje longitudinal del molar, aunque no es completamente paralela a este.

El talónido es casi tan largo como ancho. El hipocónido es la cúspide principal del talónido. Es saliente labialmente respecto al protocónido y se ubica en la mitad posterior del margen labial del talónido, siendo la posthipocrístida ligeramente oblicua al eje longitudinal del diente. El ángulo que se forma entre la posthipocrístida y la crístida oblicua es más abierto que en T. minutus, siendo cercano a $90^{\circ}$ (aunque aún menor). El entocónido está bien desarrollado, siendo ligeramente más bajo que el hipocónido y marcadamente más alto que el hipoconúlido, y está moderadamente comprimido labiolingualmente (más que en $T$. mimutus). El hipoconúlido se ubica junto al entocónido, es saliente posteriormente y presenta una morfología triangular en vista oclusal. La crístida oblicua se dirige en sentido labial a la muesca carnasial de la metacrístida, contactando al trigónido en la base del protocónido. La preentocrístida se orienta en sentido paralelo al eje longitudinal del diente. Se presenta un pequeño cíngulo labial al ectofléxido. 


\section{Ejemplares referidos}

\section{IGM 253031}

Material-m2? derecho (Fig. 5.2B).

Localidad y Estratigrafía-Localidad 22 (Universidad de Duke), San Nicolás, área de La Venta; Capas del Mono, Miembro Baraya, Formación Villavieja, Grupo Honda.

Comentarios-Este ejemplar fue referido a T. colombianus por Goin (1997). Se encuentra muy gastado y erodado. La morfología general se ajusta a la de Thylamys y su tamaño concuerda con el de T. colombianus. Las cúspides están completamente gastadas, por lo que es difícil observar su altura relativa. El paracónido aparentemente está ligeramente desplazado labialmente respecto del metacónido, mientras que este último está ligeramente desplazado posteriormente respecto del protocónido. El cingúlido anterior parece estar poco desarrollado, si bien por el desgaste no es posible determinar si esta es su condición real. El hipocónido es saliente respecto del protocónido. No es posible apreciar con claridad hacia dónde se dirige la crístida oblicua respecto de la muesca carnasial de la metacrísitida, ya que esta última se encuentra completamente desgastada, pero aparentemente sería hacia un punto labial a la muesca. Tampoco es claro si la posthipocrístida es perpendicular o ligeramente oblicua respecto al eje longitudinal del diente.

A pesar de su mala preservación, entre los taxones de La Venta, la especie a la que más se ajusta en cuanto a tamaño y morfología general es $T$. colombianus. Por esta razón no se realizó ninguna reasignación taxonómica y se decidió dejarlo dentro del grupo de los ejemplares referidos.

\section{IGM 253033}

Material-M4 derecho incompleto (Fig. 5.2C).

Localidad y Estratigrafía-Localidad 22 (Universidad de Duke), San Nicolás, área de La Venta; Capas del Mono, Miembro Baraya, Formación Villavieja, Grupo Honda.

Comentarios-Este ejemplar fue referido a T. colombianus por Goin (1997). Presenta rasgos consistentes con Thylamys, como lo son su fuerte compresión anteroposterior y el metacono fuertemente reducido (Goin, 1997); su tamaño es más consistente con el de T. colombianus que con el de T. minutus. El M4 no suele ser un molar diagnóstico entre los metaterios, por lo que en este caso lo más prudente es referirlo a T. colombianus, especie con la cual comparte rasgos sobresalientes. Por esta razón, se acepta la asignación de Goin (1997) y se mantiene como ejemplar referido.

\section{IGM 253034}

Material $-\mathrm{m} 1$ ? derecho, fuertemente desgastado (Fig. 5.2D).

Localidad y Estratigrafía-Localidad 22 (Universidad de Duke), San Nicolás, área de La Venta; Capas del Mono, Miembro Baraya, Formación Villavieja, Grupo Honda

Comentarios-Este ejemplar fue referido a T. colombianus por Goin (1997). A pesar de que 
el molar se encuentra fuertemente desgastado, se alcanzan a observar varios rasgos informativos. El tamaño es consistente con el de T. colombianus. El trigónido es más largo que el talónido y subigual en ancho. El protocónido es la cúspide principal del trigónido, seguido del metacónido y el paracónido, el cual está bien diferenciado y desarrollado. El paracónido se encuentra en una posición ligeramente mesial en el trigónido (está ligeramente desplazado labialmente, no alineado lingualmente con el metacónido), posición más marcada que en el holotipo. El metacónido se encuentra ligeramente desplazado posteriormente respecto al protocónido, pero este desplazamiento es bastante sutil. El cingúlido anterior muestra un desarrollo similar al del holotipo de T. colombianus, extendiéndose desde la base del paracónido hasta la del protocónido. La preprotocrístida está bastante desgastada pero, aparentemente, presenta una orientación similar a la del holotipo, ya que no está alineada con la postparacrístida sino que su orientación es más cercana a la del eje longitudinal del molar, y entre ellas forman un ángulo obtuso bastante abierto.

El talónido es casi tan largo como ancho. Las cúspides del talónido se encuentran fuertemente desgastadas, por lo que no es posible determinar su altura relativa. El hipocónido es ligeramente saliente labialmente respecto del protocónido y se ubica en la mitad posterior del margen labial del talónido, siendo la posthipocrístida ligeramente oblicua al eje longitudinal del diente. La posthipocrístida y la crístida oblicua se encuentran fuertemente desgastadas, pero aparentemente forman entre sí un ángulo de $90^{\circ}$ o bastante cercano (aparentemente más abierto que en el holotipo). La crístida oblicua se dirige en sentido labial a la muesca carnasial de la metacrístida, contactando al trigónido en la base del protocónido. El hipoconúlido se ubica junto al entocónido y es saliente posteriormente.

Esta morfología es consistente con la de T. colombianus; algunos rasgos (especialmente la ubicación del paracónido ligeramente más mesial y la orientación de la cristida oblicua) sugieren que su locus sería más anterior que el del holotipo.

\section{Ejemplares tentativamente referidos}

\section{IGM 251009}

Material—fragmento labial del M3? izquierdo.

Localidad y Estratigrafía-Localidad CVP-9 (localidad de screenwashing, Universidad de Duke), área de La Venta; Capa de Peces, Miembro Baraya, Formación Villavieja, Grupo Honda.

Comentarios-Se preserva la mitad labial del molar, incluyendo el metacono, paracono y la plataforma estilar. Goin (1997) refirió este ejemplar a T. colombianus. Sin embargo, en el presente trabajo se decidió incluirlo dentro del grupo de los ejemplares tentativamente referidos, ya que no hay forma de compararlo, debido a que el holotipo no tiene molares superiores y además está muy incompleto como para hacer inferencias sobre su morfología comparativa (e.g., podría compararse la morfología del talónido con la del protocono y cuenca del trígono y ver si son consistentes). Sin embargo, su morfología es consistente con la de Thylamys y su tamaño es más consistente con el 
de T. colombianus que con el de T. minutus.

El metacono es bastante más grande que el paracono. La postmetacrista está bien desarrollada, siendo claramente más larga que la preparacrista. Las cúspides estilares están bien diferenciadas, siendo la StB la más alta; la StA es la cúspide estilar más pequeña pero es distinguible, y la StC es más grande que la StD. No es inusual que la StD esté reducida en el M3; lo destacable es que sea de menor tamaño que la StC. En aquellos didélfidos que presentan StC, normalmente esta es de menor tamaño que la StD en el M3. Podría no tratarse de un M3 sino de un M2; sin embargo, tanto el ectoflexo, que es relativamente profundo, como el desarrollo de la esquina metastilar, son más afines con la morfología de un M3. El cingúlido anterior no está fuertemente desarrollado pero llega a extenderse hasta la porción anterior de la base del protocónido.

\section{IGM\# 93-142}

Material—Talónido de $\mathrm{m} 4$

Localidad y Estratigrafia-Localidad 4 (Universidad de Duke), área de La Venta; Grupo Honda.

Comentarios-Este es un material inédito. El talónido del m4 no suele ser diagnóstico en los metaterios, ya que se observa una gran viabilidad morfológica intraespecífica. Por esta razón, es muy difícil realizar una clasificación a partir de sólo un talónido. En este caso, el único criterio que se tuvo en cuenta para una tentativa clasificación fue el tamaño. Entre las especies actualmente descriptas para La Venta y las propuestas en el presente trabajo, el tamaño que más se ajusta a este ejemplar es el de T. colombianus. Pero debido a que no es posible obtener más información relevante a partir de este material, más allá del tamaño, se deja como tentativamente referido.

\section{Comentarios generales sobre Thylamys colombianus}

Esta especie presenta un tamaño mayor al de T. minutus. Goin (1997) destaca como rasgo diagnóstico de T. colombianus la ubicación del paracónido en una posición ligeramente mesial y afirma que esta condición "no se presenta en otros marmosinos, excepto en el $m 1$ de Zygolestes paranensis". Actualmente Thylamys no es considerado como marmosino (grupo que incluye a Marmosa, Tlacuatzin y Monodelphis; e.g., Voss y Jansa, 2009), pero en la presente revisión esta condición se observó igual o ligeramente más marcada en el $\mathrm{m} 1$ de varios didélfidos (e.g., Caluromys lanatus, Caluromys philander, Gracilinanus agilis, Gracilinanus microtarsus, Lestodelphys halli, Lutreolina crassicaudata, Marmosa murina, Marmosa robinsoni, Thylamys pusillus, Thylamys venustus y Tlacuatzin canescens) y bastante más marcada en Hyladelphys kalinowskii (el cual presenta una condición similar a la de Z. paranensis). De hecho, en algunos de estos taxones el rasgo se presenta también en otros molares (e.g., Hyladelphys kalinowskii, 
Lestodelphys halli, Caluromys), aunque en menor medida que en el $\mathrm{m} 1$ y haciéndose menos marcado posteriormente. En T. colombianus este rasgo está presente en el $\mathrm{m} 1$ y es casi inexistente en el $\mathrm{m} 2$.

Además de los caracteres diagnósticos, la morfología de $T$. colombianus incluye en resumen los siguientes rasgos: la preprotocrístida es abierta y no está alineada con la postparacrístida, formando con esta un ángulo obtuso bastante abierto, siendo su orientación más cercana a la del eje longitudinal del molar, aunque no completamente paralela a este; la crístida oblicua se dirige hacia el protocónido y se cierra posteriormente, formando junto con la posthipocrístida un ángulo de aproximadamente $90^{\circ}$ en el $\mathrm{m} 1$, mientras que este ángulo es ligeramente más cerrado (aunque aún cercano a $90^{\circ}$ ) en el $\mathrm{m} 2$; el cingúlido anterior está poco desarrollado, aunque más que en $T$. minutus.

MARMOSINI Hershkovitz, 1992

Marmosa Gray, 1821

Especie Tipo-Marmosa murina Linnaeus, 1758.

Subgéneros-Eomarmosa Voss et al., 2014; Exulomarmosa Voss et al., 2014; Marmosa Gray, 1821; Micoureus Lesson, 1842; y Stegomarmosa Pine, 1972. Para más información, véase Voss et al. (2014).

Comentarios-Para la revisión de los ejemplares de La Venta referibles Marmosa no se siguió una diagnosis en particular, ya que no se encontró una que se enfoque en caracteres dentarios (que son los preservados en estos materiales), ya que, al ser un género representado por especies actuales, la morfología externa suele ser elemento fundamental en la diagnosis, no profundizando en la morfología dentaria. Por ejemplo, la diagnosis de Tate (1933) es muy general y basada mayormente en morfología externa y además, en su clasificación incluye especies que ahora forman parte de Thylamys. Las revisiones recientes (e.g., Voss y Jansa, 2009; Rossi et al, 2010; Voss et al, 2014) no proponen una diagnosis, a pesar de hacer detalladas descripciones. Es por esto que la presente revisión se basó dichas descripciones y en comparaciones con materiales disponibles. En la presente tesis no se propone una diagnosis enmendada para el género a partir del análisis filogenético, ya que en este sólo se incluyeron algunas de las especies vivientes y una especie fósil, por lo cual no es posible proponer una diagnosis para todo el género a partir de sinapomorfías recuperadas en unas pocas especies. 
Marmosa (Micoureus) Lesson, 1842

Especie Tipo-Marmosa (Micoureus) paraguayana Tate, 1931.

Especies Referidas-M. alstoni Allen, 1900 (incluyendo M. nicaraguae Thomas, 1905); M. constantiae Thomas, 1904 (incluyendo M. budini Thomas, 1920); M. demerarae Thomas, 1905 (incluyendo M. areniticola Tate, 1931; M. domina Thomas, 1920; M. esmeraldae Tate, 1931; M. limae Thomas, 1920; M. meridae Tate, 1931); M. paraguayana Tate, 1931 (incluyendo M. cinerea Temminck, 1824 [ya ocupado]); M. phaea Thomas, 1899 (incluyendo M. perplexa Anthony, 1922); M. regina Thomas, 1898 (incluyendo M. germana Thomas, 1904; M. mapiriensis Tate, 1931; M. parda Tate, 1931; M. rapposa Thomas, 1899; M. rutteri Thomas, 1924).

\section{Marmosa (Micoureus) laventica Marshall, 1976a}

(Fig. 5.3)

Lista Sinonímica-Marmosa laventica Marshall, 1976a

Micoureus laventicus Goin, 1997

Holotipo-UCMP 39273, fragmento posterior de dentario derecho con m1-2, un fragmento de trigónido del m3, y el m4 completo (Fig. 5.3A).

Ejemplares Referidos-IGM 184336, IGM 250266, IGM 253035 y KU 2000-5.

Ejemplares Tentativamente Referidos-IGM 251231 y UCMP 37910.

Distribución Geográfica y Estratigráfica-Área de La Venta (Desierto de La Tatacoa, Valle Superior del Magdalena, Departamento del Huila, Colombia); Grupo Honda, Laventense, Mioceno medio (Tablas 3.1 y 5.1; Fig 3.1).

Diagnosis Emendada-Tamaño ligeramente mayor al de M. cinerea; difiere de las especies vivientes del subgénero Micoureus en el metacónido comprimido anteroposteriormente en el m4; el cingúlido anterior parcialmente desarrollado en los m1-3 y sólo completamente desarrollado en el $\mathrm{m} 4$ aunque de corta longitud.

Medidas-Tabla 5.3.

Comentarios-El ejemplar IGM 250278 se excluyó de esta especie ya que su tamaño y morfología eran más cercanos a los de los ejemplares referidos a Marmosini cf. Tlacuatzin. Los ejemplares IGM 251011 e IGM 251012 se excluyeron de esta especie porque su tamaño era demasiado pequeño, mucho más que el ejemplar IGM 250278.

\section{UCMP 39273 (Holotipo)}

Localidad y Estratigrafía_Localidad Marsupial, V4936 (UCMP), área de La Venta (Desierto de La Tatacoa, Valle Superior del Magdalena, Departamento del Huila, Colombia); Capas del Mono, Miembro Baraya, Formación Villavieja, Grupo Honda. 
Comentarios-Este ejemplar fue designado por Marshall (1976a) como el holotipo de $M$. laventica. El fragmento de dentario preservado corresponde a una porción a partir del $\mathrm{m} 1 \mathrm{y}$ la parte más anterior de la rama vertical, alcanzando a preservar parte de la fosa masetérica y la base de la cresta coronoidea. El fragmento preservado sugiere que la rama horizontal del dentario era grácil, alargada y relativamente baja. El proceso coronoides es aparentemente inclinado a subvertical $\left(\sim 112^{\circ}\right.$, medidos en la porción preservada de cresta coronoidea). El borde ventral del dentario es aparentemente curvo, al menos por delante del $\mathrm{m} 4$. El espacio retromolar está presente y no presenta ninguna perforación. Se preserva un foramen mentoniano a la altura del $\mathrm{m} 1$.

El tamaño de los molares aumenta gradualmente del $\mathrm{m} 1$ al m4. Al menos en los m1-2 el lóbulo posterior de la corona se ubica a un nivel más bajo que el anterior, siendo este rasgo más marcado en el $\mathrm{m} 1$ y poco desarrollado en el $\mathrm{m} 2$ (ausente en el $\mathrm{m} 4$ ). El protocónido es la cúspide principal del trigónido pero es tan sólo moderadamente más grande que las otras dos cúspides. El metacónido y paracónido son similares en tamaño en vista oclusal pero el metacónido es más alto. El paracónido está bien desarrollado y claramente diferenciado; de hecho, está notoriamente separado del metacónido por medio de un valle bien pronunciado, el cual es mucho más amplio en el m4. El metacónido se encuentra ligeramente desplazado posteriormente respecto al protocónido en el $\mathrm{m} 1$, pero se ubica al mismo nivel que este en los $\mathrm{m} 2$ y $\mathrm{m} 4$. Las tres cúspides son cónicas (circulares en sección transversal) en el $\mathrm{m} 1$ y se van haciendo subtriangulares posteriormente. La diferencia en tamaño y altura entre estas cúspides aumenta posteriormente. La postmetacrístida y la postprotocrístida están poco desarrolladas. Se presenta un cingúlido anterior que, en los m1-3, está sólo parcialmente desarrollado, ya que, a pesar de que se extiende desde la base del paracónido hasta la del protocónido, es tan sólo un reborde o saliencia de la corona en su porción anterior, pero en su porción posterior sí presenta una clara morfología de cíngulo; por otro lado, en el m4 sí está completamente desarrollado, presentando una clara morfología de cíngulo en toda su extensión, pero en este caso su longitud es mucho más corta.

El talónido es más ancho que el trigónido en el m1 y subigual en el m2; también es más corto, siendo mucho más corto en el $\mathrm{m} 1$ que en el $\mathrm{m} 2$. No se preserva el talónido del $\mathrm{m} 3$ pero según la tendencia observada en los molares anteriores, se esperaría que el talónido fuera subigual o ligeramente más angosto que el trigónido, teniendo el hipocónido ubicado en una posición ligeramente lingual respecto al nivel del protocónido. En el m4, el talónido está bastante reducido respecto a los demás molares, siendo más corto y mucho más angosto que el trigónido. El entocónido está fuertemente desarrollado, siendo la cúspide más alta del talónido, y está comprimido labiolingualmente. El hipocónido se ubica en una posición entre la mitad del borde labial del talónido y el extremo posterior del diente, mostrando en vista oclusal una morfología angular, ya que se forma un ángulo claramente definido $\left(<90^{\circ}\right)$ entre la cara labial y la posterior del talónido, siendo este último oblicuo al eje anteroposterior del diente. El hipoconúlido se encuentra apareado al entocónido y ubicado en una posición ligeramente posterolabial a este. Está bien desarrollado en todos los molares preservados, siendo más alto que el hipocónido en los m1-2 y 
más alto que el entocónido en el $\mathrm{m} 4$; es saliente posteriormente, presentando una morfología triangular en vista oclusal (similar al de T. colombianus). La crístida oblicua apunta en dirección labial a la muesca carnasial en el $\mathrm{m} 1$, pero se acerca mucho a la muesca carnasial en el $\mathrm{m} 2$, mientras que en el $\mathrm{m} 4$ apunta hacia esta; por lo tanto, probablemente en el $\mathrm{m} 3$ esté apuntando hacia la muesca o muy cerca de esta. La preentocrístida se dirige en sentido paralelo al eje longitudinal del diente. Se presenta un pequeño cíngulo labial al ectofléxido, que se forma donde la crístida oblicua conecta con la base del trigónido.

\section{Ejemplares referidos}

\section{IGM 184336}

Material-Fragmento de dentario derecho con los m2-4.

Localidad y Estratigrafía-Localidad 40 (Universidad de Duke), área de La Venta; unidad entre las Capas de Arenisca de Cerro Gordo y las Capas de Arenisca de Chunchullo, Formación La Victoria, Grupo Honda.

Comentarios-Este ejemplar fue referido a esta especie por Goin (1997). Es ligeramente más chico que el holotipo (ver Tabla 5.3) pero la diferencia de tamaño es muy sutil y su morfología es similar. Los molares presentan un aumento gradual de tamaño posteriormente. El tamaño relativo del talónido disminuye posteriormente, siendo relativamente más reducido respecto al trigónido en el $\mathrm{m} 3$ que en el m2, y mucho más reducido en el m4 (sobre todo en el ancho). El tamaño y la posición relativa de las cúspides son similares a los del holotipo. La postmetacrístida y la postprotocrístida están poco desarrolladas, igual que en el holotipo. El cingúlido anterior está ligeramente menos desarrollado que en el holotipo. En el $\mathrm{m} 2$, la crístida oblicua termina anteriormente en la base del protocónido, labial a la muesca carnasial, y se va orientando más lingualmente hacia el $\mathrm{m} 4$, terminando en este último bajo la muesca carnasial.

\section{IGM 250266}

Material-Fragmentos de molar inferior.

Localidad y Estratigrafía-Localidad 34B (localidad de screenwashing, Universidad de Duke), área de La Venta; niveles fosilíferos entre las Capas de Arenisca de Cerro Gordo y las Capas de Arenisca del Chunchullo, Formación La Victoria, Grupo Honda.

Comentarios-Este ejemplar fue referido a M. laventica por Goin (1997). Durante la presente revisión se encontró un material marcado con este número, sin información de localidad, que correspondía a fragmentos de un molar inferior difícilmente identificable, pero aparecía clasificado como un quiróptero. Eventualmente podría tratarse de Kiotomops (Capítulo 6). Sin embargo, ya que no aparecen medidas publicadas, ni fotografías, ni una descripción del ejemplar mencionado por Goin (1997), no se tiene certeza de que este material observado corresponda al mismo que revisó dicho autor, o si se trata de dos ejemplares con el mismo número. De todas formas, no se 
encontró ningún otro material marcado con esta identificación. Ya que existen dudas acerca de la identificación/mumeración de este ejemplar, no se modifica la asignación taxonómica previamente realizada.

\section{IGM 253035}

Material - molar superior muy roto.

Localidad y Estratigrafía-Localidad 22 (Universidad de Duke), San Nicolás, área de La Venta; Capas del Mono(?), Miembro Baraya, Formación Villavieja, Grupo Honda.

Comentarios-Este ejemplar fue referido a M. laventica por Goin (1997). Este material no fue encontrado en ninguna de las colecciones que se revisaron en la presente tesis. Por esta razón, no se puede tomar ninguna decisión taxonómica y por lo tanto se mantiene la asignación hecha por Goin (1997).

\section{Nuevo ejemplar referido}

\section{KU 2000-5}

Material-Fragmento de rama mandibular derecha con las raíces del p2 y los p3-m2 completos, aunque altamente desgastados (Fig. 5.3B).

Localidad y Estratigrafía_Localidad El Cuzco - "Masato Site" (Universidad de Kioto); Capas Rojas de El Cardón, Miembro Cerro Colorado, Formación Villavieja, Grupo Honda.

Comentarios-El dentario presenta una altura similar a la del holotipo de M. laventica, aunque los molares son moderadamente más chicos. Se presenta al menos un foramen, al nivel de la raíz anterior de $\mathrm{m} 1$, al igual que en el holotipo. El p3 está poco comprimido lateralmente, su cúspide principal es bastante cónica (de sección casi circular) aunque con el borde anterior ligeramente más convexo que el posterior, y un pequeño talón. El $\mathrm{m} 1$ es más pequeño que el $\mathrm{m} 2$, aunque la diferencia en tamaño no es muy marcada. El lóbulo posterior se encuentra a un nivel ligeramente más bajo que el anterior al menos en los m1-2, al igual que en el holotipo.

En los molares, el trigónido es más largo que el talónido en ambos molares, mientras que el talónido es más ancho que el trigónido, siendo esta diferencia mayor en el $\mathrm{m} 1$ que en el m2. Las cúspides del trigónido se disponen a manera de triángulo reverso agudo, con el paracónido en posición lingual, cercano al metacónido, aunque en el m1 se ubica en una posición ligeramente más mesial respecto al $\mathrm{m} 2$. Por consiguiente, el metacónido del $\mathrm{m} 1$ se encuentra ligeramente desplazado posterolingualmente, haciendo que la centrocrístida se oriente ligeramente oblicua respecto al eje de la hilera dentaria, mientras que en el m2 está bien alineado con el paracónido y la centrocrístida es mucho más perpendicular. Esto sugiere que, probablemente, la preparacista sea ligeramente oblicua en el M1. El protocónido es la cúspide más grande del trigónido y, debido al fuerte desgaste de las cúspides, es difícil determinar la diferencia de tamaño entre el paracónido y metacónido, pero al menos en el $\mathrm{m} 2$ se aprecia que el paracónido es más pequeño que el 
metacónido. El cingúlido anterior está bien desarrollado, extendiéndose desde el paracónido a la base del protocónido.

El talónido es más ancho que largo, al menos en m1-2. El hipocónido está localizado en la esquina posterolabial del talónido y es, aparentemente, más bajo que el entocónido. La cristida oblicua está orientada similar a la del holotipo, dirigiéndose hacia un punto labial a la muesca carnasial. El entocónido está muy desgastado, pero su base abarca gran parte del margen lingual del talónido, como ocurre en M. laventica, indicando que está bien desarrollado y probablemente fuera igual de alto; puede apreciarse que es más alto que el hipoconúlido (el cual se encuentra menos desgastado). Debido al grado de desgaste no es posible determinar la presencia de una preentocrístida. El hipoconúlido está bien desarollado y es saliente posteriormente. El hipofléxido es poco profundo (menos del $40 \%$ del ancho de talónido). Se observa un cingúlido corto ubicado labialmente al hipofléxido.

\section{Ejemplares tentativamente referidos}

\section{IGM 251231}

Material—Fragmento esquina metastilar de un molar superior (M3?)

Localidad y Estratigrafia-Localidad CVP-9 (localidad de screenwashing, Universidad de Duke), área de La Venta; Capa de Peces, Miembro Baraya, Formación Villavieja, Grupo Honda.

Comentarios-Goin (1997) refirió este ejemplar a M. laventica, pero es un material muy incompleto que no preserva ningún rasgo diagnóstico. Es muy difícil asignarlo con certeza a algún taxón pero, ya que el tamaño podría ajustarse al de $M$. laventica y a que Goin ya lo había relacionado con este taxón, se deja como tentativamente referido a este.

\section{UCMP 37910}

Material—Fragmento de dentario derecho con el alvéolo posterior del m2, los alvéolos de $\mathrm{m} 3$ y las raíces de $\mathrm{m} 4$ con una pequeña porción de la base de la corona (Fig. 5.3C).

Localidad y Estratigrafía_Localidad El Mono, V4517 (UCMP); Capas del Mono, Miembro Baraya, Formación Villavieja, Grupo Honda.

Comentarios-Este ejemplar había sido referido tentativamente a M. laventica por Marshall (1976). Es un material bastante incompleto y no se preserva ningún rasgo diagnóstico. Lo único que podría asociarlo con $M$. laventica es su tamaño, especialmente la altura y grosor del dentario, los cuales son muy cercanos a las dimensiones de esta especie. El tamaño aproximado de los molares (inferido a partir de los alveolos) también es cercano al de esta especie. Otra especie cercana en tamaño sería aquella que en este capítulo se presenta como Género A sp. 1 (Didelphimorphia fam. incertae sedis). Su morfología no es consistente con ninguna otra especie descripta para La Venta. 


\section{Comentarios generales sobre Marmosa (Micoureus) laventica}

Esta especie fue nombrada por Marshall (1976) como Marmosa laventica. Goin (1997) la renombró como Micoureus laventicus. Para el momento en que Goin (1997) realiza la revisión de los metaterios de La Venta, Micoureus era reconocido como un género; en la actualidad es reconocido como un subgénero de Marmosa (ver Voss et al., 2014). Goin (1997) destacó que la especie de La Venta presentaba una morfología más acorde con Micoureus que con Marmosa (como eran definidos en aquella época), debido a su tamaño comparativamente grande, los trigónidos de los m2-4 tan anchos como largos y los protocónidos tan sólo moderadamente más grandes que los paracónidos.

Goin (1997) comenta que esta especie muestra algunas especializaciones que no son observadas en las especies vivientes de Micoureus, como una postmetacrista bien desarrollada (especialmente en el M1) y el metacónido del m4 comprimido anteroposteriormente. Según las modificaciones realizadas en la presente revisión, el único ejemplar que con certeza corresponde a un M1 entre aquellos que Goin (1997) había referido a esta especie, en la presente revisión fue clasificado dentro de una especie de Marmosa nueva para La Venta (ver más adelante Marmosa sp. 1). Por esta razón, este fuerte desarrollo de la postmetacrista no sería, por el momento, un rasgo característico de M. laventica y por lo tanto, fue excluido de la diagnosis revisada que había sido propuesta por Goin (1997). En dicha diagnosis también se menciona que los ectoflexos de los molares superiores son relativamente poco profundos. Este punto se basó principalmente en las observaciones hechas sobre los ejemplares IGM 250278, IGM 251011 e IGM 251012, que eran los elementos más completos entre los materiales de su revisión que representaban dentición superior. Como en la presente revisión los tres ejemplares fueron reclasificados como otra especie (ver Marmosa sp. 1 y Marmosini cf. Tlacuatzin), se decidió optar por excluir por el momento también este rasgo de la diagnosis.

Esta especie se caracteriza principalmente por tener un protocónido sólo moderadamente más desarrollado que las otras cúspides del trigónido; el paracónido bien desarrollado, subigual en amplitud al metacónido (en vista oclusal) pero más bajo; el metacónido alineado posteriormente con el protocónido en los m2-4 pero ligeramente desplazado posteriormente en el $\mathrm{m} 1$; el cingúlido anterior extendido hasta la base del protocónido pero no sólo parcialmente desarrollado en los m13 y completamente desarrollado pero más corto en el m4; el hipocónido saliente labialmente respecto al protocono; el entocónido bien desarrollado, comprimido labiolingualmente y más alto que el hipoconúlido en los m1-3; el hipoconúlido triangular en vista oclusal y saliente posteriormente, estando bien desarrollado en el m4 (más alto que el entocónido); la posthipocrístida ligeramente oblicua; y la cristida oblicua contactando el trigónido en un punto labial a la muesca carnasial en el $\mathrm{m} 1 \mathrm{y}$ acercándose a esta hacia los loci posteriores, estando por debajo de ella en los m3-4. 


\section{Marmosa sp. 1}

(subgen. incertae sedis)

(Fig. 5.4)

Los ejemplares que se mencionan a continuación aparentemente pertenecen a una misma especie de Marmosa (Leson, 1842), pero la escasez y fragmentación del material no permiten asignarlos con certeza una especie conocida o nueva de este género. Sin embargo, es claro que se trata de una especie diferente a $M$. laventica y, por su pequeño tamaño (Tabla 5.2), probablemente se trate de una especie referible a un subgénero diferente de Micoureus (ver más adelante Comentarios acerca de Marmosa sp. 1).

\section{IGM 251011}

Material-M1 derecho (Fig. 5.4A).

Localidad y Estratigrafía-Localidad CVP-9 (localidad de screenwashing, Universidad de Duke), área de La Venta; Capa de Peces, Miembro Baraya, Formación Villavieja, Grupo Honda.

Comentarios-Este ejemplar fue inicialmente referido a M. laventica por Goin (1997). Presenta un tamaño casi $40 \%$ menor que el holotipo de $M$. laventica. El paracono es distinguible y más pequeño que el metacono. El metacono se ubica en una posición ligeramente más lingual que el paracono. Estas dos cúspudes son subtriangulares y se encuentran claramente separadas. El protocono es algo corto (en sentido labiolingual) y algo expandido anteroposteriormente. Al menos el metacónulo está presente aunque fuertemente reducido, casi vestigial; aparentemente no hay paracónulo. La plataforma estilar es más angosta al nivel del paracono, mientras que la porción labial al metacono es amplia y la esquina metastilar es bastante elongada posteriormente. Las cúspides estilares están claramente diferenciadas. La StA está bien diferenciada y es la más pequeña, y la StB es la más desarollada; la StC es más alta que la StD y algo comprimida labiolingualmente, pero la StD es más amplia (en área) en vista oclusal. Estas últimas dos cúspides se encuentran ligeramente desplazadas posteriormente respecto a la posición en el esquema básico de un molar tribosfénico, por lo cual la $\mathrm{StC}$ se ubica ligeramente posterior al vértice de la centrocrista y la StD no se encuentra alineada con el metacono sino en una posición ligeramente posterior. El ectoflexo es vestigial. El cíngulo anterior se encuentra bien desarrollado y expandido, uniéndose lingualmente a la cresta preprotoconular. La preparacrista es corta y se orienta perpendicular al eje longitudinal del diente, terminando labialmente en la StB. La centrocrista está bien desarrollada y presenta una morfología en "V" con una inflexión moderada. La postmetacrista está muy bien desarrollada, siendo mucho más larga que la preparacrista. Se aprecia una cresta que se extiende posterolabial al metacónulo, rodeando ligeramente la base del metacono y formando un pequeño surco en la cara posterior de este; en este caso, aparentemente esta cresta es homóloga a la cresta postmetaconular y no la postprotocrista. 


\section{IGM 251012}

Material-M2 derecho (Fig. 5.4B).

Localidad y Estratigrafía - Localidad CVP-9 (localidad de screenwashing, Universidad de Duke), área de La Venta; Capa de Peces, Miembro Baraya, Formación Villavieja, Grupo Honda.

Comentarios-Este ejemplar fue inicialmente clasificado por Goin (1997) como $M$. laventica, pero su tamaño es 38\% menor. El paracono está bien desarrollado. El metacono es más grande que el paracono y se encuentra ubicado en una posición ligeramente más lingual, aunque menos que en el ejemplar IGM 251011. Estas dos cúspides son subtriangulares y se encuentran claramente separadas. El protocono está algo expandido anteroposteriormente. Al menos el metacónulo está presente aunque fuertemente reducido, casi vestigial; no se observa un paracónulo. La plataforma estilar es más angosta al nivel del paracono, mientras que la porción labial al metacono es amplia, pero la esquina metastilar está menos elongada posteriormente que en el ejemplar IGM 251011. Esto se debe a que dicho ejemplar es un M1 y este rasgo suele ser más marcado en el primer molar superior, y se reduce hacia los loci posteriores. Presenta un ectoflexo poco profundo. Las cúspides estilares están claramente diferenciadas. Las cúspides estilares A, B, C y D están presentes. La StA es la más reducida pero está bien diferenciada. Las demás cúspides presentan tamaños muy similares entre sí, aunque $\mathrm{StB}>\mathrm{StC}>\mathrm{StD}$. La $\mathrm{StC}$ está ligeramente comprimida labiolingualmente (menos que en el M1, ejemplar IGM 251011). Las StC y StD están ligeramente desplazadas posteriormente, como ocurre en el ejemplar IGM 251011: la StC se ubica en una posición ligeramente posterior al nivel de la inflexión labial de la centrocrista, mientras que la StD se ubica en un punto posterolabial al metacono. La preparacrista se orienta casi perpendicular al eje longitudinal del diente, llegando hasta la StB. La centrocrista presenta una fuerte inflexión labial, con una morfología de $\mathrm{V}$ bien definida. La postmetacrista está bien desarrollada, siendo más larga que la preparacrista, aunque la diferencia de longitudes es menor que en el ejemplar IGM 251011. La preprotocrista se extiende labialmente hasta unirse con un cíngulo anterior bien desarrollado, que se origina en la StA. La postmetacrista es visiblemente (aunque no marcadamente) más larga que la postprotocrista, siendo este molar moderadamente carnasializado. Al igual que en el ejemplar IGM 251011, se presenta una cresta que se extiende ligeramente posterolabial al metacónulo, rodeando ligeramente la base del metacono y formando un pequeño surco en la cara posterior de este; en este caso, aparentemente, esta cresta es homóloga a la cresta postmetaconular y no la postprotocrista.

\section{IGM\# 93-136}

Material-M3? derecho incompleto (Fig. 5.4C)

Localidad y Estratigrafía-Localidad 4 (Universidad de Duke), área de La Venta; Grupo Honda.

Comentarios-Se trata de un material inédito. A pesar de que el molar no conserva la parte posterior de la plataforma estilar ni la porción posterolabial del metacono, la morfología de la 
porción preservada es bastante cercana a la del ejemplar IGM 251012 y no se observan diferencias evidentes que puedan ser resaltadas. Aparentemente, se trataría de la misma especie.

\section{Ejemplar tentativamente referido}

\section{IGM\# 93-151}

Material—Esquina metastilar derecha.

Localidad y Estratigrafía-Localidad 4 (Universidad de Duke), área de La Venta; Grupo Honda.

Comentarios-Este ejemplar es inédito. Preserva el metacono y la porción posterior de la plataforma estilar (posterior al nivel de la $\mathrm{StC}$, incluyendo de esta cúspide casi completa). El ejemplar se comparó inicialmente con aquellos clasificados en el presente trabajo como Marmosini cf. Tlacuatzin, ya que presentaba una apariencia general similar. Sin embargo, la StC es menos comprimida y su ubicación es más posterior, como ocurre en IGM 251012 (Marmosa sp. 1). La porción preservada es muy similar a la correspondiente en el ejemplar IGM 251012, incluyendo la morfología, proporciones y ubicación del metacono, la metacrista, cúspides estilares y plataforma estilar en general. Lo único que varía en este caso, es que la StD está mucho más reducida, pero esto puede deberse a que se trate de un M3, ya que siguiendo la morfología de los M1-2, puede notarse que esta cúspide se va reduciendo hacia los loci posteriores. Sin embargo, claramente se trata de un fragmento demasiado pequeño y no permite realizar una comparación más profunda para asegurar con certeza que realmente se trate de la misma especie.

\section{Comentarios generales acerca de Marmosa sp. 1}

Algunos rasgos característicos de esta especie (aunque no necesariamente únicos) son: el metacono en una posición ligeramente lingual respecto al paracono; el protocono algo expandido anteroposteriormente; al menos el metacónulo está presente aunque casi vestigial y aparentemente no hay paracónulo; la posición de las $\mathrm{StC}$ y $\mathrm{StD}$, que se encuentran ligeramente desplazadas posteriormente; la $\mathrm{StC}$ más grande que la $\mathrm{StD}$, al menos en $\mathrm{M} 1-2$; la postmetacrista bien desarrollada, siendo claramente más larga que la preparacrista; el ectoflexo vestigial en el M1 y poco profundo en el M2 (no es clara la condición en el M3); el cíngulo anterior bien desarrollado, extendiéndose lingualmente hasta unirse con la preprotocrista; la cresta que se ubica posterolabial al metacónulo y se extiende ligeramente posterolabialmente alrededor de la base del metacono formando un pequeño surco posterior, aparentemente es homóloga a la cresta postmetaconular y no la postprotocrista.

Los molares superiores presentan una carnasialización moderada, siendo la postmetacrista visiblemente más larga que la postprotocrista. Este nivel de carnasialización está presente en 
didélfidos como Marmosa, Tlacuatzin y Gracilinanus, siendo menor al de otras especies como Marmosops, Monodelphis, Chironectes, Didelphis, Lutreolina, Philander, Thylamys, Chacodelphys, Lestodelphys, entre otros (Voss y Jansa, 2009), en los cuales la postmetacrista es mucho más larga que la postprotocrista, siendo fuertemente carnasializados.

Esta especie muestra rasgos que, en conjunto, son característicos de Marmosa, como lo son el cíngulo anterior bien desarrollado y extendido hasta unirse con la preprotocrista, el ectoflexo vestigial en el M1 y poco profundo en el M2, la centrocrista con una fuerte inflexión en forma de $\mathrm{V}$, el grado de carnasialización (definido a partir de la diferencia de longitudes entre la postmetacrista y la postprotocrista), y la cresta postmetaconular extendiéndose ligeramente posterolabialmente alrededor del metacono. Se diferencia de Thylamys en el menor grado de carnasialización, la postmetacrista menos desarrollada, la plataforma estilar más angosta, el desarrollo del cíngulo anterior (mayor y continuo, mientras que en Thylamys está interrumpido), el ectoflexo menos profundo y el desarrollo y posición de las cúspides estilares.

La morfología general de esta especie se ajusta a la del género Marmosa, pero el tamaño se aleja bastante del de Marmosa (Micoureus) laventica, siendo un 40\% menor que el de esta especie, lo cual para especies de este rango de tamaño es una diferencia considerable. Entre los didélfidos actuales estudiados para la presente revisión se pudo observar que el largo del M1 es aproximadamente igual al del m2, el del M2 al del m3 y el del M3 al del m4. Si se compara, por ejemplo, el M1 (IGM 251011) o el M2 (IGM 251012) de esta especie con los m2 y m3 (respectivamente) del holotipo de $M$. laventica, la diferencia de longitud es de un poco más de 1 $\mathrm{mm}$, lo cual es aproximadamente $1 / 3$ del tamaño de M. laventica. El tamaño también es inferior al de otras especies de Micoureus, por lo que es muy probable que pertenezca incluso a otro subgénero.

Por ahora no es posible asignarlo a un subgénero específico, ya que no existen estudios detallados sobre la morfología dentaria de Marmosa que permitan diferenciar los distintos subgéneros (tal como están definidos actualmente) exclusivamente a partir de estos rasgos. Los estudios realizados basan esta diferenciación en caracteres moleculares y externos (e.g., Voss et al., 2014). Tampoco se tuvo acceso a material suficiente como para poder identificar estas diferencias. Adicionalmente, Marmosa sp. 1 se encuentra representada únicamente por 3 molares, uno de los cuales (tentativamente referido) está incompleto, por lo cual no se dispone de suficiente información para ser codificada con el fin de incluir esta especie en el análisis filogenético. En síntesis, se considera que tal revisión amerita un estudio que excede los propósitos del presente trabajo y la conclusión preliminar es que se trata de una nueva especie de Marmosa al menos para La Venta. 


\section{Marmosini cf. Tlacuatzin}

(Fig. 5.5)

\section{IGM 251232}

Material-M3 derecho unido a un fragmento de hueso del maxilar (Fig. 5.5A).

Localidad y Estratigrafía - CVP-9 (localidad de screenwashing, Universidad de Duke); Capa de Peces, Miembro Baraya, Formación Villavieja, Grupo Honda.

Comentarios-Este ejemplar fue inicialmente referido a Thylamys minutus por Goin (1997). El tamaño del molar es consistente con dicha especie. Sin embargo, presenta una serie de caracteres que lo diferencian incluso del género Thylamys (ver Comentarios acerca de Marmosini cf. Tlacuatzin).

El metacono es tan sólo moderadamente más grande que el paracono. El protocono es algo expandido anteroposteriormente, y es relativamente más grande y con una cuenca más amplia que en las especies de Marmosa de La Venta. Aparentemente, el metacónulo es vestigial y no presenta paracónulo. La plataforma estilar es amplia, aunque ligeramente más reducida en la porción labial al paracono (alrededor de un 50\% del ancho total del molar al nivel del paracono y un $60 \%$ al nivel del metacono), siendo mucho más amplia que en Marmosa laventica y Marmosa sp 1. Se presenta un ectoflexo profundo. Las cúspides estilares A, B, C y D están presentes y están claramente diferenciadas, siendo la StB la más desarrollada, seguida de la StD, la StC y la StA. La StA está bastante reducida pero es distinguible. La StC se ubica directamente labial al punto de inflexión de la centrocrista y la $\mathrm{StD}$ se encuentra alineada con el metacónido (en la posición normal de un molar tribosfénico). La StC es bastante comprimida labiolingualmente, más que en Marmosa sp1. El cíngulo anterior está bien desarrollado y se extiende lingualmente hasta contactar la preprotocrista, aunque se su amplitud disminuye notoriamente esa zona de contacto (pero la continuidad es clara). La preparacrista es casi perpendicular al eje de la hilera dentaria y termina labialmente en la base de la StB (al costado lingual). La centrocrista presenta una fuerte inflexión, con una forma de $\mathrm{V}$ bien definida. La postmetacrista más larga que la preparacrista pero es relativamente más corta que en la mayoría de didélfidos, aunque no llega a ser tan corta como la de Caluromys o Hyladelphys, presentando un desarrollo similar Glironia venusta; y es visiblemente más larga que la postprotocrista, siendo un molar moderadamente carnasializado. Se presenta una cresta que se extiende posterolabial al metacónulo, rodeando parcialmente la base del metacono (en su porción posterolingual) y formando un surco en la cara posterior de este. En este molar no es claro si esta cresta es homóloga a la cresta postmetaconular o a la postprotocrista, ya que el metacónulo está extremadamente reducido y no queda claro si presenta o no una cresta postmetaconular; sin embargo, en este caso se extiende bastante, más que en los molares conocidos de Marmosa sp. 1 (no se conoce un M3 que preserve este rasgo, pero probablemente sería más extensa que en los M1-2) y por lo tanto probablemente sea homóloga a la postprotocrista o a la unión de ambas crestas (un metacónulo tan reducido no tendría una cresta postmetaconular tan desarrollada). 


\section{IGM\# 93-139}

Material-Fragmento labial de M3 derecho.

Localidad y Estratigrafía-Localidad 4 (Universidad de Duke), área de La Venta; Grupo Honda.

Comentarios-Este ejemplar es inédito. El fragmento incluye el paracono, el metacono incompleto (sin la porción posterolingual) y la porción anterior de la plataforma estilar, hasta la altura de la StD. Es consistente en tamaño y morfología con el ejemplar IGM 251232 (más chico que $T$. canescens); no se encuentran diferencias notorias, lo cual sugiere que aparentemente se trata de la misma especie.

\section{IGM-KU 82C1-a}

Material-Fragmento de dentario izquierdo con p2, dp3 y m1-2.

Localidad y Estratigrafía-Localidad desconocida (?) (Universidad de Kioto), área de La Venta; Grupo Honda.

Comentarios-Este ejemplar es inédito. El dentario es aparentemente grácil, poco profundo con relación al tamaño de los dientes. Se presenta al menos un foramen mentoniano, que se ubica por debajo del contacto entre el p1 y el p2. El p2 es grande, siendo tan largo como el m1 y más alto, similar al de $T$. canescens; su morfología es asimétrica, con el borde anterior de la cúspide principal convexo y el posterior cóncavo, y siendo más alargada la porción posterior a la cúspide principal. Presenta una cresta anterior en forma de quilla y una posterior más larga y cortante. La cara labial es convexa y homogénea, mientras la cara lingual está dividida en dos porciones, una anterior y una posterior, aunque esta división no es tan marcada como en otros taxones (e.g., Chironectes). Esta división ocurre por medio de una cresta baja y suave, que desciende desde la cúspide principal, extendiéndose posteriormente hacia el extremo posterior de la corona, formando una especie de cingúlido posterolingual; este a su vez se une a otro posterolabial mucho más corto para formar posterocingúlido, que rodea un talón. Adicionalmente, se presenta una pequeña cúspide posterior, que se ubica sobre el postcingúlido. El dp3 es pequeño pero no vestigial. Presenta una morfología molariforme, con trigónido y talónido. El trigónido es aparentemente bicuspidado (con "para-" y "protocónido"), aunque se presenta una pequeña cúspide lingual, que está muy desplazada posteriormente a la posición de un "metacónido" y muy anterior a la de un "entocónido". Se observa una cresta que aparentemente une esta pequeña cúspide con el protocónido.

En los dos molares preservados el lóbulo posterior de la corona se ubica a un nivel más bajo que el anterior, siendo este rasgo mucho más marcado en el $\mathrm{m} 1$. El trigónido del $\mathrm{m} 2$ es marcadamente más grande que el del $\mathrm{m} 1$; el del $\mathrm{m} 1$ es más largo que ancho, mientras en el $\mathrm{m} 2$ estas dos dimensiones son subigiales. El talónido es más ancho y más corto que el trigónido en ambos molares, pero en el $\mathrm{m} 2$ es relativamente más angosto y más corto (respecto al trigónido) que 
en el $\mathrm{m} 1$.

El protocónido es la cúspide principal del trigónido, seguido en tamaño por el metacónido y el paracónido, aunque el paracónido está bien desarrollado y claramente diferenciado. Tanto el paraconido como el protoconido son triangulares en sección transversal, mientras que el metacónido es algo más circular. El metacónido se encuentra ligeramente desplazado posteriormente respecto al protocónido, haciendo que la metacrístida sea ligeramente oblicua respecto al eje longitudinal del molar; este rasgo es menos marcado en el $\mathrm{m} 2$. El paracónido se encuentra ligeramente desplazado labialmente, ubicándose en una posición ligeramente mesial, siendo este rasgo más marcado en el $\mathrm{m} 1$ que en el m2, pero no tan marcado como en Hyladelphys. El cingúlido anterior está bien desarrollado, extendiéndose hasta la base del protocónido. La preprotocrístida se orienta paralela al eje longitudinal en ambos molares preservados, por lo que no está alineada con la postparacrístida y entre ellas forman un ángulo obtuso bastante abierto; es más claramente paralela que la de T. colombianus.

El talónido es casi tan largo como ancho en ambos molares preservados, aunque ligeramente más ancho en el m2. El hipocónido es la cúspide más alta del talónido. Es bastante saliente labialmente respecto al protocónido en el $\mathrm{m} 1$ y ligeramente saliente en el $\mathrm{m} 2$, y se ubica en el extremo posterolabial del talónido, haciendo que la posthipocrístida sea perpendicular al eje longitudinal del diente; en vista oclusal, la posthipocrístida forma junto con la crístida oblicua un ángulo menor a $90^{\circ}$ claramente definido, pero más cerrado en el $\mathrm{m} 2$ que en el $\mathrm{m} 1$. El entocónido no está comprimido labiolingualmente y está bien desarrollado, siendo más grande que el hipoconúlido y ligeramente más pequeño que el hipocónido. El hipoconúlido se ubica junto al entocónido, es saliente y presenta una morfología circular en vista oclusal. La crístida oblicua contacta el trigónido en un punto labial a la muesca carnasial, en ambos molares preservados. La preentocrístida se orienta en sentido paralelo al eje longitudinal del diente. Se presenta un pequeño cíngulo externo, labial al ectofléxido.

\section{UCMP 108563}

Material-Fragmento de maxilar derecho con M1-2 completos y M3 incompleto (Fig. 5.5B).

Localidad y Estratigrafía—Localidad El Mono, V4517 (UCMP); Capas del Mono, Miembro Baraya, Formación Villavieja, Grupo Honda.

Comentarios-Este ejemplar fue clasificado por Marshall (1976) como Marmosa sp. Posteriormente, Goin (1997) lo refirió a Thylamys minutus (especie nominada en dicho trabajo).

Los M1-2 están completos y el M3 está incompleto, preservando parte del protocono, parte del paracono, parte del cíngulo anterior y parte de la porción anterior de la plataforma estilar. Por esta razón, para algunos rasgos no se mencionará la condición presente en el M3 (porque se desconoce). La única dimensión comparable con el ejemplar IGM 251232 es el ancho del M3, y es exáctamente igual (i.e., 1,75 mm). El metacono es marcadamente más grande que el paracono en el M1 y relativamente más reducido en el M2, siendo moderadamente más grande que el paracono. El 
protocono es algo extendido anteroposteriormente, y se va haciendo más desarrollado y con una cuenca más amplia hacia el M3. Aparentemente se presenta un metacónulo vestigial, al menos en el M2. Las proporciones de la plataforma estilar (vs el ancho del molar) son consistentes con las del ejemplar IGM 251232, aunque se observa que está ligeramente más reducida al nivel del paracono en el M2 y un poco más en el M1, lo cual es consistente con que sean loci diferentes. E1 ectoflexo está ausente en el M1 y es poco profundo a vestigial en el M2 (no se preserva en el M3). Las cúspides estilares $\mathrm{A}, \mathrm{B}, \mathrm{C}$ y $\mathrm{D}$ están presentes y bien diferenciadas. La cúspide estilar más grande es la $\mathrm{StB}$, siendo tan sólo ligeramente más grande que la StD y con una diferencia más marcada en el M2 (en el M3 no se preserva la StD). En el M1, la StC está más desarrollada que la $\mathrm{StD}$, pero ocurre lo contrario en el M2, ya que se va reduciendo hacia el M3, aunque en este último todavía está bien definida; es comprimida labiolingualmente pero un poco más en el M3, donde se observa una compresión y desarrollo similar a la del ejemplar IGM 251232. La StA es la cúspide estilar más pequeña, aunque es distinguible. El cíngulo anterior se origina en la StA y se extiende lingualmente hasta contactarse con la preprotocrista; está bien desarrollado pero su amplitud se va reduciendo hacia el M3, aunque sin llegar a interrumpirse el contacto con la preprotocrista. La preparacrista está más desarrollada en el M2 que en el M1, donde es bastante corta pero bien diferenciada; se encuentra orientada casi perpendicular al eje axial, tocando la base de la StB en su porción lingual, en el M1 en un punto ligeramente más anterior que en el M2. La centrocrista presenta una morfología en $\mathrm{V}$ con una marcada inflexión labial. La postmetacrista está pobremente desarrollada, siendo notoriamente más larga que la preparacrista en el M1 y relativamente más reducida en el M2, siendo moderadamente más larga que la preparacrista (similar a IGM 251232 aunque ligeramente más larga). Al igual que en el ejemplar IGM 251232 se presenta una cresta que se extiende posterolabial al metacónulo, rodeando la base del metacono y formando un surco en la cara posterior de este; tiene un desarrollo similar a la del ejemplar IGM 251232, aunque en este último aparentemente es ligeramente más larga, y en el ejemplar UCMP 108563 es ligeramente más larga en el M2 que en el M1. Como se mencionó en los comentarios del ejemplar IGM 251232, no queda clara la homología de esta cresta, pero probablemente sea la continuación de la postprotocrista o esta cresta más la cresta postmetaconular.

El tamaño y la morfología sugieren que este ejemplar pertenece a la misma especie que IGM 251232. Los pocos rasgos observables en el M3 (debido al mal estado de preservación), presentan las mismas características que en dicho ejemplar. Las diferencias que se observan en los M1-2 respecto al ejemplar IGM 251232, son muy sutiles y básicamente se trata de diferencias en algunas dimensiones (e.g., largo de crestas, tamaños relativos, etc), que claramente corresponden a variaciones que se presentan entre loci diferentes. Estas mismas diferencias se observan entre los diferentes loci de Tlacuatzin canescens. 


\section{Ejemplares tentativamente referidos}

\section{IGM 250278}

Material-M3 izquierdo incompleto (Fig. 5.5C).

Localidad y Estratigrafía-localidad CVP-5 (localidad de screenwashing, Universidad de Duke), área de La Venta; Capa de Peces, Miembro Baraya, Formación Villavieja, Grupo Honda.

Comentarios-Este ejemplar fue referido a M. laventica por Goin (1997). Sin embargo, la diferencia de tamaños entre este ejemplar y lo que se esperaría para un M3 de esta especie es bastante marcada. A pesar de que el molar se encuentra roto en su esquina metastilar, su morfología indica que el largo no sería mucho mayor al ancho (i.e., 2,30 mm), incluso podría ser menor o subigual. Se esperaría que el largo del M3 de esta especie fuera cercano al largo del m4; el largo del $\mathrm{m} 4$ del holotipo es 3,2 mm y esta longitud es muy similar en el ejemplar IGM 184336 (i.e., $\sim 2,90 \mathrm{~mm}$ ), que es algo más pequeño que el holotipo. Esta diferencia de tamaño es bastante marcada, siendo incluso mucho más corto que el $\mathrm{m} 1$ del holotipo $(2,70 \mathrm{~mm})$ y más chico que el ejemplar KU 2000-5, el cual ya es algo pequeño para esta especie. Diferencias así son significativas para molares de este rango de tamaño. Por esta razón, es dudoso que este molar pueda ser asignado a esta especie. Cabe resaltar que se trata de un molar izquierdo, ya que en el texto de Goin (1997: Pág. 194, "Hipodigma") aparece listado como un M3 derecho; sin embargo, en la Fig. 11.2, sí lo refiere correctamente.

El metacono es más grande que el paracono y sus bases se encuentran claramente separadas. El protocono está bien desarrollado y algo expandido anteroposteriomente, con una cuenca profunda. La preparacrista se orienta casi perpendicular al borde estilar, conectándose con la StB en el margen anterior de su base. La centrocrista presenta una morfología en V marcada. La postmetacrista está poco desarrollada, aparentemente (la esquina metastilar está rota) es tan sólo ligeramente más larga que la preparacrista. El cíngulo anterior está bien desarrollado y se extiende lingualmente hasta conectarse con la preprotocrista. El ectoflexo es, aparentemente, poco profundo, pero la porción posterolabial de la plataforma está rota, por lo que no es clara la profundidad; la StA es pequeña pero claramente diferenciable. La StB está bien desarrollada y la $\mathrm{StC}$ está presente, más pequeña que la $\mathrm{StB}$, pero más desarrollada que la StA, y comprimida labiolingualmente.

El su morfología general, las cúspides y crestas de este ejemplar son bastante similares a los ejemplares que aquí se refieren a Marmosini cf. Tlacuatzin, especialmente al ejemplar IGM 251232, correspondiente a un M3 derecho. Sin embargo, es aparentemente un poco más grande que los M3 referidos a ese taxón, aunque sigue siendo algo menores que el M3 de Tlacuatzin canescens (Tabla 5.2). Algo para resaltar es que, como se mencionó, el ectoflexo del ejemplar IGM 250278 es, aparentemente, poco profundo, pero no se preserva la porción metastilar de la plataforma; sin embargo, si se compara la porción preservada (anterior al nivel de la StC, incluyéndola) con la correspondiente en el ejemplar IGM 251232, se aprecia una morfología similar y la porción 
faltante (metastilar) es bastante saliente labialmente, dando al ectoflexo una apariencia de bastante profundidad.

\section{IGM 250345}

Material— dP3 derecho.

Localidad y Estratigrafía-San Nicolás (Localidad 22? - Universidad de Duke), área de La Venta; Capas del Mono, Miembro Baraya, Formación Villavieja, Grupo Honda.

Comentarios-Fue clasificado por Goin (1997) como Thylamys minutus, aparentemente por el tamaño y similitud con los molares superiores de aquellos ejemplares que él mismo refirió a dicha especie. Sin embargo, en la presente revisión, la gran mayoría de dichos ejemplares fueron clasificados como confrontables con el género Tlacuatzin. Durante esta revisión no se pudo tener acceso a molares deciduos de Tlacuatzin para poder realizar comparaciones. Sin embargo, entre los taxones presentes en La Venta o relacionados con estos, la morfología de este deciduo en efecto presenta una apariencia similar a la de un M1 de Tlacuatzin. En la mayoría de didélfidos, el área oclusal del dP3 oscila entre el 42\% y 96\% del área del M1, siendo relativamente grande; la única excepción es Hyladelphys, que presenta un dP3 vestigial, con un área menor al 10\% (Voss y Jansa, 2009). En el caso del presente ejemplar, el área oclusal es un 35\% de la del M1 ejemplar UCMP 108563 (Marmosini cf. Tlacuatzin), y alrededor del 26\% de la del ejemplar IGM 251011 (Marmosa sp.1). No existen por el momento M1 referibles a alguna de las especies de Thylamys de La Venta, pero el largo de los m2 es bastante cercano al del M1 del taxón cf. Tlacuatzin, por lo que probablemente se presentaría una diferencia de tamaño similar. Este tamaño es consistente para ocluir entre dp3 y $\mathrm{m} 1$ del ejemplar IGM-KU 82C1-a, referido también al marmosino cf. Tlacuatzin, pero el cual es ligeramente más pequeño que el UCMP 108563. Adicionalmente, la morfología es consistente con la observada en los ejemplares referidos a este taxón (e.g., área de la plataforma estilar, morfología del protocono, morfología y ubicación de cúspides estilares). Por estas razones, la decisión más parsimoniosa es asignarlo tentativamente a esta especie, ya que es la morfología más cercana entre los taxones conocidos para esta asociación.

\section{IGM\# 93-076}

Material-M1 izquierdo (Fig. 5.5D).

Localidad y Estratigrafía-Localidad 126 (Universidad de Duke), área de La Venta; Capas Rojas de Polonia, Miembro Cerro Colorado, Formación Villavieja, Grupo Honda.

Comentarios-Este ejemplar es inédito. El metacono es mucho más grande que el paracono y se encuentra ubicado en una posición más lingual. El protocono más largo (anteroposteriormente) que ancho (labiolingualmente) y con una cuenca del trígono bien definida aunque poco profunda. Se presenta un metacónulo vestigial y aparentemente no está presente el paracónulo. La plataforma estilar está más reducida en la porción labial al paracono. El ectoflexo es vestigial o ausente. Las cúspides estilares A, B, C y D están presentes. La StB es la cúspide estilar más alta pero es tan sólo 
ligeramente más alta que la $\mathrm{StD}$, aunque esta última es ligeramente más alargada (más extendida anteroposteriormente y comprimida labiolingualmente); por otro lado, a pesar de que la StC está rota, se aprecia que está bien desarrollada y comprimida labiolingualmente; aparentemente es algo más pequeña que la StD. Los tamaños relativos entre estas tres cúspides son diferentes a los del ejemplar UCMP 108563, donde la StD es la más pequeña de las tres, y a los de T. canescens, donde la StD es ligeramente más grande que la StB. La StA es la cúspide estilar más reducida pero está claramente diferenciada; de su cúspide se origina una cresta anterior vertical que está claramente separada del cíngulo anterior. El cíngulo anterior se origina en la base de la StA y se extiende lingualmente hasta unirse con la preprotocrista. La preparacrista se orienta casi perpendicular al eje longitudinal del diente, tocando la base de la StB en un punto anterolingual. La centrocrista presenta una clara inflexión labial, con una morfología en $\mathrm{V}$ bien definida. La postmetacrista bien desarrollada, siendo notoriamente más larga que la preparacrista. La cresta que se extiende sobre la cara posterior del metacono (postprotocrista?) es mucho más corta que en el ejemplar IGM 251232 o el UCMP 108563, en los cuales la extensión es como en Tlacuatzin canescens; se extiende tan sólo ligeramente posterolabialmente, siendo más similar a la de Marmosa sp. 1.

Este molar es un 20\% más largo que el M1 del ejemplar UCMP 108563, siendo también más pequeño que el M1 de $T$. canescens (un 15\% más corto). Además del tamaño general, sólo se diferencia del ejemplar UCMP 108563 en el tamaño relativo entre las cúspides estilares B, C y D, y en la extensión de la cresta que se extiende sobre la cara posterior de metacono (postprotocrista?). Se diferencia del M1 de T. canescens en la preparacrista ligeramente más larga, el protocono menos comprimido anteroposteriormente y menos saliente lingualmente, los tamaños relativos entre las cúspides estilares B, C y D, y el largo de la cresta que se extiende sobre la pared posterior del metacono.

\section{Comentarios generales sobre Marmosini cf. Tlacuatzin}

A continuación, se mencionan una serie de rasgos que en conjunto caracterizan a Marmosini cf. Tlacuatzin, aunque no son necesariamente exclusivos de este taxón.

La dentición superior se caracteriza porque la diferencia de altura entre el paracono y metacono disminuye posteriormente, siendo el metacono tan sólo moderadamente más grande que el paracono en el M3; el protocono es algo expandido anteroposteriormente; el paracónulo aparentemente está ausente y el metacónulo es vestigial (como en T. canescens); la plataforma estilar es amplia, presentando una reducción a nivel del paracono que es muy ligera en el M3 y se vuelve más marcada hacia el M1; el ectoflexo está ausente en el M1, es poco profundo a vestigial en el M2 y profundo en el M3; la StB es la cúspide estilar más grande y la StA la más chica; la StC se hace más pequeña y comprimida hacia el M3, siendo más desarrollada que la StD en el M1 y más pequeña en los M2-3; el cíngulo anterior está bien desarrollado en los M1-3, contactando 
lingualmente con la preprotocrista en todos los molares a pesar de que su amplitud horizontal disminuye hacia el M3; la preparacrista es casi perpendicular al eje longitudinal del diente, llegando hasta la base de la StB en su cara lingual; la centrocrista es marcadamente en "V"; la postmetacrista es notoriamente más larga que la preparacrista en el M1 pero sólo moderadamente más larga en los M2-3, siendo esta diferencia menor en el M3 (es más corta que en el M3 de la mayoría de didélfidos pero no llega a ser tan corta como la de Caluromys o Hyperdidelphys, presentando un desarrollo similar al de Glironia venusta); la cresta que se extiende sobre la cara posterior del metacono (postprotocrista? o postprotocrista + cresta postmetaconular?) formando un surco es bastante larga, exendiéndose a lo largo de toda la porción posterior de la base del metacono. Esta condición es diferente en el ejemplar IGM\# 93-076 (tentativamente referido a esta especie), donde esta cresta es mucho más corta (condición similar a la de Marmosa sp. 1).

La dentición inferior muestra el p2 con la cara labial convexa y homogénea, la cara lingual dividida en una porción anterior y una posterior, y una pequeña cúspide posterior; el dp3 es pequeño y molariforme (con trigónido y talónido); el paracónido es ligeramente mesial, al menos en los m1-2, siendo este rasgo más marcado en el $\mathrm{ml}$; el paracónido está algo desplazado labialmente al menos en m1-2; el metacónido está ligeramente desplazado posteriormente, es más marcado en el $\mathrm{m} 1$ que en el m2; el cingúlido anterior está bien desarrollado, extendiéndose hasta la base del protocónido; la preprotocrístida es claramente paralela al eje longitudinal del molar; la posthipocrístida es perpendicular al eje longitudinal; el entocónido es poco comprimido labiolingualmente, más grande que el hipoconúlido y ligeramente más pequeño que el hipocónido; el hipoconúlido es circular en vista oclusal; la crístida oblicua termina anteriormente en un punto labial a la muesca carnasial.

El tamaño de los ejemplares IGM 251232 e UCMP 108563 es consistente con Thylamys minutus (Tablas 5.2 y 5.3), lo cual es congruente con la identificación que les había dado Goin (1997). Sin embargo, se aprecia una serie de caracteres que los diferencian incluso del género Thylamys. El ejemplar IGM 251232 es un molar menos carnasializado que el M3 de cualquier especie de Thylamys, teniendo en cuenta tanto las dimensiones generales como la relación entre las longitudes de la postmetacrista y la postprotocrista (ver Materiales y Métodos): en Thylamys, la postmetacrista del M3 suele ser marcadamente más larga que la postprotocrista, mientras que en el ejemplar IGM 251232 esta diferencia no es muy marcada, siendo un molar moderadamente carnasializado. De igual forma, la diferencia de longitud entre la postmetacrista y la preparacrista es mayor en cualquier especie de Thylamys que en este ejemplar. El cíngulo anterior en el M3 está extendido lingualmente hasta unirse con la preprotocrista, mientras que en Thylamys el cíngulo anterior está menos desarrollado y está interrumpido, no llega a contactar la preprotocrista en el M3. El protocono es más desarrollado (más evidente en el M3: IGM 251232), más expandido anteroposteriormente, con una cuenca más amplia y de apariencia menos grácil que el de Thylamys, el cual presenta un protocono más comprimido anteroposteriormente y ligeramente más reducido. Adicionalmente, la centrocrista en Thylamys suele presentar una mayor inflexión, 
presentando una forma en $\mathrm{V}$ algo más cerrada. Estos dos últimos rasgos son congruentes con la ya mencionada menor carnasialidad de esta especie respecto a Thylamys (centrocrista menos cortante, protocono con una cuenca del trígono más amplia). La dentición inferior es más similar a la de $T$. colombianus. Sin embargo, se diferencia de esta especie por su menor tamaño (en un 20\%); el metacónido está menos desplazado posteriormente; el entocónido es más alto y menos comprimido labiolingualmente; el cingúlido anterior es más desarrollado; la preprotocrístida es claramente paralela al eje longitudinal del molar (en T. colombianus, si bien es casi paralela, presenta una ligera orientación anterolingual); la posthipocrístida se orienta en forma perpendicular al eje longitudinal (es más oblicua en T. colombianus); por último, el hipoconúlido es más circular en vista oclusal.

Esta especie es claramente referible a un didélfido, distinto de Thylamys. Entre los didélfidos con representantes actuales, se pudo descartar la mayoría de géneros debido a la ausencia de rasgos diagnósticos o marcadas diferencias en tamaño. Después de realizar un análisis morfológico exhaustivo se determinó que los taxones morfológicamente más cercanos son Gracilinanus, Marmosa y Tlacuatzin.

Se diferencia de Gracilinanus en el ectoflexo menos profundo, la StC más desarrollada y mejor definida, la postmetacrista menos desarrollada, la centrocrista más abierta (menos inflexionada labialmente), el cíngulo anterior más desarrollado (más amplio anteriormente), el protocono más corto lingualmente y la preparacrista más larga. Se diferencia de Marmosa en una plataforma estilar más amplia, el punto de inflexión del ectoflexo ubicado en una posición más posterior, en el desarrollo y ubicación de la StC (en Marmosa se ubica en una posición más posterior y está menos desarrollada en el M3), menor diferencia de longitud entre la preparacrista y postmetacrista, centrocrista ligeramente más abierta y la ausencia de paracónulo (vestigial o extremadamente reducido en algunas especies de Marmosa).

Entre los géneros con representantes actuales, la morfología que más se ajusta a la de esta especie es la de Tlacuatzin. Sólo pudo ser comparado con Tlacuatzin canescens porque era el único material disponible y no se encontró ningún estudio sobre la morfología dentaria de las especies de este género. Actualmente, Tlacuatzin está representado por cinco especies, pero los estudios que se han realizado para diferenciarlas son principalemente moleculares (e.g., Arcangeli et al., 2017). Por lo tanto, no se descarta que la especie de La Venta pueda corresponder a una especie ya nombrada de Tlacuatzin.

Entre los rasgos que comparte con $T$. canescens se destacan: la presencia de un dP3 molariforme (con una apariencia cercana a la del M1 de T. canescens) y relativamente grande (ca. 35\% del área oclusal del M1 del ejemplar UCMP 108563); molares superiores moderadamente carnasializados (postmetacrista visiblemente más larga que la postprotocrista); la diferencia de longitud entre la preparacrista y la postmetacrista en el M3, menor que en otros didélfidos, siendo la preparacrista ligeramente más corta que la postmetacrista; el paracónulo ausente y el metacónulo vestigial; la centrocrista fuertemente flexionada labialmente en los M1-3; el ectoflexo ausente en 
el M1, poco profundo en el M2 y profundo en el M3; el cíngulo anterior bien desarrollado, extendiéndose lingualmente hasta contactar la preprotocrista; el p2 grande, siendo tan largo como el m1 y más alto; el hipoconúlido apareado con el entocónido al menos en los m1-2; el entocónido más alto que el hipoconúlido en los m1-2.

Aún así, se diferencia de $T$. canescens en algunos rasgos: menor tamaño (entre 15 y $25 \%$ menor); el protocono es ligeramente menos comprimido anteroposteriormente; la preparacrista es algo más larga y en claro contacto con la StB (en el M3 de T. canescens está ligeramente separada de la base de la $\mathrm{StB}$ ); la StC es algo más comprimida labiolingualmente; la StB es más grande que la StD en los M1-3 (en T. canescens la StD es ligeramente más grande que la StB en el M1, subigual en el M2 y más pequeña en el M3); la StC es más grande que la StD en el M1 (en $T$. canescens es más baja). Sin embargo, la apariencia general y la gran mayoría de los rasgos son similares a los de Tlacuatzin, por lo cual estas diferencias podrían entrar dentro de la variabilidad del género, probablemente tratándose de una especie diferente a $T$. canescens. Aún así, el material disponible no permite corroborar esta asignación en forma inambigua; sólo es posible afirmar que, entre los didélfidos, Tlacuatzin es el taxón con el que muestra mayores similitudes.

\section{Didelphinae indet.}

(Fig. 5.6A-B)

Los siguientes ejemplares representan más de una especie. Su morfología y tamaño son consistentes con aquella de los Didelphinae pero el material disponible no permitió mayores precisiones sobre su asignación taxonómica. Algunos de ellos son fragmentarios o elementos dentales no diagnósticos. Sin embargo, se encontró que cada uno de ellos comparte similitudes (en cuanto a morfología y tamaño) con algún taxón perteneciente a esta subfamilia, pero están muy incompletos o no preservan rasgos diagnósticos que permitan asignarlos sin duda a estos. Algunos de estos ejemplares habían sido clasificados por Goin (1997) como Marmosini, gen. et sp. indet., probablemente debido a su tamaño. Sin embargo, para este autor la tribu Marmosini también incluía a Thylamys (como se puede ver en la clasificación que presenta de T. minutus). La clasificación aceptada actualmente incluye a Thylamys en una tribu propia, Thylamyini Hershkovitz, 1992 (véase Voss y Jansa, 2009). El tamaño de estos ejemplares está dentro del rango tanto de los Marmosini (sensu Voss y Jansa, 2009) como de los los Thylamini (sensu Voss y Jansa, 2009).

\section{IGM 250280}

Material-Fragmento de premolar indeterminado.

Localidad y Estratigrafía-Localidad CVP-5 (localidad de screenwashing, Universidad de Duke), área de La Venta; Capa de Peces, Miembro Baraya, Formación Villavieja, Grupo Honda. 
Comentarios-El ejemplar es muy incompleto. Goin (1997) lo había clasificado como Marmosini, gen. et sp. indet., probablemente debido a su tamaño. Sin embargo, el tamaño también es consistente con el de los Thylamini.

\section{IGM 250293}

Material—Dos premolares inferiores aislados (p2? y p3?).

Localidad y Estratigrafía-Localidad CVP-10 (localidad de screenwashing, Universidad de Duke), área de La Venta; Capa de Peces, Miembro Baraya, Formación Villavieja, Grupo Honda.

Comentarios-Estos dos premolares aparentemente pertenecen a diferentes individuos de una misma especie, la cual probablemente sea diferente de la especie a la que pertenece el ejemplar IGM 250344. El material es insuficiente para realizar una asignación precisa. Goin (1997) lo había clasificado como Marmosini, gen. et sp. indet., probablemente debido a su tamaño. Sin embargo, el tamaño y morfología también es consistente con el de los Thylamini.

\section{IGM 250343}

Material—Premolar inferior aislado (p3?).

Localidad y Estratigrafía-Localidad CVP-8 (localidad de screenwashing, Universidad de Duke), área de La Venta; Capa de Peces, Miembro Baraya, Formación Villavieja, Grupo Honda.

Comentarios-Fue referido por Goin (1997) a Marmosini, gen. et sp. indet. Aparentemente se trata de la misma especie que el ejemplar IGM 250344. Comparado con las especies descriptas para La Venta, su tamaño es más cercano al de M. laventica.

\section{IGM 250344}

Material—Dos premolares inferiores aislados (p2? y p3?)

Localidad y Estratigrafia-Localidad CVP-13C (localidad de screenwashing, Universidad de Duke), área de La Venta; Capa de Peces, Miembro Baraya, Formación Villavieja, Grupo Honda.

Comentarios-Se trata de dos premolares aislados que, aparentemente, no pertenecen al mismo individuo, pero sí a la misma especie. Aparentemente, se trata de la misma especie que el ejemplar IGM 250343. Fueron referidos por Goin (1997) a Marmosini, gen. et sp. indet. Comparados con las especies descriptas para La Venta, su tamaño es más cercano al de $M$. laventica.

\section{IGM 251214}

Material—Canino superior? aislado.

Localidad y Estratigrafía_Localidad 132 (Universidad de Duke), área de La Venta; unidad entre las Capas de Arenisca de Chunchullo y las Capas de Arenisca de Tatacoa, Formación La Victoria, Grupo Honda.

Comentarios-Fue clasificado por Goin (1997) como Marmosini, gen. et sp. indet. La 
morfología es más consistente con la de un canino superior que la de uno inferior. Está bien desarrollado y su tamaño (largo a la base de la porción extra-alveolar, 2,4 mm; alto de la porción extra-alveolar, $\sim 5 \mathrm{~mm}$ ) es consistente con un marmosino del tamaño de Micoureus, por lo que podría tratarse de un canino de $M$. laventica.

\section{IGM 253038}

Material-m1? izquierdo incompleto (Fig. 5.6B).

Localidad y Estratigrafía-Localidad 22 (Universidad de Duke), San Nicolás, área de La Venta; Capas del Mono, Miembro Baraya, Formación Villavieja, Grupo Honda.

Comentarios-Este ejemplar preserva el talónido completo y la mayor parte del trigonido, incluyendo el metacónido casi completo y el protocónido (no se preserva el cíngulo anterobasal). Fue referido a T. minutus por Goin (1997), probablemente por su tamaño cercano (Tabla 5.3) y algunos rasgos similares. Sin embargo, presenta algunas pocas (aunque quizás relevantes) diferencias con esta especie, como el talónido más ancho respecto al trigónido, con el hipocónido más saliente labialmente; la orientación de la posthipocrístida, que en este caso es oblicua al eje longitudinal del diente, mientras que en T. minutus es perpendicular; y la crístida oblícua que termina labialmente a la muesca carnasial, mientras en T. minutus termina por debajo de esta muesca. La morfología en general es similar a T. colombianus, pero el entocónido un poco menos desarrollado (aunque sigue siendo ligeramente más alto que el hipoconúlido); el hipoconúlido también presenta una morfología triangular en vista oclusal, pero este triángulo es mucho más abierto, teniendo su cara posterolabial casi alineada con la posthipocrístida. Estas diferencias con $T$. colombianus también son pocas, aunque una muy importante es el tamaño. El tamaño y gran parte de los rasgos morfológicos son cercanos al m1 de IGM-KU 82C1-a (Marmosini cf. Tlacuatzin), pero se diferencia de este en la preprotocrístida más oblicua, el entocónido menos desarrollado, la morfología del hipoconúlido (en IGM-KU 82C1-a está claramente diferenciado de la posthipocrístida y es más redondeado) y la posthipocrístida es oblicua.

Entre la variedad de didelfimorfios de La Venta, los tres taxones anteriormente mencionados son los que más se acercan a la morfología de este ejemplar. Sin embargo, las pocas diferencias que presenta con estos son bastante claras, por lo que es difícil asignarlo con seguridad o al menos tentativamente a alguna de estas tres especies. Adicionalmente, el ejemplar no preserva algunos elementos que podrían aportar algo más de información que ayude a diferenciarlos (e.g., el paracónido y el cíngulo anterobasal). De todos modos, no se descarta que en realidad este ejemplar pertenezca a una especie diferente.

\section{IGM 253040}

Material-Fragmento lingual de molar superior.

Localidad y Estratigrafía-Localidad 22 (Universidad de Duke), San Nicolás, área de La Venta; Capas del Mono, Miembro Baraya, Formación Villavieja, Grupo Honda. 
Comentarios-Es un material muy fragmentario, sólo se preserva claramente el protocono. Goin (1997) lo había identificado como Marmosini, gen. et sp. indet., probablemente debido a su tamaño. Sin embargo, el tamaño también es consistente con Thylamini y no se preserva ningún rasgo que permita asociarlo más con alguna de estas dos tribus.

\section{IGM 253041}

Material—Fragmento de dentario con las raíces de dos premolares.

Localidad y Estratigrafía-Localidad 22 (Universidad de Duke), San Nicolás, área de La Venta; Capas del Mono, Miembro Baraya, Formación Villavieja, Grupo Honda.

Comentarios-El ejemplar es incompleto y no se preserva ningún elemento diagnóstico, por lo que es imposible referirlo a algún taxón en particular. Goin (1997) lo había identificado como Marmosini, gen. et sp. indet., probablemente debido a su tamaño. Sin embargo, el tamaño también es consistente con el de los Thylamini.

\section{IGM 253046}

Material-Fragmento de dentario con raíces de un premolar o molar.

Localidad y Estratigrafía-Localidad 22 (Universidad de Duke), San Nicolás, área de La Venta; Capas del Mono, Miembro Baraya, Formación Villavieja, Grupo Honda.

Comentarios-Este ejemplar está bastante incompleto y no se preserva la dentición, por lo que es casi imposible clasificarlo. Goin (1997) lo había clasificado como Marmosini, gen. et sp. indet., probablemente debido a su tamaño. Sin embargo, el tamaño también es consistente con el de los Thylamini.

\section{IGM\# 93-078}

Material—trigónido de m2? izquierdo (Fig. 5.6A).

Localidad y Estratigrafía - Localidad 126 (Universidad de Duke), área de La Venta; Capas Rojas de Polonia, Miembro Cerro Colorado, Formación Villavieja, Grupo Honda.

Comentarios - Se trata de un ejemplar inédito. Este trigónido es aproximadamente tan largo como ancho. El protocónido es la cúspide principal, pero tiene una altura moderada, no es marcadamente más alto que las otras cúspides. El metacónido está bien desarrollado y claramente separado del protocónido; es ligeramente más alto que el paracónido, si bien este último es un poco más amplio en vista oclusal. El paracónido está bien diferenciado y se ubica en una posición ligeramente mesial. El trigónido es abierto labialmente, ya que el paracónido está bastante separado del protocónido y la paracrístida tiene una morfología de "valle" en lugar de la muesca carnasial. Esta última es de aspecto poco cortante. La metacrístida también es poco cortante, siendo el metacónido y el protocónido bastante redondeados. El cíngulo anterobasal está fuertemente reducido, observándose tan sólo como una protuberancia. Las cúspides bien separadas entre sí y su apariencia redondeada (excepto el paracono que es más triangular), junto con las crestas poco 
cortantes, sugieren hábitos más insectívoros que carnívoros. Esta morfología no se presenta en ninguno de los didélfidos hasta ahora descriptos para La Venta.

Se trata sólo de un trigónido, pero contiene información suficiente para determinar que no se trata de ninguna de las especies hasta ahora descriptas para esta asociación. El tamaño es menor que el de M. laventica y mayor que el de los demás didélfidos de La Venta. Después de comparar todas las morfologías de molares inferiores de los taxones de La Venta y taxones relacionados (extintos o vivientes), no se encontró una morfología que fuera notablemente similar. Sin embargo, entre la variedad de morfologías de los didélfidos, la apariencia de este ejemplar recuerda a la del extinto didelfino Zygolestes (Ameghino, 1898). Este taxón fue clasificado como un marmosino por Goin et al. (2000), pero para ese entonces esta tribu inclúa a tanto a los tilaminos como los marmosinos. De hecho, su morfología dentaria se asemeja más a la de Gracilinanus o Cryptonanus (tilaminos), por lo que probablemente no sería un marmosino en el sentido que se da, actualmente, a esta tribu.

Varios de los rasgos que presenta el ejemplar IGM\# 93-078 son cercanos a la morfología de Zygolestes, como lo son las proporciones de las cúspides del trigónido (similares a las de $Z$. paranensis); el paracónido bien diferenciado y ubicado en una posición ligeramente mesial; el trigónido abierto labialmente por la amplia separación entre el paracónido y el protocónido; la paracrístida de aspecto poco cortante y con una muesca carnasial ámplia, con morfología de "valle"; y la metacrístida poco cortante, siendo el metacónido y el protocónido bastante redondeados. Sin embargo, se diferencia, en general, de Zygolestes en el cíngulo anterobasal fuertemente reducido (bien desarrollado en Zygolestes), las bases del protocónido y metacónido más separadas entre sí y la metacrístida aparentemente menos desarrollada.

Las proporciones de las cúspides son mas parecidas a las de $Z$. paranensis (Ameghino, 1898), ya que en Z. tatei (Goin et al., 2000) el protocono es mucho más alto que las demás cúspides. Su largo es bastante cercano al de los trigónidos de los m2-4 de Z. paranensis (el talónido del $\mathrm{m} 1$ de $Z$. paranensis es más pequeño), pero sus proporciones son diferentes, ya que en Z. paranensis los trigónidos son más largos que anchos. El tamaño y proporciones del trigónido son similares a los del $\mathrm{m} 3$ de $Z$. tatei, aunque es menos comprimido anteroposteriormente; los trigónidos de los otros loci de Z. tatei son más largos que anchos debido a que el largo absoluto del molar incluye el cíngulo anterobasal, el cual se extiende anteriormente más allá del paracónido; no obstante, el triángulo formado por el paracónido, metacónido y protocónido es mucho más comprimido anteroposteriormente (el paracónido y metacónido están más cercanos) que en el ejemplar de La Venta. El paracónido se encuentra en una posición mesial pero no tanto como en el $\mathrm{m} 1$ de Zygolestes, siendo más parecido al del $\mathrm{m} 2$ de Z. paranensis o al de los $\mathrm{m} 2-3$ de Z. tatei. La pronunciada separación del paracónido respecto al protocónido, formando un valle en la paracrístida, puede verse claramente en $Z$. tatei.

Entre estas dos especies de Zygolestes, la morfología del ejemplar IGM\# 93-078 es, aparentemente, más cercana a la de Z. tatei, aunque las diferencias indicarían que posiblemente no 
se trata de la misma especie. Sin embargo, siendo tan incompleto el material preservado, no es posible saber si las diferencias mencionadas respecto a Zygolestes podrían encontrarse dentro del rango de variabilidad intragenérica ni es prudente tomar una decisión taxonómica respecto al ejemplar, más allá de referirlo a los didelfinos. Uno de estos rasgos es la marcada diferencia en el desarrollo del cíngulo anterobasal, el cual hace dudar que el ejemplar sea referible a este taxón. Sin embargo, entre la diversidad de morfologías de los didélfidos, la de Zygolestes es la más cercana al ejemplar de La Venta.

\section{IGM\# 93-148}

Material-Trigónido de $\mathrm{m} 1$ derecho.

Localidad y Estratigrafia-Localidad 4 (Universidad de Duke), área de La Venta; Grupo Honda.

Comentarios-En este ejemplar inédito la única cúspide completa es el protocono, el paracono está parcialmente preservado y sólo se observa la base del metacónido. La apariencia y posición de las cúspides, así como la morfología general del trigónido es más cercana a los marmosinos que a cualquier otro didélfido. Entre los didélfidos de La Venta, la especie que mejor se ajusta en tamaño a este trigónido es $M$. laventica, aunque el ejemplar es ligeramente más pequeño. La morfología general del trigónido sólo es cercana a la del $\mathrm{m} 1$ de esa especie. Sin embargo, en la pared posterior del trigónido se preserva una pequeña porción anterior del talónido donde se alcanza a observar el extremo anterior de la crístida oblicua, la cual llega hasta la muesca carnasial o un punto cercano a esta; en el $\mathrm{m} 1$ de $M$. laventica, la crístida oblicua se conecta anteriormente con el trigónido al nivel del protocono; adicionalmente se diferencia de dicha especie en que el cíngulo anterobasal está mucho menos desarrollado; en M. laventica es reducido respecto al de otros didélfidos y sólo parcialmente desarrollado, pero en este ejemplar el cíngulo es casi vestigial.

\section{KU 1995-3}

Material—Talónido derecho

Localidad y Estratigrafía_Localidad dudosa (Universidad de Kioto): "Masato site" (Capas Rojas de El Cardón, Miembro Cerro Colorado) o "Kioto site" (nivel indeterminado del Miembro Baraya; i.e., Miembro Molina sensu Takai et al., 1992); Formación Villavieja, Grupo Honda.

Comentarios-El material es inédito. Su morfología sugiere un locus entre el m1 y el m3. Es más ancho que largo. El hipocónido se ubica en el extremo posterolabial del molar. El entocónido se ubica en un punto medio del margen lingual del talónido; está bastante desgastado pero, aparentemente, es más chico que el hipocónido y ligeramente más alto que el hipoconúlido, y está ligeramente comprimido labiolingualmente. El hipoconúlido se ubica en una posición lingual, posterior al entocónido. La preentocrístida se orienta paralela al eje anteroposterior del diente. La crístida oblicua no se preserva completa (falta su extremo anterior), pero aparentemente se dirige 
hacia un punto labial a la muesca carnasial, muy cercano a esta.

El tamaño de este molar es consistente con el $\mathrm{m} 1$ de $M$. laventica y la morfología es similar, aunque presenta un aspecto más cuadrangular. Sin embargo, se consideró que el material es tan incompleto que no es suficientemente informativo para realizar una clasificación más detallada.

\section{DIDELPHIMORPHIA fam. incertae sedis}

\section{Género A}

gen. nov.

Especie Tipo-Género A sp. 1 gen. et sp. nov.

Especies Referidas-La especie tipo y Género A sp. 2 gen. et sp. nov.

Distribución-Área de La Venta (Desierto de La Tatacoa, Valle Superior del Magdalena, Departamento del Huila, Colombia); Grupo Honda, Laventense, Mioceno medio.

Diagnosis-Tamaño comparable al de las especies más grandes del subgénero Micoureus; cráneo con el foramen infraorbitario relativamente grande; el lacrimal extendido sobre el rostro; el proceso anterior del aliesfenoides contacta con el maxilar en el piso orbitario; los forámenes palatinos mayores relativamente cortos; el paracónulo y metacónulo bien desarrollados; la StC presente en los M1-3, muy grande en el M1 y disminuyendo en tamaño hacia el M3; la StD bien desarrollada en los M1-3, subigual a la StB; una StE vestigial presente; el m2 más grande que el $\mathrm{m} 3$; el hipocónido algo saliente labialmente en el m1, casi alineado con el protocono en el $\mathrm{m} 2$ y lingual al protocono en el m3; presencia de una muesca carnasial en la porción anterior de la crístida oblicua y en la preentocrístida.

\section{Género A sp. 1}

gen. et sp. nov.

(Figs. 5.7-5.8)

Holotipo-IGM-KU-IV-1, cráneo incompleto, incluyendo la porción entre el nivel de los caninos y la constricción postorbital, con los alvéolos de los caninos (con fragmentos de raíz), los P1-M2 derechos completos, el P1 izquierdo incompleto y los P2-M4 izquierdos completos.

Ejemplares Referidos-IGM 184151, dentario izquierdo incompleto, incluyendo gran parte de la rama horizontal y la base de la vertical, con los m2-4; IGM 252951, fragmento de dentario con el alveolo posterior del p1, las raíces del p2, la base de la corona del p3, m1-2 completos y las raíces de $\mathrm{m} 3$ con un fragmento anterior de la corona.

Localidad y Estratigrafía-Holotipo: Localidad “Kioto Site” (Universidad de Kioto); Capas 
del Mono, Miembro Baraya, Formación Villavieja. Ejemplares referidos: IGM184151, Localidad 22 (Universidad de Duke), San Nicolás; Capas del Mono, Miembro Baraya, Formación Villavieja; IGM 252951, Localidad 126 (Universidad de Duke); Capas Rojas de Polonia, Miembro Cerro Colorado, Formación Villavieja. Todas las localidades del área de La Venta, Grupo Honda, Laventense (Tablas 3.1 y 5.1; Fig 3.1)

Diagnosis-Tamaño menor que el del Gén. A sp. 2; molares inferiores con la crístida oblicua dirigida hacia el protocono en el $\mathrm{m} 1$, más lingual en el $\mathrm{m} 2$ y hacia la muesca carnasial de la metacrista en los m3-4.

Comentarios-El ejemplar IGM-KU-IV-1, el holotipo, es un material inédito. El ejemplar IGM 184151 había sido clasificado previamente como "tentativamente referido" a $M$. laventica (Goin, 1997), mientras que el ejemplar IGM 252951 es inédito.

La dentición de estos dos ejemplares presenta una morfología y tamaño consistentes con los del holotipo. Sin embargo, se observa que la altura del dentario del ejemplar IGM 252951 es mayor que la del IGM 184151 (Tabla 5.6), si bien la diferencia de tamaño en la dentición es ligera (Tabla 5.5). A pesar de que claramente uno de ellos era más viejo, ya que presenta un desgaste mayor, ambos individuos eran adultos, por lo cual esta diferencia en altura probablemente no se deba a un factor ontogenético. Otro factor que podría conllevar a tal diferencia de altura es el dimorfismo sexual, como ocurre en algunos didélfidos (e.g., Monodelphis: pers. obs; Goin, pers. comm.). Sin embargo, en este caso se presenta además una ligera diferencia en el tamaño de la dentición, siendo ligeramente más grande en el ejemplar IGM 252951 (Tabla 5.5); en general, aún cuando puede haber dimorfismo sexual en metaterios, los dientes no presentan esta diferencia, manteniendo un tamaño que no varía entre machos y hembras (Martin, pers. comm.). Es por esto que, dadas las similitudes en la morfología dentaria, que sólo se presenta una ligera diferencia en tamaño y que la altura del dentario, por sí sola, no representa un factor indiscutible para diferenciar especies, se concluye que probablemente se esté presentando una variación intraespecífica de tamaño, que se trate de individuos de diferente tamaño dentro del rango de variabilidad de la especie.

Con el fin de mostrar una descripción lo más completa posible de la especie, la descripción que se presenta a continuación es basada tanto en el holotipo como en los ejemplares referidos, ya que estos últimos preservan elementos mandibulares y de dentición inferior no preservados en el holotipo.

Descripción-El tamaño de esta especie es cercano al de $M$. laventica, aunque ligeramente más grande (Tablas 5.3, 5.5 y 5.8).

Del cráneo se preserva una porción entre el nivel de los caninos y el nivel de la constricción postorbital. Se preservan los maxilares, los palatinos, un fragmento anterior de yugal izquierdo, el lacrimal derecho, la porción más posterior de los nasales, los frontales y la región orbitotemporal de ambos lados. En esta última, las suturas no son claras debido al estado de preservación, por lo que no es posible delimitar claramente cada uno de los huesos que allí se ubican. Tampoco es claro si se alcanza a preservar la sutura entre los frontales y los parietales (ni en el techo craneano, ni en 
la región orbitotemporal), por lo que no es claro si se preserva o no parte de este elemento.

A juzgar por la porción preservada, el rostro es, aparentemente, corto. Los nasales sólo preservan una pequeña porción posterior, pero se observa claramente el espacio que ocupaban, a partir del cual se puede inferir su morfología. En vista dorsal, son relativamente cortos y su anchura es constante hasta el foramen infraorbitario, a partir del cual se ensanchan posteriormente; el ancho vuele a decrecer a partir de un punto al nivel del extremo más anterior del lacrimal, hasta acuñarse entre los frontales por medio de una sutura nasofrontal en forma de "W" cerrada. Contactan lateralmente al menos con el maxilar (no se preserva el premaxilar) y posteriormente con el frontal. Adicionalmente, en el plano sagital se observa una sutura recta entre ambos nasales, que puede apreciarse sobre todo en la porción más posterior (mejor preservada).

Los frontales se preservan en toda o casi toda su extensión, pero al no ser claras algunas suturas, en este caso la sutura con los parietales, no es posible saber si están o no completos en su extremo posterior. La sutura frontomaxilar es irregular, relativamente corta y oblicua al plano sagital, similar a la que se observa en Glironia, Caluromys, Didelphis, Cryptonanus, Marmosa, Micoureus, Monodelphis y Gracilinanus. Otros didélfidos extintos como Thylatheridium e Hyperdidelphys, presentan una sutura también oblicua, pero más larga. Por el contrario, Sparassocynus presenta una sutura larga y orientada perpendicular al plano sagital. Los procesos postorbitales son pequeños, aunque bien diferenciados, presentando una morfología de cuernos de punta roma, similar a la que se observa en Didelphis, Philander o Lutreolina, pero en este caso son un poco menos desarrollados, y mucho menos desarrollados que los de Sparassocynus (en este presentan otra morfología, más triangular y aplanada o "alada", y muy desarrollados). Las crestas del frontal están presentes y son coalescentes en el plano sagital formando la cresta sagital, aunque no están tan marcadas como en algunos didélfidos (i.e. Chironectes, Didelphis, Lutreolina, Philander, Caluromysiops, Thylophorops e Hyperdidelphys). Se preserva sólo una muy pequeña porción anterior de la cresta sagital, la cual es aparentemente baja, probablemente de desarrollo similar a la de Chironectes; la cresta se extiende anteriormente hasta los frontales. La sutura que separa ambos frontales es regular en gran parte de su extensión, excepto en la porción comprendida entre un punto a la altura del extremo posterior de los procesos postorbitales y el punto en que se unen las crestas del frontal.

El lacrimal se extiende anteriormente sobre el rostro hasta el nivel del M1, siendo el ancho de la porción facial del lacrimal mayor a la mitad de su altura (carácter 90), como ocurre en Philander opossum, Hyperdidelphys y Thylophorops. Esta porción facial presenta una morfología de medialuna irregular, ya que su margen anterior está conformado por dos suturas irregulares (con el extremo anterodorsal del frontal y el proceso facial del maxilar). La sutura con el proceso facial del maxilar presenta una porción anteroventral en forma de cuña (apuntando anteriormente). Esta morfología es similar a la de algunos Monodelphis (aunque más irregular) y Thylophorops, aunque en este último la cuña está en la porción anterodorsal; a su vez, difiere de muchos otros didelfoideos (e.g., Glironia, Caluromys, Chironectes, Didelphis, Metachirus, Monodelphis, 
Tlacuatzin, Thylatheridium y Sparassocynus), donde la sutura es claramente convexa anteriormente y mucho más regular. Se presentan dos forámenes lacrimales que abren afuera de la órbita. En la mayoría de didélfidos actuales, así como en Thylatheridium, Thylophorops e Hyperdidelphys, se presentan dos forámenes lacrimales (excepto en Chironectes, Hyladelphys y algunas poblaciones de Didelphis virginiana, los cuales presentan uno: Voss y Jansa, 2009), aunque en ocasiones, en didélfidos que normalmente presentan dos forámenes lacrimales, puede presentarse un único foramen en uno o ambos lados del cráneo (Voss y Jansa, 2009). En algunos casos, los forámenes lacrimales pueden ubicarse dentro de la órbita, pero usualmente abren afuera de esta o cerca del margen orbital (Voss y Jansa, 2009). En la presente revisión no se tuvo acceso a materiales de esparasocínidos que preserven claramente estos forámenes. Sin embargo, Forasiepi et al. (2009) reportan un sólo foramen lacrimal para Hesperocynus; en Sparassocynus aparentemente se presentan en general dos (Reig y Simpson, 1972; Forasiepi et al., 2009), aunque se ha observado ejemplares con un sólo foramen (e.g., MMP 172S, S. derivatus: en Reig y Simpson, 1972).

El maxilar preserva la mayor parte del proceso facial en ambos lados del cráneo. El foramen infraorbital es de tamaño relativamente grande (con relación al tamaño general del cráneo), similar al de Chironectes y Thylophorops; y presenta una forma cercana a una U, abriendo al nivel de la raíz anterior del P3, como en Glironia, Cryptonanus, Lestodelphys, Marmosops, Thylamys, Marmosa y Tlacuatzin. En Thylophorops y Sparassocynus, el foramen abre ligeramente más posterior, más cerca de la raíz posterior del P3. En vista ventral, la porción palatal del maxilar está casi completa, faltando una pequeña porción posterolateral derecha, posterior al M2, y probablemente un pequeño fragmento en el límite con el premaxilar (no preservado). El paladar es relativamente aplanado, con los márgenes laterales casi paralelos, presentando una morfología subrectangular, como ocurre en Glironia y muchos didelfinos (e.g., Didelphis, Lutreolina, Philander, Marmosops, Metachirus, Tlacuatzin, Thylophorops e Hyperdidelphys); y contrario a Sparassocynus, Hesperocynus y Thylatheridium, donde estos márgenes son notoriamente más oblicuos al plano sagital, mucho más marcado en los dos primeros, los cuales presentan una morfología triangular bastante más amplia posteriormente, mientras que en Thylatheridium el paladar es en general bastante ancho pero la morfología es de un triángulo más cerrado (subrectangular). Se preservan los bordes posteriores de los forámenes incisivos, ubicándose en posición posterior al borde anterior del alvéolo del canino. Los forámenes palatinos mayores están presentes y bien desarrollados (aunque relativamente cortos), formando claras fenestras (vacuidades), y se ubican sobre la sutura maxilopalatina, aunque la mayor parte de su extensión se ubica sobre el maxilar. Son cortos, extendiéndose desde en nivel de la unión entre los M1-2 hasta el nivel del protocono del M3, siendo menos desarrollados que en los didelfinos actuales. Entre los esparasocínidos, estas fenestras sólo están desarrolladas en Hesperocynus (aunque aparentemente más cortas que en Género A), mientras que en Sparassocynus sólo se presentan pequeños forámenes, no fenestras (ver carácter 46), tal como ocurre en Thylophorops, Thylatheridium y los calurominos. No se presentan fenestras maxilares, como en la mayoría de didélfidos (excepto 
Gracilinanus, Thylamys y Tlacuatzin) y los esparasocínidos.

Del yugal sólo se preserva un pequeño fragmento correspondiente al proceso anterior que contacta con el maxilar. No es clara la sutura maxiloyugal, pero aparentemente es oblicua a la hilera dentaria, con un ángulo menor a $45^{\circ}$ respecto de esta.

Los palatinos se extienden en vista ventral desde un punto entre el M2 y el M3, pero no se observa claramente su extremo posterior (i.e., posterior al paladar). La porción palatal está rota donde deberían ubicarse los forámenes palatinos menores (de haber estado presentes), y se observa un pequeño reborde curvo; sin embargo, debido al estado de preservación del material no es posible confirmar si se trata de una porción del borde del foramen, motivo por el cual no fue posible inferir su presencia. Los forámenes palatinos menores están presentes en la mayoría de los metaterios (e.g., didelfimorfios y la mayoría de esparasodontes), aunque en algunos no están cerrados (e.g., Arctodictis sinclairi y algunos ejemplares de Deltatheridium-Forasiepi, 2009), presentándose tan solo una muesca. El margen posterior del paladar es recto, debido a la presencia de torus palatinos, los cuales muestran esquinas menos prominentes que en Gracilinanus, Marmosops, Metachirus, Monodelphis y Thylatheridium. No hay fenestras palatinas, al igual que en Glironia, los calurominos, los hiladelfinos, algunos didelfinos (i.e., Chironectes, Metachirus, Marmosa, Monodelphis, Tlacuatzin e Hyperdidelphys), Thylatheridium y Sparassocynus.

En la región orbitotemporal se logra identificar claramente el lacrimal y se preserva la porción correspondiente al palatino, el frontal, el aliesfenoides y el proceso orbital del maxilar; sin embargo, las suturas entre estos huesos no son claras, por lo que no es posible delimitarlos con certeza. Por esta misma razón, no queda claro si se preserva también parte del parietal. Las únicas suturas claramente identificables en esta zona se ubican en el piso orbital, donde se observa parte de la sutura entre el palatino y el maxilar, y la sutura entre el palatino y el proceso anterior del aliesfenoides (más clara en el lado izquierdo); adicionalmente, se observa que este último se encuentra en contacto con el maxilar, como ocurre en Lutreolina y Monodelphis. En la mayoría de didélfidos no existe este contacto, excepto en ocasionales casos de individuos particulares (ver Voss y Jansa, 2003, carácter 43; Voss y Jansa, 2009, Fig. 7). Se identifican claramente al menos dos perforaciones: el foramen esfenopalatino y la fisura esfenorbital; inmediatamente posterior a este último aparentemente se alcanza a preservar parte de la pared medial del foramen rotundum.

El dentario es aparentemente grácil, de altura moderada en el ejemplar IGM 252951 (está incompleto pero es lo que se aprecia en relación al tamaño de los dientes), mientras que en el ejemplar IGM 184151 el dentario es más bajo. El margen ventral del dentario es curvo a lo largo de toda su extensión y es anteriormente fusiforme. La sínfisis mandibular habría sido ligamentosa (no fusionada) y llega hasta el nivel del límite entre el p2 y el p3. Esta especie presenta dos forámenes mentonianos, como la mayoría de los didelfoideos (excepto Chironectes y agunos Marmosops): en el ejemplar IGM 252951 se preservan los dos, uno por debajo de la raíz posterior del p1 y el otro a nivel de la raíz anterior del m1, casi en el límite con el p3; en el ejemplar IGM 184151 sólo se preserva el más posterior y se ubica por debajo de la raíz anterior del $\mathrm{m} 1$. El espacio retromolar 
está presente. El ángulo entre el borde anterior del proceso coronoides y la hilera dentaria es ca. $118^{\circ}$.

La dentición superior presenta una apariencia general didelfimorfia. A pesar de que no se preservan los caninos, sus alvéolos indican una morfología relativamente robusta, aunque más pequeños que en Sparassocynus; menos comprimidos que en Didelphis y ligeramente más que en Caluromys y Sparassocynus; en general su apariencia es similar a la de Hesperocynus.

E1 P1 está alineado con la hilera dentaria. Está fuertemente reducido, pero menos que en los calurominos, teniendo aproximadamente la mitad del tamaño del P2. Muestra una cúspide principal y un talón poco desarrollado. Es asimétrico en vista lateral, siendo más elongado posteriormente; no está comprimido lateralmente; su aspecto es piramidal, con una cara labial algo convexa y una lingual subdividida en dos facetas (anterolingual y posterolingual), como en Hyperdidelphys y Sparassocynus. La cresta anterior es muy corta y la posterior mucho más larga; ambas están pobremente desarrolladas. La mayoría de los didélfidos tienen el P1 reducido con respecto a los demás premolares, pero teniendo al menos cerca de la mitad de la altura del P2 (excepto Caluromys y Caluromysiops, en los que es vestigial); el P1 lateralmente comprimido, con una cúspide principal casi triangular en vista lateral y lingual, usualmente acompañada por una cúspide accesoria anterior y otra posterior (Voss y Jamsa, 2009). Existe un corto diastema $(0,45 \mathrm{~mm})$ entre el P1 y el P2, siendo proporcionalmente más corto que aquel presente en Hyperdidelphys y Thylophorops. Este diastema también está presente en los didélfidos actuales, si bien su longitud varía entre las diferentes especies. Por otro lado, en los esparasocínidos no hay diastemas entre los premolares superiores.

Los P2-3 son bulbosos y ovalados en vista oclusal, como en Didelphis, Thylophorops y Sparassocynus, y muestran un fuerte desgaste apical. Tanto el P2 como el P3 tienen un cíngulo basal que rodea por completo la corona, como ocurre en Caluromys y Caluromysiops. Ambos premolares muestran un margen anterior redondeado y suave, sin borde cortante alguno, mientras que la posterior es cortante, tal como se observa en la mayoría de didélfidos; en Chironectes y Philander aparecen pequeñas crestas hacia la base de la corona, las que no alcanzan a llegar hasta el ápice de la cúspide principal. Tanto en Hyladelphys como en los calurominos se aprecian bordes cortantes anterior y posterior. El P2 es tan sólo ligeramente comprimido lateralmente y, aparentemente, no incluye cúspides accesorias sino un reducido talón y una vestigial expansión posterolingual; no existe una cúspide accesoria posterolingual como en Sparassocynus. La cresta posterior está bien definida y se encuentra ligeramente orientada psoterolabialmente. Adicionalmente, sobre la cara lingual se presenta una cresta muy baja y suave, casi vestigial, que desciende posterolingualmente desde el ápice de la cúspide principal.

E1 P3 es más alto que el P2, como ocurre en muchos didélfidos actuales y extintos (e.g, Chironectes, Cryptonanus, Didelphis, Lestodelphys, Lutreolina, Monodelphis, Philander, Thylamys, Hyperdidelphys, Thylatheridium y Thylophorops) y en Sparassocynus. Es robusto, con una cúspide principal de morfología cónica bastante simétrica (de sección transversal circular) y 
bulbosa, y sus superficies labial y lingual son curvas y homogéneas (sin facetas). Además de la cúspide principal, se aprecia una cúspide accesoria posterior bien desarrollada, similar a la que existe en Gracilinanus agilis y más desarrollada que la de Thylatheridium; en algunos ejemplares de Thylophorops puede presentarse una cúspide posterior vestigial. La cresta posterior es bastante verticalizada y bien desarrollada. El cíngulo basal que rodea la corona del P3 se expande posteriormente formando un talón, más desarrollado que en el P2, sobre el cual se ubica la cúspide posterior.

Los molares superiores están fuertemente desgastados, siendo más marcado este desgaste en los M1-2. E1 largo del M1 es subigual al del M2, mientras el M3 es ligeramente más largo; el M4 está bastante comprimido anteroposteriormente. Por otro lado, el ancho de los molares muestra un moderado aumento de tamaño del M1 al M3, siendo el M4 ligeramente más angosto que el M3. El paracono está bastante reducido, pero es claramente diferenciable y más desarrollado que el de los esparasocínidos, y se ubica en una posición más labial con respecto al metacono. El metacono está bien desarrollado (mucho más en el M3) y es más alto que el paracono en los M1-3, como ocurre en la mayoría de los didélfidos. En el M4, el metacono es vestigial; en su lugar se aprecia un cíngulo, fuertemente reducido y comprimido anteroposteriormente, la estructura recuerda la de algunos Thylamys (e.g., T. pusillus y T. venustus). En la mayoría de los didélfidos el metacono del M4 está fuertemente reducido respecto al paracono, pero presenta una clara morfología de cúspide, sin una compresión anteroposterior ni apariencia de cíngulo. Por otro lado, el metacono del M4 es vestigial o ausente en Lutreolina crassicaudata, Monodelphis brevicaudata, Philander opossum, Hyperdidelphys y Sparassocynus. Los protoconos están algo comprimidos anteroposteriormente, como ocurre en algunos didélfidos (e.g., Chironectes minimus, Gracilinanus agilis, Lestodelphys halli, Lutreolina crassicaudata, Monodelphis brevicaudata, Philander opossum, Hyperdidelphys, Thylophorops y Thylatheridium) y son relativamente pequeños, pero menos comprimidos y más desarrollados que en los esparasocínidos. La compresión aumenta del M1 al M4. Los para- y metacónulos están presentes, siendo más desarrollados que en cualquier didélfido (incluyendo Thylatheridium, de desarrollo relativamente mayor) o esparasocínido. Son más claros en el M3, ya que los M1-2 están mucho más desgastados, y en el M4 son vestigiales. Al menos en los paracónulos de M1-3 se presenta una cresta preparaconular, pero por el desgaste en el área de la cuenca del trígono no es posible saber si había cresta postparaconular ni premetaconular; la postmetaconular aparentemente no existe. Únicamente en el M2 parece haber una cresta postmetaconular, mientras que en los M1 y M3 pareciera estar ausente (siendo esto mucho más claro en el M3), como ocurre en el metacónulo de los molares superiores de Sparassocynus bahiai (observable en los ejemplares con menor desgaste).

Los molares superiores presentan crestas cortantes bien desarrolladas. La preparacrista está orientada perpendicular al eje de la hilera dentaria, conectando con la StB, y es más corta que la postmetacrista en los M1-3. La centrocrista está ligeramente flexionada, siendo casi recta (se observa más claramente en el M3, donde está menos desgastada), similar a la de Hesperocynus y 
algunos didélfidos actuales como Hyladelphys y Glironia, pero es ligeramente menos recta que la de Sparassocynus o Thylatheridium. La postmetacrista está bien desarrollada en los M1-3, pero es más corta que en la mayoría de didelfimorfios y similar a la de Tlacuatzin canescen y Glironia venusta, pero no llega a ser tan corta como la de Caluromys o Hyladelphys. En el M4, la postmetacrista está extremadamente reducida y se conecta con el borde posterior del diente. La diferencia de longitud entre la postmetacrista y la preparacrista va disminuyendo del M1 al M3 (la preparacrista se hace relativamente más larga y la postmetacrista más corta).

La plataforma estilar es amplia, reducida en la porción labial al paracono, siendo esta reducción más marcada hacia el M1. Se presenta un ectoflexo poco profundo en el M2 y uno relativamente profundo en el M3 (comparado con el de otros didelfimorfios en general, aunque no tan profundo como en Hesperocyus o algunos otros metaterios - e.g., Deltatheroides y Deltatheridium; pers. obs.). En la mayoría de didélfidos (excepto Caluromys y Caluromysiops) se presenta ectoflexo en al menos uno de los molares superiores (ver carácter 70 en el análisis filogenético). Las cúspides estilares A, B, C y D están claramente presentes, pero en la esquina metastilar del M3 se observa lo que aparentemente sería una StE vestigial, similar a la que se observa en Mimoperadectes houdei (ejemplar USNM 482355 en Horovitz et al., 2009) y diferente de la que se observa en Philander, la cual está más desarrollada y ligeramente desplazada anteriormente. La StA es bastante reducida, siendo la siguiente cúspide estilar más pequeña después de la StE vestigia. La StB y StD son subiguales en tamaño y más grandes que la StC. Las cúspides estilares B, C y D están más desarrolladas en los M1-2 que en el M3. La StC es de gran tamaño en los M1-2 (ligeramente más reducida en el M2) y relativamente pequeña en el M3, pero claramente distinguible. El cíngulo anterior está bien desarrolado en los M2-4, conectándose lingualmente con la cresta preparaconular (ver carácter 71). La preprotocrista termina en el paracónulo, mientras la postprotocrista termia en el metacónulo (ver carácter 74).

En la dentición inferior no se presentan diastemas entre los dientes de la serie preservada en entre los ejemplares referidos (i.e., del p1 al m4). Del p1 sólo se preserva el alvéolo posterior y parte del anterior; del p2 se preservan las raíces, mientras que del p3 se preservan las raíces y parte de la base de la corona. Las raíces de los premolares son comprimidas (no son globosas). A juzgar por el tamaño de los alvéolos del p1 este diente sería significativamente más chico que los p2-3, teniendo así un cambio abrupto de tamaño entre el p1 y los p2-3. La longitud (largo) que abarcan los alveolos del p2 es mayor que el largo del p3, pero esto no necesariamente implica que el p2 fuera más alto, ya que podría estar más imbricado hacia adelante, como puede ocurrir en los premolares inferiores, o que tuviera una morfología más elongada. El p3 presenta un talón bien desarrollado.

En los molares inferiores, el lóbulo posterior de la corona es más bajo que el anterior en m13. El tamaño general de los molares presenta una variación gradual y bastante sutil. El largo total del molar no aumenta continuamente en sentido posterior, sino que $\mathrm{m} 1<\mathrm{m} 2$ y $\mathrm{m} 2>\mathrm{m} 4>\mathrm{m} 3$. No fue posible comparar directamente el tamaño del $\mathrm{m} 1$ respecto a los $\mathrm{m} 3-4$, ya que no se preservan 
juntos en un mismo ejemplar. Sin embargo, al contrastar los m3-4 del ejemplar IGM 184151 con el tamaño de los alveolos del $\mathrm{m} 1$ presentes en el mismo, aparentemente el largo del $\mathrm{m} 1$ sería menor al del m3. También se realizó un cálculo a partir de la relación del m2 vs m3 en el ejemplar IGM 184151 y del m1 vs m2 en el ejemplar IGM 252951 (regla de 3), el cual arrojó el mismo resultado, por lo que en teoría, en orden, el largo de los molares sería $\mathrm{m} 1<\mathrm{m} 3<\mathrm{m} 4<\mathrm{m} 2$. Todas las diferencias de longitud son bastante sutiles, no hay ningún cambio abrupto en el largo del molar.

El trigónido es más angosto que el talónido en el m1, subigual en el m2 y más ancho en los m3-4 (mucho más en el m4). El ancho absoluto del trigónido es $\mathrm{m} 1<\mathrm{m} 2$ y $\mathrm{m} 2 \approx \mathrm{m} 3>\mathrm{m} 4$; no fue posible comparar el ancho del $\mathrm{m} 1$ con el del $\mathrm{m} 4$ en un mismo ejemplar, pero según la diferencia de tamaño del $\mathrm{m} 1$ respecto al $\mathrm{m} 2$ (en el ejemplar IGM 252951) y del $\mathrm{m} 2$ respecto al $\mathrm{m} 4$ (en el ejemplar IGM 184151), es probable que el trigónido del $\mathrm{m} 1$ sea más ancho que el del m4. Las cúspides del trigónido se disponen formando un triángulo en todos los molares. El protocónido es la cúspide principal del trigónido y está bien desarrollado. El metacónido está bien desarrollado, se encuentra claramente separado del protocónido y ubicado al mismo nivel este en el m1 y el m4; sin embargo, en los m2-3 presenta un desplazamiento posterior, más marcado que en cualquier didelfido de La Venta, pero no llega a ser tan fuertemente marcado como en Hyladelphys. Como consecuencia, la metacrístida presenta una orientación ligeramente oblicua en los m2-3 y es perpendicular a la hilera dentaria en los $\mathrm{m} 1$ y m4. El paracónido está bien diferenciado y es más bajo que el metacónido en todos los molares; por otro lado, en vista oclusal el paracónido es más chico que el metacónido en el m1, subigual en el m2 y más amplio en el m3. Está ligeramente desplazado mesialmente en el $\mathrm{m} 1$ y alcanza a estar apenas sutilmente desplazado en el m2, mucho menos que en el m1 (es casi imperceptible); mientras en los m3-4 se ubica en una posición claramente anterolingual, alineado lingualmente con el metacónido. El paracónido presenta una cresta anterior vertical en forma de quilla. La metacrístida y la paracrístida están bien desarrolladas. El cíngulo anterobasal está bien desarrollado, extendiéndose desde la base del paracónido hasta la del protocónido, siendo relativamente amplio y más desarrollado que el de $M$. laventica. La muesca del hipoconúlido en el extremo anterior del trigónido está bien definida en todos los molares, aunque menos marcada en el $\mathrm{m} 4$.

El talónido es más corto que el trigónido en todos los molares, pero el largo aumenta relativamente (respecto al trigónido) del $\mathrm{ml}$ al $\mathrm{m} 4$. El ancho relativo (respecto al trigónido) disminuye gradualmente del $\mathrm{m} 1$ al $\mathrm{m} 4$, pero su ancho absoluto es $\mathrm{m} 1 \approx \mathrm{m} 2>\mathrm{m} 3>\mathrm{m} 4$. Todas estas diferencias, al igual que las del trigónido y del largo de los molares, son muy sutiles; la única dimensión que cambia abruptamente es el ancho del talónido del m4 (mucho menor que en cualquier otro locus). El talónido presenta un desarrollo similar al de los didélfidos, estando mucho más desarrollado que el de los esparasocínidos. La cuenca del talónido es notoriamente más ancha que larga en los m1-2, ligeramente más ancha que larga en el m3 y más larga que ancha en el m4. Las cúspides del talónido están bien desarrolladas en los m1-3 y a pesar de ser pequeñas en el m4, están bien diferenciadas. El hipocónido es la cúspide principal del talónido. Es ligeramente saliente 
labialmente en los m1-2, un poco más marcado en el m1 y casi alineado con el protocónido en el $\mathrm{m} 2$, mientras en el $\mathrm{m} 3$ se ubica en una posición ligeramente lingual respecto al protocónido, como ocurre en Chacodelphys, Lestodelphys, Lutreolina, Monodelphis, Thylatheridium e Hyperdidelphys. Esto también ocurre en los esparasocínidos, aunque cabe notar que en Sparassocynus el hipocónido está extremadamente reducido y por eso esta condición está mucho más marcada. En el m2, el hipocónido se ubica hacia la mitad del margen labial del talónido, estando al mismo nivel del entocónido; en los $\mathrm{m} 1$ y $\mathrm{m} 3$, el hipocónido se ubica en una posición ligeramente más posterior, estando ligeramente desplazado posteriormente respecto al entocónido. El entocónido está bien desarrollado, siendo más alto que el hipoconúlido en los m1-3 y tan sólo ligeramente más bajo que el hipocónido al menos en los m2-3 (los hipocónidos de los m1-2 del ejemplar IGM 252951 están muy desgastados). Presenta una morfología cónica (de sección circular), sólo ligeramente comprimido en el $\mathrm{m} 3$, y se ubica en un punto intermedio del margen lingual del talónido, entre el metacónido y el hipoconúlido. El hipoconúlido se ubica junto al entocónido en los m1-3, en una posición posterolabial a este, mientras en el m4 se ubica en una posición más posteromedial, separado del entocónido pero más cerca de este que del hipocónido. Es saliente posteriormente, con una morfología triangular en vista oclusal y es más alto que el entocónido y el hipocónido en el m4.

La cristida oblicua se orienta en sentido labial a la muesca carnasial en el m1, conectándose anteriormente con el trigónido a la base del protocónido, y se va orientando más lingualmente hacia el m3, contactando al trigónido bajo la muesca carnasial de la metacrístida en los m3-4. La crístida oblicua presenta una pequeña muesca carnasial en su porción anterior al menos en los m24 (la crístida oblicua del $\mathrm{m} 1$ está desgastada), menos marcada en el m3. Esta muesca no se observó en ninguno de los didelfoideos observados en la presente revisión (Anexo 2.1), pero ha sido reportada en algunos australidelfios como Dasyurus y Thylacinus cynocephalus, y algunos esparasodontes como Pharsophorus lacerans y Lycopsis longirostrus (matriz del Capítulo 4: Sparassodonta; Anexo 1.3 y 1.4). La posthipocrístida es oblicua respecto al eje anteroposterior en todos los molares, pero este rasgo es mucho más marcado en el m2, donde el hipocónido se ubica hacia la mitad del margen labial del talónido (ligeramente más posterior en los m1 y m3). La preentocrístida está orientada paralela al eje anteroposterior y en todos los molares presenta una muesca carnasial en su porción anterior, como ocurre en algunos didélfidos (e.g., Marmosa murina, Marmosa mexicana, Marmosa laventica, Thylamys colombianus, Tlacuatzin canescens e Hyladelphys kalinowskii). El hipofléxido es profundo y labial a este se presenta un pequeño cíngulo exterior. 


\section{Género A sp. 2}

sp. nov.

(Fig. 5.9)

Holotipo-IGM 250597, fragmento de dentario izquierdo con m2 (A), m3 izquierdo (B), fragmento de dentario derecho con $\mathrm{m} 3(\mathrm{C})$, y fragmento posterior de dentario izquierdo a la altura de la unión entre la rama horizontal y la vertical (D).

Ejemplares Referidos-IGM 184600, m3 izquierdo; IGM 253055-B, m1 izquierdo.

Localidad y Estratigrafía-Holotipo: Localidad 32 (Universidad de Duke), Quebrada La Venta, área de La Venta; Capas Rojas de El Cardón, Miembro Cerro Colorado, Formación Villavieja, Grupo Honda, Laventense (Tablas 3.1 y 5.1; Fig 3.1). Otros ejemplares: todos de localidad(es?) desconocida(s?) (Universidad de Duke) en el área de La Venta; Grupo Honda.

Diagnosis-Se diferencia de la especie tipo (Gen. A sp. 1) por su mayor tamaño y robustez; la crístida oblicua se orienta en sentido labial a la muesca carnasial de la metacrista en los m1-3, sin variación notoria entre loci; la muesca carnasial en la crístida oblicua es más marcada.

Comentarios-El número de colección IGM 253055 fue asignado a más de un ejemplar. Según una nota escrita en el rótulo del ejemplar IGM 253055-B, habría otros cinco ejemplares así numerados; es decir, en total habría seis ejemplares con este mismo número de colección. Sin embargo, en la presente revisión sólo fueron encontrados tres (IGM 253055-A e IGM 253055-B e IGM 253055-C en el presente trabajo). Este número de colección fue usado por Goin (1997) para mencionar "un molar inferior incompleto" proveniente de una localidad desconocida, clasificándolo entre los ejemplares que identificó como "Didelphidae, gen. et sp. indet". Es probable que se trate entonces del ejemplar aquí mencionado como IGM 253055-B, ya que a pesar de que se preserva la mayor parte de la corona, falta gran parte de su base, incluyendo gran parte del cíngulo anterobasal, y sólo se preserva una pequeña porción de las raíces. El ejemplar IGM 253055-A no ha sido publicado; debido a su particular morfología y dudosa taxonomía, ya que presenta rasgos compartidos tanto con Kiotomops (Capítulo 6) como con el didelfimorfio Género A (principalmente el tamaño, cercano al de Gen. A sp. 2), será discutido en el Capítulo 9. Finalmente, el ejemplar IGM 253055-C presenta una morfología que aparentemente es más cercana a la de los Paucituberculata, por lo que será mencionado en ese capítulo (Capítulo 7).

El número de colección IGM 250597 le corresponde a un conjunto de varias piezas que fueron colectadas en la misma localidad. A pesar de que están aisladas, su morfología y apariencia (desgaste, características de mineralización, estado de preservación, etc) indican que se trata fragmentos de un mismo ejemplar. Debido a que el tamaño entre los diferentes locus de esta especie es tan sutil (como en Gen. A sp. 1), fue difícil lograr identificar los loci. Adicionalmente, no se tenía la certeza de que el aumento relativo de tamaño entre estos siguiera el mismo patrón que en esa especie. Finalmente, se usaron los siguientes criterios: además de tener en cuenta la posición relativa de las cúspides del trigónido en Gen. A sp. 1, siendo el paracónido más mesial en 
el m1 (como ocurre en la mayoría de los didelfimorfios), y el metacónido alineado con el protocónido en el $\mathrm{m} 1$ y ligeramente desplazado posteriormente en los $\mathrm{m} 2-3$, se tuvo en cuenta la posición del foramen mentoniano más posterior, que se preserva en la pieza A y que en Gen. A sp. 1 se ubica al nivel de la raíz anterior del $\mathrm{m} 1$ o del límite $\mathrm{p} 3-\mathrm{m} 1$; adicionalmente, el hipoconúlido del molar de esta pieza encaja perfectamente con la muesca del hipoconúlido en el extremo anterior del molar B; y finalmente, el fragmento de dentario en la pieza $\mathrm{C}$ alcanza a preservar en su porción más posterior un fragmento de la base de la rama vertical (para confirmarlo se comparó con el fragmento $\mathrm{D}$, donde se preserva un poco más de esta rama), y se observa que entre el molar preservado y la rama vertical hay espacio para sólo un molar (el m4). Por lo tanto, los molares de las piezas $\mathrm{A}, \mathrm{B}$ y $\mathrm{C}$ corresponderían a $\mathrm{m} 1$ (izquierdo), $\mathrm{m} 2$ (izquierdo) y $\mathrm{m} 3$ (derecho), respectivamente. Este ejemplar se eligió como holotipo porque era el que brindaba mayor información, al preservar varios elementos dentales y parte del dentario. Los ejemplares IGM 184600 e IGM 253055-B están representados cada uno por un sólo molar, pero ya que su preservación es un poco mejor que la del holotipo, ayudan a complementar o confirmar la información.

Tanto el holotipo como los ejemplares referidos habían sido mencionados por Goin (1997), afirmando que eran claramente referibles a un mismo taxón. Los clasificó como "Didelphinae, gen. et sp. indet", ya que a pesar de presentar una apariencia general similar a la de M. laventica, diferían de esta en algunos rasgos importantes (más adelante Comentarios generales sobre Género A). En la presente revisión se observó que estos ejemplares claramente pertenecen a una misma especie, coincidiendo con la opinión de Goin (1997). Su morfología es bastante cercana a la de aquellos de Gen. A sp. 1, pero con un tamaño significativamente mayor, un aspecto más robusto (más ancho y menos elongado) y algunas diferencias morfológicas particulares (véase más abajo). Por estas razones, se concluyó que se trata de una especie diferente del mismo género.

Descripción-Esta especie presenta un tamaño ca. 30\% mayor al de la de Gen. A sp. 1 y, por lo tanto, mayor al de M. laventica. Los únicos elementos craneales preservados corresponden a fragmentos de dentario asociados a los molares. A pesar de la pobre preservación de estos fragmentos, se observa un pequeño foramen mentoniano, ubicado aproximadamente en el límite p3-m1, similar a la condición del ejemplar IGM 252951 (ejemplar referido para Gen. A sp. 1).

En los molares inferiores, el lóbulo posterior de la corona en vista labial es más bajo que el anterior en los m1-3. El largo total del molar varía de forma similar a Gen A sp. 1, teniendo en orden de longitud $\mathrm{m} 1<\mathrm{m} 3<\mathrm{m} 2$. El trigónido es más angosto que el trigónido en el $\mathrm{m} 1$, subigual en el $\mathrm{m} 2$ y más ancho en el $\mathrm{m} 3$, similar a Gen. A sp. El ancho absoluto del trigónido es $\mathrm{m} 1<\mathrm{m} 2 \approx \mathrm{m} 3$, siendo el del $\mathrm{m} 3$ tan sólo 0,05 $\mathrm{mm}$ más ancho que el del $\mathrm{m} 2$. El protocónido es la cúspide principal del trigónido y se encuentra bien desarrollada. El metacónido se encuentra claramente separado del protocónido y alineado posteriormente con el protocónido en el $\mathrm{m} 1$, mientras en los m2-3 está ligeramente desplazado posteriormente respecto al protocónido, similar a Gen. A sp 1. El paracónido es más bajo que el metacónido en los m1-3; sin embargo, en vista oclusal el paracónido 
es más chico que el metacónido en el m1, subigual en el m2 y más amplio en el m3, similar a lo que ocurre en la sp. 1, pero en este caso la variación es un poco más marcada. El desplazamiento mesial del paracónido es claro en el $\mathrm{m} 1$ y casi inexistente en el $\mathrm{m} 2$ (se alcanza a percibir un muy sutil desplazamiento, similar al del $\mathrm{m} 2$ de Gen. A sp. 1), mientras en el m3 está en posición anterolingual, claramente alineado lingualmente con el metacónido. El paracónido presenta una cresta anterior vertical en forma de quilla, como en Gen. A sp. 1. La metacrístida y la paracrístida están bien desarrolladas. El cíngulo anterobasal está bien desarrollado, extendiéndose desde la base del paracónido hasta la base del protocónido y presentando una longitud y amplitud similar a la de la especie 1. La muesca del hipoconúlido en el extremo anterior del trigónido está bien definida.

El talónido es más ancho que largo y esta diferencia va disminuyendo hacia el m3, ya que se va haciendo más angosto, y por consiguiente, relativamente más largo, como en Gen. A sp. 1; en el ancho del talónido es menor al del trigónido en el m3, diferente a lo que ocurre en la sp. 1, donde es ligeramente mayor. El hipocónido es la cúspide principal del talónido y es ligeramente saliente labialmente en los m1-2, menos marcado en el m2, donde está casi alineado con el protocónido (similar al Gen. A sp. 1); en el m3 ligeramente lingual respecto al protocónido, como ocurre en el m3 de Gen. A sp. 1. En el m2, el hipocónido se ubica hacia la mitad del margen labial del talónido, estando al mismo nivel del entocónido; en los $\mathrm{m} 1$ y m3, el hipocónido se ubica en una posición ligeramente más posterior, estando ligeramente desplazado posteriormente respecto al entocónido. El entocónido está bien desarrollado, siendo más alto que el hipoconúlido, al menos en los m1-3, pero más bajo que el hipocónido; no está comprimido lateralmente, presentando una morfología similar a la de Gen. A sp. 1, aunque en este último está ligeramente comprimido en el m3. El hipoconúlido se ubica junto al entocónido, en una posición posterolabial a este. Es saliente posteriormente, con una morfología triangular en vista oclusal.

La crístida oblicua se dirige en sentido labial a la muesca carnasial de la metacrístida en los m1-3, contactando al trigónido en la base del protocónido; este rasgo es diferente en Gen. A sp. 1, en el cual la crístida oblicua se va orientando más lingualmente hacia el $\mathrm{m} 3$, contactando al trigónido justo por debajo de la muesca en los m3-4. Al igual que en Gen. A sp. 1, la crístida oblicua presenta una muesca carnasial en su porción anterior, pero en este caso está mucho más marcada (más profunda), siendo más evidente en el m3. La posthipocrístida es oblicua respecto al eje anteroposterior en todos los molares, pero este rasgo es mucho más marcado en el m2, donde el hipocónido se ubica hacia la mitad del margen labial del talónido, mientras en los m1 y m3 es ligeramente más posterior, tal como ocurre en Gen. A sp. 1. La preentocrístida se orienta en sentido paralelo al eje anteroposterior del diente y también presenta una pequeña muesca en su porción anterior (más evidente en el ejemplar IGM 184600, que está menos desgastado), aunque en este caso está un poco menos desarrollada que en Gen. A sp. 1, ya que el fragmento de cresta anterior a la muesca es más corto. Se presenta un pequeño cingúlido exterior labial al ectofléxido.

La apariencia general y la morfología y desarrollo de las cúspides se asemejan a las de Gen. A sp. 1. Los únicos rasgos claramente evidentes para diferenciarlos son el tamaño y robustez de los 
molares; la orientación de la crístida oblicua y la muesca carnasial en la crístida oblicua, más marcada en la sp. 2.

\section{Comentarios generales sobre Género A}

Los ejemplares referidos por Goin (1997) como "Didelphinae, gen. et sp. indet." claramente pertenecen a un nuevo taxón para La Venta. De hecho, estos ejemplares, más los materiales inéditos aquí agregados, pertenecen a un nuevo género con dos especies. La apariencia general y la morfología y desarrollo de las cúspides son similares entre ambas especies. Sin embargo, se diferencian entre ellas principalmente en su tamaño y robustez; en el ancho del talónido menor al del trigónido en el $\mathrm{m} 3$ de la sp. 2, mientras que es ligeramente mayor en la sp. 1 (a pesar de que el ápice del hipocono se ubica en una posición lingual al protocónido en ambas); y la orientación de la crístida oblicua. La única localidad que se conoce para los ejemplares de la sp. 2 es la del holotipo, el cual proviene de un nivel estratigráfico más joven que los de la sp 1. Esto es un factor congruente con el hecho de que se trate de otra especie del mismo género. Sin embargo, aunque todos los ejemplares provinieran de niveles estratigráficos diferentes, la variación en rasgos muy puntuales y una diferencia de tamaño bastante notoria ya son argumentos suficientes para sugerir que representan otra especie del mismo género. A continuación, se discutirán las afinidades morfológicas de este género, teniendo en cuenta ambas especies en conjunto.

Ambas especies presentan una morfología con rasgos mayormente didelfimorfios. Los únicos didelfimorfios hasta ahora descriptos (publicados) para La Venta pertenecen a la familia Didelphidae. La especie Gen. A sp. 1 presenta un tamaño similar al de Marmosa (Micoureus) laventica, que es la especie de mayor tamaño entre los didélfidos de esta asociación. Goin (1997) había mencionado que los ejemplares IGM 253055 (correspondiente al IGM 253055-B de la presente revisión), IGM 184600 e IGM 250597, los únicos del Género A hasta ahora publicados y que en la presente revisión son referidos a Gen. A sp. 2, presentaban algunas semejanzas con $M$. laventica; sin embargo, resaltó que se diferenciaban en el mayor tamaño, los talónidos relativamente más cortos, los trigónidos mucho más fuertes y con protocónidos prominentes, y las paracrístidas muy desarrolladas y cortantes, indicando hábitos más carnívoros. Adicionalmente a los rasgos mencionados por Goin, el Género A presenta unos entocónidos de morfología más cónica, sin compresión lateral (en M. laventica están bastante comprimidos); los hipoconúlidos mucho más desarrollados y más salientes posteriormente; y el metacónido del m1 alineado posteriormente con el protocónido (ligeramente desplazado posteriormente en $M$. laventica) y los de los m1-3 más desplazados posteriormente.

La morfología general de los molares, que presenta un patrón metaterio claramente didelfimorfio, se diferencia claramente del patrón y desarrollo de las cúspides de los polidolopimorfios y los paucituberculados. También se descarta que se trate de un microbioterio, 
debido a su mayor tamaño, las vacuidades palatinas más reducidas, la plataforma estilar bien desarrollada ( $40-50 \%$ del ancho), los caninos más grandes, el protocono más reducido, la marcada diferencia de tamaño entre el metacono y paracono, las cúspides estilares claramente distinguibles, y el M4 poco reducido. Su tamaño es bastante pequeño para el rango de tamaño de los esparasodontes, pero además se diferencia de este grupo en el contacto frontomaxilar (ausencia de contacto nasolacrimal); la presencia de fenestras (vacuidades) palatinas; los premolares menos comprimidos lateralmente, más cilíndricos pero no tan globosos como en los boriénidos; la plataforma estilar bien desarrollada ( $\sim 40-50 \%$ del ancho); y el protocono bien desarrollado y con una cuenca relativamente amplia.

El holotipo de Gen. A sp. 1 presenta rasgos claramente didelfimorfios, como la presencia de torus palatinos (presentes en la mayoría de didélfidos); los nasales más anchos posteriormente que anteriormente, pero no tan anchos como para contactar los lacrimales, teniendo por lo tanto un contacto frontomaxilar; la presencia de dos forámenes lacrimales que abren fuera de la órbita; ausencia de tubérculos lacrimales; los procesos postorbitales distinguibles; los forámenes palatinos mayores bien desarrollados y formando vacuidades claras, separados por un septo medio y que posteriormente no sobrepasan la serie molar; la presencia del diastema entre el P1 y el P2 (común en didélfidos) y ausencia de uno entre el P2 y el P3; el relativamente buen desarrollo de los protoconos y talónidos, y sus respectivas cuencas; la plataforma estilar presente y bien desarrollada en todos los molares; las cúspides estilares bien desarrolladas pero no hipertrofiadas; los trigónidos formando un triángulo agudo sin compresión y con todas sus cúspides claramente diferenciadas y bien desarrolladas; y el cíngulo anterobasal de los molares inferiores bien desarrollado.

El aspecto general y el tamaño son comparables con los de los didélfidos. Sin embargo, se presentan algunos rasgos particulares que no son comunes en este grupo, entre los que se destacan los para- y metacónulos bien desarrollados, mucho más que en cualquier didélfido, en los cuales son vestigiales o ausentes, o a lo sumo extremadamente reducidos; y la presencia de un contacto entre el aliesfenoides y el maxilar en el piso orbital que, a pesar de que también se presenta en Lutreolina y Monodelphis, no ocurre en la mayoría de didélfidos, excepto en ocasionales casos de individuos particulares (Voss y Jansa, 2003, carácter 43; Voss y Jansa, 2009, Fig. 7). Entre los didélfidos, su morfología es más cercana a la de los didelfinos, pero se diferencia de estos en los forámenes palatinos mayores más reducidos, la presencia de un cíngulo basal completo en los P23, la ausencia de premetacrista en el M4, la StC más desarrollada; y los talónidos ligeramente más reducidos. Se diferencia de los didélfidos extintos Hyperdidelphys y Thylophorops principalmente en el tamaño, siendo bastante más pequeño, y particularmente en la morfología de los molares mucho más plesiomórfica, incluyendo la presencia de una $\mathrm{StC}$ bien desarrollada, la presencia de una StD bien desarrollada en los M1-3 y de una StE vestigial.

Presenta algunas similitudes con los esparasocínidos, como el rostro corto; los forámenes mentonianos en una posición similar a la de Hesperocynus; el canino de sección transversal y tamaño similar al de Hesperocynus; el aspecto general de los premolares, similar al menos a los de 
Sparassocynus y al P3 de Hesperocynus (sólo se conoce el P3 incompleto), aunque con algunas variaciones particulares (más adelante); y la plataforma estilar, preparacrista y postmetacrista del los M1-2 con un desarrollo similar a los de Hesperocynus. Sin embargo, se diferencia de estos en la ausencia de la expansión lateral de las "mejillas" del maxilar (proceso maxilar del arco cigomático); el paladar menos amplio posteriormente (más rectangular); la posición del foramen infraorbitario; el dentario más bajo y grácil; la presencia de un diastema entre P1 y P2; el paracono más separado del metacono y más desarrollado (incluso un poco más que en Hesperocynus); el protocono más desarrollado, más alto, con cuenca más amplia, menos comprimido anteroposteriormente y no excéntrico; los para- y metacónulos más desarrollados; la postmetacrista menos desarrollada y, por lo tanto, la esquina metastilar menos alargada posteriormente; la plataforma estilar más corta; la StC bien desarrollada (vestigial o ausente en Sparassocynidae); la StD bien desarrollada en M1-3 (poco desarrollada en M1-2 y vestigial o ausente el M3 de los esparasocínidos); la presencia de una StE vestigial (ausente en Sparassocynidade); el paracónido del m1 ubicado en una posición más lingual; el metacónido ubicado en una posición más posterior; el talónido más desarrollado (más largo, con cuenca más amplia y cúspides relativamente más desarrolladas); y el entocónido mucho más desarrollado.

La presencia de trigónidos marcadamente más altos que los talónidos en los molares inferiores, es un rasgo que siempre es mencionado como diagnóstico de los esparasocínidos (Reig y Simpson, 1972; Forasiepi et al., 2009; Abello et al., 2015). Este rasgo también está presente en ambas especies del Género A, pero está menos marcado que en los esparasocínidos y es claro principalmente en los m3-4, siendo similar a la condición presente en Thylophorops, Hyperdidelphys, Didelphis albiventris, Philander opossum, Lutreolina crassicaudata y Chironectes minimus (en este último también es bastante claro en el m2). Esta condición fue evaluada en el carácter 119.

Se presentan algunas diferencias al menos con Sparassocynus, pero debido a que no se han hallado materiales de Hesperocynus que preserven estos rasgos, no es posible saber si representan diferencias con toda la familia: los procesos postorbitarios menos desarrollados que en Sparassocynus (no se tuvo acceso a material con esta porción preservada en Hesperocynus); la constricción postorbital más angosta; la sutura nasofrontal en forma de W aguda (bastante abierta en Sparassocynus, siendo casi una curva posteriormente convexa); el foramen infraorbitario proporcionalmente más grande; el P1 más reducido y alineado con la hilera dentaria (oblicuo en Sparassocynus); la ausencia de una cúspide posterolingual en los premolares superiores; la ausencia de una cúspide accesoria anterior en los premolares superiores y de una posterior en los P1-2; la superficie anterior de los premolares redondeada y suave, sin borde cortante (al menos en Sparassocynus hay una cresta anterior suave en los P2-3); la morfología del metacono del M4 (en Sparassocynus el metacono generalmente es vestigial o ausente, pero en los pocos casos que está presente es fuertemente reducido y su morfología claramente una cúspide). Un rasgo que claramente es diferente sólo respecto a Sparassocynus es la presencia de fenestras maxilopalatinas 
(sí están presentes en Hesperocynus).

Entre los esparasocínidos, la morfología más cercana es la de Hesperocynus. Sin embargo, se diferencia de este (además de los rasgos ya mencionados entre las diferencias con Sparassocynidae) en la ausencia de fosas ("pits) palatales (presentes en Hesperocynus, aunque poco profundos); el trígono más bajo; el paracono ligeramente más desarrollado y metacono relativamente más chico; el ectoflexo menos profundo, siendo profundo sólo en M3 y presente sólo en M2-3 (en Hesperocynus está presente en los M1-3 y es profundo en M2-3); la plataforma estilar del M3 más angosta y por lo tanto la preparacrista y postmetacrista más cortas (aunque presentan un desarrollo similar en los M1-2).

Otra morfología didelfimorfia comparable, que también presenta rasgos tanto didélfidos como esparasocínidos, es la de Thylatheridium (véase Análisis Filogenético). Sin embargo, se diferencia por su menor tamaño, el paladar más rectangular (más cerrada posteriormente); los forámenes palatinos mayores desarrolladas (en Thylatheridium sólo aparecen forámenes; carácter 46); los premolares más bulbosos, los protoconos más desarrollados, menos comprimidos anteroposteriormente y menos salientes lingualmente, los paraconos más desarrollados y más separados del metacono, el metacono del M4 comprimido anteroposteriormente, la StC bien desarrollada en todos los todos los molares y bastante grande en los m1-2, la StD bien desarrollada en todos los molares, entre otros.

Debido a que el Género A está claramente relacionado a los didelfoideos pero retiene algunos rasgos más "primitivos" (e.g., presencia de para y metacónulo bien desarrollados, la StD bien desarrollada en todos los molares, la StE presente aunque vestigial, entre otros), se comparó con los peradéctidos, ya que estos rasgos también están presentes en este grupo de didelfimorfios (algunos con diferente desarrollo) y a que en análisis filogenéticos recientes estos aparecen en una posición más basal respecto a los didelfoideos (e.g., Forasiepi, 2009; Engelman y Croft, 2014; Forasiepi et al., 2015; Suarez et al., 2016), e incluso en algunos análisis han sido identificados como taxón hermano de los didelfoideos (e.g., Horovitz et al., 2009). Sin embargo, se observó que se diferencia de los peradéctidos en el paracono más reducido; el metacono del M4 fuertemente reducido y comprimido anteroposteriormente, formando un pequeño cíngulo (más desarrollado y sin compresión en los peradéctidos); en los para- y metacónulos más desarrollados; la centrocrista ligeramente menos recta; la plataforma estilar menos homogénea, más amplia en su porción metastilar y más reducida al nivel del paracono (más marcado hacia M1); la StD subigual a la StB en todos los molares (en los peradéctidos la StD está menos desarrollada). Además de estas diferencias, se diferencia particularmente de Peradectes en los protocónidos ligeramente más comprimidos anteroposteriormente y en el ectoflexo más profundo.

Presenta una morfología general similar a la de Mimoperadectes, con algunas similitudes particulares como la extensión anterior del proceso facial del lacrimal, la posición del foramen infraorbitario, la morfología del protocono similar a la de $M$. houdei y la presencia de una cúspide accesoria muy pequeña sobre la preparacrista (entre el paracono y el borde anterolabial de la 
plataforma estilar) del M4 M. labrus. Sin embargo, se diferencia en general de Mimoperadectes (además de las diferencias ya mencionadas respecto a peradéctidos) en la ausencia de una cresta sobre el margen lacrimal de la órbita, la StC mucho más desarrollada y los para- y metacónulos más desarrollados (un poco más que en M. labrus y bastante más que en $M$. houdei). Se diferencia de M. labrus (especie tipo) principalmente en la preparacrista orientada perpendicular al eje anteroposterior del diente en todos los molares (en M. labrus está orientada más anterolabialmente en M3-4); y la StC ubicada posterior al ápice del ectoflexo (anterior en M. labrus). Se diferencia de $M$. houdei en los procesos postorbitales menos desarrollados; la constricción postorbital más ancha; la sutura nasofrontal en forma de W aguda (bastante abierta en M. houdei); el ancho del M1 $<\mathrm{M} 2<\mathrm{M} 4<\mathrm{M} 3$ (en M. houdei el M4 es el molar más angosto, los demás aumentan de tamaño posteriormente); el largo del M1< M2 < M3 (= en M. labrus; en M. houdei el M2< M3<M1); la preparacrista perpendicular al eje anteroposterior del molar y conecta con la $\mathrm{StB}$, mientras en $M$. houdei, a pesar de ser casi perpendicular, presenta una ligera orientación anterolabial (dirigiéndose hacia un punto entre la StA y la StB pero más cerca de la StB) y termina antes de llegar a contactar las cúspides estilares; el ectoflexo ausente en el M1, poco profundo en el M2 y profundo en el M3 (en M. houdei es poco profundo en el M1 y profundo en los M2-3); la StD subigual a la StB (en $M$. houdei la StD es más pequeña); centrocrista incompleta en el M4, se presenta sólo la postmetacrista (se corta hacia la base del paracono, no continúa en el metacono; en M. houdei sí está completa.

Basándose únicamente en el análisis morfológico y teniendo en cuenta especialmente la sp. 1, que es la mejor representada, queda claro que el Género A se encuentra más estrechamente relacionado a los Didelphoidea (i.e., Sparassocynidae + Didelphidae) que a cualquier otro grupo, aunque presenta algunas similitudes con los peradéctidos. En el análisis filogenético realizado para testear estas relaciones (presentado más adelante en este capítulo), no se recuperaron sinapomorfías para el grupo conformado por el Género A y los Didelphoidea. Sin embargo, este agrupamiento se encuentra muy bien soportado, presentando un valor soporte de Bremer alto (i.e., >5).

\section{Didelphimorphia fam. et gen. indet.}

(Figs. 5.6C-D)

\section{IGM 250328}

Material—Incisivo aislado (I2? derecho; Fig. 5.6C)

Localidad y Estratigrafía-Localidad 22 (Universidad de Duke), San Nicolás, área de La Venta; Capas del Mono, Miembro Baraya, Formación Villavieja, Grupo Honda.

Comentarios-Por la morfología y simetría de este incisivo, muy probablemente se trate de un I2. La corona es algo oblicua respecto a la raíz y marcadamente más larga (mesiodistalmente); es labiolingualmente comprimida y presenta una morfología romboide aproximadamente simétrica, 
con bordes cortantes mesial y distal subiguales, que convergen formando un ápice central agudo. Takahashi (1974: 414) usa el término "premolariforme" para referirse a esta morfología, poniendo como ejemplo la de Monodelphis, Marmosa y Metachirus. Esta condición se presenta en la mayoría de didélfidos actuales, excepto en Caluromys, Caluromysiops, Didelphis, Glironia, Hyladelphys, Lutreolina, y Philander (Voss y Jansa, 2009), y también se presenta en Hyperdidelphys y Thylophorops.

El tamaño de este incisivo $(\sim 0,6 \mathrm{~mm})$ es grande para cualquier didélfido descripto para La Venta, incluso para M. laventica. Los didélfidos de gran tamaño (e.g., Didelphis, Lutreolina, Philander y Thylophorops), como ya se mencionó, presentan una morfología diferente. Respecto a otros Didelphimorphia, no se conocen los incisivos de Sparassocynus ni Hesperocynus y no se tuvo acceso a ningún material de Thylatheridium que preservara incisivos superiores, por lo que no es posible saber si podría estar relacionado con este taxón. Entre la variedad de morfologías de La Venta, podría llegar a estar más relacionado con Género A sp. 2, que es aproximadamente $40 \%$ más grande que $M$. laventica y del cual no se preservan incisivos.

\section{IGM 253029}

Material—dP3 izquierdo (Fig. 5.6D).

Localidad y Estratigrafía-Localidad 22 (Universidad de Duke), San Nicolás, área de La Venta; Capa del Mono, Miembro Baraya, Formación Villavieja, Grupo Honda.

Comentarios-Este molar deciduo había sido descripto como un molar superior aislado (M1?) referible a Pachybiotherium minor (Goin, 1997). Sin embargo, la morfología se asemeja más a la de un dP3 de un didélfido, bastante cercana a la de los marmosinos. Su tamaño es cercano al de los molares de el taxón cf. Tlacuatzin y los de Marmosa sp. 1. Sin embargo, en los didélfidos, norrmalmente el dP3 está reducido respecto a los molares (siendo el área de la corona entre un $42 \%$ y $96 \%$ del área del M1; Voss y Jansa, 2009). Por lo tanto, se esperaría que correspondiera a un taxón con un tamaño mayor al de las especies mencionadas. Entre los didélfidos de mayor tamaño descriptos para La Venta, podría referirse a M. laventica o Gen. A sp. 1, o incluso a Gen. A sp.2. Un rasgo que resalta Goin (1997) es que la centrocrista es recta. Este rasgo podría estar acercando este ejemplar más hacia la morfología del Género A, ya que en este la inflexión de la centrocrista es poco profunda, casi recta, mientras que en las diferentes especies de Marmosa esta inflexión siempre es fuertemente marcada.

\section{?Didelphimorphia}

(Fig. 5.6E-F)

\section{KU 1990-1-A}

Material—Fragmento (¿posterior?) de premolar (¿superior?), preservando una raíz (Fig. 
5.6E).

Localidad y Estratigrafía_Localidad dudosa (Universidad de Kioto): "Masato site" (Capas Rojas de El Cardón, Miembro Cerro Colorado) o "Kioto site" (nivel indeterminado del Miembro Baraya; i.e., Miembro Molina sensu Takai et al., 1992); Formación Villavieja, Grupo Honda.

Comentarios-Material inédito. Por la simetría y el poco desarrollo de lo que aparentemente sería la parte posterior (el "talón"), posiblemente se trate de un premolar superior. El tamaño (1,35 $\mathrm{mm}$ de ancho y $\sim 2,5 \mathrm{~mm}$ de alto) y morfología son consistentes con las de un didelfimorfio relativamente grande (para el rango de morfologías de La Venta) o un esparasodonte muy pequeño (o con premolares fuertemente reducidos). El tamaño es cercano al del Género A, más consistente con el tamaño de Gen. A sp. 2, aunque podría ser aún más grande. Sin embargo, la morfología no es consistente al menos con los premolares superiores de la sp. 1 (desconocidos en la sp. 2), ya que es bastante grácil, no robusto ni globoso como los P2-3 de esa especie ni piramidal como el P1.

\section{KU 1990-1-B}

Material—Premolar (inferior?; Fig. 5.6F)

Localidad y Estratigrafía_Localidad dudosa (Universidad de Kioto): "Masato site" (Capas Rojas de El Cardón, Miembro Cerro Colorado) o "Kioto site" (nivel indeterminado del Miembro Baraya; i.e., Miembro Molina sensu Takai et al., 1992); Formación Villavieja, Grupo Honda.

Comentarios-Material inédito. A juzgar por la simetría y morfología general, posiblemente se trate de un premolar inferior. Presenta una morfología alargada y baja. Ni la corona ni las raíces son desglobosas, aunque la apariencia es menos grácil que la del ejemplar KU 1990-1. El borde anterior es casi recto, mientras que el posterior es ligeramente cóncavo y más alargado. Ambos bordes presentan crestas cortantes. El tamaño (3,30 mm de largo y 1,25 de ancho) es consistente con un didelfimorfio relativamente grande (para el rango de morfologías de La Venta) o un esparasodonte muy pequeño (o con premolares fuertemente reducidos). El tamaño es mayor al de M. laventica y probablemente sea cercano a alguna de alguna de las especies del Género A, ya que su longitud es cercana a la que puede medirse a partir de las raíces del p2 de Género A sp. 1. Esto no significa que se trate de un $\mathrm{p} 2$ de esta especie, pero el rango de tamaño sería similar. No se conoce la morfología de la corona de los premolares inferiores de este género, pero según lo que se observa en didélfidos, aquellos con premolares superiores globosos presentan normalmente premolares inferiores menos globosos. Por esta razón, no se descarta que este ejemplar esté relacionado con dicho taxón.

\section{KU 2000-3}

Material-Canino (¿inferior?)

Localidad y Estratigrafía - Localidad El Dinde (Universidad de Kioto); nivel indeterminado del Miembro Baraya (i.e., Miembro Molina sensu Takai et al., 1992), Formación Villavieja.

Comentarios-Material inédito. Sólo preserva la porción extra-alveolaria. Es un canino 
relativamente pequeño para el tamaño de un Sparassodonta (3,2 $\mathrm{mm}$ de largo x 2,65 $\mathrm{mm}$ de ancho a la base), por lo que probablemente se trate de un didelfimorfio. Su morfología es unicuspidal curva y grácil, como ocurre en los didélfidos. Un canino con estas características no suele ser un elemento muy informativo, más allá aportar información sobre el tamaño. Eventualmente, si se tratara de un canino superior (que, aparentemente, no es el caso), permitiría diferenciarlo de algunos grupos particulares cuyos caninos presentan cúspides accesorias (e.g, Lestoros, las hembras de Caenolestes y Rhyncholestes, y algunos peramélidos), en este caso ausentes. Entre los didelfimorfios de La Venta, el tamaño que más se ajusta sería el del Género A sp. 1; sin embargo, se desconoce su morfología. Por todas estas razones, se consideró que la pieza no es lo suficientemente informativa y que el tamaño no es criterio suficiente para referirlo al Género A, ya que incluso podría tratarse de algún otro taxón diferente, de tamaño similar, pero hasta ahora no reportado. Lo que sí es muy probable, es que se trate de un didelfimorfio, ya que su tamaño se encuentra dentro del rango de este grupo. 


\section{ANÁLISIS FILOGENÉTICO}

En el presente trabajo se siguió la clasificación de Goin et al. (2016), en la cual el orden Didelphimorphia incluye las superfamilias Peradectoidea (i.e., Peradectidae + Caroloameghiniidae) y Didelphoidea (i. e., Didelphidae + Sparassocynidae). Los taxones de didelfimorfios con representantes actuales se agrupan únicamente dentro la familia Didelphidae. Hasta el momento, la revisión más completa y actualizada de la filogenia de dicho grupo es la de Voss y Jansa (2009). Estos autores realizaron una serie de análisis con diferentes metodologías, basándose tanto en caracteres no moleculares (i.e., morfológicos + cariotípicos) como moleculares.

La clasificación que Voss y Jansa (2009) proponen para los didélfidos actuales, se basa mayormente en los resultados obtenidos con base en los análisis del set de datos combinados (caracteres no moleculares + moleculares) que excluye a Chacodelphys, particularmente en el árbol de consenso de mayoría (50\%; Fig. 35 de Voss y Jansa, 2009). En esta clasificación, la familia está conformada por cuatro subfamilias: Glironiinae (Voss y Jansa, 2009), que incluye únicamente a Glironia; Caluromyinae (Kirsch, 1977), que incluye a Caluromys y Caluromysiops; Hyladelphinae (Voss y Jansa, 2009), que incluye únicamente a Hyladelphys; y Didelphinae (Gray, 1821), que se subdivide en cuatro tribus: Marmosini (i.e., Marmosa, Monodelphis y Tlacuatzin), Metachirini (que incluye únicamente a Metachirus), Didelphini (i.e., Chironectes, Didelphis, Lutreolina y Philander) y Thylamyini (i.e., Chacodelphys, Cryptonanus, Gracilinanus, Lestodelphys, Marmosops y Thylamys).

Durante la presente revisión se pudo estudiar en detalle la totalidad de los taxones didelfimorfios conocidos para La Venta e identificar nuevos taxones para esta asociación. Esto requirió comparaciones de muchos caracteres morfológicos, tanto craneales como dentales, que permitieron llevar a cabo un análisis filogenético para establecer las relaciones que existen entre estos taxones y los demás didelfimorfios. Este análisis no buscó reevaluar la filogenia de los didélfidos actuales, ya que para esto sería necesario un estudio mucho más profundo y detallado, que incluya tanto caracteres morfológicos como moleculares, así como una muestra mucho más grande de material codificable. Es por esto que se decidió seguir usando la clasificación de Voss y Jansa (2009) a lo largo de esta tesis, a pesar de que muchos de los agrupamientos definidos en su propuesta final de clasificación (basada en análisis de datos combinados) no se recuperaron en el presente análisis (como se explica más adelante). Cabe anotar que los agrupamientos obtenidos en el este análisis son en parte similares a los obtenidos por Voss y Jansa (2009) en su análisis basado en el set de datos no moleculares (morfológicos + carotípicos) que incluye a Chacodelphys, mostrando una topología bastante cercana a la del árbol de consenso estricto obtenido por estos autores (Voss y Jansa, 2009, Fig. 27), a pesar de que en el presente análisis se excluyeron algunas de las especies actuales evaluadas estos autores y se incluyeron varias especies fósiles.

Gran parte de los caracteres usados en la presente matriz fueron tomados y modificados de la matriz de Voss y Jansa (2009), pero también incluye caracteres de otros autores, así como nuevos 
caracteres propuestos en el presente trabajo (véase Anexo 2.2). Esta matriz está compuesta de un total de 121 caracteres, incluyendo 30 caracteres externos (1-30), 43 caracteres craneales (31-62 y 87-97), 44 dentales (63-82 y 98-121) y 4 caracteres cariotípicos (83-86). A todos los caracteres se les dio el mismo peso (Materiales y Métodos). La lista completa de los caracteres se presenta en el Anexo 2.2 e incluye comentarios acerca de modificaciones en los caracteres tomados de otros autores y explicaciones para los nuevos caracteres propuestos.

Teniendo en cuenta la clasificación de Goin et al. (2016) para Didelphimorphia, se intentó incluir taxones representantes tanto de Peradectoidea como de Didelphoidea. La matriz incluye, además de didelfimorfios de La Venta, 24 de las especies de didélfidos actuales evaluadas en la matriz de Voss y Jansa (2009; Materiales y Métodos) y algunos taxones fósiles: Thylatheridium, Hyperdidelphys, Thylophorops, dos esparasocínidos y un "taxón" que representa a los peradéctidos, el cual incluye a Peradectes y Mimoperadectes, como se ha realizado en análisis previos (e.g., Horovitz et al., 2009; Engelman y Croft, 2014). El taxón que se eligió para enraizar los árboles (taxón "outgroup" en TNT) fue Peradectes/Mimoperadectes, debido a la condición de los peradectoideos como grupo hermano de los Didelphoidea. La lista completa de los taxones incluidos en la matriz y los materiales revisados para cada uno de ellos se presenta en el Anexo 2.1.

Para la codificación de los didelfimorfios de La Venta que se usaron en el presente análisis, se tuvieron en cuenta no sólo los holotipos sino también materiales referidos. Contrario a lo que ocurre para los esparasodontes, la mayoría de las especies de didelfimorfios de La Venta están representadas por material muy escaso, muchas veces tan sólo por algunos dientes aislados. Por esta razón no era prudente incluirlos a todos en un análisis filogenético. Es por esto que, por ejemplo, se decidió dejar únicamente a Gen. A sp. 1 como representante de este género, debido a que la otra especie (Gen. A sp. 2) está representada prácticamente sólo por molares inferiores, ya que las porciones de dentario asociadas son muy fragmentarias y pobremente preservadas, por lo que no se observa información codificable; adicionalmente, se encontró que los pocos rasgos codificables en la sp. 2 tenían los mismos valores que los de la sp. 1.

\section{Resultados del análisis}

Inicialmente se eligieron los taxones de La Venta mejor representados, es decir, aquellos cuyos ejemplares mostraran en conjunto la información más completa posible: Género A sp. 1 (el más completo), Marmosa (Micoureus) laventica, Marmosini cf. Tlacuatzin y Thylamys minutus. Sin embargo, utilizando todos estos taxones a la vez, se obtuvo una gran cantidad de árboles más parsimoniosos (804), presentando en el árbol de consenso varias politomías entre los didélfidos excepto Monodelphis y los Didelphini (Fig. A2.1 en Anexo 2.4). A excepción del caso del Gen. A sp. 1, fueron muy pocos los caracteres que pudieron ser codificados para los taxones de La Venta debido a la escasez del material, por ende, han de contener ambigüedad dado la multiplicidad de árboles obtenidos. Cabe resaltar que Monodelphis se ubica en todos los árboles hacia la base de los 
didélfidos, no se encuentra agrupado con los Marmosini.

Posteriormente, se optó por realizar diferentes corridas a la matriz incluyendo sólo a Gen. A sp. 1 (por ser el mejor representado y estable en los primeros ensayos realizados) más alguno de los otros taxones de La Venta. En todos los árboles de consenso obtenidos permanece constante y resuelta la relación entre los peradéctidos, Gen. A sp. 1 y los Didelphoidea; la posición de Thylatheridium y Monodelphis, como taxones basales de los didélfidos; la relación entre los Didelphini; y la posición de Metachirus, a la base de un grupo conformado por todos los demás didélfidos analizados. Cabe resaltar que, en todos los árboles, los Didelphinae conforman un grupo parafilético, ya que están incluyendo a los Glironiinae, Hyladephinae y Caluromyinae; esta última subfamilia siempre conforma un grupo monofilético. En todos los árboles de consenso de estos ensayos, los Marmosini (sensu Voss y Jansa, 2009) conforman un grupo polifilético, ya que Monodelphis no se encuentra relacionado a los demás marmosinos (i.e., Marmosa y Tlacuatzin) y estos últimos no conforman un grupo natural; y Thylamyini (sensu Voss y Jansa, 2009) tampoco se recupera como grupo natural, aunque Chacodelphys, Lestodelphys y Thylamys siempre conforman un grupo monofilético.

En todos los árboles más parsimoniosos de los diferentes ensayos realizados, Gen. A sp. 1 se mantiene siempre en una posición basal dentro de Didelphimorphia, ubicándose como taxón hermano de los Didelphoidea (Sparassocynidae + Didelphidae). Por otro lado, en los ensayos individuales, en la mayoría de árboles M. laventica se relaciona con las demás especies Marmosa, pero varía el orden del agrupamiento, y en unos pocos árboles forma una politomía con Marmosa y otros taxones (e.g., Tlacuatzin e Hyladelphys); T. minutus siempre se relaciona con Thylamys y Lestodelphys, en algunos árboles agrupado con Thylamys y en otros se mostraban politomías entre las especies de ambos géneros (incluido T. minutus); y finalmente, Marmosini cf. Tlacuatzin se relaciona con Tlacuatzin o Marmosa, o formando diferentes politomías con estos dos taxones y Marmosops o Gracilinanus. No es posible llegar a conclusiones precisas a partir de estos arreglos, pero al menos es congruente la relación entre estas especies de La Venta y los géneros a los que han sido referidas tanto en la revisión taxonómica del presente trabajo como en estudios previos (e.g., Marshall, 1976a; Goin, 1997).

Para el análisis que incluía a $M$. laventica se obtuvieron 30 árboles más parsimoniosos, resultando un árbol de consenso en el cual esta especie se encuentra relacionada con las demás especies de Marmosa, pero formando una politomía con Tlacuatzin, Hyladelphys, Glironia y los calurominos (Fig. A2.2 en Anexo 2.4); este grupo no resuelto se encuentra relacionado a un grupo parafilético conformado por los Thylamyini (sensu Voss y Jansa, 2009). Para el análisis que incluía a T. minutus se obtuvieron 12 árboles más parsimoniosos, resultando un árbol de consenso en el cual esta especie conforma una politomía junto con las demás especies de Thylamys y Lestodelphys halli; los Thylamyini (sensu Voss y Jansa, 2009) también conforman un grupo parafilético, pero la politomía entre Tlacuatzin, Hyladelphys, Glironia y los calurominos está un poco más resuelta, ya que se observa un grupo monofilético conformado por Hyladelphys, Glironia y los calurominos, 
mientras Marmosa y Tlacuatzin conforman un grupo parafilético relacionado a este (Fig. A2.3 en Anexo 2.4). Para el análisis que incluía al marmosino cf. Tlacuatzin, se obtuvieron 42 árboles más parsimoniosos, a partir de los cuales se obtuvo un árbol de consenso donde este taxón de La Venta conforma una politomía con Tlacuatzin canescens, Marmosa, Gracilinanus, Marmosops, Hyladelphys, Glironia y los calurominos; por consiguiente, en este caso, los Thylamyini (sensu Voss y Jansa, 2009) constituyen un grupo poliflético, debido a esa posición de Marmosops y Gracilinanus (Fig. A2.4 en Anexo 2.4).

Finalmente se decidió realizar un análisis incluyendo únicamente a Gen. A sp. 1, que fue el que se continuó analizando, dada la estabilidad de Gen. A sp. 1 en los diferentes análisis y debido a que no era sensato sacar conclusiones a partir de ensayos realizados con ejemplares tan escasos, con una gran cantidad de entradas faltantes (91\% para T. minutus y M. laventica, y $80 \%$ para el marmosino cf. Tlacuatzin, frente a 53\% faltante para Gen. A sp. 1; véase Anexo 2.3). Este análisis final se realizó con base en un total de 31 taxones metaterios, incluyendo además de Gen. A sp. 1, los demás didelfimorfios anteriormente mencionados (i.e., las 24 especies de didélfidos vivientes y los didelfimorfios fósiles que no eran de La Venta).

Se obtuvieron cuatro árboles más parsimoniosos (Figs. 5.10-5.13), todos ellos con una longitud de 332 pasos, un índice de consistencia (CI) de 0,467 y un índice de retención (RI) de 0,685. A partir de estos se obtuvo un árbol de consenso estricto (Fig. 5.14) con una longitud de 338 pasos, $\mathrm{CI}=0,459$ y $\mathrm{RI}=0,674$. Las sinapomorfías para cada uno de los nodos del árbol de consenso se muestran en el Anexo 2.5 (Fig. A2.5 y Lista de sinapomorfías).

Se calcularon los soportes de Bremer para los diferentes grupos obtenidos en el árbol de consenso (Fig. 5.15). El tipo de soporte elegido fue el absoluto y colapsaron aquellos nodos con soporte 0 . Como resultado se obtuvo que 4 de los grupos presentan soporte de 5 o más (se hizo el ensayo reteniendo subóptimos a 9 pasos, pero los nodos que presentaban soporte de 9 o más eran los mismos de 5 o más, y ninguno tenía 6,7 u 8 , por lo que se decidió dejarlo en 5), 2 grupos con sporte 4, 5 grupos con soporte 3 y 15 grupos con valores inferiores a 2, incluyendo un grupo con soporte 0 , por lo cual el nodo colapsó (nodo 38).

En este análisis final se mantiene constante la posición de Gen. A sp. 1, hacia la base de los didelfimorfios, ubicándose como taxón hermano de los Didelphoidea. En el análisis cladístico no se identificaron sinapomorfías para esta relación (Gen. A sp. 1 + Didelphoidea; véase Anexo 2.5). Sin embargo, el soporte de Bremer de este nodo es mayor a 5 (Fig. 5.15), por lo cual se encuentra muy bien soportado. Durante el análisis morfológico habían sido identificadas similitudes tanto con los esparasocínidos como con los didélfidos, así como algunos rasgos más plesiomórficos. Lo que es bastante sorpresivo, es que un taxón externo al clado constituido por los Didelphidae vivientes esté presente en niveles estratigráficos del Mioceno medio junto a taxones del grupo corona (e.g., Marmosa, Tlacuatzin y Thylamys). Sin embargo, como ya se ha venido analizando para los metaterios, La Venta suele ser claramente un punto en el que se manifiesta el fenómeno de "museo", manteniéndose formas plesiomórficas en niveles más jóvenes de lo que se esperaría (e.g., 
Lycopsis longirostrus, Hondadelphys y los tilacosmilidos de La Venta; capítulo 4), completando vacíos en el registro de linajes que se han considerado "fantasmas" (sensu Norell, 1996).

El agrupamiento de los Didelphoidea se mantiene en todos los árboles, mostrando dos grupos principales: el de los esparasocínidos y el de los didélfidos. También se mantiene la posición de Thylatheridium, más estrechamente relacionado a los didélfidos que a los esparasocínidos; esta relación ya había sido sugerida por otros autores, habiendo incluido a Thylatheridium dentro de los Didelphidae (e.g., Voss y Jansa, 2009) e incluso sugiriendo una relación cercana con Monodelphis (e.g., Reig, 1952; Reig et al., 1987; Goin y Montalvo, 1988; Goin et al., 2000) o Lestodelphys (e.g., Simpson, 1972). Siguiendo a Thylatheridium, se ubica Monodelphis, que no conforma un grupo natural con Marmosa y Tlacuatzin (i.e., Marmosini sensu Voss y Jansa, 2009), sino que es el didélfido más basal entre aquellos taxones con representantes actuales y el resto de los didélfidos analizados. Se ubica como taxón hermano de un clado monofilético conformado por dos subgrupos: los Didelphini, que incluye a Chironectes, Didelphis, Lutreolina, Philander y a los extintos Thylophorops e Hyperdidelphys; y uno que incluye a Metachirus como taxón basal y a los demás didélfidos aquí analizados.

Respecto al primer subgrupo, este análisis soporta la relación que existe entre Thylophorops e Hyperdidelphys con los Didelphini vivientes, encontrándose incluidos dentro de esta tribu conformando un grupo monofilético completamente resuelto en todos los árboles. Dentro del segundo subgrupo, en el cual la posición basal de Metachirus se mantiene constante en todos los árboles, no se recupera la monofilia de la tribu Thylamyini (sensu Voss y Jansa, 2009), cuyos taxones se encuentran conformando un grupo parafilético. Sin embargo, la relación entre Chacodelphys, Lestodelphys y Thylamys se mantiene constantemente como grupo natural; mientras los demás Thylamyini (sensu Voss y Jansa, 2009) conforman un grupo parafilético externo a un pequeño grupo natural conformado por Marmosa, Tlacuatzin, Hyladelphys, Glironia y los calurominos. Las variaciones entre los árboles más parsimoniosos ocurren dentro de este último grupo. Allí varía la relación entre las especies de Marmosa, que en algunos árboles conforman un grupo parafilético (Figs. 5.10 y 5.11) y en otros polifilético (Figs. 5.12 y 5.13); la posición de Tlacuatzin, que en algunos árboles conforma un grupo natural con Hyladelphys, Glironia y los calurominos (Figs. 5.10 y 5.11), mientras en otros se relaciona más cercanamente con las especies de Marmosa (Figs. 5.12 y 5.13); y también varía la posición de Hyladelphys y Glironia, los cuales siempre se ubican externos a los calurominos, pero la posición entre ambos se intercambia entre los diferentes árboles más parsimoniosos (e.g., véase Fig. 5.10 vs. Fig. 5.11). Por otro lado, los calurominos se mantienen como grupo monofilético y resuelto en todos los árboles.

La posición de los calurominos, hyladelfinos y glironinos es similar a la del árbol de consenso estricto de Voss y Jansa (2009: Fig. 27), obtenido a partir de caracteres morfológicos + cariotípicos, a partir de la cual los didelfinos quedan conformando grupo parafilético. Sin embargo, estos autores realizan otra serie de análisis adicionales en los que logran recuperar la monofilia de estas cuatro subfamilias (algo similar ocurre con los Thylamyini y Marmosini). Al realizar en 
cálculo de los soportes de Bremer para el árbol de consenso en el presente análisis, el nodo que relaciona a los hyladelfinos + glironinos + calurominos con Tlacuatzin y algunas especies de Marmosa colapsó, lo cual indica que tenía un soporte cero. Por lo tanto, esta relación no está soportada y la posición del grupo natural de los hyladelfinos + glironinos + calurominos podría cambiar fácilmente agregando unos pocos caracteres o realizando algunas ligeras modificaciones en el tipo de búsqueda, lo que ocurrió en el caso de los otros análisis que realizaron Voss y Jansa (2009).

Las ambigüedades en los resultados de este análisis e incompatibilidades con los análisis previos (e.g., Voss y Jansa, 2009), permitió entender la necesidad que existe de realizar un análisis mixto, que incluya tanto caracteres morfológicos como moleculares, que permitan resolver más claramente las relaciones entre los didélfidos y la de estos con los demás didelfimorfios, incluyendo la mayor cantidad de taxones fósiles posible. Para esto, también sería necesario incluir una mayor cantidad de caracteres dentarios, ya que en la mayoría de los análisis morfológicos que se realizan, estos suelen representar un bajo porcentaje de los caracteres utilizados. La mayoría de los criterios que se usan para diferenciar las diferentes especies de didélfidos actuales, son basados en rasgos morfológicos externos; sin embargo, existe una gran cantidad de rasgos dentarios que varían entre las diferentes especies y que permiten complementar enormemente la información que permita diferenciarlas. Estos caracteres dentarios también son útiles para poder asociar más fácilmente los taxones fósiles, ya que habría una mayor cantidad de rasgos codificables disponibles. 


\section{ANÁLISIS ECOMORFOLÓGICO}

\section{Masa corporal}

Las estimaciones de masa corporal para los didelfimorfios de La Venta se realizaron a partir de variables independientes, correspondientes a medidas tomadas en la dentición (Tabla 5.7). Al momento de elegir la variable más adecuada para la estimación de la masa corporal se tuvieron en cuenta los parámetros utilizados para medir la bondad del ajuste de cada ecuación (i.e., \%PE, error de predicción porcentual; \%SEE, error estándar porcentual de la estimación. Ver Materiales y Métodos).

Las estimaciones realizadas se calcularon con base en las ecuaciones construidas por Zimicz (2012) a partir de aquellas de Gordon (2003; ver Materiales y Métodos). La mejor variable predictiva para este set de ecuaciones corresponde al largo del segundo molar para la dentición superior y el largo del tercer molar para la dentición inferior. Sin embargo, estos molares no se preservan en todos los ejemplares estudiados en la presente revisión, por lo cual para cada caso se utilizó la mejor variable disponible según el material preservado para cada especie, que no siempre corresponde a aquella con mejores indicadores de bondad del ajuste (ver estimaciones seleccionadas en la Tabla 5.8; la descripción cada variable se presenta en la Tabla 5.7). El procedimiento que se utilizó para estas estimaciones es el mismo que en el análisis de los esparasodontes y se explica detalladamente en la sección Materiales y Métodos.

En el caso de los didelfimorfios, es difícil establecer categorías discretas de tamaño, ya que se presenta un amplio espectro de tamaños intermedios y normalmente estas categorizaciones suelen ser arbitrarias (Voss y Jansa, 2009). Entre las especies de didélfidos recientes, la más pequeña es probablemente Chacodelphys formosa, con una masa corporal de unos $10 \mathrm{~g}$ (Voss et al., 2004a); mientras la más grande es Didelphis virginiana, la cual puede llegar a pesar más de $3000 \mathrm{~g}$ (Hamilton, 1958). Sin embargo, la mayoría de didélfidos actuales pesan entre 20 y 500 g (Voss y Jansa, 2009). Este último es justamente el rango de masa corporal en el que se encuentra la mayoría de los didélfidos de La Venta.

Para la mayoría de los ejemplares analizados, se pudo calcular la masa corporal con base en el largo del M2 o el largo del m3. El valor más bajo obtenido fue el de T. minutus, el didélfido más pequeño de La Venta, con una masa corporal de 23,23 g calculada a partir del largo del m3 del holotipo; mientras que el más alto fue el de una de las especies del Género A, con una masa corporal de ca. $375 \mathrm{~g}$, estimada a partir de la misma variable. La única especie para la cual no se pudo estimar la masa corporal con base en alguna de las dos variables mencionadas, fue $T$. colombianus, para la cual la mejor variable predictiva disponible fue el área del $\mathrm{m} 2$. Esta estimación se realizó para el holotipo de la especie y arrojó un valor de 58,38 g.

Debido a que la estimación realizada para T. colombianus se calculó a partir de una variable predictiva diferente a las demás especies, se decidió realizar otra estimación para compararlo con 
la otra especie de Thylamys con base en un mismo elemento dentario. El único locus que se preserva en ambas especies es el $\mathrm{m} 1$. Se eligió el área del $\mathrm{m} 1$, ya que esta variable presenta un menor \% PE que el largo. Esta estimación arrojó valores de masa corporal de 51,75 g para $T$. colombianus y 13,08 para T. minutus. Este último dato es bastante cercano a la masa corporal de Chacodelphys formosa. Sin embargo, como ya se dijo anteriormente, el dato de 23,33 g para esta especie presenta una mayor bondad de ajuste, por lo cual fue la estimación seleccionada, y según esta, $T$. minutus sería más grande que $C$. formosa, con cerca del doble del tamaño.

Entre las especies más pequeñas de La Venta se encuentra T. minutus y el marmosino cf. Tlacuatzin, el cual presenta una masa corporal de casi $34 \mathrm{~g}$ (calculada para los ejemplares más grandes), siendo incluso menor a la de T. colombianus. La siguiente especie en orden de tamaño, corresponde a aquella nominada como Marmosa sp. 1, con ca. $56 \mathrm{~g}$, que es una masa corporal cercana a la de T. colombianus. Después de estas dos especies, el siguiente valor más alto de masa corporal corresponde al de $M$. laventica, con ca. $210 \mathrm{~g}$, seguida de la del didelfimorfio Género A sp. 1, con un valor estimado de ca. 242 g y la especie más grande sería Género A sp. 2, con más de $300 \mathrm{~g}$ (ca. $375 \mathrm{~g}$ ). No se presentan taxones con masa corporal dentro del rango entre los $60 \mathrm{y}$ los $200 \mathrm{~g}$, por lo que en esta asociación se presentan dos rangos de tamaños claramente diferenciados: los más pequeños con valores de masa corporal inferiores a $60 \mathrm{~g}$, y los más grandes, con valores superiores a $200 \mathrm{~g}$.

\section{Inferencias dietarias}

La morfología de los molares de los didélfidos de La Venta presenta protoconos y talónidos bien desarrollados, con cuencas relativamente amplias y profundas, paraconos relativamente más pequeños que los metaconos, pero no fuertemente reducidos, trigónidos y talónidos de altura similar; estos rasgos reflejan hábitos alimenticios omnívoros. Por otro lado, el didelfimorfio aquí referido al Género A, presenta rasgos relativamente más carnívoros, con protoconos más comprimidos anteroposteriormente, paraconos mucho más reducidos, postmetacristas relativamente más largas, centrocristas con morfología en $\mathrm{V}$ mucho menos profunda (una forma de $\mathrm{V}$ bastante abierta), los trigónidos relativamente más altos que los talónidos (menos que en los esparasocínidos y similar a los Didelphini) y el talónido relativamente más reducido (aunque mejor desarrollado que en los esparasocínidos). Sin embargo, este taxón no llega apresentar una mofología de carnívoro estricto.

Para el análisis cuantitativo se evaluaron algunos parámetros morfométricos en los diferentes grupos estudiados, con el fin de medir el grado relativo de carnasialización de sus molares. Estos se llevaron a cabo calculando índices a partir de medidas tomadas en la dentición superior o inferior (ver Materiales y Métodos). Uno de estos parámetros fue la longitud relativa de la postmetacrista, la cual se determina a partir de la longitud total de esta cresta respecto a la longitud de la postprotocrista (ver Materiales y Métodos), la cual se evalua en el M3. A mayor diferencia entre las 
longitudes de estas dos estructuras (i.e., una postmetacrista más larga respecto a la postprotocrista), mayor será el nivel de carnasialización del molar (ver Materiales y Métodos). Este índice sólo pudo ser calculado para los taxones de La Venta que preservan el M3 (bien sea en el holotipo o material referido), que corresponden al didelfimorfio Género A sp. 1 y el marmosino cf. Tlacuatzin, y los valores obtenidos se presentan en la Tabla 5.9. En los demás taxones se realizó una comparación cualitativa a partir de los índices de carnasialización ya medidos por Voss y Jansa (2003; Fig. 12), comparando las longitudes relativas de estas crestas en los molares superiores preservados, con aquellas de los loci correspondientes en las especies a las que estos autores ya habían estudiado, y de esta forma se les asignó una de las categorías.

El índice calculado para el didelfimorfio Género A sp. 1 es de 2,44, indicando un nivel de carnasialización relativamente alto, estando ligeramente por encima de didélfidos actuales como Chironectes minimus, Lestodelphys halli, Marmosops pinheiroi, Monodelphis brevicaudata y Monodelphis emiliae, pero siendo menos carnasializado que en Monodelphis adusta y Lutreolina crassicaudata. El marmosino cf. Tlacuatzin presenta un índice de 1,30, indicando un nivel de carnasialización relativamente bajo y cercano al de Glironia venusta y Gracilinanus microtarsus, pero mayor al de los calurominos. Los índices presentados por Voss y Jansa (2003; Fig. 12) para los didélfidos actuales no incluyen a Tlacuatzin; sin embargo, las postmetacrista y postprotocrista de Tlacuatzin canescens (observado en los materiales revisados; Anexo 2.1) presentan un desarrollo cercano a las del ejemplar de La Venta. El bajo nivel de carnasialización calculado a partir de este índice para el marmosino cf. Tlacuatzin es consistente con la poco marcada diferencia de longitudes entre la postmetacrista y la preparacrista, siendo la primera ligeramente más larga que la segunda (este rasgo había sido mencionado como diagnóstico por Goin, 1997, cuando refirió estos ejemplares a T. minutus).

Entre los demás taxones de La Venta que preservan molares superiores diferentes al M3 y que tuvieron que ser evaluados cualitativamente, se observó que la postmetacrista y la postprotocrista de Marmosa sp. 1 presentan un desarrollo similar al de las especies del género Marmosa y, por lo tanto, presentaría un nivel de carnasialización similar, siendo mayor al del marmosino cf. Tlacuatzin. El ejemplar IGM 251013, referido por Goin (1997) a Thylamys minutus (tentativamente referido en el presente trabajo), presenta un desarrollo de las crestas evaluadas más cercano al de Marmosa que al de Thylamys. Esta es una de las razones por las que su clasificación dentro de este género es dudosa, ya que las especies actuales de Thylamys se caracterizan por tener molares superiores con morfologías mucho más carnasializadas.

Otros parámetros morfológicos evaluados en el análisis cuantitativo fueron el área relativa del talónido (índice de compresión areal del talonido $=\mathrm{CA}$ ) y longitud relativa del talónido (índice de compresión longitudinal del talónido $=\mathrm{CL}$ ). Estos parámetros miden la expansión o compresión del talónido respecto al trigónido (compresión/expansión del área y compresión/expansión del largo del talónido). Estos índices también son obtenidos a partir de mediciones tomadas en el m2 y permiten evaluar en los taxones omnívoros ciertas preferencias dietarias, como los hábitos 
granívoros, frugívoros, folívoros, insectívoros y faunívoros (ver Materiales y Métodos). Los resultados del cálculo de estos índices para los didelfimorfios de La Venta (aquellos que preservan el m2) se presentan en las Tablas 5.10 y 5.11. Tanto el índice CA (Tabla 5.10) como el CL (Tabla 5.11), indican hábitos insectívoros o faunívoros para todos los didelfimorfios de La Venta.

Debido a que las especies del Género A presentan ciertos rasgos con tendencia a la carnivoría, se realizó un cálculo del RGA (ver Materiales y Métodos), para la sp. 1 (la única que preserva el m4), arrojando un índice de 1,15, lo cual sugiere hábitos mayormente omnívoros.

Las inferencias dietarias que surgen a partir de la presente revisión fueron comparadas con los resultados del estudio pormenorizado realizado por Chemisquy et al. (2015), quienes evalúan los hábitos alimenticios de los didélfidos a partir de la morfoló́ga oclusal de los molares, usando morfometría geométrica. En este estudio se comparan casi todos los géneros de didélfidos actuales (excepto Tlacuatzin) y algunos fósiles (i.e., Thylatheridium y Thylophorops). A partir de los resultados de ese estudio, la morfología de Thylamys indicaría hábitos alimenticios con una mayor tendencia hacia la carnivoría, lo cual es consistente con los resultados de la presente tesis (i.e., hábitos insectívoros o faunívoros para T. colombianus). Sin embargo, los resultados para Marmosa no son consistentes con las inferencias realizadas para $M$. laventica (i.e., hábitos insectívoros o faunívoros), ya que en el estudio de Chemisquy et al. (2015) este género presenta una tendencia hacia la frugivoría. 


\section{CAPÍTULO 6. \\ OTROS TAXONES “AMERIDELFIOS”: ?STERNBERGIIDAE}

Kiotomops lopezi (Takai et al., 1991) fue originalmente descripto como un quiróptero molósido, sobre la base de dos molares superiores (el holotipo, IGM-KU 82C1, y el ejemplar IGM-KU 82C2). Posteriormente, Czaplewski et al. (2003) descartaron la pertenencia de Kiotomops a los Chiroptera, ya que carece de talón, hipocono, mesostilo y cíngulo lingual, los cuales están presentes en los molósidos. Adicionalmente, destacaron que Kiotomops presenta algunos rasgos en común con los marsupiales, como por ejemplo las grandes cúspides estilares (StB y StD sensu Czaplewski et al, 2003; StB y StC+D en el presente trabajo) separadas por un ectoflexo profundo.

En concordancia con lo dicho por Czaplewski et al. (2003), en la presente revisión se concluye que el holotipo de K. lopezi muestra afinidades claramente metaterias y que, además, presenta una serie de rasgos únicos, no vistos en ningún otro metaterio. Sin embargo, el ejemplar IGM-KU 82C2, que había sido asignado por Takai et al. (1991) al hipodigma de esta especie, a pesar de presentar un aspecto general muy similar al del holotipo, presenta diferencias en ciertos rasgos puntuales que hacen dudar que se trate del mismo taxón. Durante esta revisión fueron descriptos nuevos materiales (véase más adelante), algunos de los cuales presentan una morfología similar a la del holotipo (véase Nuevos ejemplares referidos), mientras que otros son más cercanos a la del ejemplar IGM-KU 82C2 (véase Ejemplares tentativamente referidos, Grupo 1); por esta razón, de tratarse de dos taxones diferentes, ambos estarían representados por más de un ejemplar. Adicionalmente, se describen materiales incompletos o muy desgastados (véase Ejemplares tentativamente referidos, Grupo 2), cuyas porciones preservadas no permiten referirlos claramente a Kiotomops lopezi o asociarlos con la morfología de los ejemplares del Grupo 1.

Entre la gran variedad de morfologías metaterias, la más cercana a los dos posibles morfos identificados (i.e., K. lopezi y Grupo 1; véase más abajo) es la de la del "ameridelfio" sternbérgido Carolopaulaoutoia (Eoceno temprano de Itaboraí, Brasil), si bien los ejemplares de La Venta muestran una versión más exagerada de los rasgos derivados presentes en dicho taxón, a pesar de preservar algunos rasgos plesiomórficos (véase más adelante).

Adicionalmente a Kiotomops y las formas relacionadas, durante esta revisión se encontraron otros ejemplares (i.e., IGM\# 93-135 e IGM\# 93-143) que presentan una morfología general muy similar, pero con rasgos más generalizados, siendo aún más cercanos a la morfología de los sternbérgidos. Estos ejemplares claramente representan un taxón diferente a Kiotomops, muy probablemente relacionado con la familia mencionada, y constituyen un nuevo taxón para La Venta. 


\title{
REVISIÓN TAXONÓMICA
}

\author{
MAMMALIA Linnaeus, 1758 \\ METATHERIA Huxley, 1880 \\ “AMERIDELPHIA” Szalay, 1982 \\ "AMERIDELPHIA" incertae sedis \\ ?STERNBERGIIDAE Szalay, 1994
}

Kiotomops Takai, Setoguchi, Villarroel, Cadena y Shigehara, 1991

Especie Tipo-Kiotomops lopezi Takai, Setoguchi, Villarroel, Cadena y Shigehara, 1991.

Especies Referidas-Sólo la especie tipo.

Distribución Geográfica y Estratigráfica-Área de La Venta (Desierto de La Tatacoa, Valle Superior del Magdalena, Departamento del Huila, Colombia); Grupo Honda, Laventense, Mioceno medio (Tablas 3.1 y 6.1; Fig 3.1)

Kiotomops lopezi Takai, Setoguchi, Villarroel, Cadena y Shigehara, 1991

(Fig. 6.1A-G)

Holotipo-IGM-KU 82C1, M2 izquierdo.

Ejemplares Referidos-IGM 250340, IGM-KU 96CO2.

Ejemplares Tentativamente Referidos-IGM 250262, IGM 260263, IGM\# 93-150, IGM-KU 82C2, IGM-KU 96CO1, IGM-KU 96CO3 e IGM-KU 9304.

Diagnosis Enmendada-Molares con cúspides fuertemente verticalizadas; crestas del paracono y metacono bien desarrolladas y de morfología oclusal dilambdodonte (i.e., formando una "W"); centrocrista fuertemente flexionada, con su vértice elevado y muy profunda labialmente; los para- y metacónulo muy cercanos al protocono y con crestas aladas fuertemente desarrolladas, que forman una segunda "W"; la cresta preparaconular y la preprotocrista extendiéndose anteriormente alrededor de la cara anterior del paracono, paralelas entre sí, hasta conectar con el ápice de la StA, sin formar un cíngulo continuo con el cíngulo anterior; el cíngulo anterior poco desarrollado; gran desarrollo de la St C+D (modificada de Takai et al., 1991).

Medidas-Tabla 6.2.

Comentarios-Inicialmente, $K$. lopezi fue descripto a partir de dos molares superiores: el holotipo (IGM-KU 82C1) y el ejemplar IGM-KU 82C2, el cual es incluido por Takai et al. (1991) dentro del hipodigma. Estos dos molares presentan un aspecto general muy similar; no obstante, existen diferencias en ciertos rasgos puntuales que hacen dudar que se trate del mismo taxón. En la presente revisión no pudo ser observado el material original o un calco del ejemplar IGM-KU 
$82 \mathrm{C} 2$, por lo que las comparaciones se hicieron a partir de las fotografías mostradas en la publicación de Takai et al. (1991). Estos mismos rasgos fueron comentados por Czaplewski et al. (2003), pero no los reconocen como diferencias estructurales sino como una morfología producto del desgaste (ver más adelante la discusión en los comentarios de este ejemplar). Sin embargo, Czaplewski et al. (2003) no aclaran si sus observaciones se basan también en fotografías o si pudieron estudiar el material original. Por lo tanto, hasta no corroborar estas diferencias en el material original, al igual que los nuevos ejemplares que presentan una morfología similar, se deja aquí como tentativamente referido. De ser ciertas estas observaciones, este ejemplar y aquellos con morfología similar deberían ser incluidos dentro de un nuevo taxón, diferente de K. lopezi e incluso diferente de Kiotomops, aunque estrechamente relacionados. Adicionalmente, en esta revisión se describen nuevos materiales correspondientes a molares inferiores que podrían ser referibles a cualquiera de estos dos taxones, debido a que los rasgos que varían entre los molares superiores (i.e., morfología de los cónulos y crestas conulares) no corresponden a estructuras que se vean claramente reflejadas en la morfología de los molares inferiores. De manera que, por ahora, se presentan aquí también como tentativamente referidos.

\section{IGM-KU 82C1 (Holotipo)}

Material-M2 izquierdo.

Localidad y Estratigrafia - Localidad "Kioto Site" (Universidad de Kioto); Capas del Mono, Miembro Baraya, Formación Villavieja, Grupo Honda.

Comentarios-Este molar había sido descripto por Takai et al. (1991) como un M1. Sin embargo, al ampliarse la cantidad de materiales disponibles que pudieron ser observados en la presente revisión, se interpretó que en realidad se trata de un M2 (ver más adelante Comentarios generales sobre Kiotomops para la argumentación sobre la identificación de los loci).

La morfología de este molar sigue, en general, un patrón metaterio básico. En vista lingual, las paredes de las cúspides, especialmente las del para- y el metacono, son bastante verticales, más que en los herpetotéridos y de manera similar a la de los quirópteros. El paracono es más pequeño que el metacono y este último se encuentra ubicado en una posición ligeramente más lingual. Estas dos cúspides presentan, en vista oclusal, una morfología triangular bastante cerrada. El protocono es bajo pero amplio y expandido anteroposteriormente. El paracónulo y el metacónulo están presentes. Debido al grado de desgaste, no es posible determinar su desarrollo, aunque aparentemente el paracónulo está más desarrollado; sin embargo, sí se observan sus crestas, permitiendo confirmar claramente su ubicación bastante lingual, mucho más cercana al protocono que al paracono y el metacono. Las crestas del paracono y el metacono están bien desarrolladas y tienden a ser rectas. La preparacrista es más corta que la postmetacrista y se orienta perpendicular al eje anteroposterior del molar, conectándose con la StB y formando una cresta continua hasta el ápice de esta cúspide, la cual presenta una pequeña muesca en la base de la cúspide estilar. La centrocrista está fuertemente inflexionada, se encuentra bastante elevada respecto a la base del 
trígono, con su vértice más elevado que sus extremos, y se profundiza muy labialmente, llegando hasta el nivel de las cúspides estilares, como ocurre en Carolopaulacoutoia. En vista oclusal la centrocrista forma, junto con la preparacrista y la postmetacrista, una estructura en "W" bien marcada (dilambdodonte). Las crestas para- y metaconulares son aladas y están fuertemente desarrolladas, formando entre ellas una $\mathrm{W}$ adicional, ya que las crestas postparaconular y premetaconular se extienden labialmente hasta unirse dentro de la cuenca del protocono, formando una suerte de cresta "centroconular", la cual se profundiza labialmente hasta casi tocar la pared formada entre el paracono y el metacono. La cresta postmetaconular se extiende labialmente rodeando la base del metacono y es bastante saliente, formando un surco relativamente amplio posteriormente entre esta y la pared posterior del trígono; la cresta preparaconular se extiende anteriormente alrededor de la cara anterior del paracono hasta conectar con el ápice de la StA. La preprotocrista no termina en el paracónulo sino que continúa paralela a la cresta preparaconular y aparentemente también se conecta directamente con el ápice de la StA; no parece conformar un cíngulo continuo con el cíngulo anterior, el cual se origina en la StA y está poco desarrollado.

La plataforma estilar es amplia, aunque más angosta al nivel del paracono. Las cúspides estilares A, B y E están claramente presentes, y se presenta una gran cúspide estilar en una posición intermedia entre la StC y la StD, y que probablemente sea el resultado de la fusión de estas últimas (ver más adelante Comentarios generales sobre Kiotomops, para la argumentación sobre homologías de cúspides estilares). Esta $\mathrm{StC}+\mathrm{D}$ es la cúspide estilar más grande, seguida de la $\mathrm{StB}$ bien desarrollada y una StA bastante baja, mientras que la StE es vestigial y se ubica en una posición ligeramente anterior a la punta de la esquina metastilar. El ectoflexo es profundo; se aprecia también un pequeño ectoflexo secundario, posterior a la $\mathrm{StC}+\mathrm{D}$.

Un hecho particular que se observa en este molar es que la $\mathrm{StC}+\mathrm{D}$ se encuentra fuertemente desgastada en su cara lingual. En la mayoría de los metaterios que presentan una plataforma estilar desarrollada (e.g., didelfimorfios, herpetotéridos, peradéctidos), el desgaste generado por la oclusión con el talónido suele afectar ciertas áreas de la cuenca del protocono, que corresponden a la porción que limita con las bases paracono y el metacono, así como el ápice y las crestas del protocono (véase Fig 1. B1, B2 y D de Davis, 2011). Adicionalmente, las facetas de desgaste se extienden sobre las caras del para- y metacónulo, pero estas facetas no sobrepasan labialmente a la centrocrista; en estos casos, la mayor parte de la plataforma estilar de los molares superiores no ocluye con ninguna estructura en los molares inferiores, excepto por la StA y StB (oclusión con el protocónido), aunque en individuos muy adultos puede llegar a haber algo de desgaste en las cúspides estilares (debido a movimientos laterales), pero no llega a ser tan fuerte como en el caso de la $\mathrm{StC}+\mathrm{D}$ de Kiotomops y se concentra principalmente en el ápice de las cúspides. En el caso de Kiotomops, la inflexión de la centrocrista es mucho mayor que en la mayoría de metaterios comparados y se profundiza mucho más labialmente, con su vértice llegando casi hasta el borde labial del molar, condición similar a la de los sternbérgidos). Siguiendo la morfología de la centrocrista, es esperable que el talónido de los molares inferiores tenga el hipocónido muy saliente 
labialmente y que el ángulo formado entre la crístida oblicua y la posthipocrístida sea bastante cerrado. Ya que el vértice de la centrocrista llega tan cerca de la $\mathrm{StC}+\mathrm{D}$, es muy probable que este hipocónido saliente pudiera llegar a desgastar en algún momento la cara lingual de esta cúspide estilar. De hecho, esta morfología saliente del hipocónido se observa en el ejemplar IGM-KU 96CO3 (aquí referido tentativamente a $K$. lopezi; ver comentarios sobre esta especie arriba). Además del desgaste en la $\mathrm{StC}+\mathrm{D}$, se presenta desgaste en el ápice y las crestas del protocono, pero no lo hay (o es mucho menor) en la porción inmediatamente lingual a la base de los para y metacono.

\section{Nuevos ejemplares referidos}

\section{IGM 250340}

Material—Fragmento de molar superior izquierdo (M2?; Fig. 6.1A)

Localidad y Estratigrafía_Localidad desconocida (Universidad de Duke), área de La Venta; Grupo Honda.

Comentarios-Este ejemplar preserva la porción anterior de la plataforma estilar, el paracono, un fragmento de metacono y un fragmento lingual de la cuenca del trígono. A pesar de estar tan incompleto, la porción preservada presenta todos los rasgos morfológicos característicos observables en la porción correspondiente del holotipo, incluso con un desarrollo y proporciones similares, por lo que probablemente se traten del mismo locus. Se observan claramente las crestas conulares bien desarrolladas y unidas dentro de la cuenca del trígono, el cual es un rasgo único de $K$. lopezi, no observable en ningún otro metaterio estudiado.

\section{IGM-KU 96CO2}

Material-M1 izquierdo (Fig. 6.1B).

Localidad y Estratigrafía — Localidad desconocida (Universidad de Kioto), área de La Venta; Grupo Honda.

Comentarios-Este ejemplar no ha sido publicado pero previamente a la presente revisión pero fue observado por Czaplewski, quien lo identificó como referible a Kiotomops. La morfología general es cercana a la del holotipo de Kiotomops (IGM-KU 82C1, un M2), pero se diferencia de este en varios rasgos, a saber: el paracono es más pequeño respecto del metacono; la cresta postmetaconular es más saliente, formando un surco entre esta y la pared posterior del trígono mucho más amplio; la plataforma estilar es más reducida labial al paracono y, por lo tanto, la preparacrista es más corta; la esquina metastilar es más alargada posteriormente; la StA es menos desarrollada; la $\mathrm{StC}+\mathrm{D}$ se ubica en una posición más posterior; finalmente, el ectoflexo es ligeramente menos profundo (si bien continúa siendo profundo) y no se presenta el pequeño ectoflexo secundario posterior a la $\mathrm{StC}+\mathrm{D}$. Estas diferencias son congruentes con variaciones entre los distintos loci molares. Al igual que en el holotipo, se observan las crestas conulares unidas 
dentro de la cuenca del trígono.

\section{Ejemplares tentativamente referidos}

\section{Grupo 1}

En este grupo se clasifican los molares superiores que presentan una morfología similar a la de Kiotomops, pero se diferencian en rasgos muy puntuales, los cuales eventualmente podrían indicar que se traten de otro taxón. También se incluyen los molares inferiores que presentan una morfología consistente con la de estos molares superiores.

\section{IGM-KU 82C2}

Material-M3 derecho.

Localidad y Estratigrafía_Localidad "Kioto Site” (Universidad de Kioto); Capas del Mono, Miembro Baraya, Formación Villavieja, Grupo Honda.

Comentarios-Este ejemplar fue asignado al hipodigma de Kiotomops lopezi por Takai et al. (1991). Las observaciones aquí realizadas se hacen a partir de las fotografías de la publicación de Takai et al. (1991), ya que no se tuvo acceso al material original ni a un calco. En su publicación, se dijo que se trataba de un M2 (con dudas) pero la revisión de este material (por medio de las fotografías), el holotipo y los nuevos materiales permitieron identificarlo como un M3. La morfología general es bastante cercana a la del holotipo de $K$. lopezi (M2), pero presenta algunas diferencias respecto a este, como el tamaño del paracono, que es un poco más grande, presentando una menor diferencia de tamaño respecto al metacono; el protocono es más comprimido anteroposteriormente; no se observa con claridad el paracónulo, si bien aparentemente existe un metacónulo vestigial ubicado muy cerca del protocono; la cresta postmetaconular es menos saliente, por lo que el surco que se forma con la pared posterior del trígono es menos amplio; la plataforma estilar está menos reducida labialmente al paracono, por lo que la diferencia de longitud entre la preparacrista y la postmetacrista es menor; la preparacrista es ligeramente oblicua al eje anteroposterior del molar y no se observa su extremo labial, ya que la esquina parastilar está rota; aparentemente termina entre la StA y la StB o anteriormente a la StB. No se ha preservado la StA y la StB está incompleta, aunque aparentemente está bien desarrollada; la $\mathrm{StC}+\mathrm{D}$ es la cúspide más desarrollada y se ubica más anteriormente que en el holotipo de $K$. lopezi, estando más cerca de la posición de una StC; la StE está ligeramente más desarrollada pero se ubica en la misma posición.

Todas estas diferencias son consistentes con una variación morfológica entre distintos loci molares. Sin embargo, un rasgo bastante particular que se observa en Kiotomops y los ejemplares aquí referidos con certeza a este taxón (véase el punto: Nuevos ejemplares referidos), es el fuerte desarrollo de las crestas conulares, especialmente las crestas postparaconular y premetaconular, las que forman una especie de cresta "centroconular"; este rasgo no parece estar presente en el ejemplar IGM-KU 82C2. Czaplewski et al. (2003) afirma que este ejemplar presenta "una cresta 
baja e inflada que corre desde el protocono hacia adentro de la cuenca del trigono (desgastada en el holotipo)”. En la fotografía del ejemplar IGM-KU 82C2 en la publicación de Takai et al. (1991) se observa lo que, aparentemente, sería la cresta mencionada. Sin embargo, el ángulo en que está tomada la fotografía no permite apreciar claramente si esta se origina en el protocono o en el paracónulo, el cual estaría bastante cercano al protocono; y lo más importante, si realmente se trata de una cresta. Según esta observación de Czaplewski et al. (2003), dicha cresta al desgastarse produciría la morfología que se aprecia en el holotipo, que en la presente revisión es interpretada como crestas conulares que se unen dentro de la cuenca del trígono.

Se evaluó esta interpretación de Czaplewski et al. (2003) pero no se encontró un posible escenario en el que esta porción de la cuenca se desgaste de tal manera que genere una morfología de crestas tan claramente definidas y elevadas respecto al protocono. De hecho, esta porción de la cuenca del protocono no suele presentar facetas de desgaste, únicamente suele desgastarse la porción que limita con las bases de paracono y el metacono, así como el ápice y las crestas del protocono (véase Fig 1.B1, B2 y D de Davis, 2011); estos dos últimos sí se observan claramente en el holotipo de Kiotomops.

Al igual que en el holotipo de Kiotomops, el ejemplar IGM-KU 82C2 también se presenta el desgaste en la cara lingual de la $\mathrm{StC}+\mathrm{D}$, y ya que la morfología de la centrocrista es igual, se esperaría que el talónido de los molares inferiores presentara una apariencia similar, por lo que, si se tratara de dos taxones diferentes, sería muy difícil asignar con claridad un molar inferior aislado a alguna de estas dos especies hasta no encontrar ejemplares que preserven tanto molares superiores como inferiores. Un rasgo particular que presenta en este ejemplar es la presencia de una muesca en la postparacrista, la cual no se observa claramente en el holotipo de K. lopezi debido al mayor desgaste; sin embargo, aparentemente sí está presente en el ejemplar IGM 250340.

Otra diferencia respecto al holotipo y ejemplares claramente referibles a $K$. lopezi, que probablemente no pueda asociarse a una variación entre loci, es que el cíngulo anterior, aunque es bastante estrecho, es aparentemente más largo, extendiéndose lingualmente hasta unirse con la preprotocrista, formando con esta un cíngulo continuo, y aparentemente no habría cresta preparaconular.

\section{IGM-KU 96CO1}

Material-M3 derecho (Fig. 6.1E).

Localidad y Estratigrafía — Localidad desconocida (Universidad de Kioto), área de La Venta; Grupo Honda.

Comentarios-Este ejemplar no ha sido publicado pero previamente a la presente revisión pero fue observado por Czaplewski, quien lo identificó como referible a Kiotomops (identificación para su catalogación, no publicada). Este molar presenta una morfología casi idéntica a la del ejemplar IGM-KU 82C2 (M3), indicando que se trata tanto de la misma especie como del mismo locus. El nuevo ejemplar presenta mucho menos desgaste y está completo, preservando la esquina 
parastilar faltante en el ejemplar IGM-KU 82C2. En este nuevo material se observa la presencia de una StA bien desarrollada y bastante saliente anteriormente, formando un espolón. Adicionalmente, se ve más claramente que el cíngulo anterior, aunque es estrecho, es más largo que en los ejemplares claramente referibles a Kiotomops, originándose por debajo de la StA y extendiéndose lingualmente hasta unirse con la preprotocrista, formando con esta un cíngulo continuo (aparentemente no habría cresta preparaconular). Al igual que en el ejemplar IGM-KU 82C2, la preparacrista es ligeramente oblicua, si bien en este caso sí se observa claramente que termina labialmente en un punto entre la StA y la StB. Todos estos rasgos son diferentes en el holotipo de K. lopezi y los ejemplares referidos sin dudas a esta especie, donde la StA está menos desarrollada y es menos saliente anteriormente (no se observa el "espolón"), el cíngulo anterior está mucho menos desarrollado y no forma un cíngulo continuo con la preprotocrista, y la preparacrista es claramente perpendicular al eje anteroposterior del molar, conectando labialmente con el ápice de la StB. En el ejemplar IGM-KU 96CO1, la StB parece tener el mismo desarrollo que el ejemplar IGM-KU 82C2 y aparentemente es más grande que la StA, pero está poco individualizada, estando casi fusionada a esta. Al igual que en el ejemplar IGM-KU 82C2, aparentemente no se presenta el fuerte desarrollo de crestas conulares formando una cresta "centroconular".

\section{IGM-KU 96CO3}

Material— $\mathrm{m} 3$ derecho (Fig. 6.1F).

Localidad y Estratigrafía — Localidad desconocida (Universidad de Kioto), área de La Venta; Grupo Honda.

Comentarios-Este ejemplar no ha sido publicado. Las cúspides presentan una morfología verticalizada, especialmente en vista labial, similar al aspecto que presentan los molares superiores de Kiotomops. El trigónido es más largo y angosto que el talónido, y ambos están bastante comprimidos anteroposteriormente. La cúspide principal es el protocónido, que tiene en vista oclusal una morfología triangular cuyo ángulo labial es bastante cerrado. La siguiente cúspide más grande es el metacónido, el cual es redondeado pero no completamente circular en vista oclusal, presentando una morfología en forma de gota apuntando hacia el protocónido. El paracónido es la cúspide más pequeña del trigónido; en vista oclusal presenta una morfología mayormente triangular pero con su cara lingual redondeada, formando junto con el cingúlido anterior una curva (convexa anteriormente). La paracrístida y la postprotocrístida están bien desarrolladas y son cortantes, mientras que la postmetacrístida es más corta y redondeada; sin embargo, se presenta una muesca claramente marcada entre ellas. El cingúlido anterior está fuertemente desarrollado, es bastante amplio y se extiende desde el extremo anterior del paracónido hasta la base del protocónido. El hipocónido es la cúspide más alta del talónido, es ligeramente saliente respecto al protocónido y se ubica en la esquina posterolabial del talónido; presenta en vista oclusal una morfología triangular, cuyo ángulo labial es bastante cerrado, similar a la del protocónido. El entocónido es redondeado y de sección circular; es más bajo que el hipocónido y en vista oclusal 
ocupa casi la totalidad del margen lingual del talónido. El hipoconúlido se ubica en la esquina posterolingual del talónido, por detrás del entocónido; es poco saliente posteriormente y su borde posterior es circular, presentando una apariencia de cíngulo que continúa labialmente en la posthipocrístida, la cual es ligeramente oblicua. La crístida oblicua conecta con el trigónido en la base del metacónido, muy cerca del nivel de la muesca carnasial de la metacrístida (lingual a esta). Se presenta un corto cíngulo labial al ectofléxido.

\section{IGM-KU 9304}

Material-Fragmento de dentario con el alvéolo posterior del m2, los alvéolos del m3 y el $\mathrm{m} 4$ derecho completo (Fig. 6.1D).

Localidad y Estratigrafía - Localidad desconocida (Universidad de Kioto), área de La Venta; Grupo Honda.

Comentarios-El material es inédito. La morfología del trigónido del m4 es bastante cercana a la del trigónido del ejemplar IGM-KU 96CO3. Se diferencia de este en la morfología del talónido, el cual se encuentra fuertemente reducido labiolingualmente y sus cúspides se encuentran bastante reducidas. En este molar la crístida oblicua también conecta con el trigónido en un punto lingual al nivel de la muesca carnasial de la metacrístida, más lingual que en el ejemplar IGM-KU $96 \mathrm{CO} 3$.

\section{Grupo 2}

En este grupo se incluyen materiales incompletos o muy desgastados, cuyas porciones preservadas no permiten referirlos claramente a Kiotomops lopezi o asociarlos con la morfología de los ejemplares del Grupo 1.

\section{IGM 250262}

Material-M2 derecho (Fig. 6.1C).

Localidad y Estratigrafia_-Localidad desconocida (Universidad de Duke), área de La Venta; Grupo Honda.

Comentarios-Este molar es inédito y fue estudiado por medio de un calco. Se encuentra bastante desgastado y el protocono y su cuenca parecen estar rotos. Las cúspides principales y sus crestas son claramente similares a las de Kiotomops. Sin embargo, no se preservan bien las porciones donde se observan algunos de los rasgos característicos de este taxón (e.g., no es claro si se presentan o no cónulos y crestas conulares; está desgastada la esquina parastilar y el cíngulo anterior, por lo que no es posible conocer su desarrollo; y no se observa claramente en qué cúspide estilar termina labialmente la preparacrista, pero esta aparentemente es ligeramente oblicua, por lo que podría llegar hasta un punto anterior a la StB). 


\section{IGM 260263}

Material—Fragmento de molar inferior, preservando parte de la porción posterior de la base de la corona y la raíz posterior.

Localidad y Estratigrafía - Localidad desconocida (Universidad de Duke), área de La Venta; Grupo Honda.

Comentarios-El tamaño es consistente con el de Kiotomops; sus crestas se disponen en ángulos similares a los de los molares inferiores descriptos en el Grupo 1. Sin embargo, el material es bastante fragmentario y no se puede realizar otro tipo de comparación más detallada.

\section{IGM\# 93-150}

Material-Trigónido izquierdo (Fig. 6.1G).

Localidad y Estratigrafía-Localidad 4 (Universidad de Duke), área de La Venta; Grupo Honda.

Comentarios-Este fragmento corresponde a un trigónido cuyas cúspides y crestas presentan una morfología bastante cercana a aquellas de los molares inferiores descriptos en el Grupo 1. Sin embargo, presenta algunas diferencias respecto a estos, como el desarrollo del cingúlido anterior que, a pesar de estar roto, aparentemente estaría menos desarrollado; y el paracónido menos desarrollado y aparentemente ubicado en una posición más mesial. Estas diferencias podrían deberse a que se trata de otro locus, posiblemente un $\mathrm{m} 1$.

\section{Comentarios generales sobre Kiotomops}

Tanto la StA como las StB y StE (vestigial) son claramente diferenciables en Kiotomops y se encuentran ubicadas en su posición correspondiente en el patrón metaterio básico. Sin embargo, uno de los rasgos más característicos de Kiotomops es el desarrollo de una gran cúspide estilar "central", que en algunos loci se encuentra muy cerca de la posición de una StC y en otros más hacia la posición de una StD. Entre los metaterios estudiados, en algunos casos, se observó que puede ocurrir que una de las cúspides $\mathrm{StC}$ o StD esté muy bien desarrollada mientras la otra está pobremente desarrollada y se va reduciendo hasta desaparecer en alguno de los loci (e.g., la StD en los esparasocínidos, la StC en algunos didélfidos). También se observó que, por lo general, cuando esto ocurre, la cúspide bien desarrollada que no desaparece se mantiene en su posición correspondiente en el esquema metaterio básico (o bastante cercana). También puede ocurrir que una de estas dos cúspides esté ausente (e.g., en algunos australidelfios, como Dasyurus, Sminthopsis crassicaudata y Thylacinus cynocephalus), pero la que sí está presente se ubica en su posición correspondiente (en la estructura metateria básica) y esta posición permanece constante entre los diferentes loci. En otros casos (e.g., Herpetotherium) puede ocurrir que las StC y StD se fusionen formando una sola gran cúspide. En algunos de estos casos es fácil identificar 
homologías, ya que al menos en alguno de los loci se alcanzan a diferenciar ambas cúspides, una de ellas bien desarrollada y la otra fuertemente reducida o vestigial y apareada a la grande; una de ellas tiende a "desplazarse" acercándose a la otra, por lo que su posición va variando entre los diferentes molares. En Kiotomops, no se observa ningún remanente de una cúspide estilar cerca de la gran cúspide estilar central. Sin embargo, debido al gran tamaño y a la variación de su posición entre los diferentes loci, lo más probable es que se trate de una fusión entre la StC y la StD, ya que estaría ocurriendo algo similar a lo que ocurre en el último caso mencionado, pero en una condición mucho más marcada, donde las cúspides se encuentran completamente fusionadas.

La identificación de los loci molares en dentición superior se realizó con base en la geometría del diente, el tamaño del paracono respecto al metacono, la longitud de sus crestas, el ancho de la plataforma estilar y el "desplazamiento" de la cúspide estilar "central" (interpretada como StC+D). En general, en los taxones cuya morfología presenta el patrón metaterio básico, los M1 tienden a ser asimétricos en vista oclusal, con su porción metastilar alargada posteriormente, y tienden a ser más largos que anchos; mientras que hacia el M3 se van haciendo más simétricos y "cuadrangulares". Adicionalmente, en la mayoría de los casos, tanto el paracono como la preparacrista se van reduciendo hacia el M1; del mismo modo se reduce la plataforma estilar en la porción labial al paracono. Entre los ejemplares aquí referidos a Kiotomops (incluyendo los tentativamente referidos) se observó que además de esta variación morfológica entre los diferentes loci, la cúspide $\mathrm{StC}+\mathrm{D}$ iba variando de posición, haciéndose más central (i.e., más cerca a la posición de una $\mathrm{StC}$ ) hacia el M3 y siendo más posterior (i.e., más cercana a la posición de una $\mathrm{StD})$ en el M1.

Los molares Kiotomops presentan rasgos que reflejan una morfología cercana a la de los quirópteros (i.e., cúspides verticalizadas, crestas del para- y metacono formando una "W" bien definida y la centrocrista fuertemente inflexionada y bastante profunda labialmente). Sin embargo, Czaplewski et al. (2003) sugirieron que esta morfología es más cercana a la de un metaterio (mencionado como "marsupial"), identificando algunas diferencias entre el holotipo de Kiotomops y los Molossidae (i.e., ausencia de un talón, hipocono, mesostilo y un cíngulo lingual). Adicionalmente, afirman que, al igual que en los metaterios, presenta cúspides estilares B y D (esta última aquí interpretada como $\mathrm{StC}+\mathrm{D}$ ) grandes y separadas por un ectoflexo profundo, y que como en muchos marsupiales, la preparacrista se extiende desde el paracono a la StB en lugar de conectarse con la StA (parastilo) formando un proceso en forma de gancho similar al de los molósidos. Cabe resaltar que en algunos metaterios la preparacrista se conecta con la StA (e.g., algunos didélfidos como Caluromysiops, Glironia e Hyladelphys). Por otro lado, Czaplewski et al. (2003: pág. 265, inglés en el original) afirman que el ejemplar IGM-KU 82C2 presenta "una cresta baja e inflada que corre desde el protocono hacia adentro de la cuenca del trígono (desgastada en el holotipo)". No se tuvo acceso al material original ni a calcos de este ejemplar, pero en la fotografía de la publicación de Takai et al. (1991) sí se observa dicha cresta en el ejemplar IGM$\mathrm{KU} 82 \mathrm{C} 2$; sin embargo, el ángulo en que está tomada la fotografía no permite apreciar claramente 
si esta se origina en el protocono o en el paracónulo, el cual estaría bastante cercano al protocono; en la fotografía no es posible observar claramente el paracónulo, pero su ubicación podría inferirse a partir de la posición del metacónulo (bastante cercana al protocono) y a la condición observada en el holotipo. Lo que sí es claro, es que en el holotipo, las crestas que se observan dentro de la cuenca del trígono no corresponden a los remanentes de una gran cresta desgastada que sale del protocono; claramente son crestas conulares aladas. Adicionalmente, una cresta que va desde el protocono hacia adentro de la cuenca del trígono no corresponde a ninguna estructura reconocible en un molar tribisfénico, por lo que es mucho más probable que se trate de una cresta postparaconular o una morfología generada por el desgaste.

Además de esta diferencia en las crestas conulares, se observó que en el ejemplar IGM-KU $82 \mathrm{C} 2$ la preparacrista no es completamente perpendicular al eje anteroposterior del molar (uno de los rasgos que mencionan Czaplewski et al., 2003 para diferenciar a Kiotomops de los molósidos), sino que es ligeramente oblicua, pero al no preservar la esquina parastilar, no se observa exactamente en qué punto termina labialmente. Sin embargo, entre los nuevos materiales revisados, se encontró un ejemplar (IGM-KU 96CO1) que presenta una morfología más cercana a la del ejemplar IGM-KU 82C2 que a la del holotipo de Kiotomops (i.e., las crestas conulares fuertemente desarrolladas que se unen dentro de la cuenca del trigónido están aparentemente ausentes, los cónulos son menos desarrollados), el cual está completo y presenta muy poco desgaste; en este nuevo material puede observarse que la preparacrista presenta una orientación similar a la del ejemplar IGM-KU 82C2, si bien en este caso sí es posible observar dónde termina labialmente, y es en un punto ligeramente anterior a la StB, entre esta y la StA. Sin embargo, esta diferencia con el holotipo y otros ejemplares claramente referibles a Kiotomops, en los que la preparacrista conecta directamente con la StB, probablemente no sea evidencia suficiente para confirmar que se trate de dos taxones diferentes, ya que esta orientación podría variar entre loci. De hecho, la morfología general del ejemplar IGM-KU 96CO1, el desarrollo de los para- y metacónulo, la amplitud de la plataforma estilar y la ubicación de la cúspide $\mathrm{StC}+\mathrm{D}$, sugieren que corresponde al mismo locus que el ejemplar IGM-KU 82C2.

Además de los rasgos mencionados por Czaplewski et al. (2003), Kiotomops y los materiales tentativamente referidos, se diferencian de los quirópteros en la ausencia del cingúlido labial completo en los molares inferiores y en la retención de los para- y metacónulos en los molares superiores.

Algunos de los rasgos particulares que presenta Kiotomops lopezi son la centrocrista fuertemente inflexionada, con su vértice elevado y muy profunda labialmente, y formando junto con la preparacrista y postmetacrista un perfil oclusal dilambdodonte; la presencia de una muesca en la postparacrista (similar a la que se ve en Xenostylos); el para- y metacónulo muy cercanos al protocono y con crestas aladas fuertemente desarrolladas, que también forman una "W", ya que se unen dentro de la cuenca del trígono conformando una cresta "centroconular"; la cresta preparaconular y la preprotocrista extendiéndose anteriormente alrededor de la cara anterior del 
paracono, paralelas entre sí, hasta conectar con el ápice de la StA y ninguna forma un cíngulo continuo con el cíngulo anterior que se origina en la StA; el cíngulo anterior poco desarrollado; la postprotocrista bastante corta, terminando en el metacónulo, siendo la cresta postmetaconular la que se extiende posteriormente rodeando la base del metacono; la StB formando una cresta continua con la preparacrista; y el gran desarrollo de la St C+D.

Algunos de estos rasgos no se observan en los molares superiores tentativamente referidos del Grupo 1 (i.e., crestas conulares bien desarrolladas formando una "W", la presencia de cresta preparaconular, la preprotocrista conectada con la StA y la StB formando una cresta continua con la preparacrista). Estos molares superiores claramente representan un mismo taxón y, en conjunto, se diferencian del holotipo y ejemplares claramente referibles a Kiotomops en la presencia de una StA más desarrollada y bastante saliente anteriormente, formando un espolón; el cíngulo anterior más largo, originándose por debajo de la StA y extendiéndose lingualmente hasta unirse con la preprotocrista, formando con esta un cíngulo continuo; la preparacrista ligeramente oblicua y terminando labialmente en un punto entre la StA y la StB; y la StB poco individualizada. En estos ejemplares también se presenta una muesca en la postparacrista.

Además de los rasgos metaterios mencionados por Czaplewski et al. (2003), el rasgo que más relaciona a K. lopezi con este grupo es la presencia del para- y metacónulo. Estas estructuras están presentes en la mayoría de metaterios, pero también en algunos pocos euterios, como los Dermoptera y los Soricomorpha. Sin embargo, se diferencia de estos principalmente en la cuenca del trígono más reducida, el protocono menos expandido anteroposteriormente, los para y metacónulos mucho más cercanos al protocono, el fuerte desarrollo de las crestas conulares, uniéndose dentro de la cuenca del trígono, y el fuerte desarrollo de las cúspides estilares (no diferenciables o vestigiales en los dermópteros y los soricomorfos). Adicionalmente, se diferencia de los dermópteros en el menor desarrollo de los para y metacónulos; y de los soricomorfos en la ausencia de hipocono.

Los molares superiores de Kiotomops presentan una morfología y patrón de cúspides que sin duda no corresponden a los de los Paucituberculata ni a los de los Polydolopimorphia. Adicionalmente, por su pequeño tamaño, además de las marcadas diferencias morfológicas (como el escaso desarrollo de la postmetacrista), se descarta que se trate de un Sparassodonta. Kiotomops se diferencia de los didelfimorfios en la fuerte inflexión y gran profundidad (labialmente) de la centrocrista, mucho mayor; la presencia de una muesca en la postparacrista; la posición del para- y el metacónulo, muy cercanos al protocono, y con las crestas fuertemente desarrolladas que se unen dentro de la cuenca del trígono; la presencia simultánea de la preprotocrista y la cresta preparaconular extendiéndose paralelas entre sí hasta la StA; la presencia de una estructura $\mathrm{StC}+\mathrm{D}$ de gran tamaño; la morfología verticalizada de las cúspides; la presencia de un ectoflexo mucho más profundo en los M1-3 y la presencia de un pequeño ectoflexo secundario posterior a la $\mathrm{StC}+\mathrm{D}$ al menos en los loci más posteriores; y un hipocónido mucho más saliente labialmente y comprimido anteroposteriormente. 
La mayoría de las diferencias anteriormente mencionadas también se presentan entre Kiotomops y herpetotéridos, excepto que los herpetotéridos sí presentan cúspides relativamente verticalizadas y adicionalmente sí presenta una fusión entre la StC y StD (e.g., Herpetotherium); sin embargo, en ese caso la fusión sólo es completa en el M3, mientras que en los loci anteriores todavía están diferenciadas, siendo la StC mucho menos desarrollada que la StD. En el caso de Kiotomops no se observa ningún ejemplar (ni entre los claramente referibles ni los tentativamente referibles a este taxón) donde se llegue a diferenciar alguna de estas dos cúspides individualmente, siempre aparecen fusionadas, y el tamaño es mucho mayor al de aquella estructura observada en Herpetotherium.

Uno de los rasgos particulares de Kiotomops y los ejemplares tentativamente referidos, es la presencia de una muesca en la postparacrista, como ocurre en Xenostylos, si bien en este último la muesca es mucho más marcada. Adicionalmente, Kiotomops se diferencia de Xenostylos en el paracono más pequeño que el metacono (en Xenostylos es al contrario); la cuenca del trígono más reducida; la preparacrista más corta que la postmetacrista (en Xenostylos son subiguales); la orientación de la preparacrista, perpendicular al eje anteroposterior del molar y conectando con la $\mathrm{StB}$ (ligeramente oblicua en los ejemplares tentativamente referidos y conectando en un punto anterior a la StB), mientras en Xenostylos es claramente oblicua y termina en la StA; la fuerte inflexión y gran profundidad (labialmente) de la centrocrista, mucho mayor; en Xenostylos no hay para y metacónulo distinguibles, ni crestas conulares, y la preprotocrista y postprotocrista terminan en la base del paracono y metacono respectivamente (no se extienden anterior y posteriormente rodeándolos); adicionalmente, el cíngulo anterior de Xenostylos está mucho más desarrollado que en Kiotomops, siendo más amplio y largo, extendiéndose lingualmente hasta la preprotocrista (que termina justo en la base del paracono).

Entre los demás grupos de "ameridelfios", Kiotomops presenta una morfología bastante cercana a la de los sternbérgidos (pers. obs.), principalmente a Carolopaulacoutoia. Algunos rasgos observables en este taxón son similares o representan una condición cercana a la de Kiotomops, como son: (1) las cúspides verticalizadas; (2) la ubicación del para- y metacónulo (aunque en Carolopaulacoutoia son más labiales, también presentan una tendencia a acercarse al protocono, mucho más el metacónulo); (3) la morfología de la centrocrista, fuertemente inflexionada y bastante profunda labialmente, con su vértice más elevado que sus extremos, tanto que forma una estructura similar a una cúspide estilar que se ubica en una posición lingual a estas y en un punto entre el nivel de la StC y la StD; (4) la StC relativamente grande y la StD con tendencia a reducirse (aunque todavía es distinguible, en algunos loci bien desarrollada, y claramente separada de la $\mathrm{StC}$ ), que en Kiotomops se encuentran fusionadas formando una sola estructura de gran tamaño; (5) la StB tiende a formar una cresta continua con la preparacrista pero con una pequeña muesca en la base de la cúspide estilar, tal como ocurre en Kiotomops; (6) la StE no es claramente diferenciable en Carolopaulacoutoia, si bien se aprecia un pequeño engrosamiento en el extremo de la esquina metastilar que podría corresponder a una StE vestigial, por lo que en este caso se ubicaría en una 
posición ligeramente más posterior que en Kiotomops; (7) el cíngulo anterior está poco desarrollado y casi restringido a la zona cercana a la StA; adicionalmente, (8) la StA de Carolopaulacoutoia presenta una morfología en espolón que también se observa en los molares superiores tentativamente referidos a Kiotomops. Carolopaulacoutoia, por su parte, no presenta el fuerte desarrollo de las crestas conulares presentes en Kiotomops.

En síntesis, de todas las comparaciones posibles Carolopaulacoutoia es el taxón más próximo a Kiotomops, representando este último taxón la versión exagerada de sinapomorfías ya existentes en Carolopaulacoutoia. Por lo tanto, se especula con que ambos son filogenéticamente próximos, de los cuales Kiotomops constituye la versión más derivada.

\section{?Sternbergiidae}

(gen. et sp. indet.; Fig. 6.1H-I)

\section{IGM\# 93-143}

Material-M1 derecho (Fig. 6.1H).

Localidad y Estratigrafía—Localidad 4 (Universidad de Duke); Grupo Honda.

Medidas-Tabla 6.2.

Comentarios-Este molar presenta una morfología tribosfénica básica. Es más largo que ancho y su porción metastilar es bastante alargada, por lo que parece tratarse de un M1. En vista lingual, las paredes de las cúspides, especialmente las del para- y metacono, son algo verticalizadas, aunque un poco menos que en Kiotomops, más cercana a la de los sternbérgidos. El paracono es más pequeño que el metacono y este último se encuentra ubicado en una posición ligeramente más lingual. Estas dos cúspides presentan en vista oclusal una morfología triangular bastante cerrada, similar a la de Kiotomops y a la de Carolopaulacoutoia. El protocono está bastante expandido anteroposteriormente, mucho más que en Kiotomops y en Carolopaulacoutoia. El paracónulo y metacónulo están aparentemente ausentes y tampoco se observan remanentes de crestas conulares. La preparacrista es más corta que la postmetacrista y se orienta casi perpendicular al eje anteroposterior del molar, conectándose con el ápice de la StB sin presentar esa muesca a la base de esta cúspide, la cual sí se observa en Kiotomops y en Carolopaulacoutoia. La centrocrista presenta una fuertemente inflexión y se profundiza bastante labialmente, llegando hasta la base de la StC, pero su vértice es más bajo que sus extremos, no está elevado como en Kiotomops y Carolopaulacoutoia. Esta cresta forma junto con la preparacrista y la postmetacrista una $\mathrm{W}$ bien marcada, mostrando una morfología claramente dilambdodonte. La preprotocrista se extiende anteriormente alrededor de la cara anterior del paracono. La postprotocrista a se extiende labialmente rodeando la base del metacono en su cara posterior; es bastante saliente y forma un surco amplio pero restringido sólo a una pequeña porción postero lingual al metacono, mientras que en el resto de su extensión (posterolabial) sobre esta cara, es casi vestigial, formando apenas 
una cresta muy sutil.

La plataforma estilar es amplia, pero más angosta al nivel del paracono. Las cúspides estilares A, B, C y D están claramente presentes y bien desarrolladas, y la StE aparentemente está presente pero es vestigial y se ubica en el extremo del la esquina metastilar, similar a la de Carolopaulacoutoia, y menos desarrollada y más posterior que en Kiotomops. La cúspide estilar más grande es la $\mathrm{StD}$, aunque es sólo ligeramente más grande que la $\mathrm{StC}$; sin embargo, esta última se encuentra más individualizada. La StB es más pequeña que la StC y más grande que la StA; esta última es bastante baja pero bastante saliente anteriormente y presenta una morfología de espolón. Tanto la StA como la StB son más pequeñas que en Kiotomops y Carolopaulacoutoia, pero se encuentran más individualizadas. El ectoflexo es poco profundo, casi vestigial (diferente del M1 de Kiotomops que presenta un ectoflexo relativamente profundo). El cíngulo anterior está bien desarrollado, es más largo y amplio que en Kiotomops y Carolopaulacoutoia, originándose por debajo del espolón que forma la StA y extendiéndose lingualmente hasta unirse con la preprotocrista.

Este ejemplar no es referible a ningún taxón didelfimorfio ni de otro grupo descripto para La Venta y la morfología más afín dentro de esta asociación es la de Kiotomops. Sin embargo, aunque, al menos teniendo en cuenta el material preservado, no se trataría del mismo género, se decidió no nominar por el momento uno nuevo debido a la escasez de material. Este ejemplar presenta un aspecto cercano al de Kiotomops, si bien su morfología es más generalizada, mucho más cercana a la de los sternbérgidos que a la de Kiotomops. La mayoría de los rasgos morfológicos de este ejemplar están mostrando una condición más plesiomórfica respecto a Kiotomops, si bien algunos otros rasgos son más derivados (e.g., ausencia de cónulos; StE menos desarrollada y casi inexistente). Ambos taxones parecen estar representando una condición más derivada de la morfología de los sternbérgidos, si bien cada uno de ellos desarrolló independientemente rasgos derivados diferentes.

\section{Ejemplar tentativamente referido}

\section{IGM\# 93-135}

Material-M2? derecho incompleto (Fig. 6.1I).

Localidad y Estratigrafía—Localidad 4 (Universidad de Duke); Grupo Honda.

Comentarios-Este material está muy pobremente preservado, estando incompleto y bastante desgastado. Sólo se preserva el paracono y metacono, gran parte de la plataforma estilar y una pequeña porción labial de la cuenca del trígono. El tamaño, así como la morfología y disposición de las crestas observables, se ajustan bastante a los del ejemplar IGM\# 93-143, aunque por algunas diferencias de simetría parecería tratarse de otro locus, probablemente un M2. 


\section{CAPÍTULO 7. PAUCITUBERCULATA}

Después del Mioceno medio temprano, el registro de los paleoténtidos es conocido únicamente para tres localidades, cada una de ellas en una latitud diferente (alta, media y baja) a lo largo del continente sudamericano (Engelman et al., 2017). La localidad más septentrional, de menor latitud, es la de La Venta. Hasta el momento las únicas dos especies reportadas en esta localidad son (a) Hondathentes cazador, un taxón endémico de esta localidad que constituye el único paleoténtido registrado al norte de $\operatorname{los} 15^{\circ} \mathrm{S}$, extendiendo ampliamente el rango geográfico de este grupo, y (b) Pitheculites chenche, la especie más joven hasta ahora conocida para el grupo de los abderítidos (Engelman et al., 2017).

Hasta el momento, las especies de Paucituberculata de La Venta estaban representadas únicamente por cuatro ejemplares (uno para $P$. chenche y tres para $H$. cazador). Durante el desarrollo de la presente tesis doctoral, sólo pudieron estudiarse en detalle los holotipos. Adicionalmente, en las visitas a las colecciones que alojan materiales de La Venta, fueron encontrados ejemplares inéditos adicionales, los que son descriptos y clasificados en el presente capítulo. Sin embargo, a pesar de que estos podrían eventualmente representar nuevas especies, no fue posible describirlos como tal, debido a que el material es escaso, fragmentario y, en algunos casos, con una mala preservación.

La interpretación de las homologías de las cúspides de los Paucituberculata ha cambiado desde que los materiales ya publicados de La Venta fueron descriptos originalmente. Por esta razón, las descripciones que se presentan en este capítulo varían respecto de las de Dumont y Bown (1997); esto se debe a que se siguió la interpretación de homologías de Abello (2013), más actualizada. 


\title{
REVISIÓN TAXONÓMICA
}

\author{
MAMMALIA Linnaeus, 1758 \\ METATHERIA Huxley, 1880 \\ PAUCITUBERCULATA Ameghino, 1894 \\ PALAEOTHENTOIDEA Sinclair, 1906 \\ ABDERITIDAE Ameghino, 1889
}

Pitheculites Ameghino, 1902

Especie tipo-P. minimus (Ameghino, 1902).

Especies Referidas - P. chenche (Dumont y Bown, 1997) y P. rothi (Marshall, 1990).

Distribución Geográfica y Estratigráfica-América del Sur (Argentina, Chile y Colombia); Santacrucense-Laventense.

Pitheculites chenche Dumont y Bown, 1997

(Fig. 7.1A)

Holotipo-IGM 250941, fragmento de dentario derecho con p3-m3 (Fig. 7.1A).

Ejemplares Referidos-Sólo el holotipo.

Distribución Geográfica y Estratigráfica - Área de La Venta (Desierto de La Tatacoa, Valle Superior del Magdalena, Departamento del Huila, Colombia); Grupo Honda, Laventense, Mioceno medio (Tablas 3.1 y 7.1; Fig 3.1).

Diagnosis - se diferencia de las restantes especies del género por su gran tamaño y la forma más cuadrada de los $\mathrm{m} 2-3$; se diferencia de $P$. minimus por presentar un $\mathrm{p} 3$ unirradiculado y sin crestas, menor cantidad de crestas laterales en el $\mathrm{m} 1$ y borde oclusal anterior del $\mathrm{m} 1$ más subhorizontal; se diferencia de $P$. rothi por presentar la postcrístida unida a la postentocrístida (Abello, 2007, modificada de Dumont y Bown, 1997 ).

Medidas-Tabla 7.3.

Comentarios—Dumont y Bown (1997) usan el nombre "Pithiculites" a lo largo de la mayor parte de su publicación, pero claramente se están refiriendo al género Pitheculites, ya que las especies que mencionan y sus correspondientes datos geográficos y estratigráficos coinciden con los de las especies de dicho género. Adicionalmente, usan el nombre "Pitheculites" en algunas partes del texto (e.g., en el resumen) y en ningún momento justifican un cambio nomenclatural por algún motivo en particular. Por estas razones, esta escritura, aparentemente, se debe a un error tipográfico (lapsus calami), por lo que el nombre correcto de la especie de La Venta sería Pitheculites chenche. 
La clasificación de Pitheculites dentro de los Abderitidae fue reconfirmada en trabajos posteriores al de Dumont y Bown (1997). En estos estudios (e.g., Abello, 2007, 2013; Engelman et al., 2017; Abello et al., 2018) se realizaron análisis filogenéticos en los que se recupera la monofilia del grupo, incluyendo a $P$. chenche, si bien no se resuelven las relaciones dentro de este, presentándose una politomía entre las tres especies del género.

Durante la presente revisión no se encontraron ejemplares referibles a esta especie además del holotipo, descripto por Dumont y Bown (1997). Se siguió la diagnosis revisada propuesta por Abello (2007), que corresponde a la versión más reciente.

\section{IGM 250941 (Holotipo)}

Localidad y Estratigrafía_Localidad 113 (Universidad de Duke), área de La Venta; unidad entre las Capas de Arenisca de Tatacoa y las Capas de Arenisca del Chunchullo, Formación La Victoria, Grupo Honda.

Comentarios-Este ejemplar fue descripto inicialmente por Dumont y Bown (1997) y redescripto posteriormente por Abello (2007). En la porción de dentario preservado se puede apreciar la presencia de al menos un foramen mentoniano, ubicado por debajo del nivel de la raíz posterior del $\mathrm{m} 1$. El p3 es vestigial y se ubica en la base de la corona del $\mathrm{m} 1$, en el extremo anterolingual. Los molares se encuentran altamente desgastados, por lo que no fue posible agregar información adicional a la presentada en la descripción de Abello (2007).

PALAEOTHENTIDAE Sinclair, 1906

PALAEOTHENTINAE Sinclair, 1906

Hondathentes Dumont y Bown (1997)

Especie Tipo-Hondathentes cazador Dumont y Bown (1997)

Especies Referidas-Sólo la especie tipo.

Distribución Geográfica y Estratigráfica-Área de La Venta (Desierto de La Tatacoa, Valle Superior del Magdalena, Departamento del Huila, Colombia); Grupo Honda, Laventense, Mioceno medio.

Diagnosis_La misma de la especie tipo (véase Dumont y Bown, 1997).

Hondathentes cazador Dumont y Bown (1997)

(Fig. 7.1B-C)

Holotipo-IGM 250440, fragmento de dentario derecho con p3-m2 (Fig. 7.1B). 
Ejemplares Referidos-IGM 250342, IGM 251008 e IGM-KU 82C1-d.

Distribución Geográfica y Estratigráfica-Área de La Venta (Desierto de La Tatacoa, Valle Superior del Magdalena, Departamento del Huila, Colombia); Grupo Honda, Laventense, Mioceno medio (Tablas 3.1 y 7.1; Fig 3.1).

Diagnosis—Véase Dumont y Bown (1997).

Medidas-Tablas 7.2 y 7.3 .

Comentarios - Hasta el momento sólo ha sido reconocida una especie de Hondathentes (Hondathentes cazador), que fue publicado como género y especie nuevos en Dumont y Bown (1997), siendo descripto con base en el holotipo y demás ejemplares referidos (IGM 250342 e IGM 251008). Este nombre fue usado previamente por Bown y Fleagle (1993), mencionándolo como "Hondathentes cazador Dumont y Bown in press"; en esa publicación no se realizó una descripción, no se propuso una diagnosis ni se asignó un holotipo, por lo que hasta ese momento el nombre constituía un un nomen nudum. Sin embargo, esto se hizo la publicación de Dumont y Bown (1997), validando así el nombre y quedando con su autoría.

Bown y Fleagle (1993) clasifican este taxón dentro de los Palaeothentidae, considerándolo como el taxón basal a Palaeothentinae (Sinclair, 1906) + Acdestinae (Bown y Fleagle, 1993). Cabe aclarar que este último es sinónimo junior de Decastinae (Ameghino, 1893). Poteriormente, Abello (2007, 2013) afirma que H. cazador probablemente sea un Palaeothentinae; a pesar de no haber incluido este taxón dentro de sus análisis filogenéticos, basó esta hipótesis en la observación de los ejemplares IGM 250342 e IGM 251008 y de las figuras del holotipo presentadas por Dumont y Bown (1997).

\section{IGM 250440 (Holotipo)}

Localidad y Estratigrafía-Localidad 32 (Universidad de Duke), área de La Venta; Capas Rojas de El Cardón, Formación Villavieja, Grupo Honda.

Comentarios-Este ejemplar fue descripto inicialmente por Dumont y Bown (1997). Esta porción del dentario es de altura moderada. El p3 es tan alto como el trigónido del m1; es globoso y su porción posterior se ensancha posteriormente. Los molares presentan un desgaste moderado. El m1 es marcadamente más grande que el p3 (Tabla 7.3). En este molar, el trigónido es alargado anteriormente, siendo más largo y mucho más angosto que el talónido. El paracónido es distinguible pero fuertemente reducido, siendo la cúspide más pequeña del trigónido, y está comprimido labiolingualmente; se ubica en una posición anterolingual, casi alineado con el metacónido aunque ligeramente mesial respecto al nivel de este. El protocónido está roto y el metacónido desgastado, pero aparentemente el primero es más grande que el último. El metacónido se encuentra en una posición marcadamente más posterior. La paracrístida se curva en sentido anterolingual, hacia el paracónido. La metacrístida no está bien preservada (desgastada o erodada), pero aparentemente es oblicua, debido a la posición atrasada del metacónido, orientándose en dirección anterolabial-posterolingual. El cingúlido anterior es vestigial. 
La cuenca del talónido es amplia y profunda, presentando una morfología triangular. El entocónido es la cúspide más alta del talónido, siendo más alto que el hipocónido, y se encuentra poco comprimido labiolingualmente. El hipocónido es bastante saliente labialmente respecto al protocónido y se ubica casi en la esquina posterolabial del talónido. El hipoconúlido no es distinguible. La preentocrístida está desgastada, pero aparentemente es paralela al eje anteroposterior del molar, dirigiéndose hacia el metacónido. La crístida oblicua está orientada anterolingualmente, terminando anteriormente cerca de la base del metacónido. La posthipocrístida es casi perpendicular al eje anterolingual del molar y junto con la crístida oblicua forman un ángulo agudo (i.e., $<90^{\circ}$ ). Aparentemente se presenta un postcingúlido labial del hipoconúlido vestigial (probablemente corresponde a lo que Dumont y Bown [1997] llaman “distobasal shelf”).

El $\mathrm{m} 2$ es notoriamente más corto que el $\mathrm{m} 1$ y subigual en ancho (Tabla 7.3). Este molar presenta un desgaste moderado. El trigónido es más corto que el talónido y subigual en ancho. Su margen anterior presenta una morfología casi cuadrangular. El metacónido es la cúspide principal del trigónido, siendo más grande que el protocónido; se encuentra relativamente adelantado respecto al nivel del protocónido. El paracónido está ausente, como ocurre en los paleoténtidos. La paracrístida se encuentra desgastada pero es posible observar que no es recta y continua, ya que la postparacrístida y la preprotocrístida se encuentran orientadas oblicuas (casi perpendiculares) entre sí; en la intersección de estas, en la esquina anterolabial del trigónido, se presenta un pequeño engrosamiento. La metacrístida se encuentra algo desgastada, pero aparentemente es tan sólo ligeramente oblicua respecto al eje anteroposterior del molar, en dirección anterolingualposterolabial. La cresta posterior del metacónido (sensu Abello, 2013) presenta un pequeño abultamiento en su porción más posterior, formando casi una pequeña cúspide. El cingúlido anterior es vestigial, mucho menos marcado que en el $\mathrm{m} 1$.

La cuenca del talónido es amplia y bastante larga. El entocónido es la cúspide más grande del talónido. Es ligeramente más comprimido labiolingualmente que en el $\mathrm{m} 1$ y se observa al menos un surco vertical en su cara labial (en el extremo posterior). El hipocónido no es saliente labialmente, encontrándose en una posición ligeramente lingual respecto al protocónido, aunque casi alineado con este, y se ubica en la esquina posterolabial del talónido. El hipoconúlido está fuertemente reducido y se ubica en una posición posterior, en un punto casi central del margen posterior del talónido, pero ligeramente más cercano al entocónido que al hipocónido. La preentocrístida es paralela al eje anteroposterior. La crístida oblicua está orientada hacia el protocónido, siendo ligeramente oblicua al eje anteroposterior del molar, mientras la posthipocrístida es casi perpendicular a este eje, por lo que entre ellas forman un ángulo agudo (i.e., $<90^{\circ}$ ), aunque muy cercano a $90^{\circ}$. El postcingúlido labial del hipoconúlido está poco desarrollado, pero mucho más que en el $\mathrm{m} 1$. 


\section{Ejemplares referidos}

\section{IGM 250342}

Material-M2? aislado.

Localidad y Estratigrafia - CVP-8 (localidad de screenwashing, Universidad de Duke); Capa de Peces, Miembro Baraya, Formación Villavieja, Grupo Honda.

Comentarios-Este ejemplar fue descripto inicialmente por Dumont y Bown (1997) como un M1. Posteriormente, Abello (2007) lo menciona como un M2. Cabe aclarar que aparentemente por un lapsus, Abello (2007) se refiere a dos ejemplares como "IGM 251008". Sin embargo, según el texto se entiende que se trata de aquellos descriptos por Dumont y Bown (1997), por lo que uno de ellos correspondería al ejemplar IGM 250342. Comparando los tamaños y morfología de ambos ejemplares, aquel que Abello (2007) menciona como un M2, correspondería a dicho ejemplar.

No se tuvo acceso al material original; el único registro fotográfico disponible es la Fig. 12.2 de Dumont y Bown (1997), en el que varios detalles son imposibles de apreciar. Por este motivo, no es pertinente realizar una descripción a partir de esta. Sin embargo, durante la presente revisión se encontró un ejemplar claramente referible a esta especie (IGM-KU 82C1-d), del cual se realiza más adelante una descripción detallada. La descripción que presentan Dumont y Bown (1997) no es detallada y, adicionalmente, se encuentra desactualizada en cuanto a la interpretación de las homologías de las cúspides.

Al no poder observar el ejemplar original, calcos o fotografías con una resolución adecuada, no se obtuvieron argumentos suficientes para concluir si el locus corresponde a un M2 o un M1. La revisión de Abello (2007) es posterior a la de Dumont y Bown (1997), tuvo acceso a los materiales y claramente su estudio requirió una detallada observación, pero no menciona por qué concluye que se trata de un M2 en lugar de un M1. Por esta razón, aquí se dejó indicado como M2 con dudas.

\section{IGM 251008}

Material-M3 aislado.

Localidad y Estratigrafía-Localidad CVP-9, (localidad de screenwashing, Universidad de Duke), área de La Venta (Desierto de La Tatacoa, Valle Superior del Magdalena, Departamento del Huila, Colombia); Capa de Peces, Miembro Baraya, Formación Villavieja, Grupo Honda.

Comentarios-Este ejemplar fue descripto inicialmente por Dumont y Bown (1997). El molar es marcadamente más pequeño que el M1 (ejemplar IGM 250342; Tabla 7.2), tal como suele ocurrir entre los diferentes loci de los molares de los Paucituberculata. Al igual que lo ocurrido con el ejemplar IGM 250342 (ver comentario en dicho ejemplar), tampoco se pudo tener acceso al material original y la única información disponible es la fotografía presentada por Dumont y Bown (1997, Fig. 12.2), por lo que no es pertinente realizar una descripción a partir de ésta. Sin embargo, pueden identificarse algunas diferencias respecto al M2?, como la morfología menos cuadrangular; 
la diferencia de tamaño entre las cúspides estilares, siendo la StB mucho más grande que la $\mathrm{StC}+\mathrm{D}$ (esta última está más reducida respecto a la del M1); la posición relativa de la StB respecto a la $\mathrm{StC}+\mathrm{D}$, más lingual; el metacónulo más reducido; la cuenca del trígono más amplia; y la esquina parastilar menos desarrollada, en la que no se observa la proyección anterior a la StB que aparece en los ejemplares IGM 250342 e IGM-KU 82C1-d (ver más adelante en los comentarios acerca de este último ejemplar).

\section{Nuevo ejemplar referido}

\section{IGM-KU 82C1-d}

Material-M2? derecho aislado (Fig. 7.1C).

Localidad y Estratigrafía—Localidad desconocida, área de La Venta; Grupo Honda.

Comentarios-Este ejemplar no ha sido previamente publicado. Se trata de un molar superior que, aparentemente, corresponde al mismo locus que el ejemplar IGM 250342. Presenta cuatro cúspides principales: dos labiales, correspondientes a la $\mathrm{StB}$ y la $\mathrm{StC}+\mathrm{D}$, y dos linguales, correspondientes al protocono y el metacónulo. La StB es la cúspide de mayor tamaño, seguida de la $\mathrm{StC}+\mathrm{D}$. Estas cúspides estilares son cónicas y ligeramente comprimidas labiolingualmente. El protocono es bajo, su cuenca es cuadrangular, amplia y profunda, y se ubica posterior al nivel de la $\mathrm{StB}$, no alineado con esta. El metacónulo es ligeramente más alto que el protocono pero menos amplio, y su base se ubica en un nivel más alto respecto a la base del protocono; se encuentra casi alineado con la $\mathrm{StC}+\mathrm{D}$, tan sólo ligeramente posterior. Los para- y el metacono, así como el paracónulo, son indistinguibles. Se aprecia una pequeña proyección en el extremo anterolabial del molar, sobre la cual desciende la cresta anterior de la StB; esta estructura podría corresponder a una cúspide parastilar (sensu Abello, 2013) vestigial. Allí se origina el cíngulo anterior, el cual es amplio y largo, extendiéndose lingualmente hasta unirse con la preprotocrista formando un cíngulo continuo. También se presenta un cíngulo labial, que se extiende sobre la base de la StB hasta el extremo anterior de la base de la $\mathrm{StC}+\mathrm{D}$. El ectoflexo es poco profundo.

\section{Hondathentes sp. indet.}

(?H. cazador; Fig. 7.1D-E)

Los dos ejemplares que se describen a continuación (IGM 251108-a y b) fueron encontrados asociados al ejemplar IGM 251008 (Thylacosmilidae gen. 1 sp. 1) durante su preparación y no han sido publicados hasta el momento.

\section{IGM 251108-a}

Material—Molar superior derecho (M3?; Fig. 7.1D) 
Localidad y Estratigrafía-Localidad 132 (Universidad de Duke), área de La Venta; unidad entre las Capas de Arenisca de Chunchullo y Capas de Arenisca de Tatacoa, Formación La Victoria, Grupo Honda, Laventense (Tablas 3.1 y 7.1; Fig 3.1).

Medidas-Tabla 7.2.

Comentarios-La morfología de este ejemplar es bastante cercana a la del M3 de H. cazador (ejemplar IGM 251008), pero su tamaño es más grande, aunque es ligeramente más chico que el ejemplar IGM 250342 (M1). Además del tamaño, se diferencia del ejemplar IGM 251008 en algunos rasgos puntuales, como la apariencia general menos cuadrangular (el protocono y sus crestas forman una morfología ligeramente más triangular) y el metacónulo ligeramente menos desarrollado. La escasez de material referible a $H$. cazador no permite confirmar que se trate de la misma especie, además de que no fue posible estudiar el material original del ejemplar IGM 251008. Sin embargo, entre las dos especies de Paucituberculata hasta ahora descriptas para La Venta, la morfología más cercana a este molar es la de H. cazador.

\section{IGM 251108-b}

Material-Molar inferior derecho (m2?; Fig. 7.1E)

Localidad y Estratigrafía-Localidad 132 (Universidad de Duke), área de La Venta; unidad entre las Capas de Arenisca de Chunchullo y Capas de Arenisca de Tatacoa, Formación La Victoria, Grupo Honda, Laventense (Tablas 3.1 y 7.1; Fig 3.1).

\section{Medidas-Tabla 7.3.}

Comentarios-Este ejemplar estaba asociado al ejemplar IGM 251108-a y sus dimensiones son bastante cercanas, por lo que sería muy probable que se trataran, si no del mismo individuo, al menos de la misma especie. Este molar no presenta desgaste. Su tamaño es menor al del $\mathrm{m} 2 \mathrm{del}$ holotipo de H. cazador (ver Tabla 7.3), pero su morfología general es muy similar, por lo que parecería tratarse del mismo locus en un individuo más chico o de otra especie afin.

El trigónido es más corto que el talónido y subigual en ancho (ligeramente más angosto). Su margen anterior presenta una morfología casi semicircular. El metacónido es la cúspide principal del trigónido, siendo más grande que el protocónido, y encuentra alineado con este. El paracónido está ausente. La paracrístida no es recta y continua, ya que la postparacrístida y la preprotocrístida se encuentran orientadas oblicuamente (casi perpendiculares) entre sí y la intersección de estas se ubica en una posición relativamente mesial, pero más cerca del nivel del protcónido que del metacónido. La metacrístida es casi perpendicular al eje anteroposterior del molar y la porción correspondiente a la postmetacrístida está mucho más desarrollada que la de la postprotocrístida. La cresta posterior del metacónido (sensu Abello, 2013) está poco marcada y bastante verticalizada, y no presenta ninguna protuberancia o abultamiento similar a una cúspide, como sí ocurre en el $\mathrm{m} 2$ del holotipo de H. cazador. No se presenta un cingúlido anterior.

La cuenca del talónido es amplia. El entocónido es la cúspide más grande del talónido, siendo bastante alto pero más corto que en el $\mathrm{m} 2$ del holotipo de $H$. cazador, ocupando aproximadamente 
los 2/3 posteriores de margen lingual del talónido. Se encuentra fuertemente comprimido labiolingualmente y presenta al menos un surco vertical en su cara labial (en la porción más anterior). El hipocónido es poco saliente labialmente, encontrándose alineado con el protocónido y se ubica en la mitad posterior del margen labial del talónido. El hipoconúlido está bastante reducido y poco saliente; se ubica en una posición posterior, en un punto casi central del margen posterior del talónido, pero ligeramente más cercano al entocónido que al hipocónido. La crístida oblicua termina anteriormente en la base del protocónido, en un punto ligeramente más lingual que en el $\mathrm{m} 2$ del holotipo de $H$. cazador. La posthipocrístida es ligeramente oblicua, orientándose en dirección anterolabial-posterolingual, y forma con la crístida oblicua un ángulo obtuso (i.e., $>90^{\circ}$ ). La preentocrístida es paralela al eje anteroposterior en su porción más proximal, si bien se curva labialmente, orientándose en sentido anterolabial en su porción más distal, similar a lo que ocurre en Palaeothentes (véase Abello, 2013: Fig. 3H). Sin embargo, esta termina en un punto dentro de la cuenca del talónido, no en la base del metacónido. El postcingúlido labial del hipoconúlido está poco desarrollado, siendo mucho menos desarrollado que en el $\mathrm{m} 2$ del holotipo de $H$. cazador.

En general, su morfología es bastante cercana a la del M3 de $H$. cazador, pero su tamaño es bastante más chico que los molares preservados del holotipo. Es común entre los paucituberculados que existan estas marcadas diferencias de tamaño entre loci, por lo que no sería extraño que se tratara de un locus no preservado en el holotipo, o simplemente se trate de un individuo más pequeño, no pudiéndose descartar un posible dimorfismo sexual. Sin embargo, tampoco se descarta que se trate de otra especie, ya que además del tamaño se observan algunas diferencias: apariencia más elongada, ausencia de la pequeña protuberancia posterior al metacónido, la orientación de la preentocrístida, el desarrollo del postcingúlido labial del hipoconúlido, la morfología del margen anterior del trigónido y el ángulo de orientación de la crístida oblicua. La escasez del material disponible no permite determinar si estas diferencias se deben a una variación morfológica intraespecífica o si tal vez se trata de otra especie del mismo género. Sin embargo, sí es posible afirmar que, de las dos especies de Paucituberculata hasta ahora descriptas para La Venta, la morfología más cercana es la de H. cazador.

\section{PALAEOTHENTIDAE gen. et sp. indet.}

(?Hondathentes; Fig. 7.1F)

\section{SN 2}

Material—Fragmento posterior de dentario derecho con el $\mathrm{m} 3$ y el alvéolo del $\mathrm{m} 4$.

Localidad y Estratigrafía—Localidad desconocida en el área de La Venta; Grupo Honda.

Medidas-Tabla 7.3.

Comentarios-Se preserva un fragmento de dentario que incluye la porción más posterior de la rama horizontal (posterior al nivel del límite m2-3) y la base de la rama vertical. Esta porción 
del dentario es relativamente alta. El espacio retromolar es largo, con una longitud cercana al largo del m3. El m3 es marcadamente más grande que el m4. Este molar presenta un desgaste moderado y es marcadamente más pequeño que el $\mathrm{m} 2$ del holotipo de H. cazador (ver Tabla 7.3). Sin embargo, este no sería un argumento para afirmar que no se trate de la misma especie, ya que entre los Paucituberculata puede verse tal diferencia de tamaño entre el m2 y el m3 (e.g., ejemplar SN1, descripto más adelante; ver Tabla 7.3).

El trigónido es tan ancho como el talónido y más corto. Su margen anterior presenta una morfología casi cuadrangular, similar a la del $\mathrm{m} 2$ del holotipo de $H$. cazador. El paracónido está ausente, como ocurre en los paleoténtidos. El metacónido es la cúspide principal del trigónido, siendo más grande que el protocónido; se encuentra bastante adelantado respecto al esquema tribosfénico básico, ubicándose en un punto bastante anterior respecto al nivel del protocónido y generando que la metacrístida sea marcadamente oblicua respecto al eje anteroposterior del molar, en dirección anterolingual-posterolabial. La postparacrístida y la preprotocrístida se encuentran orientadas de forma oblicua (casi perpendiculares) entre sí y la intersección de estas se ubica en una posición relativamente mesial, pero más cerca del nivel del protcónido que del metacónido. Aparentemente se presenta una cresta posterior al protocónido, que se dirige posterolingualmente hasta unirse con la crístida oblicua. La cresta posterior del metacónido (sensu Abello, 2013) presenta un pequeño abultamiento en su porción más posterior, formando casi una pequeña cúspide, la cual es ligeramente más desarrollada que la del holotipo de H. cazador. No se observa un cingúlido anterior.

La cuenca del talónido es amplia y bastante larga, ya que debido a la posición muy adelantada del metacónido, la cuenca del talónido se extiende bastante anteriormente. El entocónido es la cúspide más grande del talónido, siendo bastante alto y largo, extendiéndose sobre casi todo el margen lingual del talónido. Se encuentra fuertemente comprimido labiolingualmente y presenta dos grandes surcos verticales en su cara labial. El hipocónido es poco saliente labialmente, encontrándose alineado con el protocónido y se ubica en la mitad posterior del margen labial del talónido. El hipoconúlido es reducido y poco saliente; se ubica en una posición posterior, en un punto casi central del margen posterior del talónido, pero ligeramente más cercano al entocónido que al hipocónido. La preentocrístida es paralela al eje anteroposterior en su porción más proximal, pero se "dobla" labialmente, orientándose en sentido anterolabial en su porción más distal, similar a lo que ocurre en Palaeothentes (ver Fig. 3H, en Abello, 2013); y se presenta una postentocrístida que se dirige hacia el hipoconúlido. La crístida oblicua está orientada ligeramente oblicua al eje anteroposterior del molar (anterolingualmente), mientras la posthipocrístida es ligeramente oblicua a este eje y ligeramente oblicua respecto al eje labiolingual, orientándose en dirección anterolabialposterolingual; por lo tanto, estas dos crestas forman entre sí un ángulo obtuso (i.e., $>90^{\circ}$ ). El postcingúlido labial del hipoconúlido está poco desarrollado, siendo menos marcado que en el $\mathrm{m} 2$ del holotipo de $H$. cazador. 


\section{Palaeothentoidea fam., gen. et sp. indet.}

(?Palaeothentidae; Fig. 7.1G)

\section{SN 1}

Material-Fragmento de dentario derecho con el $\mathrm{m} 2$ y alveolos de los m3-4.

Localidad y Estratigrafía_-Localidad desconocida en el área de La Venta; Grupo Honda.

Medidas-Tabla 7.3.

Comentarios-Se preserva un fragmento de dentario que incluye la porción más posterior de la rama horizontal (posterior al nivel del límite m1-2) y una pequeña porción de la base de la rama vertical. Esta porción del dentario es relativamente baja, presentando por debajo del $\mathrm{m} 2$ una altura de menos de dos veces el largo de este molar. Se observa una marcada reducción posterior de tamaño de los molares, del $\mathrm{m} 2 \mathrm{al} \mathrm{m} 4$. El $\mathrm{m} 2$ es marcadamente más grande que el $\mathrm{m} 2$ del holotipo de H. cazador (ver Tabla 7.3). Presenta un desgaste mayor al del ejemplar SN2.

El trigónido es más corto que el talónido y subigual en ancho (ligeramente más angosto). La morfología del margen anterior es mucho más triangular que la del ejemplar SN2. El metacónido es la cúspide principal del trigónido, siendo más grande que el protocónido; se encuentra bastante adelantado respecto al esquema tribosfénico básico, ubicándose en un punto bastante anterior respecto al nivel del protocónido. Se presenta una ruptura en el extremo posterior de la preparacrístida, por lo que no se observa claramente si hay un paracónido distinguible, ya que el molar se encuentra roto en esa zona, pero aparentemente estaría ausente, ya que se presenta un valle muy amplio anterolabial al metacónido (cuando el paracónido está presente en los paucituberculados, se ubica muy cerca del metacónido). No se preserva la postparacrístida pero la preprotocrístida se encuentra orientada anterolingualmente, dirigiéndose hacia el extremo mesial del molar. Se presenta una cresta posterior al protocónido, que se dirige posterolingualmente hasta unirse con la crístida oblicua. La metacrístida está completamente desgastada, por lo que no es posible ver claramente su orientación, pero aparentemente es oblicua en dirección anterolingualposterolabial (debido a la posición adelantada del metacónido), aunque pareciera ser mucho menos oblicua (más cerca de ser perpendicular) que la del ejemplar SN2. Se observa una expansión posterior al metacónido, aunque presenta forma de pequeño abultamiento, no de cresta, formando casi una pequeña cúspide. Se observa un cingúlido anterior vestigial.

La cuenca del talónido es amplia y bastante larga, ya que debido a la posición muy adelantada del metacónido, la cuenca del talónido se extiende bastante anteriormente. El entocónido es la cúspide más grande del talónido; se ubica en la esquina posterolingual del talónido y se encuentra restringido a esta posición, no se extiende anteriormente como el del ejemplar SN2 o como en el $\mathrm{m} 2$ del holotipo de H. cazador. Se encuentra sólo ligeramente comprimido labiolingualmente y aparentemente no presenta surcos verticales en su cara labial, aunque cabe resaltar que esta muestra un alto grado de desgaste. El hipocónido es ligeramente saliente labialmente respecto al protocónido y se ubica en la mitad posterior del margen labial del 
talónido. El hipoconúlido está roto, pero es claro que se ubica en una posición posterior, en un punto casi central del margen posterior del talónido, algo más cercano al entocónido que al hipocónido. La preentocrístida se orienta en sentido anterolabial, marcadamente más oblicua que en Hondathentes cazador y similar a la orientación que se observa en el m2 de Acdestis owenii (Abello, 2013; Fig. 3I), y es corta, terminando en un punto dentro de la cuenca del talónido relativamente lejano de la base del metacónido, por lo que se presenta un gran valle entre el entocónido y el metacónido. También se presenta una postentocrístida, que se dirige hacia el hipoconúlido. La crístida oblicua está orientada ligeramente oblicua al eje anteroposterior del molar (anterolingualmente), mientras la posthipocrístida es oblicua a este eje y ligeramente oblicua respecto al eje labiolingual, orientándose en dirección anterolabial-posterolingual; por lo tanto, estas dos crestas forman entre sí un ángulo obtuso (i.e., $>90^{\circ}$ ). El postcingúlido labial del hipoconúlido está aparentemente poco desarrollado.

Este ejemplar es referible sin duda a los Palaeothentoidea, ya que presenta los siguientes rasgos rescatados como sinapomorfías de este grupo en el análisis filogenético de Abello (2013): presencia de una expansión posterior del metacónido; presencia de una cresta posterior al protocónido; presencia de postentocrístida. Sin embargo, aunque su apariencia general es más congruente con la morfología de los Palaeothentidae, los rasgos identificados como sinapomorfías este grupo (Abello, 2013) no se preservan en este molar, aunque uno de ellos estaría aparentemente presente, que es la ausencia del paracónido en el m2. Ninguna de las sinapomorfías observables en el m2 para los Abderitidae o los Pichipilidae están presentes en este molar. Sin embargo, su morfología no es consistente con ninguna de las especies de paleotentoideos hasta ahora descriptas para La Venta, es una morfología diferente y claramente referible a un nuevo taxón para esta asociación.

\section{?PAUCITUBERCULATA}

\section{IGM 253055-C}

Material—molar inferior izquierdo incompleto.

Localidad y Estratigrafía — Localidad desconocida (Universidad de Duke), área de La Venta; Grupo Honda.

Comentarios-Este número de colección fue usado para numerar a seis ejemplares diferentes colectados en un mismo lugar. En la presente revisión se encontraron tres de ellos, uno de los cuales ya había sido publicado por Goin (1997) y que en la presente tesis es referido al didelfimorfio Género A sp. 2 (ver Capítulo 5); el otro es un material inédito, pero también fue referido al mismo taxón. El IGM 253055-C sería el tercero, si bien este molar aparentemente no está relacionado con dicho taxón, ya que su apariencia es más próxima a la de un molar plaugiaulacoideo. Desafortunadamente, este ejemplar fue revisado rápidamente durante la visita a 
la colección de la Universidad de Duke y no se alcanzó a tomar fotografías del mismo. Por este motivo, y por el momento, no es posible relacionarlo con algún taxón en particular. Teniendo en cuenta su morfología plaugiaulacoidea, se menciona provisionalmente en esta sección hasta tanto se realice una revisión pormenorizada del mismo.

\section{ANÁLISIS ECOMORFOLÓGICO}

\section{Masa corporal}

Las estimaciones de masa corporal de los Paucituberculata de La Venta realizaron por medio de la ecuación de Zimicz (2004), en la que la variable predictiva utilizada es el área del m2 (Tabla 7.4). Por lo tanto, estas estimaciones fueron realizadas únicamente para aquellos ejemplares que preservaban molares claramente identificables como $\mathrm{m} 2$. El procedimiento que se utilizó para estas estimaciones es el mismo que en el análisis de los esparasodontes y didelfimorfios, y se explica detalladamente en la sección Materiales y Métodos.

Entre las estimaciones realizadas para los Paucituberculata de La Venta se encontró que $P$. chenche es la especie más pequeña, con casi 140 g, y la más grande correspondería al paleotentoideo indeterminado (ejemplar SN 1), con una masa corporal de ca. 321 g. Por otro lado, H. cazador presenta una masa corporal más cercana a la de P. chenche, con ca. 147 g. El ejemplar SN 2 (?Hondathentes) no preserva el $\mathrm{m} 2$, por lo que no fue posible realizar una estimación por medio de esta ecuación. Sin embargo, al comparar sus medidas longitudinales (Tabla 7.3), se aprecia que tendría un tamaño muy cercano al del holotipo de $P$. chenche. Al no poder identificarse con certeza el locus de los ejemplares IGM 251108-a e IGM 251108-b, por el momento no es posible realizar comparaciones respecto a su tamaño.

Estudios previos (e.g., Abello y Ortiz Jaureguizar, 2009; Abello et al., 2018) han hecho estimaciones de masa corporal para $P$. chenche y las demás especies del género, encontrando que esta es la especie de mayor tamaño. Sin embargo, los datos obtenidos muestran un valor menor al alcanzado en la presente revisión (i.e., 94 g y 109 g, respectivamente). 


\section{CAPÍTULO 8. MICROBIOTHERIA}

La diversidad de los microbioterios fue relativamente estable y baja durante el Paleógeno (Goin et al., 2016); los representantes de este orden alcanzaron su acmé durante el Mioceno temprano (Goin y Abello, 2013) y su registro continúa hasta la actualidad.

Los microbioterios son actualmente clasificados en dos familias: Woodburnodontidae (Goin et al., 2007b) y Microbiotheriidae (Ameghino, 1887). Los Woodburnodontidae son más generalizados, poco diversos, estrictamente paleógenos y de distribución patagónica y antártica (Goin et al., 2007b). Los Microbiotheriidae son claramente más diversos y su distribución temporal va del Eoceno medio hasta la actualidad, distribuyéndose desde la Antártida hasta Colombia. Pachybiotherium es incluido dentro de esta última, conformando junto con Clenia (Ameghino, 1904) y Eomicrobiotherium (Marshall, 1982) la subfamilia Pachybiotheriinae (Goin et al., 2016). Las especies de Pachybiotherium son los representantes de mayor tamaño de la familia Microbiotheriidae (Goin et al., 2010). Se destacan por presentar un gran desarrollo vertical del dentario por debajo de la serie molar, un rasgo compartido con numerosos grupos de primates de hábitos alimentarios frugívoros, así como también con los extintos marsupiales Caroloameghiniidae y Polydolopimorphia, de hábitos inferidos similares (Goin, 2006; Goin et al., 2010; Vinyard et al., 2007).

Pachybiotherium minor es la única especie de microbioterio hasta ahora registrada para La Venta. Fue descripta por Goin (1997) a partir del holotipo (IGM 253051) y cuatro ejemplares referidos (IGM 253026, IGM 253027, IGM 253028 e IGM 253029), todos provenientes de la misma localidad. Durante la presente revisión se determinó que este último ejemplar en realidad corresponde al dP3 de un didelfimorfio, por lo que se describe en el capítulo correspondiente a dicho grupo. Por su parte, el ejemplar IGM 253028 es tan fragmentario que no fue posible durante la presente revisión siquiera confirmar su locus ni a qué porción del molar corresponde, por lo que no fue incluido dentro de los materiales referibles a Pachybiotherium. A estos materiales ya publicados se suma un nuevo ejemplar, del que se desconoce el paradero pero se dispone de dos calcos; sobre estos últimos se realizó su descripción. Este material muestra rasgos similares a Pachybiotherium si bien presenta algunas diferencias puntuales con los representantes del género, e incluso con los microbioterios en general. Sin embargo, estas diferencias bien podrían tratarse de rasgos particulares de una especie que incluso podría ser $P$. minor, ya que se presentan en porciones no preservadas en los materiales previamente conocidos. Adicionalmente, algunas pocas diferencias observadas respecto a $P$. minor podrían ser en realidad producto de defectos en los calcos, únicos elementos reservados de este ejemplar. 


\title{
REVISIÓN TAXONÓMICA
}

\author{
MAMMALIA Linnaeus, 1758 \\ METATHERIA Huxley, 1880 \\ MICROBIOTHERIA Ameghino, 1889 \\ MICROBIOTHERIIDAE Ameghino, 1887 \\ PACHYBIOTHERIINAE Goin et al., 2016
}

Pachybiotherium Ameghino, 1902

Especie Tipo-Pachybiotherium acclinum Ameghino, 1902

Especies Referidas - P. acclinum; P. minor Goin, 1997; y P. illuminatum Goin et al., 2010.

Distribución Geográfica y Estratigráfica-América del Sur, Mioceno temprano-medio.

Pachybiotherium minor Goin, 1997

(Fig. 8.1A-E)

Holotipo-IGM 253051, fragmento posterior de dentario izquierdo con las raíces de m2-3 y el m4 completo.

Ejemplares Tentativamente Referidos-IGM 253026, IGM 253027 e IGM-KU 8605.

Distribución Geográfica y Estratigráfica-Área de La Venta (Desierto de La Tatacoa, Valle Superior del Magdalena, Departamento del Huila, Colombia); Grupo Honda, Laventense, Mioceno medio (Tablas 3.1 y 8.1; Fig. 3.1).

Diagnosis_-Véase Goin (1997).

Medidas-Tabla 8.2.

\section{IGM 253051 (Holotipo)}

Material-Fragmento posterior de dentario, incluyendo la porción más posterior de la rama horizontal y la base de la rama vertical; las raíces de m2-3 y el m4 completo (Figs. 8.1A-B).

Localidad y Estratigrafía-Localidad 22 (Universidad de Duke), San Nicolás, área de La Venta; Capas del Mono, Miembro Baraya, Formación Villavieja, Grupo Honda.

Comentarios-Este ejemplar preserva la porción posterior de la rama horizontal y la base de la rama vertical del dentario. La rama horizontal es alta y robusta, como ocurre en la correspondiente porción en Pachybiotherium. A juzgar por las proporciones de las raíces de los $\mathrm{m} 2-3$, estos presentarían un tamaño cercano al del $\mathrm{m} 4$, siendo este último ligeramente más chico, por lo que no existe un cambio muy marcado de tamaño entre estos. Sin embargo, por delante del $\mathrm{m} 2$ el dentario presenta un ensanchamiento, probablemente indicando un gran tamaño de alguno de 
los elementos dentales más anteriores que no fueron preservados (e.g., el m1 o el p3).

El m4 es el único molar que preserva la corona, aunque las cúspides y crestas del trigónido se encuentran fuertemente desgastadas. Presenta un trigónido bien desarrollado y un talónido relativamente reducido, con una mayor reducción en su longitud labiolingual. El protocónido es la cúspide más grande del trigónido, seguida de un paracónido bien desarrollado; el metacónido está relativamente reducido, siendo la cúspide más pequeña de estas tres, y se encuentra bastante cercano al protocónido. Estas proporciones difieren de otras especies de Pachybiotherium, en las cuales el paracónido está mucho más reducido y el metacónido es más desarrollado. Al igual que en las demás especies del género, el cingúlido anterior se encuentra pobremente desarrollado y el metacónido se ubica en una posición posterior respecto al nivel del protocónido. La paracrístida se encuentra bien desarrollada, mientras la metacrístida está, aparentemente, poco desarrollada, al menos en la porción correspondiente a la postmetacrístida, debido al reducido tamaño del metacónido y su cercanía al protocónido. El talónido es más corto que el trigónido y mucho más angosto. El hipoconúlido es la cúspide más grande del talónido y se ubica en una posición casi central en el borde posterior de la corona, mientras el hipocónido, mucho más reducido, se ubica en cerca de la mitad del borde labial; el entocónido está ausente. La crístida oblicua presenta una ligera inflexión, orientándose en su porción más posterior en sentido lingual, en dirección al metacónido, pero a partir de un punto cambia de sentido, orientándose labialmente y terminando anteriormente en el protocónido, en un punto muy cercano al nivel de la muesca carnasial de la metacrístida.

Además de las diferencias ya mencionadas, este $\mathrm{m} 4$ difiere del de P. illuminatum en el talónido más reducido labiolingualmente, la orientación de la crístida oblicua (casi paralela al eje anteroposterior del molar en P. illuminatum) y la ausencia del entocónido. Como lo afirma Goin (1997), P. minor presenta una morfología menos derivada que la de $P$. acclinum, ya que este último tiene la rama horizontal más alta y robusta. A este rasgo, Goin (1997) agrega que el hipoconúlido se encuentra más separado del entocónido, especialmente en los molares más anteriores, pero esto puede ser observado en el ejemplar IGM 253026, que en la presente revisión es clasificado como tentativamente referible a esta especie.

\section{Ejemplares tentativamente referidos}

\section{IGM 253026}

Material-m1? izquierdo incompleto (Fig. 8.1C).

Localidad y Estratigrafía-Localidad 22 (Universidad de Duke), San Nicolás, área de La Venta; Capas del Mono, Miembro Baraya, Formación Villavieja, Grupo Honda.

Comentarios - Cuando se describió por primera vez este ejemplar, se encontraba completo (Goin, 1997, Fig. 11.2.B). Sin embargo, cuando fue estudiado en la presente revisión, estaba incompleto, preservando el trigónido y sólo una pequeña porción anterior del talónido (Fig. 8.1). 
Goin (1997) describió este ejemplar como un m3, pero la posición marcadamente mesial del paracónido (casi en el extremo más anterior del molar) y bastante posterior del metacónido (respecto al protocónido), sugieren que podría corresponder a un $\mathrm{m} 1$. En este molar el metacónido está bien desarrollado (aunque más chico que el protocónido), el paracónido está reducido y el entocónido está bien desarrollado, similar al $\mathrm{m} 1$ de P. acclinum y contrario a lo que ocurre en el $\mathrm{m} 4$ del holotipo de P. minor. El trigónido angosto y alargado, el cingúlido anterior poco desarrollado, la posición bastante posterior del metacónido respecto al protocónido y el hipoconúlido claramente separado del entocónido, son caracteres diagnósticos de Pachybiotherium presentes en este ejemplar. Debido a que tanto este ejemplar como el holotipo de $P$. minor fueron encontrados en la misma localidad, la hipótesis más parsimoniosa sería que se trate de la misma especie; sin embargo, hasta no encontrar una serie molar más completa, no es posible confirmar si las diferencias observadas entre estos dos ejemplares corresponden a una variación morfológica entre loci, o si en realidad pertenecen a dos especies diferentes de Pachybiotherium.

\section{IGM 253027}

Material-Trigónido derecho aislado (Fig. 8.1E).

Localidad y Estratigrafía-Localidad 22 (Universidad de Duke), San Nicolás, área de La Venta; Capas del Mono, Miembro Baraya, Formación Villavieja, Grupo Honda.

Comentarios-Goin (1997) lo identificó como un trigónido derecho aislado. Este material fue fotografiado durante las primeras etapas del desarrollo de esta tesis doctoral y no fue posible realizar una descripción sobre el material original en aquel momento. La apariencia general se asemeja a la del ejemplar IGM 253026, aunque aparentemente podría tratarse de otro locus, ya que el metacónido no se encuentra tan retrasado respecto al protocónido y el paracónido pareciera ubicarse en una posición menos mesial. Las fotografías (Fig. 8.1E) en vista oclusal no fueron tomadas con un ángulo adecuado, son más una vista oclusolabial, por lo que se observan algunos rasgos extraños, que bien podrían ser un efecto visual producto de esta inclinación. Por ejemplo, la preprotocrístida presenta una particular curvatura cóncava labialmente, y anteriormente se une a la postparacrístida formando un ángulo bastante agudo, dando una apariencia acuñada. Este material se deja por el momento como tentativamente referido ya que, al igual que ocurre con el ejemplar IGM 253026, hasta no encontrar una serie molar más completa de P. minor, no es posible confirmar si las diferencias corresponden a una variación morfológica entre loci, o si representan especies diferentes de Pachybiotherium.

\section{IGM-KU 8605}

Material—calco de un dentario derecho incompleto con p3-m4 (Fig. 8.1D).

Localidad y Estratigrafía_Localidad desconocida en el área de La Venta; Grupo Honda.

Comentarios-Durante la visita a las diferentes colecciones que alojan materiales de La Venta no pudo ser encontrado el material original, por lo que esta descripción se realiza con base 
en un calco disponible MLP, enviado a Francisco Goin posteriormente a la publicación de Goin (1997), y otro que fue facilitado por Richard Kay durante la visita a la colección de la Universidad de Duke. El dentario es bastante robusto y alto con relación al tamaño de los dientes. Su altura va disminuyendo anteriormente, con una reducción ligeramente más marcada por delante del $\mathrm{m} 1$, pero es menor que el fuerte desnivel que se presenta en $P$. acclinum. El dentario se ensancha ligeramente por delante, a partir del nivel del p3. Al menos un foramen mentoniano es identificable y se ubica por debajo de la raíz posterior del p3. La morfología general del dentario es similar a la de la porción preservada en el holotipo de P. minor. El p3 es robusto y globoso, mucho más alto, ancho y largo que cualquiera de los molares, siendo más grande que el m1 (Tabla 8.2). Los p3-m2 se encuentran fuertemente desgastados. El m1 es más largo que el m2, el cual es subigual al m3, y el m4 es el molar más corto. El ancho del trigónido disminuye posteriormente, mientras el talónido se va haciendo relativa y absolutamente más angosto. El protocónido es la cúspide más grande del trigónido. El paracónido se encuentra, aparentemente, en una posición bastante mesial en el m1, y en morfología general, proporciones y configuración de las cúspides es muy similar a las del $\mathrm{m} 1 \mathrm{de}$ P. acclinum y a las del ejemplar IGM 253026, aunque en este último el paracónido parece estar más reducido (más cercano a la condición de $P$. acclinum). El paracónido es tan sólo ligeramente mesial en los demás molares. En el m4, parece presentar una suerte de muesca que le da la apariencia de ser bicúspide. El tamaño del paracónido va disminuyendo posteriormente, estando bastante reducido en el $\mathrm{m} 4$, pero en general no está tan reducido como en P. illuminatum y es consistente con la proporción de tamaño del $\mathrm{m} 4$ del holotipo de $P$. minor (aunque no presenta esa condición bicúspide). El metacónido está bastante reducido al menos en los $\mathrm{m} 2-3$, siendo más chico que el paracónido; en el m1 el trigónido está muy desgastado, pero aparentemente ocurre la misma relación de tamaño, mientras que en el m4 aparentemente el metacónido está ausente, pero se presenta una suerte de cíngulo que recorre el borde lingual del molar, desde el paracónido hasta aproximadamente la mitad del margen lingual del talónido. Este cíngulo se ensancha lingualmente al nivel de donde debería estar ubicado el metacónido. En los m1-3, el metacónido se ubica en una posición posterior respecto al nivel del protocónido, más marcada en el m1. El cingúlido anterior se encuentra poco desarrollado.

La cúspide principal del talónido es el hipocónido. No es posible determinar (por el desgaste) la diferencia de alturas entre el hipoconúlido y el entocónido, pero sí es posible observar que en los m1-2 el entocónido está presente y el hipoconúlido es saliente posteriormente y se encuentra algo separado del entocónido. Por otro lado, en los m3-4 el entocónido parece estar ausente, mientras el hipoconúlido está bien desarrollado y es saliente posteriormente. El extremo anterior de la crístida oblicua se va acercando al nivel de la muesca carnasial de la metacrístida, pero aparentemente no porque su orientación cambie, sino simplemente porque el talónido se va haciendo más angosto hacia los loci posteriores. Su orientación permanece casi paralela al eje anteroposterior del molar en todos los loci. En el m4 aparentemente no se presenta ese cambio en la orientación de la crístida oblicua que puede observarse en el $\mathrm{m} 4$ del holotipo de $P$. minor. 
El ejemplar IGM KU 8605 comparte con el holotipo de P. minor el gran tamaño del cuerpo mandibular en relación a los molares y la gran altura de la rama horizontal. Los molares inferiores preservados muestran algunos rasgos presentes en los Microbiotheriidae. Fundamentalmente, el metacónido retrasado respecto al protocónido, el paracónido reducido al igual que el entocónido, y la posición del hipoconúlido, relativamente alejada del entocónido. Sin embargo, difiere de los microbiotheriidae conocidos en que la rama horizontal pareciera ensancharse a la altura de los premolares como si contuviera la o las raíces de incisivos hipertrofiados. Por otra parte, si bien Pachybiotherium (e.g., P. acclinum) tiene el p3 grande con respecto a los p1-2, el único premolar preservado del ejemplar IGM-KU 8605 es muy grande (en ancho y altura) cuando se lo compara con el $\mathrm{m} 1$, y globoso. Otra diferencia con P. acclinum es que en este ultimo, al igual que en las de Clenia y Eomicrobiotherium (los Pachibiotheriinae sensu Goin et al., 2016), existe un claro desnivel en el plano alveolar de los molares respecto a al de los premolares (el plano alveolar de los premolares inferiores está claramente por debajo del de los molares, mientras que el plano alveolar de los premolares superiores está claramente por encima del de los molares superiores). En IGM-KU 8605 no parece haber tal diferencia marcada de altura entre los planos alveolares de las series premolar y molar, se ve tan sólo una ligera diferencia.

Debe tenerse en cuenta que el material IGM-KU es un calco solamente, no habiéndose podido encontrar el ejemplar original ni en Japón ni en ninguna de las colecciones visitadas. Algunos rasgos presentes en el material IGM-KU 8605 (por ejemplo, el peculiar paracónido bicúspide y la ausencia de metacónido), podrían ser en realidad artefactos del calco, más que una realidad morfológica. Por estos motivos, y hasta tanto no se cuente con más materiales o aparezca el ejemplar original, cuyo calco tiene el número IGM-KU 8605, se optó por referir este ejemplar tentativamente a Pachybiotherium minor. Cabe resaltar, además, que algunas de las diferencias con Pachybiotherium podrían considerarse como dentro de la variabilidad de un género. Por ejemplo, Didelphis solimoensis presenta un $\mathrm{p} 3$ bastante grande y robusto respecto a los molares, mucho más que las demás especies del género. Por lo tanto, el hecho de presentar un premolar con tales características no implica que este ejemplar se encuentre muy alejado taxonómicamente de las restantes especies de Pachybiotherium (e.g., otra familia). Por el momento, no se conoce ningún p3 inequívocamente referible a $P$. minor.

\section{Pachybiotherium}

(Fig. 8.1F)

\section{IGM 253028}

Material—Fragmento de molar ¿superior? (Fig. 8.1F)

Localidad y Estratigrafía-Localidad 22 (Universidad de Duke), San Nicolás, área de La Venta; Capas del Mono, Miembro Baraya, Formación Villavieja, Grupo Honda (Tablas 3.1 y 8.1; 
Fig. 3.1).

Comentarios-Este ejemplar fue incluido por Goin (1997) dentro del hipodigma de P. minor y fue descripto como un fragmento de molar superior. Sin embargo, el material es tan fragmentario, que incluso es difícil determinar el locus y a qué parte del molar corresponde, por lo cual no es posible identificar claramente rasgos que permitan asignarlos con certeza a Pachybiotherium. Por esta razón, en la presente revisión se refiere tentativamente a Pachybiotherium. 


\section{CAPÍTULO 9. METATHERIA INDET. Y MAMMALIA INDET.}

Entre los ejemplares de La Venta estudiados en las colecciones visitadas durante el desarrollo de la presente revisión, se observaron algunos que aparecían identificados en su etiqueta como "Metatheria" o "Marsupialia", pero en la presente revisión se encontró que su clasificación es bastante dudosa, bien sea por su morfología o por la mala preservación. Algunos de estos incluso podrían no ser metaterios. Otros ejemplares habían sido previamente referidos a grupos particulares de metaterios (e.g., Sparassodonta), pero se observó que su morfología es más consistente con la de los euterios.

Aparentemente, ninguno de los ejemplares mencionados en el presente capítulo ha sido publicado. La información geográfica y estratigráfica de estos se resume en la Tabla 9.1 (ver también Fig. 3.1 y Tabla 3.1) y las medidas se presentan en la Tabla 9.2. Las fotografias de estos ejemplares se muestran en las Figs. 9.1 y 9.2.

\section{Metatheria indet.}

Los ejemplares se mencionan a continuación presentan una morfología consistente con la de los metaterios, pero no fue posible establecer una clasificación más precisa. Estos ejemplares claramente representan dos taxones diferentes, por lo que fueron así diferenciados.

\section{Taxón 1}

\section{IGM 253055-A}

Material-Un m4 izquierdo aislado (Fig. 9.1A).

Localidad y Estratigrafía_Localidad desconocida (Universidad de Duke), área de La Venta; Grupo Honda.

Comentarios-Este ejemplar no ha sido publicado. Entre todos los didelfimorfios de La Venta, el tamaño es consistente únicamente con Gen. A sp. 2, si bien no existe otro m4 referible a esta especie que permita realizar comparaciones. Se comparó el trigónido con el de los m1-3, ya que en una misma especie los trigónidos suelen tener una apariencia general similar en todos los loci, cosa que no ocurre con el talónido, el cual suele ser diferente en el m4. El trigónido de este ejemplar es más cerrado anteroposteriormente, estando el paracónido más cerca del metacónido, y es más ancho que largo, con el protocónido y el metacónido más separados, mientras que en el 
taxón innominado en Gen. A sp. 2 muestran una morfología triangular más simétrica, similar a los de los m1-4 de Gen. A sp. 1. Debido a la estrecha similitud entre las especies del Género A, se comparó este molar con el m4 de Gen. A sp. 1, encontrando algunas diferencias claras. Además del tamaño marcadamente mayor, se diferencia de Gen. A sp. 1 en que el margen lingual del molar es convexo; el trigónido es más comprimido anteroposteriormente, estando el paracónido más cerca del metacónido, y es más ancho que largo, con el protocónido y el metacónido más separados; el trigónido es mucho más alto respecto del talónido; la paracrístida forma en vista labial un ángulo bastante abierto (entre la postparacrista y la preprotocrista), mostrando una tendencia a alinearse verticalmente, mientras que la postparacrista y preprotocrista están bastante más inclinadas, formando un ángulo más agudo entre sí; el talónido está orientado en forma oblicua (anterolingualmente) respecto del trigónido y es mucho más comprimido lateralmente, mientras que en Gen. A sp. 1. el talónido es oblicuo (anterolingualmente) respecto del trigónido y, aunque es pequeño, no muestra tal compresión; la muesca del hipoconúlido en el extremo anterior del trigónido está mucho menos desarrollada, siendo prácticamente vestigial, lo que podría estar indicando (si bien esta no es necesariamente la única posibilidad) un hipoconúlido más reducido en el m3 de ese individuo; las cúspides del talónido están poco desarrolladas, siendo casi indiferenciables; por último, la crístida oblicua está orientada en sentido lingual a la muesca carnasial. Este último también es un rasgo extraño si se tratara de la sp. 2, ya que se presentaría un cambio abrupto, pasando de tener una orientación claramente labial a la muesca carnasial en los m1-3 (con casi nada de variación), a ser lingual a la muesca. Lo más común es que, de existir un cambio en la orientación entre los diferentes loci, este cambio sea gradual, como ocurre por ejemplo en Gen. A sp. 1 o en Marmosa laventica. Debido a estas diferencias respecto de la sp. 1 y a que el principal rasgo que permite asociarlo a la sp. 2 es el tamaño, no se consideró pertinente referirlo con certeza esta especie.

La morfología de este ejemplar presenta rasgos bastante cercanos a los del m4 de Kiotomops, a saber: margen labial curvo (labialmente convexo); la altura del trigónido respecto al talónido, aunque en este ejemplar esta diferencia de alturas es aparentemente más marcada; sus cúspides forman paredes bastante verticales en vista labial; la paracrista tiende a ser bastante abierta en vista labial, formando un ángulo bastante abierto entre la postparacrista y la preprotocrista, aunque en este ejemplar el rasgo es aparentemente más pronunciado. Las principales diferencia con Kiotomops son su tamaño mucho mayor y el trigónido y talónido menos comprimidos anteroposteriormente.

En síntesis, el ejemplar tiene un tamaño bastante próximo al del didelfimorfio Género A, si bien su morfología recuerda más a la de los molares inferiores de Kiotomops; las diferencias morfológicas observadas impiden referirlo de modo inambiguo a cualquiera de estos taxones. 


\section{Taxón 2}

\section{IGM\# 93-137 / IGM\# 93-141}

Material-Talónido (IGM\# 93-137) y trigónido (IGM\# 93-141) de un m1 izquierdo. Corresponden a dos fragmentos de un mismo molar (Fig. 9.1B).

Localidad y Estratigrafia_Localidad 4 (Universidad de Duke), área de La Venta; Grupo Honda.

Comentarios-Los materiales identificados bajo estos dos números de colección fueron colectados por separado en una misma localidad y catalogados como ejemplares diferentes. Durante la presente revisión se encontró que estos ejemplares correspondían a dos fragmentos (trigónido y el talónido) de un mismo diente. En la figura 9.1.B aparecen unidos, si bien se trata de mitades con numeración diferente.

Este molar, que no ha sido publicado, fue identificado en la presente revisión como un $\mathrm{m} 1$, debido a la marcada posición mesial del paracónido, lo cual ocurre normalmente en los m1 de los metaterios de morfología generalizada (e.g., Didelphimorphia). El trigónido es más largo y ligeramente más ancho que el talónido. La cúspide principal del talónido es el protocónido. El metacónido está poco desarrollado, siendo ligeramente más alto que el paracónido, y presenta un muy sutil desplazamiento posterior respecto del protocónido; este último rasgo es apenas perceptible, por lo que la metacrístida es casi perpendicular al eje anteroposterior. El paracónido está bien diferenciado y se orienta mesialmente, ubicándose más cerca del nivel del protocónido que del metacónido. La paracrístida está bien desarrollada. El cingúlido anterior es bastante angosto, pero es largo, extendiéndose hasta la base del protocónido. La muesca hipoconúlida es amplia.

El talónido es casi tan largo como ancho. El hipocónido es la cúspide principal del talónido, no es saliente labialmente, estando alineado con el protocónido. El entocónido está bastante reducido, siendo incluso más pequeño que el hipoconúlido, y está muy adelantado respecto del hipocónido. El hipoconúlido se ubica posterior al entocónido y es bastante saliente posteriormente. La crístida oblicua se conecta con la pared del trigónido bajo la muesca carnasial. La posthipocrístida es ligeramente oblicua. El cingúlido labial está bien desarrollado y persiste el postcingúlido, aunque es corto. Este postcingúlido se ubica hacia la base de la pared posterior del talónido y no se origina en ninguna cúspide, por lo que sería homólogo a aquel descripto en el carácter 67 de Luo (2003), no al del carácter 81 del mismo autor (Fig. 2.2).

Este molar comparte muchos rasgos con los didelfimorfios, pero presenta rasgos plesiomórficos que no son comunes en este grupo, como la presencia del postcingúlido, así como también algunos rasgos derivados, como la reducción del cingúlido anterior y el entocónido. Existen tres taxones del paleógeno a los cuales se asemeja por su morfología general y varios rasgos, incluyendo la presencia del postcingúlido y la disposición de las cúspides del trigónido: Marmosopsis, Monodelphopsis y Carolopaulacoutoia, aunque se acerca más a la morfología de los 
dos primeros. Sin embargo, es muy difícil relacionarlo claramente con alguno de estos taxones por por tratarse de tan escaso material. A pesar de que no se tiene seguridad acerca de si representa o no un nuevo taxón para la ciencia, sin dudas representa un nuevo taxón para la asociación de La Venta y es un ejemplo más para agregar al grupo de formas de esta asociación que retienen rasgos plesiomórficos.

\section{Mammalia indet.}

A continuación, se mencionan algunos ejemplares cuya morfología es tentativamente cercana a la de los metaterios, pero existen dudas acerca de su clasificación; y otros que aparentemente no corresponden a metaterios, algunos de los cuales posiblemente sean referibles a los euterios.

\section{IGM\# 93-140}

Material-Molar indeterminado (Fig. 9.1C).

Localidad y Estratigrafía-Localidad 4 (Universidad de Duke), área de La Venta; Grupo Honda.

Comentarios-Es un material inédito. Está pobremente preservado y no se logra siquiera identificar claramente su estructura para poder determinar si se trata de un molar superior o inferior. Presenta unas crestas marcadamente definidas y unidas entre sí, formando una suerte de zigzag. Podría tratarse de un quiróptero.

\section{KU 1990-1-C}

Material—Fragmento de molar (trigónido?; Fig. 9.1D)

Localidad y Estratigrafía-Localidad dudosa (Universidad de Kioto): "Masato site" (Capas Rojas de El Cardón, Miembro Cerro Colorado) o "Kioto site" (nivel indeterminado del Miembro Baraya; i.e., Miembro Molina sensu Takai et al., 1992); Formación Villavieja.

Comentarios-Este material es inédito. No es claro si se trata o no de un trigónido y, en caso de serlo, si se trata de un trigónido derecho o izquierdo. Si se toma como referencia la cúspide más grande, que normalmente sería el protocónido, se trataría de un trigónido derecho. Sin embargo, el cingúlido anterior estaría interrumpido y pareciera estar conectado posteriormente con lo que sería un metacónido, lo cual no ocurre en los metaterios. Si se toma como referencia entonces el cingúlido anterior, se trataría de un trigónido izquierdo, pero el protocónido estaría fuertemente reducido y el metacónido fuertemente desarrollado, siendo la cúspide principal del trigónido, lo cual tampoco suele verse en los metaterios.

\section{KU 1990-1-D}

Material—Molar superior? (Fig. 9.1E) 
Localidad y Estratigrafía_Localidad dudosa (Universidad de Kioto): "Masato site" (Capas Rojas de El Cardón, Miembro Cerro Colorado) o "Kioto site" (nivel indeterminado del Miembro Baraya; i.e., Miembro Molina sensu Takai et al., 1992); Formación Villavieja.

Comentarios-El material es inédito. La corona está compuesta por tres cúspides ubicadas formando un triángulo, y se presentan tres raíces. Las cúspides son cónicas y no presentan cuencas. Dos de las cúspides están unidas por sus bases fusionadas y, de estas dos, una está bastante comprimida (labiolingualmente?). El esquema de cúspides no corresponde al de un molar tribosfénico y no se asemeja al de ningún grupo de metaterios conocido. Claramente no presenta la morfología de un molar de quiróptero, de un roedor, de un insectívoro ni de ningún euterio conocido que entre dentro de este rango de tamaño. Eventualmente, podría tratarse de un premolar superior molarizado de un euterio. No se trata de un diente de pez, ya que, generalmente, en aquellos dientes de pez que presentan raíz, esta es simple (no presentan tres raíces). No se trata de un diente de reptil porque estos presentan un patrón de corona normalmente unicuspidado y sin raíz.

\section{KU 1990-1-E}

Material-Fragmento lingual de un molar superior? (Fig. 9.1F)

Localidad y Estratigrafía - Localidad dudosa (Universidad de Kioto): "Masato site” (Capas Rojas de El Cardón, Miembro Cerro Colorado) o "Kioto site" (nivel indeterminado del Miembro Baraya; i.e., Miembro Molina sensu Takai et al., 1992); Formación Villavieja.

Comentarios-El material es inédito. Es un molar incompleto. En vista oclusal pareciera corresponder a un talónido. Sin embargo, presenta tres raíces, ubicadas formando un triángulo, como ocurre en los molares superiores de los metaterios. Tomándolo como un molar superior, podría representar una cuenca del trígono extremadamente amplia, con el paracono y el metacono notablemente separados entre sí y con la centrocrista describiendo una particular forma curva (lingualmente cóncava). En general, su morfología es sumamente inusual comparada con los molares superiores de cualquier metaterio; tampoco parece ser referible a ningún grupo conocido de euterio.

\section{KU 1990-1-F}

Material—m4? izquierdo (Fig. 9.2A).

Localidad y Estratigrafía_Localidad dudosa (Universidad de Kioto): "Masato site” (Capas Rojas de El Cardón, Miembro Cerro Colorado) o "Kioto site" (nivel indeterminado del Miembro Baraya; i.e., Miembro Molina sensu Takai et al., 1992); Formación Villavieja, Grupo Honda.

Comentarios-El material es inédito. Llama la atención la marcada desproporción entre el tamaño del trigónido y el talónido. Se identifica tentativamente como un $\mathrm{m} 4$ justamente debido a la fuerte reducción del talónido, lo que suele ocurrir en este locus para algunos metaterios. Sin embargo, la morfología tanto del trigónido como del talónido no se asemeja a la de ningún 
metaterio conocido. El trigónido es bastante ancho, estando relativamente comprimido anteroposteriormente. El paracónido es bajo pero bastante amplio horizontalmente, y pareciera estar comprimido anteroposteriormente. La cúspide principal del talónido es el protocónido. La paracrista y la metacrista forman un ángulo bastante cerrado, tal como ocurre en los quirópteros. Otro rasgo que lo acerca a la morfología de los quirópteros es que las paredes de las cúspides son sumamente verticales.

\section{UCMP 39600}

Material—Cintura pélvica izquierda (Fig. 9.2B).

Localidad y Estratigrafía_-Localidad El Mono, V4517 (UCMP); Capas del Mono, Miembro Baraya, Formación Villavieja, Grupo Honda (Tablas 3.1 y 4.1).

Comentarios-Este ejemplar se encontró en la colección de la Universidad de Berkeley, clasificado como Borhyaenidae. Aparentemente no ha sido publicado. Se preserva la cintura pélvica izquierda casi completa, preservando parte de los tres elementos principales de la cintura pélvica y el acetábulo completo, estando ausente el ala ilíaca y un fragmento ventral del hueso innominado (isquion + pubis). Aunque es consistente en tamaño con Lycopsis longirostrus, su morfología es diferente, siendo más grácil, con un cuello ilíaco más alargado y delgado, al igual que la porción anterodorsal del hueso innominado. El acetábulo parece ser más grande. Además de la cintura pélvica del holotipo de Lycopsis longirostrus y del ejemplar IGM 250974 (referido a esta misma especie), no se tiene disponible más material comparable, al menos entre los esparasodontes conocidos de La Venta que presenten un rango de tamaño similar. Sin embargo, pudo observarse que este ejemplar presenta muchos caracteres que no concuerdan con la morfología de los esparasodontes: el tubérculo isquiático esta muy desarrollado; el ala ilíaca esta rotada dorsalmente; no existe un tubérculo para el recto femoris (en su lugar existe una cavidad); existe una gran interrupción ventral en la superficie lunada; y el borde dorsal de la superficie lunada es muy protruyente, definiendo una superficie acetabular profunda (véase Sinclair 1906; Argot 2003 a,b; 2004 a,b,c: Babot 2005; Forasiepi 2009). Dado el tamaño de este ejemplar y que aparentemente no se trata de un Sparassodonta, podría llegar a tratarse de un euterio. 


\title{
PARTE III: DISCUSIÓN Y CONCLUSIONES
}

\author{
CAPÍTULO 10. \\ DISCUSIÓN
}

\section{GENERALIDADES}

La asociación de mamíferos del Mioceno medio de La Venta (Colombia) es una de las más ricas conocidas para el Neógeno sudamericano y con claridad la fauna de referencia para toda el área intertropical de las Américas. Esta asociación presenta un total de 87 especies de mamíferos, representantes de al menos 36 familias, entre los cuales se encuentran metaterios y euterios (Anexo $3.1)$.

El registro fósil de La Venta (tanto fauna como flora) indica que esta área presentaba para el Mioceno medio una altitud inferior a los $1000 \mathrm{msnm}$, con temperaturas que variaban entre $\operatorname{los} 23^{\circ} \mathrm{y}$ $\operatorname{los} 30^{\circ} \mathrm{C}$, que las precipitaciones podrían llegar a superar los $2000 \mathrm{~mm}$ anuales y que, además, había periodos de inundación a lo largo del año (Kay y Madden, 1997; ver Marco Geológico: Paleoclima). Uno de los argumentos para concluir estas condiciones es el registro de madera fósil referida a Goupioxylon stutzeri, perteneciente a la familia Goupiaceae. Los representantes actuales de esta familia (género Goupia) habitan ambientes con estas condiciones.

Por otro lado, los datos geológicos (e.g., Anderson et al., 2016) sugieren una precipitación anual de entre 1100 y $1400 \mathrm{~mm}$ anuales, mucho mayor a la que se registra en la actualidad. Adicionalmente, indican que son mínimos los cambios paleoclimatológicos atribuidos al levantamiento topográfico detectados durante el período de depositación del Grupo Honda (13,811,6 Ma) y que, aparentemente, no existía una barrera topográfica elevada importante. Esto es congruente con datos biológicos que sugieren que tanto la flora como la fauna en el Valle del Magdalena comenzaron a diferenciarse de la Cuenca del Amazonas recién hacia los ca. $10 \mathrm{Ma}$ (Hoorn et al., 2010; Ochoa et al., 2012; Aguilera et al., 2013).

Estos datos, sumados a la presencia de mamíferos que indican ambientes con árboles (e.g., primates, quirópteros y metaterios frugívoros, y algunos perezosos de hábitos arborícolas), junto con algunas plantas (e.g., Terminalioxylon portae) y peces (e.g., Lepidosiren) indicadores de períodos de inundación, permiten inferir un ambiente selvático húmedo inundable, similar a lo que hoy ocurre en una selva húmeda tropical o en los bosques en galería a lo largo de los grandes ríos en los trópicos. De hecho, el conjunto de peces de La Venta muestra afinidades con aquellos que viven hoy en las tierras bajas del Orinoco y Amazonas.

Entre los diferentes grupos de mamíferos de La Venta, uno de los más significativos es el de 
los primates (e.g., Kay y Madden, 1997; Takai et al., 2001; Muñoz-Saba, 2018). Los fósiles de primates son sumamente inusuales en América del Sur, particularmente aquellos relativamente antiguos, y suelen ser bastante fragmentarios (Croft, 2016). Sin embargo, los primates de La Venta presentan una excelente preservación, estando representados por al menos 11 especies pertenecientes a las cinco familias vivientes (Muñoz-Saba, 2018; ver Anexo 3.1). Otro grupo bastante diverso es el de los quirópteros, con un registro de más de 10 especies (e.g., Czaplewski et al., 2003; Morgan y Czaplewski, 2012; ver Anexo 3.1). Esta gran diversidad para ambos grupos es mucho mayor a la de cualquier otra localidad fosilífera de América del Sur (Croft, 2016).

Otro grupo importante y sumamente representativo es el de los metaterios, debido a que es una de las faunas sudamericanas con mayor proporción de metaterios respecto a la totalidad de grupos de mamíferos (ver más adelante), con representantes de la mayoría de órdenes de este grupo. Dentro de los mamíferos de La Venta, la asociación de metaterios es la más rica conocida para todo el Neógeno de América del Sur.

\section{DIVERSIDAD}

En este trabajo de tesis se estudiaron 130 ejemplares representativos de al menos 22 especies, 17 géneros, siete familias y cuatro órdenes de metaterios (Tablas 10.1, 10.2 y 10.4; véase 'Conteo de taxones' en Materiales y Métodos, Revisión Taxonómica), pertenecientes a la asociación de mamíferos de La Venta (Colombia). Cabe resaltar que algunos géneros no están clasificados dentro de familias definidas (e.g., Lycopsis y Dukecynus, clasificados dentro de los Borhyaenoidea pero por fuera de las familias definidas para este grupo) y algunos taxones no están clasificados dentro de órdenes definidos (e.g., Sternbergiidae).

La proporción de metaterios en la asociación de mamíferos de La Venta no es tan alta como en las faunas paleógenas sudamericanas del climax del EECO (“Early Eocene Climatic Optimum”; e.g., la fauna de Itaboraí; ver Tablas 10.2 y 10.3) pero tampoco tan pauperizada como las actuales, ocupando una posición intermedia. Sin embargo, la riqueza taxonómica de los metaterios (i.e., número total de especies) es mayor que la de algunas asociaciones paleógenas (e.g., Tiupampa, Gran Barranca, Salla; ver Tablas 10.2 y 10.3). Por otro lado, la proporción de metaterios en la asociación de mamíferos de La Venta es mayor que en otras faunas sudamericanas del Neógeno (Tabla 10.2), incluso ligeramente mayor que la de Santa Cruz (Mioceno temprano: 18 a $16 \mathrm{Ma}$ sensu Vizcaíno et al., 2012 y literatura citada), en Argentina, que es quizás la fauna sudamericana con mayor riqueza taxonómica, por lo que esta sería la fauna de metaterios más diversa para el Neógeno sudamericano. Es importante destacar que, cronológicamente, la fauna de La Venta se ubica justo después del óptimo climático del Mioceno medio, lo que podría estar explicando ese ligero pico de diversidad. De hecho, se observa cómo la diversidad disminuye posteriormente, teniendo por ejemplo faunas del Mioceno tardío con una proporción de metaterios muy inferior 
(e.g., Arroyo Chasicó con $\sim 11 \%$ de metaterios, vs. $\sim 25 \%$ para La Venta; Tabla 10.2).

\section{Sparassodonta}

De todos los metaterios de La Venta, los esparasodontes son los mejor representados, con al menos ocho especies. Esta es una cantidad superior a la de la mayoría de las asociaciones sudamericanas, aunque no tantas como la diversa asociación de Santa Cruz (Santacrucense, Mioceno temprano, Argentina) representada por once especies. (Tablas 10.2 y 10.3). Entre los esparasodontes de La Venta, la mayoría de las especies es referible a tres familias (i.e., Hondadelphidae, Hathliacynidae y Thylacosmilidae), mientras que dos de ellas (i.e., Lycopsis longirostrus y Dukecynus magnus) son asignables a la superfamilia Borhyaenoidea, pero no están incluidas dentro de las familias hasta ahora definidas para ese clado. La mayoría de los ejemplares representan a los Hondadelphidae, Borhyaenoidea, y Thylacosmilidae, con unos pocos ejemplares referibles a Hathliacynidae.

\section{Didelphimorphia}

La asociación de metaterios de La Venta también incluye la mayor cantidad de especies de didelfimorfios comparada con las diferentes asociaciones sudamericanas, teniendo incluso más especies que la fauna de Itaboraí (Tablas 10.2 y 10.3). Los Didelphimorphia incluyen al menos siete especies referibles a cuatro géneros, la mayoría de ellos pertenecientes a la familia Didelphidae, mientras que uno posiblemente corresponde a un didelfimorfio basal, taxón hermano de los Didelphoidea. Este taxón tan basal contrasta con las especies de didélfidos de La Venta, ya que todas ellas pertenecen a géneros con representantes actuales. Incluso, una de ellas es bastante similar a una especie actual (i.e., Tlacuatzin canescens). En este aspecto, La Venta también es única, siendo la fauna con mayor múmero de géneros didelfimorfios con representación actual. Resulta notable que los didelfimorfios de La Venta incluyan tanto formas basales como taxones sumamente derivados (ver Implicaciones paleobiogeográficas y cronoestratigráficas).

Para la asociación de La Venta no se han registrado hasta ahora ejemplares referibles a Caluromyinae. Esta subfamilia está mayormente representada por taxones actuales, pero existe una ocurrencia en el registro fósil, que corresponde a un ejemplar del Colhuehuapense, proveniente de la Formación Sarmiento (Provincia de Chubut, Argentina) y que fue clasificado como "? Caluromyidae gen. et sp. indet." (Goin et al., 2007a; en ese entonces los calurominos eran clasificados como familia). Los calurominos actuales son formas intertropicales/neotropicales, de hábitos arborícolas y mayoritariamente frugívoros (Goin et al., 2007a). Siendo La Venta una fauna tan diversa en metaterios y dada su ubicación septentrional en América del Sur (i.e., neotropical), era esperable encontrar ejemplares referibles a este grupo, ya que para el Colhuehuapense (Mioceno temprano) ya estaban presentes en latitudes mayores. Existen varios posibles factores 
que podrían explicar la ausencia de registros de Caluromyinae, entre los que se encuentran un sesgo de colección, sesgo preservacional, algún factor de control geográfico, o simplemente, que el nicho ecológico correspondiente a esta subfamilia estaba ocupado por otro taxón (euterio o metaterio; e.g., Pachybiotherium). Se descarta que se trate de una escasez de ambientes arbóreos, ya que varios taxones de euterios (e.g., algunos perezosos, primates y quirópteros) son indicativos de este tipo de ambientes, muchos de ellos con dietas esencialmente frugívoras. A estos se suma la presencia de algunos boidos como Eunectes stirtoni, que habitaba el lecho de hojas del bosque (Kay y Madden, 1997).

\section{“Ameridelphia" incertae sedis (?Sternbergiidae)}

Entre los ejemplares que fueron identificados como posibles sternbérgidos aparecen al menos dos especies: una de ellas es Kiotomops lopezi, originalmente descripta como un Chiroptera (Takai et al., 1991); la segunda especie pertenece a un género diferente de Kiotomops y tiene varias similitudes con Carolopaulacoutoia, aunque probablemente tampoco sea referible a este último género. Estos dos taxones, probablemente forman parte de una misma familia; por sus rasgos compartidos con el género de Itaboraí, probablemente corresponda a la familia Sternbergiidae, aunque no se descarta que se trate de una nueva familia estrechamente relacionada con esta, debido a que presentan varios rasgos derivados respecto a los sternbérgidos, mucho más marcados en Kiotomops. Sin embargo, debido a la escaséz del material disponible, la opción más parsimoniosa es referirlos tentativamente a los Sternbergidae. Cabe destacar que eventualmente podría tratarse de tres especies, si los ejemplares del "grupo 1" de los tentativamente referidos a K. lopezi resultaran ser otra especie de Kiotomops.

\section{Paucituberculata}

Hasta el momento han sido descriptas únicamente dos especies de paucituberculados para La Venta (i.e., Pitheculites chenche y Hondathentes cazador). Sin embargo, en la presente revisión se encontró que existe al menos una especie más, un paleotentoideo indeterminado, pero claramente referible a una especie diferente de las ya reportadas para esta asociación. Los paucituberculados de La Venta incluyen tanto abderitidos como paleoténtidos, pero notablemente no hay registros de cenoléstidos, ya que desde el Paleógeno existen registros en zonas cercanas a Colombia, como Perú (e.g., fauna de Santa Rosa; Goin y Candela, 2004). En la actualidad, la mayoría de las especies de cenoléstidos vive por encima de los $1100 \mathrm{msnm}$, hasta alrededor de los $4000 \mathrm{msnm}$, y habita ambientes de bosques montañosos, páramos y selva valdiviana. Esta diferencia de ambientes podría estar explicando esta ausencia. Cabe resaltar que en la asociación de Quebrada Honda, contemporánea a la asociación de La Venta y ubicada en una latitud intermedia, tampoco se han registrado cenoléstidos (ver Implicaciones paleobiogeográficas y cronoestratigráficas). Abello et al. 
(2018) consideran que los paucituberculados de esta antiguedad son poco abundantes y los cenoléstidos, en general, fueron a lo largo de su historia menos diversos y abundantes que los paleoténtidos y abderitidos. Este sería un argumento de peso para entender la ausencia de registros de este grupo.

No se descarta que exista algún sesgo preservacional o de colección, ya que, de por sí, el registro de paucituberculados en La Venta es bastante bajo como para concluir que realmente no existían cenoléstidos entre esta asociación. También podría tratarse de un sesgo tafonómico, o una expresón de su particular historia biogeográfica (entre otros aspectos). De hecho, se presentan varios "vacíos" taxonómicos o ecológicos en esta asociación, no sólo dentro de los paucituberculata. También es notable la ausencia de metaterios quiebrahuesos y la escasez (casi ausencia) de carnívoros pequeños (ver Paleoecología). También llama la atención la completa ausencia de polidolopimorfios: si bien los Polydolopimorphia fueron particularmente abundantes durante el Paleógeno, el linaje de los argirolagoideos se registra en América del Sur a lo largo de todo el Neógeno hasta el fin del Plioceno (Goin et al., 2016). Una posibilidad es que esta ausencia tenga que ver con los ambientes disponibles en La Venta. Las inferencias sobre el modo de vida de los argiroláguidos mencionan que estos serían análogos a lagomorfos o algunos roedores de ambientes abiertos. Si La Venta presentara ambientes similares a las selvas tropicales actuales, sería esperable que la comunidad de metaterios no tuviera argiroláguidos. Este podría ser un argumento que se sume a esta interpretación sobre los ambientes de La Venta.

\section{Microbiotheria}

Hasta el momento, ha sido descripta para La Venta únicamente una especie de microbioterio (i.e., Pachybiotherium minor). A partir de los resultados obtenidos en la revisión taxonómica, surgen dudas sobre la existencia de una o dos especies: en esta revisión se describe un ejemplar morfológicamente similar a $P$. minor, si bien no hay suficientes loci molares comparables en la dentición; las pocas diferencias observadas podrían deberse a la variabilidad entre loci, o bien tratarse de otra especie no necesariamente referible al mismo género.

\section{TAXONOMÍA Y RELACIONES FILOGENÉTICAS}

\section{Sparassodonta}

El agrupamiento general obtenido dentro de Sparassodonta se mantuvo en todos los árboles obtenidos en los análisis realizados. Este agrupamiento incluye, además de los esparasodontes más basales (i.e., Patene, Hondadelphys y Stylocynus), dos clados principales: Hathliacynidae y Borhyaenoidea. El clado Hathliacynidae aparece completamente resuelto y la relación entre sus 
taxones difiere de otros análisis previos en los que se usó esta misma matriz (i.e., Forasiepi, 2009; Engelman y Croft, 2014; Forasiepi et al., 2015; Suarez et al., 2016). En esta distribución aparece Cladosictos + Acyon como grupo hermano de Sipalocyon + Notogale, y Sallacyon como taxón basal del grupo. Dentro de clado Borhyaenoidea, el género Lycopsis aparece en una posición basal, lo cual es consistente con los análisis previos mencionados; por su parte, los Borhyaenidae aparecen como el grupo más derivado. Las únicas variaciones entre los árboles más parsimoniosos ocurren para los Proborhyaenidae Callistoe vincei y Paraborhyaena boliviana: en dos de ellos (árboles 2 y 3: Figs. 4.26 y 4.27) conforman un grupo monofilético, grupo hermano de Borhyaenidae; en los otros dos árboles (1 y 4: Figs. 4.25 y 4.28), conforman un grupo parafilético, basal a Borhyaenidae; en ningún árbol se recuperaron como grupo hermano de Thylacosmilidae (contra Babot et al., 2002; Forasiepi, 2009; Engelman y Croft, 2014; Forasiepi et al., 2015; y Suarez et al., 2016).

El esparasodonte más basal de La Venta sería Hondadelphys; en el análisis filogenético realizado aparece claramente incluido dentro de este grupo (con Patene en una posición más basal a este). Este taxón fue inicialmente descripto como un didelfino (Marshall, 1976a) y su inclusión dentro de Sparassodonta ha sido discutida por varios autores (e.g., Aplin y Archer, 1987; Marshall et al., 1990; Goin, 1997). Uno de los argumentos para poner en duda su clasificación original es que no se preservaba en el cráneo la porción donde se presenta el contacto nasolacrimal (Aplin y Archer, 1987), el cual es diagnóstico de los esparasodontes. Aún así, en los últimos análisis realizados (e.g., Forasiepi, 2009; Engelman y Croft, 2014; Forasiepi et al., 2015; Suárez et al., 2016; y el presente trabajo) este taxón aparece claramente incluido dentro de Sparassodonta. Sin embargo, en la presente tesis doctoral se describen dos ejemplares referibles a este género (referibles a dos nuevas especies), los cuales habían sido mencionados por Goin (1997). En estos ejemplares sí se preserva esta porción del cráneo y se observa un claro contacto nasolacrimal.

Tradicionalmente, el género Lycopsis era agrupado junto con Prothylacynus, Pseudolycopsis, Pseudothylacynus, Stylocynus (e.g., Marshall, 1978a; 1979), y posteriormente, Dukecynus (Goin, 1997; Forasiepi et al., 2004), dentro de los "Prothylacyninae". Sin embargo, recientes análisis cladísticos mostraron que los "Prothylacyninae" no constituyen un grupo natural (Muizon, 1999; Babot et al., 2002; Forasiepi, 2009; Forasiepi et al., 2006, 2014; Engelman y Croft, 2014; Suarez et al., 2016). En el presente análisis, estos taxones conforman un grupo polifilético.

La monofilia de Lycopsis ha sido previamente cuestionada debido a que los rasgos usados para caracerizar este taxón eran consideradas plesiomorfías (e.g., Forasiepi, 2009). Sin embargo, únicamente L. longirostrus había sido incluido en análisis cladísticos. En el análisis de Suarez et al. (2016), donde se describe una nueva especie de Lycopsis para Colombia (L. padillai), se incluyen por primera vez todas las especies del género y se recupera la monofilia del grupo. En el presente análisis también se incluyeron todas las especies de Lycopsis y, nuevamente, se recupera la monofilia del género, a pesar de algunos cambios que se realizaron en la codificación de los caracteres, posteriores a la publicación de Suarez et al. (2016). En todos los árboles obtenidos, 
Lycopsis padillai es el taxón hermano de L. torresi, L. viverensis lo es de este grupo, mientras que L. longirostrus es el taxón hermano de todos ellos, siendo la especie más basal del grupo a pesar de no tener el registro más antiguo.

En el presente análisis, el clado Lycopsis es el grupo hermano de un gran grupo conformado por los Thylacosmilidae, Proborhyaenidae, Borhyaenidae y otros borienoideos. Los resultados del presente análisis filogenético soportan la monofilia de Thylacosmilidae, así como la inclusión de Thylacosmilidae gen. 1 sp. 1 dentro de esta familia. Se encontró que el taxón más basal del grupo es un ejemplar aun no descripto procedente de Arroyo Chasicó (Suarez et al., in prep.; véase Anexo 1.1, Thylacosmilidae gen. 2 sp. 1), mientras que Thylacosmilidae gen. 1 sp. 1 sería el tilacosmílido más basal de La Venta. En el análisis morfológico se observaron algunos rasgos que muestran un cambio progresivo entre las diferentes especies, presentándose en la mayoría de los casos la condición más derivada en T. atrox. Sin embargo, en el ejemplar de Chasicó se registra una combinación de rasgos muy particular, con algunos caracteres plesiomórficos en la porción anterior de la mandíbula (i.e., en el dentario y dentición anterior a los molares) y una morfología bastante derivada en los molares, incluso más derivada que en $P$. goini y A. gracilis. Esto sugiere que se diferenció tempranamente del grupo y retuvo algunos rasgos plesiomórficos en el dentario. Por otro lado, T. atrox muestra algunos rasgos en la dentición que no se verifican en las demás especies; la existencia de estos rasgos independientes también se ven reflejados en la posición dentro de los árboles, diferenciándose claramente del grupo P. goini + A. gracilis.

El presente análisis también soportó la estrecha relación que existe entre $P$. goini y $A$. gracilis. Las diferencias entre los materiales referibles a ambos taxones (véase Comentarios generales sobre Thylacosmilidae en la Revisión Taxonómica) permiten reafirmar su asignación a dos especies diferentes. Sin embargo, teniendo en cuenta la estrecha relación filogenética y las similitudes morfológicas presentes tanto en el cráneo como en la dentición (véase descripción de Anachlysictis y Comentarios generales sobre Thylacosmilidae en la Revisión Taxonómica), algunas de ellas observadas en el ejemplar identificado como B:p2-154 (proveniente de Río Rosario, una localidad cercana a Quebrada Honda, Bolivia; véase Anexo 1.1, Patagosmilus goini), no se descarta que en realidad estos dos taxones pertenezcan a un mismo género. De hecho, esta hipótesis ya había sido en parte planteada por Goin y Carlini (1993), al comparar los tres ejemplares (i.e., B:p2-154 y los holotipos de $P$. goini y A. gracilis) cuando estas dos especies aún no habían sido aún descriptas, sugiriendo que posiblemente pertenecían a una misma especie o al menos a especies cercanamente relacionadas. Esta hipótesis podrá ser evaluada con mayor claridad cuando se encuentre más material craneano de A. gracilis, así como una mandíbula más completa de $P$. goini. Por el momento, se puede afirmar que la evidencia recuperada a partir de la presente revisión indica que Patagosmilus estaría más cercanamente relacionado a Anachlysictis que a Thylacosmilus (contra Forasiepi y Carlini, 2010).

Estudios previos han sugerido una relación cercana entre Hondadelphys y los tilacosmílidos (e.g., Goin y Carlini, 1993; Goin, 1997). Sin embargo, los análisis filogenéticos que han incluido a 
estos taxones (e.g., Forasiepi, 2009; Engelman y Croft, 2014; Forasiepi et al., 2015; Suarez et al., 2016) muestran a Hondadelphys a la base de Sparassodonta y no se encuentra relacionado a los Thylacosmilidae. En el presente estudio, a pesar de que en el análisis filogenético de los esparasodontes (capítulo 4) Hondadelphys tampoco aparece estrechamente relacionado a los tilacosmílidos, durante el análisis morfológico se observaron algunos rasgos, especialmente en la dentición inferior, que parecieran representar la expresión más plesiomórfica de la condición presente en los tilacosmílidos, especialmente Thylacosmilidae gen. 1, Anachlysictis y Patagosmilus, acercándose mucho más a la del primero (véase Comentarios generales sobre Thylacosmilidae). Se espera a futuro poder evaluar la hipótesis sobre una posible relación entre estos taxones, en un análisis más inclusivo y con más caracteres, en el que se revisen los rasgos que muestran similitudes (véase más adelante 'Hipótesis a contrastar a futuro y próximos estudios', capítulo 11), teniendo en cuenta que estos rasgos podrían estar representando convergencias o simplemente podría tratarse de rasgos plesiomórficos que sólo se mantienen en los tilacosmílidos (en una condición más derivada que en Hondadelphys), pero no en los demás esparasodotes.

Otro taxón incluido en el análisis filogenético fue Dukecynus magnus. Su posición dentro de Sparasodonta se mantuvo constante en todos los árboles, estando relacionado a un grupo monofilético conformado por Callistoe vincei, Paraborhyaena boliviana y Borhyaenidae. Esta relación no es consistente con la clasificación que había sido propuesta previamente para esta especie (i.e., Goin, 1997), que sugería su relación con los "protilacininos". Los taxones estudiados en el presente análisis y que en ese entonces eran incluidos en dicha subfamilia (i.e., Lycopsis, Prothylacynus patagonicus, Pharsophorus lacerans y Dukecynus magnus), en este análisis se encuentran conformando un grupo polifilético.

\section{Didelphimorphia}

El análisis filogenético realizado en la presente tesis doctoral muestra resultados en parte similares a los obtenidos por Voss y Jansa (2009) en su análisis basado en el set de datos no moleculares (morfológicos + carotípicos) que incluye a Chacodelphys, mostrando una topología similar a la del árbol de consenso estricto obtenido por estos autores (Voss y Jansa, 2009, Fig. 27), teniendo en cuenta que en el presente análisis se excluyeron algunas de las especies actuales evaluadas estos autores y se incluyeron varias especies fósiles. Sin embargo, los árboles obtenidos en la presente revisión no son congruentes con algunos de los agrupamientos de la clasificación finalmente propuesta por Voss y Jansa (2009; e.g., Didelphinae, Thylamyini, Marmosini), la cual se basa en análisis del set de datos combinados (caracteres no moleculares + moleculares) que excluye a Chacodelphys, particularmente, en el árbol de consenso de mayoría - 50\% (Voss y Jansa, 2009: Fig. 35).

A pesar de que se presentaron muchas politomías en los árboles obtenidos en los análisis preliminares que incluyeron a Gen. A sp. 1 y algunos didélfidos de La Venta (i.e., Thylamys 
minutus, Marmosa laventica y Marmosini cf. Tlacuatzin; véase Anexo 2.4), en todos ellos aparecía resuelta la posición de Gen. A sp. 1, como grupo hermano de los Didelphoidea (i.e., Sparassocynidae + Didelphidae), mientras que los didélfidos de La Venta aparecían generalmente relacionados con las especies del género al cual fueron referidas, lo que permitió sustentar las observaciones surgidas a partir de los análisis morfológicos en la revisión taxonómica.

En en el análisis final también se mantuvo constante la posición de Gen. A sp. 1 entre los diferentes árboles obtenidos, ubicándose hacia la base de los didelfimorfios, como grupo hermano de los Didelphoidea. El agrupamiento de los Didelphoidea se mantiene en todos los árboles, mostrando dos grupos principales: el de los esparasocínidos y el de los didélfidos. También se mantiene la posición de Thylatheridium, más estrechamente relacionado a los didélfidos que a los esparasocínidos; esta relación ya había sido sugerida por otros autores, habiendo incluido a Thylatheridium dentro de los Didelphidae (e.g., Simpson, 1972; Reig, 1952; Reig et al., 1987; Goin y Montalvo, 1988; Goin et al., 2000; Voss y Jansa, 2009). Siguiendo a estos autores y teniendo en cuenta su posición en el presente análisis, se asume la inclusión de este taxón dentro de esta familia. Monodelphis sería el taxón más basal entre los demás didélfidos analizados, que incluyen, además de las especies vivientes, a los extintos Thylophorops e Hyperdidelphys (dentro de los Didelphini).

Algunas filogenias que han incluido taxones didelfimorfios fósiles muestran a los Peradectoidea como grupo hermano de los Didelphoidea (e.g., Horovitz et al., 2009). Entre los resultados obtenidos en el presente análisis, los representantes de los peradectoideos seleccionados para enraizar los árboles se encuentran claramente separados de los Didelfoidea. Sin embargo, en este caso, es Género A sp. 1 el que aparece como grupo hermano de los Didelphoidea, conformando un grupo monofilético hermano los Peradectoidea. Futuras revisiones que incluyan un mayor número de taxones (e.g, más didelfimorfios no didelfoideos) y caracteres (e.g., más caracteres craneanos) podrían resolver si el Género A debería incluirse dentro de los Didelphoidea o si en realidad representa un clado independiente dentro de Didelphimorphia.

La condición basal de Género A no es del todo sorpresiva, ya que en el análisis morfológico habían sido identificadas similitudes tanto con los esparasocínidos como con los didélfidos, así como algunos rasgos más plesiomórficos. Llama la atención que un taxón tan generalizado esté presente en niveles estratigráficos del Mioceno medio (ver discusión más adelante en Implicaciones paleobiogeográficas y cronoestratigráficas).

\section{“Ameridelphia" incertae sedis (?Sternbergiidae)}

Kiotomops lopezi (Takai et al, 1991) fue originalmente descripto como un quiróptero molósido. Czaplewski et al. (2003) refutaron esta clasificación y argumentaron que podría estar más relacionado con los marsupiales. En la presente revisión no se realizó un análisis filogenético que incluyera a esta especie, pero a partir de sus rasgos morfológicos se sugirió una relación cercana 
con los sternbérgidos, que debería ser confrontada en futuros análisis que incluyan varias especies de sternbérgidos y grupos cercanamente relacionados. Adicionalmente, se describen materiales que claramente representan un nuevo taxón para La Venta, los cuales presentan una morfología general cercana a la de Kiotomops pero también algunos rasgos más plesiomórficos, mucho más cercanos a la morfología de sternbérgidos como Carolopaulacoutoia.

Estos ejemplares representan uno de los hallazgos más importantes para esta asociación de metaterios y su taxonomía es quizás uno de los aspectos más inesperados que han resultado de la presente tesis doctoral, ya que se trataría de probables sternbérgidos en el Neógeno sudamericano (ver más adelante Implicaciones paleobiogeográficas y cronoestratigráficas).

Se espera que futuros análisis puedan contribuir no sólo a confirmar la presencia en La Venta de "ameridelfios" posiblemente relacionados con los sternbérgidos, sino también a testear la monofilia de esa familia y la evaluar la probable exclusión de varios taxones previamente referidos a Sternbergia. Es relevante resaltar la importancia de futuros trabajos de campo que se enfoquen específicamente en la colección de sedimento para ser procesado en búsqueda de ejemplares de pequeño tamaño (tamizado y "picking"), ya que claramente para La Venta existe un sesgo de colección en el que predominan los tamaños grandes.

\section{Paucituberculata}

Hasta el momento, han sido descriptas para La Venta únicamente dos especies de Paucituberculata (Hondathentes cazador y Pitheculites chenche), representadas por unos pocos restos. De hecho, para $P$. chenche, ha sido descripto únicamente un ejemplar bastante fragmentario (el holotipo). En la presente revisión no se realizó un análisis filogenético para este grupo. Sin embargo, se describen algunos materiales que posiblemente puedan estar representando especies diferentes a estas dos ya publicadas, algunos claramente referibles a los Palaeothentidae y otro muy probablemente referible a Palaeothentoidea. No se encontraron ejemplares asignables a cenoléstidos.

La posición de $H$. cazador no ha sido evaluada hasta ahora en ningún análisis filogenético. Sin embargo, Abello (2013) sugiere que la morfología de esta especie es congruente con los caracteres diagnósticos de los paleotentinos (resultantes de su estudio), por lo que H. cazador probablemente sea miembro de los Palaeothentinae. En ese mismo estudio, al igual que en el de Engelman et al. (2017) sí se incluye a $P$. chenche entre los taxones evaluados. En ambas filogenias, esta especie conforma un grupo monofilético junto con las otras dos especies del género Pitheculites, el cual aparece como grupo hermano de Abderites, estando incluido dentro de la familia Abderitidae. 


\section{PALEOBIOLOGÍA}

\section{Masa corporal}

Los metaterios neotropicales del Mioceno medio de La Venta muestran un amplio rango de tamaños, desde didélfidos más pequeños que el rango de tamaño de la mayoría de formas actuales, hasta los esparasodontes, que son los de mayor tamaño.

Los esparasodontes de La Venta muestran un amplio rango de tamaño, desde ca. $4 \mathrm{~kg}$ para Hondadelphys fieldsi, hasta casi $50 \mathrm{~kg}$ para Dukecynus magnus. Incluso, el ejemplar KU 1995-5, uno de los hatliacínidos descriptos en el capítulo 4, tendría una masa corporal de un poco más de 3 kg (Tabla 4.7) tratándose del esparasodonte más pequeño para esta asociación. El estudio realizado por Prevosti et al. (2013) había arrojado una estimación de masa corporal mucho menor para $D$. magnus (i.e., 24,61 kg). Discusiones previas acerca de rangos de masa corporal para los esparasodontes de La Venta (e.g., Suarez et al., 2016) habían sido basadas en dicha estimación. Sin embargo, dicha estimación no fue realizada directamente sobre el material de D. magnus, sino sobre Arminiheringia cultrata, ya que según Prevosti et al. (2013, material suplementario), era de un tamaño similar (probablemente no pudieron acceder a materiales referibles a D. magnus). Las estimaciones mostradas en la presente revisión sí se realizaron a partir de medidas tomadas sobre el material original de D. magnus. En comparación con otras estimaciones realizadas para esparasodontes de La Venta en el análisis de Prevosti et al. (2013), en la presente revisión se muestran resultados cercanos para L. longirostrus $(40,29 \mathrm{~kg}$ contra $42,51 \mathrm{~kg})$, mientras que para $A$. gracilis la masa corporal estimada fue mayor $(25,29 \mathrm{~kg}$ contra $16,07 \mathrm{~kg})$. Es importante resaltar las limitaciones de estimar la masa con la dentición, en comparación con estimaciones realizadas con base en postcraneo. Muchas veces resulta evidente por comparaciones de medidas lineales que con la dentición se obtienen valores supra- o mayormente infraestimados. Arctodictis munizi es un ejemplo (véase Prevosti et al., 2012; Prevosti y Forasiepi, 2018).

Al comparar con otras asociaciones sudamericanas, los esparasodontes de La Venta presentan un rango de masa corporal más restringido aunque bastante cercano al de aquellas de latitudes más altas, como la asociación del Mioceno temprano de la Formación Santa Cruz, de la Patagonia argentina, la cual presenta un rango entre $1 \mathrm{~kg}$ (e.g., Pseudonotictis pusillus) hasta más de $50 \mathrm{~kg}$ (e.g., Arctodictis munizi) (Ercoli et al., 20013; Prevosti et al., 2013). Adicionalmente, los datos obtenidos en esta tesis muestran un fenómeno notable entre los esparasodontes de La Venta: no habría especies dentro del rango de masa corporal intermedio (según la clasificación de Prevosti et al. 2013; ver Materiales y Métodos) y este rango de masa corporal no estaría siendo ocupado por otros metaterios. A pesar de que sí habría en La Venta euterios que se encontraran dentro de ese rango de masa corporal (e.g., proterotéridos como Lambdaconus colombianus, el notoungulado Miocochilius o primates grandes como Stirtonia victoriae y S. tatacoensis), estos no ocuparían el mismo nicho ecológico de los esparasodontes, ya que ninguno de ellos tendría hábitos orientados a 
la carnivoría.

En el caso de los didelfimorfios de La Venta, se presenta un rango de masa corporal entre $\sim 13$ $\mathrm{g}$ (para T. minutus) hasta casi $380 \mathrm{~g}$ (para Género A sp. 2). Un aspecto notable es la ausencia de didélfidos de gran tamaño (e.g., grandes didelfinos como Hyperdidelphys o Thylophorops). Sin embargo, su nicho ecológico podría estar siendo ocupado por los hatliacínidos o tilacosmílidos pequeños (e.g., Thylacosmilidae gen. 1 sp. 1). Entre las especies de didélfidos recientes, la más pequeña es probablemente Chacodelphys formosa, con una masa corporal de unos $10 \mathrm{~g}$ (Voss et al., 2004a); mientras la más grande es Didelphis virginiana, la cual puede llegar a pesar más de $3000 \mathrm{~g}$ (Hamilton, 1958). Sin embargo, la mayoría de didélfidos actuales pesan entre 20 y 500 g (Voss y Jansa, 2009). Este último es, justamente, el rango de masa corporal en el que se encuentra la mayoría de los didélfidos de La Venta. Sin embargo, estos se agrupan principalmente en dos rangos de tamaños claramente diferenciados: los más pequeños, con valores de masa corporal inferiores a 60 g, y los más grandes, con valores superiores a $200 \mathrm{~g}$. Masas corporales dentro del rango de los 60 y los $200 \mathrm{~g}$ no fueron detectadas. No obstante, parte de este rango lo ocupan la mayoría de los Paucituberculata hallados hasta ahora en La Venta, los microbioterios y Kiotomops.

Los Paucituberculata de esta asociación incluyen formas desde casi $140 \mathrm{~g}$ hasta un poco más de 320 g. Las dos especies hasta ahora descriptas presentan un tamaño bastante cercano, siendo $P$. chenche la más chica (i.e., 139,50 g) y H. cazador la más grande (i.e., 146,48 g). Adicionalmente, entre los nuevos materiales descriptos aparece un paleotentoideo con más de dos veces el tamaño de estos (i.e., 320,84). Por otro lado, tanto Kiotomops lopezi como Pachybiotherium minor, muestran valores de masa corporal que rondan los $91 \mathrm{~g}$ (Tablas 6.3-6.4 y 8.3). El otro posible sternbérgido de La Venta es mucho más pequeño que Kiotomops, con aproximadamente $25 \mathrm{~g}$, siendo cercano en tamaño a T. minutus (ver Tabla 6.3-6.4).

\section{Inferencias dietarias}

Las inferencias dietarias realizadas para los metaterios del Mioceno medio de La Venta estarían indicando la presencia de taxones omnívoros, insectivoros/faunívoros y carnívoros en esta asociación. Los esparasodontes de La Venta, en particular, también muestran un espectro de hábitos alimentarios relativamente amplio, desde dietas hipercarnívoras hasta dietas más omnívoras. Los diferentes análisis realizados (cualitativos y cuantitativos) para inferir las preferencias dietarias de las diferentes especies de este grupo mostraron en general resultados bastante similares, con algunas ligeras variaciones en algunas especies. Para el caso de D. magnus y A. gracilis, todos los análisis muestran una dieta hipercarnívora, con tendencia al consumo de tejidos blandos (i.e., hipercarnívoro consumidor de carne). Del mismo modo, para Hondadelphys fieldsi, todos los resultados sugieren una dieta omnívora. Por otro lado, se presentaron algunas variaciones en los resultados obtenidos tanto para L. longirostrus como para Thylacosmilidae gen. $1 \mathrm{sp}$. 1. En el caso de L. longirostrus, tanto el análisis morfológico cualitativo como el de RGA, indican una dieta 
mesocarnívora, con algo de tendencia a la hipercarnivoría; mientras que el índice LRMC indica hábitos carnívoros quiebrahuesos. Sin embargo, este último resultado es descartado debido a que la grácil morfología de la dentición, así como la de la mandíbula, y en general la escasa robustez del cráneo, no son consistentes con este tipo de hábitos. Para el caso de Thylacosmilidae gen. 1 sp. 1, ambos análisis cuantitativos (i.e., RGA y LRMC) indican una dieta omnívora; mientras que en el análisis cualitativo (i.e., análisis de morfología del talónido) se había sugerido una dieta mesocarnívora, lo cual no es del todo inconsistente con los análisis cuantitativos, ya que en uno de ellos (i.e., RGA) el resultado obtenido se ubica en valores muy cercanos al límite con la mesocarnivoría.

Según las observaciones realizadas en la revisión taxonómica, tanto Thylacosmilidae gen. 1 sp. 1 como $H$. fieldsi muestran rasgos derivados asociados a la carnivoría bastante desarrollados (e.g., reducción del metacónido, protocónido bien desarrollado, crestas del trigónido bien desarrolladas y cortantes). Sin embargo, el índice RGA calculado indica una dieta omnívora, ya que la cuenca del talónido aún se encuentra relativamente bien desarrollada (mucho más en $H$. fieldsi). A partir de estas observaciones y del análisis ecomorfológico, se interpretó que, como es común en pequeños a medianos carnívoros (metaterios o euterios), este conjunto de rasgos podría entonces estar indicando una dieta oportunista, es decir que podría ser preferentemente carnívora, pero en caso de no haber presas disponibles podrían haber consumido otro tipo de alimento, ya que su dentición estaba adaptada para ello.

Los diferentes análisis muestran que, en general, los taxones de La Venta podrían haber tenido una tendencia a consumir mayormente tejidos blandos, ya que a excepción de algunos pocos restos dudosamente asignados a la familia Borhyaenidae, ningún taxón muestra morfologías "quiebrahuesos". Esto indicaría que los esparasodontes de La Venta eran más probablemente depredadores que carroñeros. Eventualmente, el gran caimán Purussaurus neivensis, con enormes y robustos dientes, podría no sólo estar abarcando el rango de presas de gran tamaño (ver más adelante), sino también ocupando el nicho de los “quiebrahuesos". La Venta no es el único caso en el que los esparasodontes no ocupan todo el espectro de nichos carnívoros. Por ejemplo, en el caso de Santa Cruz (Mioceno temprano, Argentina), ocurre que los taxones presentes son hipercarnívoros y, aparentemente, no hay ningún taxón mesocarnívoro o hipocarnívoro (Croft et al., 2018).

Además de los taxones que ocupan el nicho carnívoro y omnívoro, los metaterios de La Venta también incluyen formas insectívoras o insectívoro-faunívoras. Estos nichos son ocupados por los didelfimorfios y los paucituberculados. No se realizó ningún análisis de inferencias dietarias para Pachybiotherium. Sin embargo, las especies de Pachybiotherium se destacan por presentar una gran altura del dentario, rasgo compartido con grupos de hábitos alimenticios frugívoros, como numerosos grupos de primates y los extintos Caroloameghiniidae y Polydolopimorphia (Vinyard et al., 2007; Goin, 2006; Goin et al., 2010). "Los molares inferiores presentan talónidos anchos y los superiores robustos protoconos, indicando una importante 
función de "mortero" de estas estructuras antagónicas. Adicionalmente, las estructuras de corte (paracristida, postmetacrista) son proporcionalmente reducidas. Estos rasgos sugieren la hipótesis de que los representantes del género eran de hábitos alimentarios esencialmente frugívoros" (Goin et al., 2010).

Comentarios sobre posibles tamaños de presa: los herbívoros en asociaciones neotropicales presentan un amplio rango de masa corporal (e.g., La Venta, Kay y Madden, 1997), incluyendo tamaños mayores que el tamaño de presa estimado para los depredadores mamíferos (Ercoli et al., 2014) conocidos hasta el momento en estos sitios fosilíferos. Esto podría estar indicando que, o bien hay un sesgo en el registro fósil, que excluyó la preservación de mamíferos predadores de gran tamaño, o la posibilidad de una mayor participación de vertebrados no mamíferos en el nicho carnívoro. Las especies de gran tamaño o con fuertes corazas (gliptodontes) o caparazones (tortugas) presentes en La Venta, probablemente era presa más fácil para reptiles de gran tamaño, como Purussaurus neivensis. De hecho, se han encontrado restos en los que se observan marcas que probablemente se corresponden con el tamaño y morfología de los dientes de Purussaurus (pers. obs.; Moreno-Bernal, pers. comm.; Moreno-Bernal et al., in prep.) Hasta el momento, no ha sido reportada evidencia alguna que indique la presencia de predadores avianos (como grandes fororrácidos) en La Venta, ni en ninguna otra localidad fosilífera de Colombia.

Siguiendo a Ercoli et al. (2014) y teniendo en cuenta las categorías de masa corporal propuestas por Kay y Madden (1997) para la asociación de mamíferos de La Venta y las estimaciones realizadas en la presente tesis doctoral, se puede hipotetizar las posibles presas para cada uno de los esparasodontes de La Venta, que serían los depredadores mamíferos de esta asociación. Cabe aclarar que esta comparación busca identificar los posibles tamaños de presa, principalmente con el objetivo de tener una idea sobre el tamaño máximo que podrían abarcar cada uno de los taxones de La Venta. Es importante tener en cuenta que los organismos más grandes podrían comer desde las presas mencionadas a continuación, hasta organismos muy pequeños, en función de su disponibilidad.

Para todos los esparasodontes de La Venta, cualquiera de los demás metaterios de esta asociación podría ser incluido entre su espectro de posibles presas. Los primates de La Venta se encuentran dentro del rango de masa corporal de las posibles presas de algunos esparasodontes (e.g., D. magnus, A. gracilis, L. longirostrus y el tilacosmílido gen. 1 sp. 1). Sin embargo, sus hábitos arborícolas podrían, en general, facilitarles estar fuera del alcance de estos taxones con hábitos probablemente más cursoriales. Entre las posibles presas de D. magnus, además de los metaterios no esparasodontes, podría encontrarse también cualquiera de los demás esparasodontes; adicionalmente, podría cazar cualquiera de las especies de roedores presentes en esta asociación, algunos notoungulados pequeños como Miocochilius, xenartros no acorazados y de hábitos terrestres como perezosos (e.g., Pseudoprepotherium confusum y Neonematherium falabellatum; este último probablemente con hábitos mixtos, tanto terrestres como arborícolas) y hormigueros (e.g., Neotamandua borealis), e incluso litopternos como Prolicaphrium sanalfonsensis, 
Lambdaconus colombianus y Villarroelia totoyoi.

Entre las posibles presas para A. gracilis, el otro hipercarnívoro de La Venta, pordía encontrarse cualquiera de los esparasodontes más chicos de esta asociación (i.e., H. fieldsi, el tilacosmílido gen. 1 sp. 1 y el hatliacínido); roedores como las diferentes especies de equímidos, dinómidos como las especies de "Scleromys", dasipróctidos como "Neoremys" huilensis, los cávidos y los eretizóntidos.

Entre los esparasodontes no hipercarnívoros, L. longirostrus, de hábitos inferidos mayormente mesocarnívoros, tendría un espectro de presas similar al de D. magnus, excepto quizás algunas de las formas más grandes (e.g., algunos litopternos y perezosos de gran tamaño). De hecho, existe evidencia de que $L$. longirostrus comería pequeños roedores, ya que durante la preparación del holotipo se encontraron preservados en la cavidad abdominal, entre las costillas y la tibia derecha (Marshall, 1977a: Fig. 4), varios huesos de roedor rotos y un molar superior de "Scleromys" colombianus (véase Fields, 1957: p. 360; Marshall, 1977a). Otros huesos y un incisivo fueron hallados en una posición inmediatamente posterior a la pelvis y por debajo de la base de la cola, que aparentemente serían restos de heces producidas en el momento de su muerte (Marshall, 1977a: p. 641, Fig. 4).

Dentro de las posibles presas del tilacosmílido gen. $1 \mathrm{sp} .1$ se encuentran los equímidos, los dasipróctidos, "Scleromys", pequeños perezosos e incluso pequeños notoungulados como Miocochilius. Por otro lado, el espectro de presas tanto para H. fieldsi como para el hatliacínido incluiría mayormente roedores, como los equímidos y los dasipróctidos. Dentro de este rango de masa corporal para posibles presas también están algunos primates como Neosaimiri y Mohanamico hershkovitzi, pero debido a lo ya comentado anteriormente, serían una presa menos fácil debido a sus hábitos arborícolas. Cabe resaltar que este hatliacínido sería el único metaterio carnívoro de pequeño tamaño para La Venta. Esto es un factor relevante, ya que llama la atención la escasez de pequeños carnívoros. Adicionalmente, no han sido encontrados hasta el momento restos referibles a comadrejas grandes (i.e., Didelphini). Esto podría estar relacionado con que algunos sparassodonta omnivoros pequeños (e.g., Hondadelphys y el tilacosmílido gen. 1 sp. 1) estén ocupando ese nicho.

\section{IMPLICACIONES PALEOBIOGEOGRÁFICAS Y CRONOESTRATIGRÁFICAS}

\section{Relación de La Venta con otra asociación contemporánea}

Una de las asociaciones de mamíferos más importantes del neógeno de América del Sur y que ha sido claramente referida a la Edad Laventense, es la de Quebrada Honda (Departamento del Tarija, Bolivia), que se ubica geográficamente en el límite austral de la zona tropical (Madden et al., 1997). Hasta el momento, para esta asociación de latitudes medias han sido reportadas 35 especies 
de mamíferos (Croft, 2007, 2016, 2018; Croft et al., 2011, 2013; Pujos et al., 2011, 2014; Engelman y Croft, 2014; Engelman et al., 2015, 2017; McGrath et al., 2018), entre las que se encuentran ocho especies de metaterios: tres esparasodontes, cuatro paleoténtidos y un argirolágido (ver Tablas 10.1, 10.2 y 10.4). La riqueza taxonómica de Quebrada Honda es mucho menor que en La Venta, aunque cabe aclarar que en el área de La Venta haya existido una mayor actividad paleontológica. Sin embargo, claramente es una cantidad de especies de mamíferos considerable y llama la atención que entre todas ellas no haya ninguna en común entre ambas asociaciones. Únicamente se presentan coincidencias a nivel de género, teniendo en común a Miocochilius y Acarechimys. Entre los metaterios, no existen especies ni géneros compartidos entre estas asociaciones (Tabla 10.4) y, a pesar de que la riqueza de metaterios de Quebrada Honda es mucho menor (Tablas 10.2 y 10.4), presenta una proporción de metaterios respecto a los euterios cercana, aunque aún siendo más baja que la de La Venta (Tabla 10.2).

Tanto la Fauna de La Venta como la de Quebrada Honda son de edad Laventense (13,5-11,8 Ma), pero según estudios geológicos recientes (i.e., Mora et al., 2010; Anderson et al, 2016), aparentemente, para ese momento no existiría una barrera topográfica significativa entre estas dos localidades, ya que cuando comenzó a depositarse el Grupo Honda, en el área de La Venta no se había comenzado a levantar la Cordillera Oriental y finalizando su depositación aún no se encontraba completamente cerrada (Fig. 3.2; ver en el Marco Geológico 'Paleotopografía, paleocorrientes y ambientes de depositación' y 'Paleoclima'). Adicionalmente, la sección que estaba levantada no tendría una altura suficiente como para generar una barrera sustancial, que pudiera incluso producir un efecto de sombra orográfica, lo que ocurriría después de los $3 \mathrm{Ma}$ (Mora et al., 2008; Anderson et al., 2016). La barrera terminaría de cerrarse posterior a los $6 \mathrm{Ma} \mathrm{y,}$ después de ese momento, ocurriría el mayor y más rápido pulso de levantamiento (Anderson et al., 2016).

Estos hallazgos son congruentes con los datos biológicos, que sugieren que la flora y fauna en el Valle del Magdalena comenzaron a diferenciarse de la Cuenca del Amazonas recién hacia los ca. $10 \mathrm{Ma}$ (Hoorn et al., 2010; Ochoa et al., 2012; Aguilera et al., 2013). Por esta razón, es extraño que tan sólo exista coincidencia en estos pocos géneros y que no haya ninguna especie compartida entre ellas. Análisis sobre la fauna de Quebrada Honda (e.g., Croft, 2007) indican que esta asociación de latitudes medias sería más similar a la de Collón Curá, más antiguas y de altas latitudes, que a la de La Venta, contemporánea y de bajas latitudes, sugiriendo que mecanismos de aislamiento entre las latitudes bajas y medias estaban presentes durante el Mioceno temprano o medio (Croft, 2007). Sin embargo, un mecanismo de aislamiento no necesariamente representa una barrera topográfica. Por ejemplo, algunos autores (e.g., Mora et al., 2010; Hoorn et al., 2010) plantean la presencia de grandes pantanos y lagos del Sistema de Pebas, al oeste de la Amazonía. Esto podría representar una barrera significativa que impidiera la interacción entre ambas asociaciones, aunque también podría ocurrir debido a las diferencias de latitud entre estas localidades (ver más adelante Provincialismo entre faunas del Neógeno sudamericano). Sin 
embargo, no debería descartarse del todo que este fenómeno pudiera explicarse (al menos en parte) debido a algún tipo de sesgo preservacional o de colección.

\section{Relación de La Venta con faunas neógenas patagónicas}

La Fauna de La Venta es bastante diferente a la de las asociaciones patagónicas en su composición y diversidad. Una de las faunas neógenas más similares, al menos en cuanto a diversidad, es la del Mioceno temprano de Santa Cruz (Argentina). Como ya se mencionó, esta fauna tiene un número mayor de especies mamalianas, pero presenta una proporción de metaterios ligeramente menor a la de La Venta (Tabla 10.2). Esta fauna ocurre antes del óptimo climático del Mioceno medio, mientras que la fauna de La Venta ocurre justo después, por lo que este pico de diversidad en La Venta podría ser explicado como consecuencia de este cambio climático. Cabe resaltar que la fauna de Santa Cruz ha sido mucho más estudiada, sus afloramientos son mucho más extensos (abarcando grandes zonas de Patagonia) y han sido más explorados que los de La Venta, lo que estaría también influyendo en la cantidad de ejemplares reportados y, por lo tanto, en la cantidad de especies descriptas. Aún así, la fauna de La Venta sigue siendo casi tan diversa como la de Santa Cruz.

Entre estas faunas no se presentan especies compartidas, pero sí hay al menos un género en común, Lycopsis, que curiosamente tiene su representante más basal en La Venta (L. longirostrus) y una de sus especies con morfología más derivada en Santa Cruz (L. torresi). Este factor es relevante debido a que se estaría registrando un taxón con una morfología más plesiomórfica en rocas de edad mucho más reciente (ver más adelante Implicaciones paleobiogeográficas y cronoestratigráficas: La Venta como ejemplo de "cradle" o "museum"; Hipótesis: radiación y linajes "fantasma"). Otro posible taxón compartido podría ser Sipalocyon: en este trabajo se describe un hatliacínido que comparte muchos rasgos con este género, pero debido a que se trata de un material fragmentario y pobremente preservado, no pudo ser referido con certeza a este taxón. Adicionalmente, se describe otro ejemplar que comparte más rasgos con Cladosictis que con Sipalocyon, pero tan sólo se trata del talónido de un $\mathrm{m} 4$, por lo cual es difícil realizar una asignación clara, pero, eventualmente, podría estar sumando un taxón más.

\section{Provincialismo entre faunas del Neógeno sudamericano}

La biogeografía sudamericana podría dividirse en dos dominios principales, siguiendo a Morrone (2002, 2006): la Región Neotropical (incluida en el Reino Holotropical) y la Región Andina (incluida en el Reino Austral); esta última está conformada por Patagonia y una estrecha franja cordillerana que llega hasta el nivel de los Andes Centrales. La naturaleza dual de la biogeografía y paleobiogeografía de América del Sur ayuda a comprender la evolución mamaliana en este continente (Goin et al., 2012), ya que la biota presente en cada una de estas regiones sería distintiva 
de cada una de ellas, tanto en la composición taxonómica como trófica. Diferencias taxonómicas entre sitios fosilíferos neotropicales y de zonas templadas han sido explicadas como consecuencia de la posición latitudinal de dichas asociaciones (e.g., Croft, 2007; Carrillo et al., 2015). Esto podría explicar la gran riqueza de Paucituberculata y otros órdenes "australes" en Patagonia, y la presencia de Didelphimorphia en el norte de Sudamérica.

Estudios previos han documentado la evidencia de provincialismo faunístico entre las asociaciones de mamíferos neógenas sudamericanas de latitudes bajas y altas (Carlini et al., 1997, 2008; Croft, 2007; Croft et al., 2009; Goin et al., 2012; Carrillo et al., 2015). Esto es evidente entre algunos metaterios, ya que, por ejemplo, los registros de Didelphimorphia en la fauna de La Venta son abundantes, pero son escasos o ausentes en otras faunas neógenas sudamericanas de latitudes medias y altas (Tablas 10.1-10.2). En general, los metaterios de La Venta reflejan el fenómeno de provincialismo, al menos a nivel de especie, ya que, aparentemente, ninguna de las especies de esta asociación ha sido registrada (claramente identificada) en otra fauna Sudamericana. Sin embargo, se presentan algunos casos particulares a nivel de género (e.g., Lycopsis, Pitheculites y Pachybiotherium).

En el caso de los esparasodontes en general (los de La Venta y otras faunas sudamericanas), a pesar de existir aparentemente un provincialismo a nivel de especie (e.g., no hay especies compartidas entre faunas contemporáneas de latitudes bajas y medias: Quebrada Honda y La Venta), sí se presentan géneros ampliamente distribuidos a lo largo del continente sudamericano. El género Acyon ha sido reportado en una latitud de $\sim 22^{\circ} \mathrm{S}$ (Quebrada Honda, Bolivia) y también de $\sim 51^{\circ} \mathrm{S}$ (Patagonia, Argentina) (Forasiepi et al., 2006); Sipalocyon, en latitudes de $\sim 12^{\circ} \mathrm{S}$ (Madre de Dios, Peru), $\sim 47^{\circ} \mathrm{S}$ (Alto Río Cisnes, Chile) y $\sim 51^{\circ} \mathrm{S}$ (Patagonia, Argentina) (Marshall, 1990; Antoine et al., 2013); Borhyaenidium, en latitud $\sim 17^{\circ} \mathrm{S}$ (Achiri, Bolivia) y $\sim 38^{\circ} \mathrm{S}$ (La Pampa, Argentina) (Villarroel y Marshall, 1983); Patene, tanto en $\sim 23^{\circ} \mathrm{S}$ (Itaboraí, Brazil) como en $\sim 45^{\circ} \mathrm{S}$ (Patagonia, Argentina); y finalmente Lycopsis, con la distribución más amplia de cualquier grupo metaterio, presente desde los $\sim 12^{\circ} \mathrm{N}$ (La Guajira, Colombia; Suarez et al., 2016) hasta $\sim 51^{\circ} \mathrm{S}$ (Patagonia, Argentina; Cabrera, 1927) (ver Suarez et al., 2016, Fig. 1). Inclusive, dos taxones hermanos (L. torresi y L. padillai) son registrados en puntos extremos del continente. Sin embargo, el registro de Lycopsis aún es escaso, con cada una de sus especies representadas por uno o pocos individuos. Es por esto que el rango geográfico de cada una de ellas es aún desconocido, por lo que no es posible todavía realizar algún tipo de inferencia sobre provincialismo a nivel de las especies de este género. Adicionalmente, en la presente tesis se plantea la posibilidad de que Anachlysictis y Patagosmilus sean sinónimos, por lo que este sería otro género ampliamente distribuido, presente tanto en La Venta (Goin, 1997) como en la Provincia de Río Negro, Argentina (Forasiepi y Carlini, 2010) y en la localidad de Río Rosario, cercana a Quebrada Honda (Goin y Carlini, 1993; MacFadden y Wolff, 1981; Anexo 1.1, Patagosmilus goini). Sin embargo, aún si esta hipótesis fuera descartada, se tendrían registros de Patagosmilus al menos para Argentina y Bolivia, lo cual es una distribución relativamente amplia. 
Es notable que todos estos taxones son relativamente grandes (o medianos a grandes), habiendo pocos taxones pequeños compartidos en un rango geográfico tan amplio. Sin embargo, este fenómeno se observa también actualmente en los grandes mamíferos depredadores. Los ejemplos mencionados muestran que, tal como ocurre en estos, la naturaleza "dual" de la biogeografía y paleobiogeografía de América del Sur no es evidente a nivel de género, ya que no estarían siguiendo una regionalización geográfica (neotropical o andina), sino que se encontrarían distribuidos sobre más de una región en este continente. Entre los grandes depredadores actuales, este fenómeno ocurre no sólo a nivel de género sino también de especie, usualmente ocupando grandes rangos de distribución, como ocurre con Puma (e.g., Puma concolor), Panthera (e.g., Panthera onca) y Herpailurus (e.g., Herpailurus yagouaroundi), los cuales están distribuidos en varios biomas a lo largo de las Américas (Caso et al., 2008a, 2008b, 2008c). Cabe resaltar que este fenómeno es visible también en algunos mamíferos más pequeños, por ejemplo, algunos metaterios vivientes como Didelphis.

Esto puede estar indicando que el provincialismo podría no estar reflejado en el análisis de la distribución de grandes depredadores que, en el caso del registro fósil sudamericano, están representados por los esparasodontes. La ausencia de esta amplia dispersión a nivel de especie podría estar reflejando algún tipo de sesgo preservacional o de colección, o incluso, una inflación en la taxonomía: es común en paleontología clasificar como especies diferentes formas cuyas diferencias, si se comparan con especies actuales, muchas veces se encontrarían dentro del rango de variabilidad de una misma especie. Es por esto que es importante tener en cuenta los estudios de variabilidad y variación en especies actuales. Sin embargo, en el caso de las especies vivientes, se tienen más herramientas de clasificación además de la morfología de los huesos y dientes (e.g., morfología externa y caracteres moleculares), que permiten ajustar el criterio con el cual se toman las decisiones taxonómicas. Adicionalmente, muchos grupos fósiles no tienen representación actual, lo que hace más subjetivo este tipo de comparaciones al intentar elegir cuál sería el grupo actual más adecuado para realizarlas. Otro factor a tener en cuenta es el intentar comparar, en lo posible, faunas contemporáneas (e.g., La Venta vs. Quebrada Honda), ya que, si se comparan faunas de diferentes edades, la posibilidad de encontrar taxones en común se reduce.

Además de los esparasodontes, se observa provincialismo únicamente a nivel de género entre otros metaterios de La Venta. Por ejemplo, el género Pitheculites está presente también en Chile $\left(\sim 44^{\circ} \mathrm{S}\right.$, Formación Río Frías, Alto Rio Cisnes) y Argentina ( $\sim 40^{\circ} \mathrm{S}$, Formación Cerro Bandera, Provincia de Neuquén; $\sim 43^{\circ}$, Capas de Colpodon, Patagonia), aunque no existen especies compartidas. Sin embargo, estos registros más australes son de faunas del Mioceno temprano (ver más adelante Implicaciones paleobiogeográficas y cronoestratigráficas: La Venta como ejemplo de "cradle" o "museum"; Hipótesis: radiación y linajes "fantasma"). Algo similar ocurre con Pachybiotherium (ver La excepcionalidad de Pachybiotherium en Colombia). Adicionalmente, cabe resaltar la presencia de posibles sternbérgidos en La Venta, que presentan afinidades con taxones de la fauna de Itaboraí. Dicha fauna es mucho más antigua que La Venta (ver más adelante 
Implicaciones paleobiogeográficas y cronoestratigráficas: La Venta como ejemplo de "cradle" o "museum"; Hipótesis: radiación y linajes "fantasma") y estos nuevos ejemplares estarían representando nuevos géneros o incluso una nueva familia, con rasgos mucho más derivados, por lo que no existirían taxones en común entre estas dos faunas a nivel de género o especie. Por otro lado, los géneros de didélfidos de La Venta con representantes vivientes (excepto Thylamys), actualmente son de representación amazónica o al menos intertropical. Esto es congruente con que estos taxones didélfidos no sean compartidos con faunas neógenas sudamericanas de gran diversidad en otras latitudes (e.g., Quebrada Honda y Santa Cruz).

\section{La excepcionalidad de Pachybiotherium en Colombia}

Los microbioterios vivientes están representados únicamente por Dromiciops gliroides, que habita los bosques subantárticos templado-fríos del surde Chile y Argentina (Mann, 1955; Hershkovitz, 1999; Martin 2010). La especie viviente es de hábitos nocturnos y mayormente arborícolas, y se alimenta de frutos de plantas nativas, larvas y pupas de insectos (Mann, 1955; Rodriguez-Cabal et al., 2007; Martin, 2008). Las especies de Pachybiotherium y el registro de los microbioterios en general, están restringidos a las latitudes más australes de América del Sur. Las dos especies de Pachybiotherium diferentes a P. minor (i.e., P. aclinum y P. illuminatum) provienen de localidades del Mioceno temprano de Argentina (Gran Barranca, Formación Sarmiento, Colhuehuapense; y localdad Portezuelo Sumich Sur, Formación Pinturas, Santacrucense, respectivamente).

Es por esta distribución austral y por el hecho de que los microbioterios vivientes estén asociados, normalmente, con climas templados, resulta interesante la presencia de $P$. minor en un rango geográfico netamente tropical. Sin embargo, como lo advierte Goin et al. (2010b), Hinojosa (2005) reportan el desarrollo hacia los $34^{\circ} \mathrm{S}$, de una "Flora Subtropical Neógena" en coincidencia con el óptimo climático del Mioceno (ca. 15-17 Ma), que se caracterizaba por una dominancia de elementos neotropicales. Esta flora se extendería incluso desde el Mioceno temprano (ca. $20 \mathrm{Ma}$, Coluehuapense). Justamente dentro de este rango temporal se ubican los registros de $P$. illuminatum y $P$. acclinum. A pesar de que no se tiene certeza si esta flora se extendía hasta las correspondientes localidades donde se registraron estas dos especies, según Goin et al. (2010b), este fenómeno explicaría la elevada proporción de frugívoros en la asociación faunística a la que pertenece $P$. illuminatum, y sería congruente con el registro colhuehuapense no sólo de $P$. acclinum, sino también la especie indeterminada de ?Caluromyinae (Goin et al., 2007a), cuyos taxones relacionados vivientes son mayoritariamente frugívoros (Goin et al., 2010).

A todos estos factores se suma la presencia de Pachybiotherium en el neotrópico, en una latitud bastante alejada de los demás registros, pero cuyo ambiente asociado podría ser similar a aquel en el que vivían las demás especies del género (i.e., ambientes tropicales, cálidos y arbóreos). Esto estaría indicando que Pachybiotherium sería un microbioterio con preferencias dietarias y hábitos similares a los microbioterios actuales (i.e., frugívoros, hábitos arborícolas), pero que vivía 
en ambientes mucho más cálidos, asociados a vegetación más tropical.

\section{La Venta como ejemplo de "cradle" o "museum"}

Los trópicos pueden ser vistos bien sea como "cradle" ("cunas"), áreas de altas tasas de diversificación, o como "museos", que son áreas de bajas tasas de extinción (e.g., Stenseth, 1984; MacFadden, 2006; Mannion et al., 2014). Sin embargo, muchos autores consideran que ambos escenarios se pueden aplicar para los trópicos (e.g., Candela y Morrone, 2003; Jablonski et al., 2006; McKenna y Farrell, 2006; Mittelbach et al., 2007; Vucetich et al., 2010; Goin et al., 2012; Rolland et al., 2014). Por ejemplo, Candela y Morrone (2003) remarcan la persistencia en el Mioceno medio de La Venta (Colombia) de últimos registros de linajes más antiguos y plesiomorfos, coexistiendo con primeros registros de linajes más modernos y representados en la actualidad.

En cuanto a los metaterios, la asociación de La Venta ha sido considerada como representativa del modelo "cradle" al punto de ser interpretado como un "hotspot" de la radiación neógena de los didelfimorfios actuales (Goin, 1997), ya que, como se ha venido comentando a lo largo de esta tesis, todas las especies de didélfidos de La Venta pertenecen a géneros con representantes vivientes. Por otro lado, esta misma asociación da varios ejemplos del modelo de "museo" para varios de los órdenes metaterios allí presentes, ya que se presentan taxones con rasgos plesiomórficos y que, en los análisis filogenéticos presentados en esta tesis, aparecen en una posición basal dentro del grupo correspondiente, e incluso en una posición más basal que otros taxones relacionados de edades más antiguas. El grupo de La Venta en el que se presenta la mayor cantidad de ejemplos es el de los esparasodontes; tal es el caso de (1) Hondadelphys, ubicado junto con taxones paleógenos en una posición basal dentro de la filogenia de los esparasodontes; (2) Lycopsis longirostrus, que en la filogenia aparece como la especie más basal de este grupo, siendo más plesiomórfica que otras especies de edades más antiguas, como L. torresi, proveniente del Santacrucense de la Patagonia argentina (18 a $16 \mathrm{Ma}$ ) e incluso L. padillai, registrada en una localidad mucho más cercana (La Guajira, Colombia, Formación Castilletes, ca. 15,3Ma); (3) los tilacosmílidos (Thylacosmilidae gen. 1 y Anachlysictis), cuya morfología es notablemente plesiomórfica respecto a la de Thylacosmilus, mucho más en Thylacosmilidae gen. 1, lo cual es evidente en la filogenia, ya que aparece como uno de los taxones basales de esta familia. Sin embargo, curiosamente, Anachlysictis presenta una morfología marcadamente más derivada que la de Thylacosmilidae gen. 1 y ambos se encuentran registrados dentro de la misma asociación. Este podría ser un caso en el que La Venta se ajusta, al mismo tiempo, tanto al modelo "museo" como el modelo "cradle".

Otro claro ejemplo del modelo museo se encuentra entre los didelfimorfios de La Venta. La posición filogenética obtenida del Género A. sp. 1, a la base de los didelfoideos (o también podría interpretarse como taxón hermano de estos), no es del todo sorpresiva, ya que en el análisis 
morfológico habían sido identificadas similitudes tanto con los esparasocínidos como con los didélfidos, así como algunos rasgos más plesiomórficos.

Finalmente, se reporta la presencia de, al menos, dos taxones "ameridelfios" que posiblemente pertenezcan a la familia Sternbergiidae, o que estén estrechamente relacionados con estos. De confirmarse la pertenencia de estos taxones a dicha familia, se estaría extendiendo notablemente su registro.

\section{Hipótesis: radiación y linajes "fantasma"}

Algunos de los taxones de La Venta permiten plantear algunas hipótesis de radiación y detectar linajes "fantasma" dentro de la filogenia. Por ejemplo, la filogenia de Lycopsis implica una diversificación previa al Santacrucense (Mioceno temprano), ya que esa es la edad del registro más antiguo, pero este no corresponde a la morfología más plesiomórfica, por lo que el grupo tuvo que haberse diversificado antes de ese momento. También implica la presencia de, al menos, dos linajes fantasmas, tanto para L. longirostrus (la morfología más plesiomórfica pero presente en el Mioceno medio) como para L. viverensis, el cual se registra en el Mioceno tardío (Chasiquense) de Arroyo Chasicó (Argentina), pero es más basal que las especies más antiguas (L. padillai y L. torresi). Estos linajes "fantasma" pueden observarse claramente en la Figura 4 de Suarez et al. (2016). La filogenia de este grupo indica también, al menos dos eventos de migración entre los trópicos y las regiones templadas de Sudamérica, y en ambas instancias, se originó una nueva especie en una región templada.

La morfología de los tilacosmílidos de La Venta y su filogenia también permiten plantear algunas hipótesis. En primer lugar, el taxón más basal del grupo es el tilacosmílido de Arroyo Chasicó (Suarez et al., in prep; Anexo 1.1, “Thylacosmilidae gen. 2 sp. 1”), pero proviene de rocas del Mioceno tardío. El registro más antiguo de tilacosmílido (Goin et al., 2007) proviene del Mioceno temprano (Colhuehuapense) de la Formación Sarmiento (Gran Barranca, Argentina), y presenta una morfología más cercana a la de Thylacosmilus, que es claramente la más derivada del grupo. Esto estaría indicando que la diversificación de los tilacosmílidos tuvo que ocurrir antes de del Mioceno temprano, presentándose así un linaje fantasma para el tilacosmílido de Chasicó, el cual abarcaría al menos casi todo el Mioceno. El siguiente tilacosmílido más basal es Thylacosmilidae gen. 1 sp. 1, de La Venta, que claramente presenta rasgos bastante plesiomórficos. Curiosamente Thylacosmilus muestra los rasgos más derivados del grupo y, adicionalmente, muestra rasgos que no están presentes en los demás, pero aparece en el análisis filogenético como grupo hermano de aquel conformado por Anachlysictis y Patagosmilus, o si se quiere, como taxón basal a estos. Esto podría estar indicando un evento de diversificación temprano para este taxón en zonas templadas, separándose evolutivamente del grupo y desarrollando rasgos independientes.

Otro linaje "fantasma" aparece para Género A sp. 1, que es tal vez el mejor ejemplo para el modelo de museo en La Venta. Dada su posición en la filogenia de los didelfimorfios como taxón 
basal o taxón hermano de los Didelphoidea (i.e., Sparassocynidae + Didelphidae), este linaje fantasma iría al menos desde el Mioceno temprano, cuando se registran los restos más antiguos indudablemente referibles a Didelphidae (Goin et al., 2007a).

Por otro lado, los didélfidos de La Venta extienden el registro de algunos géneros actuales hasta el Mioceno medio, pudiendo ser de hecho el momento de diversificación para estos taxones (o al menos se tomaría así hasta que aparezca un registro más antiguo).

\section{COMENTARIOS SOBRE ALGUNAS HOMOLOGÍAS EN LOS MOLARES DE LOS DIDÉLFIDOS (DIDELPHIDAE, METATHERIA).}

Según Voss y Jansa (2009), el para- y metacónulo son indistinguibles o ausentes en los molares superiores didélfidos, y remarcan que la literatura es inconsistente en este tema, ya que diferentes autores afirman haber observado entre didélfidos recientes una variación taxonómica significativa en la ocurrencia de estos cónulos y que, de hecho, una observación detallada en dientes sin desgaste usualmente revela una pequeña protuberancia angulosa ("chevron") esmaltada sobre la postprotocrista, que es presumiblemente homóloga con el metacónulo; y que estructuras equivalentes en la preprotocrista (presumibles paracónulos vestigiales) son observados menos frecuentemente. "El hecho de que los cónulos hayan sido codificados como presentes o ausentes en un mismo taxón por diferentes autores (e.g., Didelphis, en Reig et al., 1987 versus Wroe et al., 2000) refleja la ambigüedad en la interpretación de dichas estructuras" (Voss y Jansa, 2009: pág. 50 , pie de página).

Durante la revisión de los materiales incluidos en el presente trabajo, sin embargo, se observa que en algunos didélfidos (e.g., ejemplar IGM 251012, Tlacuatzin canescens (actual), los ejemplares cf. Tlacuatzin, los ejemplares actuales de Marmosa utilizados en el análisis filogenético y comparaciones, los ejemplares referidos a Marmosa sp. 1; ver caracteres 110 y 111 en la matriz de Didelphimorphia) son distinguibles el para- y metacónulo o al menos una de estas dos cúspulas (generalmente el metacónulo). Esto es mucho más claro en los materiales con poco o nada de desgaste, ya que, en general, estos cónulos se encuentran bastante reducidos o son vestigiales; sin embargo, se observó que, en general, las crestas para- y metaconulares se mantienen distinguibles y, a partir de estas, es posible determinar la presencia de estas cúspulas, a pesar de su desgaste. Suele ocurrir que, cuando una cúspide se reduce hasta ser vestigial o desaparecer en cierto taxón, generalmente persisten sus crestas asociadas, siendo claramente visibles en los dientes sin desgaste. Esto puede facilitar algunas interpretaciones de homologías.

A partir de estas observaciones surgen algunos conflictos en los caracteres propuestos por Voss y Jansa (2003 y 2009). Por ejemplo, el carácter 105 de Voss y Jansa (2009), que es el mismo carácter 60 de Voss y Jansa, 2003), habla de la extensión anterolabial de la preprotocrista y su unión con el cíngulo anterior, asumiendo que la cresta que se une al cíngulo anterior es la 
preprotocrista, en todos los casos en que esto ocurre. Estos autores evalúan dos estados para este carácter: 0 , preprotocrista y cíngulo anterior unidos formando una plataforma continua a lo largo del margen anterior del molar; y 1, preprotocrista y cíngulo anterior separados, sin formar una plataforma continua. Sin embargo, en la presente revisión se observó que los ejemplares que presentan un paracónulo (en cualquier estado de desarrollo), generalmente la cresta que se conecta con el cíngulo anterior corresponde a la cresta preparaconular y no a la preprotocrista (ver carácter 71 de la matriz de Didelphimorphia). Otros autores (e.g., Rougier et al., 1998, car. 26; Forasiepi, 2009, car. 149) han tratado este carácter de forma diferente, tomándolo desde la perspectiva de la extensión del cíngulo anterior, presentando las condiciones de "expandido" o "corto", siendo expandido cuando es continuo entre el margen estilar y el paracónulo, o la base lingual del paracono si el paracónulo está ausente; y corto, cuando está interrumpido entre el margen estilar y el paracónulo, o la base lingual del paracono si el paracónulo está ausente. Otros autores (e.g., Archer, 1976: p.3) utilizan el término "cíngulo anterior completo" para el primer caso (i.e., expandido).

Algo similar ocurre con el carácter 106 de Voss y Jansa (2009), donde describen la postprotocrista diferenciando dos condiciones: 1, porstprotocrista sin muesca (i.e., se extiende posteriormente hasta desaparecer gradualmente sobre la cara posterior del metacono, formando así un surco posterior; explicación tomada de Voss y Jansa, 2009: p. 54), o 2, postprotocrista con muesca (i.e., termina en la base del metacono y se presenta una muesca carnasial; explicación tomada de Voss y Jansa, 2009: p. 54). La forma como fueron definidos estos dos estados parte de asumir que no existe metacónulo en los didélfidos. En la presente revisión se observó que algunos de los taxones que Voss y Jansa (2009) codificaron con el estado 1, presentan metacónulo, vestigial en algunos casos, pero con crestas identificables. En estos ejemplares, la estructura que se extiende posteriormente es la cresta postmetaconular, no la postprotocrista. Por esta razón, este carácter tal como está definido, no podría ser aplicable a dichos taxones, porque las estructuras evaluadas no son homólogas.

Debido a estas discrepancias respecto a la interpretación de las homologías tratadas por Voss y Jansa $(2003,2009)$, en el análisis filogenético para los didelfimorfios de la presente tesis (capítulo 5) se hicieron algunas modificaciones a los caracteres propuestos por estos autores. En el caso de los caracteres que describen la preprotocrista y el cíngulo anterior, en la presente tesis se optó por no usar el carácter 105 de Voss y Jansa (2009; 2003, car. 60), que habla de la extensión anterolabial de la preprotocrista y su unión con el cíngulo anterior, debido al conflicto de homologías arriba mencionado. Sin embargo, se optó por evaluar la extensión del cíngulo anterior (siguiendo a Rougier et al., 1998 y Forasiepi, 2009), usando el carácter 102 de Voss y Jansa (2009), que evaluaba la presencia o ausencia de este cíngulo para diferenciar a los didélfidos de otros grupos de marsupiales (e.g., algunos peramelemorfios). Como este cíngulo estaba presente en todos los taxones evaluados en el análisis de esta tesis, se modificó el carácter para evaluar únicamente su desarrollo (ver carácter 71 de la matriz de Didelphimorphia), quedando con dos 
estados: 0, expandido (i.e., continuo entre el margen estilar y el paracónulo, o la base lingual del paracono si el paracónulo está ausente; Figs. 10.1A-B); 1, interrumpido (i.e., interrumpido entre el margen estilar y el paracónulo, o la base lingual del paracono si el paracónulo está ausente; Figs. 10.1C-D). Es necesario aclarar que todos los autores mencionados recomiendan evaluar este carácter preferentemente en el M3, debido a que en este molar se presenta un claro desarrollo de este rasgo (i.e., puede estar expandido en el M3 pero interrumpido en los loci anteriores).

En el caso del carácter que describe la postprotocrista (Voss y Jansa, 2009: car. 106; carácter 74 en la presente matriz), se optó por modificar ligeramente los estados y, adicionalmente, según lo observado entre los materiales revisados, se optó por agregar un estado más, quedando entonces los siguientes: 0, postprotocrista extendida posterolabialmente alrededor de la base del metacono (i.e., la postprotocrista se extiende posterolabialmente y va decreciendo a medida que rodea la base del metacono, dejando un surco en la pared posterior del trígono; Fig. 10.2A); 1, conecta con la base del metacono, formando una muesca carnasial distinguible cerca de esta (Fig. 10.2B); 2, conecta con el metacónulo (distinguible o vestigial; Figs. 10.2C-D). En el estado 0, el metacónulo está ausente y la postprotocrista se extiende pasando posterolabialmente alrededor de la base del metacono, formando un surco o canal con la cara posterior del trígono, y decreciendo gradualmente en altura y ancho hasta desaparecer en dicha superficie (Voss y Jansa, 2009). En el estado 1, el metacónulo también está ausente pero la postprotocrista conecta directamente con el extremo más lingual de la base del metacono, sin dejar ningún surco ni canal en la cara posterior del trígono; en cambio, se observa una muesca carnasial en la base del metacono (Voss y Jansa, 2009). Esta condición puede observarse claramente en Chironectes, Didelphis, Lutreolina y Philander (Voss y Jansa, 2009), pero en la presente revisión también se observó en Monodelphis brevicaudata (por eso se codificó como tal). El estado 2 (Figs. 10.2C-D) se agregó para incluir aquellos taxones que presentaban metacónulo (bien desarrollado o vestigial pero claramente distinguible). En este caso, la postprotocrista termina en el metacónulo. En algunos de estos taxones (e.g., el didelfimorfio Género A sp. 1) el metacónulo no presenta una cresta postmetaconular (Fig. 10.2D), por lo que se observa un pequeño espacio entre el metacónulo y el metacono, no hay una cresta que conecte o rodee posteriormente la base del metacono. En aquellos taxones que sí presentan cresta postmetaconular, esta se extiende posterolabialmente rodeando la base del metacono (Fig. 10.2C), pero claramente esta estructura no es homóloga a la cresta postprotoconular y por esto no fueron codificados con el estado 0. En algunos casos, esta cresta postmetaconular es bastante corta (e.g., Thylatheridium), mientras que en otros (e.g., Cryptonanus) la cresta postmetaconular se extiende mucho más posterolabialmente y pareciera bordear toda la extensión posterior de la base del metacono, como lo que ocurre con la postprotocrista en varios taxones que presentan el estado 0 . Por esta razón, muchos de estos taxones habían sido codificados con el estado 0 por Voss y Jansa (2009), asumiendo que esta cresta era la postprotocrista; pero como se plantea acá, en realidad se trata de la cresta postmetaconular.

Adicionalmente, en la presente revisión, se observaron algunos taxones fósiles donde la 
cresta que se extiende posteriormente (bien sea la postprotocrista o la cresta postmetaconular) llega hasta la base del metacono o se extiende tan sólo ligeramente por detrás, pero, adicionalmente, sobre la pared posterior del trígono y en una posición más posterior, se presenta una cresta corta y poco marcada, casi vestigial (i.e., "cresta indeterminada" en Fig. 10.2E), alineada con la postprotocrista o cresta postmetaconular (e.g., en algunos ejemplares referidos a Hyperdidelphys). Es decir, pareciera que la cresta estuviese interrumpida y sólo se presentaran sus dos extremos. Debido a esta observación, se sugiere que a futuro se evalúen las homologías de estas estructuras (i.e., la cresta que se extiende posteriormente y la pequeña cresta más posterior sobre la pared posterior del trígono) teniendo en cuenta los taxones extintos, ya que, según lo observado, existiría posibilidad de que lo que se extiende posteriormente sobre la pared posterior del trígono, rodeando al metacono y formando un pequeño surco posterior, no sea ni la cresta postmetaconular ni la postprotocrista, sino un "postcíngulo" que se origina en la porción posterior de la pared posterior del trígono y continúa lingualmente hasta unirse a la cresta que esté presente, independientemente de cuál sea. 


\section{CAPÍTULO 11. CONCLUSIONES}

La asociación de mamíferos de La Venta (Colombia) es una de las que presenta mayor riqueza taxonómica para el Neógeno de América del Sur, siendo sólo superada por la fauna de Santa Cruz, del Mioceno temprano (Santacrucense) de Argentina. Sin embargo, es la que presenta la mayor proporción de metaterios, incluso ligeramente más que la de Santa Cruz. Estas cifras podrían incrementarse con futuros esfuerzos de colección, ya que es evidente que la riqueza taxonómica de la fauna del Santacrucense está directamente relacionada con una amplia trayectoria de investigación, que incluye mayor exploración y número de estudios que para La Venta. La gran diversidad de metaterios en La Venta, comparada con otras asociaciones neógenas sudamericanas, podría estar vinculada a un proceso de radiación ocurrido previamente: La Venta es inmediatamente posterior al evento conocido como Optimo Climático del Mioceno Medio.

La asociación de metaterios de La Venta está representada por al menos 22 especies, 17 géneros, siete familias y cuatro órdenes, incluyendo los Sparassodonta, Didelphimorphia, Paucituberculata y Microbiotheria. Adicionalmente, se presentan ejemplares referibles a órdenes aún no definidos de "ameridelfios". De esas 22 especies, 12 son propuestas en la presente tesis como especies nuevas para La Venta (algunas no necesariamente nuevas para la ciencia y una sugerida previamente más no descrita ni nombrada; i.e., Thylacosmilidae gen. 1 sp. 1, Goin, 1997). La mayor diversidad entre los metaterios de La Venta se observa en los esparasodontes, con al menos ocho especies, seis géneros y tres familias; algunas de estas especies se ubican dentro de Borhyaenoidea, pero no se encuentran incluidas dentro de ninguna de las familias definidas para este clado (i.e., Lycopsis longirostrus y Dukecynus magnus). Entre los esparasodontes, la mayor diversidad se observa en las familias Hondadelphidae, con tres especies (dos nuevas propuestas en el presente estudio), y Thylacosmilidae, que incluye formas con diferente desarrollo de los rasgos típicos de esta familia.

Entre la diversidad de morfologías de esta asociación, resulta notoria la ausencia de grandes didelfinos. Sin embargo, esto puede deberse a que su nicho ecológico es ocupado por otros taxones de morfología y hábitos similares (e.g., Hondadelphys, Thylacosmilidae gen.1, o hatliacínidos). También llama la atención la ausencia de cenoléstidos y calurominos. Esto podría deberse a que los nichos de estos taxones estaban siendo ocupados en La Venta por otros metaterios o incluso otros mamíferos. En el caso de los cenoléstidos, esto podría deberse a que el ambiente en L La Venta durante el Mioceno medio era muy diferente a los ambientes 
en los que suelen habitar los representantes de este grupo. Adicionalmente, los paucituberculados de esta antiguedad son poco abundantes, mucho menos los cenoléstidos (Abello et al. 2018). En el caso de los calurominos, es probable que su nicho haya sido ocupado por los microbioterios o por taxones de euterios (¿primates?). También es remarcable la ausencia de polidolopimorfios que, si bien fueron particularmente abundantes durante el Paleógeno, el linaje de los Argyrolagoidea se registra en América del Sur a lo largo de todo el Neógeno hasta fines del Plioceno. Esta ausencia podría estar relacionada con el tipo de ambientes disponibles en La Venta, diferente al que podría llegar a inferirse para los argirolagoideos (i.e., posiblemente ambientes abiertos).

La presente revisión permitió realizar análisis filogenéticos para los dos grupos mejor representados en La Venta (i.e., Sparassodonta y Didelphimorphia). Entre los resultados obtenidos en el análisis de los esparasodontes se destaca la ubicación basal de Hondadelphys, la cual es concordante con análisis recientes realizados por otros autores (i.e., Forasiepi, 2009; Engelman y Croft, 2014; Forasiepi et al., 2015; Suarez et al., 2016). En el análisis morfológico se observó que Hondadelphys muestra una serie de rasgos comunes con los tilacosmílidos, donde los representantes de este género parecen presentar una expresión más plesiomórfica de la condición observada en los tilacosmílidos de La Venta. Sin embargo, esta relación no es recuperada en el análisis filogenético y es necesario realizar una revisión más minuciosa para determinar si estos rasgos están indicando una relación cercana entre esos taxones, si son producto de convergencias o si simplemente se trata de rasgos plesiomórficos (presentes originalmente en Hondadelphys) que sólo se mantuvieron en los tilacosmílidos. Entre los resultados para los tilacosmílidos evaluados en este análisis, se destaca la clara posición de Thylacosmilidae gen. 1 sp. 1 dentro de esta familia, así como la posición de Patagosmilus, estaría más cercanamente relacionado a Anachlysictis que a Thylacosmilus (contra Forasiepi y Carlini, 2010). Esta posición es consistente con lo observado en el análisis morfológico, en el que se destacan varias similitudes entre estos taxones hermanos. Una de las hipótesis a contrastar en el presente estudio era la estrecha relación entre Dukecynus magnus y los "protilacininos". Sin embargo, el presente análisis muestra una relación más estrecha con los boriénidos y proboriénidos.

Entre los resultados obtenidos en el análisis para Didelphimorphia, se destaca la cercana relación entre los didélfidos de La Venta con especies actuales de los géneros a los que fueron referidos, confirmando así la asignación que se había realizado previamente (i.e., Goin, 1997) y reiterando así que los didélfidos de La Venta representan el registro más antiguo de algunos géneros vivientes de amplia distribución en América Central y del Sur (e.g., Thylamys y Marmosa; Goin, 1997). A esto se suma que en la revisión taxonómica se identificó la posible presencia de una especie referible a otro género actual (i.e., Tlacuatzin), así como una nueva especie de Marmosa. Adicionalmente, se concluyó que los materiales referidos a "Didelphinae, gen. et sp. indet." por Goin (1997: p. 194) y materiales no publicados asociados, representan 
un nuevo género de didelfimorfio basal, el cual es taxón hermano de Didelphoidea.

Además de los resultados obtenidos en los análisis filogenéticos, se pudieron hacer algunas inferencias taxonómicas a partir del análisis morfológico comparativo. Una de las más destacables es la reafirmación de la hipótesis planteada por Czaplewski et al. (2003), acerca de la clasificación de Kiotomops lopezi, originalmente referido a un quiróptero Molossidae (Takai et al. 1991), pero que presenta una gran variedad de rasgos que permiten referirlo al clado Metatheria. Adicionalmente, en la presente revisión se sugiere la posible relación de Kiotomops con los Sternbergiidae, además de la identificación de una nueva especie para La Venta, relacionada a Kiotomops. Las claras afinidades sternbérgidas indican que estas dos especies bien podrían ser parte de esta familia o de una nueva familia estrechamente relacionada con ella. También se destaca la identificación de al menos una nueva especie de paucituberculado paleotentoideo y al menos una de hatliacínido, además de un nuevo taxón aún cuya clasificación es aún incierta, pero que presenta rasgos claramente plesiomórficos y representa un nuevo taxón para esta asociación.

Muchos de estos resultados están sugiriendo que el área de La Venta es un ejemplo tanto del modelo "cradle" como del modelo "museo". Es un centro de diversificación para algunos taxones, como algunos géneros de didélfidos actuales, mientras que también persisten taxones basales entre los diferentes clados (i.e., el didelfimorfio basal, Kiotomops y el nuevo taxón incierto con morfología plesiomórfica).

Los análisis ecomorfológicos llevados acabo en este estudio incluyeron tanto estimaciones de masa corporal como inferencias dietarias. Las estimaciones de obtenidas están mostrando que no existiría un espectro continuo de masa corporal para los metaterios de La Venta, ya que que existirían "vacíos" dentro del rango ocupado por estos (i.e., entre los $\sim 13 \mathrm{~g}$ y los $\sim 50 \mathrm{~kg}$ ); principalmente, entre los esparasodontes, que por el momento no incluyen especies de tamaño intermedio (i.e., 7-15 kg, según la clasificación de Prevosti et al. 2013; ver Materiales y Métodos) y este rango de no está siendo ocupado por ninguna otra especie de metaterios. Lo mismo ocurre en el caso de los didelfimorfios, aunque con un rango menor, ya que no se presentan taxones de masa corporal dentro de los 60 y los $200 \mathrm{~g}$, pero en este caso, entre los demás marsupiales se abarca parte de este espectro (menor a $\sim 91 \mathrm{~g}$ y mayor a $\sim 140$ ). Los rangos no ocupados por los metaterios podrían estar siendo abarcados por algunos euterios, aunque probablemente no el nicho ecológico de todos (i.e., no han sido reportados euterios con hábitos orientados a la carnivoría).

En la asociación de vertebrados de La Venta (Colombia), el rol ecológico de los depredadores sería ocupado por los esparasodontes y posiblemente algunos reptiles (i.e., crocodilomorfos). Sin embargo, el nicho carnívoro de La Venta no incluye, aparentemente, grandes quiebrahuesos, y los pequeños carnívoros (e.g., hatliacínidos) están pobremente representados. Entre los esparasodontes se presentarían tanto formas mesocarnívoras como carnívoras estrictas. Por otro lado, para los didelfimorfios de La Venta se infieren hábitos 
principalmente insectívoros o faunívoros; por su parte, la morfología del didelfimorfio Género A, identificado por Goin (1997) como "Didelphinae indet." (Didelphimorphia), además de estar indicando estos hábitos, también sugiere una tendencia a la omnivoría. Por su parte, los paucituberculados y los microbioterios presentarían hábitos orientados a la frugivoría. La presencia de Pachybiotherium en La Venta estaría sumando un argumento para soportar la hipótesis que sugiere para este taxón preferencias dietarias y hábitos similares a los microbioterios actuales (i.e., frugívoros, hábitos arborícolas), pero habitando en ambientes mucho más cálidos, asociados a vegetación más tropical (Goin, 1997; Goin et al., 2010b). Esto, más que una preferencia por determinado tipo de ambientes, podría estar sugiriendo que taxones predominantemente australes como los microbiotéridos, ante la continuidad ambiental ocurrida durante el óptimo climático del Mioceno, se habrían expandido hacia ambientes boscosos tropicales.

Finalmente, la comparación entre la fauna de La Venta y otras faunas neógenas sudamericanas está mostrando, en general, una tendencia al provincialismo controlado por la latitud. El carácter dual de la biogeografía sudamericana (Goin et al. 2012 y bibliografía allí citada) se ve reflejado para la asociación de metaterios de La Venta (Colombia), principalmente a nivel de especie. Esto se ve incluso reflejado entre los euterios, ya que los escasos taxones compartidos, por ejemplo, entre La Venta (Colombia) y la fauna contemporánea de Quebrada Honda (Bolivia), se clasifican dentro de este grupo: un notoungulado (Miocochilius) y un roedor (Acarechimys). Sin embargo, existen algunas excepciones para los grandes carnívoros, los esparasodones, que a nivel genérico muestran algunos ejemplos de amplia dispersión a lo largo del continente, tal como ocurre entre los grandes carnívoros euterios.

\section{HIPÓTESIS A CONTRASTAR A FUTURO Y PRÓXIMOS ESTUDIOS}

- Se espera poder realizar futuros trabajos de campo enfocados en las formas más pequeñas, principalmente Paucituberculata, Microbiotheria y ?Sternbergiidae, con el fin de tener una mayor cantidad de material que permita realizar una revisión más profunda de estos grupos. Uno de los principales objetivos de estos futuros estudios es confirmar la presencia de sternbérgidos (o taxones relacionados) en bajas latitudes de América del Sur durante el Mioceno medio, realizando un análisis filogenético que incluya los ejemplares aquí tentativamente referidos a dicho grupo y taxones con morfologías similares que pudieran eventualmente estar relacionados.

- Futuros trabajos de campo también estarían enfocados en la búsqueda de nuevos restos referibles a Anachlysictis grailis, con el fin de encontrar materiales que puedan ser claramente comparables con el holotipo de Patagosmilus goini y así poder contrastar la hipótesis acerca de la pertenencia de estas dos especies a un mismo género. Sólo el hallazgo de materiales que 
preserven estructuras craneales homólogas y su inclusión dentro de un análisis filogenético permitirán reforzar o descartar esta hipótesis. También se espera poder obtener los permisos necesarios para realizar un estudio detallado del material original del ejemplar B:p2-154, proveniente de Río Rosario, una localidad cercana a Quebrada Honda (Bolivia) y que en la presente tesis fue referido a $P$. goini, el cual se encuentra actualmente alojado en la Unidad de Paleontología del Museo Nacional de Historia Natural de La Paz (Bolivia). Este ejemplar provee nuevos e importantes datos acerca de la anatomía de esta especie que deberían ser publicados.

- Se espera poder realizar una revisión detallada con un análisis filogenético orientado a contrastar la hipótesis acerca de la relación entre Hondadelphys y Thylacosmilidae, con el fin de evaluar la posibilidad de que Hondadelphys sea en realidad un tilacosmílido o un taxón estrechamente relacionado a esta familia; otra posibilidad es que los rasgos comunes entre estos sean sólo producto de convergencias o que simplemente se trate de rasgos plesiomórficos que sólo se mantienen en los tilacosmílidos (en una condición más derivada que en Hondadelphys), pero no en los demás esparasodontes.

- Se espera poder realizar futuras revisiones que incluyan un mayor número de taxones didelfimorfios no didelfoideos (e.g, más peradectoideos algunos representantes de la familia Caroloameghiniidae) y caracteres (e.g., más caracteres craneanos), con el fin de determinar si el didelfimorfio Género A debería incluirse dentro de Didelphoidea (por ahora se identifica como grupo hermano) o si en realidad representa un nuevo clado independiente dentro de Didelphimorphia.

- Entre la amplia variedad de morfologías de los metaterios de La Venta, se encontró un rasgo particular que varía dentro de todo el espectro observable en los metaterios, y es la morfología de la centrocrista: en La Venta se presentan tanto taxones con centrocrista en forma de V bastante profunda, como otros con la centrocrista casi recta. Esta es una buena oportunidad para proponer la estandarización de un parámetro de medición (e.g., longitudes y ángulos), para poder realizar comparaciones más precisas (e.g., al momento de codificar esta condición en una matriz) y, eventualmente (si llegara a surgir a partir de tal revisión), realizar algún tipo de inferencia evolutiva para los metaterios de La Venta teniendo en cuenta la morfología de la centrocrista.

- Un importante estudio publicado recientemente (i.e., Chemisquy et al., 2015) evalúa los hábitos alimenticios de los didélfidos a partir de la morfoló́ga oclusal de los molares, usando morfometría geométrica. En este estudio se comparan casi todos los géneros de didélfidos actuales (excepto Tlacuatzin) y algunos fósiles (i.e., Thylatheridium y Thylophorops). Se espera a futuro poder realizar un estudio tan pormenorizado, enfocado en este tipo de análisis morfológicos para las especies de La Venta, usando una metodología similar.

- En la presente tesis doctoral se realizaron algunas sugerencias acerca de posibles tamaños de presa para los esparasodontes de La Venta. Las inferencias sobre la distribución predador-presa 
de esta asociación deberían ser contrastadas por medio de alguna metodología analítica. Por esta razón, se espera poder realizar un estudio enfocado en este análisis, con el fin de evaluar la hipótesis acerca de que los esparasodontes de esta asociación no habrían abarcado todo el espectro de posibles presas en La Venta y que este podría ser en parte ocupado por otros grupos no mamíferos, como los reptiles (e.g., Purussaurus neivensis). Este análisis deberá incluir comparaciones con faunas actuales, ya que es necesario tener en cuenta que, en algunos casos, los depredadores no abarcan todo el espectro de posibles presas adultas (e.g., ocurre actualmente con los elefantes adultos, que se encuentran por fuera del rango de predación de los grandes depredadores que cohabitan con ellos).

Comentarios: se espera poder publicar al menos un artículo por cada uno de los capítulos contenidos en la Parte II del presente trabajo (eventualmente más de un artículo para los capítulos más largos), que incluya la taxonomía, filogenia y paleobiología de cada uno de los principales grupos metaterios presentes en La Venta, además de los aspectos discutidos en la Parte III (discusión y conclusiones). En este momento se están preparando tres artículos que surgieron a partir del presente trabajo: (1) la descripción del tilacosmílido más basal hasta ahora encontrado (el ejemplar proveniente de Arroyo Chasicó; véase Thylacosmilidae gen. 2 sp. 1 en el Anexo 1.1), con algunas inferencias paleobiológicas y paleoecológicas; (2) la revisión de la filogenia de la familia Thylacosmilidae; y (3) la descripción del didelfimorfio basal de La Venta como un nuevo género con dos especies (Didelphimorphia gen. A spp. 1 y 2). 


\section{BIBLIOGRAFÍA CITADA}

Abello, M. A. 2007. Sistemática y bioestratigrafía de los Paucituberculata (Mammalia: marsupialia) del Cenozoico de América del Sur. Tesis doctoral, Universidad de La Plata, Argentina, $381 \mathrm{pp}$.

Abello, M. A. y Ortiz Jaureguizar, E. 2009. Climatic-environmental changes and body mass evolution in South American mammals: the Abderitidae's case (Marsupialia: Paucituberculata). In 10th International Mammalogical Congress 331-332A.

Abello, M. A. 2013. Analysis of dental homologies and phylogeny of Paucituberculata (Mammalia: Marsupialia). Biological Journal of the Linnean Society 109(2):441-465.

Abello, M. A., Toledo, N., Ortiz-Jaureguizar, E. 2018. Evolution of South American Paucituberculata (Metatheria: Marsupialia): adaptive radiation and climate changes at the Eocene-Oligocene boundary. Historical Biology, 1-18.

Abello, M. A., De Los Reyes, M., Candela, A. M., Pujos, F., Voglino, D. y Quispe, B. M. 2015. Description of a new species of Sparassocynus (Marsupialia: Didelphoidea: Sparassocynidae) from the late Miocene of Jujuy (Argentina) and taxonomic review of Sparassocynus heterotopicus from the Pliocene of Bolivia. Zootaxa 3937(1):147-160.

Abdala, F., Flores, D. A. y Giannini, N. P. 2001. Postweaning ontogeny of the skull of Didelphis albiventris. Journal of Mammalogy 82(1):190-200.

Abreu-Júnior, E. F., Freitas, M. A., Lapenta, M. J., Venâncio, M. N., França, D. P. F. y Percequillo, A. R. 2016. Marsupials and rodents (Didelphimorphia and Rodentia) of upper Rio Acre, with new data on Oxymycterus inca Thomas, 1900 from Brazil. Check List 12(5):1956.

Aguilera, O., Lundberg, J., Birindelli, J., Sabaj Pérez, M., Jaramillo, C. y Sánchez-Villagra, M. R. 2013. Palaeontological evidence for the last temporal occurrence of the ancient western Amazonian river outflow into the Caribbean: PLoS One 8(9):e76202, doi: 10.1371 / journal.pone.0076202.

Alonso-Mejía, A. y Medellín, R. A. 1992. Marmosa mexicana. Mammalian species 421:1-4.

Aplin, K. P. y Archer, M. 1987. Recent advances in marsupial systematics with a new syncretic classification; pp. 15-72 en M. Archer (Ed.), Possums and opossums: studies in evolution 1. Sydney: Surrey Beatty.

Ameghino, F. 1887. Enumeración sistemática de las especies de mamíferos fósiles coleccionados por Carlos Ameghino en los terrenos eocenos de la Patagonia austral y depositados en el Museo de La Plata. Boletín del Museo de La Plata 1:1-26.

Ameghino, F. 1889. Contribución al conocimiento de los mamíferos fósiles de la República Argentina. Actas de la Academia Nacional de Ciencias de Córdoba 6(XXXIII):1027. 
Ameghino, F. 1893. Les premiers mammifères. Relations entre les mammifères diprodontes éocènes de l'Amérique du Nord et ceux de la République Argentine. Revue Générale des Sciences Pures et Appliquées 4:77-81.

Ameghino, F. 1894. Enumération synoptique des espèces de mammifères fossiles des formations éocènes de Patagonie. Boletín de la Academia Nacional en Ciencias, Córdoba 13:259-452.

Ameghino, F. 1898. Sinopsis geológico-paleontológica de la República Argentina. Segundo censo de la República Argentina 1:112-255.

Ameghino, F. 1902. Première contribution à la connaissance de la fauna mammalogique des couches à Colpodon [First contribution to the knowledge of the mammalian fauna of the Colopdon Beds]. Boletin de la Academia Nacional de Ciencias de Córdoba 17:71-141

Ameghino, 1904. Nuevas especies de mamíferos, cretáceos y terciarios de la República Argentina [New species of mammals, Cretaceous and Tertiarty, from the Argentine Republic]. Anales de la Sociedad Cientifica Argentina 56-58:1-142.

Ameghino, F. 1906. Les formations sédimentaires du crétacé supérieur et du tertiaire de Patagonie avec un parallèle entre leurs faunes mammalogiques et celles de l'ancien continent. Anales del Museo Nacional de Buenos Aires 15:1-568.

Anderson, V. J., Horton, B. K., Saylor, J. E., Mora, A., Tesón, E., Breecker, D. O. y Ketcham, R. A. 2016. Andean topographic growth and basement uplift in southern Colombia: Implications for the evolution of the Magdalena, Orinoco, and Amazon river systems: Geosphere 12(4): 1-22, doi:10.1130/GES01294.1.

Antoine, P. O., Roddaz, M., Brichau, S., Tejada-Lara, J., Salas-Gismondi, R., Altamirano, A., Louterbach, M., Lambs, L., Otto, T., and Brusset, S. 2013. Middle Miocene vertebrates from the Amazonian Madre de Dios subandean zone, Perú. Journal of South American Earth Sciences 42:91-102.

Archer, M. 1976a. The basicranial region of marsupicarnivores (Marsupialia), interrelationships of carnivorous marsupials, and affinities of the insectivorous peramelids. Zoological Journal of the Linnean Society 59:217-322.

Archer, M., 1976b. The dasyurid dentition and its relationships to that of didelphids, thylacinids, borhyaenids (Marsupicarnivora) and peramelids (Peramelina: Marsupialia). Australian Journal of Zoology Supplementary Series 24(39):1-34.

Argot, C. 2003a. Functional adaptations of the postcranial skeleton of two Miocene borhyaenoids (Mammalia, Metatheria) Borhyaena and Prothylacynus, from South America. Palaeontology 46:1213-1267.

Argot, C. 2003b. Postcranial functional adaptations in the South American Miocene borhyaenoids (Mammalia, Metatheria): Cladosictis, Pseudonotictis, and Sipalocyon. Alcheringa 27:303356.

Argot, C. 2004a. Functional-adaptive analysis of the postcranial skeleton of a Laventan borhyaenoid, Lycopsis longirostris (Marsupialia, Mammalia). Journal of Vertebrate 
Paleontology 24(3):689-708.

Argot, C. 2004b. Evolution of South American mammalian predators (Borhyaenoidea): anatomical and palaeobiological implications. Zoological Journal of the Linnean Society 140(4):487521.

Argot, C. 2004c. Functional-adaptive features and paleobiologic implications of the postcranial skeleton of the late Miocene sabretooth borhyaenoid, Thylacosmilus atrox (Metatheria). Alcheringa 28:229-266.

Astúa, D. 2015. Morphometrics of the largest New World marsupials, opossums of the genus Didelphis (Didelphimorphia, Didelphidae). Oecologia Australis 19(1):117-142.

Beck, R. M. D. 2012. An 'ameridelphian' marsupial from the early Eocene of Australia supports a complex model of Southern Hemisphere marsupial biogeography. Naturwissenschaften 99:715-729.

Babot, M. J. 2005. Los Borhyaenoidea (Mammalia, Metatheria) del Terciario inferior del Noroeste argentino. Aspectos filogenéticos, paleobiológicos y bioestratigráficos. Tesis doctoral sin publicar, Universidad Nacional de Tucumán, Tucumán, Argentina, 454 pp.

Babot, J. y Forasiepi, A. M. 2016. Mamíferos predadores nativos del Cenozoico sudamericano: evidencias filogenéticas y paleoecológicas; pp. 219-230 en F. L. Agnolin, F. B. Egli, N. R. Chimento y F. E. Novas (eds.), Historia Evolutiva y Paleobiogeográfica de los Vertebrados de América del Sur. XXX Jornadas Argentinas de Paleontología de Vertebrados. Contribuciones del MACN No.6, Museo Argentino de Ciencias Naturales "Bernardino Rivadavia" and Instituto Nacional de Investigación de las Ciencias Naturales. Buenos Aires, Argentina.

Babot, M. J., Powell, J. E. y Muizon, C. de. 2002. Callistoe vincei, a new Proborhyaenidae (Borhyaenoidea, Metatheria, Mammalia) from the early Eocene of Argentina. Geobios 35(5):615-629.

Bakioglu, K.B., 2014, Garzón Massif Basement Tectonics: A Geophysical Study, Upper Magdalena Valley, Colombia [M.S. thesis]: Columbia, University of South Carolina, 54 p.

Bown, T. M. y Fleagle, J. G. 1993. Systematics, biostratigraphy, and dental evolution of the Palaeothentidae, later Oligocene to early-middle Miocene (Deseadan-Santacrucian) caenolestoid marsupials of South America. Journal of Palaeontology (supplement Memoir 29) $67: 1-76$.

Bustamante, C., Cardona, A., Bayona, G., Mora, A. R., Valencia, V., Gehrels, G. E. y Vervoort, J. 2010. U-Pb LA-ICP-MS geochronology and regional correlation of Middle Jurassic intrusive rocks from the Garzón Massif, Upper Magdalena Valley and Central Cordillera, southern Colombia: Boletín de Geología 32:93-109.

Butler, K., y Schamel, S. 1988. Structure along the eastern margin of the central Cordillera, upper Magdalena Valley, Colombia: Journal of South American Earth Sciences 1:109- 120, doi: 10.1016/0895-9811(88)90019-3. 
Caballero, V., Mora, A., Quintero, I., Blanco, V., Parra, M., Rojas, L. E., Lopez, C., Sanchez, N., Horton, B. K., Stockli, D. y Duddy, I. 2013. Tectonic controls on sedimentation in an intermontane hinterland basin adjacent to inversion structures: The Nuevo Mundo syncline, Middle Magdalena Valley, Colombia; pp. 315-342 en Nemčok, M., et al. (eds.), Thick-Skin-Dominated Orogens: From Initial Inversion to Full Accretion: Geological Society of London Special Publication 377, doi: 10.1144/SP377.12.

Cabrera, A. 1927. Datos para el conocimiento de los dasiúridos fósiles argentinos. Revista del Museo de La Plata 30:271-315.

Caceres, N. C. y Carmignotto, A. P. 2006. Caluromys lanatus. Mammalian Species (American Society of Mammalogists) 803:1-6.

Candela, A. M. y Morrone, J. J. 2003. Biogeografia de puercoespines neotropicales (Rodentia: Hystricognathi): Integrando datos fósiles y actuales a través de un enfoque panbiogeográfico. Ameghiniana 40(3):361-378.

Carlini, A. A., Vizcaíno, S. F. y Scillato-Yané, G. J. 1997. Armored xenarthrans: a unique taxonomic and ecologic assemblage; pp. 213- 226 en R. F. Kay, R. H. Madden, R. L. Cifelli y J. Flynn (eds.), Vertebrate Paleontology in the Neotropics: The Miocene Fauna of La Venta, Colombia. Smithsonian Institution Press, Washington, D. C., and London.

Carlini, A. A., Zurita, A. E., Scillato-Yané, G. J., Sánchez, R. y Aguilera O. 2008. A new glyptodont species from Codore Formation (Pliocene), Estado Falcón (Venezuela), and the 'Asterostemma' problem. Palaeontologische Zeitschrift 82:139-152.

Carrillo, J. D, Forasiepi, A., Jaramillo C. y Sánchez-Villagra M. R. 2015. Neotropical mammal diversity and the Great American Biotic Interchange: spatial and temporal variation in South America's fossil record. Frontiers in Genetics 5(451):1-11.

Caso, A., Lopez-Gonzalez, C., Payan, E., Eizirik, E., de Oliveira, T., Leite-Pitman, R., Kelly, M. y Valderrama, C. 2008a. Herpailurus yagouaroundi. The IUCN Red List of Threatened Species, version 2014.2. Disponible en www.iucnredlist.org. Último acceso: November 5, 2014.

Caso, A., Lopez-Gonzalez, C., Payan, E., Eizirik, E., de Oliveira, T., Leite-Pitman, R., Kelly, M. y Valderrama, C. 2008b. Panthera onca. The IUCN Red List of Threatened Species, version 2014.2. Disponible en www.iucnredlist.org. Último acceso: November 5, 2014.

Caso, A., Lopez-Gonzalez, C., Payan, E., Eizirik, E., de Oliveira, T., Leite-Pitman, R., Kelly, M., Valderrama, C. y Lucherini, M. 2008c. Puma concolor. The IUCN Red List of Threatened Species, version 2014.2. Disponible en: www.iucnredlist.org. Último acceso: October 21, 2014.

Chemisquy, M. A., Prevosti, F. J., Martin, G. y Flores, D. A. 2015. Evolution of molar shape in didelphid marsupials (Marsupialia: Didelphidae): analysis of the influence of ecological factors and phylogenetic legacy. Zoological Journal of the Linnean Society 173(1):217235. 
Chorowicz, J., Chotin, P. y Guillande, R. 1996. The Garzón fault: Active southwestern boundary of the Caribbean plate in Colombia: Geologische Rundschau 85:172-179, doi: 10 .1007/ s005310050066.

Cifelli, R. L. 1993. Early Cretaceous mammal from North America and the evolution of marsupial dental characters. Porcedings of the National Academy of Sciences 90:9413-9416.

Cifelli, R. L. y de Muizon, C. 1997. Dentition and jaw of Kokopellia juddi, a primitive marsupial or near-marsupial from the medial Cretaceous of Utah. Journal of Mammalian Evolution 4(4):241-258.

Clark, C. T. y Smith, K. K. 1993. Cranial osteogenesis in Monodelphis domestica (Didelphidae) and Macropus eugenii (Macropodidae). Journal of Morphology 215:119-149.

Clemens, W. A. 1966. Fossil mammals of the type Lance Formation. Part II. Marsupialia. University of California Publications in Geological Sciences 62:1-122.

Clemens, W. A. 1968. A mandible of Didelphodon vorax (Marsupialia, Mammalia). Los Angeles Museum Contributions in Science 133:1-11.

Coues, E. 1872. The osteology and myology of Didelphis virginiana. Memoirs of the Boston Society of Natural History 2:41-154.

Croft, D. A. 2007. The middle Miocene (Laventan) Quebrada Honda fauna, southern Bolivia and a description of its notoungulates. Palaeontology 50:277-303.

Croft, D. A. 2016. Horned armadillos and rafting monkeys: the fascinating fossil mammals of South America. Indiana University Press, EE.UU., 304 pp.

Croft, D. A., Chick, J. M. y Anaya, F. 2011. New middle Miocene caviomorph rodents from Quebrada Honda, Bolivia. Journal of Mammalian Evolution 18(4):245-268.

Croft, D. A., Engelman, R. K., Dolgushina, T. y Wesley, G. 2018. Diversity and disparity of sparassodonts (Metatheria) reveal non-analogue nature of ancient South American mammalian carnivore guilds. Proceedings of the Royal Society B: Biological Sciences 285(1870):20172012.

Croft, D. A., Anaya, F., Auerbach, D., Garzione, C., y MacFadden, B. J. 2009. New data on Miocene neotropical provinciality from Cerdas, Bolivia. Journal of Mammalian Evolution 16(3):175-198.

Croft, D. A., Anaya, F., Catena, A., Ciancio, M. R., y Engelman, R. 2013. New species, local faunas, and paleoenvironmental data for the middle Miocene Quebrada Honda Fauna, Bolivia. In 73rd Annual Meeting SVP, Journal of Vertebrate Paleontology, Program and Abstracts Book (Vol. 109).

Czaplewski N. J., Masanaru T., Naeher, T. M., Shigehara, N. y Setoguchi, T. 2003. Additional bats from the middle Miocene La Venta fauna of Colombia. Rev. Acad. Colomb. Cienc. 27(103):263-282.

Davis, B. M. 2011. Evolution of the tribosphenic molar pattern in early mammals, with comments on the "dual-origin" hypothesis. Journal of Mammalian Evolution 18(4):227-244. 
Defler, T. 2019. The genesis of the modern Amazon River basin and andean uplift and their roles in mammalian diversification; pp. 235-257 en N. H. Landman y P. J. Harries, (eds.), History of Terrestrial Mammals in South America. Topics in Geobiology 42. Springer Nature, Cham, Siza.

Degrange, F. J. 2012. Morfología del cráneo y complejo apendicular posterior de aves fororracoideas: implicancias en la dieta y modo de vida. Tesis doctoral, Universidad Nacional de La Plata, La Plata, Buenos Aires, Argentina, 390 pp.

Degrange, F. J., Noriega, J. I. y Areta, J. I. 2012. Diversity and paleobiology of the Santacrucian birds; pp. 138-155 en S. F. Vizcaíno, R. F. Kay y M. S. Bargo (eds.), Early Miocene Paleobiology in Patagonia: High-Latitude Paleocommunities of the Santa Cruz Formation. Cambridge University Press, New York.

Díaz de Gamero, M. L. 1996. The changing course of the Orinoco River during the Neogene: a review. Palaeogeography, Palaeoclimatology, Palaeoecology 123(1-4):385-402.

Díaz-Nieto, J. F., Jansa, S. A., y Voss, R. S. 2016. Phylogenetic relationships of Chacodelphys (Marsupialia: Didelphidae: Didelphinae) based on "ancient" DNA sequences. Journal of Mammalogy 97(2):394-404.

Dumont, E. R. y Bown, T. M. 1997. New caenolestoid marsupials; pp. 207-212 en R. F. Kay, R. H. Madden, R. L. Cifelli, y J. Flynn (eds.), Vertebrate paleontology in the neotropics: The Miocene fauna of La Venta, Colombia. Smithsonian Institution Press, Washington, D.C., EE.UU. y Lodres, Inglaterra.

Engelman, R. K. y Croft, D. A. 2014. A new species of small-bodied sparassodont (Mammalia, Metatheria) from the middle Miocene locality of Quebrada Honda, Bolivia. Journal of Vertebrate Paleontology 34:672-688.

Engelman, R. K., Anaya, F. y Croft, D.A. 2015. New specimens of Acyon myctoderos (Metatheria, Sparassodonta) from Quebrada Honda, Bolivia. Ameghiniana 52:204-225. doi:10.5710/ AMGH. 19.11.2014.2803

Engelman, R. K., Anaya, F. y Croft, D. A. 2017. New palaeothentid marsupials (Paucituberculata) from the middle Miocene of Quebrada Honda, Bolivia, and their implications for the palaeoecology, decline and extinction of the Palaeothentoidea, Journal of Systematic Palaeontology 15(10):787-820, doi: 10.1080/14772019.2016.1240112.

Engelman, R. K., Anaya, F. y Croft, D. A. 2018. Australogale leptognathus, gen. et sp. nov., a Second Species of Small Sparassodont (Mammalia: Metatheria) from the Middle Miocene Locality of Quebrada Honda, Bolivia. Journal of Mammalian Evolution, 1-18, doi: https:// doi.org/10.1007/s10914-018-9443-z

Egbue, O. y Kellogg, J. 2010. Pleistocene to Present North Andean "escape": Tectonophysics 489:248-257, doi: 10.1016/j.tecto.2010.04.021.

Egbue, O., Kellogg, J., Aguirre, H. y Torres, C. 2014. Evolution of the stress and strain fields in the Eastern Cordillera, Colombia: Journal of Structural Geology 58:8-21, doi: 10.1016 /j.jsg. 
2013.10.004.

Ercoli, M. D., Prevosti, F. J. y Forasiepi, A. M. 2014. The structure of the mammalian predator guild in the Santa Cruz Formation (late early Miocene). Journal of Mammalian Evolution 21:369-381.

Evans, H. E. 1993. Miller's anatomy of the dog. W. B. Saunders, Filadelfia, EE.UU., 1130pp.

Evans, H. E. y de Lahunta, A. 1972. Disección del Perro de Miller (1st edition in Spanish). Editorial Interamericana, México, 283 pp.

Fernicola, J. C. y Albino, A. 2012. Amphibians and squamate reptiles from the Santa Cruz Formation (late early Miocene), Santa Cruz Province, Argentina: paleoenvironmental and paleobiological considerations; pp. 129-137 en S. F. Vizcaíno, R. F. Kay y M. S. Bargo (eds.), Early Miocene Paleobiology in Patagonia: High-Latitude Paleocommunities of the Santa Cruz Formation. Cambridge University Press, New York.

Fields, R. W. 1957. Hystricomorph rodents from the late Miocene of Colombia, South America. University of California Publications in Geological Sciences32(5):273-404.

Fields, R. W. 1959. Geology of the La Venta badlands, Colombia, South America. University of California Publications in Geological Sciences 32:405-44.

Flores, D. A. 2009. Phylogenetic analyses of postcranial skeletal morphology in didelphid marsupials. Bulletin of the American Museum of Natural History 320:1-81.

Flores, D. A. y Díaz, M. M. 2009. Postcranial skeleton of Glironia venusta (Didelphimorphia, Didelphidae, Caluromyinae): description and functional morphology. Zoosystematics and Evolution 85(2):311-339.

Flores, D. A., Abdala, F. y Giannini, N. 2010. Cranial ontogeny of Caluromys philander (Didelphidae: Caluromyinae): a qualitative and quantitative approach. Journal of Mammalogy 91(3):539-550.

Flynn, J. J. y Swisher, C. C. III 1995. Cenozoic South American Land Mammal Ages: Correlation to global geochronologies; pp. 317-333 en W. A. Berggren, D. V. Kent, M. P. Aubry y J. Hardenbol (eds.), Geochronology, time scales, and global stratigraphic correlation. SEPM (Society for Sedimentary Geology) Special Publication 54, 386 pp.

Flynn, J. J., Guerrero, J. y Swisher, C. C. I., 1997, Geochronology of the Honda Group; pp. 44-60 en R. F. Kay, R. H. Madden, R. L. Cifelli, y J. Flynn (eds.), Vertebrate Paleontology in the Neotropics: The Miocene Fauna of La Venta, Colombia. Smithsonian Institution Press, Washington, D.C., EE.UU. y Lodres, Inglaterra.

Forasiepi, A. M. 2006. Anatomy of Arctodictis sinclairi (Mammalia, Metatheria) and the phylogenetic relationships of Sparassodonta, large carnivores of the cenozoic of South America. Tesis doctoral, Universidad de Louisville, Kentuchy, Estados Unidos, 394 pp.

Forasiepi, A. M. 2009. Osteology of Arctodictis sinclairi (Mammalia, Metatheria, Sparassodonta) and phylogeny of Cenozoic metatherian carnivores from South America. Monografías del Museo Argentino de Ciencias Naturales, new series 6:1-174. 
Forasiepi, A. M. y Carlini, A. A. 2010. A new thylacosmilid (Mammalia, Metatheria, Sparassodonta) from the Miocene of Patagonia, Argentina. Zootaxa 2552:55-68.

Forasiepi, A. M., Babot, M. J. y Zimicz, N. 2015. Australohyaena antiqua (Mammalia, Metatheria, Sparassodonta), a large predator from the late Oligocene of Patagonia. Journal of Systematic Palaeontology 13:503-525.

Forasiepi, A. M., Goin, F. J. y di Martino, V. 2003. Una nueva especie de Lycopsis (Metatheria, Prothylacyninae) de la Formación Arroyo Chasicó (Mioceno tardío) de la provincia de Buenos Aires. Ameghiniana 40:249-253.

Forasiepi, A. M., Goin, F. y Martinelli, A. G. 2009. Contribution to the knowledge of the Sparassocynidae (Mammalia, Metatheria, Didelphoidea), with comments on the age of the Aisol Formation (Neogene), Mendoza Province, Argentina. Journal of Vertebrate Paleontology 29(4):1252-1263.

Forasiepi, A., Goin, F. J. y Tauber, A. 2004. Las especies de Arctodictis Mercerat, 1891 (Metatheria, Borhyaenidae), grandes carnívoros del Mioceno de América del Sur. Revista Española de Paleontología 19(1):1-22.

Forasiepi, A. M., Sánchez-Villagra, M. R., Goin, F. J., Takai, M., Shigehara, N. y Kay, R. F. 2006. A new species of Hathliacynidae (Metatheria, Sparassodonta) from the middle Miocene of Quebrada Honda, Bolivia. Journal of Vertebrate Paleontology 26:670-684.

Fox, R. C. 1979a. Mammals from the Upper Cretaceous Oldmae Formation, Alberta. I. Alphadon Simpson (Marsupialia). Canadian Journal of Earth Sciences 16(1):91-102.

Fox, R. C., 1979b. Mammals from the Upper Cretaceous Oldman Formation, Alberta. II. Pediomys Marsh (Marsupialia). Canadian Journal of Earth Sciences 16(1):103-113.

Fox, R. C., 1983. Notes on the North American Tertiary marsupials Herpetotherium and Peradectes. Canadian Journal of Earth Sciences 20(10):1565-1578.

Fox, R. C. y Naylor B. G. 1986. A new species of Didelphodon Marsh (Marsupialia) from the Upper Cretaceous of Alberta, Canada - Palaeobiology and phylogeny. Neues Jahrbuch für Geologie und Paläontologie, Abhandlungen 172:357-360.

Fox, R. C. y Naylor, B. G. 1995. The relationships of the Stagodontidae, primitive North American Late Cretaceous mammals; pp. 247-250 en A. Sun y Y. Wang (eds.), VI Symposium on Mesozoic Terrestrial Ecosystems and Biota, Short Papers.Giannini, N. P., Abdala, F. y Flores, D. A. 2004. Comparative postnatal ontogeny of the skull in Dromiciops gliroides (Marsupialia: Microbiotheriidae). American Museum Novitates 3460:1-17.

Giarla, T. C., Voss, R. S. y Jansa, S. A. 2010. Species limits and phylogenetic relationships in the didelphid marsupial genus Thylamys based on mitochondrial DNA sequences and morphology. Bulletin of the American Museum of Natural History 346:1-67.

Gray, J. E. 1821. On the natural arrangement of vertebrose animals. London Medical Repository 15(1):296-310.

Goin, F. J. 1993. Living South American opposums are not living fossils; pp. 335 en M. Augee 
(ed.), VI Theriological Conference (Sydney), Abstracts.

Goin, F. J. 1997. New clues for understanding Neogene marsupial radiations; pp. 185-204 en R. F. Kay, R. H. Madden, R. L. Cifelli, y J. Flynn (eds.), Vertebrate Paleontology in the Neotropics: The Miocene Fauna of La Venta, Colombia. Smithsonian Institution Press, Washington, D.C., EE.UU. y Lodres, Inglaterra.

Goin, F. J. 2006. A review of the Caroloameghiniidae, Paleogene South American "primate-like" marsupials (?Didelphimorphia, Peradectoidea); pp. 57-67 en D. Kalthoff, T. Martin y T. Möors (eds.), Festband für Herrn Professor Wighart v. Koenigswald anlässlich seines 65. Geburtstages. Palaeontographica Abteilung A 278. E. Schweizerbart'sche Verlagsbuchhandlung, Stuttgart.

Goin, F. J. y Abello, M. A. 2013. Los Metatheria sudamericanos de comienzos del Neógeno (Mioceno temprano, edad mamífero Colhuehuapense): Microbiotheria y Polydolopimorphia. Ameghiniana 50(1):51-78.

Goin, F. J. y Candela, A. M. 2004. New Paleogene marsupials from the Amazon Basin of eastern Peru. The Paleogene Mammalian Fauna of Santa Rosa, Amazonian Peru. Natural History Museum of Los Angeles County, Science Series 40:15-60.

Goin, F. J. y Carlini, A. A. 1993. The most primitive South American sabretooth marsupials: their significance in the reassessment of sparassodont phylogeny. Abstract in Sixth International Theriological Congress (Sydney), p. 113.

Goin, F. J. y C. Montalvo. 1988. Revisión sistemática y reconocimiento de una nueva especie del género Thylatheridium Reig (Marsupialia, Didelphidae). Ameghiniana 25:161-167.

Goin, F. J. y Pascual, R. 1987. News on the biology and taxonomy of the marsupials Thylacosmilidae (late Tertiary of Argentina). Anales de la Academia Nacional de Ciencias Exactas, Físicas y Naturales (Argentina) 39:219-246.

Goin, F. J., Montalvo, C. y Visconti, G. 2000. Los marsupiales (Mammalia) del Mioceno superior de la Formación Cerro Azul (provincia de La Pampa, Argentina). Estudios Geológicos 56:101-126.

Goin, F. J., Palma, R. M., Pascual, R. y Powell, J. E. 1986. Persistencia de un primitivo Borhyaenidae (Mammalia, Marsupialia) en el Eoceno temprano de Salta (Fm. Lumbrera, Argentina). Aspectos geológicos y paleoambientales relacionados. Ameghiniana, 23(1-2): $47-56$.

Goin, F. J., Tejedor, M. F., Abello, M. A. y Martin, G. M. 2010. Un nuevo microbiotérido (Mammalia, Marsupialia, Microbiotheria) de la Formación Pinturas (Mioceno temprano) de la provincia de Santa Cruz. Ameghiniana 47(1):117-122.

Goin, F. J., Gelfo, J. N., Chornogubsky, L., Woodburne, M. O. y Martin, T. 2012. Origins, radiations, and distribution of South American mammals: from greenhouse to icehouse worlds; pp. 20-50 en B. D. Patterson y L. P. Costa (eds.), Bones, Clones, and Biomes: An 80-Million Year History of Recent Neotropical Mammals. University of Chicago Press, 
Chicago, Illinois.

Goin, F. J., Woodburne, M. O., Zimicz, A. N., Martin, G. M. y Chornogubsky, L. 2016. A brief history of South American metatherians: Evolutionary contexts and intercontinental dispersals. Springer, $237 \mathrm{p}$.

Goin, F. J., Abello, A., Bellosi, E., Kay, R., Madden, R. y Carlini, A. A. 2007a. Los Metatheria sudamericanos de comienzos del Neógeno (Mioceno Temprano, edad-mamífero Colhuehuapense). Parte I: Introducción, Didelphimorphia y Sparassodonta. Ameghiniana 44:29-71.

Goin, F. J., Zimicz, N.,Reguero, M. A., Santillana, S. N., Marenssi S. A. y Moly, J. J. 2007b. New marsupial (Mammalia) from the Eocene of Antarctica, and the origins and affinities of the Microbiotheria. Revista de la Asociación Geológica Argentina 62(4):597-603.

Goloboff, P. A., Farris, J. S. y Nixon, K. C. 2008. TNT, a free program for phylogenetic analysis. Cladistics 24:774-786.

Gordon, C. L. 2003. A first look at estimating body size in dentally conservative marsupials. Journal of Mammalian Evolution 10:1-21.

Gregory, W. K. y Simpson G. G. 1926. Cretaceous mammal skulls from Mongolia. American Museum Novitates 225:1-20.

Guerrero, J. 1990. Stratigraphy and sedimentary environments of the mammal-bearing middle Miocene Honda Group of Colombia. Tesis de Maestría, Universidad de Duke, Durham, N. C., EE.UU., 178 p.

Guerrero, J., 1993, Magnetostratigraphy of the upper part of the Honda Group and Neiva Formation, Miocene uplift of the Colombian Andes. Tesis doctoral, Universidad de Duke, Durham, N. C. EE.UU., 210 p.

Guerrero, J. 1997. Sedimentary environments, and the Miocene uplift of the Colombian Andes; pp. 14-43 en R. F. Kay, R. H. Madden, R. L. Cifelli, y J. Flynn (eds.), Vertebrate Paleontology in the Neotropics: The Miocene Fauna of La Venta, Colombia. Smithsonian Institution Press, Washington, D.C., EE.UU. y Lodres, Inglaterra.

Hamilton, W. J., Jr. 1958. Life history and economic relations of the opossum (Didelphis marsupialis virginiana) in New York State. Cornell University Agricultural Experiment Station Memoir 354: 1-48.

Head, J. J., Bloch, J. I., Hastings, A. K., Bourque, J. R., Cadena, E. A., Herrera, F. A., Polly, D. y Jaramillo, C. A. 2009. Giant boid snake from the Palaeocene neotropics reveals hotter past equatorial temperatures. Nature 457(7230):715.

Hershkovitz, P. 1982. The staggered marsupial lower third incisor (I3). Geobios 15:191-200.

Hershkovitz, P. 1992. The South American gracile mouse opossums, genus Gracilinanus Gardner and Creighton, 1989 (Marmosidae, Marsupialia): a taxonomic review with notes on general morphology and relationships. Fieldiana Zoology (New Series) 39(i-vi):1-56.

Hershkovitz, P. 1997. Composition of the family Didelphidae Gray, 1821 (Didelphoidea: 
Marsupialia), with a review of the morphology and behavior of the included four-eyed pouched opossums of the genus Philander Tiedemann, 1808. Fieldiana - Zoology, new series $86: 1-103$.

Hershkovitz, P. 1999. Dromiciops gliroides Thomas, 1894, Last of the Microbiotheria (Marsupialia), with a review of the family Microbiotheriidae. Fieldiana, Zoology, New Series 93:1-60.

Hettner, A. 1892. Die Kordillere von Bogotá. Petermanns Geographische Mittelungen, Ergänzungsheft, Heft. 104 (Bd. 22).

Hiatt, J. L. y Gartner, L. P. 2001. Textbook of head and neck anatomy (3rd edition). Lippincott Williams \& Wilkins, Filadelfia, EE.UU., 352 pp.

Hinojosa, L. F. 2005. Cambios climáticos y vegetacionales inferidos a partir de paleofloras cenozoicas del sur de Sudamérica. Revista Geológica de Chile 32:95-115.

Hoffstetter, R. y Petter, G. 1983. Paraborhyaena boliviana et Andinogale sallensis, deuxmarsupiaux (Borhyaenidae) nouveaux du Déséadien (Oligocène infèrieur de Salla (Bolivie). Comptes Rendus de l'Academie des Sciences 296:205-208.

Hoorn, C. 1994. Fluvial palaeoenvironments in the intracratonic Amazonas Basin (early Mioceneearly middle Miocene, Colombia): Palaeogeography, Palaeoclimatology, Palaeoecology 109:1-54, doi: 10.1016/0031-0182(94)90117-1.

Hoorn, C., Guerrero, J., Sarmiento, G. A y Lorente, M. A. 1995. Andean tectonics as a cause for changing drainage patterns in Miocene northern South America: Geology 23:237-240, doi: $10.1130 / 0091-7613(1995) 023<0237$.

Hoorn, C., Wesselingh, F. P., Ter Steege, H., Bermudez, M. A., Mora, A., Sevink, J. et al. 2010. Amazonia through time: Andean uplift, climate change, landscape evolution, and biodiversity. Science 330(6006):927-931.

Horovitz, I. y Sánchez-Villagra, M. R. 2003. A morphological analysis of marsupial mammal higher-level phylogenetic relationships. Cladistics 19:181-212.

Horovitz, I., Ladevèze, S., Argot, C., Macrini T. E., Hooker, J. J., Kurz, C. y de Muizon, C. 2008. The anatomy of Herpetotherium cf. fugax Cope, 1873, a metatherian from the Oligocene of North America. Palaeontographica Abteilung A, 284:109-141.

Horovitz, I., Martin, T., Bloch, J., Ladevèze, S., Kurz, C. y Sánchez-Villagra, M. R. 2009. Cranial anatomy of the earliest marsupials and the origin of opossums. PLoS ONE(12):e8278.

Horton, B. K., Anderson, V. J., Saylor, J. E., Parra, M. y Mora, A. R. 2015. Application of detrital zircon $\mathrm{U}-\mathrm{Pb}$ geochronology to surface and subsurface correlations of provenance, paleodrainage, and tectonics of the Middle Magdalena Valley Basin of Colombia: Geosphere 11:1790-1811, doi: 10.1130/GES01251.1.

Huxley, J. S. 1880. On the application of the law of evolution to the arrangement of the Vertebrata, and more particularly to the Mammalia. Proceedings of the Zoological Society of London 43:649-662. 
Jablonski, D., Roy, K. y Valentine, J. W. 2006. Out of the tropics: evolutionary dynamics of the latitudinal diversity gradient. Science 314:102-106.

Jouffroy, F. K., Lessertisseur, J., Saban, R. y Souteyrand-Boulonger, J. D. 1971. Traité de Zoologie. Anatomie, Systématique, Biologie. Tome XVI: Mammifères. Musculature des Members, Musculature Peaucière, Musculature des Monotrèmes. Arthrologie. (Fascicule III). Masson et Cie. Éditeurs, Paris, 1209 pp.

Kay, R. F. y Madden, R. H. 1997. Paleogeography and Paleoecology; pp. 520-550 en R. F. Kay, R. H. Madden, R. L. Cifelli y J. Flynn (eds.), Vertebrate Paleontology in the Neotropics: The Miocene Fauna of La Venta, Colombia. Smithsonian Institution Press, Washington, D.C., EE.UU. y Londres, Inglaterra.

Kirsch, J. A. 1977. The comparative serology of Marsupialia, and a classification of marsupials. Australian Journal of Zoology, supplementary series 25(52):1-152.

Kraglievich, L. 1930. La formación friaseana del Río Frías, Río Fénix, Laguna Blanca, etc. y su fauna de mamíferos. Physis 10:127-161.

Krishtalka, L. y Stucky, R. K. 1983. Paleocene and Eocene marsupials of North America. Annals of Carnegie Museum 52:229-263.

Ladeveze, S., de Muizon, C., Beck, R. M., Germain, D. y Cespedes-Paz, R. 2011. Earliest evidence of mammalian social behavior in the basal Tertiary of Bolivia. Nature 474(7349):83-86.

Lessertisseur, J. y Saban, R. 1967. Mammifères, tegument et squelette; pp. 709-1078 en P. Grasse (ed.), Traité de zoologie. Anatomie, Systématique, Biologie 16(1). Masson et Cie. Éditeurs, Paris, Francia.

Lillegraven, J. A. 1969. Latest Cretaceous mammals of upper part of Edmonton Formation of Alberta, Canada, and review of marsupial-placental dichotomy in mammalian evolution. University of Kansas Paleontological Contributions 50:1-122.

Linnaeus, C. 1758. Systema Naturae per Regna tria Naturae, secundum Classes, Ordines, Genera, Species, cum Characteribus, Differentis, Synonymis, Locis, 10th edition. Laurentii Salvi, Stockholm, 824 p.

Lobo, L. M., Santos, A. C., Rosa, R. A., Carvalho, A. F., Costa, G. M. y Mançanares, C. A. F. 2016. Morphological and ultrastructural analysis of the teeth of guaiquica (Gracilinanus microtarsus, Wagner, 1842). Journal of Morphological Science 33(2):73-78.

Luo, Z. X., Ji, Q., Wible, J. R. y Yuan, C. X. 2003. An Early Cretaceous tribosphenic mammal and metatherian evolution. Science 302:1934-1940.

MacFadden, B. J. 2006. Extinct mammalian biodiversity of the ancient New World tropics. Trends in Ecology and Evolution 21:157-165.

MacFadden, B. J. y Wolff, R. G. 1981. Geological investigations of Late Cenozoic vertebratebearing deposits in southern Bolivia. Anais II Congreso Latinoamericano de Paleontología, Porto Alegre 2:765-778.

MacKenna, M. C. y Bell, S. K. 1997. Classification of mammals above the species level. New 
York, Columbia University Press, $640 \mathrm{p}$

Macrini, T. 2005. Dasyurus hallucatus. Digital Morphology. Imágenes disponibles en http:// digimorph.org/specimens/Dasyurus_hallucatus. Último acceso: Junio 15, 2017.

Macrini, T. 2009. Sminthopsis crassicaudata. Digital Morphology. Imágenes disponibles en http:// digimorph.org/specimens/Sminthopsis_crassicaudata. Último acceso: Junio 15, 2017.

Madden, R. H., Guerrero, J., Kay, R. F., Flynn, J. J. y Swisher, C. C. The Laventan Stage and Age; pp. 409-519 en R. F. Kay, R. H. Madden, R. L. Cifelli, y J. Flynn (eds.), Vertebrate paleontology in the neotropics: the Miocene fauna of La Venta, Colombia. Smithsonian Institution Press, Washington, D.C., EE.UU. y Lodres, Inglaterra.

Maddison, W. P. 1993. Missing data versus missing characters in phylogenetic analysis. Systematic Biology 42(4):576-581.

Maddison, W. P. y Maddison, D. R. 2017. Mesquite: a modular system for evolutionary analysis. Version 3.31, available online: http://mesquiteproject.org.

Mann, G. 1955. Monito del monte Dromiciops australis Philippi. Investigaciones Zoológicas Chilenas 2:159-166.

Mannion, P. D., Upchurch, P., Benson, R. B. y Goswami A. 2014. The latitudinal biodiversity gradient through deep time. Trends in Ecology and Evolution 29:42-50.

Marshall, L. G. 1976a. New didelphine marsupials from the La Venta fauna (Miocene) of Colombia, South America. Journal of Paleontology 50(3):402-418.

Marshall, L. G. 1976b. Evolution of the Thylacosmilidae, extinct saber-tooth marsupials of South America. PaleoBios (Museum of Paleontology, University of California) 23:1-30.

Marshall, L. G. 1977a. A new species of Lycopsis (Borhyaenidae, Marsupialia) from the La Venta fauna (late Miocene) of Colombia, South America. Journal of Paleontology 51:633-642.

Marshall, L. 1977b. Lestodelphys halli. Mammalian Species 81:1-3, doi: 10.2307/3503903.

Marshall, L. G. 1978a. Evolution of the Borhyaenidae, extinct South American predaceous marsupials. University of California Publications in Geological Sciences 117:1-89.

Marshall, L. G. 1978b. Dromiciops australis. Mammalian Species 99:1-5.

Marshall, L. G. 1979. Review of the Prothylacyninae, an extinct subfamily of South American 'dog-like' marsupials. Fieldiana, new series 3:1-50.

Marshall, L. G. 1981. Review of the Hathliacyninae, an extinct subfamily of South American "doglike" marsupials. Fieldiana, Geology, New Series 7:1-120.

Marshall, L. G. 1982. Systematics of the South American marsupial family Microbiotheriidae. Fieldiana, Geology, new series 10:1-75.

Marshall, L. G. 1990. Fossil Marsupialia from the type Friasian Land Mammal Age (Miocene), Alto Rio Cisnes, Aisen, Chile. Revista Geológica de Chile 17(1):19-55.

Marshall, L. G. y de Muizon, C. 1995. Part II: the skull; pp. 21-90 en C. de Muizon (ed.), Pucadelphys andinus (Marsupialia, Mammalia) from the early Paleocene of Bolivia. Mémoires du Muséum National d'Histoire Naturelle ,165p. 
Marshall, L. G, y Cifelli, R. L. 1990. Analysis of changing diversity patters in Cenozoic land mammal age faunas, South America. Palaeovertebrata 19:169-210.

Marshall, L. G., Case, J. A. y Woodburne, M. O. 1990. Phylogenetic relationships of the families of marsupials. Current mammalogy 2:433-505.

Martin, G. M. 2005. Intraspecific variation in Lestodelphys halli (marsupialia: didelphimorphia). Journal of Mammalogy 86(4):793-802.

Martin, G. M. 2008. Sistemática, distribución y adaptaciones de los marsupiales patagónicos. Tesis doctoral, Universidad Nacional de La Plata.

Martin, G. M. 2009. Sobre la identidad de Thylamys (Marsupialia, Didelphidae) del oeste pampeano y centrosur del Espinal, Argentina. Mastozoología neotropical 16(2):333-346.

Martin, G. 2010. Geographic distribution and historical occurrence of Dromiciops gliroides Thomas (Metatheria: Microbiotheria). Journal of Mammalogy 91(4): 1025-1035.

Martin, G. M. 2013. Intraspecific variability in Lestoros inca (Paucituberculata, Caenolestidae), with reports on dental anomalies and eruption pattern. Journal of Mammalogy 94(3):601617.

Martin, G. M. 2017. Variability and variation in Dromiciops Thomas, 1894 (Marsupialia, Microbiotheria, Microbiotheriidae). Journal of Mammalogy 99(1):159-173.

Martin, G. M. 2017. Rhyncholestes raphanurus (versión modificada de la evaluación de 2015). The IUCN red list of threatened species: e.T19710A116333652. http://dx.doi.org/10.2305/ IUCN.UK.2017-2.RLTS.T19710A116333652.en.

Martin, G. M., Flores, D. y Teta, P. 2015. Dromiciops gliroides. The IUCN red list of threatened species, e.T6834A22180239, doi: http://dx.doi.org/10.2305/IUCN.UK. 2015-4.RLTS.T6834A22180239.en.

Martinelli, A. G., Ferraz, M. L. F. y Teixeira, V. P. A. 2011. Range extension and first record of Cryptonanus chacoensis (Mammalia, Didelphimorphia, Didelphidae) in west Minas Gerais State, Brazil. Historia Natural 1(2):113-118.

Matthew, W. D. 1916. A marsupial from the Belly River Cretaceous: with critical observations upon the affinities of the Cretaceous mammals. Bulletin of the AMNH 35:477-500, plates I-VI.

McGrath, A. J., Anaya, F. y Croft, D. A. 2018. Two new macraucheniids (Mammalia: Litopterna) from the late middle Miocene (Laventan South American Land Mammal Age) of Quebrada Honda, Bolivia. Journal of Vertebrate Paleontology 38(3):e1461632.

Mirioni, H. 1965. Etude anatomique de quelques bois tertiaires de Colombie. Boletin de Geologia 20.

Mittelbach, G. G., Schemske, D. W., Cornell, H. V., Allen, A. P., Brown, J. M., Bush, M. B., Harrison, S. P., Hurlbert, A. H., Knowlton, N., Lessios, H. A., McCain, C. M., McCune, A. R., McDade, L. A., McPeek, M. A., Near, T. J., Price, T. D.,. Ricklefs, R. E, Roy, K., Sax, D. F., Schluter, D., Sobel, J. M. y Turelli, M. 2007. Evolution and the latitudinal diversity 
gradient: speciation, extinction and biogeography. Ecology Letters 10:315-331.

McKenna, D. D. y Farrell B. D. 2006. Tropical forests are both evolutionary cradles and museums of leaf beetle diversity. Proceedings of the National Academy of Sciences of the United States of America 103:10947-10951.

Mojica, J., y Franco, R. 1990. Estructura y Evolucion Tectonlca del Valle Medio y Superior del Magdalena, Colombia: Geologia Colombiana 17:41-64.

Montellano, M. 1988. Alphadon halleyi (Didelphidae, Marsupialia) from the Two Medicine Formation (Late Cretaceous, Judithian) of Montana. Journal of Vertebrate Paleontology 8(4):378-382.

Mora, A., Parra, M., Strecker, M. R., Sobel, E. R., Hooghiemstra, H., Torres, V., y VallejoJaramillo, J. 2008. Climatic forcing of asymmetric orogenic evolution in the Eastern Cordillera of Colombia: GSA Bulletin 120:930-949.

Mora, A., Baby, P., Roddaz, M., Parra, M., Brusset, S., Hermoza, W. y Espurt, N. 2010. Tectonic history of the Andes and sub-Andean zones: Implications for the development of the Amazon drainage basin; pp. 38-60 en C. Hoorn y F.P. Wesselingh (eds.), Amazonia: Landscape and Species Evolution: A Look into the Past: Oxford, UK, Wiley-Blackwell, doi:10.1002/9781444306408.ch4.

Morgan, G. S. y Czaplewski, N. J. 2012. Evolutionary history of the Neotropical Chiroptera: the fossil record. pp. 105-161 en G. F. Gunnell y N.B. Simmons (eds.), Evolutionary history of bats: fossils, molecules and morphology. Cambridge University Press.

Morrone, J. J. 2002. Biogeographical regions under track and cladistic scrutiny. Journal of Biogeography 29:149-152.

Morrone, J. J. 2006. Biogeographic areas and transition zones of Latin America and the Caribbean islands based on panbiogeographic and cladistic analyses of the entomofauna. Annual Review of Enthomology 51:467-94.

Muizon, C. de 1994. A new carnivorous marsupial from the Palaeocene of Bolivia and the problem of marsupial monophyly. Nature 370(6486):208-211.

Muizon, C. de 1998. Mayulestes ferox, a borhyaenoid (Metatheria, Mammalia) from the early Palaeocene of Bolivia. Phylogenetic and palaeobiologic implications. Geodiversitas 20(1): 19-142.

Muizon, C. de 1999. Marsupial skulls from the Deseadan (late Oligocene) of Bolivia and phylogenetic analysis of the Borhyaenoidea (Marsupialia, Mammalia). [Crânes de Marsupiaux du Déséadien (Oligocène supérieur) de Bolivie et analyse phylogénétique des Borhyaenoidea (Marsupialia, Mammalia)]. GeoBios 32(3):483-509.

Muizon, C. de, Cifelli, R. L. y Céspedes Paz, R. 1997. The origin of the dog-like borhyaenoid marsupials of South America. Nature 389(6650):486-489.

Muñoz-Saba, Y. D. S. (2018). Paleoambientes y vertebrados asociados con los primates del Mioceno medio de la Venta, Colombia. Tesis doctoral, Universidad Nacional de La Plata, 
La Plata, Buenos Aires, Argentina, 195 pp.

Museums Victoria Collections. Dasyurus hallucatus. Imágenes disponibles en https:// collections.museumvictoria.com.au/specimens/1838884. Último acceso: June 15, 2017.

Myers, P., Espinosa, R., Parr, C. S., Jones, T., Hammond, G. S. y Dewey, T. A. 2018a. Chironectes minimus. The Animal Diversity Web, University of Michigan Museum of Zoology. Fotografías disponibles en: https://animaldiversity.org/accounts/Chironectes_minimus/ specimens/. Último acceso: Junio 1, 2018.

Myers, P., Espinosa, R., Parr, C. S., Jones, T., Hammond, G. S. y Dewey, T. A. 2018b. Didelphis albiventris. The Animal Diversity Web, University of Michigan Museum of Zoology. Fotografías disponibles en: https://animaldiversity.org/accounts/Didelphis_albiventris/ specimens/. Último acceso: Junio 1, 2018.

Myers, P., Espinosa, R., Parr, C. S., Jones, T., Hammond, G. S. y Dewey, T. A. 2018c. Philander opossum. The Animal Diversity Web, University of Michigan Museum of Zoology. Fotografías disponibles en: https://animaldiversity.org/accounts/Philander_opossum/ specimens/. Último acceso: Junio 1, 2018.

Myers, P., Espinosa, R., Parr, C. S., Jones, T., Hammond, G. S. y Dewey, T. A. 2018d. Metachirus nudicaudatus. The Animal Diversity Web, University of Michigan Museum of Zoology. Fotografías disponibles en: https://animaldiversity.org/accounts/Metachirus_nudicaudatus/ specimens/. Último acceso: Abril 1, 2018.

Myers, T. J. 2001. Prediction of marsupial body mass. Australian Journal of Zoology 49:99-118.

Natural History Museum, 2014. Dataset: Collection specimens. Resource: Specimens. Imágenes disponibles en http://dx.doi.org/10.5519/0002965. Último acceso: Junio 15, 2018.

Nixon, K. C. y Davis, J. I. 1991. Polymorphic taxa, missing values and cladistic analysis. Cladistics 7(3):233-241.

Noé, U. y D'Elía, G. 2015. Additions to the Paraguayan mammal fauna: the first records of two marsupials (Didelphimorphia, Didelphidae) with comments on the alpha taxonomy of Cryptonanus and Philander. Mammalia 79(3):343-356.

Norell, M. A. 1996. Ghost taxa, ancestors, and assumptions: a comment on Wagner. Paleobiology 22(3):453-455.

Ochoa, D., Hoorn, C., Jaramillo, C., Bayona, G., Parra, M. y De la Parra, F. 2012. The final phase of tropical lowland conditions in the axial zone of the Eastern Cordillera of Colombia: Evidence from three palynological records: Journal of South American Earth Sciences 39:157-169, doi: 10.1016/j.jsames.2012.04.010.

Osgood, W. H. 1921. A monographic study of the American marsupial Caenolestes. Field Museum of Natural History, zoological series 14(1):1-162.

Parker, W. K. 1886. On the structure and development of the skull in the Mammalia. Philosophical Transactions of the Royal Society of London 176:1-275.

Parra, L. N. 2015. Revisiting stratigraphy, geochronology and paleogeography at La Venta 
Formation, Tatacoa Desert, Colombia. GSA Annual Meeting, Baltimore, Maryland, EE.UU. Paper 317:21.

Parra Sánchez, L. N. y Restrepo-Moreno, S. A. 2015. El Mioceno del Desierto de La Tatacoa. IV Congreso Colombiano de Zoología, Libro de resúmenes.

Patterson, B. y Marshall, L. G. 1978. The Deseadan, early Oligocene, Marsupialia of South America. Fieldiana, Geology 41(2):37-100.

Patterson, B. y Pascual, R. 1968. The fossil mammal fauna of South America. Quarterly Review of Biology, 43, 409-451.

Petter, G. y Hoffstetter, R. 1983. Les marsupiaux du Déséadien (Oligocène inférieur) de Salla (Bolivie). Annales de Paléontologie (Vert.-Invert.) 69:175-234.

Platnick, N. I., Griswold, C. E. y Coddington, J. A. 1991. On missing entries in cladistic analysis. Cladistics 7(4):337-343.

Pons, D. 1969. A propos d'une Goupiaceae du Tertiaire de Colombia: Goupioxylon stutzeri Schonfeld. Palaeontographica 128:65-80.

Pons, D. 1983. Contribution a l'étude paléobotanique du Mésozoïque et du Cénozoïque de Colombie. Tesis doctoral, Université Pierre et Marie Curie, Paris, 655 p.

De Porta, J. 1966. Geología del extremo sur del Valle Medio del Magdalena entre Honda y Guataqui (Colombia). Boletín de Geología, Universidad Industrial de Santander (Bucaramanga) 22-23:1-318.

De Porta, J. 1974. Colombie. Pt. 2. Territaire et Quaternaire; en R. Hoffstetter (ed.) Amerique Latine, Lexique Stratigraphique International 6(4b). Paris, Centre National de la Recherche Scientifique.

Prevosti, F. J. y Chemisquy, M. A. 2010. The impact of missing data on real morphological phylogenies: influence of the number and distribution of missing entries. Cladistics 26(3): 326-339.

Prevosti, F. J., Forasiepi, A. y Zimicz, N. 2013. The evolution of the Cenozoic terrestrial mammalian predator guild in South America: competition or replacement? Journal of Mammalian Evolution 20:3-21.

Prevosti, F. J., Forasiepi, A. M., Ercoli, M. D. y Turazzini, G. F. 2012. Paleoecology of the mammalian carnivores (Metatheria, Sparassodonta) of the Santa Cruz Formation (late early Miocene); pp. 173-193 en S. F. Vizcaíno, R. F. Kay y M. S. Bargo (eds.), Early Miocene Paleobiology in Patagonia: High-Latitude Paleocommunities of the Santa Cruz Formation. Cambridge University Press, Nueva York, EE.UU.

Prevosti, F. J. y Forasiepi, A. M. 2018. Evolution of South American Mammalian Predators During the Cenozoic: Paleobiogeographic and Paleoenvironmental Contingencies. Springer, 196p.

Pujos. F., De Iuliis, G., y Quispe, B. M. 2011. Hiskatherium saintandrei, gen. et sp. nov.: an unusual sloth from the Santacrucian of Quebrada Honda (Bolivia) and an overview of middle Miocene, small megatherioids. Journal of Vertebrate Paleontology 31(5):1131- 
1149.

Pujos, F., De Iuliis, G., Quispe, B. M. y Flores, R. A. (2014). Lakukullus anatisrostratus, gen. et sp. nov., a new massive nothrotheriid sloth (Xenarthra, Pilosa) from the middle Miocene of Bolivia. Journal of Vertebrate Paleontology 34(5);1243-1248.

Rasia, L. L. y Candela, A. M. 2019. Upper molar morphology, homologies and evolutionary patterns of chinchilloid rodents (Mammalia, Caviomorpha). Journal of Anatomy 234(1): $50-65$.

Reig, O. A. 1952. Descripción previa de nuevos ungulados y marsupiales fósiles del Plioceno y del Eocuartario argentinos. Revista del Museo Municipal de Ciencias Naturales y Tradicional de Mar del Plata 1:119-129.

Reig, O. A. 1957. Sobre la posición sistemática de Zygolestes paranensis Amegh. y de Zygolestes entrerrianus Amegh., con una reconsideración de la edad y correlación del “Mesopotamiense". Holmbergia 5(12-13):209-226.

Reig, O. A. 1958. Comunicación preliminar sobre nuevas especies del género Thylatheridium Reig. Neotropica 4:89-95.

Reig, O. 1981. Teoría del origen y desarrollo de la fauna de mamíferos de América del Sur. Museo Municipal de Ciencias Naturales Lorenzo Scaglia, Mar del Plata, Argentina, 162 pp.

Reig, O. A. y Simpson, G. G. 1972. Sparassocynus (Marsupialia, Didelphidae), a peculiar mammal from the Late Cenozoic of Argentina. Journal of Zoology 167:511-539.

Reig, O. A., Kirsch, J. A. W. y Marshall, L. G. 1987. Systematic relationships of the living neocenozoic American "opossum-like" marsupials (suborder Didelphimorphia), with comments on the classification of these and of the Cretaceous and Paleocene New World and European metatherians; pp. 1-89 en M. Archer (ed.), Possums and Opossums Studies in Evolution 1. Surrey Beatty and Sons, Sidney, Australia.

Riggs, E. S., 1933. Preliminary description of a new marsupial saber-tooth from the Pliocene of Argentina. Field Museum of Natural History, Geological Series 6:61-66.

Riggs, E. S. 1934. A new marsupial saber-tooth from the Pliocene of Argentina and its relationships to other South American predaceous marsupials. Transactions of the American Philosophical Society, new series 24:1-31.

Rodríguez-Cabal, M. A., Aizen, M. A. y Novaro, A. J. 2007. Habitat fragmentation disrupts a plantdisperser mutualism in the temperate forest of South America. Biological Conservation 139(1):195-202.

Rolland, J., Condamine, F. L., Jiguet, F. y Morlon, H. 2014. Faster speciation and reduced extinction in the tropics contribute to the mammalian latitudinal diversity gradient. PLoS Biology 12:e1001775.

Rossi, R. V., Voss, R. S. y Lunde, D. P. 2010. A Revision of the didelphid marsupial genus Marmosa, Part 1. The species in Tate's 'mexicana' and 'mitis' sections and other closely related forms. Bulletin of the American Museum of Natural History 334:1-83. 
Rougier, G. W., Wible, J. R. y Novacek, M. J. 1998. Implications of Deltatheridium specimens for early marsupial history. Nature 396(6710):459-463.

Rougier, G. W., Wible, J. R. y Novacek, M. J. 2004. New specimen of Deltatheroides cretacicus (Metatheria, Deltatheroida) from the late Cretaceous of Mongolia. Bulletin of Carnegie Museum of Natural History 36:245-266.

Royo y Gómez, J. 1942. Contribución al conocimiento de la geología del Valle Superior del Magdalena (Departamento del Huilia). Compilación de los estudios geológicos oficiales en Colombia 5:261-324.

De la Sancha, N. U. y D'Elía, G. 2015. Additions to the Paraguayan mammal fauna: the first records of two marsupials (Didelphimorphia, Didelphidae) with comments on the alpha taxonomy of Cryptonanus and Philander. doi: 10.1515/mammalia-2013-0176.

Sánchez-Villagra, M., Ladevèze, S., Horovitz, I., Argot, C., Hooker, J. J., Macrini, T. E., Martin, T., Moore-Fay, S., de Muizon, C., Schmelzle, T. y Asher, R. J. 2007. Exceptionally preserved North American Paleogene metatherians: adaptations and discovery of a major gap in the opossum fossil record. Biology Letters 3(3):318-322.

Sarmiento, L. y Rangel, A. 2004. Petroleum systems of the Upper Magdalena Valley, Colombia: Marine and Petroleum Geology 21:373-391, doi: 10.1016/j.marpetgeo.2003.11.019.

Sauthier, D. U. y Pardiñas, U. F. J. (2007). Mammalia, Marsupialia, Didelphidae, Lestodelphys halli: New records, distribution extension and filling gaps. Check List 3(2):137-140.

Schaller, O. 2007. Illustrated veterinary anatomical nomenclature. Ferdinand Enke Verlag, Stuttgart, Alemania, $614 \mathrm{pp}$.

Scheyer, T. M., Aguilera, O. A., Delfino, M., Fortier, D. C., Carlini, A. A., Sánchez, R. S, CarrilloBriceño, J. D., Quiroz, L. y Sánchez-Villagra M. R. 2013. Crocodylian diversity peak and extinction in the late Cenozoic of the northern Neotropics. Nature Communications 4:1907, doi: 10.1038/ncomms2940.

Schneider, C. A., Rasband, W. S. y Eliceiri, K. W. 2012. NIH Image to ImageJ: 25 years of image analysis. Nature methods 9(7):671-675, PMID 22930834. Software libre disponible en: https://imagej.nih.gov/ij/

Scott, C. S. y Fox, R. C. 2015. Review of Stagodontidae (Mammalia, Marsupialia) from the Judithian (Late Cretaceous) Belly River Group of southeastern Alberta, Canada. Canadian Journal of Earth Sciences 52(8):682-695.

Silva, A., Mora, A., Caballero, V., Rodriguez, G., Ruiz, C., Moreno, N., Parra, M., Ramirez-Arias, J. C., Ibanez, M. y Quintero, I. 2013. Basin compartmentalization and drainage evolution during rift inversion: Evidence from the Eastern Cordillera of Colombia; pp. 369-409 en M. Nemčok (eds.), Thick-skin-dominated orogens: from initial inversion to full accretion: Geological Society of London Special Publication 377, doi:10.1144/SP377.15.

Simpson, G. G. 1972. Didelphidae from the Chapadmalal Formation in the Museo Municipal de Ciencias Naturales of Mar del Plata. Publicaciones del Museo Municipal de Ciencias 
Naturales de Mar del Plata 2:1-40.

Sinclair, W. J. 1906. Mammalia of the Santa Cruz beds: Marsupialia. Reports of the Princeton University, Expedition to Patagonia 4(3):333-460.

Sisson, S. 1965. Anatomía de los animales domésticos (4a edición). Salvat, Barcelona, 952 pp.

Smith, R. J. 1993. Logarithmic transformation bias in allometry. American Journal of physical Anthropology 90:215-228.

Stenseth, N. C. 1984. The tropics: cradle or museum? Oikos 43:417-420.

Sokal, R. R. y Rohlf, F. J. 1995 Biometry: The Principles and Practice of Statistics in Biological Research. 3rd Edition, W.H. Freeman and Co., New York, 889 p.

Solari, S. 2003. Diversity and distribution of Thylamys (Didelphidae) in South America, with emphasis on species from the western side of the Andes; pp. 82-101 en M. Jones, C. Dickman, y M. Archer (eds.), Predators with Pouches. CSIRO Publishing, Collingwood, Australia.

Stirton, R. A. 1953. Vertebrate Paleontology and continental stratigraphy in Colombia. Bulletin of Geological Society of America 64:603-622.

Suarez, C., Forasiepi, A. M., Goin, F. J. y Jaramillo, C. 2016. Insights into the Neotropics prior to the Great American Biotic Interchange: new evidence of mammalian predators from the Miocene of northern Colombia. Journal of Vertebrate Paleontology 36(1): e1029581, https://doi.org/10.1080/02724634.2015.1029581

Szalay F. S. 1982. A new appraisal of marsupial phylogeny and classification; pp. 621-640 en Archer M (Ed.) Carnivorous marsupials. Royal Zoological Society, New South Wales, Sydney, Australia.

Szalay, F. S. 1994. Evolutionary history of the marsupials and an analysis of osteological characters. Cambridge University Press, Nueva York, EE.UU, 481 pp.

Szalay, F. S. y Trofimov, B. A. 1996. The Mongolian Late Cretaceous Asiatherium, and the early phylogeny and paleobiogeography of Metatheria. Journal of Vertebrate Paleontology 16(3):474-509.

Szalay, F. S. 2006. Evolutionary history of the marsupials and an analysis of osteological characters. Cambridge University Press, Chicago, EE.UU., 481 pp.

Takahashi, F. 1974. Variaçao morfológica de incisivos em didelfídeos (Marsupialia, Didelphinae). Anais Academia Brasileira de Ciencias 46:413-416.

Takai, M., Anaya, F., Suzuki, H., Shigehara, N. y Setoguchi, T. 2001. A new platyrrhine from the middle Miocene of La Venta, Colombia, and the phyletic position of Callicebinae. Anthropological Science 109(4):289-307.

Takai, M., Setoguchi, T., Villarroel, C., Cadena, A. y Shigehara, N. 1991. A new Miocene molossid bat from La Venta, Colombia, South America. Mem. Faculty Sci., Kyoto U., Ser. Geol. Mineral. 56(1-2):1-9.

Takai, M., Takemura, K., Takemura, A., Villarroel, C., Hayashida, A., Danhara, T., Ohno, T., 
Franco, R., Setoguchi, T. y Nogami, Y. 1992. Geology of La Venta, Colombia, South America. Kioto University Overseas Research, Reports of the New World Monkeys 8:117.

Tate, G. H. H. 1933. A systematic revision of the marsupial genus Marmosa: with a discussion of the adaptive radiation of the murine opossums (Marmosa). Bulletin of the AMNH 66, artículo 1.

Teta, P., D'Elía, G., Flores, D. y de La Sancha, N. 2009. Diversity and distribution of the mouse opossums of the genus Thylamys (Didelphimorphia, Didelphidae) in northeastern and central Argentina. Gayana 73(2):180-199.

Teta, P., Abba, A. M., Cassini, G. H., Flores, D. A., Galliari, C. A., Lucero, S. O. y Ramírez, M. 2018. Lista revisada de los mamíferos de Argentina. Mastozoología Neotropical 25:163198.

Vallejo-Pareja, M. C., Carrillo, J. D., Moreno-Bernal, J. W., Pardo-Jaramillo, M., RodriguezGonzalez, D. F. y Muñoz-Duran, J. 2015. Hilarcotherium castanedaii, gen. et sp. nov., a new Miocene astrapothere (Mammalia, Astrapotheriidae) from the Upper Magdalena Valley, Colombia. Journal of Vertebrate Paleontology 35(2):e903960.

Van Valkenburgh, B. 1991. Iterative evolution of hypercarnivory in canids (Mammalia: Carnivore): evolutionary interactions among sympatric predators. Paleobiology 17:340-362.

Van der Wiel, A. M. y van den Bergh, G. D. 1992. Uplift, subsidence, and volcanism in the southern Neiva Basin, Colombia, Part 1: Influence on fluvial deposition in the Miocene Honda Formation: Journal of South American Earth Sciences 5: 153-173, doi:10.1016 / 0895-9811(92)90036-X.

Velandia, F., Acosta, J., Terraza, R. y Villegas, H. 2005. The current tectonic motion of the northern Andes along the Algeciras fault system in SW Colombia: Tectonophysics 399:313-329, doi: 10.1016/j.tecto.2004.12.028.

Villa Nova, P., Avilla, L. S. y Oliveira, E. V. 2015. Didelphidae marsupials (Mammalia, Didelphimorphia) from the Late Pleistocene deposit of the Gruta dos Moura Cave, northern Brazil. Anais da Academia Brasileira de Ciências 87(1):193-208.

Villarroel, C. y Marshall, L. G. 1982. Geology of the Deseadan (early Oligocene) Age 'Estratos Salla' in the Salla-Luribay basin, Bolivia, with description of new Marsupialia. Géobios 15:201-211.

Villarroel, C. y Marshall, L. G. 1983. Two new late Tertiary marsupials (Hathliacyninae and Sparassocyninae) from the Bolivian altiplano. Journal of Paleontology 57:1061-1066.

Vinyard, C. J., Ravosa, M. J., Williams, S. H., Wall, C. E., Johnson, K. R. y Hylander, W. L. 2007. Jaw-Muscle Function and the Origin of Primates; pp. 179-231 en M.J. Ravosa y M. Dagosto (eds.), Primate origins: adaptations and evolution. Springer, New York.

Voss, R. S. y Jansa, S. A. 2003. Phylogenetic studies on didelphid marsupials II. Nonmolecular data and new IRBP sequences: separate and combined analyses of didelphine relationships 
with denser taxon sampling. Bulletin of the American Museum of Natural History 276:182.

Voss R. S. y Jansa S. A. 2009. Phylogenetic relationships and classification of didelphid marsupials, an extant radiation of New World metatherian mammals. Bulletin of American Museum of Natural History 322:1-177.

Voss, R. S., A. L. Gardner y S. A. Jansa. 2004. On the relationships of "Marmosa" formosa Shamel, 1930 (Marsupialia: Didelphidae), a phylogenetic puzzle from the Chaco of northern Argentina. American Museum Novitates 3442:1-18.

Voss, R. S., Gutiérrez, E. E., Solari, S., Rossi, R. V. y Jansa, S. A. 2014. Phylogenetic relationships of mouse opossums (Didelphidae, Marmosa) with a revised subgeneric classification and notes on sympatric diversity. American Museum Novitates 3817:1-27.

Vucetich, M. G., Carlini, A. A., Aguilera, O. y Sánchez-Villagra M. R. 2010. The tropics as reservoir of otherwise extinct mammals: the case of rodents from a new Pliocene faunal assemblage from northern Venezuela. Journal of Mammalian Evolution 17:265-273.

Wellman, S. S., 1970, Stratigraphy and petrology of the nonmarine Honda Group (Miocene), Upper Magdalena Valley, Colombia: Geological Society of America Bulletin 81:23532374, doi:10.1130/0016-7606(1970)81[2353:SAPOTN]2.0.CO;2.

Wible, J. R. 2003. On the cranial osteology of the short-tailed opossum Monodelphis brevicaudata (Didelphidae, Marsupialia). Annals of Carnegie Museum 72(3):137-202.

Wible, J.R \& T.J. Gaudin. 2004. On the cranial osteology of the yellow armadillo Euphractus sexcinctus (Dasypodidae, Xenarthra, Placentalia). Annals of Carnegie Museum 73:117196.

Wible, J. R. y Rougier, G. W. 2000. The cranial anatomy of Kryptobaatar dashzevegi (Mammalia, Multituberculata), and its bearing on the evolution of mammalian characters. Bulletin of the American Museum of Natural History 247:1-124.

Wilson, G. P., Ekdale, E. G., Hoganson, J. W., Calede J. J. y Vander Linden, A. 2016. A large carnivorous mammal from the Late Cretaceous and the North American origin of marsupials. Nature Communications 7:13734, doi: 10.1038/ncomms13734.

Wroe, S., Ebach, M., Ahyong, S., Muizon, C. y Muirhead, J., 2000. Cladistic analysis of dasyuromorphian (Marsupialia) phylogeny using cranial and dental characters. Journal of Mammalogy 81(4):1008-1024.

Zan, S., Wood, C. B., Rougier, G. W., Jin, L., Chen, J. y Schaff, C. R. 2006. A new "middle" Cretaceous zalambdalestid mammal, from a new locality in Jilin Province, northeastern China. Journal of Paleontological Society of Korea 22(1)153-172.

Zimicz, A. N. 2004. Paleoecología y extinción de los marsupiales con dentición plagiaulacoide de América del Sur: un estudio basado en los cambios en el tamaño corporal. Tésis de Licenciatura (inédita). Universidad Nacional de la Patagonia San Juan Bosco. Puerto Madryn. Argentina. 
Zimicz, A. N. 2012. Ecomorfología de los marsupiales paleógenos de América del Sur. Tesis doctoral no publicada, Universidad Nacional de La Plata, Argentina, 454 pp. 